\title{
Methodische Entwicklung einer modularen Lasersintermaschine zur Herstellung von bioresorbierbaren Implantatmatrizen
}

\author{
vorgelegt von \\ Clemens Kolja Kautz, M.Sc. \\ geboren in Berlin
von der Fakultät V - Verkehrs- und Maschinensysteme
der Technischen Universität Berlin \\ zur Erlangung des akademischen Grades
}

Doktor der Ingenieurwissenschaften

- Dr.-Ing. -

genehmigte Dissertation

Promotionsausschuss:

Vorsitzender: Prof. Dr.-Ing. Robert Liebich

Gutachter: $\quad$ Prof. Dr.-Ing. Dietmar Göhlich

Gutachter: $\quad$ Prof. Dr.-Ing. Roland Lachmayer

Tag der wissenschaftlichen Aussprache: 22. März 2019

Berlin 2019 



\section{Inhaltsverzeichnis}

Vorwort $\quad$ V

$\begin{array}{lll}\text { Kurzfassung VII } & \text { V }\end{array}$

Abstract IX IX

1. Einführung 1

1.1. Ausgangssituation und Problemstellung ................... 2

1.2. Zielsetzung der Arbeit . . . . . . . . . . . . . . . . . 3

2. Grundlagen $\mathbf{5}$

2.1. Additive Fertigung $(\mathrm{AM}) \ldots \ldots \ldots \ldots$

2.1.1. Einführung in die Fertigungstechnik . . . . . . . . . . . . . . 6

2.1.2. Terminologie und Normen der additiven Fertigung . . . . . . . . . 6

2.1.3. Systematische Einteilung der additiven Fertigungsverfahren . . . . 7

2.1.4. Beschreibung der additiven Fertigungsverfahren . . . . . . . . . . 8

2.1.5. Datentransfer der Modelldaten für den AM-Prozess . . . . . . . . 13

2.2. Tissue Engineering (TE) . . . . . . . . . . . . . . . . . 17

2.2.1. Grundbausteine des künstlichen Gewebeaufbaus . . . . . . . . . 17

2.2.2. Prozesskette zur Herstellung eines Implantats mittels TE und AM 17

2.2.3. Anforderungen an eine bioresorbierbare Implantatmatrix . . . . . 19

2.2.4. Werkstoffe für bioresorbierbare Implantatmatrizen . . . . . . . . . 20

2.2.5. Auswahl eines AM-Verfahrens zur Herstellung der Matrizen . . . . 22

2.3. Lasersintern (LS) . . . . . . . . . . . . . . . . . . . . . 23

2.3.1. Systematische Einordnung des AM-Verfahrens . . . . . . . . . 23

2.3.2. Thermoplastische Materialien für das Lasersintern . . . . . . . . . 24

2.3.3. Beschreibung des Lasersinterprozesses . . . . . . . . . . . . . . . 27

2.3.4. Prozessparameter und Prozessbedingungen beim Lasersintern . . . 31

3. Stand der Technik und Wissenschaft 33

3.1. Kommerzielle Maschinen zum Lasersintern von Polymeren . . . . . . . . . 34

3.1.1. Industrie- und Produktionsmaschinen (Fabricator) . . . . . . . . . 34

3.1.2. Einstiegs- und Benchtopmaschinen (Prototyper) . . . . . . . . . . 40

3.2. Spezifische Merkmale kommerzieller Maschinen zur Metallverarbeitung . . 40

3.2.1. Kleinformatmaschinen und Bauraumverkleinerungen . . . . . . . . 41

3.2.2. Faserlaser-Scanner-Systeme mit geringem Fokusdurchmesser . . . . 43

3.2.3. Prozessgasbereitstellung und Vakuum-Inertisierung . . . . . . . . . . 43

3.2.4. Monitoring-Systeme zur Prozessüberwachung . . . . . . . . . . . . 44 
3.3. Lasersintern zur Herstellung bioresorbierbarer Implantatmatrizen . . . . . 46

3.3.1. Kommerzielle Lasersintermaschinen mit Bauraumverkleinerung . . 47

3.3.2. Eigenentwickelte Lasersintermaschinen . . . . . . . . . . . . . . . 48

3.3.3. Pulverauftrag und fluidisierende Beschichtereinheiten . . . . . . . . 49

3.3.4. Aufheizvorgang und Temperaturregelbereiche . . . . . . . . . . 50

3.3.5. Laserenergieeintrag und Laserstrahlabschwächungssysteme . . . . . 51

4. Forschungsbedarf

53

4.1. Wechselwirkungsdreieck im Tissue Engineering Kontext . . . . . . . . . . 54

4.2. Forschungsansatz . . . . . . . . . . . . . . . . . 55

4.3. Abgrenzung der Arbeit . . . . . . . . . . . . . . . . 56

5. Generelle Anforderungen an Lasersintermaschinen zur Implantatherstellung $\mathbf{5 7}$

5.1. Anforderungen an die Prozessführung . . . . . . . . . . . . . . 59

5.2. Anforderungen an die Produktarchitektur . . . . . . . . . . . . . . . . 62

5.3. Anforderungen aus dem medizinischen Gerätebau . . . . . . . . . . . . . 65

6. Methodische Entwicklung einer modularen Lasersintermaschine 69

6.1. Planen und Konzipieren . . . . . . . . . . . . . . . . . . . . . 70

6.1.1. Spezifische Anforderungsliste . . . . . . . . . . . . . 71

6.1.2. Funktionsstruktur einer Lasersintermaschine . . . . . . . . . . . . 72

6.1.3. Identifikation prinzipieller Lösungen . . . . . . . . . . . . . . . . 73

6.1.4. Modularisierung der Lasersintermaschine . . . . . . . . . . . . 80

6.1.5. Auswahl eines geeigneten Gesamtkonzepts . . . . . . . . . . . . 85

6.2. Entwerfen und Ausarbeiten . . . . . . . . . . . . . . . . . . 92

6.2.1. Gestaltung der spezifischen Module . . . . . . . . . . . . . . 92

6.2.2. Fertigungs- und Montagevorbereitung . . . . . . . . . . . . 112

7. Auswahl der materialspezifischen Laser-Scanner-Einheit am Beispiel PLGA 115

7.1. Mechanische Korngrößenreduktion des Ausgangsmaterials . . . . . . . . 117

7.1.1. Prozess der Pulveraufbereitung durch Mahlen und Sieben . . . . . 118

7.1.2. Einfluss des Aufbereitungsprozesses auf die Partikelsphärizität . . 120

7.2. DSC-Messungen zur Bestimmung thermischer Eigenschaften . . . . . . . 122

7.2.1. DSC-Kurvenverläufe von PA12 und PLGA . . . . . . . . . . 122

7.2.2. Lasersintern mit amorphem PLGA . . . . . . . . . . . . . . . 123

7.3. FTIR-Spektroskopie zur Bestimmung optischer Eigenschaften . . . . . . 125

7.3.1. FTIR-Spektren von PA12 und PLGA . . . . . . . . . 126

7.3.2. Bestimmung der Wellenlänge zum Lasersintern von PLGA . . . . . 127

7.4. Laser-Scanner-Einheit zur Verarbeitung von PLGA . . . . . . . . . . . . 129

7.4.1. Spezifische Anforderungsliste . . . . . . . . . . . . . . . . 129

7.4.2. Auswahl eines geeigneten Teilsystems für das Lasermodul . . . . . 131 
8. Montage, Inbetriebnahme und Erprobung der Lasersintermaschine 133

8.1. Mechatronisches Gesamtsystem . . . . . . . . . . . . . . . . . 134

8.1.1. Lasersintermaschine . . . . . . . . . . . . . . . . . . 135

8.1.2. Steuereinheit der Lasersintermaschine . . . . . . . . . . . . . . . . 142

8.2. Funktionsabsicherung der mechatronischen Teilsysteme . . . . . . . . . . 147

8.2.1. Sicherheitseinrichtungen . . . . . . . . . . . . . . . . . 147

8.2.2. Antriebsachsen . . . . . . . . . . . . . . . . . . . . 148

8.2.3. 6-Kanal-Heizsystem . . . . . . . . . . . . . . . 153

8.2.4. Prozessgasversorgungssystem und Sauerstoff-Messsysteme . . . . . 155

8.2.5. Laser-Scanner-Demonstrator und Weitwinkelkamera . . . . . . . . 157

8.2.6. Diskussion zur Funktionsabsicherung . . . . . . . . . . . . . . 159

$\begin{array}{lr}\text { 9. Zusammenfassung und Ausblick } & 165\end{array}$

9.1. Zusammenfassung . . . . . . . . . . . . . . 166

9.2. Ausblick . . . . . . . . . . . . . . . . . . . . . . . . 169

$\begin{array}{lr}\text { Anhang } & 171\end{array}$

$\begin{array}{ll}\text { A. Spezifische Anforderungsliste der Lasersintermaschine } & 173\end{array}$

$\begin{array}{ll}\text { B. Detaillierte Darstellung spezifischer Baugruppen } & 179\end{array}$

C. Detaillierte Darstellung der Steuereinheit 205

C.1. Verwendete Schaltschranktechnik . . . . . . . . . . . . . . . . . 206

C.2. National Instruments CompactRIO-Controller 9035 . . . . . . . . . . . . 207

C.3. Verkabelungskonzept zwischen Maschine und Schaltschrank . . . . . . . . 208

C.4. Baugruppenträger des NI cRIO-Controllers 9035 . . . . . . . . . . . . . . 211

C.5. Baugruppenträger des NI cRIO-Erweiterungschassis 9144 . . . . . . . . 216

C.6. Baugruppenträger der Bosch Rexroth Antriebsregelgeräte . . . . . . . . . 220

C.7. Baugruppenträger und Steuercomputer des Laser-Scanner-Dummys . . . . 224

D. Inbetriebnahme der Bosch Rexroth Antriebstechnik 227

D.1. Verwendete Bosch Rexroth Antriebskomponenten . . . . . . . . . . . . . . 228

D.2. Erstinbetriebnahme und Reglerparametrierung . . . . . . . . . . . . 231

D.3. Begrenzung des Fahrbereichs . . . . . . . . . . . . . . . 232

D.4. Kompensation von Steigungsabweichungen der Kugelgewindetriebe . . . . 236

D.5. Umbau der Kupplungen an den Festo Führungseinheiten . . . . . . . . . . 241

D.6. Maschinenreferenzierte Drehgeberwertausgabe . . . . . . . . . . . . . 242

$\begin{array}{ll}\text { E. Messung der Positioniergenauigkeiten der Hubantriebsachsen } & 247\end{array}$

E.1. Positioniergenauigkeiten der Hubantriebsbaugruppen . . . . . . . . . . . . 248

E.2. Positioniergenauigkeiten der Plattformen . . . . . . . . . . . . . . . . . 252

F. Sonstiges $\quad \mathbf{2 5 5}$

F.1. Öffnungshilfe für einen Mahlbecher der Retsch CryoMill . . . . . . . . . 255 
F.2. Laser-Wegmesssystem Keyence LC-2400 . . . . . . . . . . . . . . . . 256

F.3. Betreute Abschlussarbeiten . . . . . . . . . . . . . . . . 258

F.4. Konferenzbeiträge und eigene Veröffentlichungen . . . . . . . . . . . 260

$\begin{array}{ll}\text { Abkürzungsverzeichnis } & 261\end{array}$

$\begin{array}{lr}\text { Symbolverzeichnis } & 267\end{array}$

$\begin{array}{lr}\text { Abbildungsverzeichnis } & 269\end{array}$

$\begin{array}{lr}\text { Tabellenverzeichnis } & 273\end{array}$

$\begin{array}{lr}\text { Literatur } & 273\end{array}$ 


\section{Vorwort}

Die vorliegende Arbeit ist im Zeitraum von Oktober 2014 bis Januar 2019 während meiner Tätigkeit als wissenschaftlicher Mitarbeiter an der Technischen Universität Berlin, zunächst im 3D-Labor und ab Januar 2018 am Fachgebiet Methoden der Produktentwicklung und Mechatronik (MPM), entstanden.

Mein besonderer Dank gilt meinem Doktorvater Herrn Prof. Dr.-Ing. Dietmar Göhlich, dem Leiter des Fachgebiets MPM der Technischen Universität Berlin, für die wissenschaftliche Betreuung der vorliegenden Arbeit, die Bereitstellung der Räumlichkeiten und Werkstattkapazitäten zum Aufbau der Lasersintermaschine sowie die gewährten Freiheiten bei der Anfertigung der Dissertation. Für die Bereitschaft zur Begutachtung meiner Arbeit und dem fachlichem Austausch möchte ich mich bei Herrn Prof. Dr.-Ing. Roland Lachmayer, dem Leiter des Instituts für Produktentwicklung und Gerätebau der Leibniz Universität Hannover, bedanken. Herrn Prof. Dr.-Ing. Robert Liebich, dem Leiter des Fachgebietes Konstruktion und Produktzuverlässigkeit der Technischen Universität Berlin, danke ich für die Übernahme des Prüfungsvorsitzes.

Herrn Prof. Dr. Hartmut Schwandt, dem Leiter des 3D-Labors der Technischen Universität Berlin, danke ich für die vertrauensvolle Übertragung des Entwicklungsauftrags einer Lasersintermaschine im Rahmen des interdisziplinären Forschungsprojekts „Herstellung vitaler Herzklappen unter Verwendung von Tissue Engineering und 3D-Druck (3D-TERM)" in Kooperation mit dem DHZB (Deutsches Herzzentrum Berlin). Dem Bundesministerium für Bildung und Forschung danke ich für die Förderung des Forschungs- und Entwicklungsvorhabens mit dem Förderkennzeichen 13GW0067, sowie Herrn Dr. Gerhard Stumm und Herrn Michael Faber vom VDI Technologiezentrum für die wissenschaftliche bzw. betriebswirtschaftliche Begleitung des Projekts.

$\mathrm{Zu}$ guter Letzt möchte ich mich bei den Kolleginnen, Kollegen, Studierenden, Vertriebsmitarbeitern und vor allem meinen Eltern bedanken, die zum Gelingen dieser Arbeit beigetragen haben. 



\section{Kurzfassung}

Eine aus dem Bereich der regenerativen Medizin stammende visionäre Anwendung der AM-Technologie ist die Fertigung von individuell angepassten Implantaten und Organen. Werden zur Herstellung von Implantatmatrizen, dem Gerüst zum Gewebeaufbau, bioresorbierbare Werkstoffe mittels Lasersintern verarbeitet, verbleibt das erzeugte Implantat nach der Transplantation im Körper des Patienten und wird dort durch biologische Prozesse in natürliches Gewebe umgesetzt. Um einen Beitrag zum Lasersintern mit bioresorbierbaren Polymeren wie PLA, PLGA oder PCL zu leisten, wurde im Rahmen der vorliegenden Arbeit eine spezifische Lasersintermaschine mit einem kleinen Bauvolumen, wechselbarer Beschichtereinheit und einer materialspezifischen Laser-Scanner-Einheit entwickelt. Das methodische Vorgehen bei der Entwicklung des Gesamtsystems orientierte sich an den VDI-Richtlinien 2221 bzw. 2206 und ist dargestellt in den Abschnitten:

- Generelle Anforderungen an Lasersintermaschinen zur Implantatherstellung

- Methodische Entwicklung einer modularen Lasersintermaschine

- Auswahl der materialspezifischen Laser-Scanner-Einheit am Beispiel PLGA

- Montage, Inbetriebnahme und Erprobung der Lasersintermaschine

Das modulare Konzept der grundlagenforschungstauglichen Lasersintermaschine teilt das mechatronische Gesamtsystem in die Module "Maschinengestell“, „Baustempelmodul“, „Pulverzuführmodul“, „Pulverauftragsmodul“, „Beschichtereinheit“, „Prozessgasmodul“, „IR-Heizmodul" und „Lasermodul" auf. Bei der Auslegung der Laser-Scanner-Einheit, einer Baugruppe aus dem Lasermodul, ist neben der Laserleistung vor allem die Wellenlänge der Strahlquelle von großer Bedeutung. Aufgrund des materialspezifischen Absorptionsspektrums muss die zur Generierung der bioresorbierbaren Implantatmatrizen verwendete Laserwellenlänge auf das zu verarbeitende Material abgestimmt sein. Insbesondere bei der Verarbeitung von PLGA kann durch die Verwendung eines $\mathrm{CO}_{2}$-Lasers mit einer

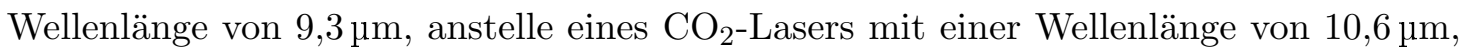
die Absorption der elektromagnetischen Strahlung um den Faktor 10 auf ca. $33 \%$ gesteigert werden. Die vorliegende Arbeit leistet einen Beitrag zur zukünftigen Fertigung von individuell angepassten Implantaten und Organen mittels Lasersintern. 



\section{Abstract}

A visionary application of the AM-technology in the field of regenerative medicine is to manufacture individually adapted implants and organs. If bioresorbable materials are processed by laser sintering (also known as SLS) for the production of implant scaffolds, the framework for tissue build-up, the generated implant remains in the patient's body after transplantation and is converted into natural tissue by biological processes. In order to contribute to laser sintering with bioresorbable polymers such as PLA, PLGA or PCL, a specific laser sintering machine with a small build volume, an exchangeable coater unit and a material-specific laser-scanner-unit was developed within the scope of the present work. The methodical procedure for the development of the system was based on the VDI guidelines 2221 respectively 2206 and is described in the sections:

- General requirements for laser sintering machines for implant production

- Methodical development of a modular laser sintering machine

- Selection of the material-specific laser-scanner-unit using the example PLGA

- Assembly, commissioning and testing of the laser sintering machine

The modular concept of the laser sintering machine, suitable for basic research, divides the mechatronic system into the modules „machine frame“, „build volume module“, „powder feed module“, „powder application module“, „,coater unit", „process gas module“, „infrared heating module" and "laser module“. When designing the laser-scanner-unit, an assembly within the laser module, the wavelength of the beam source is of great importance in addition to the laser power. Due to the material-specific absorption spectrum, the laser wavelength used to generate the bioresorbable implant scaffolds must be matched to the material to be processed. When processing PLGA the use of a carbon dioxide laser with a wavelength of $9,3 \mu \mathrm{m}$, instead of a carbon dioxide laser with a wavelength of $10,6 \mu \mathrm{m}$, can increase the absorption of electromagnetic radiation by a factor of 10 on approximately $33 \%$. The present work contributes to the future production of individually adapted implants and organs by means of laser sintering. 



\section{Einführung}

Das Additive Manufacturing (AM) wird in verschiedenen Industriebereichen zur Herstellung von Prototypen, Werkzeugen, Serienbauteilen und zur Reparatur von Verschleißteilen eingesetzt [LLF16, S. 1-3]. Die durch die Anwendung eines spezifischen AM-Verfahrens erzeugte Bauteilqualität ist das Ergebnis einer komplexen Wechselwirkung (visualisiert durch das AM-Wechselwirkungsdreieck - vgl. Abbildung 1.1) aus Maschine, Material und Prozess. Eine aus dem Bereich der regenerativen Medizin stammende visionäre

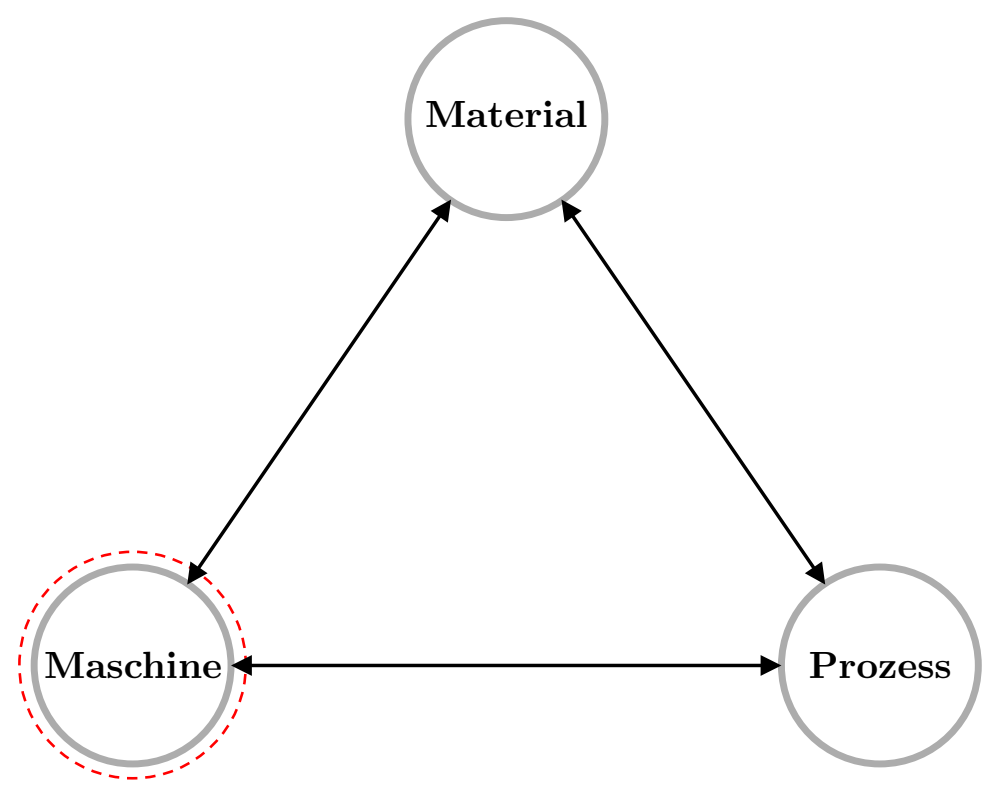

Abbildung 1.1.: AM-Wechselwirkungsdreieck [Ver16, S. 27]

Anwendung der Technologie ist die Fertigung von individuell angepassten Implantaten und Organen [Lac17, S. 1-6]. Die in der medizinischen Diagnostik mittels Magnetresonanz- oder Computertomographie erfassten 2-dimensionalen Bilddaten sind nach deren Volumetrisierung direkt für den AM-Prozess nutzbar [LLK18, S. 2-15]. Leidet ein Patient beispielsweise an einem komplexen Knochenbruch oder einem akuten Organversagen könnte das benötigte Implantat patientenspezifisch und unverzüglich „gedruckt" werden. Das Tissue Engineering (TE) befasst sich in diesem Zusammenhang mit der Herstellung von bioartifiziellen Ersatzgeweben zur Einbettung in den menschlichen Körper [Ver16, S. 43-44]. Jeder operative Eingriff birgt unvorhersehbare Risiken. Durch den Einsatz synthetischer anstelle von biologischen Implantatmaterialien wird das Risiko einer Krankheitsübertragung und Antigenität deutlich reduziert. Werden zur Herstellung 
der Implantatmatrizen, dem Gerüst zum TE-Gewebeaufbau, bioresorbierbare Werkstoffe eingesetzt, verbleibt das erzeugte Implantat nach der Transplantation im Körper des Patienten und wird dort durch biologische Prozesse in natürliches Gewebe umgesetzt. Im Hinblick auf den digitalen Datentransfer der Modelldaten und die Möglichkeit zur Herstellung geometrisch komplexer Strukturen ist die Anwendung der AM-Technologie prädestiniert für die Fertigung individueller Medizinprodukte [RSZ17, S. 21-40]. Das Lasersintern (LS) erzeugt durch den Einsatz eines Lasers mechanisch belastbare Serienbauteile aus einem pulverförmigen (mittlere Korngröße ca. $60 \mu \mathrm{m}$ ) Ausgangsmaterial. Bioresorbierbare Polymere wie PLA (Poly(Lactic Acid)), PGA (Poly(Glycolic Acid)), PLGA (Poly(Lactic-co-Glycolic Acid)) oder PCL (Polycaprolacton) werden synthetisch hergestellt, gelten im Tissue Engineering Kontext als „Standardwerkstoffe“ und sind als Thermoplaste grundsätzlich für das Lasersintern geeignet [CLT13].

\subsection{Ausgangssituation und Problemstellung}

Die zum Lasersintern kommerziell verfügbare Materialpalette ist, nach dem derzeitigen Stand der Technik, stark begrenzt. Schätzungen zufolge basieren $85 \%$ der Lasersintermaterialien auf PA12 (Polyamid 12) und PA11 (Polyamid 11), wobei das ungefüllte PA12 mit Abstand am häufigsten zum Lasersintern verwendet wird [Sch15a, S. 15-17]. Zur Erweiterung des Anwendungsbereichs des Lasersinterns muss, gemäß aktuellen Handlungsempfehlungen, die Auswahl an produktorientierten Lasersintermaterialien deutlich gesteigert werden [Ver14, S. 11] [Ver16, S. 29] [Uni16, S. 29]. Die zur Herstellung von bioresorbierbaren Implantatmatrizen notwendigen TE-Werkstoffe PLA, PGA, PLGA oder PCL sind als Lasersintermaterialien kommerziell jedoch nicht erhältlich. Die Forschung im Bereich der patientenspezifischen Implantatfertigung mittels Lasersintern wird bereits seit dem Jahr 2005 mit beeindruckenden Ergebnissen voran getrieben. Interdisziplinäre Forschergruppen, bestehend aus Medizinern, Ingenieuren und Werkstoffwissenschaftlern, verarbeiten ihre selbst hergestellten Materialien (Labormaterialien) in ihren Lasersintermaschinen zu zellbesiedlungsfähigen Gerüststrukturen. Kommerzielle Lasersintermaschinen sind von den OEMs ausschließlich für die Verarbeitung von kommerziellen Lasersintermaterialien ausgelegt. Da sich die Eigenschaften der bioresorbierbaren Materialien stark von den kommerziellen Lasersintermaterialien unterscheiden, muss im Hinblick auf das AM-Wechselwirkungsdreieck sowohl der Prozess als auch die Maschine angepasst werden. Diesbezüglich wurden in den jeweiligen Forschungsprojekten vor der Verarbeitung der bioresorbierbaren Labormaterialien häufig die folgenden Bereiche der kommerziellen Lasersintermaschinen angepasst:

Bauvolumen Aufgrund der hohen Werkstoffpreise und der im Labormaßstab hergestellten Materialmengen ist eine möglichst kleine Bauraumgröße eine wesentliche Anforderung an die Maschine. Industrielle Lasersintermaschinen im „Kleinformat“ besitzen hingegen ein Bauvolumen von $200 \mathrm{~mm} \times 250 \mathrm{~mm} \times 330 \mathrm{~mm}$. Erst durch den Einsatz spezifischer Bauraumverkleinerungen, einem Maschinenadapter der in das Bauvolumen der Basismaschine eingesetzt wird, können kleinere Gerüststrukturen auch in kommerziellen Lasersintermaschinen gefertigt werden. 
Beschichtereinheit Die Optimierung der bioresorbierbaren Labormaterialien hinsichtlich des medizinischen Verwendungszwecks kann unter Umständen zu einer geringen Fließfähigkeit des hergestellten Pulvers führen. Kommerziell eingesetzte Beschichtereinheiten tragen fließfähige Lasersintermaterialien mittels starrer Klinge oder rotierender Rolle vor dem Laserenergieeintrag gleichmäßig und annähernd porenfrei oberhalb der Bauplattform auf. Der Pulverauftrag der Labormaterialien in kommerziellen Lasersintermaschinen kann infolge der verminderten Fließfähigkeit zu einem mangelhaften Pulverauftragsergebnis führen. Einige wenige Forscher entwickelten diesbezüglich „fluidisierende“ Beschichtereinheiten.

Heizsystem Zur Verarbeitung eines teilkristallinen PA12-Lasersintermaterials (Schmelztemperatur ca. $176^{\circ} \mathrm{C}$ ) werden die Lasersintermaschinen auf eine Temperatur knapp unterhalb von $171^{\circ} \mathrm{C}$ vorgeheizt. Aufgrund der amorphen Sekundärstruktur der bioresorbierbaren Werkstoffe darf die Vorheiztemperatur zur Verarbeitung der bioresorbierbaren Labormaterialien einen Wert von $60^{\circ} \mathrm{C}$ nicht übersteigen. Da der Parameter der Vorheiztemperatur an kommerziellen Lasersintermaschinen in der Regel nur in einem beschränkten Wertebereich weit oberhalb von $60^{\circ} \mathrm{C}$ einstellbar ist, muss das Heizsystem zur Verarbeitung der bioresorbierbaren Labormaterialien ausgeschaltet werden.

Laser-Scanner-Einheit Ein wesentlicher Prozessparameter zur Bauteilschichtgenerierung ist die für den Laserenergieeintrag in das Pulverbett gewählte Laserleistung. Bei der Verarbeitung von bioresorbierbaren Labormaterialien werden diesbezüglich auffallend geringe Werte bis unter $1 \mathrm{~W}$ eingestellt. Kommerzielle Lasersintermaschinen sind mit Laser-Scanner-Einheiten mit einer maximalen Laserleistung zwischen $30 \mathrm{~W}$ und $100 \mathrm{~W}$ ausgestattet. Zur Gewährleistung einer hohen Strahlqualität muss die Strahlquelle allerdings eine Laserleistung von mindestens 10\% der Nennleistung emittieren. Ein häufig umgesetzter Kompensationsansatz ist die Nachrüstung eines Strahlabschwächungssystems.

Im Hinblick auf die Anzahl der durchzuführenden Modifikationen ist festzustellen, dass kommerzielle Lasersintermaschinen nur bedingt zur Verarbeitung bioresorbierbarer Materialien geeignet sind. Die Verwendung einer vollumfänglich modifizierten Lasersintermaschine zur Herstellung der bioresorbierbaren Implantatmatrizen ist nicht bekannt.

\subsection{Zielsetzung der Arbeit}

Um einen Beitrag zur zukünftigen Fertigung individuell angepasster Implantate und Organe mittels Lasersintern zu leisten, soll im Rahmen der vorliegenden Arbeit eine spezifische Lasersintermaschine zur Herstellung von bioresorbierbaren Implantatmatrizen neuentwickelt werden. Auf Basis der themenbezogenen Grundlagen (vgl. Kapitel 2) und dem Stand der Technik und Wissenschaft (vgl. Kapitel 3) wird der Ansatz zur methodischen Entwicklung einer modularen Lasersintermaschine in Kapitel 4 dargestellt. 



\section{Grundlagen}

In diesem Kapitel werden die Grundlagen zum Verständnis der vorliegenden Arbeit erläutert. Die additive Fertigung (AM) ist eine Technologie der Fertigungstechnik und wird in Abschnitt 2.1 grob umrissen. Das Tissue Engineering (TE), beschrieben in Abschnitt 2.2, wird unter anderem zur künstlichen Gewebezüchtung für die medizinische Regeneration eingesetzt. Zur Herstellung von Implantatmatrizen, dem Gerüst zum Gewebeaufbau, wird das Lasersintern als geeignetes additives Fertigungsverfahren identifiziert und abschließend detailliert in Abschnitt 2.3 vorgestellt. 


\subsection{Additive Fertigung (AM)}

Das „Additive Manufacturing“ (AM) wird in Abschnitt 2.1.1 im Kontext der Fertigungstechnik kategorisiert. In Abschnitt 2.1.2 werden die Normen der additiven Fertigung und die anzuwendende Terminologie vorgestellt. Der Abschnitt 2.1.3 teilt sämtliche AM-Verfahrensklassen systematisch ein, sodass die zugehörigen AM-Verfahren in Abschnitt 2.1.4 beschrieben werden können. Der Datentransfer der Modelldaten für die additive Fertigung, dargestellt in Abschnitt 2.1.5, ermöglicht immanent das „Drucken“ patientenspezifischer Implantatgeometrien.

\subsubsection{Einführung in die Fertigungstechnik}

Die Fertigungstechnik ist ein Teilgebiet der Produktionstechnik und befasst sich mit der wirtschaftlichen Herstellung von Werkstücken unter Zuhilfenahme von Fertigungsverfahren [FS15, S. 1]. Im englischsprachigen Raum wird die Gesamtheit der Fertigungsverfahren in substraktive, formative und additive Fertigungsverfahren unterteilt. Bei der Anwendung von substraktiven Fertigungsverfahren (z. B.: Bohren, Fräsen) wird durch einen definierten Materialabtrag die gewünschte Werkstückgeometrie aus einem Halbzeug erzeugt. Die formativen Verfahren (z. B.: Tiefziehen, Strangpressen) formen Halbzeuge bei Volumenkonstanz zur gewünschten Werkstückgeometrie um. Bei den additiven Fertigungsverfahren (z. B.: Kleben, 3D-Drucken) wird die gewünschte Werkstückgeometrie durch das Aneinanderfügen einzelner Volumenelemente erzeugt. Die generativen Fertigungsverfahren (Gruppe der additiven Fertigungsverfahren) sind automatisierte Verfahren, die aus 3D-Computerdaten die Einzelschichten der Werkstückgeometrie erzeugen und sie korrekt ausgerichtet aneinanderfügen. Die Geometrie und Stoffeigenschaften entstehen demnach simultan [Geb13, S. 1-2]. Die im deutschsprachigen Raum häufig verwendete Norm DIN 8580 [DIN 8580] teilt die Fertigungsverfahren in sechs Hauptgruppen ein. Alle existierenden oder denkbaren Verfahren können diesen Hauptgruppen zugeordnet werden. Fertigungsverfahren werden eingesetzt zur Schaffung einer Form (1. Hauptgruppe), der Änderung einer Form (2. bis 5. Hauptgruppe) oder der Änderung von Stoffeigenschaften (6. Hauptgruppe) [DIN 8580, S. 6-7] [FS12, S. 1]. Alle generativen Fertigungsverfahren schaffen schichtweise einen Werkstoffzusammenhalt und sind daher dem Urformen (1. Hauptgruppe) zuzuordnen.

\subsubsection{Terminologie und Normen der additiven Fertigung}

Der englische Begriff „Additive Manufacturing“ (AM) beschreibt Fertigungsverfahren zur automatisierten, meist schichtweisen Herstellung von Bauteilen durch ein Aneinanderfügen von Volumenelementen aus 3D-Computerdaten. Dieser Begriff ist in den USA gemäß ISO ASTM 52900 [ISO ASTM 52900] genormt. Das „Additive Manufacturing“ wurde in der Vergangenheit unter anderem durch die Begriffe „Additive Fabrication“, „Additive Processes“, „Additive Techniques“, „Additive Layer Manufacturing“, „Layer Manufacturing“, „Solid Freeform Fabrication“ oder „Freeform Fabrication" beschrieben [ISO ASTM 52900, S. 1]. Im Juni 2017 wurde die deutsche Fassung der amerikanischen Norm mit der 
Nummer DIN EN ISO/ASTM 52900 [DIN EN ISO ASTM 52900] veröffentlicht, in der die "Additive Fertigung“ als deutsches Pendant zum Begriff „Additive Manufacturing“ vorgestellt wird. Bereits im Vorwort der Norm wird berichtet, dass bewusst auf den Begriff „Generative Fertigung“ verzichtet wird. Die VDI-Richtlinie 3405 [VDI 3405] mit dem Titel „Additive Fertigungsverfahren" verwendet die Begriffe „Additive Fertigung", "Generative Fertigung" und „Additive Manufacturing“ [VDI 3405, S. 3] zur Beschreibung der Technologieebene. Zusätzlich wird auf die umgangssprachlich genutzte Bezeichnung „3D-Drucken“ aufmerksam gemacht [VDI 3405, S. 3]. Die AM-Technologie kann zur Fertigung von Prototypen („Rapid Prototyping“), Werkzeugen („Rapid Tooling“), Endprodukten („Rapid Manufacturing“) oder zur Reparatur („Rapid Repair“) bestehender Bauteile angewendet werden [BHS13, S. 7] [KK15, S. 130].

\subsubsection{Systematische Einteilung der additiven Fertigungsverfahren}

Zur systematischen Einteilung der additiven Fertigungsverfahren werden unter anderem die folgenden Klassifizierungsansätze verwendet:

- Klassifizierung nach der Art des Werkstoffs (Metall, Polymer, Keramik), der dem AM-Prozess zugeführt wird (gemäß DIN EN ISO/ASTM 52900)

- Klassifizierung nach dem Aggregatzustand des Werkstoffs (fest, flüssig, gasförmig), der dem AM-Prozess zugeführt wird (in Anlehnung an die DIN 8580)

Die Klassifizierung der additiven Fertigungsverfahren nach dem Aggregatzustand des Werkstoffs ist in Abbildung 2.1 dargestellt. Die drei klassischen Aggregatzustände sind

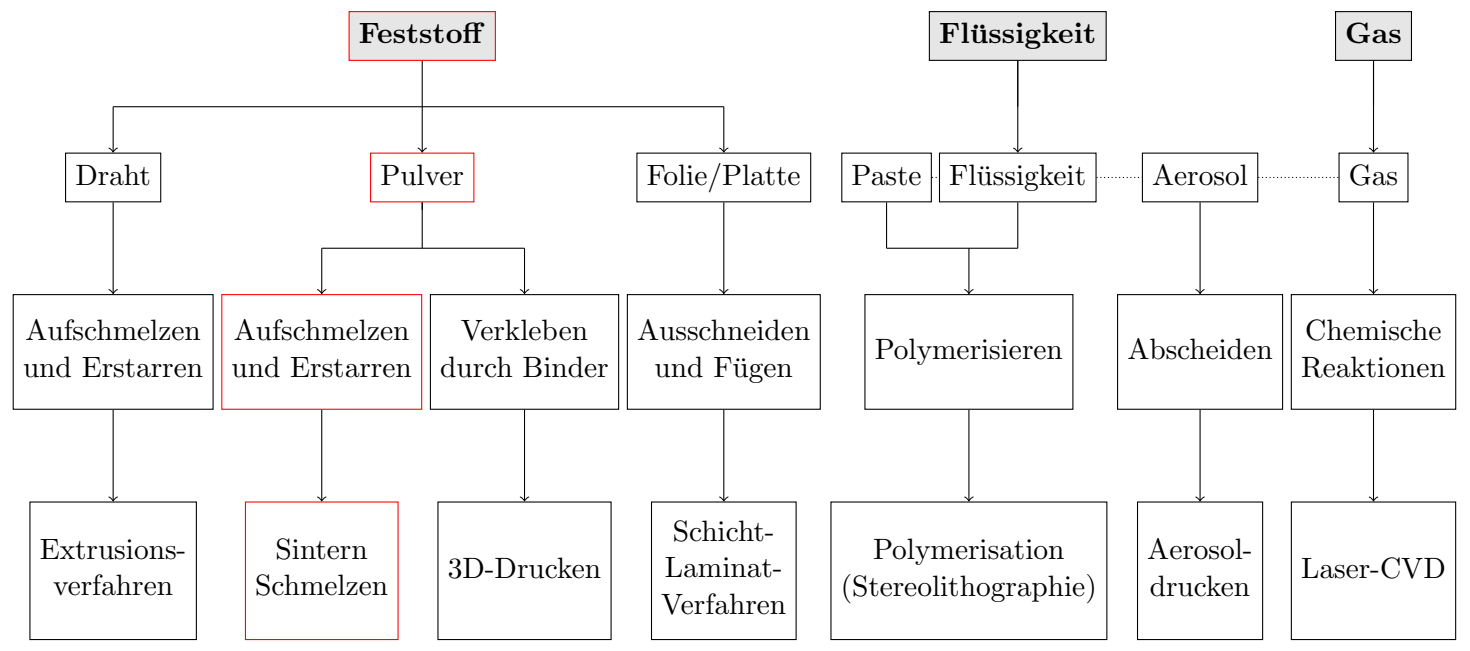

Abbildung 2.1.: Klassifizierung der additiven Fertigungsverfahren nach dem Aggregatzustand in Anlehnung an die DIN 8580 [Geb13, S. 92]

fest, flüssig oder gasförmig [Mes15, S. 296]. Die zweite Gliederungsebene klassifiziert die Erscheinungsform des Ausgangsmaterials. Ein festes Ausgangsmaterial kann beispielsweise draht-, pulver- oder folienförmig dem additiven Fertigungsprozess zugeführt werden. Wird 
einer Flüssigkeit ein gewisser Feststoffanteil beigemengt, entsteht eine Paste (Suspension). Ein Aerosol bezeichnet ein Gas in dem sich Schwebeteilchen befinden [LK07, S. 167,189]. Die Verarbeitung dieser Mehrphasensysteme ist mittels additiver Fertigung ebenfalls möglich. In der dritten Gliederungsebene wird der Mechanismus der Schichtgenerierung aufgezeigt. Die Verbindung eines pulverförmigen Ausgangsmaterials kann durch ein „Verkleben mittels Binder" oder durch „Aufschmelzen mit anschließendem Erstarren“ technisch realisiert werden. Die letzte und vierte Gliederungsebene etikettiert das additive Fertigungsverfahren mit einer generischen Bezeichnung (Gattungsbezeichnung), die nicht in einem marken- oder produktspezifischen Zusammenhang steht [Geb13, S. 91-93,102]. Durch das Schichtbauprinzip weisen die AM-Verfahren im Anwendungsbezug die folgenden besonderen Eigenschaften auf [Gru15, S. 33] [Zäh13, S. 14]:

- Beliebige Bauteilkomplexität herstellbar (z. B. schwammartige Strukturen)

- Bauteilgenerierung direkt aus digitalen Daten (z. B. CT-Datensatz)

- Geringe Stückzahlen wirtschaftlich herstellbar (Massenindividualisierung)

\subsubsection{Beschreibung der additiven Fertigungsverfahren}

Grundsätzlich gilt, dass jedes additive Fertigungsverfahren spezifische Stärken und Schwächen aufweist. Sofern ein konkurrierendes, gegebenenfalls konventionelles Fertigungsverfahren anwendungsspezifisch keine wirtschaftlich oder qualitativ hinreichende Lösung offeriert, kann der Einsatz eines entsprechenden AM-Verfahrens Abhilfe schaffen. Additiv gefertigte Bauteile werden entweder aus Modellmaterialien oder Konstruktionswerkstoffen hergestellt. Ein Anschauungsobjekt aus einem Modellwerkstoff kann aufgrund der geringen mechanischen Festigkeit nicht als Funktionsbauteil eingesetzt werden [Geb13, S. 93-99]. Die in Abschnitt 2.1.3 systematisch eingeteilten AM-Verfahren werden im Folgenden vorgestellt.

Extrusionsverfahren (engl. „Fused Layer Modeling/Manufacturing“) ist eine Verfahrensklasse, die in Abhängigkeit der Düsenanzahl weiter in „Einzeldüse“ und „Mehrfachdüsen" unterteilt werden kann. Das konturierende Element zur Bauteilschichtgenerierung ist der Extruder. Kommerziell etablierte Verfahren tragen die Bezeichnungen „Fused Deposition Modelling“ (FDM) und „Multi-Jet Modelling“6 (MJM). Als Ausgangsmaterial werden draht- bzw. filamentförmige (mit oder ohne Füllstoff) Thermoplaste oder Wachse eingesetzt. Der Draht wird durch Erhitzung in einen pastösen Zustand versetzt und unter Volumenkonstanz durch eine Düse extrudiert. Durch die Bewegung des Düsenkopfs in der horizontalen x-y-Ebene wird eine Bauteilschicht generiert. Ist der Schichtaufbau abgeschlossen, senkt sich die Bauplattform samt Bauteil um eine Schichtstärke ab, sodass die folgende Bauteilschicht aufgetragen werden kann. Beim Auftreffen des erhitzten Materials auf die zuvor generierte Bauteilschicht schmilzt diese leicht an und verfestigt anschließend durch die Wärmeleitung. Damit das extrudierte Material auf die zuvor generierte Bauteilschicht kraftarm aufgedrückt werden kann, muss der Abstand zwischen Düsenaustritt und Bauteiloberfläche kleiner als der Extrusionsquerschnitt sein [Geb13, 
S. 88-89]. Zur Fertigung überstehender Bauteilbereiche müssen Stützstrukturen gesetzt werden. Das Stützstrukturmaterial ist in modernen Anlagen wasserlöslich und wird aus einer separaten Düse schichtweise aufgetragen. Wasserlösliche Stützstrukturen werden im Rahmen des Post-Processings ausgewaschen. Unlösliche Strukturen müssen mechanisch getrennt werden. Zur Herstellung filigraner Strukturen eignen sich die Extrusionsverfahren in der Regel nicht [Geb13, S. 248-264] [VDI 3405, S. 12-14] [MKM+16] [ES14] [SS13] [BWB11].

Sintern/Schmelzen (engl. „Sintering“/,Melting“) ist eine Verfahrensklasse, die in Abhängigkeit der Energiequelle weiter in „Elektronenstrahl“, „Infrarotstrahler“ und "Laserstrahl" unterteilt werden kann. Alle Verfahren generieren die Bauteile aus pulverförmigen Werkstoffen mittels Wärmeenergieeintrag. Das „Electron Beam Melting“ (EBM) ist ein pulverbettbasiertes AM-Verfahren das einen metallischen Ausgangswerkstoff verarbeitet. Die feinen Metallpartikel werden durch eine Beschichterbewegung über der Bauplattform gleichmäßig verteilt. Der fokussierte Elektronenstrahl wird im Vakuum über ein Magnetfeld in der horizontalen x-y-Ebene positioniert. Beim Aufprall der emittierten Elektronen auf die Pulverbettoberfläche schmilzt das Metallpulver auf. Ist die Bauteilschicht generiert, senkt sich die Bauplattform in vertikaler z-Richtung um eine Schichtstärke ab, sodass die nächste Pulverpartikelschicht aufgetragen werden kann. Zur Reduktion von Verzug werden die Bauteile mit Stützstrukturen unterstützt. Diese metallischen Strukturen müssen im Rahmen des Post-Processings entfernt werden [Geb13, S. 205-210] [VDI 3405, S. 11-12] [DS15] [LH04] [MLF+17]. Jene Verfahren die Partikel in einem Pulverbett mittels IR-Strahler aufschmelzen, werden unter anderem als „Thermo Transfer Sintering“" (TTS) bezeichnet [VDI 3405, S. 18]. Bei diesem Verfahren wird ein sogenannter Thermotransfer-Druckkopf in der horizontalen x-y-Ebene über das Pulverbett bewegt. Die Wärmestrahlung die der Druckkopf emittiert, führt zu lokalem Sintern der Partikel in dem Pulverbett. Das „Selective Mask Sintering“ (SMS) ist aufgebaut aus einem Flächeninfrarotstrahler, dem Bauraum samt Beschichter und einer Baugruppe zur elektrostatischen Erzeugung einer Maske. Zur Belichtung der gesamten Bauteilschicht werden die Schichtkonturen als Maske auf eine transmittierende Oberfläche aufgebracht und über das Bauvolumen bewegt. Das pulverförmige Polymer wird lokal in jenen Bereichen gesintert, in denen die Wärmestrahlung die Maske durchdringen kann. Kühlt der Ausgangswerkstoff ab, entsteht die Bauteilschicht. Die Generierung der folgenden Bauteilschicht wird durch das Absenken der Bauplattform und der Entladung bzw. Reinigung der Glasplatte initiiert. Verfahrensbedingt sind keine Stützstrukturen notwendig [Geb13, S. 210-213] [KRD09] [KD11]. Die laserstrahlbasierten Sinter- und Schmelzverfahren werden wiederum weiter unterteilt in „Pulverbett“, „Pulverdüse“ und „Hybrid“ [Geb13, S. 163]. Die pulverbettbasierten Lasersinter- und Laserstrahlschmelzverfahren gelten als stark etablierte AM-Verfahren zur Herstellung von Funktionsbauteilen. Das konturierende Element zur Bauteilschichtgenerierung ist der Laser. Der emittierte Laserstrahl wird durch einen Galvanometer-Scanner abgelenkt und in der horizontalen x-y-Ebene auf der Pulverbettoberfläche positioniert. Das Lasersintern (engl. „Laser Sintering“ 
(LS)) baut Bauteile aus pulverförmigen Werkstoffen schichtweise durch lokales Sintern bei Laserenergieeintrag auf. Als Ausgangsmaterial kann Kunststoff, Formsand, Metall oder Keramik, wobei in der Regel teilkristalline Polymere wie Polyamid 12 verwendet werden [VDI 3405, S. 8] [Geb13, S. 164-181] [WW13] [RKD09]. Das kommerziell etablierte Verfahren trägt die Bezeichnung „Selective Laser Sintering“6 (SLS) und benötigt keine Stützstrukturen. Das Laserstrahlschmelzen (engl. „Laser Beam Melting“ (LBM)) ist ein mit dem Lasersintern eng verwandter additiver Fertigungsprozess zur Herstellung metallischer Bauteile. Durch das vollständige Aufschmelzen (Schweißen) der pulverförmigen Metallpartikel entstehen nach dem Erstarren annähernd porenfreie Bauteile. Kommerziell etablierte Verfahren tragen die Bezeichnungen „Selective Laser Melting“ (SLM), „Laser Metal Fusion“ (LMF), „Direct Metal Laser Sintering“ (DMLS), „LaserCUSING“ und „Laser Powder Bed Fusion“ (LPBF). Der Laserstrahl einer LBM-Maschine kann im Vergleich zu LS-Maschinen aufgrund der materialspezifischen Wellenlänge auf geringere Spotgrößen fokussiert werden. Sämtliche Bauteile sind zur Reduktion von Verzug durch Wärmeableitung über Stützstrukturen mit einer Substratplatte verbunden, die vor dem Prozessstart auf die Bauplattform geschraubt wird. Im Rahmen des Post-Processings wird die Substratplatte samt Bauteilen aus der Maschine entnommen. Die Stützstrukturen werden durch mechanische Nacharbeit entfernt [VDI 3405, S. 10-11] [Geb13, S. 181-205] [KS09a] [SW09]. Schmelzverfahren mit einer Pulverdüse werden häufig als Pulver- oder Laserauftragsschweißen bezeichnet. Bei Maschinen dieses Verfahrens sind mehrere Düsen um den Faser- oder Diodenlaser angeordnet. Der pulverförmige Werkstoff wird durch die Düsen in den Laserfokusbereich eingebracht, unter Schutzgasatmosphäre aufgeschmolzen und in einer flüssigen Schmelze auf die Bauteiloberfläche aufgebracht. Die Erstarrung der generierten Bauteilschicht erfolgt nach der Abkühlung infolge der Wärmeleitung. Kommerzialisierte Verfahren tragen die Bezeichnungen „Direct Metal Deposition“ (DMD) und „Laser Engineered Net Shaping“ (LENS), wobei sich die Letztere aus der rasterförmigen Scanstrategie ableitet. Dieses AM-Verfahren wird in der Regel zu Reparaturzwecken verwendet, wodurch Stützstrukturen gegebenenfalls entfallen können [Geb13, S. 220-227] [Geb05] [Hut05]. Hybridverfahren weisen auf eine Kombination von Fertigungsprozessen hin. Das „Controlled Metal Build Up“ (CMB) kombiniert beispielsweise die Verfahren Auftragsschweißen mit dem Fräsen in einer Maschine [Geb13, S. 286-288]. Hybridmaschinen werden unter anderem in die Kategorie „AM Advanced Technologies“ eingeteilt. Die Aufbauraten dieser Verfahren sind mitunter sehr hoch. Eine CNC-basierte Nachbearbeitung muss durchgeführt werden.

3D-Drucken (engl. „3D-Printing“) ist eine Verfahrensklasse, die in Abhängigkeit der Düsenanzahl weiter in „Einzeldüse“ und „Mehrfachdüsen“ unterteilt werden kann. Das Einzeldüsenverfahren wird im Zusammenhang des Aerosoldruckens beschrieben. Bei dem teilweise mehrstufigen AM-Verfahren wird eine Binderflüssigkeit durch einen Druckkopf in die Oberfläche des Pulverbetts aus Kunststoff, Formsand, Metall oder Keramik eingespritzt. Der Binder generiert örtlich die jeweilige 
Bauteilschicht und verbindet diese mit der darunterliegenden. Unbenetztes Pulver stützt das Bauteil. Der Druckkopf wird in der horizontalen x-y-Ebene über dem Bauvolumen bewegt. Ist die jeweilige Bauteilschicht mit dem Binder versorgt, senkt sich die Bauplattform um eine Schichtstärke ab, sodass der Beschichter die neue Pulverschicht auftragen kann. Werden Modelle aus Gips mittels „3D-Printing“6 (3DP) generiert, muss das teilfertige Bauteil zunächst vorsichtig aus dem Bauvolumen entfernt werden. Filigrane Bauteilbereiche müssen gegebenenfalls mittels Stützstruktur verstärkt werden. Nach der Infiltration mit einem Epoxidharz oder Wachs erhält das Bauteil seine mechanische Festigkeit. Durch das Mischen farbiger Binderflüssigkeiten können kolorierte Anschauungsobjekte gefertigt werden. Die Verfahrensbezeichnung „Direct Metal Printing“ (DMP) weist im Kontext des 3D-Druckens auf die Grünteilfertigung aus metallischen Partikeln hin. Durch den nachgelagerten Sinterprozess in einem Ofen entsteht das gebrauchsfertige Bauteil. Formsande werden zur Herstellung von Kernen und Formen für Gießprozesse verwendet. Die Bauteilschichten in Formsand-Druckern härten bereits in den jeweiligen Maschinen aus. Das Verfahren „Direct Shell Production Casting“ (DSPC) verarbeitet keramische Materialien zur Herstellung von Formen für den Feinguss [Geb13, S. 264-282] [Ede08] [Ede07].

Schicht-Laminat-Verfahren (engl. „Layer Laminate Manufacturing“) ist eine Verfahrensklasse, die in Abhängigkeit des konturierenden Schneidwerkzeugs weiter in „Laserstrahl“, „Messer“, „Fräser“ und „Wasserstrahl“ unterteilt werden kann. Alle Verfahren generieren die Bauteile aus konturierten Folien bzw. Platten, die durch Fügen miteinander verbunden werden. Als Ausgangsmaterial wird Papier, Kunststoff, Metall oder Keramik verwendet [VDI 3405, S. 16]. Das „Layer Laminated Manufacturing“ (LLM) wird vor allem zur Herstellung von großen und massiven Modellen eingesetzt. Die Fertigung filigraner Strukturen und komplexer Hinterschnitte ist nur bedingt möglich. Papier- und Kunststofffolien werden miteinander verklebt. Metalle werden im Bereich der Konturen geschweißt oder in der Fläche mittels Diffusionsschweißen verbunden. Unverfestigte Innenbereiche werden zur einfachen Entnahme in kleinere Quadrate geschnitten. Kommerziell etablierte Verfahren tragen unter anderem die Bezeichnungen „Laminated Object Manufacturing“ (LOM), ,Selective Adhesive and Hot Press Process" (SAHP) und „Layer Milling Process“ (LMP) [Geb13, S. 227-247] [Wei08] [Sei07].

Polymerisation/Stereolithographie (engl. „Stereolithography“) ist eine Verfahrensklasse, die in Abhängigkeit des konturierenden Elements weiter in „Laser“, „Lampe“ und „Druckkopf“ unterteilt werden kann. Sämtliche Verfahren setzen flüssig oder pastöse Monomere durch eine Polymerbildungsreaktion (Polymerisation) in ein festes Polymer (Photopolymer) um. Als Ausgangsmaterialien werden UV-aktivierbare (photosensitive) Kunstharze oder Acrylate verwendet, die optional mit metallischen oder keramischen Partikeln als Füllstoff angereichert sind. Die Verfahrensklasse eignet sich zur Herstellung filigraner Bauteilstrukturen und glatten Oberflächen. Bauteilbereiche die in späteren Schichten aufgebaut werden, müssen mit Stützstrukturen ab Fertigungsprozessbeginn unterstützt werden. Zusätzlich müssen Stützen 
zur Schrumpfungskompensation und bei der Fertigung von Überhängen generiert werden [Geb13, S. 105-156]. In den Maschinen des Verfahrens „Stereolithography“ (SL) wird das flüssige Harz durch eine Beschichterbewegung über der Bauplattform verteilt. Der in der horizontalen x-y-Ebene positionierte Laserstrahl verfestigt das Monomer durch Polymerisation. Sind die Schichtinformationen übertragen, senkt sich die Bauplattform um eine Schichtstärke ab, sodass die nächste Bauteilschicht generiert werden kann [VDI 3405, S. 8-9] [KA05]. Das lampenbasierte Verfahren mit der Bezeichnung „Digital Light Processing“ (DLP) verwendet anstelle des Lasers einen DLP-Projektor und belichtet die gesamte Bauteilschicht zeitgleich [VDI 3405, S. 17]. Das Harzbad in diesen Maschinen ist auf der Unterseite durch einen Glasboden begrenzt, unter dem der Projektor positioniert ist. Die Bauplattform taucht von der Oberseite in das Harzbad ein und bewegt sich im Bauprozess in vertikaler z-Richtung aufwärts. Aufgrund des Aufbaus wird die Formulierung der „Über-Kopf-Bauweise“ verwendet. Die generierten Bauteile müssen anschließend in einer UV-Kammer nachvernetzt werden [Gru11]. Druckkopfbasierte Verfahren werden herstellerabhängig als „Multi-Jet Modelling“ (MJM) und „Poly-Jet Modelling“ (PJM) bezeichnet. Die als Baumaterial verwendeten Acrylate werden durch die Druckköpfe schichtweise auf die Bauteiloberfläche aufgetragen und zeitgleich durch eine mitgeführte UV-Lampe ausgehärtet. Jene Schichtbereiche, die nicht dem Bauteil angehören, werden simultan durch einen weiteren Druckkopf mit wasserlöslichem Stützmaterial aufgefüllt. Bei diesem Verfahren wird ein gesamter Block aus der Maschine entnommen. Die Druckkopfeinheit in einer MJM-Maschine wird in der vertikalen y-z-Ebene geführt. Die Bauplattform bewegt sich in der $\mathrm{x}$-Richtung. Bauplattformen der PJM-Maschinen verfahren in der vertikalen z-Richtung [VDI 3405, S. 14-15] [Eic10].

Aerosoldrucken (engl. „Aerosolprinting“) ist ein 3DP-Verfahren, das prinzipiell für die 2D-Mikrostrukturierung entwickelt wurde. Das Aerosol besteht aus einer Trägerflüssigkeit, in der entsprechende Kunstoff-, Metall- oder Keramikpartikel (Durchmesser $<200 \mathrm{~nm}$ ) beigemengt sind. Beim „Maskless Masoscale Material Deposition“ (M3D) wird ein Aerosolfluidstrom mit einem Durchmesser zwischen $1 \mu \mathrm{m}$ und $5 \mu \mathrm{m}$ durch einen Druckkopf auf das zu bedruckende Bauteil gelenkt. In dem Düsensystem wird das Aerosol von einem Gasmantelstrom umschlossen und geführt (aerodynamische Fokussierung). Prallt das Aerosol auf das zu strukturierende Bauteil auf, ergibt sich nach der Verdampfung der Trägerflüssigkeit eine feste Beschichtung. Mittels Laserenergieeintrag können die Partikel auf der Bauteiloberfläche nachversintert werden [Geb13, S. 283-285] [NUF+15].

Laser Chemical Vapor Deposition (Laser-CVD) ist ein laserbasiertes Verfahren, das mittels chemischer Gasphasenabscheidung zur Herstellung von Mikrostrukturen aus aluminiumhaltigen Distickstoffmonoxid (Lachgas) angewendet wird. Mit diesem AM-Verfahren wurden in der Vergangenheit Aluminiumoxidstäbe mit einem Durchmesser von $5 \mu \mathrm{m}$ bis $20 \mu \mathrm{m}$ generiert [Geb13, S. 76-77] [VM08, S. 61-76]. 


\subsubsection{Datentransfer der Modelldaten für den AM-Prozess}

Die Norm DIN EN ISO 17296-4 [DIN EN ISO 17296-4] beschreibt den grundlegenden Informationsaustausch zur Beschreibung von Geometrien bzw. Bauteilen im Hinblick auf die Verwendung in der additiven Fertigung. Der Datentransfer der Modelldaten innerhalb dieser digitalen Prozesskette, dargestellt in Abbildung 2.2, kann in die Schritte „Datenerfassung oder Datenerstellung“, „Datenaufbereitung“ und „Datennutzung“ unterteilt werden [DK08]. Die Teilprozessschritte werden im Folgenden erläutert.

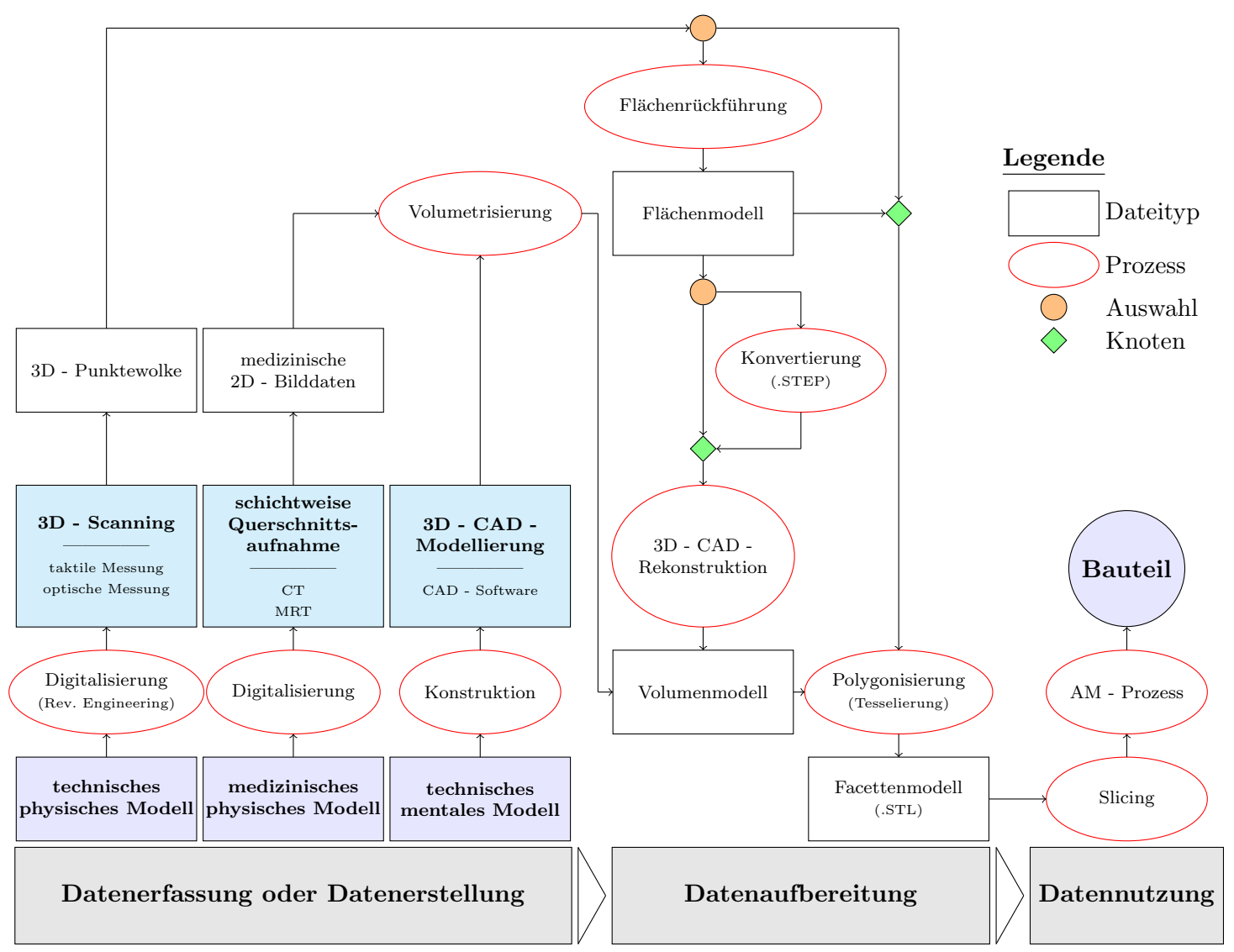

Abbildung 2.2.: Datentransfer der Modelldaten für den AM-Prozess [DK08]

Datenerfassung oder Datenerstellung Die Datenerfassung wird zur Digitalisierung eines physischen Modells angewendet. Technisch physische Modelle werden in der Regel mit Hilfe eines 3D-Scanners erfasst und in einer digitalen 3D-Punktewolke beschrieben. Zur Erhebung von Geometriedaten eines medizinisch physischen Modells werden Computer- oder Magnetresonanztomographen verwendet, die beispielsweise für eine Individualisierung eines Implantats genutzt werden können. Die 2D-Bilddaten werden entsprechend volumetrisiert. Technisch mentale Modelle, die in einer Produktidee grob umrissen sind, werden im Konstruktionsprozess mittels CAD-Software modelliert und anschließend volumetrisiert. 
Datenaufbereitung Die AM-gerechte Datenaufbereitung dient der Überführung des Datensatzes mittels Polygonisierungsalgorithmus in ein Facettenmodell. Neben dem bekannten Dateiformat STL (Standard Tessellation Language) werden unter anderem auch VRML- (Virtual Reality Modeling Language) oder 3DS- (Autodesk 3D Studio) Formate verwendet, die bezogen auf die additive Fertigung jeweils Vorund Nachteile aufweisen [WH14]. Die Norm DIN EN ISO/ASTM 52915 [DIN EN ISO ASTM 52915] beschreibt das im Jahr 2011 erstmals veröffentlichte Dateiformat AMF (Additive Manufacturing File Format) für die Verwendung in der additiven Fertigung. In dem „STL 2.0“- Dateiformat können unter anderem Farben, Texturen und Werkstoffe für das Bauteil zusätzlich festgelegt werden [HH09].

Datennutzung Die Initiierung des AM-Prozesses durch dessen Pre-Processing gilt im Kontext des dargestellten Datentransfers als Datennutzung. Das „Slicing“ ist ein Vorgang bei dem das Facettenmodell maschinenspezifisch in aufeinanderfolgende Schichten bestimmter Stärke zerschnitten wird. Nach der schichtweisen Aufteilung des Modells verlieren die „gesliceten“ Konturdaten ihren Bezug untereinander. Eine nachträgliche Skalierung ist nicht mehr möglich. Die Konturdaten samt Prozessparameter werden zur Fertigung an die AM-Maschine gesendet.

Zur Fertigung qualitativer Bauteile sind durch die gesamtheitliche Betrachtung des Datentransfers die Notwendigkeit von Modelldaten entsprechender Qualität implizit gefordert. Qualitätsmerkmale wie die mechanische Festigkeit, Maßhaltigkeit und Oberflächenqualität additiv gefertigter Bauteile sind jedoch abhängig von dem gewählten Fertigungsverfahren bzw. der Maschine. Eine im Maschinenbau gebräuchliche Anwendung der additiven Fertigung zur Herstellung von Bauteilen direkt aus den CAD-Daten ist in Abbildung 2.3 exemplarisch dargestellt. Durch die 3D-Modellierung in einer CAD-Software wird der

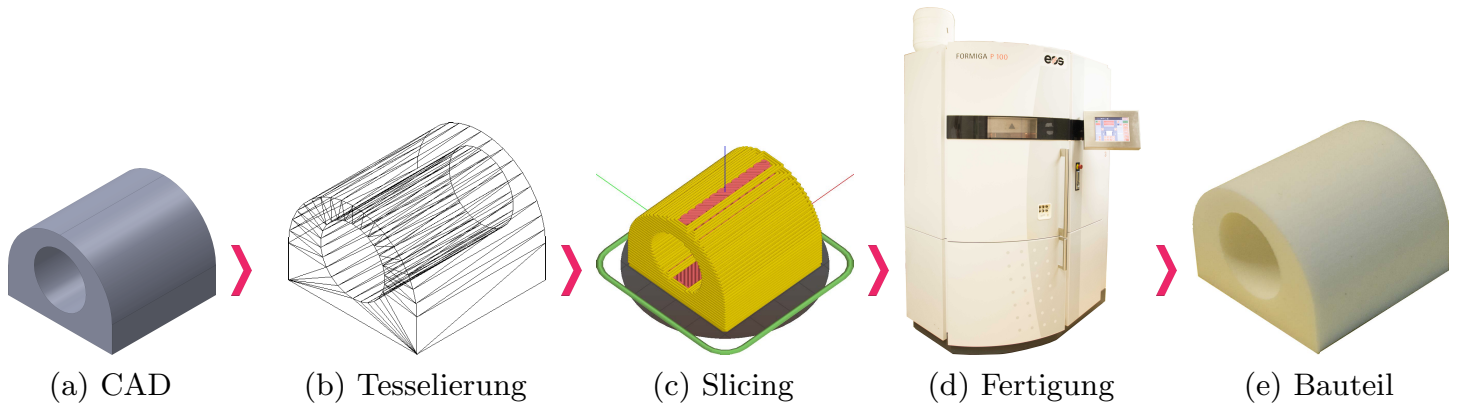

Abbildung 2.3.: Exemplarische Prozesskette der additiven Fertigung

Datensatz des zu fertigenden Volumenkörpers erstellt. Bedingt durch eine AM-gerechte Datenaufbereitung wird das Volumenmodell mittels Polygonisierungsalgorithmus approximiert und in einem Facettenmodell-Dateiformat abgespeichert. Das im Bereich der additiven Fertigung häufig verwendete STL-Format (Standard Tessellation Language) beschreibt die Oberfläche des Volumenkörpers mit Hilfe von Dreiecksfacetten (Tesselierung). Die Auflösung der Tessellation hat einen erheblichen Einfluss auf die Da- 
teigröße und die Höhe des geometrischen Informationsverlustes des zu approximierenden CAD-Volumenkörpers. Die Abbildung 2.4 stellt das Facettenmodell des in CAD modellierten Bauteils dar. Die Datennutzung wird mit dem Beginn der Fertigungsvorbereitung

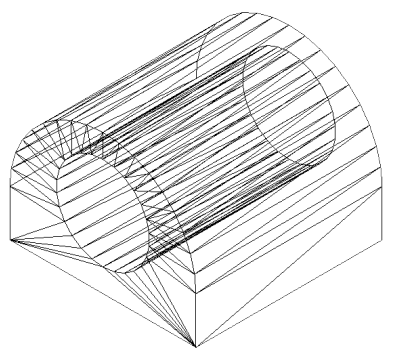

(a) „Grob“ (188 Dreiecke / 9kb)

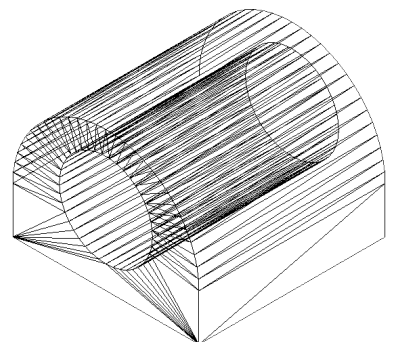

(b) „Standard“ (296 Dreiecke)

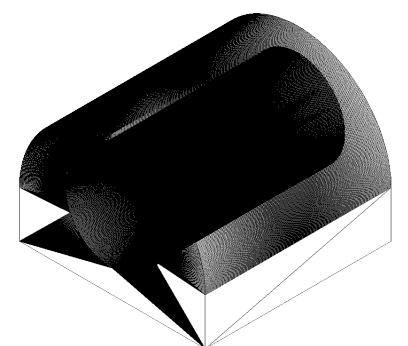

(c) „Fein“ (4332 Dreiecke / 217kb)

Abbildung 2.4.: Ergebnis einer STL-Tesselierung in Abhängigkeit der Auflösung

(Pre-Processing) eingeleitet. Bevor interpretierbare Schichtdaten an die AM-Maschine übermittelt werden können, muss das zu fertigende Bauteil in dem Bauvolumen orientiert, gegebenenfalls mit Stützstrukturen unterstützt und "geslicet“ werden. Die DIN EN ISO/ASTM 52921 [DIN EN ISO ASTM 52921] definiert dazu kartesische Koordinatensysteme für additive Fertigungsanlagen und der Bauteilausrichtung in deren Bauvolumen, dessen Ursprung mittig auf Bauplattform festgelegt ist. „Bei Verfahren, in denen planar und schichtweise Werkstoffe hinzugefügt werden, muss die positive z-Richtung von der ersten Schicht zu den nachfolgenden verlaufen“ [DIN EN ISO ASTM 52921, S. 7]. Ausge-

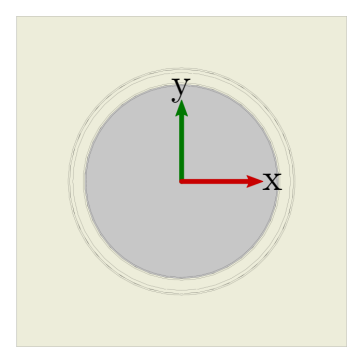

(a) Draufsicht

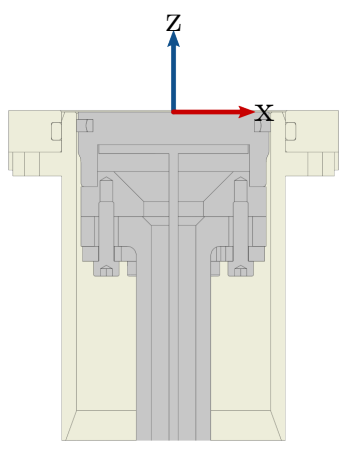

(b) Vorderansicht

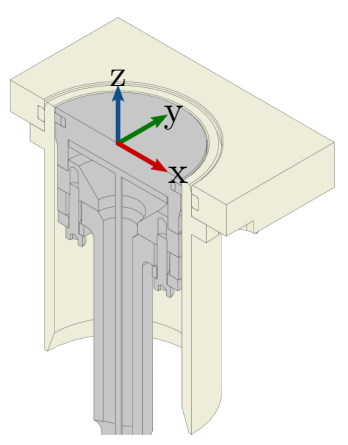

(c) ISO-Ansicht

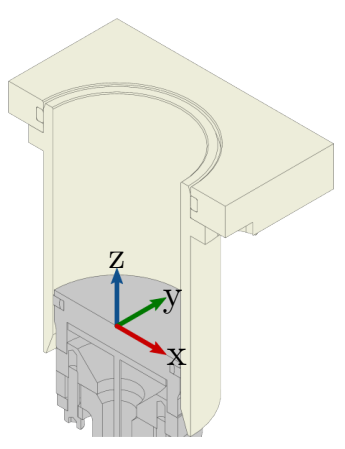

(d) ISO-Ansicht

Abbildung 2.5.: Koordinatensystem eines Bauvolumens einer Lasersintermaschine

hend von der Maschinenvorderseite ist die positive x-Richtung horizontal von links nach rechts definiert. Maschinen für das Lasersintern (vgl. Abbildung 2.5) bauen die Bauteile aufwärts gerichtet auf, wodurch die positive z-Richtung von der ersten Pulverschicht zu den nachfolgenden definiert ist. Bei entsprechendem Verhältnis zwischen Bauteil- und Bauraumgröße ist die simultane Fertigung mehrerer Bauteile möglich. Die Abbildung 2.6 stellt ein zu fertigendes Bauteil in einem zylinderförmigen Bauvolumen in verschiedenen 
Orientierungen dar. Neben der Bauteilorientierung hat vor allem die Schichtstärke einen großen Einfluss auf die Bauteilqualität [DK09]. Der für die additiven Fertigungsverfahren charakteristische Treppenstufeneffekt hat einen verstärkt negativen Einfluss auf die Darstellungsmöglichkeit von gewölbten Bauteilbereichen quer zur Baurichtung (z-Richtung). Die Reduktion der uniformen Schichtstärke verbessert die Bauteilqualität, führt jedoch gleichzeitig zu einer verlängerten Bauzeit. Die für die Zerlegung der 3D-Geometrie gewählte Schichtstärke kann konstant (uniform) oder variabel (adaptiv) gewählt werden. Die adaptive Schichtzerlegung ist ein Mehrzieloptimierungsansatz der zur Erhöhung der
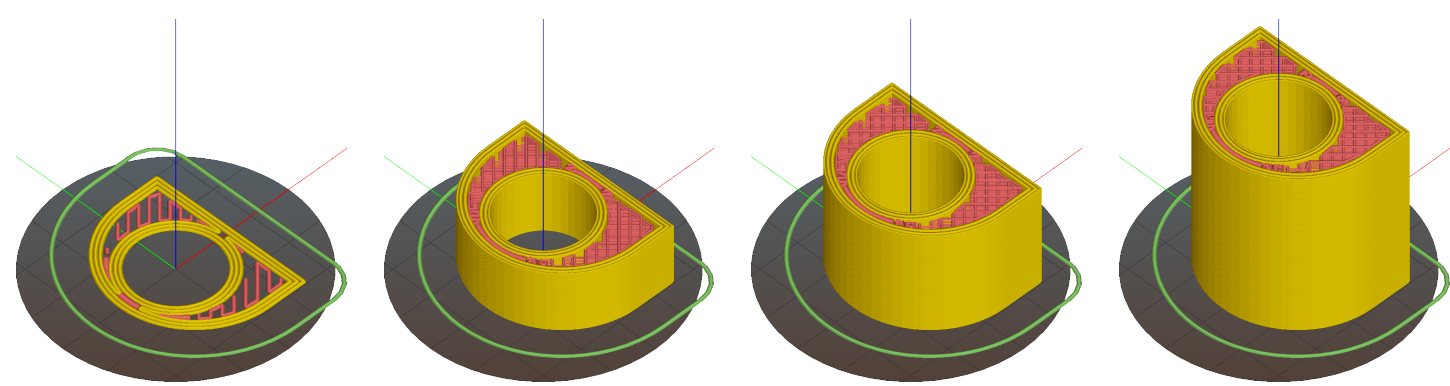

(a) Bohrung entlang der Baurichtung / Treppenstufeneffekt kompensiert
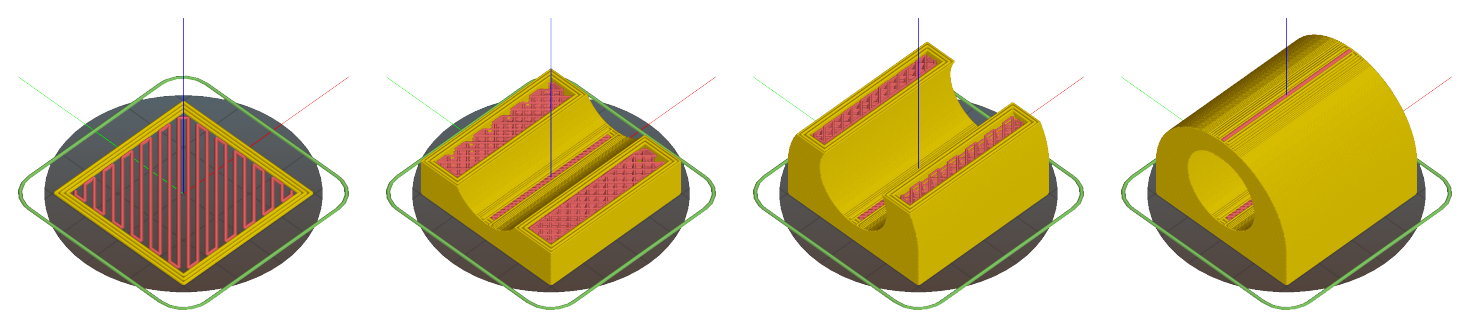

(b) Bohrung quer zur Baurichtung / Treppenstufeneffekt nicht kompensiert

Abbildung 2.6.: Schichtgenerierung in Abhängigkeit der Bauteilorientierung

Aufbaurate bei gleichbleibender Bauteilqualität angewendet wird. Dabei wird die Schichtstärke in Bauteilbereichen mit hohen Qualitätsanforderungen entsprechend verringert [MK11]. Sofern das gewählte Fertigungsverfahren Stützstrukturen benötigt, müssen die Stützen an die Bauteile nach der Orientierung im Bauraum mittels geeigneter Software konstruiert werden. Beim Slicing wird die Bauteilgeometrie samt Stützstrukturen (falls vorhanden) über die gesamte Höhe parallel zur Bauplattform in Schichten spezifischer Schichtstärke zerlegt und anschließend in Konturen und Flächenbereiche überführt [Mar15, S. 16-18]. Diese Daten werden verfahrensspezifisch in Abhängigkeit des konturierenden Elements durch Zugabe von entsprechenden Prozessparametern weiterverarbeitet und als Schichtdatensatz an die Maschine versendet. Das schichtgenerierende Werkzeug ist am Beispiel einer Lasersintermaschine der Laser. Auf Basis der Schichtdaten werden hier die Belichtungspfade zur Generierung der Kontur (engl. „Outline“) und der Füllung (engl. "Hatch“ bzw. „Fill“) berechnet. Die Realisierung der Belichtung wird unter dem Begriff der Scanstrategie zusammengefasst [Kad10]. Bei der Berechnung von Belichtungspfaden in der maschinenspezifischen Software werden entsprechende Prozessparameter (Laserleis- 
tung, Scangeschwindigkeit, etc.) ergänzt, in dem Dateiformat SLI (Slice Layer Interface) abgespeichert und an die Maschine versendet [ZPG+13].

\subsection{Tissue Engineering (TE)}

Das „Tissue Engineering“ (TE) wird unter anderem zur Züchtung bioartifizieller Gewebe angewendet. Die Grundbausteine des Gewebeaufbaus werden in Abschnitt 2.2.1 vorgestellt. Diesbezüglich wird in Abschnitt 2.2.2 eine beispielhafte Prozesskette zur Herstellung einer künstlichen Herzklappe und eines Knochenimplantats skizziert. Sämtliche Anforderungen an die bioresorbierbaren Implantate aus Abschnitt 2.2.3 müssen für die Zulassung als Medizinprodukt und den Einsatz im menschlichen Körper erfüllt sein. In Abschnitt 2.2.4 werden mögliche Werkstoffe für das Tissue Engineering diskutiert. Abschließend wird in Abschnitt 2.2.5 ein additives Fertigungsverfahren zur Herstellung von bioresorbierbaren Implantatmatrizen ausgewählt.

\subsubsection{Grundbausteine des künstlichen Gewebeaufbaus}

Das Tissue Engineering (TE) befasst sich mit der Entwicklung bioartifizieller „Gewebe oder Gewebe-Ersatzsystemen zur Unterstützung oder Substitution von kranken Geweben oder Organen“ als mögliche Alternative zu einer Organtransplantation [WH09, S. 373]. Der Verbund spezifischer Zellen mit Oberflächenbereichen der extrazellulären Matrix wird als Gewebe bezeichnet, dessen Funktion und Struktur auf den Wechselwirkungen von Gerüst/Zelle und Zelle/Zelle basieren. Störungen der Interaktionen führen zu einer Fehlfunktion oder Erkrankung. Zum bioartifizellen Gewebeaufbau mittels Tissue Engineering sind die Grundbausteine „Gerüst“, „Zellen“ und „Wachstumsfaktoren“ notwendig [GR08, S. 263] [OBr11, S. 89]. Gewebespezifische Zellen werden in der Regel durch enzymatische Methoden aus entnommenem Gewebematerial isoliert und „ex vivo“ (außerhalb des Patienten) flächig expandiert. Zur geometrisch bestimmten Gewebebildung werden die vermehrten Zellen auf ein dreidimensionales Trägergerüst (Scaffold / Matrix) aufgebracht und in entsprechenden Gefäßen kultiviert. Verfahrenstechnisch automatisierte Kulturgefäße, in der Literatur als Bioreaktoren (vgl. [DE10244859 B4] [EP2151491 B1] [EP2617389 B1] [DE10349688 A1]) bezeichnet, versorgen das mit Zellen besiedelte Scaffold stetig mit Nahrung/Sauerstoff und transportieren Stoffwechselprodukte/Kohlendioxid ab, damit das bioartifizielle Gewebe „in vitro“ (in Laborumgebung) reifen kann [Li17, S. 25-27] [GR08, S. 263-264]. Neben der Verwendung von dezellularisiertem Gewebe werden zur Herstellung eines gewebespezifischen Gerüsts geeignete Polymere, Metalle, Keramiken und Verbundwerkstoffe eingesetzt [dBS17].

\subsubsection{Prozesskette zur Herstellung eines Implantats mittels TE und AM}

Eine schematische Prozesskette zur Herstellung eines Herzklappenimplantats mittels Tissue Engineering (TE) und additiver Fertigung (AM) ist in Abbildung 2.7 dargestellt. Die geometrischen Daten für das patientenspezifische Implantat werden durch den Einsatz von Magnetresonanz- oder Computertomographie genau erfasst. Unter Berücksichtigung 
fertigungstechnischer Aspekte wird der Datensatz zu einer porösen, schwammartigen, zellbesiedlungsfähigen Gerüststruktur digital nachbearbeitet und in ein für die additive Fertigung geeignetes Dateiformat konvertiert. Das Scaffold wird aus einem bioresorbierbaren, für den Einsatz als Medizinprodukt zugelassenem, Polymer mittels geeignetem AM-Verfahren gefertigt. Die körpereigenen Zellen werden in einem Bioreaktor auf die bioresorbierbare Matrixstruktur aufgebracht und mit Nährstoffen versorgt. Wachstums-

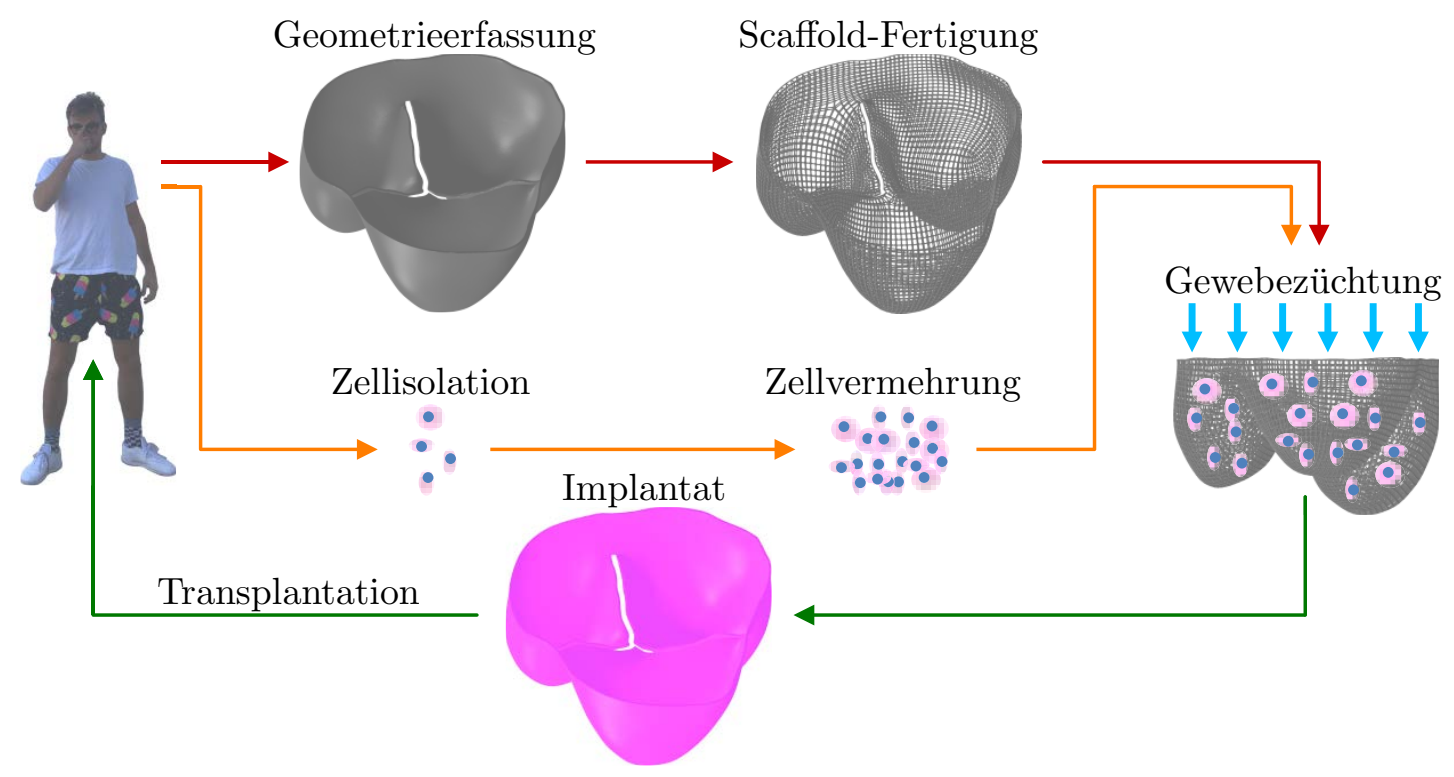

Abbildung 2.7.: Prozesskette zur Herstellung vitaler Herzklappen mittels TE und AM

faktoren führen zu weiterer Zellvermehrung, die sich in der Gerüststruktur ablagern und geometrisch geführt einen künstlichen Gewebeverband aufbauen. Zur Konditionierung werden spezielle Pulsationsbioreaktoren für das kardiovaskuläre Tissue Engineering verwendet, die zusätzlich mechanische Reize in Form pulsatiler Durchströmung auf das bioartifizielle Gewebe ausüben. Durch eine abgestimmte Degradationsdauer des Scaffolds können die Zellen den gewünschten Gewebeverband aufbauen. Die Gewebezüchtung gilt als abgeschlossen, wenn die Zellen die künstliche Gerüststruktur durch einen biologischen Prozess (Stoffwechsel) abgebaut und durch eine eigene extrazelluläre Matrix ersetzt haben. Das funktionstüchtige Implantat kann dem Bioreaktor entnommen werden. Abschließend wird die vitale Herzklappe transplantiert. Das aus den körpereigenen Zellen gezüchtete Gewebe wird vom Immunsystem des Patienten nicht als fremd identifiziert und daher nicht abgestoßen [LJH+14]. Die Herstellung von kardiovaskulären Geweben wird in die Kategorie „Soft Tissue Engineering“ eingeteilt. Das „Bone Tissue Engineering“ hingegen wird bei der Entwicklung von künstlichem Knochengewebe angewendet. Zur Korrektur von Knochendefekten im Kiefer- oder Schädelbereich werden derzeit sowohl metallische als auch alloplastische Materialien verwendet. Titanimplantate werden, sofern sie nicht für den permanenten Einsatz vorgesehen sind, in einer zweiten Operation entfernt. Synthetische (alloplastische) Knochenersatzmaterialien können durch den menschlichen Körper 
in körpereigenes Knochenmaterial umgewandelt werden und zum Regenerationszweck im Körper verbleiben. Die in Abbildung 2.7 schematisch dargestellte Prozesskette kann für die additive Fertigung von Knochenimplantaten entsprechend angepasst werden. Die zur patientenspezifischen Rekonstruktion notwendigen Geometriedaten des geschädigten Knochens werden durch bildgebende Verfahren ermittelt und digital nachbearbeitet. Für die additive Fertigung des Knochens wird ein TE-spezifisches Knochenersatzmaterial verwendet. Abschließend wird das Knochenimplantat transplantiert. Bei diesem Ansatz entsteht das natürliche Gewebe im Körper [RKV+08] [HM09] [Roh14].

\subsubsection{Anforderungen an eine bioresorbierbare Implantatmatrix}

Für medizinische Anwendungen ist vor allem die Beurteilung des biologischen Risikos relevant [KK11, S. 179] [Tür14, S. 53]. Die 18-teilige DIN EN ISO 10993, der Normenreihe für die „Biologische Beurteilung von Medizinprodukten“, ist bei der methodischen Entwicklung neuer Medizinprodukte zum Schutz des Menschen zu verwenden. Der Begriff der „Biokompatibilität“ beschreibt die „Fähigkeit eines Medizinprodukts oder Materials, mit einer angemessenen Host-Reaktion Leistung in einer spezifischen Anwendung zu erbringen" [DIN EN ISO 10993-1b, S. 9]. Bei der Verwendung von bioinkompatiblen Produkten werden durch die Freisetzung toxischer Inhaltsstoffe im Wechselwirkungsprozess mit dem lebendigen Organismus Immun- oder Abstoßungsreaktionen hervorgerufen [WH08, S. 60]. Die Medizinprodukte lassen sich nach der "Art des Körperkontakts" (ohne / kurzzeitig / zu Körperoberflächen / von außen mit dem Inneren des Körpers / implantierbar) oder der „Kontaktdauer“ (kurz / länger / dauerhaft) einteilen. Bei einer Anwendungszeit von mehr als 30 Tagen wird die Kontaktdauer bereits als „Dauerkontakt" eingestuft [DIN EN ISO 10993-1a, S. 13-15]. Implantate rufen nach dem medizinischen Eingriff eine Reaktion im Empfängergewebe hervor. Die Interaktion zwischen Implantat und Gewebe findet im Bereich der Kontaktzone statt und wird mit den Begriffen „toxisch“, „inert“, „bioaktiv“ oder „degradabel“ beschrieben. Das implantieren toxischer Werkstoffe führt zu einer Gewebenekrose. Bei der Verwendung bioaktiver Werkstoffe entsteht zwischen Gewebe und Implantat eine chemische Bindung hoher Festigkeit. Bildet sich lediglich ein Bindegewebe geringer Festigkeit um das Implantat herum, wird die Implantateigenschaft als „inert" eingestuft. Der Einsatz bioresorbierbarer Implantate dient dem sukzessiven Implantatersatz durch das umliegende Gewebe. Die Geschwindigkeit des kontrollierten Implantatabbaus (Resorptionsrate) richtet sich nach der Tragfähigkeit des neugebildeten Gewebes, sodass es die Funktion des Implantats übernehmen kann [Bra13, S. 10] [WH08, S. 62-64] [DIN EN ISO 10993-6a, S. 9] [DIN EN ISO 10993-6b, S. 4] [DIN EN ISO 10993-9, S. 6] [CI02, S. 990] [EP0835895 B1]. Bevor die Bestimmung der Biokompatibilität und Bioresorbierbarkeit von Implantatwerkstoffen in klinischen Studien am Menschen durchgeführt werden darf, müssen Testreihen in hierarchischer Ordnung zunächst „in vitro" (künstliche Umgebung) und anschließend „in vivo" (lebender Organismus) die prognostizierten Leistungen für eine sachdienliche Risikobeurteilung erbringen [WH08, S. 64] [DIN EN ISO 10993-2, S. 9]. Die Anforderungen an die Matrizen, aus denen in den Folgeschritten transplantierbare Implantate direkt oder indirekt entstehen, definiert das Tissue Engineering wie folgt $[\mathrm{TCP}+17][\mathrm{OBr} 11]$ : 
Biokompatibilität Die Scaffold-Ausgangsmaterialien sowie deren Abbauprodukte dürfen unter keinen Umständen toxisch sein. Zusätzlich darf das Implantat in keinem Fall eine Immun- oder Abstoßungsreaktion im Empfängerkörper verursachen.

Biodegradierbarkeit Das kontrollierte Matrix-Degradationsverhalten muss zeitlich so abgestimmt sein, sodass die Gewebefestigkeit über den gesamten Entstehungsprozess konstant bleibt. Zellen im Empfängergewebe müssen in der Lage sein eine eigene extrazelluläre Matrix aufbauen zu können. Zeitgleich muss das behelfsmäßig gefertigte Scaffold durch einen enzymatischen oder biologischen Prozess im Empfänger oder Bioreaktor abgebaut werden.

Bioaktivität Verwendete Scaffold-Ausgangsmaterialien sind neben der bloßen Interaktion auch fähig eine aktive Bindung mit dem umliegenden Empfängergewebe aufzubauen. Matrizen für das „Bone Tissue Engineering“ müssen osteokonduktive (Erleichterung Knochenwachstum) und osteoinduktive (Anregung Knochenneubildung) Eigenschaften besitzen. Durch Einbeziehung biologischer Reize und Wachstumsfaktoren muss das Einwachsen, Anhaften und die Differenzierung der Zelle angeregt sein.

Geometrische Eigenschaften Die interkonnektierenden Poren (Makroporosität) in der Matrix ermöglichen eine Zellmigration in die Gerüststruktur und die notwendige Versorgung mit Nährstoffen. Die Größe der Poren muss gewebe- und zellspezifisch angepasst sein. Eine Mikroporosität des Scaffolds dient der Flächenvergrößerung für die Gerüst/Zelle-Wechselwirkung. Die Scaffold-Geometrie muss sowohl die Bildung neuer Blutgefäße als auch den Wachstum bestehender Blutgefäßen erlauben, ohne dabei die mechanischen Eigenschaften der Gerüststruktur zu verschlechtern.

Mechanische Eigenschaften Die mechanische Festigkeit des Scaffolds muss den spezifischen Belastungen im Körper entsprechen. Die Schwingfestigkeit und das Elastizitätsmodul des Scaffolds sind im Idealfall identisch mit dem zu ersetzenden Gewebe. Die mechanischen Eigenschaften müssen auch „in vivo“ bestehen bleiben.

Im Kontext der additiven Fertigung ist die Biokompatibilität, Biodegradierbarkeit und Bioaktivität ein Werkstoffentwicklungsthema mit stark ausgeprägten Schnittstellen zur Medizin. Geometrische und mechanische Eigenschaften sind in Abhängigkeit des gewählten Werkstoffs in geeigneten Maschinen mit einer entsprechenden Prozessstrategie zu fertigen.

\subsubsection{Werkstoffe für bioresorbierbare Implantatmatrizen}

Die Anforderungen (vgl. Abschnitt 2.2.3) an die Biokompatibilität, Biodegradierbarkeit und der Bioaktivität des Scaffolds implizieren eine anwendungsgerechte Werkstoffwahl unter medizinischen Aspekten. Grundsätzlich lassen sich entsprechende Biomaterialien in die folgenden drei Gruppen einteilen [SK16] [OBr11]:

Biologisches Material unterteilt sich weiter nach der Herkunft. Autogenes Material wird dem Empfänger zuvor entnommen. Der Einsatz allogener (gleiche Spezies / anderes Individuum) und xenogener (andere Spezies) Materialien hat das Risiko der Krankheitsübertragung und Antigenität. 
Synthetisches Material umfasst die Werkstoffgruppen der Polymere, Metalle und Keramiken. Die alloplastischen Materialien haben durch ihren synthetischen Ursprung kein Risiko bezüglich einer Krankheitsübertragung.

Kompositmaterial besteht aus organischen und anorganischen Komponenten.

Im Kontext der additiven Fertigung ist vor allem der Einsatz von synthetischen Materialien als Ausgangsmaterial zur Herstellung der Implantatmatrizen hervorzuheben. Um die Anforderung der Biodegradierbarkeit zu erfüllen, werden im Bereich des Tissue Engineerings bioresorbierbare Polymere, stark korrodierende Metalle, Biokeramiken oder Biogläser verwendet [TCP+17, S. 9] [SK16] [OBr11] [Hög10, S. 4].

Bioresorbierbare Polymere Bei der Herstellung von Polymeren werden Monomere durch eine chemische Reaktion (vgl. Abschnitt 2.3.2) miteinander verknüpft. Die Eigenschaft der synthetisierten Werkstoffe basiert auf den Grundeigenschaften ihrer Bestandteile [CI02] [CLT13]. Polycaprolacton, abgekürzt als „PCL", besteht aus dem Monomer $\varepsilon$-Caprolacton, zählt zu den Thermoplasten und wird im Bereich des „Bone Tissue Engineerings“ eingesetzt [PDG+13] [SCR+16]. Polyvinyl Alcohol, abgekürzt als „PVA“, besteht aus dem Monomer Vinylalkohol, wird beispielsweise durch eine Umesterung von Polyvinylacetat hergestellt und zählt zu den thermoplastischen Kunststoffen. PVA ist wasserlöslisch, wird im Kontext der additiven Fertigung als Stützstrukturmaterial oder für das „Soft Tissue Engineering" verwendet [SCC00] [BWS+12] [HKP+18]. Poly(Lactic Acid), abgekürzt als „PLA“, basiert auf chemischer Synthese von Milchsäuren und ist mengenmäßig eines der wichtigsten Biopolymere [ES09, S. 103]. Das PLA wird in Abhängigkeit der synthetisierten Milchsäuren (L-/D-Milchsäure) weiter unterteilt in PLLA (Poly(L-Lactic Acid)), PDLA (Poly(D-Lactic Acid)), PDLLA (Poly(D,L-Lactic Acid)) und PLDLLA (Poly(L-Lactic-co-D,L-Lactic Acid)). Im Allgemeinen ist die Struktur des thermoplastischen PLAs als amorph zu rubrizieren. Zur Steigerung der chemischen Stabilität kann die Kristallinität durch entsprechende Prozessführungsschritte erhöht werden [DLH+13, S. 3919] [CLT13, S. 614-616] [MS11, S. 1378-1380]. Poly(Glycolic Acid), abgekürzt als „PGA“, besteht aus dem Monomer Glycolsäure, ist hochgradig kristallin und wird in der Medizin unter anderem als resorbierbares Material zur Herstellung von Fäden verwendet [GFC+09, S. 1441] [LGN10, S. 129] [MS11, S. 1379] [GCC+14, S. 3641]. Poly(Lactic-co-Glycolic Acid), abgekürzt als „PLGA“ ist ein Copolymer, dessen Makromoleküle aus PLA und PGA aufgebaut sind. Kommerziell erhältliche PLGA-Copolymere unterscheiden sich in den copolymerisierten Makromolekülen, deren Molverhältnis, der inhärenten (logarithmischen) Viskosität und spezifischen Modifizierungen. Typische Molverhältnisse von PLA zu PGA sind 50:50, 75:25 und 85:15 [Sho10, S. 585] [NL07, S. 769-770]. Das amorphe PLGA wird zur Herstellung von Nanopartikeln als Genoder Wirkstoffträger und für das Tissue Engineering genutzt [TTZ+12, S. 266-272] [SSH+16, S. 95-96] [GCC+14, S. 3640-3643] [DAG+17, S. 297-298].

Stark korrodierende Metalle Metallische Werkstoffe sind durch die mechanischen Eigenschaften insbesondere zur Regenration von Knochendefekten geeignet [Dor14] 
[CXS+14]. Magnesium, abgekürzt als „Mg“, ist als Elektrolyt ein natürlicher Nahrungsbestandteil für den menschlichen Körper und wird durch Korrosion abgebaut. MAGNEZIX ${ }^{\circledR}$ (Marke der Syntellix AG) ist beispielsweise ein magnesiumbasierter Werkstoff für bioresorbierbare Schrauben und Stifte, der seit dem Jahre 2013 eine CE-Kennzeichnung trägt. Magnesium-Implantate werden unter anderem mit Calcium (Ca), Zirconium (Zr), Zink (Zn) oder Mangan (Mn) versetzt [SEK+18] [PW18] [CKM+16].

Biokeramik Im Kontext des Tissue Engineerings zählt das Calciumphosphat zu den wichtigsten bioaktiven Keramiken für Anwendungen in der Orthopädie [WH09, S. 1601]. Sowohl Hydroxylapatit (HA) als auch Tricalciumphosphat (TCP) werden als synthetische Knochenersatzmaterialien eingesetzt [DE02] [SEK+18] $[\mathrm{HTF}+18]$. Biogläser werden als Untergruppe der Biokeramiken klassifiziert.

Biogläser Bioaktive Gläser werden im Bereich des „Bone Tissue Engineerings“ verwendet, sind aus den Komponenten Natriumoxid $\left(\mathrm{Na}_{2} \mathrm{O}\right)$, Kaliumoxid $\left(\mathrm{K}_{2} \mathrm{O}\right)$, Magnesiumoxid $(\mathrm{MgO})$, Calciumoxid $(\mathrm{CaO})$, Siliciumdioxid $\left(\mathrm{SiO}_{2}\right)$, Phosphorpentoxid $\left(\mathrm{P}_{2} \mathrm{O}_{5}\right)$ bzw. Bortrioxid $\left(\mathrm{B}_{2} \mathrm{O}_{3}\right)$ zusammengesetzt und werden entsprechend der prozentualen Gewichtsanteile in die Gruppen der Phosphatgläser, Boratgläser oder der silikatischen Gläser eingeteilt [LRC+17] [YYG+18] [RDB+11]. Bioglas, häufig als Henchglas bezeichnet, wird seit dem Jahr 1985 klinisch eingesetzt [Hen06].

Zur gezielten Variation der Werkstoffeigenschaften können die genannten Materialien zu einem Verbundwerkstoff gemischt werden.

\subsubsection{Auswahl eines AM-Verfahrens zur Herstellung der Matrizen}

Die Anforderungen (vgl. Abschnitt 2.2.3) an die geometrischen und mechanischen Eigenschaften des Scaffolds implizieren die anwendungsgerechte Auswahl eines entsprechenden Fertigungsverfahrens unter Berücksichtigung medizinischer Aspekte. Zur Herstellung interkonnektierender Porenstrukturen ist die additive Fertigung ideal geeignet. Die mechanischen Bauteileigenschaften entstehen simultan zum Geometrieaufbau und können durch eine entsprechende Prozessführung gezielt beeinflusst werden. Die Auswahl des AM-Verfahrens geschieht unter der Annahme, dass die Kontur des Implantats einem Hüllkörper mit quadratischen Seitenfächen im Bereich ab $20 \mathrm{~mm}$ entspricht und ein polymerbasiertes Biomaterial als Ausgangswerkstoff verwendet wird. Der Lösungsraum wird aufgespannt durch die in Abschnitt 2.1.4 beschriebenen AM-Verfahrensklassen. Das Laser-CVD und Aerosoldrucken sind Technologien zur Herstellung von Bauteilen im Mikrometerbereich und werden daher nicht weiter in Betracht gezogen. Schicht-LaminatVerfahren sind aufgrund ihres substraktiven Charakters nicht zur Fertigung komplexer Porenstrukturen geeignet. In der Literatur werden 3D-Drucken, Extrusionsverfahren, Sintern/Schmelzen und Polymerisation als mögliche Verfahrensklassen zur Herstellung von bioresorbierbaren Implantatmatrizen diskutiert, wobei keines der genannten Verfahren für die skizzierte Anwendung zertifiziert ist [GAT+14] [TCP+17]. Das pulverbettbasierte 3D-Drucken wird primär für das „Bone Tissue Engineering“ verwendet, wobei 
Calciumphosphat-Keramiken als Ausgangswerkstoffe verarbeitet werden. Die gedruckten Matrizen müssen nachversintert werden [HGD+08] [SRI+05] [SDL+09]. Veröffentlichungen über 3DP-gefertigte Polymermatrizen konnten im Rahmen der Recherche nicht ausfindig gemacht werden. Vor dem Hintergrund, dass bei der Verarbeitung von polymerbasierten Partikeln zu einem mechanisch belastbaren Bauteil mittels 3DP neben der Materialentwicklung zusätzlich ein geeignetes nicht toxisches und bioresorbierbares Bindemittel identifiziert werden muss, wird das Verfahren nicht weiter betrachtet. Zum Extrudieren von Matrizen aus bioresorbierbaren Polymeren wie PLA oder PCL werden in der Regel modifizierte „Open Source"-FDM-Maschinen verwendet. Die Porengrößen der generierten Scaffolds sind im Durchschnitt zwischen $600 \mu \mathrm{m}$ und $1000 \mu \mathrm{m}$ groß. Im Fertigungsprozess wird das strangförmige Ausgangsmaterial in einem Kreuzmuster übereinander gelegt $[\mathrm{RBF}+16][\mathrm{CGN}+17]$. Aufgrund der vergleichsweise geringen Festigkeit und begrenzten Abbildungsgenauigkeit wird das Extrusionsverfahren nicht weiter betrachtet. Mit dem Polymerisationsverfahren werden PLA- oder PCL-basierte Photopolymere verarbeitet. Durch das flüssige Ausgangsmaterial können hochgradig feine Strukturen mit Porengrößen von bis zu $200 \mu \mathrm{m}$ erzeugt werden. Zur photochemischen Härtung des Ausgangsmaterials werden Photoinitiatoren beigemengt. Eine wesentliche Herausforderungen bei der Entwicklung geeigneter Materialien ist die Einhaltung der Biokompatibilität $[\mathrm{ETH}+11][\mathrm{MKW}+17][\mathrm{MBG}+10]$. Aufgrund des materialspezifischen toxischen Potentials wird das Verfahren, trotz der hervorragenden Abbildungsqualität, nicht weiter in Betracht gezogen. Das pulverbettbasierte Sintern/Schmelzen erzeugt im Vergleich zu den bereits diskutierten einstufigen AM-Verfahren die mechanisch stabilsten bioresorbierbaren Polymer-Scaffolds. Die ohnehin verwendete Schutzgasatmosphäre im Fertigungsprozess verhindert das Eindringen von Fremdstoffen in das Scaffold. Zudem benötigt das Verfahren keine Stützstrukturen. Das Sintern/Schmelzen wird daher als AM-Verfahren zur Herstellung von bioresorbierbaren Matrizen ausgewählt.

\subsection{Lasersintern (LS)}

Das Lasersintern (LS) wird in Abschnitt 2.3.1 systematisch in die AM-Verfahrensklasse „Sintern/Schmelzen“ eingeordnet. Durch den Energieeintrag eines Lasers in ein Pulverbett aus thermoplastischen Partikeln generiert das Lasersintern Funktionsbauteile. Die thermoplastischen Ausgangswerkstoffe zeichnen sich durch ihre Schmelzfähigkeit aus und werden in Abhängigkeit der Makromolekülanordnung in amorphe oder teilkristalline Thermoplaste unterteilt. Der Abschnitt 2.3.2 stellt die Grundlagen der Kunststofftechnik, die thermischen Zustandsbereiche beider Thermoplasten und kommerziell verwendete Materialien zum Lasersintern dar. Der Abschnitt 2.3.3 beschreibt den Lasersinterprozess sowie funktionale Baugruppen einer Lasersintermaschine. Abschließend werden in Abschnitt 2.3.4 die Prozessparameter und Einflussgrößen auf das Lasersintern dargestellt.

\subsubsection{Systematische Einordnung des AM-Verfahrens}

Die AM-Verfahrensklasse „Sintern/Schmelzen“ verarbeitet feste, pulverförmige Materialien. Die Schichtgenerierung geschieht durch ein Aufschmelzen und anschließendes 
Erstarren des Materials. Der Energieeintrag in das Pulver kann durch einen „Infrarotstrahler“, „Laserstrahl“ oder „Elektronenstrahl“ erfolgen. Die vorliegende Arbeit befasst sich ausschließlich mit dem Sintern/Schmelzen pulverförmiger Materialien durch das Einwirken eines Laserstrahls. Der Laserstrahl wird in der horizontalen x-y-Ebene durch einen Galvanometer-Scanner auf der Pulverbettoberfläche positioniert. Die VDI-Richtlinie 3405 [VDI 3405] stellt diesbezüglich die Laser-Scanner-Verfahren „Lasersintern“ und „Laserstrahlschmelzen“ vor. Das Lasersintern (engl. „Laser Sintering“/ Abk. LS) wird primär zur Herstellung von Kunststoffbauteilen verwendet. Die Herstellung metallischer Bauteile durch das Lasersintern entspricht einem zweistufigen Prozess, bei dem das Bauteil durch die geringe Koaleszenz im Anschluss an den AM-Prozess in einem Ofen nachversintert wird. Das Laserstrahlschmelzen (engl. „Laser Beam Melting“/ Abk. LBM) ist ein mit dem Lasersintern vergleichbarer, einstufiger Prozess zur Herstellung metallischer Bauteile. Durch das LBM-Verfahren werden die Metallpartikel vollständig aufgeschmolzen. Da sich die Produktstrukturen der Lasersinter- und Laserstrahlschmelzmaschinen aufgrund funktional gleichwertiger Baugruppen stark ähneln, wird das Laserstrahlschmelzen in der Einordnung entsprechend berücksichtigt.

\subsubsection{Thermoplastische Materialien für das Lasersintern}

Kunststoffe (Polymere) werden eingeteilt in die Gruppen der „Thermoplaste“, „Elastomere" und „Duromere“ [Bon14, S. 33] [EEH05, S. 3]. Bei ihrer Herstellung werden Monomere durch eine chemische Reaktion zu Makromolekülen netz- oder kettenartig miteinander verknüpft [BS12, S. 397] [WDJ15, S. 364] [RMS16, S. 281]. Die Vernetzungsgrade der Polymergruppen sind in Abbildung 2.8 dargestellt. Thermoplastische Kunststoffe sind

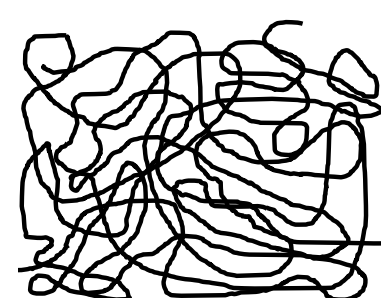

(a) Thermoplaste

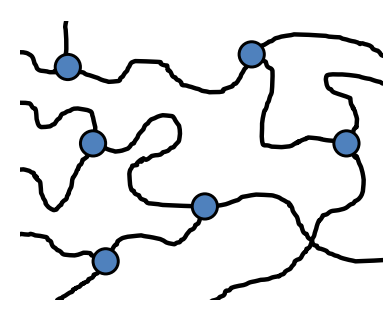

(b) Elastomere

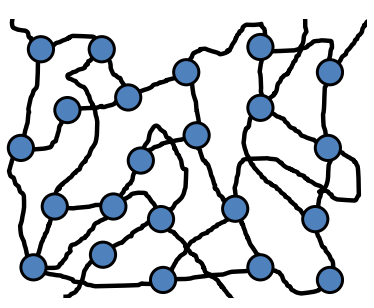

(c) Duromere

Abbildung 2.8.: Strukturmodelle der Polymergruppen [Bon14, S. 34]

unvernetzt, plastisch verformbar, erweichen bzw. schmelzen durch das Einbringen thermischer Energie und verfestigen nach dem Abkühlen. Das Aufschmelzen und anschließende Erstarren kann ohne eine chemische Veränderung mehrfach wiederholt werden. Elastomere sind chemisch, schwach (weitmaschig) vernetzt, entropieelastisch (gummielastisch) und nicht schmelzbar. Duromere sind durch ihre chemische, starke (engmaschige) Vernetzung weder schmelzbar noch elastisch verformbar [Bon14, S. 33-36] [BS12, S. 398-399] [EEH05, S. 5-13] [WDJ15, S. 364-366] [EEH08, S. 4]. Durch ihre Schmelzfähigkeit sind lediglich Polymere mit thermoplastischem Werkstoffverhalten für den Lasersinterprozess geeignet [Sch15b, S. 68] [Geb13, S. 60]. Die unvernetzten Kunststoffe lassen sich weiter unterteilen 
in ,amorphe Thermoplaste“ und „teilkristalline Thermoplaste“. Die Anordnung der Makromoleküle (Sekundärstruktur) der thermoplastischen Polymere ist in Abbildung 2.9 dargestellt. In amorphen Strukturen sind die Makromoleküle unregelmäßig ineinander bzw.

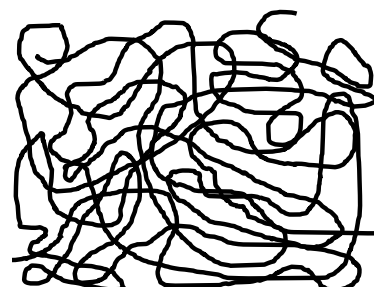

(a) amorph

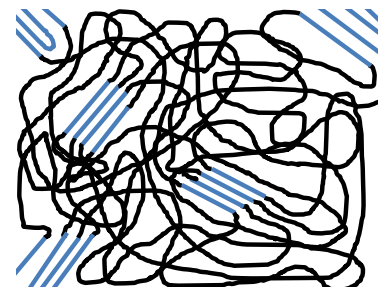

(b) teilkristallin

Abbildung 2.9.: Strukturmodelle der thermoplastischen Polymere [EEH08, S. 6]

nebeneinander angeordnet (statistische Knäuel). Aufgrund der chaotischen Molekülstruktur besitzen amorphe Thermoplaste lediglich eine Nahordnung. Die Makromoleküle der teilkristallinen Polymere hingegen können sich in einigen Bereichen regelmäßig, parallel, nah aneinanderlagern und Kristalle bilden. Da nicht alle Domänen kristallisieren, besitzen die teilkristallinen Thermoplaste amorphe (ungeordnete) Bereiche. Amorphe Polymere erscheinen transparent. Mit steigender Kristallinität nimmt die Opazität (Trübung) der teilkristallinen Thermoplaste zu [Bon14, S. 38-39] [EEH05, S. 79-81]. Zur Ermittlung mechanischer Materialkennwerte werden Zugversuche durchgeführt. Dabei wird ein Zugstab mit bekanntem Querschnitt $\left(A_{0}\right)$ durch eine Zugkraft $(F)$ bis zum Bruch gedehnt. Die Zugfestigkeit $\left(\sigma_{\mathrm{M}}=F_{\max } / A_{0}\right)$ entspricht der Spannung, die sich aus der maximalen Zugkraft bezogen auf den Anfangsquerschnitt berechnet. Der Kennwert der Bruchdehnung $\left(\varepsilon_{\mathrm{B}}\right)$ gibt die bleibende Längenänderung nach dem Probenbruch bezogen auf die Anfangsmesslänge an und charakterisiert die Duktilität [GBG18, S. E24-E26]. Die Abbildung 2.10 stellt den Temperatureinfluss auf die Materialkennwerte von Zugfestigkeit und Bruchdehnung für amorphe bzw. teilkristalline Thermoplaste dar. Bei niedrigen Tempe-

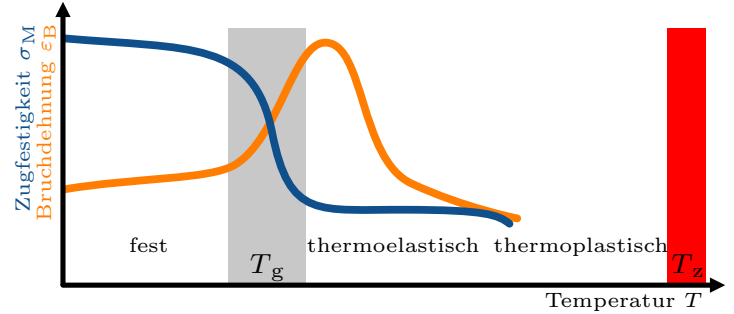

(a) amorph

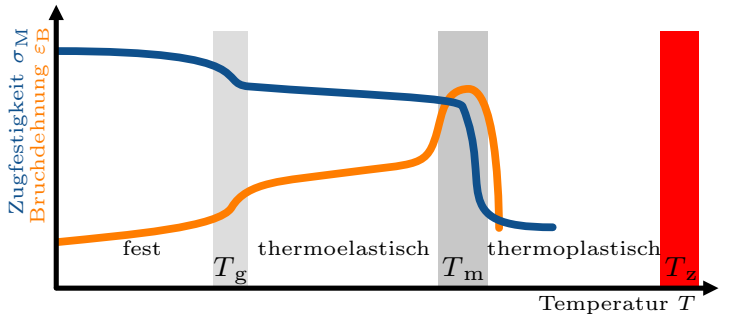

(b) teilkristallin

Abbildung 2.10.: Thermische Zustandsbereiche von Thermoplasten [Bon14, S. 51-52]

raturen $\left(T<T_{\mathrm{g}}\right)$ zeigen sowohl amorphe als auch teilkristalline Thermoplaste ein sprödes (festes) Werkstoffverhalten [IRH06, S. 145]. Oberhalb der Glasübergangstemperatur $\left(T_{\mathrm{g}}\right)$ beginnen die amorphen Molekülstrukturen zu erweichen. Durch den Wärmeenergieein- 
trag findet eine zunehmende Molekülbewegung in den Polymerketten statt, wodurch eine Dehnung bereits bei geringerer Krafteinwirkung einsetzt [EEH05, S. 78-79]. Bei weiterer Erhöhung der Temperatur $\left(T>T_{\mathrm{g}}\right)$ gehen amorphe Thermoplaste kontinuierlich vom thermoelastischen in den thermoplastischen Zustandsbereich über (vgl. (a) Abbildung 2.10). In teilkristallinen Thermoplasten sind die Temperaturbereiche in denen sich der Werkstoff elastisch bzw. plastisch verhält durch die Kristallitschmelztemperatur eindeutig voneinander getrennt (vgl. (b) Abbildung 2.10). Die kristallinen Bereiche, die zur Steigerung der Werkstofffestigkeit auch oberhalb der Glasübergangstemperatur beitragen, lösen sich aufgrund der Molekularbewegung auf. Teilkristalline Thermoplaste gehen bei einer Temperatur oberhalb der Kristallitschmelztemperatur $\left(T>T_{\mathrm{m}}\right)$ unmittelbar in den thermoplastischen Zustand über. Wird die Zersetzungstemperatur $\left(T_{\mathrm{z}}\right)$ überschritten, lösen sich die Hauptvalenzkräfte in den Polymerketten auf [Bon14, S. 51-52]. Thermoplastische Lasersintermaterialien sind grundsätzlich pulverförmig. Neben der verwendeten Maschine und den gewählten Prozessparametern haben vor allem die Eigenschaften des eingesetzten Materials, dargestellt in Abbildung 2.11, einen erheblichen Einfluss auf die generierten Bauteileigenschaften. Lasersintermaterialien werden unter anderem von den

\begin{tabular}{|c|c|c|}
\hline Thermische Eigenschaften & Pulvereigenschaften & Zusammensetzung \\
\hline \begin{tabular}{|l} 
- Schmelztemperatur \\
- Schmelzenthalpie \\
- Kristallisationstemperatur \\
- Kristallisationsenthalpie \\
- Kristallisationsgeschwindigkeit \\
- Zersetzungstemperatur \\
- Größe Prozessfenster \\
- Wärmekapazität \\
- Wärmeleitfähigkeit \\
- Wärmeausdehnung \\
- Isotherme Kristallisation
\end{tabular} & \begin{tabular}{|l} 
- Kornform \\
- Sphärizität \\
- Korngrößenverteilung \\
- Fließfähigkeit \\
- Feuchtigkeit \\
- Herstellungsverfahren \\
- Aufladung \\
- Fließhilfen \\
- Schüttdichte \\
- Struktur
\end{tabular} & \begin{tabular}{|l} 
- Polymertyp \\
- Füllstoffe \\
- Additive \\
- Anteile \\
- Blend-Anteil \\
- Herstellungsverfahren \\
- amorph/teilkristallin \\
- Fremdstoffe
\end{tabular} \\
\hline \multicolumn{3}{|c|}{ Eigenschaften eines thermoplastischen Materials zum Lasersintern } \\
\hline $\begin{array}{l}\text { - Viskosität } \\
\text { - Alterungsbeständigkeit } \\
\text { - Oberflächenspannung } \\
\text { - Oberflächenenergie } \\
\text { - Benetzungswinkel } \\
\text { - Molekulargewicht } \\
\text { - Molekularverteilung }\end{array}$ & $\begin{array}{l}\text { - Absorption/Emission } \\
\text { - Brechungsindex } \\
\text { - Reflexion } \\
\text { - Absorber } \\
\text { - Eindringtiefe } \\
\text { - Streuung }\end{array}$ & $\begin{array}{l}\text { - Kristallinität } \\
\text { - Lamellendicke } \\
\text { - Sphärolithgröße } \\
\text { - Verteilung Füllstoffe/Additive } \\
\text { - Füllstoffgeometrie } \\
\text { - Füllstoffgröße }\end{array}$ \\
\hline Rheologische Eigenschaften & Optische Eigenschaften & Mikrostruktur \\
\hline
\end{tabular}

Abbildung 2.11.: Eigenschaften eines Materials zum Lasersintern [Weg15, S. 8]

Firmen EOS, ALM, 3D-Systems, Arkema, ExcelTec, Windform, Solvay, Lehmann \& Voss und Rowak produziert. Da Material und Maschine aufeinander abgestimmt sein müssen, ist der Markteintritt für maschinenunabhägige Materialproduzenten mit entsprechenden Hürden verbunden. Die folgenden thermoplastischen Polymere werden kommerziell zum Lasersintern eingesetzt [Sch15a, S. 15-17]:

- Polyamid 12 (PA12) natur oder gefüllt

- Polyamid 11 (PA11) natur oder gefüllt

- Polyamid 6 (PA6) 
- Polystyrol (PS)

- Polyetheretherketon (PEEK) natur oder gefüllt

- Polyetherketonketon (PEKK) natur oder gefüllt

- Polypropylen (PP)

- Polyphenylensulfid (PPS)

- Thermoplastische Elastomere (TPE)

- Thermoplastisches Polyurethan (TPU)

Die gefüllten Materialien sind angereichert mit Aluminium, Glas oder Kohlenstofffasern. PA12-basierte Lasersintermaterialien werden mit Abstand am häufigsten zum Lasersintern verwendet [Sch15a, S. 16] [Geb13, S. 60-63]. Für die medizinische Anwendbarkeit eines Materials sind vor allem die Biokompatibilität, Biodegradierbarkeit und Bioaktivität entscheidend. Bioresorbierbare Polymere (vgl. Abschnitt 2.2.4) gelten im Kontext des Lasersinterns als Sonderwerkstoffe.

\subsubsection{Beschreibung des Lasersinterprozesses}

Die Abbildung 2.12 stellt schematisch den Aufbau einer Lasersintermaschine und entsprechende Bauteilbezeichnungen dar, die zur Prozessbeschreibung genutzt werden. Die gedichtete Prozesskammer ist über der Bauplattform optisch durch ein Laserglas geöffnet. Gelb markierte Bereiche weisen auf elektrische Heizelemente hin. In dem Galvanometer-Scanner sind zwei drehbare Spiegel verbaut, die den Laserstrahl in der x-y-Ebene positionieren. Die Abbildung 2.13 stellt den zeitlichen Ablauf eines Lasersinterprozesses grafisch dar. Die schichtspezifischen Teilprozessschritte „Pulverzuführung“, „Pulverauftrag“

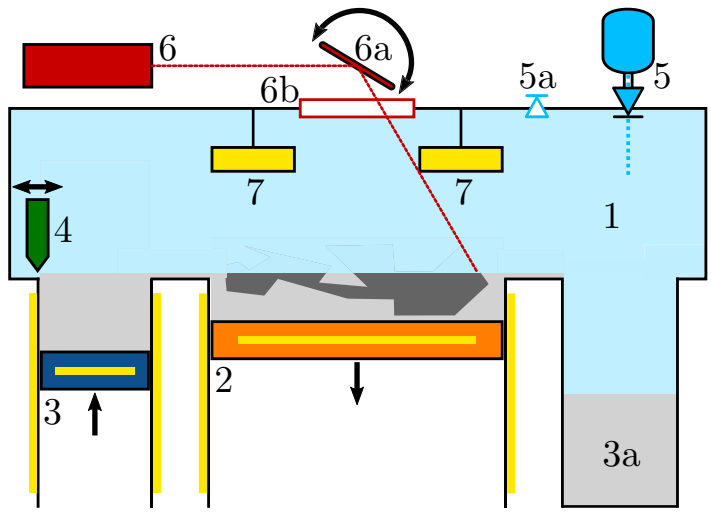

(1) LS-Maschine mit Prozesskammer

(2) Bauplattform mit Heizeinheit

(3) Pulverzuführplattform mit Heizeinheit

(3a) Pulverüberlaufbehälter

(4) Pulverauftragseinrichtung

(5) Inertgastank und Intertgaseinleitung

(5a) Ventil zum Inertgasauslass

(6) $\mathrm{CO}_{2}$-Laser

(6a) Galvano-Scanner

(6b) Laser-Einkoppelfenster

(7) Heizeinheit für Pulverbettoberfläche

Abbildung 2.12.: Bauteilbezeichnungen zur Beschreibung des Lasersinterprozesses

und „Laserenergieeintrag“ werden wiederholt bis die gesamte Bauteilhöhe generiert ist. Der Lasersinterprozess wird in das „Pre-Processing“, „In-Processing“ und „Post-Processing“ aufgeteilt. Im Folgenden wird der Lasersinterprozess detailliert dargestellt. 
Pre-Processing Vor Prozessstart muss die Lasersintermaschine zunächst für einen Baujob vorbereitet werden. Die additiv zu fertigenden Bauteile werden durch entsprechende Computerprogramme in dem Bauvolumen der Maschine angeordnet. In Abhängigkeit der Schichtstärke und Belichtungsstrategie werden die Pfadinformationen für die Laserstrahl-Ablenkeinheit (Galvano-Scanner) durch das "Slicing“ berechnet und als Schichtinformation an die Maschine versendet. Die gewählten Prozessparameter wie Laserleistung oder Schichtstärke stehen in einem materialspezifischen Zusammenhang. Der pulverförmige Werkstoff wird bei heruntergefahrener Pulverzuführplattform in den Pulvervorratsbehälter eingefüllt. Die Bauplattform (z-Koordinate $0 \mathrm{~mm}$ ) und die Pulverauftragseinrichtung (linke Fahrbereichsgrenze) befinden sich auf ihren Nullpositionen (vgl. (a) Abbildung 2.13).

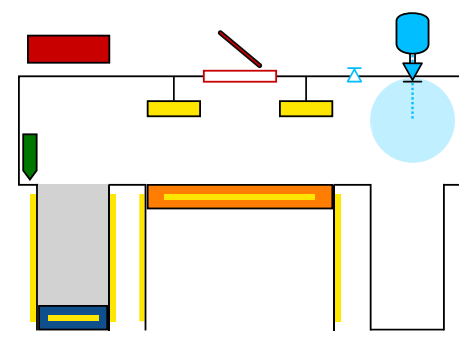

(a) Inertisierung \& Vorheizen

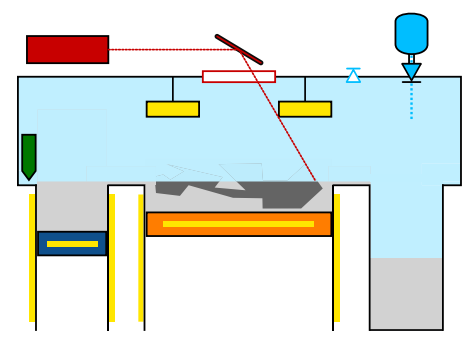

(d) Laserenergieeintrag

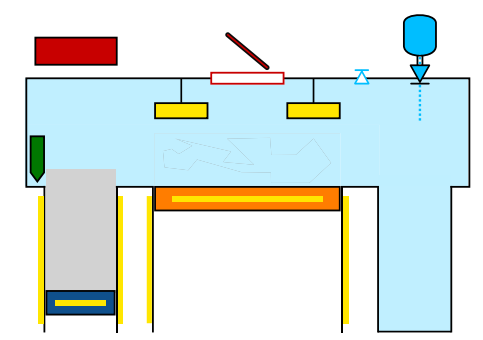

(b) Pulverzuführung

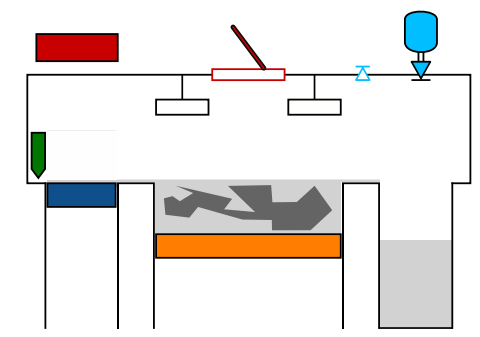

(e) Abkühlen

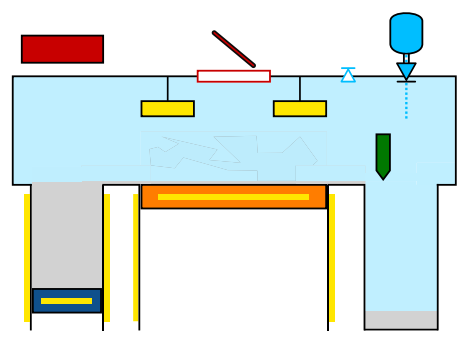

(c) Pulverauftrag

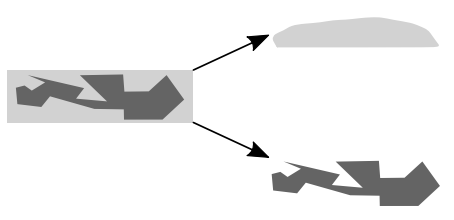

(f) Entpacken

Abbildung 2.13.: Lasersinterprozess vom Maschinenstart bis zur Bauteilentnahme

Inertisierung Die soweit permanenten Bestandteile der Luft sind Stickstoff $(78,09 \%$ vol), Sauerstoff $(20,95 \% \mathrm{vol})$, Argon $(0,93 \% \mathrm{vol})$, Neon $\left(18,21 \cdot 10^{-4} \% \mathrm{vol}\right)$, Helium $\left(5,24 \cdot 10^{-4} \% \mathrm{vol}\right)$, Krypton $\left(1,14 \cdot 10^{-4} \% \mathrm{vol}\right)$ und Xenon $\left(0,087 \cdot 10^{-4} \% \mathrm{vol}\right)$ [RW11, S. 15]. Um Brand- und Explosionsgefahren zu vermeiden, muss die Luft und der darin enthaltene Sauerstoff aus der Prozesskammer verdrängt werden. Bei geschlossener Maschine wird ein Inertgas, in der Regel Stickstoff, mit geringem Überdruck in die Prozesskammer eingeleitet. Das Luft-Inertgas-Gemisch entweicht über ein Auslassventil (vgl. (a) Abbildung 2.13). Die Inertisierung gilt als abgeschlossen, wenn ein zuvor definierter Restsauerstoffgehalt in der Prozesskammer unterschritten ist.

Aufheizvorgang Zum Lasersintern werden thermoplastische (teilkristallin oder amorph) Polymere (vgl. Abschnitt 2.3.2) verwendet. Um den zum Aufschmelzen des Pul- 
vers nötigen Energiebetrag durch den Laser zu reduzieren, wird die Maschine vorgeheizt. Die in Abbildung 2.13 dargestellte Maschine ist mit insgesamt vier Widerstandsheizeinheiten in den Plattformen und im Wandbereich ausgestattet. Die Pulverbettoberfläche in der Prozessebene wird durch Infrarot-Heizstrahler beheizt. Die geregelten Heizeinheiten beheizen den pulverförmigen Werkstoff homogen bis zu einem Wert unterhalb der Schmelz- bzw. Erweichungstemperatur (vgl. (a) Abbildung 2.13). Bei der Verwendung von teilkristallinen Thermoplasten liegt die Vorheiztemperatur oberhalb der Kristallisationstemperatur.

Pulverzuführung Durch die Aufwärtsbewegung der Pulverzuführplattform wird das Pulver über die Prozessebene in die Prozesskammer gehoben (vgl. (b) Abbildung 2.13). Das dem Pulverauftragsprozess bereitgestellte Pulvervolumen ist abhängig vom Hubweg der Plattform. Zum Zeitpunkt der Zuführung befindet sich der Pulverauftragskörper in der linken Fahrbereichsgrenze.

Pulverauftrag Der Beginn des Pulverauftragsprozesses ist durch ein Absenken der Bauplattform um den Betrag einer Schichtstärke gekennzeichnet. Eine horizontale Bewegung der Pulverauftragseinrichtung aus der Referenzposition nach rechts verteilt das zugeführte Pulver über der Bauplattform. Da das Volumen des zugeführten Pulvers größer als das zu füllende Schichtvolumen über der Bauplattform ist, befindet sich auch nach dem Überfahren des Bauvolumens Restpulver vor der Beschichtereinheit. Erreicht der Beschichter seine rechte Fahrbereichsgrenzposition fällt das überschüssige Pulver durch den Einfluss der Gewichtskraft in den Überlaufbehälter (vgl. (c) Abbildung 2.13). Anschließend fährt der Beschichter zurück zu seinem Referenzpunkt, der sich links neben dem Pulvervorratsbehälter befindet. Das Prozessergebnis ist der Auftrag einer dünnen, planparallelen Pulverschicht zwischen $60 \mu \mathrm{m}$ und $120 \mu \mathrm{m}$ über der Bauplattform. Bevor die erste Schicht des zu generierenden Bauteils belichtet wird, werden auf der Bauplattform einige Leerschichten (Thermoblockschicht) erzeugt, die unter anderem einen unmittelbaren Laserenergieeintrag in die Bauplattform verhindern.

Bauteilschichtgenerierung Der durch den $\mathrm{CO}_{2}$-Laser emittierte Laserstrahl wird durch den Galvano-Scanner in Richtung der Bauplattform umgelenkt und mittels koordinierter Spiegeldrehung präzise in der x-y-Ebene (vgl. (d) Abbildung 2.13) über die Pulverbettoberfläche bewegt. Durch den Laserenergieeintrag in das vorgeheizte Pulverbett steigt die Temperatur im Idealfall kurzzeitig auf einen Wert oberhalb der Schmelztemperatur an, sodass die Oberflächen der aneinanderliegenden Pulverpartikel selektiv angeschmolzen werden. Der auf den Schichtquerschnitt bezogene Energieeintrag (Flächenenergiedichte) ist abhängig von der Laserleistung, der Laserablenkgeschwindigkeit und dem Laserspurabstand. Zur Angabe der Volumenenergiedichte wird die Schichtstärke wie folgt berücksichtigt [Sch15b, S. 21-22]:

$$
E_{\mathrm{A}}=\frac{P_{\mathrm{L}}}{v_{\mathrm{L}} \cdot h_{\mathrm{L}}} \quad \text { bzw. } \quad E_{\mathrm{V}}=\frac{P_{\mathrm{L}}}{v_{\mathrm{L}} \cdot h_{\mathrm{L}} \cdot d_{\mathrm{P}}}
$$

$E_{\mathrm{A}}$ : Flächenenergiedichte $\left[\mathrm{J} / \mathrm{mm}^{2}\right]$

$E_{\mathrm{V}}$ : Volumenenergiedichte $\left[\mathrm{J} / \mathrm{mm}^{3}\right]$ 
$P_{\mathrm{L}}:$ Laserleistung $[\mathrm{J} / \mathrm{s}]$

$v_{\mathrm{L}}$ : Laserablenkgeschwindigkeit (Scangeschwindigkeit) $[\mathrm{mm} / \mathrm{s}]$

$h_{\mathrm{L}}$ : Laserspurabstand $[\mathrm{mm}]$

$d_{\mathrm{P}}$ : Schichtstärke $[\mu \mathrm{m}]$

Zwischen den einzelnen Partikeln bilden sich im Bereich der Wärmeeinflusszone sogenannte Sinterhälse, die nach dem Abkühlen den Partikelverbund bewirken. Die Generierung einer Bauteilschicht geschieht in der Regel durch das Abfahren der Außenkontur und der Verfestigung der Innenfläche. Die unversinterten Pulverpartikel stützen das zu generierende Bauteil im Bauvolumen ab. Der Betrag der eingebrachten Energie in das Pulverbett muss ausreichend hoch sein, um mit der darunterliegenden Bauteilschicht eine mechanisch belastbare Verbindung erzeugen zu können. Zur Generierung filigraner Strukturen muss die Laser-Scanner-Einheit physikalisch in der Lage sein den Laserstrahl auf der Pulverbettoberfläche auf einen möglichst geringen Durchmesser zu fokussieren. Bei der Verwendung eines Lasers mit einer gaußförmigen Intensitätsverteilung (vgl. [DIN EN ISO 11145]) kann der Fokusdurchmesser durch die folgende Formel $^{1}$ abgeschätzt werden:

$$
d_{\mathrm{L}}=M^{2} \cdot k \cdot \lambda \cdot \frac{f}{D_{\mathrm{L}}}
$$

$d_{\mathrm{L}}$ : Durchmesser des fokussierten Laserstrahls in $\mu \mathrm{m}$ (Spotsize)

$M^{2}$ : Beugungsmaßzahl (Wert eines idealen Gauß-Strahls $1 /$ Realwert $>1$ )

$k$ : Korrekturfaktor (Idealwert 1,27 / Realwert zwischen 1,5 und 2)

$\lambda$ : Wellenlänge des Lasers (Abhängig vom Lasertyp $500 \mathrm{~nm}$ bis $11 \mu \mathrm{m}$ )

$f$ : Brennweite in mm (Abstand zwischen optischer Linse und Brennpunkt)

$D_{\mathrm{L}}$ : Durchmesser des Laserstrahls vor der Fokussierung in mm

Neben den technischen Qualitätsmerkmalen der Einzelkomponenten haben vor allem die Laserwellenlänge und der Arbeitsabstand (korreliert mit der Prozesskammerhöhe) wesentlichen Einfluss auf den Fokusdurchmesser. Der Korrekturfaktor ist unter anderem von der verwendeten Apertur am Scanner abhängig. Der Fokusdurchmesser („Spotsize“) entspricht dem Strahldurchmesser, der 86,5\% Leistung beinhaltet. Die folgenden Prozessschritte werden in der angezeigten Reihenfolge wiederholt bis der gesamte Baujob abgeschlossen ist:

1. Pulverzuführung: Aufwärtsfahrt der Pulverzuführplattform

2. Absenkung Bauplattform: Abwärtsfahrt um den Betrag einer Schichtstärke

3. Pulverauftrag: Beschichterbewegung parallel zur Bauplattform

4. Laserenergieeintrag: Positionierung des Laserstrahls in der Prozessebene

Vor der folgenden Bauteilschichtgenerierung wird die Temperatur an der Pulverbettoberfläche durch die Infrarot-Heizeinheit auf den Sollwert korrigiert.

${ }^{1}$ Quelle der Berechnungsformel: Firma Scanlab - http://www. scanlab.de/de/service/glossary/f 
Abkühlvorgang Sind alle Schichtinformationen durch den Laser in das Pulverbett übertragen, gilt der Schichtbauprozess als abgeschlossen. Die letzte Bauteilschicht wird mit einigen Leerschichten (Thermoblockschicht) abgedeckt, sodass sämtliche additiv gefertigten Bauteile in dem Bauvolumen von einem „Pulverkuchen“ umgeben sind. Zur Vermeidung lokaler Spannungen durch schlagartiges Abkühlen wird die Bauraumtemperatur zur Bauteilentnahme langsam abgesenkt (vgl. (e) Abbildung 2.13). Bei inhomogener Abkühlung teilkristalliner Thermoplaste erfolgt eine unkontrollierte Kristallisation, die zu Schwund und Bauteilverzug führt. Der Effekt der geometrischen Abweichung wird häufig als „Curling“ oder „Warpage“ bezeichnet. Mit sinkender Temperatur steigt die mechanische Bauteilfestigkeit.

Post-Processing Nach Entnahme des abgekühlten Bauvolumens aus der Maschine können die losen Pulverpartikel des „Pulverkuchens“ grob abgeklopft werden. Das unversinterte Pulver kann für den folgenden Schichtbauprozess kontrolliert wiederverwendet werden. Durch das Glasperlstrahlen werden die Bauteile von lose anhaftenden Partikeln intensiv gereinigt. Eine weitere Verbesserung der Bauteiloberfläche kann durch Schleifen erzielt werden (vgl. (f) Abbildung 2.13).

\subsubsection{Prozessparameter und Prozessbedingungen beim Lasersintern}

Die VDI-Richtlinie 3405 Blatt 1 [VDI 3405 Blatt 1] befasst sich mit der Güteüberwachung von lasergesinterten Kunststoffbauteilen. Zur Verarbeitung eines Lasersintermaterials werden an einer Lasersintermaschine Prozessparameter eingestellt, die in Wechselwirkung mit dem Material zu maschinenspezifischen Prozessbedingungen führen. Die Qualität eines lasergesinterten Bauteils, welches unter gewissen Prozessbedingungen generiert worden ist, definiert sich durch die folgenden Bauteileigenschaften [VDI 3405 Blatt 1, S. 14-15] [WWD+11, S. 12-35]:

- Dichte bzw. Porosität

- Formhaltigkeit

- Maßhaltigkeit

- Mechanische Eigenschaften

- Oberflächenqualität

Die robuste Prozessführung zielt auf eine Reproduzierbarkeit der Fertigungsergebnisse ab, die auf eine Spezifizierung der Prozessparameter und einer Werkstoffüberwachung zurückzuführen ist. Der Prozessparameter im Kontext des Lasersinterns definiert eine Möglichkeit zur Beeinflussung des Fertigungsprozesses mit einer spezifischen Maschine. Grundsätzlich ist eine Lasersintermaschine aus einer Kombination aus mechatronischen Teilsystemen aufgebaut, mit denen die Teilprozessschritte (vgl. Abschnitt 2.3.3) des Lasersinterns ausgeführt werden. Softwareseitige Prozessparameter (z. B. Vorheiztemperatur, Aufheizzeit, Schichtstärke, Feedrate, Beschichtergeschwindigkeit, Laserleistung, Scangeschwindigkeit, Scanabstand) können, sofern die Software dafür ausgelegt ist, in einem definierten Bereich an der Maschine eingestellt werden. Einige Prozessparameter 
(z. B. Beschichtergeometrie, Gasart, Laserwellenlänge) sind gekoppelt an spezifische Komponenten des mechatronischen Teilsystems und können lediglich durch einen Umbau bzw. Wechsel des jeweiligen Systems variiert werden. Die Überwachung von Prozessparametern und Prozessbedingungen ist in der VDI-Richtlinie in die folgenden drei Eingriffstiefen eingeteilt [VDI 3405 Blatt 1, S. 11-12]:

- Überwachungsintervall geknüpft an Wartungsintervall (alle 6 bis 12 Monate)

- Überwachung pro Bauprozess (am Anfang und Ende jedes Baujobs)

- Kontinuierliche Überwachung für jede Schicht (Echtzeit-Überwachung)

Als Prozessbedingung werden die Raumtemperatur, Luftfeuchtigkeit und der Restsauerstoffgehalt in der Prozesskammer genannt. Erst die Verwendung einer Echtzeit-Überwachung erlaubt durch den wiederholten Soll-Ist-Abgleich der Prozessparameter den direkten Rückschluss auf die Bauteilqualität [VDI 3405 Blatt 1, S. 12-13]. 


\section{Stand der Technik und Wissenschaft}

In dem vorliegenden Kapitel wird der Stand der Technik kommerzieller Lasersinter- und Laserstrahlschmelzmaschinen, sowie der Stand der Wissenschaft zur Herstellung von bioresorbierbaren Implantatmatrizen mittels Lasersintern zusammengefasst. In Abschnitt 3.1 werden diesbezüglich die aktuellen Maschinen aller namhaften Hersteller zur Verarbeitung von Polymeren vorgestellt. In dem Abschnitt 3.2 sind ausgewählte Merkmale kommerzieller Maschinen zur Metallverarbeitung dargestellt, die bei der Entwicklung einer Maschine zum Lasersintern berücksichtigt werden können. Aufgrund spezifischer Eigenschaften der bioresorbierbaren Werkstoffe können kommerzielle Maschinen nur bedingt zu deren Verarbeitung verwendet werden. Die detaillierte Darstellung der Produktmerkmale aus Abschnitt 3.1 bzw. Abschnitt 3.2 dient als Grundlage zur Entwicklung einer modularen Lasersintermaschine. Die bereits formulierten Herausforderungen bei der Herstellung von Implantatmatrizen aus bioresorbierbaren Materialien mit einer Lasersintermaschine werden im Kontext der Maschinenentwicklung in Abschnitt 3.3 zusammengefasst. 


\subsection{Kommerzielle Maschinen zum Lasersintern von Polymeren}

In Abhängigkeit des Funktionalitäts- und Preisniveaus werden AM-Maschinen in die Maschinenklasse der „Prototyper“ oder „Fabricator" eingeteilt [Geb13, S. 17-19]. Bis vor wenigen Jahren war die Verfahrensklasse „Sintern / Schmelzen“ aufgrund der hohen Maschinenpreise der „Fabricator“ und der notwendigen Infrastruktur ausschließlich für Industrieunternehmen oder Forschungseinrichtungen zugänglich. In den letzten fünf Jahren sind zunehmend „Prototyper“-Maschinen für den semiprofessionellen Gebrauch auf den Markt gekommen, die trotz günstiger mechatronischer Bauteile beachtliche Fertigungsergebnisse erzeugen. In dem Zeitraum zwischen 2014 und 2018 wurden die Veränderungen in den Produktportfolios sämtlicher Hersteller von Lasersintermaschinen im Rahmen einer Marktrecherche zum Zwecke des „Benchmarkings“ mitverfolgt.

\subsubsection{Industrie- und Produktionsmaschinen (Fabricator)}

Die Industrie- und Produktionsmaschinen der „Fabricator“-Maschinenklasse sind in der Regel ab einem Anschaffungspreis von $150.000 €$ erhältlich. Die aktuellen Lasersintermaschinen der Firmen 3D-Systems (USA), EOS (Deutschland), Aspect (Japan) und Farsoon (China) werden mit den entsprechenden Vertriebs- und Entwicklungspartnern (Ricoh / Prodways) im Folgenden detailliert vorgestellt. Für die industrielle Anwendbarkeit ist neben gleichbleibender Produktionsqualität vor allem die Bauraumgröße, Prozessstabilität, Rüst- und Baugeschwindigkeit ein wichtiges Kriterium bei der Beschaffung einer neuen Produktionsmaschine. Durch steigende Laserleistungen werden höhere Scangeschwindigkeiten bei gleichbleibendem Volumenenergieeintrag zur Erhöhung der Baugeschwindigkeit technisch realisiert. Durch den Einsatz mehrerer Laser-Scanner-Einheiten können die Bauvolumina der Maschinen erheblich vergrößert werden. Eine Baufläche (x-y-Ebene) von $200 \mathrm{~mm} \times 200 \mathrm{~mm}$ gilt dabei als Kleinformat. Ein weiterer Trend ist die Entwicklung hochtemperaturfähiger Maschinen (EOS, Farsoon), um die Verarbeitung von Hochleistungskunststoffen (natur oder gefüllt) wie Polyetheretherketon (PEEK) oder Polyetherketonketon (PEKK) zu ermöglichen. Bauteile aus den genannten Kunststoffen können aufgrund ihrer Eigenschaften zur Substitution von Metallbauteilen eingesetzt werden.

3D-Systems (ehemals DTM) Das Lasersintern wurde von Carl Deckard anfangs der 80er an der Universität Texas in Austin (Fachbereich Maschinenbau) entwickelt und im Jahr 1986 patentiert [The12]. Die Patentschrift beschreibt sowohl das Verfahren als auch die Maschine zur schichtweisen Herstellung von Bauteilen aus pulverförmigen Werkstoffen mittels „Selective Sintering“. In der eingereichten Skizze der Erfindung wird der Nd:YAG-Laserstrahl über zwei Spiegel abgelenkt [US4863538 A]. Kurz nach der Patentierung wurde das Verfahren kommerzialisiert. Zunächst verkauft die Firma DTM 1990 Maschinen mit der Bezeichnung „Mod A“, „Mod B“ und „125s“. Zwei Jahre später wurde das Produkt mit neuem Design unter der Bezeichnung „SinterStation 2000“ und „SinterStation 2500“ vertrieben. 3D-Systems kaufte DTM im Jahr 2001 auf [The12] [Geb13, S. 164]. Die Tabelle 3.1 fasst die aktuellen Lasersintermaschinen zur Polymer-Verarbeitung zusammen [3D-15] [3D-14] 
[3D-18]. Ein besonderes Merkmal der 3D-Systems Maschinen ist der Pulverauftrag über der Bauplattform durch eine gegenläufig rotierende Rolle (Precision Counter Rotating Roller), die laut Herstellerangabe für eine hohe Pulververdichtung sorgt [3D-18, S. 3]. Die Kinematik des Pulverauftrags ist auf ein durch Joseph Beaman und Carl Deckard eingereichtes Patent [US4938816 A] aus dem Jahr 1990 zurückzuführen. Das „ProX“-Modell verfügt zusätzlich über die Möglichkeit der Drehzahlregelung der Auftragsrolle [3D-15, S. 2] [3D-14, S. 4].

Tabelle 3.1.: 3D-Systems Maschinen für das Lasersintern

\begin{tabular}{c|c|c}
\hline Maschine & CO $_{\mathbf{2}}$-Laser & Bauvolumen (x, y, z) \\
\hline ProX SLS 6100 & $100 \mathrm{~W}$ & $381 \mathrm{~mm}, 330 \mathrm{~mm}, 460 \mathrm{~mm}$ \\
\hline sPro 60 & $30 \mathrm{~W} / 70 \mathrm{~W}(\mathrm{HS})$ & $381 \mathrm{~mm}, 330 \mathrm{~mm}, 460 \mathrm{~mm}$ \\
\hline sPro 140 & $70 \mathrm{~W} / 200 \mathrm{~W}(\mathrm{HS})$ & $550 \mathrm{~mm}, 550 \mathrm{~mm}, 460 \mathrm{~mm}$ \\
\hline sPro 230 & $70 \mathrm{~W} / 200 \mathrm{~W}(\mathrm{HS})$ & $550 \mathrm{~mm}, 550 \mathrm{~mm}, 750 \mathrm{~mm}$ \\
\hline
\end{tabular}

Die typische Schichtstärke bei der Verarbeitung von Polymeren beträgt $100 \mu \mathrm{m}$. Anwendungsabhängig ist der Schichtstärkenparameter im Bereich von $80 \mu \mathrm{m}$ bis $150 \mu \mathrm{m}$ einstellbar. Die „sPro“-Modelle sind je nach Konfiguration mit verschiedenen $\mathrm{CO}_{2}$-Lasern und Scannern ausgestattet. Die Produktionsmaschine „sPro 60“ wird in den Varianten „SD“ (Standard Definition), „HD Base“ (High Definition) und „HD-HS“ (High Definition - High Speed) vertrieben [3D-14, S. 4]. Die Begriffe „Base“ und „HS“ beziehen sich auf die Leistungsklassen der Laser. Alle „HD“-Varianten sind mit digitalem Scanner ausgestattet, der komplexere Scanstrategien unterstützt [Geb13, S. 166]. Durch die Variation der Komponenten lässt sich die Aufbaurate annähernd verdoppeln. Kommerziell bietet 3D-Systems die Materialien PA12 (natur oder gefüllt), PA11 (natur oder gefüllt), TPE und PS zum Lasersintern an. Der marktbeherrschende PA12-Werkstoff der Firma 3D-Systems wird „DuraForm PA“ genannt [Sch15a, S. 17].

EOS (Electro Optical Systems) Die Firma EOS führt 1994 die Lasersintermaschine „EOSINT P 350“ zur Fertigung von Kunststoffprototypen ein. Die Kürzel „P“ (Polymer), „M" (Metall) oder „S“ (Sand) in der Maschinenbezeichnung geben Hinweis auf den Ausgangswerkstoff. In Tabelle 3.2 sind die aktuellen Lasersintermaschinen zur Verarbeitung von Polymeren zusammengefasst [EOS13a] [EOS13b] [EOS17c] [EOS16b] [EOS14b] [EOS18]. Alle Polymer-Maschinen der Firma EOS sind mit $\mathrm{CO}_{2}$-Lasern der Wellenlänge 10,6 $\mu \mathrm{m}$ ausgestattet und besitzen zur Erhöhung der Abbildungsqualität eine Planfeldlinse (F-Theta-Linse) am Strahlenausgang des Galvanometer-Scanners. Die großen Modelle (ab „P 500“) erreichen ihre mögliche Belichtungsfeldgröße durch den Einsatz von zwei simultan arbeitenden Laser-Scanner-Einheiten. Der Bauraum befindet sich in einem Wechselbehälter mit integrierter Bauplattform als Teil des Wechselrahmensystems. Die geregelte Beheizung der oberen Prozess- und unteren Entnahmekammer erfolgt getrennt und verfügt in Abhängigkeit der Maschinengröße über mehrere Heizkreise. Zur Reduktion der 
Stillstandszeit kann der im Wechselbehälter befindliche Pulverkuchen nach Beendigung des Lasersinterprozesses in einer gesonderten Abkühlstation kontrolliert abkühlen [EOS17d]. Zur Inertisierung der Prozesskammer und Kühlung der Optik wird Stickstoff eingesetzt.

Tabelle 3.2.: EOS Maschinen für das Lasersintern

\begin{tabular}{c|c|c}
\hline Maschine & CO $_{2}$-Laser & Bauvolumen $(\mathbf{x}, \mathbf{y}, \mathbf{z})$ \\
\hline P 110 & $30 \mathrm{~W}$ & $200 \mathrm{~mm}, 250 \mathrm{~mm}, 330 \mathrm{~mm}$ \\
\hline P 396 & $70 \mathrm{~W}$ & $340 \mathrm{~mm}, 340 \mathrm{~mm}, 600 \mathrm{~mm}$ \\
\hline P 500 & $2 \times 70 \mathrm{~W}$ & $500 \mathrm{~mm}, 330 \mathrm{~mm}, 400 \mathrm{~mm}$ \\
\hline P 770 & $2 \times 70 \mathrm{~W}$ & $700 \mathrm{~mm}, 380 \mathrm{~mm}, 580 \mathrm{~mm}$ \\
\hline P 800 & $2 \times 50 \mathrm{~W}$ & $700 \mathrm{~mm}, 380 \mathrm{~mm}, 560 \mathrm{~mm}$ \\
\hline P 810 & $2 \times 70 \mathrm{~W}$ & $700 \mathrm{~mm}, 380 \mathrm{~mm}, 380 \mathrm{~mm}$ \\
\hline
\end{tabular}

Die Maschinen besitzen einen Stickstoffgenerator, der Pressluft aus einem Kompressor in Sauerstoff und Stickstoff trennt [EOS14c] [EOS14a] [EOS08]. Die aktuelle „Formiga P 110“ ist durch die Laser-Scanner-Einheit zur Herstellung filigraner Bauteile geeignet [Geb13, S. 178] [EOS13a]. Laut Herstellerangabe wird der emittierte Laserstrahl um den Faktor 3,5 aufgeweitet, im Scanner abgelenkt und durch die Planfeldlinse mit einem Aperturdurchmesser von $20 \mathrm{~mm}$ bei einer Brennweite von $440 \mathrm{~mm}$ im Belichtungsfeld auf einen Durchmesser von $<500 \mu \mathrm{m}$ fokussiert, wodurch minimale Wandstärken von $400 \mu \mathrm{m}$ gefertigt werden können [EOS13a] [EOS14c, S. 3]. Die EOS „P 396“ deckt mit einem möglichen Belichtungsfeld von $350 \mathrm{~mm} \times 350 \mathrm{~mm}$ mittlere Bauvolumenbereiche im Bereich des Lasersinterns ab. Durch den Einsatz höherer Laserleistungen bei höheren Scangeschwindigkeiten lassen sich Bauraten erhöhen. Bei gleicher Aperturgröße, gleichem Aufweitungsverhältnis und einer größeren Brennweite von $500 \mathrm{~mm}$ erreicht die „P 396“ im Vergleich zur „P 110“ einen fokussierten Strahldurchmesser von $<600 \mu \mathrm{m}$, was den Zielkonflikt zwischen Genauigkeit und Bauraumgröße beschreibt [EOS13b] [EOS14a, S. 4]. Die „P 800“ ist im Speziellen auf die Verarbeitung des teilkristallinen Hochleistungspolymers PEEK ausgelegt. Polyetheretherketon zeichnet sich durch seine Dauergebrauchstemperatur von bis zu $260^{\circ} \mathrm{C}$, einer Schmelztemperatur von $372^{\circ} \mathrm{C}$ und der Zugfestigkeit von $90 \mathrm{MPa}$ aus [EOS10a]. Polyamid 12 schmilzt bereits bei einer Temperatur von $176^{\circ} \mathrm{C}$ und besitzt eine vergleichsweise niedrige Zugfestigkeit von $45 \mathrm{MPa}$ [EOS16a]. Die EOS „P 800“ gilt durch die Prozesskammerheizung, die eine maximale Bautemperatur von $385^{\circ} \mathrm{C}$ erzeugen kann, als Hochtemperaturanlage [EOS08, S. 2] [EOS14b]. Die „P 810“, vorgestellt im April 2018, basiert auf der „P 800 “ und wird in Verbindung mit dem „HT-23“-PEKK (flammhemmendes, mit Kohlefaser gefüllter Polyetherketonketon) beworben [Kun18]. Kommerziell bietet EOS die Materialien PA12 (natur oder gefüllt), PA11 natur, TPE, PS und das PAEK (natur oder gefüllt) zum Lasersintern an. Der marktbeherrschende PA12-Werkstoff der Firma EOS wird „PA2200“ bzw. „PA2201“ genannt [Sch15a, S. 17]. Je nach Ma- 


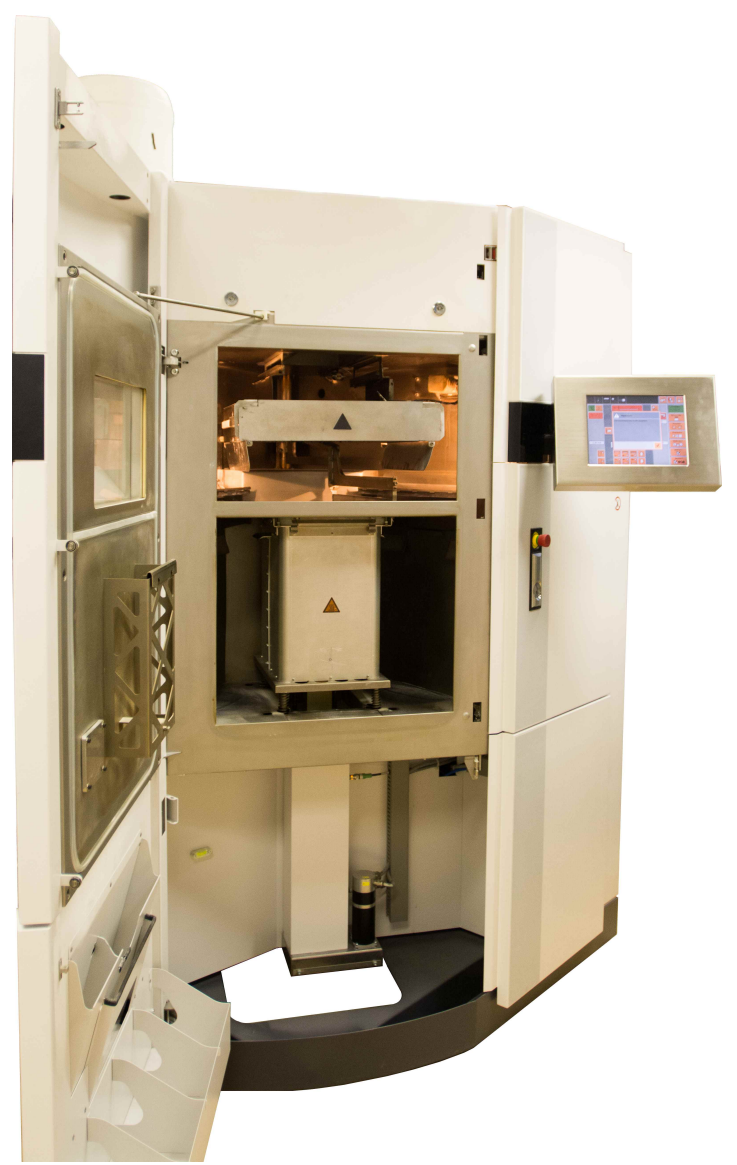

(a) Geöffnete Maschine

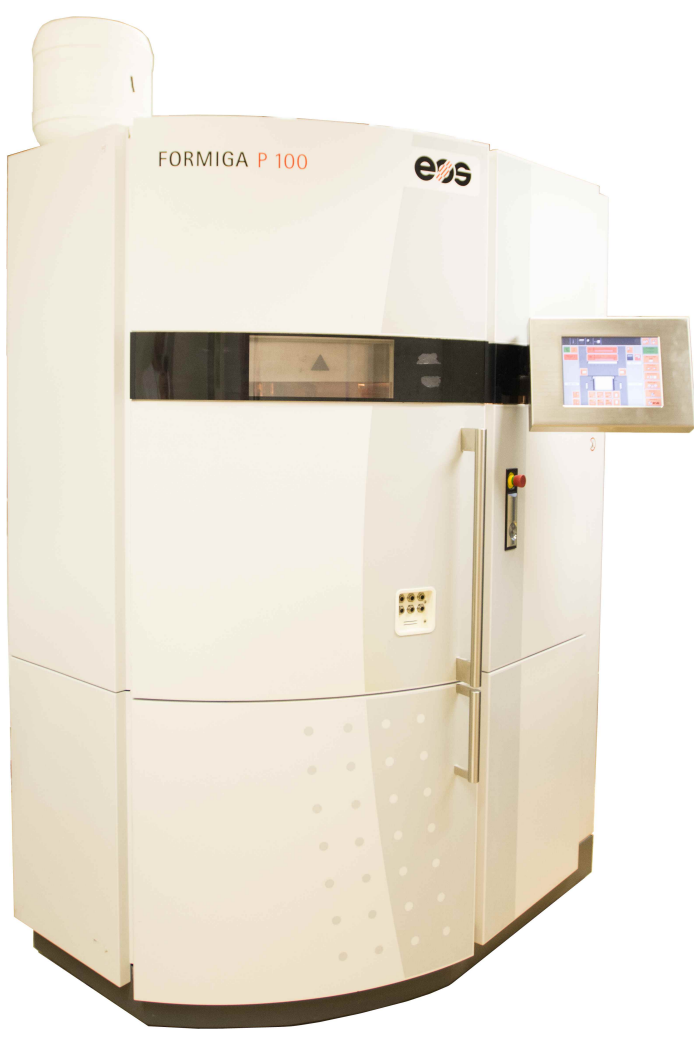

(b) Geschlossene Maschine

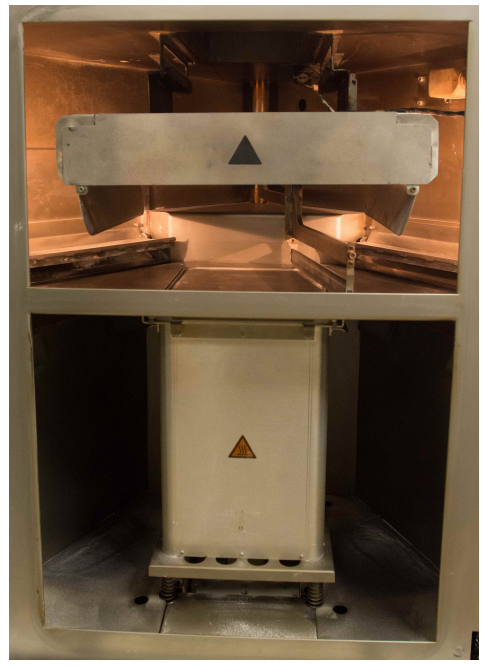

(c) Heizung \& Wechselbehälter

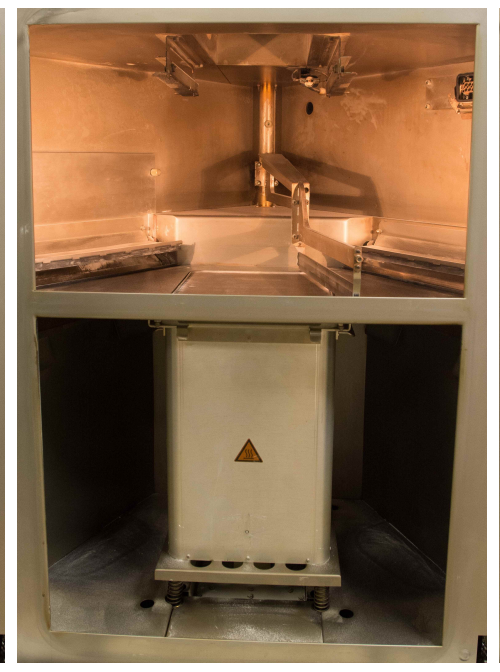

(d) Wechselbehälter

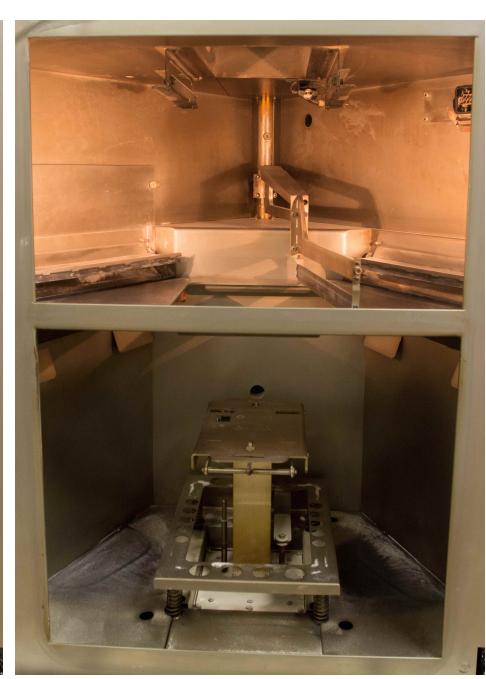

(e) Hubantrieb für Bauplattform

Abbildung 3.1.: Lasersintermaschine EOS Formiga P 100 (eigene Aufnahmen) 
schine und Material wird der Schichtstärkenparameter auf $60 \mu \mathrm{m}, 100 \mu \mathrm{m}, 120 \mu \mathrm{m}$, $150 \mu \mathrm{m}$ oder $180 \mu \mathrm{m}$ eingestellt. Die „P 500“ wurde im November 2017 als industrielle Produktionsmaschine mit entsprechendem Automatisierungsgrad, Aufbaurate und Bauteilqualität zur wirtschaftlichen Fertigung von Polymer-Bauteilen vorgestellt. Zum Pulverauftrag in der „P 500“ wird eine Beschichtereinheit mit zwei rotierenden Rollen und integriertem Heizelement verwendet, die mit einer Geschwindigkeit von bis zu $600 \mathrm{~mm} / \mathrm{s}$ über der Bauplattform bewegt wird. Alle anderen EOS-Maschinen verwenden dazu eine Beschichterklinge. Zur Fertigung von Implantatmatrizen mit hochauflösenden, interkonnektierenden Porenstrukturen muss die Laser-Scanner-Einheit der Lasersintermaschine den Laserstrahl im Belichtungsfeld in einem möglichst kleinen Durchmesser fokussieren. Aus der Anforderung an die Abbildungsgenauigkeit gilt die „Formiga P 110“ aufgrund der hohen Bauteilqualität („Formiga Qualität“) im Bereich des Lasersinterns als potentiell geeignete Maschine. Die „Formiga P 100“ (Vorgängermodell der „P 110“) des 3D-Labors der TU-Berlin

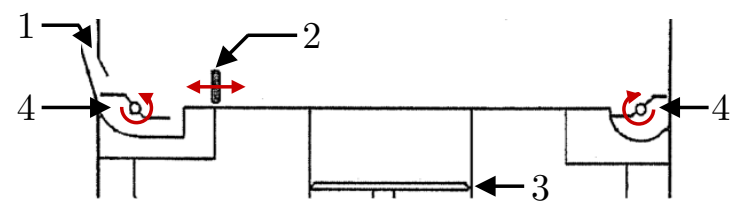

(1) Pulverzuführung

(2) Beschichterklinge

(3) Bauplattform

(4) Pulvervorratsschaufel

Abbildung 3.2.: Zuführung und Pulverauftrag der Formiga P 100 [US7713048 B2, S. 5]

diente als Referenzmaschine für die vorliegende Arbeit [EOS10b]. Der Aufbau der „P 100“ ist den Skizzen des Patents mit der Veröffentlichungsnummer US7713048 B2 [US7713048 B2] zu entnehmen. Das Pulver gelangt über einen trichterförmigen Zuführmechanismus auf der Maschinenoberseite (vgl. (1) Abbildung 3.2) in die Prozesskammer unterhalb des Belichtungsfeldes. Durch eine koordinierte Rotation der Vorratsschaufeln (4) wird das Pulver vor die Beschichterklinge (2) gehoben. Durch die radial verlaufende Auftragsbewegung der Klinge wird eine homogene Pulverschicht über der Bauplattform (3) erzeugt. Die Abbildung 3.1 stellt die „P 100" geschlossen, mit geöffneter Prozesskammer- und Hubantriebswartungstür sowie Detailansichten aus der Prozesskammer dar. Das 1-Zonen-Heizelement (vgl. (c) Abbildung 3.1) über der Beschichtereinheit, in dem Nachfolgemodell „P 110“ durch ein 4-Zonen-Heizelement ersetzt, wird zur Reinigung der Maschine entnommen.

Aspect / Ricoh Die Firma Aspect entwickelt und vertreibt Lasersintermaschinen auf Basis der älteren DTM-Technologie [Sch15b, S. 33-34]. Die Lasersintermaschinen mit der Bezeichnung „RaFaEl“ („Rapid Fabrication Evolution“) sind in Tabelle 3.3 zusammengefasst [Asp15]. Der symmetrische Grundaufbau ist bei allen drei Maschinen identisch. Rechts und links neben dem mittig angeordneten Bauvolumen sind Vorratsvolumina verbaut, die vor dem Prozessstart mit Frischpulver befüllt werden. Das Bauvolumen wird von der Oberseite (IR-Heizeinheiten) und im Bereich der Mantelfäche beheizt. Das zugeführte Frischpulver wird vor dem Pulverauftrag lediglich von der Oberseite beheizt. Der Hersteller bewirbt seine Maschinen mit hoher Genauigkeit (geringe Spotsize, digitaler Scanner) und Aufbaurate (hohe 
Scangeschwindigkeit mit „Zigzag“-Scanstrategie) [MTH13]. Auf Wunsch kann der $\mathrm{CO}_{2}$-Laser (vgl. Tabelle 3.3) herstellerseitig gegen einen $50 \mathrm{~W}$ Faserlaser getauscht werden. Durch die Verwendung der laserspezifisch zehnfach kürzeren Wellenlänge eines Faserlasers kann die Spotsize in etwa halbiert werden [YKN16].

Tabelle 3.3.: Aspect Maschinen für das Lasersintern

\begin{tabular}{c|c|c}
\hline Maschine & CO $_{2}$-Laser & Bauvolumen (x, y, z) \\
\hline RaFaEl II 150 & $30 \mathrm{~W}$ & $150 \mathrm{~mm}, 150 \mathrm{~mm}, 200 \mathrm{~mm}$ \\
\hline RaFaEl II 300 & $60 \mathrm{~W}$ & $300 \mathrm{~mm}, 300 \mathrm{~mm}, 400 \mathrm{~mm}$ \\
\hline RaFaEl II 550 & $100 \mathrm{~W}$ & $550 \mathrm{~mm}, 550 \mathrm{~mm}, 500 \mathrm{~mm}$ \\
\hline
\end{tabular}

Kommerziell bietet Aspect die Materialien PA12 (natur oder gefüllt), PA11, PA6, TPE und PS zum Lasersintern an. Die Firma Ricoh hat nach eigenen Angaben in Zusammenarbeit mit Aspect eine Lasersintermaschine mit der Bezeichnung "AM S5500P" (CO $\mathrm{CO}_{2}$-Laser mit $100 \mathrm{~W} /$ Bauvolumen von $550 \mathrm{~mm} \times 550 \mathrm{~mm} \times$ $500 \mathrm{~mm}$ ) entwickelt [Ric15b] [Ric15a]. Sowohl optisch als auch technisch erscheint die Maschine baugleich zu der „RaFaEl II 550“. Firma Ricoh bietet die Materialien PA12 (natur oder gefüllt), PA11, PA6 (gefüllt) und PP zum Lasersintern an.

Farsoon / Prodways Die aktuellen Lasersintermaschinen der Firma Farsoon Technologies (Hunan Farsoon High-tech Co. Ltd) sind in Tabelle 3.4 zusammengefasst [Far17b] [Far17a] [Far16]. Einige Maschinen können im Bestellprozess konfiguriert werden. Bei der Auswahl der Variante „HT“ (High Temperature - bis $220^{\circ} \mathrm{C}$ ) bzw. „ST" (Super Temperature - bis $280^{\circ} \mathrm{C}$ ) kann die Prozesskammertemperatur der Maschine auf einen höheren Wert (Basisversion bis $190^{\circ} \mathrm{C}$ ) zur Verarbeitung von Polymeren mit höheren Schmelzpunkten geregelt werden.

Tabelle 3.4.: Farsoon Maschinen für das Lasersintern

\begin{tabular}{c|c|c}
\hline Maschine & CO $_{\mathbf{2}}$-Laser & Bauvolumen $(\mathbf{x}, \mathbf{y}, \mathbf{z})$ \\
\hline eForm & $30 \mathrm{~W}$ & $250 \mathrm{~mm}, 250 \mathrm{~mm}, 320 \mathrm{~mm}$ \\
\hline 252P Serie & $60 \mathrm{~W}(\mathrm{HT}) / 100 \mathrm{~W}(\mathrm{ST})$ & $250 \mathrm{~mm}, 250 \mathrm{~mm}, 320 \mathrm{~mm}$ \\
\hline 403P Serie & $30 \mathrm{~W} / 70 \mathrm{~W}(\mathrm{HS}) / 100 \mathrm{~W}(\mathrm{SS} / \mathrm{HT})$ & $400 \mathrm{~mm}, 400 \mathrm{~mm}, 450 \mathrm{~mm}$ \\
\hline HT1001P & $2 \mathrm{x} 100 \mathrm{~W}$ & $1000 \mathrm{~mm}, 500 \mathrm{~mm}, 450 \mathrm{~mm}$ \\
\hline
\end{tabular}

Die Angaben „HS“ (High Speed) und „SS“ (Super Speed) weisen auf die Verwendung eines höherwertigen Scanners hin, der entsprechend höhere Scangeschwindigkeiten unterstützt. Für den Pulverauftrag verwendet Farsoon analog zur älteren DTM-Technologie eine rotierende Rolle. Als offene Plattform bietet Farsoon neben proprietären Materialien auch Parametersätze zur Verarbeitung von diversen „Fremdpulvern“ der Firmen BASF, ALM oder beispielsweise Lehmann \& Voss an. Im Jahr 2014 einigten sich Farsoon und die Prodways Group auf eine Techno- 
logiepartnerschaft. Alle Prodways-,Promaker“-Maschinen sind identisch zu den Farsoon-Maschinen. Farsoon bietet zum Lasersintern die Materialien PA12 (natur oder gefüllt), PA11 (natur oder gefüllt), PA6, PP, TPE, TPU und PPS an.

\subsubsection{Einstiegs- und Benchtopmaschinen (Prototyper)}

Die Lasersintermaschinen aus der Maschinenklasse der „Prototyper“ werden zur funktionalen Prototypenfertigung eingesetzt und sind erhältlich für einen Anschaffungspreis zwischen 5.000€ und 15.000€. Die Lasersintermaschinen der Firmen Formlabs (USA), Natural Robotics (Spanien), Red Rock (Russland), Sharebot (Italien), Sinterit (Polen) und Sintratec (Schweiz) sind nach der Größe des Bauvolumens sortiert in Tabelle 3.5 zusammengefasst [For17] [Sha17] [Sin17] [Sin18a] [Sin18b] [Sin18c].

Tabelle 3.5.: „Prototyper“-Maschinen für das Lasersintern

\begin{tabular}{c|c|c}
\hline Maschine & Bauvolumen $\mathbf{( x , y , z )}$ & Laser \\
\hline Sharebot SnowWhite & $100 \mathrm{~mm}, 100 \mathrm{~mm}, 100 \mathrm{~mm}$ & $14 \mathrm{~W} \mathrm{CO}_{2}$-Laser \\
\hline Sintratec Kit & $110 \mathrm{~mm}, 110 \mathrm{~mm}, 110 \mathrm{~mm}$ & $2,3 \mathrm{~W}$ Diodenlaser \\
\hline Sintratec S1 & $130 \mathrm{~mm}, 130 \mathrm{~mm}, 180 \mathrm{~mm}$ & $2,3 \mathrm{~W}$ Diodenlaser \\
\hline Sinterit Lisa & $150 \mathrm{~mm}, 200 \mathrm{~mm}, 150 \mathrm{~mm}$ & $5 \mathrm{~W}$ Diodenlaser \\
\hline Red Rock 3D SLS & $200 \mathrm{~mm}, 200 \mathrm{~mm}, 180 \mathrm{~mm}$ & $5 \mathrm{~W}$ Diodenlaser \\
\hline Sinterit Lisa 2 & $150 \mathrm{~mm}, 200 \mathrm{~mm}, 260 \mathrm{~mm}$ & $5 \mathrm{~W}$ Diodenlaser \\
\hline Formlabs Fuse 1 & $165 \mathrm{~mm}, 165 \mathrm{~mm}, 320 \mathrm{~mm}$ & $10 \mathrm{~W}$ Faserlaser \\
\hline Natural Robotics VIT SLS & $250 \mathrm{~mm}, 250 \mathrm{~mm}, 300 \mathrm{~mm}$ & $40 \mathrm{~W} \mathrm{CO}_{2}$-Laser \\
\hline
\end{tabular}

Als Ausgangsmaterialien werden in der Regel PA12 und PA11 angeboten. Zur Verwendung von günstigen Diodenlasern mit geringer Leistung sind die Ausgangswerkstoffe zur Erhöhung der Absorption dunkel eingefärbt. Die „VIT SLS“ der Firma Natural Robotics verarbeitet mit dem leistungsstarken $\mathrm{CO}_{2}$-Laser weißes PA12. Der Diodenlaser der „3D SLS“ der Firma Red Rock wird mittels x-y-Tisch über das Pulverbett bewegt. Die „VIT SLS“ nutzt zur Positionierung des Laserstrahls in der Prozessebene einen Galvano-Scanner. Die Prozesskammern der Maschinen aus dem Tiefpreissegment werden in der Regel nicht inertisiert.

\subsection{Spezifische Merkmale kommerzieller Maschinen zur Metallverarbeitung}

Das Verfahren „Selective Laser Melting“ (SLM) verarbeitet metallische Werkstoffe, basiert auf dem Lasersintern und wurde vom Fraunhofer-Institut für Lasertechnik (ILT) aus Aachen in Kooperation mit der Fockele \& Schwarze Stereolithographietechnik GmbH (Ausgründung der Universität Paderborn) ab 1995 entwickelt [Geb13, S. 131]. Drei Jahre später wurde die erste Maschine mit dem Namen „SLM-Realizer“ vorgestellt. Die Fraunhofer Gesellschaft meldete das „Verfahren zur Herstellung eines Formkörpers“ 1996 
zum Patent [DE19649865 C1] an. Fotos der im Patent skizzierten Maschine können in der Dissertation von Wilhelm Meiners [Mei99, S. 69-72], einem der drei eingetragenen Erfinder, eingesehen werden. Mit dem Titel „Selective laser sintering at melting temperature“ wurde die Erfindung im Jahr 2001 in den Vereinigte Staaten von Amerika patentiert [US6215093 B1]. Bei der Generierung von Metallbauteilen mittels Laserstrahlschmelzen sind im Vergleich zum Polymer-Lasersintern die folgenden Unterschiede festzustellen:

Pre-Processing Im Rüstprozess einer Laserstrahlschmelzmaschine wird eine wechselbare Substratplatte (Bauplatte) auf der Bauplattform (vgl. Patent [DE19511772 C2]) befestigt. Zur Reduktion von Verzug müssen sämtliche Bauteile über Stützstrukturen direkt oder indirekt mit der Substratplatte verbunden sein.

Inertisierung Zur Inertisierung der Prozesskammer wird materialspezifisch Stickstoff oder Argon verwendet. Im Fertigungsprozess wird das Inertgas mit hoher Strömungsgeschwindigkeit über Düsen parallel zur Prozessebene eingeleitet und auf der gegenüberliegenden Seite abgesaugt. Durch die erzwungene Strömung werden Rauch und aufsteigende Partikel, die durch den Laserenergieeintrag mit hoher Leistung in das Pulverbett entstehen, aus der Prozesskammer abgeführt. Um den Gasverbrauch zu senken, rüsten einige Hersteller ihre Maschinen mit Filtersystemen zur Reinigung und Wiederverwendung des Prozessgases aus.

Bauteilschichtgenerierung Maschinen zum Laserstrahlschmelzen sind mit leistungsstarken Faserlasern (Nd:YAG oder Yb:YAG) ausgestattet, die Schichtstärken von durchschnittlich $40 \mu \mathrm{m}$ aufschmelzen. Zur Reduktion von Eigenspannungen durch den Fügeprozess werden in einigen Anwendungen die Bauplattform bzw. das Bauvolumen vorgeheizt. Die Werkstoffreservoirs sind in der Regel nicht beheizt.

Post-Processing Aufgrund der hohen Wärmeleitfähigkeit von Metallen ist der Abkühlvorgang vergleichsweise schnell abgeschlossen. In Abhängigkeit des Bauvolumens werden nicht geschmolzene Pulverpartikel zur Pulverrückführung häufig unter Prozessgasatmosphäre bei geschlossener Prozesskammertür abgesaugt. Nach Entnahme der Substratplatte werden die additiv gefertigten Bauteile von ihr entfernt. Die zuvor gestützten Bauteilbereiche werden anschließend spanend nachbearbeitet.

Aufgrund funktional gleichwertiger Baugruppen ähneln sich die Produktstrukturen der Maschinen zur Polymer- und Metallverarbeitung. In dem Zeitraum zwischen 2014 und 2018 wurden die Veränderungen in den Produktportfolios der Firmen 3D-Systems (kaufte 2013 Phenix Systems auf), Concept Laser (2016 von GE aufgekauft), EOS, Realizer (2017 von DMG MORI aufgekauft), Renishaw, Sisma (Trumpf Entwicklungspartner), SLM Solutions (2014 Börsengang) und Trumpf mitverfolgt. Im Folgenden werden technische Merkmale kommerzieller Laserstrahlschmelzmaschinen vorgestellt, die bei der Entwicklung einer Lasersintermaschine entsprechend berücksichtigt werden können.

\subsubsection{Kleinformatmaschinen und Bauraumverkleinerungen}

Kleinformatmaschinen werden in der Regel zur Herstellung filigraner Bauteile im Bereich der Dental- und Schmuckindustrie verwendet. In Tabelle 3.6 sind Laserstrahlschmelzmaschinen mit einer Baufäche kleiner als $100 \mathrm{~mm} \times 100 \mathrm{~mm}$ zusammengefasst [Rea17] 
[Con16a] [Con16b] [EOS16c] [EOS17b] [Tru16]. Die Realizer „SLM 50“ ist eine türgängige Benchtopmaschine, in der die Metallpartikel durch eine radial bewegte Doppel-RakelBeschichtereinheit über der runden Bauplattform aufgetragen werden. Die uniforme Schichtstärke aller Maschinen variieren laserleistungs- und materialabhängig zwischen $15 \mu \mathrm{m}$ und $50 \mu \mathrm{m}$. Die „Mlab cusing“ der Firma Concept Laser ist in drei verschiedenen Bauvolumengrößen erhältlich. Das Bau- und Pulvervorratsvolumen ist in einem Schubladensystem angeordnet und wird zum Pre- bzw. Post-Processing aus der Maschinenvorderseite ausgezogen. Die EOS „Precious M 080“ verarbeitet ausschließlich Edelmetallpulver für die Uhren- und Schmuckindustrie.

Tabelle 3.6.: Kleinformatmaschinen für das Laserstrahlschmelzen

\begin{tabular}{c|c|c}
\hline Maschine & Bauvolumen $(\mathbf{x}, \mathbf{y}, \mathbf{z})$ & Laser-Spotsize \\
\hline Realizer SLM 50 & $\varnothing 70 \mathrm{~mm}, 40 \mathrm{~mm}$ oder $80 \mathrm{~mm}$ & $\varnothing 10 \mu \mathrm{m}$ oder $\varnothing 20 \mu \mathrm{m}$ \\
\hline \multirow{2}{*}{ Concept Laser Mlab cusing } & $50 \mathrm{~mm}, 50 \mathrm{~mm}, 80 \mathrm{~mm}$ & \\
& $70 \mathrm{~mm}, 70 \mathrm{~mm}, 80 \mathrm{~mm}$ & $\varnothing 50 \mu \mathrm{m}$ \\
\hline EOS Precious M 080 & $\varnothing 0 \mathrm{~mm}, 90 \mathrm{~mm}, 80 \mathrm{~mm}$ & \\
\hline EOS M 100 & $\varnothing 100 \mathrm{~mm}, 95 \mathrm{~mm}$ & $\varnothing 30 \mu \mathrm{m}$ \\
\hline Trumpf TruPrint 1000 & $\varnothing 100 \mathrm{~mm}, 100 \mathrm{~mm}$ & $\varnothing 30 \mu \mathrm{m}$ oder $\varnothing 55 \mu \mathrm{m}$ \\
\hline
\end{tabular}

Zwischen der Laser-Scanner-Einheit und der Bauplattform samt Hubantriebsbaugruppe wird in horizontaler Richtung ein Kartuschensystem auf einem Schlitten bewegt, der sich bei Maschinenstart links von der Bauplattform befindet. Die Materialvorratskartusche wird auf der rechten Schlittenseite oberhalb der Beschichtereinheit eingesetzt und geöffnet. Auf der linken Seite des Schlittens wird eine zylinderförmige Prozesskammer mittels Schnellspannverschluss befestigt. Bei der Bewegung des Schlittens in Richtung der rechten Fahrbereichsgrenzposition wird das Pulver über der Bauplattform aufgetragen und die Prozesskammer mitbewegt. Wenn der Schlitten die rechte Fahrbereichsgrenzposition erreicht hat, ist die Prozesskammer zwischen der Laser-Scanner-Einheit und der Bauplattform positioniert. Die EOS „M 100“ ist mit geringfügig größerem Bauvolumen baugleich mit der „Precious M 080“. Die „TruPrint 1000“ der Firma Trumpf kann bei der Auswahl des Optionspakets „Lab“ mit verschiedenen Bauraumverkleinerungen für Forschungszwecke umgerüstet werden. Durch die Verwendung dieser Maschinenadapter kann der Bauraumdurchmesser von $\varnothing 100 \mathrm{~mm}$ auf $\varnothing 63,5 \mathrm{~mm}$ oder $\varnothing 34,5 \mathrm{~mm}$ reduziert werden. Die Firmen SLM Solutions und Renishaw bieten ebenfalls Bauraumverkleinerungen für einige Maschinen an. Das Bauvolumen der Renishaw „AM 400“ (250 mm $\times 250 \mathrm{~mm} \times 300 \mathrm{~mm})$ wird durch die Verwendung des Maschinenadapters auf $78 \mathrm{~mm} \times 78 \mathrm{~mm} \times 56 \mathrm{~mm}$ verringert [Ren17, S. 33]. Die Maschinen „SLM 125“ (125 mm $\times 125 \mathrm{~mm} \times 125 \mathrm{~mm})$ und „SLM 280 2.0“ $(280 \mathrm{~mm} \times 280 \mathrm{~mm} \times 365 \mathrm{~mm})$ werden nach der Montage einer Bauraumverkleinerung im Bauvolumen auf $50 \mathrm{~mm} \times 50 \mathrm{~mm} \times 50 \mathrm{~mm}$ bzw. $\varnothing 90 \mathrm{~mm} \times 100 \mathrm{~mm}$ reduziert [SLM17b] [SLM17a]. Einige Bauraumverkleinerungen verfügen zusätzlich über hochtemperaturfähige (bis $500^{\circ} \mathrm{C}$ ) Heizeinheiten. 


\subsubsection{Faserlaser-Scanner-Systeme mit geringem Fokusdurchmesser}

Für Anwendungen in der Lasertechnik wird Yttrium-Aluminium-Granat (YAG) in Abhängigkeit der gewünschten Wellenlänge unter anderem mit Neodym (Nd) oder Ytterbium $(\mathrm{Yb})$ dotiert. Aufgrund der kurzen Wellenlänge können die Nd:YAG- oder Yb:YAG-Festkörperlaser im Gegensatz zu $\mathrm{CO}_{2}$-Lasern einer Lasersintermaschine durch ein Glasfaserkabel geleitet und über ein Kollimationsmodul direkt an den Scanner angeschlossen werden [Sca17]. Zum Aufschmelzen der Metallpartikel werden in der Regel Faserlaser der Wellenlänge $1060 \mathrm{~nm}$ (EOS) oder 1070 nm (3D-Systems / Renishaw / Trumpf) in den Laserstrahlschmelzmaschinen verwendet [Tru16] [EOS17a] [Phe12] [Ren16]. Die Kombination aus Faserlaserwellenlänge und der geringen Prozesskammerhöhe einer Kleinformatmaschine erlaubt die Fokussierung des Laserstrahls auf einen Durchmesser von durchschnittlich $33 \mu \mathrm{m}$. Die EOS „Formiga P 110“ (200 $\mathrm{mm} \times 250 \mathrm{~mm} \times 330 \mathrm{~mm})$ fokussiert den $\mathrm{CO}_{2}$-Laserstrahl (vgl. Abschnitt 3.1.1) mit einer Wellenlänge von 10,6 um auf einen Durchmesser von $500 \mu \mathrm{m}$. In Tabelle 3.7 sind metallverarbeitende Maschinen samt Fokusdurchmesser zusammengefasst, die ein „Formiga P 110“ ähnlich großes Bauvolumen besitzen [Con15a] [Con15b] [DMG17] [EOS17a] [Ren15] [SLM17c].

Tabelle 3.7.: Laserstrahlschmelzmaschinen mit EOS P 110 ähnlichem Bauvolumen

\begin{tabular}{c|c|c}
\hline Maschine & Bauvolumen $(\mathbf{x}, \mathbf{y}, \mathbf{z})$ & Laser-Spotsize \\
\hline Concept Laser M2 cusing & $250 \mathrm{~mm}, 250 \mathrm{~mm}, 280 \mathrm{~mm}$ & $\varnothing 50 \mu \mathrm{m}$ \\
\hline DMG MORI Lasertec 30 SLM & $300 \mathrm{~mm}, 300 \mathrm{~mm}, 300 \mathrm{~mm}$ & $\varnothing 70 \mu \mathrm{m}$ \\
\hline EOS M 290 & $250 \mathrm{~mm}, 250 \mathrm{~mm}, 325 \mathrm{~mm}$ & $\varnothing 70 \mu \mathrm{m}$ \\
\hline Renishaw AM 400 & $250 \mathrm{~mm}, 250 \mathrm{~mm}, 300 \mathrm{~mm}$ & $\varnothing 70 \mu \mathrm{m}$ \\
\hline SLM Solutions SLM 2802.0 & $280 \mathrm{~mm}, 280 \mathrm{~mm}, 365 \mathrm{~mm}$ & $\varnothing 80 \mu \mathrm{m} \mathrm{bis} \varnothing 115 \mu \mathrm{m}$ \\
\hline
\end{tabular}

Die „SLM 280 2.0“ ist in den Optikkonfigurationen „Single“ (1× $400 \mathrm{~W} / 700 \mathrm{~W})$, „Twin“ $(2 \times 400 \mathrm{~W} / 700 \mathrm{~W})$ und „Dual“ (700 W \& $1000 \mathrm{~W})$ verfügbar. Die hohe Aufbaurate beruht auf der Nutzung einer Mehrstrahltechnik in Kombination mit einer komplexeren Hülle-Kern-Scanstragie. Nachdem die Bauteilaußenkontur (Hülle) mit einem schmalen Gauß-Laserprofil (Fokusdurchmesser ca. $100 \mu \mathrm{m}$ ) erzeugt ist, wird die Bauteilinnenkontur (Kern) mit einem breiten Top-Hat-Laserprofil (Fokusdurchmesser ca. $700 \mu \mathrm{m}$ ) verfestigt [EP2596901 B1, S. 2]. Eine weitere Methodik zur Steigerung der Aufbaurate wird technisch durch die Verwendung eines Drei-Achs-Scansystems realisiert, das die gezielte Defokussierung des Laserstrahls von beispielsweise $75 \mu \mathrm{m}$ auf $500 \mu \mathrm{m}$ ermöglicht [Ren16]. Zum Aufschmelzen großflächiger Bauteilschichtbereiche wird der defokussierte Laserstrahl bei reduzierter Scangeschwindigkeit in der x-y-Ebene bewegt.

\subsubsection{Prozessgasbereitstellung und Vakuum-Inertisierung}

Beim Aufschmelzen von reaktiven Werkstoffen wie Titan oder Aluminium wird Argon als Schutzgas in Laserstrahlschmelzmaschinen verwendet. Zur Reduktion der Nebenkosten kann bei der Fertigung von Bauteilen aus nicht reaktivem, un- bzw. niedriglegiertem Stahl 
auch Stickstoff als Prozessgas verwendet werden. Concept Laser bietet zur Verarbeitung reaktiver Materialien einige Maschinen in der „R"-Variante an, die über einen Schutzgasanschluss entweder mit Stickstoff oder mit Argon betrieben werden können. Unabhängig vom eingeleiteten Gas wird der Status der Inertisierung innerhalb der Prozesskammer durch Sauerstoffsensoren ermittelt. In kommerziellen Maschinen, die ausschließlich Stickstoff zur Inertisierung nutzen, wird das Prozessgas aus einem Druckgasbehälter oder einem Generator entnommen. Sowohl Membran- als auch PSA-Gasgeneratoren benötigen einen zusätzlichen Druckluft-Kompressor samt Filtereinheiten zum Abscheiden des Stickstoffs aus der Luft [Par13]. Argon wird stets aus Druckgasbehältnissen entnommen. Die Inertisierung dient unter anderem dem kontrollierten Austausch der sauerstoffhaltigen Atmosphäre innerhalb der geschlossenen Prozesskammer gegen eine inerte Prozessgasatmosphäre. Nach der Herstellung einer inerten Atmosphäre mittels Druckwechsel- oder Spülmethoden muss diese über die gesamte Fertigungsprozessdauer erhalten bleiben [VDI 2263 Blatt 2, S. 9-10] [Nit15, S. 68-73]. Bei der häufig angewendeten Spülmethode wird Inertgas bei geringem Überdruck durch das Prozesskammervolumen hindurch geleitet. Die Ein- und Austrittsstelle an der Kammer ist dabei so zu platzieren, dass bei der Durchspülung kein Totraum entsteht. Nach der VDI-Richtlinie 2263 [VDI 2263 Blatt 2] ist ein bis zu 6-facher Volumenwechsel notwendig. Die Firma Renishaw hingegen reduziert den Gasverbrauch durch die Anwendung einer Druckwechselmethode. Dafür wird die Prozesskammer mittels Vakuumpumpe bis zu einem spezifischen Restdruck zunächst evakuiert. Der dabei entstandene Unterdruck wird durch die Einleitung des Prozessgases aufgehoben. Technische Voraussetzung für die Unterdruckmethode ist die entsprechende Festigkeit und Dichtheit der Prozesskammer. Renishaw verbaut diesbezüglich geschweißte und entsprechend versiegelte Kammern.

\subsubsection{Monitoring-Systeme zur Prozessüberwachung}

In der additiven Fertigung dient die Prozessüberwachung der integrierten Qualitätssicherung gefertigter Bauteile, dem systematischen Aufbau eines Prozessverständnisses und der Entwicklung von Steuerungs- bzw. Regelungsalgorithmen [PKS14]. Die Grundlage jeder Prozessüberwachung ist die sensorische Erfassung optischer, akustischer, mechanischer oder elektrischer Signale, die im Anschluss kontextbezogen verarbeitet werden. Auf Basis extrahierter Merkmale wird eine Analyse und Bewertung durchgeführt, um abschließend eine Entscheidung herbeizuführen. Um den regulatorischen Qualitätsanforderungen gewisser Industriezweige (z. B.: Medizin, Luftfahrt) gerecht zu werden, verbauen die Hersteller seit dem Jahr 2015 zunehmend einzel- oder mulitsensorbasierte „In-Process"-Überwachungssysteme in die Laserstrahlschmelzmaschinen [EOS15] [ASW16]. Im Zusammenhang der Überwachung von Prozessemissionen sind die Systeme in Abhängigkeit ihrer Anordnungen in „On-Axis“ mit räumlich indirekter Auflösung und „Off-Axis“ mit räumlich direkter Auflösung zu unterteilen. Bei einer koaxialen („On-Axis“) Anordnung werden die Emissionen von der Pulverbettoberfläche aus dem Strahlengang der Scannerund Fokussieroptik durch die Verwendung entsprechender Strahlteiler und optischer Filter ausgekoppelt. Zur Erzeugung eines räumlich aufgelösten Bildes der Bearbeitungsebene müssen die zeitversetzt aufgenommenen Signale mit Zusatzinformationen wie der 
zeitabhängigen x-y-Scanposition kombiniert werden. Ein „Off-Axis"-System ist in einem nach Möglichkeit steilen Winkel gegenüber der Prozessebene fest installiert und kann die Bearbeitungsebene entsprechend ganzheitlich aufösen [EHS+16]. Im Folgenden werden Prozessüberwachungssysteme kommerzieller Laserstrahlschmelzmaschinen vorgestellt. Qualitätssicherungsmaßnahmen, die das eingesetzte Pulver oder die Umgebungseinflüsse betreffen, werden nicht diskutiert. Industrielle Produktionsmaschinen für das Lasersintern verfügen zunehmend über eine Maschinenzustandsüberwachung und einer Live-VideoFunktion. Kommerzielle Lasersintermaschinen mit einer Schmelzbadüberwachung sind hingegen nicht bekannt.

Maschinenzustand Bei der Maschinenzustandsüberwachung (engl. „Condition Monitoring") werden relevante Prozessparameter während der Fertigung überwacht und protokolliert. Die kontinuierlich oder diskret aufgenommenen Messwerte (Istwerte) werden mit den zuvor eingestellten Prozessparametern (Sollwerte) verglichen und können im Rahmen einer Analyse ausgewertet werden. Zur Zustandsbewertung des Schutzgassystems können zusätzlich zur Sauerstoffmessung, Druck- und Durchfluss ermittelt werden, um den Maschinennutzer beispielsweise auf einen Filterwechsel hinzuweisen. Stand der Technik ist die Erfassung punktueller Temperaturen beheizter Bereiche, abgegebener Laserleistung und Füllständen in Pulverzuführsystemen.

Live-Video Durch das Anbringen einer Flächenkamera außerhalb der Prozesskammer kann per Fernzugriff der gesamte Bewegungsbereich der Beschichtereinheit oder lediglich der Schmelzbereich über der Bauplattform beobachtet und gespeichert werden. Zur Verringerung der Datenmenge können Einzelbilder vom Ergebnis des Pulverauftrags und dem Laserenergieeintrag aufgenommen werden. Die Bilder dieses kamerabasierten „Off-Axis“-Systems werden nicht algorithmisch verarbeitet.

Pulverbett Ein homogener Pulverauftrag über der Bauplattform gilt als Grundvoraussetzung zur Generierung qualitativ hochwertiger Bauteile mittels pulverbettbasierter Schichtbauverfahren. Maschinenspezifische Ursachen für inhomogene Pulverauftragsergebnisse sind unter anderem ein Defekt an der Beschichtereinheit, unzureichend zugeführtes Pulvervolumen oder bereits generierte Bauteilbereiche, die aufgrund von thermischen Eigenspannungen über die Pulverbettoberfläche hinaus ragen. Das Inspektionssystem ist aufgebaut aus drei spezifisch positionierten Lichtquellen und einem auf die Baufläche gerichteten „Off-Axis“-Kamerasystem. Zur Detektion von Fehlstellen oder Unregelmäßigkeiten auf der Pulverbettoberfläche werden mindestens sechs Einzelbilder pro aufgetragener Schicht (vor und nach dem Laserenergieeintrag) in entsprechender Belichtungsrichtung mittels Bildverarbeitungssoftware auf Schattenwurf untersucht [CCY+11] [zKS+13].

Schmelzbad Die Bauteilschichtgenerierung beim Laserstrahlschmelzen basiert auf den Schmelz- und Erstarrungsvorgängen der eingesetzten Pulver. Aus den zeit- und ortsabhängigen Temperaturmessdaten einer Bauteilschicht können unter anderem Aussagen über den Schweißprozess oder die mechanische Bauteilfestigkeit abgeleitet werden [MWL+14]. Kommerzielle Systeme zur „On-Axis“-Schmelzbadüberwachung (engl. „Melt Pool Monitoring“) dienen der Erfassung infraroter Schmelzbademis- 
sionen mittels einer meist multisensorischen Kombination aus Photodioden, pyroelektrischer Sensoren und Kamerasystemen [CCK+12] [GD14]. Zur diskret kontinuierlichen Überwachung von Schmelzbad und Schmelzbadumgebung ist aufgrund der hohen Scangeschwindigkeit eine Aufnahmefrequenz von bis zu $10 \mathrm{kHz}$ technisch zu realisieren [CCY+11]. Die optische Tomographie (OT) kann durch die „Off-Axis"-Anordnung einer hochauflösenden CCD- oder CMOS-Kamera Unregelmäßigkeiten auch außerhalb der Schmelzbadumgebung in der jeweiligen Bauteilschicht detektieren [EP2666612 A1]. Dem Prinzip einer Langzeitbelichtung folgend, werden die hochfrequent aufgenommenen Einzelbilder zu einem einzelnen schichtspezifischen Auswertbild verrechnet und abschließend anhand der Strahlungsintensitäten auf „Hot-Spots“ und „Cold-Spots" untersucht [ZHH+14].

\subsection{Lasersintern zur Herstellung bioresorbierbarer Implantatmatrizen}

Die Forschung im Bereich der patientenspezifischen Implantatfertigung mittels Lasersintern wird von internationalen Forschungsgruppen vorangetrieben. Erste Veröffentlichungen zur Verarbeitung von PCL in einer DTM „Sinterstation 2000“ zu einer Matrize für das „Bone Tissue Engineering“" sind bereits im Jahr 2005 von J.M. Williams et al. aus Michigan (USA) erschienen [WAS+05]. Zur gleichen Zeit veröffentlichten K.H. Tan et al. in Singapur gewählte Prozessparameter (Lasersintermaschine nicht angegeben) zur Verarbeitung von PCL, PLA, PVA, PEEK (nicht bioresorbierbar) und PEEK/HA (nicht bioresorbierbar) [TCL+05]. Das Fraunhofer-Institut für Lasertechnik (ILT) führte in Zusammenarbeit mit insgesamt neun Partnern im Zeitraum zwischen Oktober 2006 und März 2010 ein durch das BMWi geförderte Verbundprojekt mit dem Titel „Generative Fertigung von Knochenersatzimplantaten aus resorbierbaren Werkstoffen (Resobone)" in Aachen durch [HD10] [Fra10, S. 111,112]. S. Hoeges et al. verarbeiteten die Kompositwerkstoffe Henchglas/TCP und PLA/TCP in einer eigenentwickelten Maschine [HLM+10]. Das Anschluss-Verbundprojekt mit dem Titel „Biodegradierbare Kompositwerkstoffe für die generative Fertigung bioaktiver Knochenersatzimplantate (ActiveBone)" fand im Zeitraum zwischen November 2012 und April 2016 mit der Prozessentwicklung von dem Kompositwerkstoff aus PLA/TCP/PCC (Polylactid/Tricalciumphosphat/Calciumcarbonat) in einer von der Firma EOS modifizierten EOS „Formiga P 110“ am ILT in Aachen statt. Die mit interkonnektierender Porenstruktur gefertigten Implantate wurden zur Wachstumsstimulation anschließend mit einem Protein beschichtet [Gro16] [BPL+16] [Fra15, S. 132]. Im Zeitraum zwischen 2007 und 2010 veröffentlichten W. Y. Zhou et al. und B. Duan et al. von der Universität Hong Kong erste Verarbeitungsergebnisse von PLA und PLA/HA in einer DTM „Sinterstation 2000“ mit verkleinertem Bauraum [ZLW+07] [ZLW+08] [DWZ+10]. In Singapur verarbeiteten F.E. Wiria et al. und $R$. L. Simpson die Materialien PLA/HA und PLGA in einer DTM "Sinterstation 2500" [WLC+07] [SWA+08]. K. C. R. Kolan et al. erforschten in Missouri (USA) zwischen 2010 und 2012 die Verarbeitung von Henchglas in einer DTM „Sinterstation 2000“ [KLH+10] $[\mathrm{KLH}+12]$. Zeitgleich wurden Studien aus Irland von S. Lohfeld et al. und S. Eosoly et 
al. zur Verarbeitung von PCL, PCL/HA und PCL/TCP in einer DTM „Sinterstation 2500 plus" mit einem verkleinerten Bauraum veröffentlicht [LTC+10] [EVL+12]. Der Kompositwerkstoff PCL/HA und reines PCL wurden nochmals im Jahr 2015 in Wuhan (China) in einer Wuhan Binhu "HRPS-IV" Lasersintermaschine von $Y$. Du et al. verarbeitet [DLS+15]. Im Zeitraum 2011 bis 2013 verarbeiteten C. Shuai et. al sowohl HA als auch PLGA auf einer eigenentwickelten Lasersintermaschine in Changsha (China) [SGN+11] [SYP+13]. Zur Verarbeitung des Copolymers PLGA wird an der Technischen Universität in Berlin seit 2014 eine EOS „Formiga P 100“ mit einer eigenentwickelten Bauraumverkleinerung verwendet [LJH+14]. Im Folgenden werden die in den Forschungsprojekten verwendeten Maschinen, durchgeführten Modifikationen und bereits formulierten Herausforderungen bei der Wechselwirkung von polymerbasiertem Material, Prozess und Maschine im Kontext der Maschinenentwicklung detailliert vorgestellt.

\subsubsection{Kommerzielle Lasersintermaschinen mit Bauraumverkleinerung}

Zur Herstellung von Implantatmatrizen mittels Lasersintern werden im Bereich der Forschung sowohl kommerzielle als auch eigenentwickelte Maschinen eingesetzt. Aufgrund der hohen Werkstoffpreise und der teilweise im Labormaßstab hergestellten Materialmengen sind die Bauräume der kommerziellen Lasersintermaschinen in den meisten Projekten durch die Verwendung spezifischer Maschinenadapter (Bauraumverkleinerung) stark verkleinert. Verwendet wurden die folgenden Basismaschinen:

- DTM Sinterstation 2000 [WAS+05] [DWZ+10] [KLH+12]

- DTM Sinterstation 2500 [WLC+07] [SWA+08]

- DTM Sinterstation 2500 plus [LTC+10] [LCB+12]

- Wuhan Binhu HRPS-IV [DLS+15]

- EOS Formiga P $100[\mathrm{LJH}+14]$

- EOS Formiga P 110 [Gro16] [BPL+16]

Die aufgezählten Maschinen der Firma DTM wurden im Jahr 1992 auf den Markt gebracht und im Oktober 2008 von 3D-Systems durch die „sPro 140“ und „sPro 230“ ersetzt [WG14]. Der Aufbau der „HRPS-IV“ der chinesischen Firma Wuhan Binhu Mechanical \& Electrical Co. Ltd. gleicht optisch dem Aufbau der DTM-Maschinen. Die Verarbeitung von Kleinstmengen PLA auf einer kommerziellen DTM „Sinterstation 2000“ in Kombination mit einer Bauraumverkleinerung veröffentlichten $W$. Y. Zhou et al. (Hong Kong) erstmals im Jahr 2007. Der eigenentwickelte Maschinenadapter, der in das Bauvolumen $(\varnothing 305 \mathrm{~mm} \times 381 \mathrm{~mm})$ der DTM „Sinterstation 2000 “ eingesetzt wurde, besaß eine stark verkleinerte runde Bauplattform, zwei eckige Zuführplattformen und war rundum mit Überlaufbehältern ausgestattet. Die Hubbewegungen der drei Plattformen wurden jeweils durch einen Schrittmotor angetrieben. Die Bauplattform der Basismaschine wurde im Betrieb mit der Bauraumverkleinerung nicht bewegt [ZLW+07]. F. E. Wiria et al. (Singapur) beschäftigten sich intensiv mit der Entwicklung einer Bauraumverkleinerung für die DTM „Sinterstation 2500“ und veröffentlichten 2010 einen mechanisch 
angetriebenen Maschinenadapter. Die verkleinerte Bauplattform $(80 \mathrm{~mm} \times 100 \mathrm{~mm})$ war mechanisch über eine Zahnstange mit der Bauplattform der Basismaschine verbunden. Durch eine entsprechende Kinematik löste eine Abwärtsbewegung der Bauplattform die Aufwärtsbewegung beider Pulverzuführplattformen aus [ESF+10]. Die im Rahmen des „ActiveBone“-Projekts entwickelte OEM-Bauraumverkleinerung für die EOS „Formiga $\mathrm{P} 110$ " besaß ein reduziertes Bauvolumen $(\mathrm{x} \times \mathrm{y} \times \mathrm{z})$ von $60 \mathrm{~mm} \times 75 \mathrm{~mm} \times 75 \mathrm{~mm}$, zwei Pulverzuführplattformen, zwei Überlaufbehälter und war in einem Wechselbehälter verbaut. M. Bullemer et al. diskutierten die Vor- und Nachteile einer vollintegrierten Variante (Verwendung von drei identischen Achsen unabhängig von der Basismaschine) bzw. einer teilintegrierten Variante (Verwendung von zwei Achsen und die Integration der z-Achse der Basismaschine) und lieferten die teilintegrierte Lösung 2015 aus [BPL+16]. Die Überlegenheit dieses OEM-Integrationsansatzes gegenüber einer Fremdmodifikation kommerzieller Maschinen besteht in der Umsetzung der Elektrik und der Anpassung der Steuersoftware. Der Schaltschrank wurde um eine weitere SPS erweitert, ungenutzte Sensoren im Betrieb überbrückt, Maschinenparameter angepasst und die Bedienung der Bauraumverkleinerung geschah über einen zusätzlichen Touchscreen-Monitor. Ein großer Vorteil der Realisierung einer teilintegrierten Bauraumverkleinerung besteht in der Übertragung der Stellgenauigkeit der Basismaschinen-z-Achse auf die reduzierte Bauplattform durch die mechanische Kopplung.

\subsubsection{Eigenentwickelte Lasersintermaschinen}

Einige wenige Forschungsgruppen nutzten eigenentwickelte Lasersintermaschinen mit kleinen Bauräumen für die Verarbeitung von bioresorbierbaren Materialien. Technische Details können den folgenden Veröffentlichungen entnommen werden:

- L. Hao et al. (Großbritannien) zur Verarbeitung von HA/PE [HSZ+06]

- Hoeges et al. (Aachen) zur Verarbeitung von Henchglas bzw. PLA/TCP [HLM+10]

- C. Shuai et al. (China) zur Verarbeitung von HA [SGN+11]

Die „experimentelle Prozesskammer" der Forschungsmaschine von L. Hao et al. besaß zwei runde Plattformen (Bau- und Pulverzuführplattform) mit einem Durchmesser von $103 \mathrm{~mm}$ und eine Überlauföffnung. Die Beschichtereinheit bestand aus einer starr montierten Welle und wurde über einen Riementrieb in horizontaler Richtung bewegt. Sowohl die Bau- und Vorratszylinder als auch die Pulverbettoberfläche waren beheizt. Ein $\mathrm{CO}_{2}$-Laser (Wellenlänge 10,6 $\mu \mathrm{m}$ ) der Firma Synrad (Modell bzw. Leistungsklasse nicht angegeben) emittierte die elektromagnetische Strahlung. Nach Fokussierung des Laserstrahls in der Prozessebene betrug der Fokusdurchmesser $193 \mu \mathrm{m}$. Der verwendete Galvano-Scanner ist in der Veröffentlichung nicht beschrieben. Die Prozesskammer wurde vor dem Fertigungsstart mit Stickstoff (Restsauerstoffgehalt $<5 \%$ ) befüllt. Die im Rahmen des „Resobone“-Projekts durch Hoeges et al. verwendete Fraunhofer-ILT-Maschine wurde ursprünglich von Meiners vor 1999 für die Entwicklung des Laserstrahlschmelzens (vgl. Abschnitt 3.2) aufgebaut. Die „Prototypenanlage“ war aus einer Prozesskammer, einem Nd:YAG-Lasermarkiersystem (Typ „Marker 150 Q“) der Firma Rofin-Sinar, einer 
Gasversorgung und einem Steuercomputer aufgebaut. Die Prozesskammer besaß ein Bauund ein Pulverzuführvolumen $(\varnothing 150 \mathrm{~mm} \times 100 \mathrm{~mm})$ und wurde bei der Verarbeitung von Metallpartikeln mit zwei Schutzgasen gleichzeitig gespült. Das zugeführte Pulver wurde mittels linear bewegtem Schieber über der Bauplattform verteilt. Eine Heizanlage war nicht verbaut [Mei99, S. 69-73]. Zur Verarbeitung der Kompositmaterialien Henchglas/TCP bzw. PLA/TCP wurde als Ergebnis entsprechender Untersuchungen (vgl. Abschnitt 3.3.5) das Nd:YAG-Lasermarkiersystem gegen einen $80 \mathrm{~W} \mathrm{CO}_{2}$-Laser (Wellenlänge 10,6 $\mathrm{m}$ ) der Firma FEHA (Typ „SM 400 P“) in Kombination mit einem Scanlab „hurrySCAN 20“ Scanner samt F-Theta-Linse getauscht [HM09]. Eine Inertisierung fand nicht statt. Die Durchmesser der Bau- und Pulverzuführplattformen der von Hoeges et al. verwendeten Prozesskammer waren mit $50 \mathrm{~mm}$ angegeben und besaßen ein Heizelement. Weiterhin wurden insgesamt drei Beschichtereinheiten zur Optimierung des Pulverauftrags (vgl. Abschnitt 3.3.3) aufgebaut [HD10, S. 19-21]. Die Lasersintermaschine von $C$. Shuai et al. war aus einem in vertikaler Richtung montierten $100 \mathrm{~W} \mathrm{CO}_{2}$-Laser der Firma Synrad (Typ „firestar t-Serie“) samt konvexer Linse und einer runden Bauplattform aufgebaut, die durch einen Lineartisch in allen drei Raumrichtungen translatorisch bewegt werden konnte. Der Aufbau verfügte weder über einen Pulverauftrag, noch über eine Prozessgasversorgung. Zur Generierung einer Bauteilschicht wurde die Bauplattform in der x-y-Richtung unterhalb des starren Laserstrahls bewegt. Durch ein Absenken der Bauplattform in der vertikalen z-Richtung wurde der minimale Fokusdurchmesser von $50 \mu \mathrm{m}$ defokussiert.

\subsubsection{Pulverauftrag und fluidisierende Beschichtereinheiten}

Ein definiertes Ziel des „Resobone“-Projekts war die Erforschung eines reproduzierbaren Pulverauftrags für die Kompositwerkstoffe Henchglas/TCP und PLA/TCP, die am Lehrstuhl für Keramik und feuerfeste Werkstoffe der RWTH Aachen entwickelt wurden [HD10]. Bei der Herstellung des Werkstoffs PLA/TCP reduzierten M. Lindner et al. die Korngrößen der angelieferten PLA- und TCP-Partikel (jeweils $100 \mathrm{~g}$ ) durch mechanisches Mahlen innerhalb eines Prozesses [LFT10, S. 15-19]. Bedingt durch den Aufbereitungsprozess entsprach weder die Kornform noch die Sphärizität des PLA/TCPs einem klassischen Lasersintermaterial und führte infolge verminderter Fließeigenschaften zu einem mangelhaften Pulverauftragsergebnis. Zur maschinenspezifischen Kompensation der Pulvereigenschaften baute $S$. Hoeges die folgenden Beschichtereinheiten auf:

- Rotierender Rolle

- Schwingende Kohlefaserbürste

- Schwingende und gleichzeitig angewinkelte Klinge

- Schwingende Kohlefaserbürste mit schwingender und angewinkelter Klinge

Die Verwendung einer Beschichtereinheit mit rotierender Rolle ist aus den DTM-Maschinen hinreichend bekannt und wurde nach subjektiver Bewertung der Kriterien „Streifenbildung“, „Kompression“, „Reproduzierbarkeit“ und „Justage“ zum Pulverauftrag des PLA/TCPs in Aachen verwendet. Die „Streifenbildung“ auf der Oberfläche der 
aufgetragenen Pulverschicht führte $S$. Hoeges auf die Bildung von Agglomeraten am Auftragskörper zurück, die bei der Beschichterbewegung die Pulverschicht ,aufreißen“. Durch eine auf die Auftragsgeometrie übertragene, hochfrequente Schwingung quer zur Pulverauftragsrichtung verringerte sich die „Streifenbildung“ durch den Abbau (Fluidisierung) der Agglomerationen [Hög10, S. 63-69]. Das Pulverauftragskonzept mit einem vibrierenden Abstreifelement ist, geschützt durch Gebrauchsmuster (vgl. [DE9400346 U1] von 1994) und Patent (vgl. [DE4400523 C2] von 1996), geistiges Eigentum der Firma EOS. Die bauraumverkleinerte EOS „Formiga P 110“ aus dem „ActiveBone“-Projekt verwendete für den Pulverauftrag die standardmäßig verbaute Wechselklinge. Der Einsatz einer Fluidisierklinge wurde jedoch als mögliche Alternative für ein verbessertes Pulverauftragsergebnis positiv bewertet [BPL+16, S. 36].

\subsubsection{Aufheizvorgang und Temperaturregelbereiche}

Um den zum Aufschmelzen des bioresorbierbaren Werkstoffs notwendigen Energiebetrag durch den Laser zu reduzieren, werden die Lasersintermaschinen auf einen Temperaturwert unterhalb der materialspezifischen Schmelz- bzw. Erweichungstemperatur vorgeheizt. Ein wesentliches Qualitätskriterium bei der Bewertung der verbauten Heizsysteme ist die Homogenität und Regelstabilität der Temperatur im Bereich des Bauvolumens über die gesamte Prozessdauer. Ein Über- bzw. Unterschwingen in Bezug zum vorgegebenen Sollwert führt bei konstantem Laserenergieeintrag zu unterschiedlichen mechanischen Eigenschaften des generierten Bauteils. Kommerzielle Lasersintermaschinen sind in der Regel auf die Verarbeitung von Polyamid 12 (Vorheiztemperatur ca. $170^{\circ} \mathrm{C}$ ) ausgelegt. Die EOS „Formiga P 100“ des 3D-Labors der TU Berlin (vgl. Abbildung 3.1) verfügt über eine Entnahmekammerheizung (einstellbar von $130^{\circ} \mathrm{C}$ bis $170^{\circ} \mathrm{C}$ ) und eine 1-Zonen-Prozesskammerheizung (einstellbar von $159^{\circ} \mathrm{C}$ bis $179^{\circ} \mathrm{C}$ ), die über einen Schieberegler auf dem Touchscreen-Monitor im genannten Wertebereich eingestellt oder deaktiviert werden. Die von Y. Du et al., W. Y. Zhou et al. und F. E. Wiria et al. gewählte Pulverbetttemperatur zur Verarbeitung der bioresorbierbaren Werkstoffe lagen aufgrund ihrer Sekundärstruktur im Bereich zwischen $40^{\circ} \mathrm{C}$ und $60^{\circ} \mathrm{C}$ [DLS+15] [ZLW+08] [WLC+07]. Die Übertragung dieses Prozessparameters auf die „Formiga P 100“ ist folglich nicht ohne weitere Modifikation möglich. Die Prozesskammerheizungen der „Formiga P 100“ (1-Zonen) und „Formiga P 110“ (4-Zonen) emittieren elektromagnetische Strahlung im infraroten Bereich. M. Bullemer et al. regten in einem entsprechenden Arbeitspaket im „ActiveBone“-Projekt die Untersuchung der Wechselwirkung zwischen Material und IR-Strahlung in Bezug auf die Biokompatibilität der generierten Implantatmatrizen an. Entsprechende Tests wurden aufgrund einer Prozessentwicklung bei deaktivierter Prozesskammerheizung nicht durchgeführt. Weiterhin sollte die Funktionsfähigkeit eines für den Betrieb um $170^{\circ} \mathrm{C}$ entworfenen Heizsystems für ein stark abweichendes Betriebsszenario um beispielsweise $50^{\circ} \mathrm{C}$ überprüft werden. Die von $M$. Bullemer et al. entwickelte OEM-Bauraumverkleinerung war für einen Betrieb in einer Umgebungstemperatur von maximal $50^{\circ} \mathrm{C}$ ausgelegt $[\mathrm{BPL}+16, \mathrm{~S} .66]$. Die im Wechselrahmen befindlichen Baugruppen der Bauraumverkleinerung erwärmen sich bei geschlossener Prozesskammertür durch die räumliche Nähe zur Prozessebene. Im Falle einer nicht aktiv gekühlten Bau- 
raumverkleinerung ist die maximale Einsatztemperatur der Baugruppe stets durch die bauteilspezifischen Temperaturfestigkeiten limitiert.

\subsubsection{Laserenergieeintrag und Laserstrahlabschwächungssysteme}

Im Rahmen einer Prozessentwicklung mit bioresorbierbaren Werkstoffen variierten die Forschungsgruppen die Laserleistung, Scangeschwindigkeit, Spurabstand, Scanvektorlänge sowie die Schichtstärke in dem maschinenspezifisch zulässigen Wertebereich zur Bauteilschichtgenerierung. Die Auswahl einer geeigneten Laserwellenlänge zur Verarbeitung des spezifischen Materials fand bei der Verwendung von kommerziellen Lasersintermaschinen, aufgrund des damit verbundenen Modifikationsaufwands, nicht statt. Die im Rahmen des „Resobone"-Projekts durchgeführten spektrometrischen Untersuchungen von PLA/TCP, Henchglas/TCP, TCP und PLA zeigten eine entsprechend höhere Absorption bei der Wellenlänge von 10,6 $\mathrm{mm}\left(\mathrm{CO}_{2}\right.$-Laser) im Vergleich zu 1,064 $\mu \mathrm{m}$ (Faserlaser). Auf Grundlage dieser Ergebnisse bauten Hoeges et al. ein $\mathrm{CO}_{2}$-Laser auf ihre eigenentwickelte Prozesskammer [HD10, S. 15-17]. Bei dem Vergleich gewählter Laserleistungen wurden auffallend geringe Werte im Bereich von unter $1 \mathrm{~W}$ bis zu $10 \mathrm{~W}$ zur Verarbeitung der resorbierbaren Werkstoffe gewählt [Köh15, S. 87-89] [HD10] [DLS+15] [HSZ+06] [LTC+10] [EVL+12] $[\mathrm{KLH}+12][\mathrm{LHM}+11]$. M. Bullemer et al. regten in einem entsprechenden Arbeitspaket im „ActiveBone“-Projekt die Untersuchung der Regelstabilität des Lasers (Synrad „firestar v30" mit $30 \mathrm{~W}$ ) der EOS „Formiga P 110" im unteren Leistungsgrenzbereich an, um bei einer Sollwertvorgabe unterhalb von $10 \%$ eine entsprechende Strahlqualität gewährleisten zu können [BPL+16, S. 7-8]. Im Falle unzureichender Ergebnisse wurden die folgenden Modifikationsvorschläge genannt:

- Strahlabschwächungssystem in Kombination mit dem 30 W Synrad Laser

- Wechsel auf eine Laserleistungsklasse bis maximal $10 \mathrm{~W}$

Die Verarbeitung des Kompositmaterials PLA/TCP/PCC wurde jedoch ohne weitere Modifikation im Bereich des Lasers durchgeführt. Die von Hoeges et al. eigenentwickelte Lasersintermaschine mit einem $80 \mathrm{~W} \mathrm{CO}$-Laser (vgl. Abschnitt 3.3.2) wurde zur Verarbeitung des PLA/TCP-Materials durch den Einsatz eines „Compact CMA-E"-Leistungsabschwächers der Firma ULO Optics auf eine Leistung von 0,2 W bis $10 \mathrm{~W}$ gedrosselt [Hög10, S. 62]. Die Modifikation einer kommerziellen Lasersintermaschine mit einem Laser der Leistungsklasse bis maximal $10 \mathrm{~W}$ im Kontext der Implantatfertigung ist nicht bekannt. 



\section{Forschungsbedarf}

Das Tissue Engineering (TE) wird unter anderem zur künstlichen Gewebezüchtung für die medizinische Regeneration eingesetzt. Zur Herstellung von patientenspezifischen Implantatmatrizen, dem Gerüst zum Gewebeaufbau, sollen zukünftig bioresorbierbare Polymere mittels Lasersintern verarbeitet werden. Diesbezüglich wird in Abschnitt 4.1 das AM-Wechselwirkungsdreieck im Tissue Engineering Kontext dargestellt. Aus dem Stand der Technik und Wissenschaft aus Kapitel 3 leitet sich zur Beeinflussung des AM-TE-Wechselwirkungsdreiecks ein Forschungsbedarf bezüglich der Entwicklung einer spezifischen Lasersintermaschine ab. In Abschnitt 4.2 wird das methodische Vorgehen bei der Entwicklung der modularen Lasersintermaschine zur Verarbeitung von bioresorbierbaren Polymeren diskutiert. Abschließend wird die Zielstellung der vorliegenden Arbeit in Abschnitt 4.3 abgegrenzt. 


\subsection{Wechselwirkungsdreieck im Tissue Engineering Kontext}

Die durch das Additive Manufacturing (AM) erzeugte Bauteilqualität ist das Ergebnis einer komplexen Wechselwirkung aus Material, Maschine und Prozess. Zur Herstellung filigraner Strukturen im Kontext des Lasersinterns muss sowohl die Maschine (z. B. Spotsize), das Material (z. B. Partikelgröße) als auch die Prozessführung (z. B. Scan-Strategie) technische Mindestvoraussetzungen erfüllen und gleichermaßen in Kombination zu einem reproduzierbaren Fertigungsergebnis führen. Bei der additiven Fertigung von

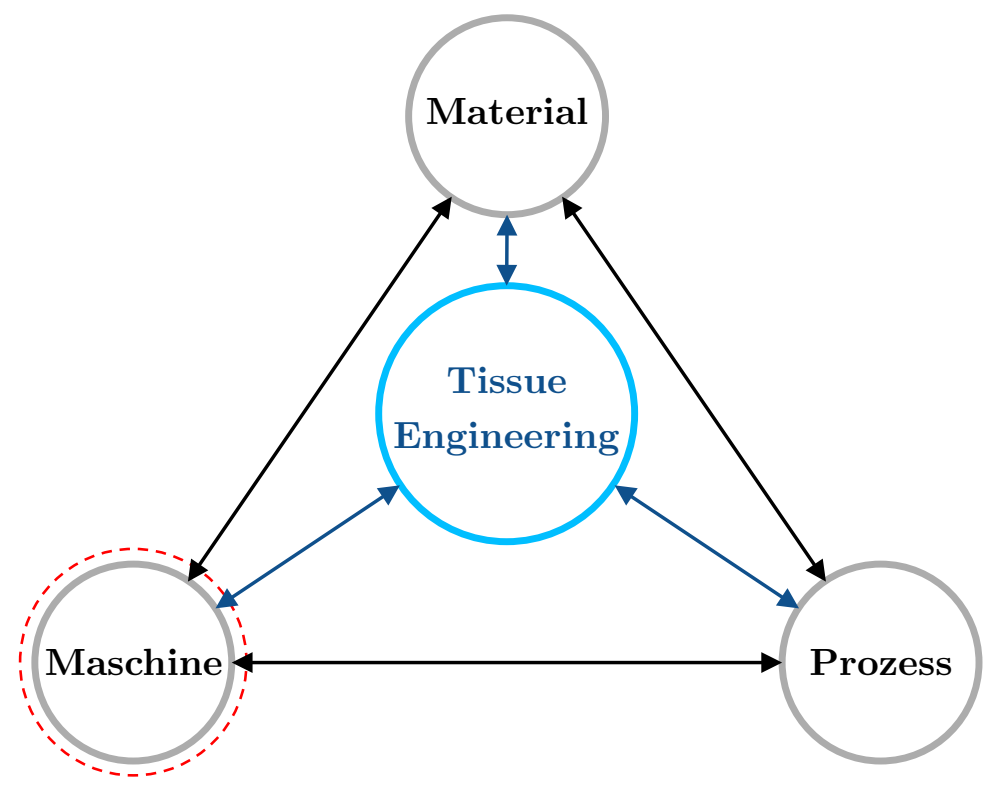

Abbildung 4.1.: AM-TE-Wechselwirkungsdreieck

bioresorbierbaren Implantatmatrizen für das Tissue Engineering (TE) erhöht sich, wie in Abbildung 4.1 dargestellt, die Komplexität der Wechselwirkung durch die spezifischen Qualitätsmerkmale des Tissue Engineerings. Der medizinische Verwendungszweck hat durch die Kopplung an entsprechende Regularien und Gesetze einen erheblichen Einfluss auf die Definition der technischen Mindestanforderungen von Material, Maschine und Prozess. Die im Stand der Wissenschaft in Kapitel 3 dargestellten Forschungsergebnisse haben gezeigt, dass die Verwendung der Materialien von beispielsweise PLA, PLGA oder PCL bei der Entwicklung von bioartifiziellem Gewebe zielführend ist. Kommerzielle Lasersintermaschinen sind ausgelegt für die Verarbeitung von kommerziellen Lasersintermaterialien. Da sich die Eigenschaften der bioresorbierbaren Polymere stark von kommerziellen Lasersintermaterialien unterscheiden, muss folglich sowohl der Prozess als auch die Lasersintermaschine angepasst werden. Zur Qualifizierung des Lasersinterns als Herstellungsverfahren für bioresorbierbare Implantatprodukte müssen zusätzlich die Anforderungen nach GMP (engl. „Good Manufacturing Practice“) erfüllt sein. In dem GMP-Regelwerk ${ }^{1}$ [Bun06] [Bun15] sind unter anderem die Anforderungen an Produkti-

\footnotetext{
${ }^{1}$ GMP-Richtlinie in der EU: https://ec.europa.eu/health/documents/eudralex/vol-4_en
} 
onsabläufe und die dabei verwendete Ausrüstung für eine „gute“ Herstellungspraxis von Arzneimitteln festgelegt. Die Lasersintermaschine muss zur Minimierung des Kontaminationsrisikos bei der Herstellung der bioresorbierbaren Implantatmatrizen in jedem Fall hygiene- und reinigungsgerecht konstruiert sein.

\subsection{Forschungsansatz}

Die mechatronischen Teilsysteme kommerzieller Lasersintermaschinen (vgl. Stand der Technik aus Abschnitt 3.1) sind abgestimmt auf die Verwendung kommerzieller Lasersintermaterialien wie beispielsweise PA12 oder PEEK. Zur optimierten Verarbeitung eines bioresorbierbaren Werkstoffs in einer kommerziellen Lasersintermaschine müssen aufgrund der spezifischen Werkstoffcharakteristik, die erheblich von den kommerziellen Lasersintermaterialien abweicht, die folgenden Modifikationen (vgl. Stand der Wissenschaft aus Abschnitt 3.3) an der Maschine durchgeführt werden:

- Verkleinerung des Bauraums

- Anpassung des Heizsystems für den vorgeheizten Betrieb bis maximal $80^{\circ} \mathrm{C}$

- Einsatz einer fluidisierenden Beschichtereinheit zum Pulverauftrag

- Abschwächung der Laserleistung beim Laserenergieeintrag

Die Existenz einer hygiene- und reinigungsgerechten Lasersintermaschine in Kombination mit allen aufgeführten technischen Eigenschaften zur Verarbeitung von bioresorbierbaren Polymeren ist nicht bekannt. Um einen Beitrag zur zukünftigen Herstellung von bioresorbierbaren Implantatmatrizen für das Tissue Engineering mittels Lasersintern zu leisten, muss folglich die Neuentwicklung einer spezifischen Lasersintermaschine durchgeführt werden. Da der Einsatz einer neuen Maschine zwangsweise (vgl. AM-TE-Wechselwirkungsdreieck in Abbildung 4.1) zu einer Anpassung des Prozesses führt, muss die Lasersintermaschine zur Grundlagenforschung eingesetzt werden können. Änderungen an dem Aufbau einer Lasersintermaschine zur Verbesserung des Lasersinterprozesses gelten als aufwändig [Seh10, S. 7-14] [Weg15, S. 7-9]. Die Produktstruktur einer grundlagenforschungstauglichen Lasersintermaschine muss im Gegensatz zu industriellen Produktionsmaschinen für einen regelmäßigen Austausch gewisser Baugruppen im Versuchsablauf ausgelegt sein. Da die Forschungsmaschine zunächst primär zur Prozessentwicklung mit bioresorbierbaren Polymeren verwendet werden soll, müssen die mechatronischen Teilsysteme für die Variation von Prozessparametern konzipiert sein.

Das methodische Vorgehen bei der Entwicklung der neuen Lasersintermaschine orientiert sich an der VDI-Richtlinie 2221 [VDI 2221]. Zur Erfüllung des ersten Arbeitsschritts, dem „Klären und präzisieren der Aufgabenstellung“, werden zunächst generelle Anforderungen an Lasersintermaschinen integrativ aus dem AM-TE-Wechselwirkungsdreieck (vgl. Abschnitt 4.1) und den Prozesserkenntnissen der Forschung erhoben [VDI 2221, S. 9]. Die generellen Anforderungen, dargestellt in Kapitel 5, dienen der Absicherung der notwendigen „Variabilität“ bzw. „Offenheit“ des Gesamtsystems. Bei der Lösung der 
Entwicklungsaufgabe entspricht dies der Konkretisierungsstrategie der Richtlinie: „vom Abstrakten oder Allgemeinen zum Konkreten, Besonderen“ [VDI 2221, S. 5].

In Kapitel 6 wird die Lasersintermaschine durch die Anwendung der VDI-Richtlinie 2221 [VDI 2221] methodisch entwickelt. Das systematische Vorgehen gliedert sich in die Phasen „Planen“, „Konzipieren“, „Entwerfen“ und „Ausarbeiten“. Die wesentlichen Ergebnisse der jeweiligen Phase werden zusammengefasst dargestellt.

Bei der Auslegung einer Laser-Scanner-Einheit für eine Lasersintermaschine ist neben der Laserleistung vor allem die Wellenlänge der Strahlquelle von großer Bedeutung. Aufgrund des materialspezifischen Absorptionsspektrums muss die zur Generierung der bioresorbierbaren Implantatmatrizen verwendete Laserwellenlänge auf das zu verarbeitende Material abgestimmt sein. In Kapitel 7 wird die Auswahl einer materialspezifischen Laser-Scanner-Einheit auf Basis entsprechender Materialuntersuchungen dargestellt.

Die VDI-Richtlinie 2206 [VDI 2206] befasst sich mit der Entwicklung mechatronischer Produkte. Durch das generische Vorgehen gemäß dem „V-Modell“ muss der Entwurfsfortschritt „fortlaufend anhand des spezifizierten Lösungskonzepts und der Anforderungen" durch die Eigenschaftsabsicherung überprüft werden [VDI 2206, S. 30]. In Kapitel 8 werden die Nachweise über die Funktionsfähigkeit der mechatronischen Teilsysteme nach der Montage und Inbetriebnahme der Lasersintermaschine erbracht.

\subsection{Abgrenzung der Arbeit}

Da der gesamte Produktentstehungsprozess einer Lasersintermaschine einen erheblichen Arbeitsaufwand darstellt, muss der Umfang der vorliegenden Arbeit eingeschränkt werden. Ein materialspezifischer Lasersinterprozess, der zur Herstellung von bioresorbierbaren Implantatmatrizen notwendig ist, wird im Rahmen der vorliegenden Arbeit nicht entwickelt. Die Steuersoftware der Lasersintermaschine wird im Rahmen der Dokumentation nicht dargestellt. 


\section{Generelle Anforderungen an Lasersintermaschinen zur Implantatherstellung}

Bei der Neuentwicklung einer spezifischen Lasersintermaschine zur Implantatherstellung bildet das in Abschnitt 4.1 beschriebene AM-Wechselwirkungsdreieck im Tissue Engineering Kontext den Ausgangspunkt für das Anforderungsmanagement. Die Erhebung eindeutiger Anforderungen an die Maschine ist jedoch nach derzeitigem Entwicklungsstand der Technologie nicht möglich. Da weder ein spezifisches Material mit sämtlichen Eigenschaften, noch ein materialspezifischer Lasersinterprozess in hygienischer Umgebung exakt charakterisiert ist, muss die Maschine zur Grundlagenforschung geeignet sein. Die

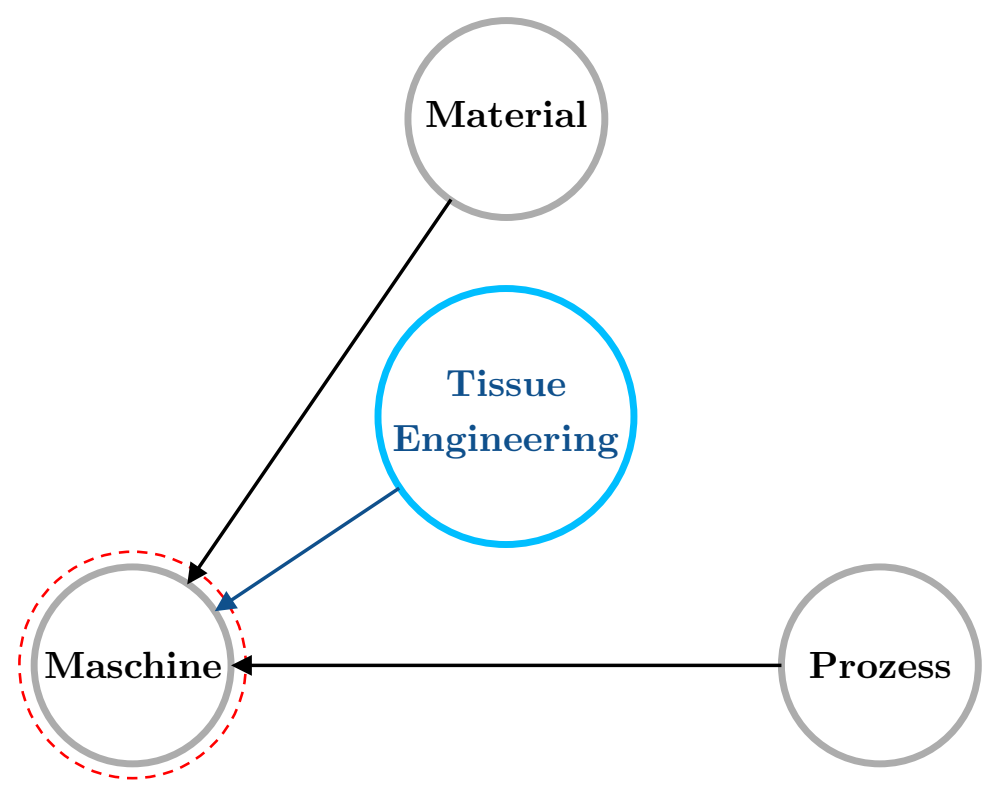

Abbildung 5.1.: Anforderungserhebung aus dem AM-TE-Wechselwirkungsdreieck

Hauptfunktion der neuartigen Maschine ist folglich die Erforschung der Wechselwirkungen zur Verbesserung der spezifischen Merkmale der Wechselwirkungspartner, um zukünftig bioresorbierbare Implantatmatrizen mittels Lasersintern herstellen zu können. Der integrative Ansatz zur Erhebung der Anforderungen an die grundlagenforschungstaugliche Maschine ist dargestellt in Abbildung 5.1. Die Wechselwirkungspartner „Material“ und „Prozess" sind bei der Entwicklung einer Lasersintermaschine eng miteinander verknüpft, müssen jedoch für die Erhebung der Anforderungen klar voneinander abgegrenzt 
werden. Unter dem Einfluss des Prozesses auf die Maschinenentwicklung, beschrieben in Abschnitt 5.1, werden jene Anforderungen an die Prozessführung erfasst, die eine materialspezifische Prozessentwicklung (z. B. Variation eines Softwareparameters) mit der bestehenden Lasersintermaschine ermöglichen. Der Umbau spezifischer Bauteile oder Baugruppen (z. B. Austausch des Lasers) ist ein Eingriff in die Produktstruktur unter dem Einfluss des Materials und wird als Anforderung an die Produktarchitektur in Abschnitt 5.2 diskutiert. Ein Umbau kann unter Umständen zur Erhöhung bzw. Reduktion der Gesamtanzahl an Prozessparametern führen. Der Einfluss des Tissue Engineerings auf die Maschinenentwicklung wird in den Anforderungen aus dem medizinischen Gerätebau abschließend in Abschnitt 5.3 diskutiert. Die folgenden generellen Anforderungen müssen bei der Neuentwicklung einer Lasersintermaschine zur Herstellung von bioresorbierbaren Implantatmatrizen erfüllt werden:

Generelle Anforderungen an die Prozessführung

1. Großer Einstellbereich der Prozessparameter

2. Möglichkeit der Regelung zielführender Prozessparameter

3. Kenntnis über die parameterspezifische Leistungsfähigkeit der Teilsysteme

4. Möglichkeit zur vorübergehenden Integration zusätzlicher Messtechnik

5. Data Logging sämtlicher Prozessparameter

6. Möglichkeit zur Anpassung der Steuersoftware

$\underline{\text { Generelle Anforderungen an die Produktarchitektur }}$

1. Hohes Maß an Modularität

2. Modifikationsfreundliche Produktstruktur

3. Erweiterbarkeit des Steuersystems

4. Kleines Bauvolumen zur wirtschaftlichen Fertigung filigraner Strukturen

5. Bevorzugte Verwendung von multifunktionalen Teilsystemen

6. Bevorzugte Verwendung von geregelten Teilsystemen

7. Einsatz spezifischer Sensorik

8. Kenntnis über die komponentenspezifische Leistungsfähigkeit der Teilsysteme Generelle Anforderungen aus dem medizinischen Gerätebau

1. Bevorzugte Verwendung von hygienegerechten Werkstoffen

2. Reinigungsgerechte Gestaltung sämtlicher Bauteilgeometrien

3. Hygienegerechte Gestaltung von Bauteilverbindungen

4. Vermeidung von Toträumen in Baugruppen

5. Fertigung qualitativ hochwertiger Oberflächenbeschaffenheiten

6. Bevorzugte Verwendung von hygienekonformen Zukaufteilen

7. Einsatz einer medizinischen Gasversorgung zur Inertisierung 


\subsection{Anforderungen an die Prozessführung}

Die Entwicklung oder Optimierung eines materialspezifischen Lasersinterprozesses basiert auf der Identifikation einer Kombination von Prozessparametern, die zur Generierung spezifischer Qualitätsmerkmale führen. Ein im Rahmen der Forschung häufig verwendeter Ansatz besteht in der Variation von Prozessparametern an der Maschine, um kausale Zusammenhänge aus einer methodisch gestützten Versuchsdurchführung ableiten zu können. Bei der Entwicklung einer grundlagenforschungstauglichen Lasersintermaschine werden die folgenden Anforderungen an die Prozessführung gestellt:

1. Großer Einstellbereich der Prozessparameter Beim Lasersintern mit einem teilkristallinen Polyamid 12 wird die Maschine auf eine Temperatur von ca. $170{ }^{\circ} \mathrm{C}$ vorgeheizt. Der Parameter der Vorheiztemperatur kann an der EOS „Formiga P 100“, dargestellt im Stand der Technik in Abbildung 3.1, zum Ausgleich äußerer Einflüsse im Bereich von $159^{\circ} \mathrm{C}$ bis $179^{\circ} \mathrm{C}$ eingestellt werden. Eine Versuchsdurchführung bei einer Vorheiztemperatur von beispielsweise $60^{\circ} \mathrm{C}$ (vgl. Stand der Wissenschaft in Abschnitt 3.3.4) ist folglich nicht möglich. Zur Gewährleistung der Durchführbarkeit der Grundlagenforschung mit einer Lasersintermaschine müssen die steuerbzw. regelbaren Prozessparameter (vgl. Grundlagen in Abschnitt 2.3.4) in einem möglichst großen Wertebereich in der Steuersoftware variiert werden können. Ist die softwaretechnische Implementierung dieser Anforderung aufgrund mangelnder Leistungsmerkmale des mechatronischen Teilsystems nicht möglich, muss die Maschine hardwareseitig (vgl. Abschnitt 5.2) modifizierbar sein.

2. Möglichkeit der Regelung zielführender Prozessparameter Im Allgemeinen kann die Variation eines Prozessparameters direkt oder indirekt durch die Steuerung oder Regelung eines mechatronischen Teilsystems der Lasersintermaschine erreicht werden. Das bestimmende Merkmal zwischen einer Steuerung oder einer Regelung, dargestellt in Abbildung 5.2, ist das Vorhandensein der Rückkopplung. In einem

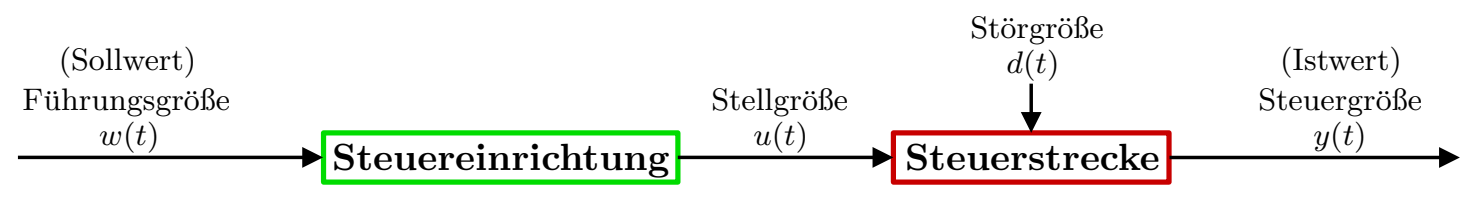

(a) Wirkungsplan eines Steuerungssystems

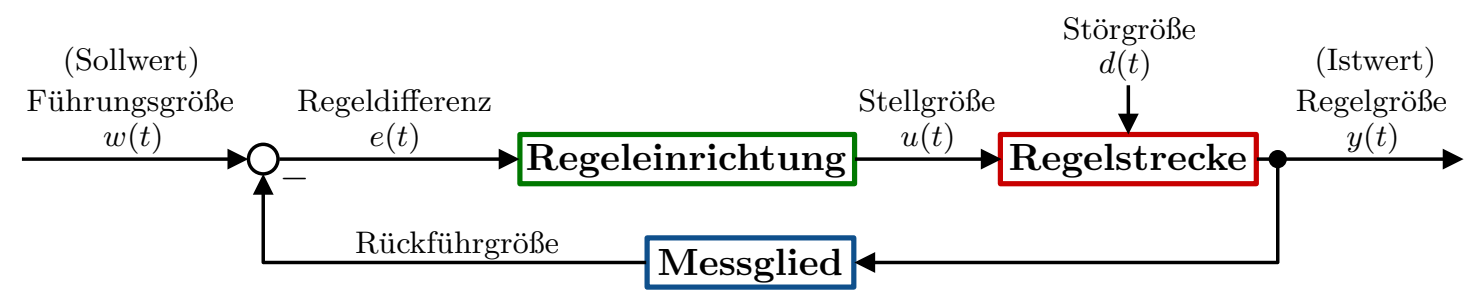

(b) Wirkungsplan eines Regelungssystems

Abbildung 5.2.: Steuerungssystem / Regelungssystems [DIN IEC 60050-351, S. 42-43] 
geschlossenen Regelkreis wird die Erfüllung des Regelungsziels $(y(t)=w(t))$ durch die wiederholte Durchführung der Prozessschritte „Messen“, „Vergleichen“ und "Stellen“ abgesichert. Um das gewünschte Ziel $(y(t)=w(t))$ mit Hilfe eines Steuerungssystems erreichen zu können, müssen die dynamischen Eigenschaften der Steuerstrecke bekannt und die Steuerstrecke ungestört sein. Aufgrund der fehlenden Rückkopplung kann die Steuereinrichtung nicht auf Störungen reagieren. Eine Regelung erreicht das Regelungsziel im Vergleich zu einer offenen Wirkungskette (Steuerung) auch wenn „die Regelstrecke instabil“ (Stabilisierung), „die Regelstrecke durch nichtmessbare Störungen beeinflusst wird“ (Störkompensation) und „die dynamischen Eigenschaften der Regelstrecke nicht genau bekannt sind oder sie sich zeitlich verändern" (Robustheit) [Lun16, S. 10]. Wird beispielsweise der Einfluss der Laserleistung auf die mechanische Zugfestigkeit eines Probebauteils untersucht, erwartet das Bedienpersonal der grundlagenforschungstauglichen Maschine eine Übereinstimmung von vorgegebenem Sollwert und dem vom Laser emittierten Istwert. Da grundsätzlich die abgegebene Laserleistung einer Strahlquelle infolge intensiver Nutzung abnimmt, ist die Verwendung eines geregelten Lasersystems zur Prozessentwicklung notwendig. Das Attribut „zielführend“ weist, aufgrund der höheren Investitionskosten bei der Beschaffung eines geregelten Systems, auf den betriebswirtschaftlichen Einfluss im Rahmen des Entscheidungsprozesses hin.

\section{Kenntnis über die parameterspezifische Leistungsfähigkeit der Teilsysteme Eine}

Lasersintermaschine ist aufgebaut aus einer Kombination von geregelten oder gesteuerten mechatronischen Teilsystemen. Zur Entwicklung eines Lasersinterprozesses ist neben der Variationsmöglichkeit der Prozessparameter vor allem die Kenntnis über die spezifischen Leistungsmerkmale der eingesetzten Teilsysteme von hoher Bedeutung. Wird beispielsweise der Einfluss der Laserleistung auf die mechanische Zugfestigkeit eines Probebauteils bei uniformer Schichtstärke untersucht, ist zu beachten, dass die Abweichung der Volumenenergiedichte bei der Bauteilschichtgenerierung (vgl. Grundlagen in Abschnitt 2.3.3) abhängig von dem Regel- bzw. Steuerverhalten des Lasers und dem Antrieb der Bauplattform ist. Folglich müssen bei der Auswertung der Versuche sowohl die Genauigkeiten bei der Positionierung der Bauplattform und der Abgabe der Laserleistung als auch die erzeugte Zugfestigkeit bekannt sein. Neben der "Genauigkeit im Beharrungszustand“ ist eine Kenntnis über die Leistungsmerkmale „Stabilität“, „Totzeit“, „Anregelzeit“, „Ausregelzeit“, „Überschwingweite“ und beispielsweise der „Empfindlichkeit gegenüber einer Parameteränderung“ bei der Prozessentwicklung förderlich, die bei der Auslegung der Steuerung bzw. Regelung der mechatronischen Teilsysteme entsprechend berücksichtigt wurden [Sch08, S. 333] [DIN IEC 60050-351, S. 81]. Ist die mangelnde Positioniergenauigkeit der geregelten Hubantriebsbaugruppe beispielsweise auf eine unzureichende Leistungsfähigkeit des verbauten Messsystems zurückzuführen, ist die softwareseitige Optimierung der Regeleinrichtung nicht zielführend. Der Umbau der Hubantriebsbaugruppe ist ein Eingriff in die Produktarchitektur (vgl. Abschnitt 5.2) der Lasersintermaschine. 
4. Möglichkeit zur vorübergehenden Integration zusätzlicher Messtechnik Die Entwicklung von Algorithmen zur Steuerung oder Regelung spezifischer Teilsysteme einer Lasersintermaschine basiert auf der sensorischen Erfassung optischer, akustischer, mechanischer oder elektrischer Signale. Die thermischen Eigenschaften spezifischer Materialien können sich unter anderem in der Wärmeleitfähigkeit und der Wärmekapazität unterscheiden. Soll beispielsweise das Material „A“ (hohe Wärmekapazität / geringe Wärmeleitfähigkeit) anstelle des Materials „B“ (niedrige Wärmekapazität / hohe Wärmeleitfähigkeit) in der grundlagenforschungstauglichen Maschine bei identischer Vorheiztemperatur verarbeitet werden, wird sich die Aufheizzeit vor dem ersten Laserenergieeintrag entsprechend verlängern. Das Aufheizverhalten des Materials oberhalb der Bauplattform wird durch die berührende oder optische Messung der Temperatur bestimmt. Sofern die Lasersintermaschine nicht über ein derartiges Messsystem verfügt, muss die Möglichkeit zur nachträglichen Integration entsprechender Messtechnik (z. B. freie Messkanäle zum Anschluss eines PT1000-Messfühlers) bestehen. Das Attribut „vorübergehend“ weist darauf hin, dass es sich dabei nicht um eine dauerhafte, funktionale Erweiterung der Maschine handelt, sondern lediglich um die zeitlich begrenzte Durchführung von Einzelmessungen. Der Einbau eines zusätzlichen Messsystems ist als Eingriff in die Produktarchitektur (vgl. Abschnitt 5.2) zu bewerten.

5. Data Logging sämtlicher Prozessparameter Bei der Entwicklung oder Optimierung eines materialspezifischen Lasersinterprozesses führt die in Abschnitt 3.2.4 diskutierte Maschinenzustandsüberwachung (engl. „Condition Monitoring“) zu einer verbesserten Früherkennung von Störgrößen. Die Zustandsüberwachung setzt sich aus den Prozessschritten „Zustandserfassung“, „Zustandsvergleich“ und der „Zustandsdiagnose" zusammen. Die Zustandsüberwachung unterteilt sich in die sensorische Erfassung von Signalen und der anschließenden Speicherung der aufgenommenen Sensordaten. Die Verwendung von Regelungssystemen impliziert die Ausstattung mit entsprechenden Messgliedern, jedoch nicht die Speicherung der rückgeführten Istwerte. Folglich muss die Möglichkeit der Datenspeicherung („Data Logging“) sämtlicher Prozessparameter als Anforderung ergänzend definiert sein. Zusätzlich muss eine mit der Systemzeit synchronisierte Zusammenführung der gespeicherten Daten realisierbar sein, um einen möglichen Qualitätsmangel, als Ergebnis eines gestörten Prozesses, am bzw. im Bauteil lokalisieren zu können.

6. Möglichkeit zur Anpassung der Steuersoftware Der Begriff „Steuersoftware“ umfasst im Kontext der vorliegenden Arbeit die nicht physische Komponente (Komplement zur Hardware) aller Mess-, Steuerungs-, Regelungs- und Überwachungssysteme, sowie das zum Betrieb der Lasersintermaschine notwendige Programm, wobei die Steuersoftware auf dem Steuersystem (Hardware) der Maschine installiert ist. Sofern durch eine softwareseitige Anpassung die parameterspezifische Leistungsfähigkeit (vgl. Anforderung „Kenntnis über die parameterspezifische Leistungsfähigkeit der Teilsysteme“) einzelner Teilsysteme verbessert wird, muss eine solche Optimierungsmöglichkeit an einer grundlagenforschungstauglichen Maschine bestehen. Soll 
beispielsweise ein elektrisches Heizsystem mit einem maximalen Regelbereich von $159^{\circ} \mathrm{C}$ bis $179^{\circ} \mathrm{C}$ auf eine Temperatur von $70^{\circ} \mathrm{C}$ geregelt werden, kann durch die Anpassung der Regelglieder bei unveränderter Hardware das einstellen (vgl. Anforderung „Großer Einstellbereich der Prozessparameter“) der gewünschten Vorheiztemperatur erreicht werden. Der Lasersinterprozess besteht aus einer geordneten Abfolge von Teilprozessen (Inertisierung, Aufheizvorgang, Pulverzuführung, Pulverauftrag, Bauteilschichtgenerierung, Abkühlvorgang), die in der Regel zeitverzögert nacheinander oder durchgehend ablaufen. Abseits der vergleichsweise komplexen, softwaretechnischen Anpassung der mechatronischen Teilsysteme kann bereits die Erhöhung der Pausenzeiten zwischen den Teilprozessschritten den Lasersinterprozess positiv beeinflussen. Folglich muss auch eine zeitliche Verschiebung der einzelnen Sequenzen realisierbar sein.

\subsection{Anforderungen an die Produktarchitektur}

Die Produktarchitektur, dargestellt in Abbildung 5.3, verknüpft die Funktionsstruktur (funktionale Zusammenhänge) mit der Produktstruktur (bauliche Zusammenhänge) sowie ebenfalls die Beziehungen (Transformation) zwischen den Komponenten und den Funktionen eines Produkts. Die physische Produktstruktur, einer Kombination aus gegebenenfalls gruppierten Komponenten zu einem Produkt, beschreibt eine mögliche

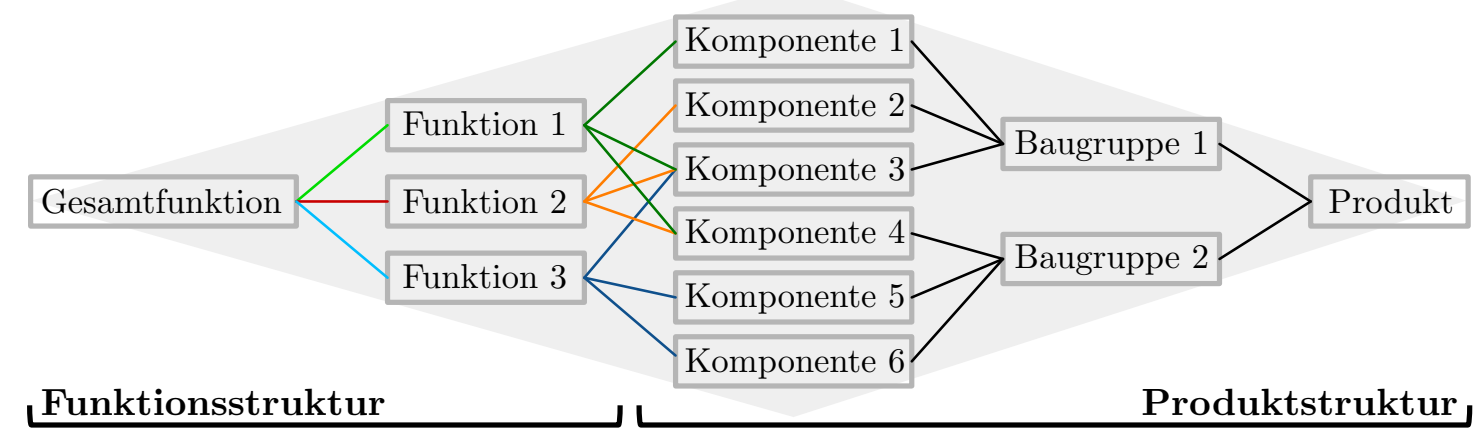

Abbildung 5.3.: Produktarchitektur dargestellt als „METUS-Raute“ [PBF+13, S. 257]

Umsetzung der geforderten Produktfunktionen. In Abhängigkeit der angewendeten Wirkprinzipien ergeben sich bei identischer Produktfunktionalität eine Vielzahl an möglichen Produktstrukturen [KG18, S. 72] [PBF+13, S. 255-256]. Die Gesamtfunktion „Grundlagenforschung zum Lasersintern von bioresorbierbaren Implantatmatrizen" mit dem Produkt „Lasersintermaschine“ impliziert die Durchführung einer Produktentwicklung auf Basis begrenzter Kenntnisse. Sowohl die gewünschten Funktionen (Funktionsstruktur) als auch die physischen Komponenten (Produktstruktur) der grundlagenforschungstauglichen Maschine können sich auf Basis neuer Erkenntnisse verändern. Bei der Entwicklung einer entsprechenden Lasersintermaschine werden die folgenden Anforderungen an die Produktarchitektur zur Erfüllung der „Variabilität" bzw. „Offenheit“ gestellt: 
1. Hohes Maß an Modularität Produktarchitekturen werden anhand der funktionalen und physischen Unabhängigkeiten der Produktbestandteile in modular oder integral unterteilt. Die modulare Produktarchitektur, dargestellt in (b) Abbildung 5.4, besteht im Vergleich zur integralen Produktarchitektur „aus funktional und physisch relativ unabhängigen, abgeschlossenen Einheiten (Modulen)" [PBF+13, S. 259]. Durch die Aufteilung (Entkopplung) einer Lasersintermaschine in Module wird die Komplexität des Produkts auf die einzelnen Module verteilt, wobei die Anzahl der Wechselwirkungen zwischen den Modulen nach Möglichkeit gering zu halten ist. Die Definition von Schnittstellen zwischen den Modulen ermöglicht eine Parallelisierung der modulspezifischen Entwicklungsarbeiten und kann zur Verkürzung der Produktentwicklungszeit beitragen. Die Entwicklung eines Moduls ist ausgerichtet

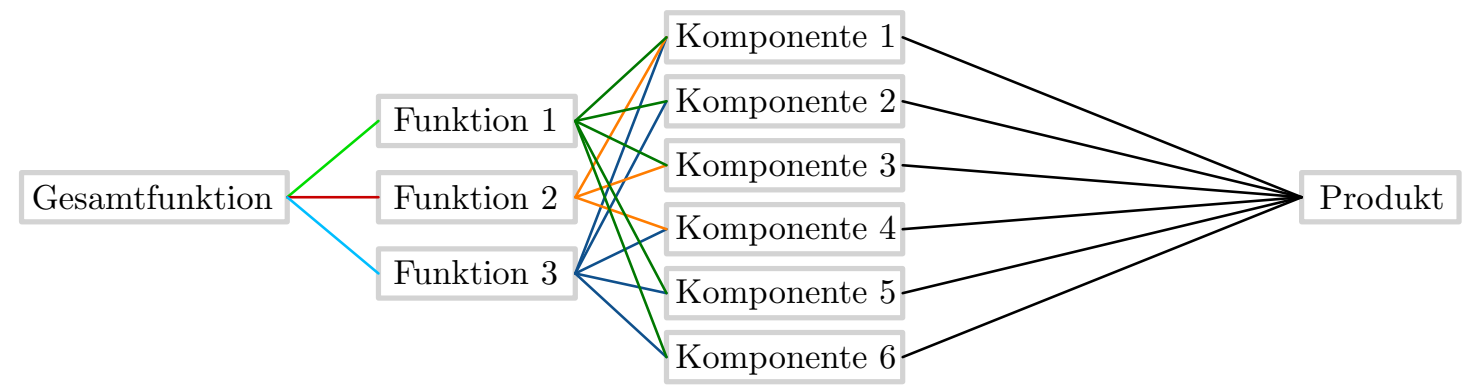

(a) Integrale Produktarchitektur

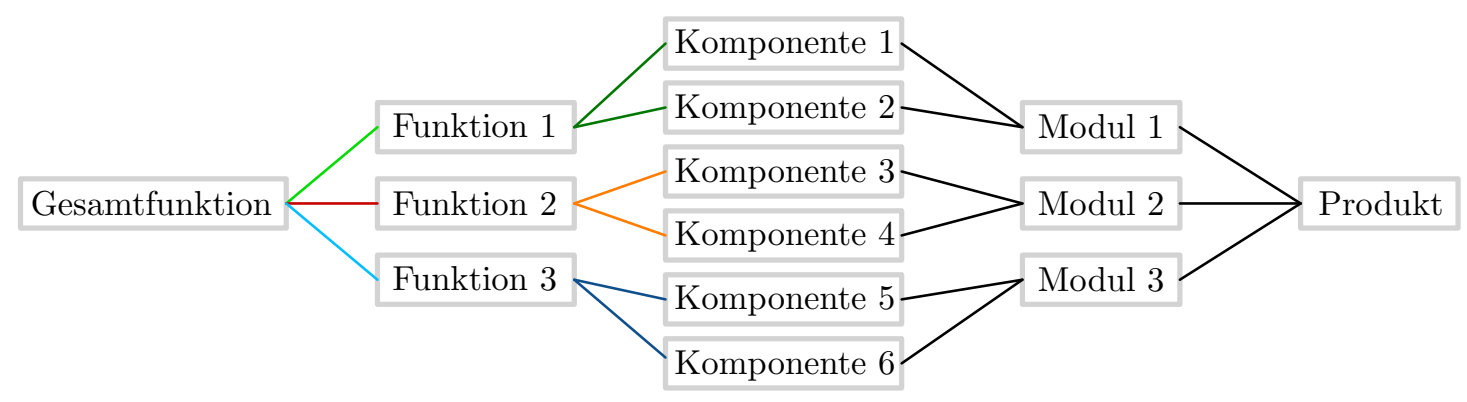

(b) Modulare Produktarchitektur

Abbildung 5.4.: Integrale / Modulare Produktarchitektur [PBF+13, S. 260]

auf die Erfüllung (Funktionsbindung) von einem zuvor definierten Satz aus Funktionen. Die Modifikation der Maschine basiert dementsprechend auf dem Austausch eines spezifischen Moduls. Zusätzlich gelten modulare Produktarchitekturen als erweiterbar. Muss die Produktfunktionalität der Maschine ergänzt werden, wird ein weiteres Modul hinzugefügt [KG18, S. 101-105] [PBF+13, S. 261-263]. Zur Erfüllung der eingangs geforderten „Offenheit“ der Lasersintermaschine muss die Produktarchitektur folglich modular sein.

2. Modifikationsfreundliche Produktstruktur Die Modifikation einer modularen Lasersintermaschine basiert auf dem Austausch, dem Hinzufügen oder dem Entfernen von Modulen entlang zuvor definierter Schnittstellen innerhalb der Produktstruktur. 
Neben der Verbindung physischer Strukturen interagieren die jeweiligen Module in der Regel durch einen Informations,- Energie- oder Stoffaustausch miteinander [KG18, S. 104]. Das Attribut „modifikationsfreundlich“ bezieht sich zusätzlich auf den im Konstruktionsprozess kalkulierten Bauraum für die Anordnung der Komponenten (engl. „Packaging“) innerhalb der Produktstruktur. Der Austausch eines Moduls muss trotz variierender Abmessungen der Module mit geringem technischen Aufwand möglich sein.

3. Erweiterbarkeit des Steuersystems Der Begriff „Steuersystem“ bezeichnet im Kontext der vorliegenden Arbeit eine physische Steuereinheit (engl. „Controller"), die durch den Anwender programmiert werden kann und alle zur Prozessführung notwendigen Mess-, Steuerungs-, Regelungs- und Überwachungsanwendungen hardwareseitig durch eine entsprechende Konnektivität unterstützt. Zur Nutzung der Lasersintermaschine muss die Steuersoftware auf dem Steuersystem installiert sein. Die zusätzliche Forderung nach der Erweiterbarkeit gilt der Absicherung der Grundlagenforschungstauglichkeit der Maschine. Zur vorübergehenden Integration zusätzlicher Messtechnik (vgl. Abschnitt 5.1) müssen entsprechende Eingänge (engl. „Inputs") zur Signalverarbeitung vorab vorhanden oder mit geringem technischen Aufwand nachrüstbar sein. Muss beispielsweise eine Beschichtereinheit mit rotierender Rolle in die Maschine integriert werden, ist es notwendig entsprechende Ausgänge (engl. „Outputs“) zur Motorsteuerung bereitzustellen. Soll außerplanmäßig ein weiteres, beispielsweise über einen CAN-Bus (Controller Area Network) kommunizierendes System integriert werden, muss die entsprechende Schnittstelle am Steuersystem bereits vorhanden oder nachrüstbar sein.

4. Kleines Bauvolumen zur wirtschaftlichen Fertigung filigraner Strukturen Ein wesentliches Produktmerkmal einer Lasersintermaschine ist die Größe des Bauvolumens. Mit steigender Baufäche (x-y-Ebene) steigt die zum Lasersintern notwendige Materialmenge. Da im Bereich der Grundlagenforschung in der Regel kleine Materialmengen im Labormaßstab hergestellt werden und die Kosten für ein FDA-zertifiziertes Ausgangsmaterial zur Herstellung von Implantatmatrizen hoch sind, muss das Bauvolumen entsprechend klein ausgeführt werden. Die Bestimmung einer geeigneten Bauraumgröße kann in Abhängigkeit des zu fertigenden Produkts durchgeführt werden. Zur Fertigung von interkonnektierenden Porenstrukturen gilt der Fokusdurchmesser von ca. $400 \mu \mathrm{m}$ bei einer Baufläche (x-y-Ebene) von $200 \mathrm{~mm} \times 250 \mathrm{~mm}$ und einer Brennweite von $440 \mathrm{~mm}$ der EOS „Formiga P 110“ derzeit (vgl. Stand der Technik in Abschnitt 3.1.1) als technische Referenz. Bei der Entwicklung einer Kleinformatmaschine (Baufläche $<100 \mathrm{~mm} \times 100 \mathrm{~mm}$ ) kann durch die Kombination aus geringer Prozesskammerhöhe, der kleinen Baufläche und der Wahl einer entsprechenden Scanner-Optik (vgl. Grundlagen in Abschnitt 2.3.3) eine weitaus geringere Spotsize als die der EOS Maschine realisiert werden.

5. Bevorzugte Verwendung von multifunktionalen Teilsystemen Die Multifunktionalität eines Teilsystems ermöglicht die Verwendung des identischen Objekts zur Erfüllung verschiedener Aufgaben im Hinblick auf eine Vergrößerung des Einstellbereichs eines Prozessparameters. Ein Prozessgasversorgungssystem ist unter 
anderem aufgebaut aus einem geregelten System zur Prozessgasdosierung und einem Messsystem zur Zustandsüberwachung der inerten Gasatmosphäre innerhalb der Prozesskammer. Wird im Rahmen einer Prozessentwicklung beispielsweise der Einfluss der Gasart auf den Lasersinterprozess untersucht, kann durch die Verwendung eines multifunktionalen Gasdosiersystems (z. B. Massendurchflussregler mit Multi-Gas-Funktion) sowohl Argon, Stickstoff oder Helium zur Inertisierung verwendet werden. Wenn für die Auswertung der Versuche der Argon-, Stickstoffoder Heliumgehalt nicht von Interesse ist, sondern lediglich ob die Inertisierung (vgl. Grundlagen in Abschnitt 2.3.3) abgeschlossen ist, sollte das Messsystem mit einem Sauerstoffsensor ausgestattet sein. Ein multifunktionales Antriebsregelungssystem kann den zugehörigen Motor kraft-, drehzahl- oder positionsgeregelt betreiben.

6. Bevorzugte Verwendung von geregelten Teilsystemen Ein geregeltes System ist aufgrund der Rückkopplung (vgl. Abschnitt 5.1) stabiler und weniger störanfällig als ein gesteuertes System. Im Hinblick auf die Entwicklung eines materialspezifischen Lasersinterprozesses sollten die Vorteile eines geregelten Teilsystems, trotz der höheren Anschaffungskosten, in Bezug auf die damit verbundene Prozessführung beim Auswahlprozess der Teilsysteme bevorzugt berücksichtigt werden.

7. Einsatz spezifischer Sensorik Sensorsysteme zur Erfassung optischer, akustischer, mechanischer und elektrischer Signale in einer Lasersintermaschine bilden die Grundlage für den Aufbau (vgl. Stand der Technik in Abschnitt 3.2.4) einer Prozessüberwachung. Zur Absicherung der Grundlagenforschungstauglichkeit wird der Einsatz einer entsprechenden Sensorik gefordert. Bei der Verwendung von geregelten Teilsystemen sind funktionsspezifische Messglieder bereits vorhanden.

\section{Kenntnis über die komponentenspezifische Leistungsfähigkeit der Teilsysteme}

Jedes mechatronische Teilsystem einer Lasersintermaschine ist in seiner technischen Gesamtleistungsfähigkeit begrenzt durch die Komponenten, aus denen es aufgebaut ist. Um die funktionale Erfüllung von spezifischen Prozessschritten im Rahmen der Prozessentwicklung abschätzen zu können, ist eine weitreichende Kenntnis über die Leistungsfähigkeit der einzelnen Komponenten zwingend erforderlich. Wird das Bauvolumen einer Lasersintermaschine durch ein geregeltes, elektrisches Heizsystem vorgewärmt und eine signifikante Abweichung des Istwerts vom zuvor eingestellten Sollwert festgestellt, kann dies beispielsweise von der Genauigkeitsklasse des Messglieds oder von der Regelungssoftware abhängen. Die Eingrenzung der potentiellen Fehlerquellen und der Unterscheidung zwischen einem Hard- oder Softwaremangel ist lediglich bei entsprechender Kenntnis über die komponentenspezifische Leistungsfähigkeit möglich und folglich zur Erfüllung der Grundlagenforschungstauglichkeit gefordert.

\subsection{Anforderungen aus dem medizinischen Gerätebau}

Bei der Herstellung von bioresorbierbaren Implantatmatrizen stellt die Lasersintermaschine eine hygienekritische Produktionsumgebung dar. Eine zentrale Anforderung bei 
der additiven Fertigung des patientenspezifischen Medizinprodukts ist die Vermeidung sämtlicher Kontaminationsrisiken des Zellträgers. Die Gefährdungen sind durch biologische (z. B. Bakterien, Viren), chemische (z. B. Reinigungsflüssigkeiten, Schmierstoffe) oder physikalische (z. B. Allergene, Fremdkörper) Ursachen möglich [DIN EN ISO 14159, S. 8] [DIN EN 1672-2, S. 8]. Hygienegerechte Gestaltungsrichtlinien (engl. „Hygienic Design“) für Maschinen zum Produzieren unter reinen Bedingungen sind unter anderem in den spezifischen Richtlinien oder Normen der „European Hygienic Engineering and Design Group“ (EHEDG), „Food and Drug Administration“ (FDA), „Good Manufacturing Practice“ (GMP), „International Society for Pharmaceutical Engineering“ (ISPE) oder „International Organization for Standardization“ (ISO) dokumentiert [Hau08b] [Hau08a]. Zur Entwicklung einer reinigungs- und hygienegerechten Lasersintermaschine müssen die folgenden Anforderungen aus dem medizinischen Gerätebau erfüllt sein:

1. Verwendung von hygienegerechten Werkstoffen Zur Auswahl eines geeigneten Konstruktionswerkstoffs für die Fertigung einer Lasersintermaschine wird eine Unterteilung in „produktberührte Oberflächen“ (z. B. Bauvolumen, Beschichter, Prozessebene) und „nicht-produktberührte Oberflächen“ (z. B. Türfläche, Prozesskammerdecke, Stellfüße) durchgeführt, wobei die Anforderungen an die Werkstoffe der produktberührten Oberflächen entsprechend höher sind. Hygienegerechte Konstruktionswerkstoffe sind abriebfest, temperaturbeständig, nicht absorbierend, nicht toxisch, nicht kontaminierend und korrosionsbeständig gegenüber dem zu fertigenden Produkt und den eingesetzten Reinigungs- und Desinfektionsmitteln [Eur18, S. 8-9]. Sämtliche produktberührten, metallischen Oberflächen müssen aus nichtrostenden Stählen gefertigt sein. Eine Identifikation von geeigneten Werkstoffnummern kann mit Hilfe der 14-teiligen Normenreihe DIN ISO 5832 [DIN ISO 5832-1] für chirurgische Implantate, der Norm DIN EN ISO 7153-1 [DIN EN ISO 7153-1] für chirurgische Instrumente oder spezifischer Informationsmaterialien [Heu09] der Stahlindustrie durchgeführt werden. Die nichtrostenden Stähle 1.4016, 1.4301, 1.4404 oder 1.4305 sind aufgrund des geringen Nickelaustrags medizinisch unbedenklich und folglich als Konstruktionswerkstoff zur Fertigung einer Lasersintermaschine geeignet [Heu09, S. 14]. Aluminiumoberflächen in nicht-produktberührten Bereichen müssen in der Regel beschichtet sein. Nichtmetalle wie Elastomere (z. B. FKM), Kunststoffe (z. B. PTFE), Glas oder keramische Werkstoffe können, sofern sie den Anforderungen entsprechen, ebenfalls als Konstruktionswerkstoffe für produktberührte Oberflächen verwendet werden [DIN EN ISO 14159, S. 11-12]. Schmierstoffe von Kugelgewindetrieben oder Lagereinheiten sind klassische Beispiele nicht hygienischer Betriebsstoffe, die in jedem Fall von dem zu fertigenden Produkt fern gehalten werden müssen. Geschmierte Antriebsmechanismen müssen räumlich getrennt von produktberührten Oberflächen installiert sein [DIN EN ISO 14159, S. 14].

2. Reinigungsgerechte Gestaltung sämtlicher Bauteilgeometrien Eine Lasersintermaschine zur Fertigung von Medizinprodukten muss in regelmäßigen Abständen mit chemischen Lösungen oder entsprechenden Flüssigkeiten gereinigt, desinfiziert oder sterilisiert werden. In der Regel wird die Reinigung einer solchen Anlage ohne Demontage (engl. „Cleaning in Place“) durchgeführt. Ein reinigungsgerecht ge- 
staltetes Bauteil besitzt abgerundete Kanten, Kehlungen bzw. Radien in inneren Winkeln und Ecken sowie Rillen, die breiter als tief sind. Öffnungen oder Toträume in Bauteilen müssen vermieden werden, da sie ein erhöhtes Hygienerisiko darstellen [DIN EN ISO 14159, S. 12-13].

3. Hygienegerechte Gestaltung von Bauteilverbindungen Dauerhafte Verbindungen zwischen zwei metallischen Bauteilen müssen ringsum bzw. umlaufend geschweißt sein. Die Nähte der Schweißverbindungen müssen frei von Einschlüssen, Löchern oder Rissen sein und abschließend geglättet werden. Silberlot kann zum Glätten oder Auffüllen von Kehlungen zur Herstellung der Mindestradien verwendet werden. Alle gefügten Oberflächen müssen bündig abschließen. Die dauerhaften Verbindungen zwischen Metall/Nichtmetall oder Nichtmetall/Nichtmetall müssen geklebt oder geschweißt sein. Passungen (Schrumpf- bzw. Pressverbände) oder Lötverbindungen sind anzuwenden, wenn das Schweißen oder Kleben aus technischen Gründen nicht möglich ist. Der Einsatz lösbarer Verbindungselemente wie Schrauben, Niete oder Bolzen muss grundsätzlich vermieden werden. Alle Verbindungselemente müssen, sofern sie zur Anwendung kommen, reinigungsgerecht gestaltet sein. Gewindebohrungen sind aufgrund ihrer Toträume im Bereich produktberührter Oberflächen zu vermeiden. Statische oder dynamische Dichtungen wie Flachdichtungen oder O-Ringe müssen reinigungsgerecht gestaltet und nach Möglichkeit im Bereich nichtproduktberührter Oberflächen angeordnet sein. Wärmedehnung, Schrumpfung und die Gestaltänderung der Dichtung infolge einer montagebedingten Quetschung müssen bei der Gestaltung der Bauteilverbindung entsprechend berücksichtigt werden [DIN EN ISO 14159, S. 13].

4. Vermeidung von Toträumen in Baugruppen Sämtliche Oberflächen der Baugruppen, die durch das Verbinden von reinigungsgerecht gestalteten Bauteilen entstehen, müssen für die Reinigung bündig sein. Die Entwicklung integrativer Bauteile reduziert die Bauteilanzahl einer Baugruppe und vermindert das Risiko eines Totraums [DIN EN 1672-2, S. 6].

5. Fertigung qualitativ hochwertiger Oberflächenbeschaffenheiten Neben einer Verwendung hygienegerechter Konstruktionswerkstoffe ist vor allem die gefertigte Oberflächenbeschaffenheit der Bauteile, Bauteilverbindungen und Baugruppen ein grundlegendes Kriterium bei der Bewertung des Hygienerisikos. Alle Oberflächen müssen zur einfachen Reinigung frei von Defekten sein. Die geometrischen Definitionen einer Oberflächenbeschaffenheit sind in der Norm DIN EN ISO 4287 [DIN EN ISO 4287] festgelegt. Die EHEDG fordert für Oberflächen aus nichtrostenden Stählen einen arithmetischen Mittenrauwert von $R_{\mathrm{a}} \leq 0,8 \mu \mathrm{m}$, der in der Regel durch die Anwendung eines Fertigungsverfahrens aus der Fein- und Fertigbearbeitung (z. B. Schleifen, Polieren) erreicht wird [Eur18, S. 10-11]. Die Norm DIN 11866 [DIN 11866] definiert für aseptische Anwendungen im Bereich der pharmazeutischen Industrie für Rohre aus den nichtrostenden Stahlsorten 1.4404, 1.4435 und 1.4539 bei der qualitativ hochwertigsten Rauheitsempfehlung „H5“ einen arithmetischen Mittenrauwert von $R_{\mathrm{a}} \leq 0,25 \mu \mathrm{m}$. 
6. Bevorzugte Verwendung von hygienekonformen Zukaufteilen Bei der Auswahl geeigneter Normelemente zur Entwicklung einer Lasersintermaschine sollten die Produktportfolios der Zulieferer nach „Hygienic Design“-Produktfamilien durchsucht werden. Die Zukaufteile besitzen in der Regel hohe Oberflächengüten, sind frei von Toträumen, haben gedichtete Anschraubbereiche, sind aus hygeniegerechten Werkstoffen gefertigt und zertifiziert nach den entsprechenden Richtlinien der „Food and Drug Administration“ (FDA), „European Hygienic Engineering and Design Group“ (EHEDG), „United States Pharmacopeia“ (USP) oder „3-A Sanitary Standards, Inc." (3-A SSI). Richtlinienkonforme Bauteile wie Dichtungen, Griffe oder Schrauben können bedenkenlos eingesetzt werden.

7. Einsatz einer medizinischen Gasversorgung zur Inertisierung Zur Reduktion des Kontaminationsrisikos der additiv zu fertigenden Implantatmatrizen muss die Lasersintermaschine in einem nach DIN EN ISO 14644 genormten Reinraumbereich mit entsprechender Luftreinheit [DIN EN ISO 14644-1] aufgestellt sein [Gro16, S. 34-35]. Im Rahmen der Inertisierung (vgl. Grundlagen in Abschnitt 2.3.3) wird die Raumluft innerhalb der Prozesskammer gegen das verwendete Inertgas ausgetauscht. Dazu müssen ausschließlich reine Gase verwendet werden. Im klinischen Umfeld werden medizinische Gase wie beispielsweise Sauerstoff oder Lachgas zur Patientenversorgung bzw. Stickstoff für den Betrieb chirurgischer Werkzeuge eingesetzt. Ein medizinisches Gasversorgungssystems ist bei entsprechender Werkstoffwahl in der Regel aus einem mit Gas befüllten Druckbehälter samt Ventil [DIN EN ISO 10524-3], einer Entnahmestelle [DIN EN ISO 9170-1] samt Druckminderern [DIN EN ISO 10524-1] und einem Rohrleistungssystem [DIN EN ISO 7396-1] aufgebaut. Die harmonisierten europäischen Normen können zur Planung eines Gasversorgungssystems einer Lasersinteranlage angewendet werden. 


\section{Methodische Entwicklung einer modularen Lasersintermaschine}

Die VDI-Richtlinie 2221 [VDI 2221] ist betitelt als „Methodik zum Entwickeln und Konstruieren technischer Systeme und Produkte“ und „behandelt allgemeingültige, branchenunabhängige Grundlagen methodischen Entwickelns und Konstruierens und definiert diejenigen Arbeitsabschnitte und Arbeitsergebnisse, die wegen ihrer generellen Logik und Zweckmäßigkeit Leitlinie für ein Vorgehen in der Praxis sein können" [VDI 2221, S. 2]. Die Anwendung der Richtlinie zur Entwicklung einer Lasersintermaschine wird dementsprechend als zielführend bewertet. Das generelle Vorgehen bei der Entwicklung und Konstruktion des Gesamtsystems gliedert sich in die folgenden Arbeitsabschnitte mit den jeweiligen Arbeitsergebnissen [VDI 2221, S. 9]:

1. „Klären und präzisieren der Aufgabenstellung“ $\rightarrow$ Anforderungsliste

2. „Ermitteln von Funktionen und deren Strukturen“ $\rightarrow$ Funktionsstrukturen

3. „Suchen nach Lösungsprinzipien und deren Strukturen“ $\rightarrow$ Prinzipielle Lösungen

4. "Gliedern in realisierbare Module" $\rightarrow$ Modulare Strukturen

5. "Gestalten der maßgebenden Module" $\rightarrow$ Vorentwürfe

6. „Gestalten des gesamten Produkts“ $\rightarrow$ Gesamtentwurf

7. „Ausarbeiten der Ausführungs- und Nutzungsangaben“ $\rightarrow$ Produktdokumentation

Der Entwicklungs- und Konstruktionsprozess wird zudem in die vier Phasen „1. Planen“, „2. Konzipieren“, „3. Entwerfen" und „4. Ausarbeiten" unterteilt, wobei eine scharfe Zuordnung zu den jeweiligen Arbeitsschritten nicht immer möglich ist [PBF+07, S. 193-200]. Um aus den prinzipiellen Lösungen im Rahmen der zweiten Phase modulare Strukturen der Lasersintermaschine ableiten zu können, war die Anfertigung einiger Vorentwürfe (3. Phase) notwendig. Im Folgenden sind die Ergebnisse der Arbeitsabschnitte 1. bis 4. in den Phasen „Planen und Konzipieren“ in Abschnitt 6.1 dargestellt. Die wesentlichen Ergebnisse der Arbeitsabschnitte 5. bis 7. sind in den Phasen „Entwerfen und Ausarbeiten“ in Abschnitt 6.2 zusammengefasst. 


\subsection{Planen und Konzipieren}

Die Motivation zur Neuentwicklung einer Lasersintermaschine ist im Forschungsbedarf in Kapitel 4 dargestellt. Zur Verarbeitung von bioresorbierbaren Polymeren muss die Lasersintermaschine die folgenden technischen Anforderungen erfüllen:

- Kleines Bauvolumen zum Lasersintern mit geringen Materialmengen

- Vorheiztemperatur einstellbar bis zu einem Maximalwert von $80^{\circ} \mathrm{C}$

- Modularer Aufbau im Bereich der Beschichtereinheit

- Einsatz eines $\mathrm{CO}_{2}$-Lasers mit geringer Leistung

Neben der Einarbeitung in die anwendungsspezifischen Grundlagen (vgl. Kapitel 2) und den Stand der Technik und Wissenschaft (vgl. Kapitel 3) wurden im Rahmen der Planungsphase zusätzlich Informationen bezüglich institutsspezifischer Vorgaben und Möglichkeiten beschafft. Die technische Ausstattung der institutseigenen Werkstatt ist bei der Herstellung von Komponenten und Baugruppen ein limitierender Faktor bei der Auswahl des zu realisierenden Konzepts. Vorgaben bezüglich Kosten, Ressourcen, Meilensteinen und Beschaffungen wurden bei der Planung berücksichtigt, werden in der vorliegenden Arbeit jedoch nicht dargestellt. Die Hauptfunktion der neuartigen Lasersintermaschine ist gemäß Kapitel 5 wie folgt definiert:

Die Hauptfunktion der zu entwickelnden Lasersintermaschine ist die Erforschung der Wechselwirkungen zwischen der Maschine, einem bioresorbierbaren Material und dem Prozess zur Verbesserung der spezifischen Merkmale der Wechselwirkungspartner, um zukünftig bioresorbierbare Implantatmatrizen mittels Lasersintern herstellen zu können.

Die zu entwickelnde Lasersintermaschine wird explizit für die Anwendung im Bereich der Forschung konzipiert und mit dem Begriff der "Grundlagenforschungstauglichkeit" beschrieben. Sowohl bei der Qualifizierung von bioresorbierbaren Sonderwerkstoffen für das Lasersintern als auch bei der Verarbeitung von Kleinstmengen spezifischer Materialchargen (Materialherstellung im Labormaßstab) wird es im Betriebsablauf der Forschungsmaschine häufig zu einem Materialwechsel kommen. Da insbesondere die Teilprozessschritte „Pulverauftrag“ und „Bauteilschichtgenerierung“ zur Fertigung von geometrisch und mechanisch geeigneten Implantatmatrizen von großer Bedeutung sind, muss der modulare Charakter der Lasersintermaschine im Bereich der Beschichtereinheit und Laser-Scanner-Einheit betont ausgeprägt sein. Klassische Leistungsmerkmale einer industriellen Produktionsmaschine, wie eine besonders hohe Produktivität oder die möglichst intuitive Bedienbarkeit bei hohem Automatisierungsgrad, sind bei der Entwicklung einer Forschungsmaschine nicht gefordert. Die Skalierung des Fertigungsprozesses, beispielsweise durch die Durchführung einer Parallelfertigung in einem großen Bauraum mit mehreren Laser-Scanner-Einheiten, ist im Rahmen der Kommerzialisierung mit maßgeblicher Industriebeteiligung im Anschluss an die hier betriebene Grundlagenforschung isoliert zu behandeln. Der Produktentstehungsprozess (PEP) samt Einzelfertigung der Lasersintermaschine musste innerhalb eines Zeitraums von 
drei Jahren abgeschlossen sein. Ein Pflichtenheft lag nicht vor. Im Hinblick auf das systematische Vorgehen nach der VDI-Richtlinie 2221 (vgl. Kapitel 6) wird im Folgenden eine spezifische Anforderungsliste (Abschnitt 6.1.1) erstellt, eine Funktionsstruktur (Abschnitt 6.1.2) erfasst, prinzipielle Lösungen (Abschnitt 6.1.3) zur Erfüllung dieser Funktionen identifiziert und eine Modularisierung (Abschnitt 6.1.4) der Lasersintermaschine durchgeführt. Die farbliche Kodierung zur Kennzeichnung der spezifischen Module ( Maschinengestell Baustempelmodul Pulverzuführmodul Pulverauftragsmodul Beschichtereinheit Prozessgasmodul Lasermodul IR-Heizmodul ) wird in Kapitel 6 einheitlich verwendet. Die Auswahl eines geeigneten Konzepts wird in Abschnitt 6.1.5 abschließend dargestellt.

\subsubsection{Spezifische Anforderungsliste}

Die Grundlage jeder Produktentwicklung ist die Erarbeitung einer Anforderungsliste. Zur Erfüllung des ersten Arbeitsschritts, dem „Klären und präzisieren der Aufgabenstellung" [VDI 2221, S. 9] wurden in Kapitel 5 zunächst generelle Anforderungen an die Lasersintermaschine integrativ aus dem AM-TE-Wechselwirkungsdreieck und den Prozesserkenntnissen der Forschung erhoben. Die generellen Anforderungen an die Prozessführung, an die Produktarchitektur und aus dem medizinischen Gerätebau wurden mit entsprechender Nummerierung in die Anforderungsliste überführt. Die spezifische Anforderungsliste der modularen Lasersintermaschine ist in Anhang A vollumfänglich dargestellt und besteht aus den folgenden zwölf Anforderungsgruppen:

1. Generelle Anforderungen an die Prozessführung

2. Generelle Anforderungen an die Produktarchitektur

3. Generelle Anforderungen aus dem medizinischen Gerätebau

4. Aufstellbedingungen für die Lasersintermaschine

5. Anforderungen an die Fertigung der Komponenten

6. Anforderungen an das bzw. aus dem Maschinengestell

7. Anforderungen an das bzw. aus dem Baustempelmodul

8. Anforderungen an das bzw. aus dem Pulverzuführmodul

9. Anforderungen an das bzw. aus dem Pulverauftragsmodul

10. Anforderungen an das bzw. aus dem Submodul Beschichtereinheit

11. Anforderungen an das bzw. aus dem Prozessgasmodul

12. Anforderungen an das bzw. aus dem Lasermodul

Anhand der angegebenen Anforderungsnummer lässt sich die zugehörige Anforderungsgruppe identifizieren. Die Anforderung „Einsatz einer medizinischen Gasversorgung“ (vgl. Anforderung 3.7 in Tabelle A.1) ist die siebte Anforderung aus der dritten Anforderungsgruppe. Die eingangs genannten technischen Anforderungen an die Größe des Bauvolumens, den Prozessparametern der Vorheiztemperatur bzw. Laserleistung und die 
Modularität im Bereich der Beschichtereinheit sind in den generellen Anforderungen (vgl. Anforderungen 2.4 / 1.1 / 2.1 in Tabelle A.1) abstrakt enthalten. Zur Aufstellung der Lasersintermaschine wurde eine geeignete Fläche im Labor für Maschinensysteme an der Technischen Universität Berlin identifiziert. Die räumlichen Aufstellbedingungen (vgl. 4. Anforderungsgruppe in Tabelle A.1) sind als Anforderungen in der Anforderungsliste erfasst. Zur Einhaltung der knapp bemessenen Kosten- und Terminvorgaben war die Einbindung der Ressourcen des Fachgebiets MPM (Methoden der Produktentwicklung und Mechatronik) zur Herstellung der Lasersintermaschine unerlässlich. Die ausschließlich substraktiven Fertigungsmöglichkeiten sind als Anforderungen an die Fertigung der Komponenten (vgl. 5. Anforderungsgruppe in Tabelle A.1) in der Anforderungsliste dokumentiert. Die initialen bzw. vorläufigen Anforderungen, die zur Erarbeitung des Konzepts aus Abschnitt 6.1.5 notwendig waren, sind in der 1. bis 5. Anforderungsgruppe in Tabelle A.1 dokumentiert. Alle weiteren Anforderungen (ab der 6. Anforderungsgruppe in Tabelle A.1) wurden als ein Arbeitsergebnis der Entwicklung der spezifischen Module (vgl. „Entwerfen und Ausarbeiten“ in Abschnitt 6.2) iterativ ergänzt. Diesbezüglich werden qualitative Angaben wie „Kleines Bauvolumen“ (vgl. Anforderung 2.4 in Tabelle A.1) durch modulspezifisch quantitative Werte wie „Geometrie des nicht wechselbaren Bauvolumens: $\varnothing 65 \mathrm{~mm} \times 80 \mathrm{~mm}$ " (vgl. Anforderung 7.1 in Tabelle A.1) widerspruchsfrei ergänzt. Die Anforderungen sind in Forderung (F) und Wunsch (W) unterschieden. Die Erfüllung der Anforderungen 3.2 bis einschließlich 3.5 sind eng mit den verwendeten Fertigungsverfahren bzw. den technischen Möglichkeiten bei der Herstellung des Systems verknüpft. Da die Umsetzung einer polierten Schweißkonstruktion aus nichtrostendem Edelstahl in der institutseigenen Werkstatt aus technischen Gründen nicht möglich war, wurden diese generellen Anforderungen aus dem medizinischen Gerätebau lediglich als Wunsch klassifiziert. Der „übergangsweise Einsatz eines Laser-Scanner-Demonstrators“ (vgl. Anforderung 12.6 in Tabelle A.1) impliziert die Notwendigkeit eines nachträglichen Baugruppenaustauschs. Da zum Zeitpunkt der Maschinenentwicklung die Auswahl eines geeigneten bioresorbierbaren Werkstoffs nicht abgeschlossen war und die Laser-Scanner-Einheit zur Herstellung der Implantatmatrizen materialspezifisch abgestimmt sein muss, wurde die Beschaffung eines spezifischen Teilsystems auf einen späteren Zeitpunkt verschoben. Die Vorgehensweise zur Auswahl einer materialspezifischen Laser-Scanner-Einheit ist in Kapitel 7 am Beispiel von Poly(Lactic-co-Glycolic Acid) (PLGA) dargestellt. Das Data Logging sämtlicher Prozessparameter ist aufgrund der Datenmenge derzeit als Wunsch klassifiziert. Die sensorische Erfassung bzw. die Ausgabe des Messwerts (ohne Speicherung) bleibt als Forderung für die Entwicklung einer grafischen Benutzeroberfläche bestehen.

\subsubsection{Funktionsstruktur einer Lasersintermaschine}

Eine im Rahmen der Produktentwicklung häufig eingesetzte Methode zur abstrakten Betrachtung eines Systems ist die Erstellung der Funktionsstruktur des Systems [PBF +07, S. 242-252]. Durch die Funktionsmodellierung wird die Gesamtfunktion der zu entwickelnden Lasersintermaschine in einzelne Funktionen aufgeteilt. Im Hinblick auf die generelle Anforderung an die Produktarchitektur „Hohes Maß an Modularität“ (vgl. Anforderung 
2.1 in Tabelle A.1) ist es sinnvoll die Funktionen der Lasersintermaschine unabhängig voneinander zu betrachten [Lin09, S. 116-122]. Nach Lindemann ist die Funktionsstruktur in Form einer Liste darzustellen. Die Funktionsstruktur zum Lasersintern eines Bauteils (Gesamtfunktion) wird durch die folgenden Funktionen gebildet:

1. Befülltes Pulvervorratsvolumen für den Lasersinterprozess vorbereiten

2. Geschlossene Prozessumgebung innerhalb der Maschine inertisieren

3. Spezifische Bereiche der Maschine aktiv heizen

4. Pulver aus dem Vorratsbehälter dem Pulverauftragskörper dosiert zuführen

5. Bauplattform innerhalb des Bauvolumens positionieren

6. Pulver durch Pulverauftragskörper über der Bauplattform auftragen

7. Überschüssig zugeführtes Pulver in ein Überlaufvolumen bewegen

8. Laserenergie in das Pulverbett zur Bauteilschichtgenerierung einbringen

9. Prozessparameter und Prozessbedingungen kontinuierlich überwachen

10. Spezifische Bereiche der Maschine aktiv kühlen

11. Lasergesintertes Bauteil aus der Maschine entnehmen

12. Überschüssig zugeführtes Pulver aus der Maschine entnehmen

Bei der Herstellung von bioresorbierbaren Implantatmatrizen entspricht die kontinuierliche Überwachung von Prozessparametern und Prozessbedingungen (9. Funktion) einer elementaren Funktion zur Absicherung der Grundlagenforschungstauglichkeit und zur Güteüberwachung (vgl. Grundlagen in Abschnitt 2.3.4) des lasergesinternten Bauteils. Wird die Lasersintermaschine ausschließlich zur Herstellung von funktionalen Prototypen (vgl. Stand der Technik in Abschnitt 3.1.2) mit geringeren Qualitätsanforderungen verwendet, genügt es die Überwachungshäufigkeit der 9. Funktion entsprechend zu reduzieren. Zur Wahrung der Allgemeingültigkeit wird die lösungsneutrale Funktionsstruktur nicht feiner unterteilt.

\subsubsection{Identifikation prinzipieller Lösungen}

Lasersintermaschinen sind seit dem Jahr 1990 kommerziell erhältlich. Zur Identifikation prinzipieller Lösungen der in Abschnitt 6.1.2 dargestellten Funktionen wurden die Produktstrukturen kommerzieller Lasersintermaschinen analysiert. Die Prozesse vom Laserstrahlschmelzen und dem Lasersintern sind funktional eng miteinander verwandt. Bei der Durchführung der Analyse wurden die Laserstrahlschmelzmaschinen daher entsprechend mit berücksichtigt. Technische Alleinstellungsmerkmale sind in der Regel patentiert oder durch ein Gebrauchsmuster geschützt. Die Modellbeizeichnungen und Produktstrukturen sämtlicher Lasersinter- oder Laserstrahlschmelzmaschinen sind, nach Verfahren und Herstellern sortiert, im Stand der Technik in Abschnitt 3.1 und Abschnitt 3.2 dargestellt. Im Folgenden wird der Zusammenhang zwischen der Funktionsstruktur einer Lasersintermaschine und einigen bereits umgesetzten oder denkbaren physischen Produktstrukturen nach spezifischen Merkmalen gegliedert zusammengefasst. 
1. Befülltes Pulvervorratsvolumen für den Lasersinterprozess vorbereiten Für das Rüsten einer EOS „Formiga P 100“ bzw. „Formiga P 110“ werden zwei Kunststoff-Weithalsfässer mit einem Füllvolumen von jeweils 15,4l mit dem zu verarbeitenden Material befüllt, im Bereich der Maschinenoberseite eingeschraubt und abschließend eingeschwenkt. Detektiert der Füllstandssensor I eine unzureichende Materialmenge in Behälter I wird umgehend auf Behälter II umgeschaltet. Die EOS „Precious M 080“ bzw. „M 100“ besitzt eine einzelne bewegte Materialkartusche, die bei geöffneter Prozesskammer oberhalb des Bauvolumens eingesetzt wird. Lasersintermaschinen, die auf der DTM-Technologie basieren, besitzen rechts und links neben dem mittig angeordneten Bauvolumen jeweils ein Vorratsvolumen. Zum Rüsten der Ricoh „AM S5500P“ werden die eckigen Vorratsbehälter mit dem zu verarbeitenden Pulver befüllt und als Komponente eines Wechselrahmensystems vor Prozessstart in die Lasersintermaschine eingeschoben. Die „Mlab cusing“ der Firma Concept Laser besitzt ein einzelnes Vorratsvolumen neben dem Bauvolumen. Zum Rüsten dieser Laserstrahlschmelzmaschine wird das Material bei ausgezogener Schublade aus einem Behältnis händisch in das Vorratsvolumen (> Bauvolumen) eingefüllt. Die technischen Merkmale werden wie folgt gegliedert:

- Anzahl/Geometrie/Wechselbarkeit der Pulvervorratsvolumina

- Anordnung der Pulvervorratsvolumina relativ zum Bauvolumen

2. Geschlossene Prozessumgebung innerhalb der Maschine inertisieren Um die Prozessumgebung innerhalb einer Lasersintermaschine gegenüber der Umwelt abzugrenzen, wird eine Prozesskammer im Bereich zwischen Galvano-Scanner und dem Bauvolumen in die Produktstruktur integriert. Zum Zweck der Bauteilentnahme oder der Durchführung von Wartungsarbeiten können die Prozesskammern in der Regel über eine Tür (vgl. Foto der EOS „Formiga P 100“ in Abbildung 3.1) geöffnet werden. Erfüllt die geschweißte Prozesskammer alle Anforderungen an die Dichtheit und Druckfestigkeit kann zur Inertisierung des Prozesskammervolumens die Vakuummethode (vgl. Abschnitt 3.2.3) anstelle der Spülmethode angewendet werden. Die Prozessgaseinleitung über das Laserglas bildet einen Gasvorhang (vgl. Patent [DE102006021504 A1]) an der Laserglasoberfläche und reduziert die Ablagerung von Materialausgasungen am Laserglas. Zur gerichteten Kondensation der freigesetzten Dämpfe können zuzüglich gekühlte Abscheideoberflächen (vgl. Patent [DE102011085154 A1] bzw. [EP2586597 A1]) in der Prozesskammer installiert werden. In Abhängigkeit der Gastemperatur ist die konvektive Kühlung spezifischer Komponenten einer Lasersintermaschine durch das Prozessgas (vgl. Patent [EP2484512 A1]) zusätzlich realisierbar. Der Prozessgasverbrauch verhält sich proportional zum Volumen der Prozesskammer. Eine geringe Prozesskammerhöhe, bedingt durch den Einfluss der Brennweite auf den minimalen Fokusdurchmesser, ist obligatorisch bei der Fertigung filigraner Strukturen. Erfindungen bezüglich dem Aufbau eines Gaskreislaufs, vornehmlich in großen Produktionsmaschinen umgesetzt, erfordern den Einsatz eines Filtersystem (vgl. Patent [DE102012004587 A1]) zur Reinigung des verschmutzten Prozessgases. Die Inertisierung mit Edelgasen wie Helium oder Argon anstelle der charakteristischen Verwendung von Stickstoff 
ist denkbar. Zur Messung der Sauerstoffkonzentration innerhalb der Prozesskammer sollten die zwei Zirconiumdioxid-Sensoren des Gasüberwachungssystems (vgl. Gebrauchsmuster [DE202016004832 U1]) möglichst nah am Bauvolumen platziert werden. Aufgrund der hohen Anforderungen an die Schutzgasströmung beim Laserstrahlschmelzen sind in Laserstrahlschmelzmaschinen in der Regel Brennstoffzellen (vgl. Richtlinie [VDI 2263 Blatt 2, S. 13-14]) mit begrenzter Lebensdauer eingesetzt. Die technischen Merkmale werden wie folgt gegliedert:

- Mechanischer/Geometrischer Aufbau der Prozesskammer

- Methode der Inertisierung

- Typ/Anzahl der Sensoren zur Messung der Sauerstoffkonzentration

- Funktionalitäten die durch das bzw. mit dem Prozessgas erfüllt werden

3. Spezifische Bereiche der Maschine aktiv heizen Lasersintermaschinen besitzen in der Regel Wärmequellen (vgl. Patent [US7713048 B2]) im Bereich des Bauvolumens, den Pulvervorratsvolumina und der Prozesskammer oberhalb der Pulverbettoberfläche. Die Beheizung der Flächen eines Volumens kann mittels Fluid, einem Heizgas, einer Widerstandsheizung oder einer Strahlungsheizung durchgeführt werden. Sind die Bau- und Vorratsvolumina in Wechselbehältern untergebracht, wird die Umsetzung der Heizfunktion (vgl. Patent [DE102005030854 B3]) wesentlich komplexer. Die Unterteilung der zu beheizenden Flächen in mehrere Zonen kann im Hinblick auf eine homogene Temperaturverteilung zielführend sein. Zur Beheizung der Pulverbettoberfläche werden bevorzugt IR-Strahlungsheizungen verbaut. Die Bauform des Heizstrahlers (vgl. Patent [DE19516972 C1]) richtet sich nach der Geometrie des Baufeldes. Zur Vermeidung von Temperaturgradienten auf der Pulverbettoberfläche kann die Manipulation der Abstrahlcharakteristik der Strahlungsheizung (vgl. Gebrauchsmuster [DE202009012628 U1]), durch das Einfügen einer Abschottungsvorrichtung oder einer inhomogenen Anordnung der Heizwiderstände innerhalb des Heizelements, in Betracht gezogen werden. Zur berührungslosen Temperaturmessung werden in der Regel Pyrometer (vgl. Patent [DE102005015870 B3]) verwendet. Zusätzlich kann das Laserglas (vgl. Patent [DE102005034155 B3]), die Beschichtereinheit (vgl. Patent [DE102005022308 B4]) und das einzuleitende Prozessgas beheizt werden. Zum Aufbau der Regelung einer elektrischen Flächenheizung werden häufig Thermoelemente oder Platin-Messwiderstände verwendet. Die technischen Merkmale werden wie folgt gegliedert:

- Temperierung des Prozessgases vor der Einleitung in die Prozessumgebung

- Typ/Anzahl/Einbauort/Bauform der regelbaren Wärmequelle

- Typ/Anzahl/Einbauort/Messort des Systems zur Messung der Temperatur

4. Pulver aus dem Vorratsbehälter dem Pulverauftragskörper dosiert zuführen Die mechanische Umsetzung der Pulverzuführung richtet sich nach der Anordnung der Pulvervorratsvolumina innerhalb der Lasersintermaschine. Befindet sich das Pulvervorratsvolumen direkt neben dem Bauvolumen, wird das Material mittels 
Plattformbewegung (vgl. Grundlagen in Abschnitt 2.3.3) vor den Pulverauftragskörper gehoben. Die Pulverzuführschaufeln einer EOS „Formiga P 100“ bzw. „Formiga P 110" heben das Material aus einer U-förmigen Rinne durch eine Schaufelrotation (vgl. Patent [DE102005016940 B4]) vor den Beschichter. Die Materialkartusche der EOS „Precious M 080“ bzw. „Precious M 100“ befindet sich oberhalb der Beschichtereinheit. Durch den Einfluss der Gewichtskraft fällt das Material aus der Vorratskartusche in das Kerbvolumen (vgl. Patent [DE19530295 C1]) einer horizontal gelagerten Förderwalze. Die dosierte Materialzuführung erfolgt durch die inkrementelle Drehung der Kerbwalze. Der Pulvertransport über längere Distanzen, beispielsweise durch die Verwendung eines Schneckenförderers, kann zu einer unerwünschten Vorverdichtung der Polymerpartikel führen. Das Einbringen einer Rüttelbewegung (vgl. Gebrauchsmuster [DE202008011727 U1]) oder die Einleitung von Druckluft (vgl. Patent [DE19530296 B4]) kann zur Auflockerung des Schüttguts führen. Die technischen Merkmale werden wie folgt gegliedert:

- Methode des Pulvertransports zur Dosiereinheit bzw. Beschichtereinheit

- Aufbau/Lage der Dosiereinheit (sofern vorhanden)

5. Bauplattform innerhalb des Bauvolumens positionieren Der Bauraum bzw. die Bauplattform einer Lasersintermaschine ist entweder rund oder eckig. Zur translatorischen Bewegung der Bauplattform in der vertikalen z-Richtung werden aufgrund der Anforderung an die Stellgenauigkeit ausschließlich elektromechanische Antriebssysteme verbaut. Zur Erzeugung der schrittweisen Hubbewegung kann entweder ein Linearmotor oder ein Kugelgewindetrieb (Industriestandard) in Kombination mit einem Schritt- oder Servomotor eingesetzt werden. Durch die Verwendung einer entsprechenden Lagereinheit wird die Bewegung der Bauplattform innerhalb der Mantelfläche, abgedichtet mittels Lippendichtung (vgl. Gebrauchsmuster [DE29506204 U1]), geführt. Die Überwachung des Lageistwerts (Achskontrolle) kann indirekt über einen Drehgeber am Motor und/oder direkt mit einem Längenmessgerät an der Bauplattform umgesetzt werden. Analog zu den Pulvervorratsvolumina kann durch die Verwendung eines Wechselbehältersystems (vgl. Patent [DE19846478 C5]) das Bauvolumen aus der Lasersintermaschine entnommen werden. Die lösbare Ankopplung des Antriebssystems an die Bauplattform (Unterseite Wechselbehälter) und die reproduzierbare Positionierung der Mantelfäche (vgl. Patent [DE19939616 C5]) innerhalb der Maschine (Oberseite Wechselbehälter) ist bei der Umsetzung eines Wechselbehältersystems zusätzlich zu entwickeln. Die technischen Merkmale werden wie folgt gegliedert:

- Geometrie/Wechselbarkeit des Bauvolumens

- Aufbau/Stellgenauigkeit/Verfahrweg/Messsystem des Antriebssystems

6. Pulver durch Pulverauftragskörper über der Bauplattform auftragen Das mechatronische Teilsystem zum Auftrag einer neuen Pulverschicht kann in die Baugruppen "Beschichtereinheit" und „Aufnahme der Beschichtereinheit samt Antriebssystem“ unterteilt werden. Je nach Aufbau des Antriebssystems wird die Beschichtereinheit entweder in einer radialen (vgl. EOS „P 110“ bzw. Realizer „SLM 50“) oder einer 
translatorischen (vgl. EOS „P 396“ bzw. SLM Solutions „SLM 280 2.0“) Bewegung parallel zur Bauplattform geführt. Die Drehachse eines Radialsystems verläuft dabei parallel zur vertikalen z-Richtung und befindet sich in der Regel im Bereich der Maschinenrückseite. Die Aufnahme für die Beschichtereinheit ist mittels geteilter Klemmverbindung an der Drehachse verschraubt und ragt als einseitig befestigter Träger (vgl. Foto der „P 100“ in Abbildung 3.1) in die Prozesskammer. Die Bewegung einer translatorisch gelagerten Beschichtereinheit verläuft entweder parallel (vgl. EOS „P 396“ mit zwei Linearführungen auf der Maschinenrückseite) oder quer (vgl. SLM Solutions „SLM 280 2.0" mit je einer Linearführung auf der linken bzw. rechten Maschinenseite) zur Maschinenvorderseite. In Abhängigkeit der Einbaulage der Linearführungen ragt die Aufnahme der Beschichtereinheit entweder einseitig in die Prozesskammer (vgl. EOS „P 398“) oder verläuft zwischen zwei gegenüberliegenden Prozesskammerseiten. Die klassischen Auftragskörper in einer Beschichtereinheit sind Klinge oder Rolle. Die Realizer „SLM 50“ besitzt eine Beschichtereinheit mit einer Doppelklinge. Durch eine entsprechende Kinematik in der Doppelklingenkassette wird die bewegungsrichtungsabhängig vordere Klinge angehoben, sodass lediglich die hintere Klinge das Material über der Bauplattform ablegt. Die Beschichtereinheit der EOS „P 500“ besitzt zwei rotierende Rollen. Die Verwendung einer Beschichtereinheit mit einem vibrierenden Abstreifelement (vgl. Patent [DE4400523 C2]) zum Pulverauftrag von bioresorbierbaren Kompositwerkstoffen ist im Stand der Forschung in Abschnitt 3.3.3 dargestellt. Experimentelle Beschichtereinheiten nutzen zum Zweck der Pulverfluidisierung elektrische Felder (vgl. Patent [DE19813742 C1]), eingeleitete Gase (vgl. Patent [DE102006053121 B3]) oder bewegte Polymerbänder (vgl. Patent [US8568124 B2]). Die Umsetzung eines Monitoring-Systems zur Überwachung des Pulverauftrags ist in Abschnitt 3.2.4 dargestellt. Die technischen Merkmale werden wie folgt gegliedert:

- Aufbau/Lagerung des Antriebssystems samt Aufnahme der Beschichtereinheit

- Aufbau/Kinematik/Fluidisierungsmethode der Beschichtereinheit

- Material/Geometrie/Rauheit/Beschichtung des Pulverauftragkörpers

7. Überschüssig zugeführtes Pulver in ein Überlaufvolumen bewegen Das dem Pulverauftragskörper dosiert zugeführte Pulvervolumen ist in der Regel größer als das durch die Bewegung der Bauplattform aufzufüllende Volumen. Hat die Auftragsklinge der EOS „Formiga P 100“ bzw. „Formiga P 110“ das Bauvolumen passiert, wird die Auftragsbewegung fortgesetzt bis das überschüssig zugeführte Pulver in die nicht wechselbare Rinne (vgl. Pulverauftrag der „P 100“ in Abbildung 3.2) vor oder auf die Pulvervorratsschaufel fällt. Ist die Beschichtereinheit als Doppelklingenkassette umgesetzt, wird das überschüssig zugeführte Pulver stets zwischen den beiden Klingen mitgeführt und nicht in ein Überlaufvolumen bewegt. Die Produktstruktur einer auf der DTM-Technologie basierenden Lasersintermaschine besitzt je einen Überlaufbehälter an den zwei Fahrbereichsgrenzen des Beschichters. Zur Wiederverwendung des Pulvers können die Überlaufbehälter nach Abschluss des generativen Fertigungsprozesses entnommen werden. Die Laserstrahlschmelzmaschine „SLM 
280 2.0" der Firma SLM Solutions besitzt lediglich ein Überlaufvolumen gegenüber der Referenzposition der Beschichtereinheit. Die überschüssig zugeführten Metallpartikel werden automatisiert vom Überlaufbehälter in das Pulvervorratsvolumen befördert. Die technischen Merkmale werden wie folgt gegliedert:

- Anzahl/Geometrie/Wechselbarkeit der Überlaufvolumina

- Methode der Wiederverwendung des Pulvers aus dem Überlaufvolumen

8. Laserenergie in das Pulverbett zur Bauteilschichtgenerierung einbringen Die spezifischen Komponenten einer optischen Bank (vgl. Gebrauchsmuster [DE9410503 U1]) dienen der Erzeugung, Führung und Formung des Laserstrahls. Die Produktmerkmale eines Lasers sind unter anderem die Leistung $P_{\mathrm{L}}$, Wellenlänge $\lambda$, Beugungsmaßzahl $M^{2}$, emittierter Strahldurchmesser $D_{\mathrm{L}}$, Intensitätsprofil (vgl. Stand der Technik in Abschnitt 3.2.2) und die Betriebsart. Erste Forschungsergebnisse zur Wechselwirkung zwischen Laser und bioresorbierbaren Materialien sind in Abschnitt 3.3.5 dargestellt. Besitzt die jeweilige Lasersintermaschine lediglich einen Laser ist der Galvanometer-Scanner mittig über dem Bauvolumen außerhalb der Prozesskammer über dem Laserglas montiert. Die erzielbare Dynamik und Präzision bei der Positionierung des Laserstrahls auf der Pulverbettoberfläche ist abhängig von den Ausstattungsmerkmalen in Kombination mit der Regelung des Scanners. Die Detektion der Spiegelpositionen wird in höherwertigen 2-Achs-Systemen mit digitalen anstelle von analogen Winkelgebern durchgeführt [DD14]. Die Funktion der Strahlformung wird unter anderem durch einen Strahlaufweiter (zwischen Laser und Scanner) und einer F-Theta-Linse (zwischen Scanner und Pulverbettoberfläche) umgesetzt. Im Hinblick auf die Entwicklung einer Lasersintermaschine mit kleinem Bauvolumen ist der Einsatz eines telezentrischen Objektivs anstelle des F-Theta-Objektivs denkbar. Durch die Verwendung eines dynamischen Strahlaufweiters (vgl. Gebrauchsmuster [DE202014009275 U1]) in Kombination mit einem x-y-Scanner (3-Achs-System) lässt sich der Laserfokus im Betrieb entlang der z-Achse zur Variation der Spotsize positionieren. Die F-Theta-Linse ist an der Strahlaustrittsseite des Scanners verschraubt und abgestimmt auf die Brennweite und Größe des Arbeitsfeldes. Die Umsetzung eines Monitoring-Systems zur Überwachung des Laserenergieeintrags (vgl. Patent [EP1466718 A2] bzw. [DE102007062129 B3]) ist in Abschnitt 3.2.4 dargestellt. Die technischen Merkmale werden wie folgt gegliedert:

- Maximale Leistung/Wellenlänge/Betriebsart des Lasers

- Anzahl Achsen/Fokusdurchmesser/Dynamik/Genauigkeit des Scan-Systems

9. Prozessparameter und Prozessbedingungen kontinuierlich überwachen Einige Monitoring-Systeme zur Prozessüberwachung sind im Stand der Technik in Abschnitt 3.2.4 dargestellt. Bei der Umsetzung einer Echtzeit-Überwachung ist neben der Erfüllung der generellen Anforderungen an die Prozessführung und die Produktarchitektur aus Kapitel 5 vor allem auf die Auswahl eines deterministischen Steuersystems mit ausreichender Rechenleistung zu achten. Da die anzuwendende Überwachungsmethode vom Aufbau des jeweiligen mechatronischen Teilsystems abhängig ist, wird lediglich in „überwacht“ und „nicht überwacht“ 
gegliedert. Empfehlungen bezüglich der zu überwachenden Prozessparameter und Prozessbedingungen sind der VDI-Richtlinie 3405 Blatt 1 [VDI 3405 Blatt 1] zu entnehmen.

10. Spezifische Bereiche der Maschine aktiv kühlen Kurz nach Abschluss des Lasersinterprozesses befinden sich die beheizten Bereiche der Lasersintermaschine samt generiertem Bauteil bzw. unversintertem Pulver innerhalb des Bauvolumens nahe der Prozesstemperatur. Wird die Energieversorgung der Wärmequellen vollständig unterbrochen, kühlen die jeweiligen Bauteile oder Baugruppen passiv durch eine natürliche Konvektion ab. Der Wärmeabtransport kann durch die Umsetzung eines aktiven Kühlsystems (erzwungene Konvektion) gesteigert werden. Das Einbringen einer Wärmeisolation beschleunigt den Aufheizvorgang, verlangsamt jedoch den Abkühlvorgang. Erfolgt der Wärmeabtransport zu dynamisch kann die Temperatur der Wärmequellen mittels geeignetem Regler sukzessive reduziert werden. Der Einsatz gekühlter Abscheideoberflächen innerhalb der Prozesskammer ist in der 2. Funktion in Abschnitt 6.1.3 diskutiert. Spezifische Komponenten einer optischen Bank, insbesondere Strahlquelle und Galvano-Scanner, sind ab einer gewissen Leistung (vgl. 8. Funktion in Abschnitt 6.1.3) standardmäßig aktiv gekühlt. Die technischen Merkmale werden wie folgt gegliedert:

- Aufbau/Methode/Einbauort des aktiven Kühlsystems

11. Lasergesintertes Bauteil aus der Maschine entnehmen Die Methode der Bauteilentnahme ist abhängig von der Wechselbarkeit des Bauvolumens. Ist die jeweilige Lasersintermaschine mit einem Wechselbehältersystem ausgerüstet, wird der Wechselbehälter samt Bauplattform und Pulverkuchen bei spezifischer Entnahmetemperatur aus der Maschine in eine Auspackstation (vgl. Gebrauchsmuster [DE29506716 U1]) bewegt. Bei der EOS „Precious M 080“ wird zur Entnahme des LBM-Bauteils die auf dem Schlitten befindliche Prozesskammer gegen eine Entnahmekartusche ausgetauscht. Durch die Aufwärtsbewegung der Bauplattform innerhalb des Bauvolumens (nicht wechselbar) wird das auf der Bauplatte befindliche laserstrahlgeschmolzene Bauteil samt loser Metallpartikel zunächst in die Kartusche und abschließend aus der Maschine bewegt. Einige Laserstrahlschmelzmaschinen (vgl. Realizer „SLM 300i“) sind mit einem integrierten System zur Pulveraufbereitung ausgestattet. Der Eingriff in den Innenraum der Prozesskammer ist über Handschuhboxen im Bereich der Prozesskammertür von außen möglich. Die losen Metallpartikel werden mittels Absaugeinrichtung, geführt durch die Handschuhbox hindurch, abgesaugt. Ist dieser Prozessschritt beendet, wird die Bauplattform aufwärts bewegt und das laserstrahlgeschmolzene Bauteil samt Bauplatte aus der Maschine entnommen. Besitzt die jeweilige Lasersintermaschine ein kleines Bauvolumen mit einer gut zugänglichen Prozesskammer kann die Bauplattform aufwärts bewegt, die lasergesinterten Bauteile händisch von losem Pulver innerhalb der Prozesskammer grob befreit und abschließend aus der Maschine bewegt werden.

12. Überschüssig zugeführtes Pulver aus der Maschine entnehmen Die Entnahmemethode des überschüssig zugeführten Pulvers ist abhängig von der Wechselbarkeit 
der Überlaufvolumina. Das in den U-förmigen Rinnen (nicht wechselbar) der EOS „Formiga P 100“ bzw. „Formiga P 110“ befindliche Pulver wird zur Reinigung der Lasersintermaschine bei ausgebauten Pulvervorratsschaufeln zur Entsorgung abgesaugt. Wechselbare Überlaufvolumina können zur Pulverrückgewinnung aus der Lasersintermaschine entnommen werden. Die Umsetzung einer automatisierten Materialrückgewinnung (vgl. Gebrauchsmuster [DE20107262 U1]) ist in der 7. Funktion beschrieben.

\subsubsection{Modularisierung der Lasersintermaschine}

Zur Entwicklung des Gesamtsystems wird die Lasersintermaschine in die Module „Maschinengestell“, „Baustempelmodul“, „Pulverzuführmodul“, „Pulverauftragsmodul“, „Beschichtereinheit" (Submodul des Pulverauftragmoduls), „Prozessgasmodul“, „Lasermodul“ und „IR-Heizmodul“ (Bestrahlung der Pulverbettoberfläche von oben) gegliedert.

Tabelle 6.1.: Zuordnung zwischen den Funktionen und Modulen

\begin{tabular}{|c|c|c|c|c|c|c|c|c|c|}
\hline \multirow{2}{*}{\multicolumn{2}{|c|}{ Funktionen der Lasersintermaschine }} & \multicolumn{8}{|c|}{ Module der Lasersintermaschine } \\
\hline & & 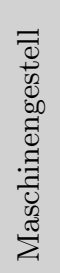 & 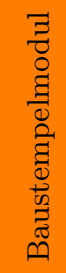 & 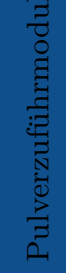 & 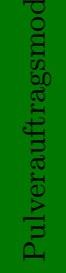 & 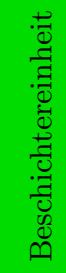 & 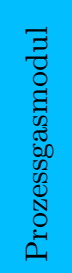 & 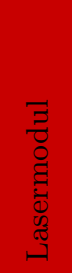 & 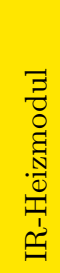 \\
\hline 1. & $\begin{array}{l}\text { Befülltes Pulvervorratsvolumen für den } \\
\text { Lasersinterprozess vorbereiten }\end{array}$ & & & $\times$ & & & & & \\
\hline 2. & $\begin{array}{l}\text { Geschlossene Prozessumgebung inner- } \\
\text { halb der Maschine inertisieren }\end{array}$ & & & & & & $\times$ & & \\
\hline 3. & $\begin{array}{l}\text { Spezifische Bereiche der Maschine aktiv } \\
\text { heizen }\end{array}$ & & $\times$ & $\times$ & & $x$ & $x$ & & $\times$ \\
\hline 4. & $\begin{array}{l}\text { Pulver aus dem Vorratsbehälter dem } \\
\text { Pulverauftragskörper dosiert zuführen }\end{array}$ & & & $\times$ & & & & & \\
\hline 5. & $\begin{array}{l}\text { Bauplattform innerhalb des Bauvolu- } \\
\text { mens positionieren }\end{array}$ & & $x$ & & & & & & \\
\hline 6. & $\begin{array}{l}\text { Pulver durch Pulverauftragskörper } \\
\text { über der Bauplattform auftragen }\end{array}$ & & & & $\times$ & $\times$ & & & \\
\hline 7. & $\begin{array}{l}\text { Überschüssig zugeführtes Pulver in ein } \\
\text { Überlaufvolumen bewegen }\end{array}$ & & & & $\times$ & $\times$ & & & \\
\hline 8. & $\begin{array}{l}\text { Laserenergie in das Pulverbett zur Bau- } \\
\text { teilschichtgenerierung einbringen }\end{array}$ & & & & & & & $\times$ & \\
\hline 9. & $\begin{array}{l}\text { Prozessparameter und Prozessbedin- } \\
\text { gungen kontinuierlich überwachen }\end{array}$ & $x$ & $(\times)$ & $(\times)$ & $(\times)$ & $(\times)$ & $(\times)$ & $(\times)$ & $(\times)$ \\
\hline 10. & $\begin{array}{l}\text { Spezifische Bereiche der Maschine aktiv } \\
\text { kühlen }\end{array}$ & & $\times$ & & & & $x$ & $\times$ & \\
\hline 11. & $\begin{array}{l}\text { Lasergesintertes Bauteil aus der Ma- } \\
\text { schine entnehmen }\end{array}$ & & $\times$ & & & & $\times$ & & \\
\hline 12. & $\begin{array}{l}\text { Überschüssig zugeführtes Pulver aus } \\
\text { der Maschine entnehmen }\end{array}$ & & & $\times$ & & & & & \\
\hline
\end{tabular}


Die Kombination der Module bildet eine grundlagenforschungstaugliche Lasersintermaschine zur Herstellung von bioresorbierbaren Implantatmatrizen. Die Tabelle 6.1 stellt, durch die Verknüpfung der Funktionsstruktur aus Abschnitt 6.1.2 mit der modularen Struktur der Lasersintermaschine, die funktionale Bindung (vgl. „METUS-Raute“ in Abbildung 5.4) des jeweiligen Moduls dar. Die kontinuierliche Überwachung der Prozessparameter und Prozessbedingungen (vgl. 9. Funktion) wird durch das Maschinengestell ausgeführt. Die Beteiligung der spezifischen Module (in Form einer Rückmeldung) an der Prozessüberwachung wird durch die Angabe einer indirekten Verknüpfung (vgl. Kennzeichnung „ $(\times)^{“}$ in Tabelle 6.1) verdeutlicht. Auf Basis der in Abschnitt 6.1.3 identifizierten Lösungen zur Umsetzung der spezifischen Funktionen werden die Module der Lasersintermaschine im Hinblick auf die Auswahl einer Gesamtlösung beschrieben.

Maschinengestell Das Maschinengestell beinhaltet diejenigen strukturellen Elemente, die zur Integration der mechatronischen Teilsysteme aus dem „Baustempelmodul“, „Pulverzuführmodul“, „Pulverauftragsmodul“, „Beschichtereinheit“ (Submodul des Pulverauftragmoduls), „Prozessgasmodul“, „Lasermodul“ und dem „IR-Heizmodul" vorhanden sein müssen. Die physischen Baugruppen der genannten Module müssen diesbezüglich in einem Grundrahmen in den Raumrichtungen definiert miteinander verbunden und aneinander ausgerichtet werden. Die für den Betrieb der Lasersintermaschine notwendigen Mess-, Steuerungs-, Regelungs- und Überwachungsanwendungen (9. Funktion) der spezifischen Module werden auf einer zentralen Steuereinheit (vgl. „Erweiterbarkeit des Steuersystem“ in Abschnitt 5.2) durch die Steuersoftware (vgl. „Möglichkeit zur Anpassung der Steuersoftware“ in Abschnitt 5.1) ausgeführt. Das Steuersystem ist zusammen mit der Elektronik der mechatronischen Teilsysteme in einem Schaltschrank innerhalb des Grundrahmens oder separat neben der Lasersintermaschine verbaut. Alle physischen Komponenten des Maschinengestells müssen als integrative Strukturelemente in der frühen Phase der Produktentwicklung festgelegt werden. Die nachträgliche Änderung zu einem späteren Zeitpunkt ist mit einem hohen finanziellen oder zeitlichen Aufwand verbunden [EKL+14, S. 12-16]. Bei der Ausarbeitung der mechatronischen Teilsysteme der Module ist auf die Verträglichkeit mit dem Maschinengestell zu achten. Die zur Entwicklung des Maschinengestells erforderlichen Schritte lauten wie folgt:

- Auswahl eines erweiterbaren/frei programmierbaren Steuersystems

- Entwicklung eines Grundrahmens zur Anordnung/Ausrichtung der Module

Baustempelmodul Das Bauvolumen unterhalb der Prozessebene wird durch die Umsetzung einer Prozessplatte, Mantelfläche, Bauplattform und dem Einbau einiger Dichtungen erzeugt. Die geführte Positionierung der Bauplattform innerhalb der Bauvolumenmantelfläche relativ zur Prozessplatte ist in der 5. Funktion in Abschnitt 6.1.3 durch die Umsetzung eines Antriebssystems dargestellt. Das homogene aufheizen (3. Funktion) und koordinierte abkühlen (10. Funktion) des Bauvolumens sollte bei der Entwicklung eines geregelten Heizsystems zusammenhängend bearbeitet werden. Bei der Verarbeitung von teilkristallinen Polymeren sollte zur Vermeidung inhomogener Kristallisation die Abkühldauer länger als die eigentliche 
Generierungsdauer des Baujobs sein [Sch15b, S. 51-52]. Bei der Verarbeitung von amorphen Polymeren kann die Umsetzung eines aktiven Kühlsystems zur Verringerung der Prozessnebenzeit hingegen zielführend sein. Das Konzept zur Bauteilentnahme (11. Funktion) ist primär abhängig von der Größe des Bauvolumens. Der Nutzen eines Wechselbehältersystems ist dem zusätzlichen Entwicklungsaufwand (vgl. 3. und 5. Funktion in Abschnitt 6.1.3) bei der Umsetzung des entkoppelbaren Antriebs- und Heizsystems gegenüberzustellen. Die zur Entwicklung des Baustempelmoduls erforderlichen Schritte lauten wie folgt:

- Festlegung der Geometrie des Bauvolumens

- Auswahl eines geeigneten Konzepts zur Bauteilentnahme

- Entwicklung eines geeigneten Antriebssystems samt Lagerung

- Entwicklung eines Heizsystems/Kühlsystems (optional)

Pulverzuführmodul Der zum Lasersintern eines zuvor definierten Bauvolumens notwendige Pulvervorrat ist zur Vermeidung von Baujobabbrüchen konservativ abzuschätzen. Das Rüsten mit dem pulverförmigen Material (1. Funktion) und die dosierte Zuführung (4. Funktion) vor die Beschichtereinheit sollte bei der Entwicklung des Pulverzuführmoduls zusammenhängend bearbeitet werden. Zur Umsetzung des robusten Pulverzuführkonzepts auf Basis der DTM-Technologie (zwei Pulvervorratsvolumina/Überlaufbehälter neben dem mittig angeordneten Bauvolumen) können die für das Baustempelmodul entwickelten Teilsysteme (Wechselbehältersystem/Heizsystem/Antriebssystem/Kühlsystem) auf das Pulverzuführmodul übertragen und unterhalb der Prozessplatte angeordnet werden. Die dosierte Pulverzuführung geschieht durch die inkrementelle Aufwärtsbewegung der Plattform innerhalb der Mantelfläche des Vorratvolumens. Die Möglichkeit zur sukzessiven Pulverzuführung aus Behältnissen außerhalb der Lasersintermaschine (vgl. 1. und 4. Funktion in Abschnitt 6.1.3) ist insbesondere bei der Umsetzung von großen Produktionsmaschinen von Vorteil. Bei der Entwicklung der mechatronischen bzw. pneumatischen Teilsysteme für den Transport und die Dosierung des Materials ist auf einen für den Pulverauftrag geeigneten Pulverzustand zu achten. Die $\mathrm{Zu}-$ standsgröße „Temperatur" wird durch das Vorheizen (3. Funktion) des Pulvers mit einem Heizsystem umgesetzt. Zur nicht automatisierten (vgl. 7. Funktion in Abschnitt 6.1.3) Entnahme des überschüssig zugeführten Pulvers (12. Funktion) werden wechselbare Überlaufbehälter unterhalb der Prozessplatte angeordnet. Die zur Entwicklung des Pulverzuführmoduls erforderlichen Schritte lauten wie folgt:

- Berechnung des notwendigen Pulvervorrats/Überlaufs (ca. $2 \times$ Bauvolumen)

- Auswahl eines geeigneten Konzepts zur Pulverzuführung/Pulverentnahme

- Festlegung der Geometrie/Anzahl/Anordnung der Pulvervorratsvolumina

- Entwicklung der notwendigen mechatronischen/pneumatischen Teilsysteme

- Entwicklung eines Heizsystems

Pulverauftragsmodul samt Beschichtereinheit Das Pulverauftragsmodul samt Beschichtereinheit dient dem möglichst homogenen und porenfreien Auftrag einer 
Pulverschicht über der Bauplattform. Der Pulverauftragskörper hat direkten Kontakt mit dem durch das Pulverzuführmodul dosiert zugeführten Material und ist ein Bauteil der Beschichtereinheit. Die Funktionalitäten, die durch die Umsetzung spezifischer Beschichtereinheiten erfüllt werden können, sind in der 6. Funktion in Abschnitt 6.1.3 beschrieben. Die Beschichtereinheit ist dementsprechend ein Submodul des Pulverauftragmoduls. Die Aufnahme der Beschichtereinheit (physische Schnittstelle zwischen Modul und Submodul) führt relativ zum Bauvolumen entweder eine radiale oder eine translatorische Bewegung (6. Funktion) parallel zur Prozessplatte aus. Bei der Entwicklung der Aufnahme für die Beschichtereinheit sollten die dynamischen Lasten beim Betrieb eines vibrierenden Pulverauftragkörpers oder die geometrischen Abmessungen einer Walze konservativ berücksichtigt werden. Bei der Umsetzung der Lagerung der Beschichtereinheit-Aufnahme ist die ausreichende Steifigkeit in der vertikalen z-Richtung eine technische Grundvoraussetzung zur Erzeugung einer „dellenfreien“ Pulverschicht. Bei der Festlegung der Bewegungsgrenzen (7. Funktion) ist zu prüfen, ob das Pulverzuführmodul der modularen Lasersintermaschine Überlaufvolumina besitzt. Der Ansatz zur Integration eines Heizelements in die Beschichtereinheit (vgl. 3. Funktion in Abschnitt 6.1.3) wurde bereits dargestellt. Die zur Entwicklung des Pulverauftragmoduls samt Beschichtereinheit erforderlichen Schritte lauten wie folgt:

- Auswahl der Bewegung für den Pulverauftrag

- Festlegung der Geometrie der Beschichtereinheit-Aufnahme

- Entwicklung eines geeigneten Antriebssystems samt Lagerung

- Entwicklung spezifisch funktionaler Beschichtereinheiten

Prozessgasmodul Das Prozessgasmodul beinhaltet als Mindestanforderung zur Inertisierung der geschlossenen Prozessumgebung (2. Funktion) die Umsetzung eines gegen Gasaustritt gedichteten Gehäuses und eines Prozessgasversorgungssystems samt Sauerstoffsensorik. Im Hinblick auf die Entwicklung einer reinigungs- und hygienegerechten Lasersintermaschine (vgl. Generelle Anforderungen aus dem medizinischen Gerätebau in Abschnitt 5.3) sind die Prozesskammer und die darin befindlichen Bauteile des Pulverzuführmoduls durch ihre produktberührten bzw. produktnahen Oberflächen als hygienekritische Baugruppen einzustufen. Diesbezüglich muss das Antriebssystem samt Lagerung für die Aufnahme der Beschichtereinheit außerhalb der Prozesskammer angeordnet sein. Bei der Umsetzung der translatorischen Bewegung der Beschichtereinheit müssen die Linearführungen in räumlich getrennten Nebenkammern, die gegenüber der Prozesskammer abgedichtet sind, installiert werden. Die Abdichtung der Drehachse einer radial bewegten Beschichtereinheit gegenüber der Prozesskammer ist hingegen mühelos durch die Verwendung eines Radialwellendichtrings möglich. Soll das lasergesinterte Bauteil händisch aus der Maschine entnommen (11. Funktion) werden, ist eine Türgängigkeit der Prozesskammer zu berücksichtigen. Methoden der Inertisierung, Messsysteme zur Messung der Sauerstoffkonzentration und die Funktionalitäten die durch das bzw. mit dem Prozessgas erfüllt werden können sind in der 2. Funktion in Abschnitt 6.1.3 dargestellt. 
Um die Verschmutzung des Laserglases (Bauteil des Lasermoduls) zu reduzieren, kann das Prozessgas über das Laserglas eingeleitet (2. Funktion), das Laserglas beheizt (3. Funktion) oder gekühlte Abscheideoberflächen (10. Funktion) installiert werden. Insbesondere die Einleitung von temperiertem Gas (2. und 3. Funktion) kann integrativ zur Inertisierung der Prozessumgebung und zur Beheizung der Pulverbettoberfläche genutzt werden. Die zur Entwicklung des Prozessgasmoduls erforderlichen Schritte lauten wie folgt:

- Entwicklung eines gasdichten Prozessgasgehäuses samt Prozesskammer

- Entwicklung eines spezifisch funktionalen Prozessgasversorgungssystems

- Integration eines Messsystems zur Messung der Sauerstoffkonzentration

Lasermodul Das Lasermodul einer Lasersintermaschine besteht hauptsächlich aus einer Laser-Scanner-Einheit (Laser / Galvano-Scanner / Optik) und der zum Betrieb notwendigen Peripherie (Ansteuerelektronik / Netzteil). Kohlenstoffdioxidlaser ab einer Ausgangsleistung von ca. $50 \mathrm{~W}$ werden in der Regel mit einem integrierten aktiven Kühlsystem (10. Funktion) ausgeliefert. Zur Abstimmung (Wellenlänge / Leistung / Apertur) des kommerziell erhältlichen Teilsystems (vgl. 8. Funktion in Abschnitt 6.1.3) müssen Informationen bezüglich der Einbausituation (Arbeitsabstand / Arbeitsfeld) innerhalb der Maschine und der optischen Eigenschaften (Absorption / Eindringtiefe) des zu verarbeitende Materials vorliegen. Bei der Generierung des Bauteils ist die Interaktion von Laserstrahlung mit dem Material ein wesentlicher Prozessschritt beim Lasersintern. Trifft die vom Laser emittierte energiehaltige Strahlung einer spezifischen Wellenlänge auf das pulverförmige Material wird diese von dem Material aufgenommen (Absorption), durchgeleitet (Transmission) oder zurückgeworfen (Reflexion). Die Absorption führt zu einer für den Schmelzvorgang notwendigen Energieaufnahme durch das Material. Die Eindringtiefe der transmittierten Laserstrahlung sorgt, sofern diese größer als die Schichtstärke ist, für die Generierung eines mechanisch belastbaren Verbunds zwischen den Bauteilschichten. Die optischen Eigenschaften werden unter anderem durch die Durchführung von Messungen mit einem FTIR-Spektrometer (Absorption) oder einer Ulbricht-Kugel (Transmission / Reflexion) ermittelt [Sch15b, S. 91-95]. Einige Hersteller von Galvano-Scanner-Lösungen bieten spezifische Kameraadapter als Zubehör für die Ablenkeinheiten an. Die Anwendbarkeit eines solchen „On-Axis“-Schmelzbadüberwachungssystems (Stand der Technik für Laserstrahlschmelzmaschinen) in Kombination mit einem $\mathrm{CO}_{2}$-Laser ist zu prüfen. Die zur Entwicklung des Lasermoduls erforderlichen Schritte lauten wie folgt:

- Messen der optischen Eigenschaften des zu verarbeitenden Materials

- Beschaffung und Integration einer materialspezifischen Laser-Scanner-Einheit

- Integration eines transmittierenden Laserglases in das Prozessgasmodul

- Optionale Integration eines „On-Axis“-Schmelzbadüberwachungssystems

IR-Heizmodul Das 1-Zonen-Heizelement der EOS „Formiga P 100“ (vgl. Abbildung 3.1 im Stand der Technik) heizt (3. Funktion) die Pulverbettoberfläche von oben mittels 
infraroter Strahlung und ist durch die modulare Bauweise mit wenigen Handgriffen aus der Prozesskammer zu entnehmen. Das zugehörige Punkt-Pyrometer ist außerhalb der Prozesskammer im Bereich des Galvanometer-Scanners platziert. Da IR-Heizelemente weder reinigungs- noch hygienegerecht gestaltet (vgl. Generelle Anforderungen aus dem medizinischen Gerätebau in Abschnitt 5.3) sind, sollten diese nach Möglichkeit außerhalb der Prozesskammer platziert werden. Im Hinblick auf die geringe Vorheiztemperatur (vgl. Abschnitt 3.3.4 im Stand der Wissenschaft) bei der Verarbeitung von amorphen, bioresorbierbaren Polymeren ist die Notwendigkeit zur Entwicklung dieser zusätzlichen Wärmequelle zu prüfen. Insbesondere die Kenntnis über die Temperatur-Zeit-Verläufe auf der Pulverbettoberfläche sind eine Grundvoraussetzung für die Entwicklung eines robusten Lasersinterprozesses. Diesbezüglich beinhaltet das IR-Heizmodul ein „Off-Axis“ angeordnetes IR-Kamerasystem (vgl. Messaufbau in [Weg15, S. 184-185]) mit entsprechender Aufnahmefrequenz zur Untersuchung der Aufschmelzvorgänge. Die zur Entwicklung des IR-Heizmoduls erforderlichen Schritte lauten wie folgt:

- Entwicklung einer IR-Heizeinheit (Position ggf. außerhalb Prozesskammer)

- Beschaffung und Integration eines IR-Kamerasystems („Off-Axis“)

- Integration eines transmittierenden Kameraglases in das Prozessgasmodul

\subsubsection{Auswahl eines geeigneten Gesamtkonzepts}

Neben der Zuordnung zwischen den Funktionen und Modulen der Lasersintermaschine sind in Abschnitt 6.1.4 die möglichen Produktstrukturen zur Umsetzung der modulspezifischen Funktionssätze grob umrissen. Die Auswahl eines geeigneten Gesamtkonzepts erfolgt durch die grobe Abarbeitung der modulspezifischen Entwicklungsschritte. Im Hinblick auf die Herstellung und Inbetriebnahme der Lasersintermaschine ist die technische Realisierbarkeit, die insbesondere die Einhaltung der Kosten- und Terminvorgaben impliziert, ein elementares Ausschlusskriterium bei der Auswahl (vgl. modulspezifische Entwicklungsschritte in Abschnitt 6.1.4) eines spezifischen Teilkonzepts. Abschließend wird das ausgewählte Gesamtkonzept der modularen Lasersintermaschine visualisiert.

Maschinengestell Im akademischen Bereich ist die Nutzung von LabVIEW weit verbreitet. In dieser von National Instruments (NI) entwickelten grafischen Programmierumgebung verdrahtet der Benutzer Symbole nach dem Datenflussprinzip in einem Blockdiagramm. Der dadurch generierte G-Code wird durch einen Compiliervorgang in Maschinensprache übersetzt und gilt als vergleichsweise leicht verständlich [KS09b, S. 28] [GH15, S. 19] [Nat13]. Durch den plattformbasierten Ansatz bietet NI neben der Software vor allem modulare Hardware. Im Hinblick auf die Implementierung der in Abschnitt 6.1.4 skizzierten Teilsysteme wird ein NI CompactRIO-Controller 9035 (EtherCAT-Master) in Kombination mit einem CompactRIO-Erweiterungschassis 9144 (EtherCAT-Slave I) als leistungsstarkes, frei programmierbares und beliebig erweiterbares Steuersystem gewählt. Der cRIO-Controller wird diesbezüglich in Anhang C.2 detailliert vorgestellt. Zur Bedienung der modularen Lasersintermaschine 
wird der zugehörige 17" Touchscreen-Monitor TSM-1017 an den Embedded-Controller angeschlossen. Das Steuersystem und die Elektronik der mechatronischen Teilsysteme werden in einem 19" Schaltschrank der Firma Pentair Schroff (Standard am Fachgebiet für den Prüfstandsbau) neben der Lasersintermaschine angeordnet. Die verwendete Schaltschranktechnik ist ergänzend in Anhang C.1 dargestellt. Für den Aufbau des maschinenseitigen Grundrahmens werden stranggepresste Konstruktions-Aluminiumprofile verwendet. Der Vorteil gegenüber einem geschweißten Gestell ist die Möglichkeit zur Realisierung von lösbaren bzw. modifikationsfreundlichen Verbindungen. Wird ein zusätzliches Gewinde am Profil benötigt, kann ein passender Nutenstein nachträglich in die Profilnut eingeschwenkt werden.

Baustempelmodul Um die Anforderung „Kleines Bauvolumen zur wirtschaftlichen Fertigung filigraner Strukturen" (vgl. Anforderung 2.4 in Tabelle A.1) zu erfüllen, wird das Bauvolumen der modularen Lasersintermaschine zunächst auf $\varnothing 65 \mathrm{~mm} \times 80 \mathrm{~mm}$ ( $\widehat{=}$ ca. $265 \mathrm{ml}$ ) festgelegt (vgl. Anforderung 7.1 in Tabelle A.1). Die roten Flächen

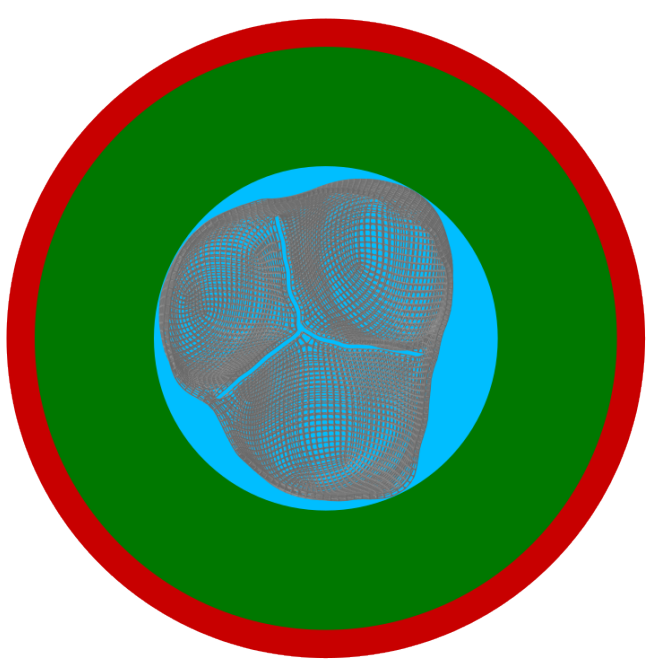

(a) Draufsicht (x-y-Ebene)

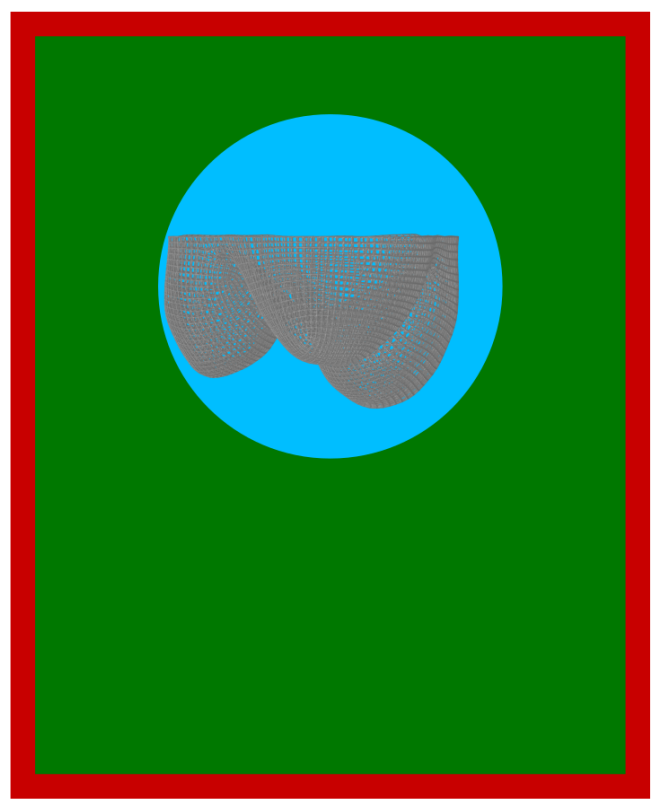

(b) Schnittansicht (x-z- bzw. y-z-Ebene)

Abbildung 6.1.: Darstellung (1:1) eines Scaffolds im $\varnothing 65 \mathrm{~mm} \times 80 \mathrm{~mm}$ Bauraum

(untere Ebene) der Abbildung 6.1 stellen maßstabsgetreu den runden Bauraum dar. Der beim Lasersintern zur Innenwandung notwendige Abstand wird rundum mit 2,5 mm abgeschätzt, sodass sich das nutzbare Bauvolumen, dargestellt als grüne Fläche (mittlere Ebene), in der Belichtungsebene auf einen Durchmesser von $60 \mathrm{~mm}$ reduziert. Zur Fertigung eines Aortenklappen-Scaffolds [LJH+14, S. 596] in beliebiger Orientierung ist ein kugelförmiger Hüllkörper mit einem Durchmesser von $35 \mathrm{~mm}$, dargestellt als hellblaue Fläche (obere Ebene), als Mindestanforderung 
an die Bauraumgröße vorzusehen. Im Hinblick auf die Zellbesiedelung innerhalb eines Bioreaktors (vgl. TE-Grundlagen in Abschnitt 2.2.2) besteht bei dem Bauraumdurchmesser von $65 \mathrm{~mm}$ zusätzlich die Möglichkeit zur Integration einer Haltestruktur an die Implantatmatrix. Die stabile Haltestruktur am Scaffolds dient dem vereinfachten Post-Processing, als Lagerung innerhalb des Reaktors und wird vor der Transplantation des Implantats entfernt. Die Entwicklung eines materialspezifischen Lasersinterprozesses beruht unter anderem auf der Untersuchung der generierten mechanischen Eigenschaften anhand von genormten Probekörpern [VDI 3405 Blatt 1, S. 2] [MDV+12]. Sowohl die verkleinerten Vielzweckprobekörper (Typ A) als auch die kleinen Zugprobekörper (Typ C) mit einer nach DIN EN ISO 20753 [DIN EN ISO 20753] genormten Gesamtlänge von $60 \mathrm{~mm}$ können gefertigt werden. Aufgrund des geringen Pulvervolumens von maximal $265 \mathrm{ml}$ (Wechselbehälter der EOS „Formiga P 100“ fasst ca. $16000 \mathrm{ml}$ ) wird festgelegt, dass das Bauvolumen des Baustempelmoduls nicht wechselbar ausgeführt und die Bauteilentnahme nach dem groben Entpulvern innerhalb der Prozesskammer über eine Tür aus der Lasersintermaschine entnommen wird. Die Bauvolumen-Mantelfläche und die runde Bauplattform (Baustempel) sollen im Betrieb elektrisch beheizt werden. Zur Positionierung der Bauplattform innerhalb des Bauvolumens soll die Kolbenstange eines Kugelgewindetriebs mittig unter der Plattform befestigt werden. Da die Positioniergenauigkeit der Antriebsachse auf der Leistungsfähigkeit des Drehgebers beruht, muss eine entsprechend hohe Drehgeber-Auflösung gefordert werden. Zur Reinigung der Bauvolumen-Oberflächen (Wischdesinfektion) wird der Stempel in der vertikalen z-Richtung nach unten aus dem Baustempelgehäuse bewegt. Der zusätzlich notwendige Verfahrweg muss bei der Projektierung der Hubantriebsachse entsprechend berücksichtigt werden. Da die Integration eines Kühlsystems zum Lasersintern nicht zwingend notwendig jedoch nachträglich möglich ist, beinhaltet das auszuarbeitende Gesamtkonzept keine aktive Kühlung des Bauvolumens.

Pulverzuführmodul Zur Befüllung des Bauvolumens muss die Lasersintermaschine in etwa $530 \mathrm{ml}$ Pulver bevorraten können. Aufgrund des Bauteilentnahmekonzepts (Entpulvern innerhalb der Prozesskammer) wird das Überlaufvolumen konservativ auf $700 \mathrm{ml}$ festgelegt. Im Hinblick auf die Reduktion des Entwicklungsaufwands (keine zusätzliche Dosiereinheit notwendig) und die Vorteile bei der Pulverkonditionierung (Vorheiztemperatur / Restfeuchte / Vorverdichtung) wird das Vorratsvolumen gemäß dem robusten DTM-Konzept neben dem Bauvolumen (vgl. Abbildung 6.2) unterhalb der Prozessebene angeordnet. Zur Umsetzung des Pulverzuführmoduls kann der Pulvervorrat aus einem Vorratsvolumen $(530 \mathrm{ml})$ oder zwei Vorratsvolumina (je $265 \mathrm{ml}$ ) in der vertikalen z-Richtung dem Pulverauftragskörper zugeführt werden. Aufgrund der symmetrischen Anordnung von Wärmequellen um das Bauvolumen herum, der Möglichkeit zur Verwendung exakt identischer Bauteile (Gehäuse / Heizeinheiten / Antriebe) und der Option zum Pulverauftrag in alternierender Richtung wird die Variante mit zwei Vorratsvolumina ausgearbeitet. Die Überlaufvolumina müssen zur Entnahme und Wiederverwendung des Pulvers in jedem Fall wechselbar gestaltet werden. 


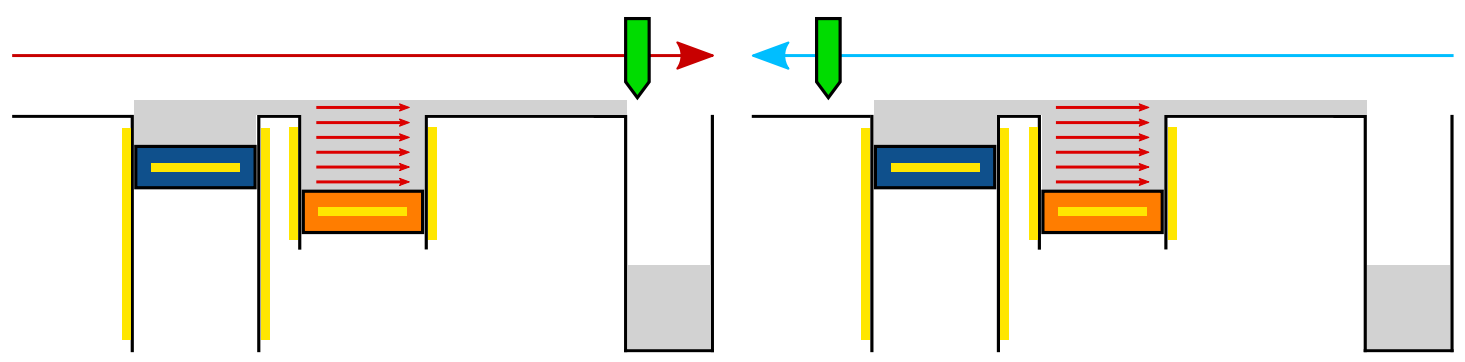

(a) Pulverauftragsbewegung von links nach rechts

(b) Bewegung in die Referenzposition (Leerfahrt)

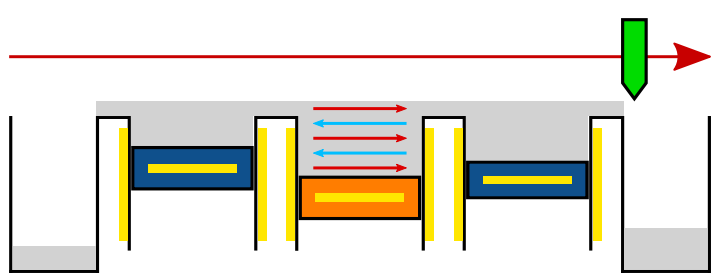

(c) Pulverauftragsbewegung von links nach rechts

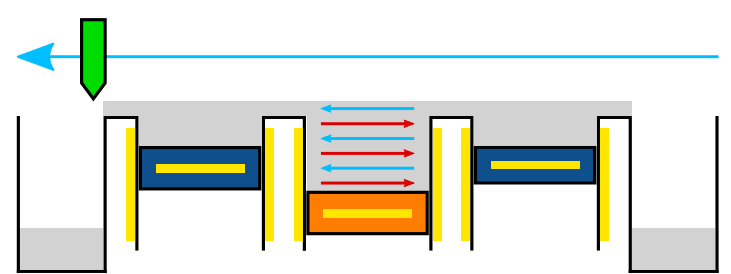

(d) Pulverauftragsbewegung von rechts nach links

Abbildung 6.2.: Pulverauftrag mit einer Pulverzuführung bzw. zwei Pulverzuführungen

Pulverauftragsmodul samt Beschichtereinheit Die Fließfähigkeit eines pulverförmigen Materials definiert sich über die physikalischen Eigenschaften wie die mittlere Korngröße, Korngrößenverteilung, Partikelmorphologie, Rieselfähigkeit und die Volumenverminderung (Hausner-Faktor) durch Rütteln bzw. Stampfen. Für den Pulverauftrag mittels starrer Klinge (vgl. EOS „Formiga P 100“ aus Abbildung 3.1) verweist die Firma EOS auf die Verwendung des hervorragend fließfähigen (Referenzwerte vgl. [BPL+16, S. 33]) Polyamidpulvers „PA2200“. Bei dem Pulverauftrag von weniger fließfähigen Materialien können sich unter Umständen Pulveragglomerationen bilden, die durch den Einsatz einer fluidisierender Beschichtereinheit gelöst werden können. Zum Pulverauftrag der bioresorbierbaren Materialien sol-

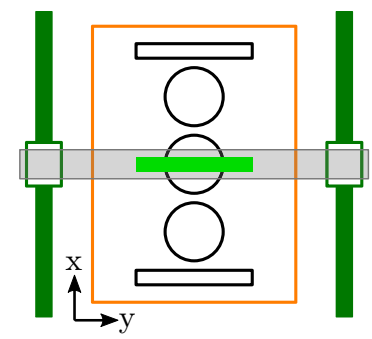

(a) Horizontale Verteilung der Linearführungen

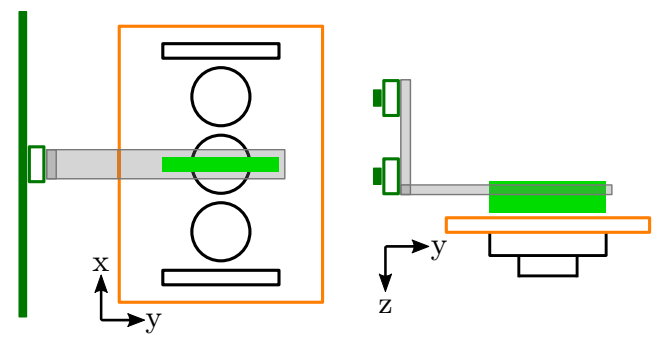

(b) Vertikale Verteilung der Linearführungen

Abbildung 6.3.: Anordnung der Linearführungen für den translatorischen Pulverauftrag

len, neben einer standardmäßigen starren Klinge, vor allem Beschichtereinheiten mit einer rotierenden Rolle und einer schwingenden Klinge ausgearbeitet werden. 
Ein wesentlicher Prozessparameter für den Prozessschritt „Pulverauftrag“ ist die konstante Pulverauftragsgeschwindigkeit über der Bauplattform. Im Hinblick auf die Bewegungsüberlagerung von Beschichtereinheit-Aufnahme und Pulverauftragskörper (rotieren/schwingen) wird festgelegt, dass die Beschichtereinheit-Aufnahme eine translatorische Pulverauftragsbewegung ausführt. Zur Erhöhung der Steifigkeit in der vertikalen z-Richtung wird die Beschichtereinheit-Aufnahme beidseitig (vgl. (a) Abbildung 6.3) gelagert. Die wechselbare Beschichtereinheit (Submodul des Pulverauftragmoduls) wird mit der Beschichtereinheit-Aufnahme verschraubt.

Prozessgasmodul Das Prozessgasmodul wird unterteilt in Prozessgasgehäuse und Prozessgasgasversorgung samt Sauerstoff-Messsystem. Durch die horizontale Verteilung der Linearführungen für den translatorischen Pulverauftrag ist die grobe Gestalt des Prozessgasgehäuses indirekt vorgegeben. Im Hinblick auf die Entwicklung einer reinigungs- und hygienegerechten Lasersintermaschine sind die Linearführungen (samt Antriebsachse) in Nebenkammern rechts und links neben der mittigen Prozesskammer (vgl. Anforderung 11.1 in Tabelle A.1) anzuordnen. Zur Reinigung aller produktberührten Oberflächen (Wischdesinfektion) und der Entnahme der Bauteile soll die Prozesskammer über eine Türbaugruppe auf der Vorder- und Rückseite der Maschine großflächig geöffnet werden können. Zur Inertisierung des Prozessgasgehäuses soll eine integrative Baugruppe zur Aufnahme eines Laserglases und der Prozessgaseinleitung in die Prozesskammer aufgebaut werden. Die Gasströmung wird auf der Oberseite der Laserglas-Prozessgas-Armatur eingeleitet, innerhalb der Baugruppe um $90^{\circ}$ umgelenkt und durch einen Diffusor hindurch laminar über die Unterseite des Laserglases geführt. Zur Begrenzung des Prozesskammerinnendrucks wird im Bereich des Gasauslasses ein Überdruckventil platziert. Sollte das Laserglas wider Erwarten stark verschmutzen, können aktiv gekühlte Abscheideoberflächen bedarfsgerecht nachgerüstet werden. Bei der Auswahl eines geeigneten Massendurchflussregelventils sollte die Option der Einleitung eines vorgeheizten Prozessgases mit berücksichtigt werden. Das Prozessgas (Stickstoff) wird aufgrund der Aufstellbedingungen (vgl. Anforderung 4.2 aus Tabelle A.1) aus einer Gasflasche (vgl. Anforderung 11.12 in Tabelle A.1) entnommen. Zur redundanten Messung der Sauerstoffkonzentration sollen zwei Sauerstoff-Messsysteme im Bereich des Bauvolumens verbaut werden.

Das Gesamtkonzept der modularen Lasersintermaschine ist in Abbildung 6.4 visualisiert. Die mechatronischen Komponenten der jeweiligen Module werden auf horizontal verlaufenden Etagen (Antriebsetage / Prozessetage / Laseretage) angeordnet, die mit dem Grundrahmen des Maschinengestells verbunden und in horizontaler Richtung zueinander ausgerichtet werden. Die untere Etage (Antriebsetage) dient der Aufnahme der insgesamt drei Hubantriebsbaugruppen aus dem Baustempel- und Pulverzuführmodul. Die beheizten Gehäuse und Überlaufbehälter sind allesamt an einer wechselbaren Einsatzplatte (Prozesseinsatzplatte) befestigt, die von der Unterseite mit der Prozessrahmenplatte (montiert an der Prozessetage) verschraubt wird. Muss das Bauvolumen weiter verkleinert oder auf eckig umgebaut werden, wird die gesamte Einsatzplatte mit sämtlichen Anbauteilen und den zugehörigen Plattformen ausgetauscht. Im Bereich der oberen Etage 
(Laseretage) ist die Lasereinsatzplatte des Lasermoduls auf der Oberseite der Laserrahmenplatte montiert. Durch die Anwendung des Prinzips „Rahmenplatte / Einsatzplatte“

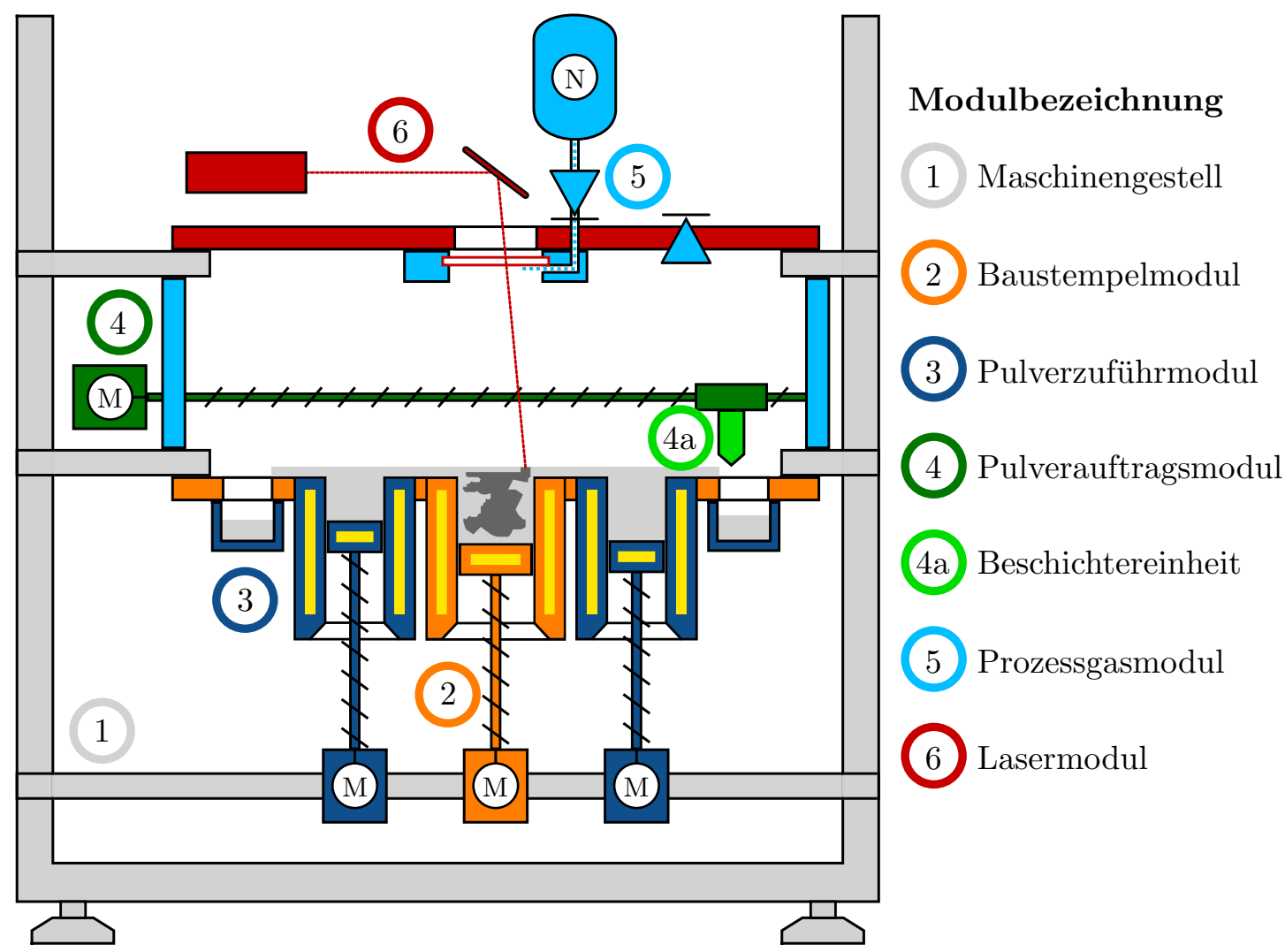

Abbildung 6.4.: Gesamtkonzept der modularen Lasersintermaschine

besteht das Prozessgasgehäuse des Prozessgasmoduls lediglich aus vertikal verlaufenden Wänden, die mit den Rahmenplatten verschraubt werden. Zur Erforschung des Teilprozessschritts „Pulverauftrag“ in Kombination mit verschiedenen Beschichtereinheiten genügt der Aufbau des Baustempelmoduls, Pulverzuführmoduls, Pulverauftragmoduls und des unteren Grundrahmens. Für Versuche zum Prozessschritt „Bauteilschichtgenerierung" ohne automatisieren Pulverauftrag genügt der Aufbau des Lasermoduls und des oberen Grundrahmens.

Lasermodul Das Lasermodul setzt sich aus der bereits diskutierten Lasereinsatzplatte und einer materialspezifisch abgestimmten Laser-Scanner-Einheit zusammen. Aufgrund der Wellenlängenabhängigkeit des Laserglases, verbaut in der Laserglas-Prozessgas-Armatur, wird die Komponente dem Lasermodul zugeordnet.

IR-Heizmodul Die Entwicklung eines IR-Heizmoduls ist im aktuellen Konzept, aufgrund der geringen Vorheiztemperatur, nicht vorgesehen. Zur Positionierung des Infrarot-Heizelements innerhalb der Prozesskammer (vgl. Abbildung 6.5) wird die Lasereinsatzplatte mit einer entsprechenden Aufnahme ergänzt. Ist die Integration 
eines Heizelements wider Erwarten notwendig, kann das IR-Heizmodul bedarfsgerecht nachgerüstet werden. Die Positionierung außerhalb der Prozesskammer ist aufgrund der reinigungs- und hygienegerechten Gestaltung zu bevorzugen. Die Beschaffung einer „Off-Axis“ angeordneten Wärmebildkamera ist im Rahmen der vorliegenden Arbeit nicht vorgesehen.

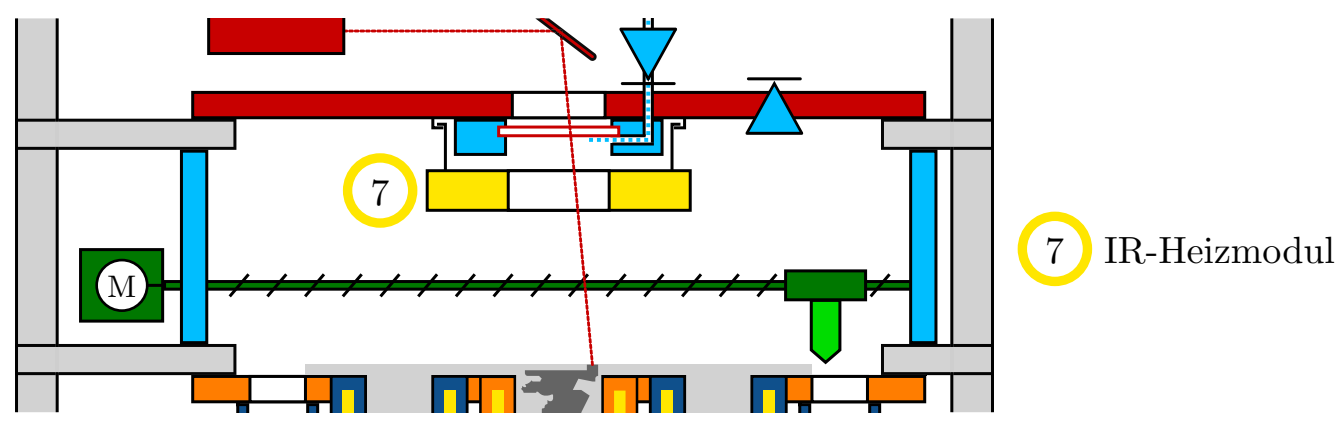

Abbildung 6.5.: IR-Heizmodul (optional) innerhalb der Prozesskammer 


\subsection{Entwerfen und Ausarbeiten}

Das in Abschnitt 6.1.5 dargestellte Gesamtkonzept wird im Folgenden entworfen und ausgearbeitet. Diesbezüglich werden die spezifischen Module der Lasersintermaschine in Abschnitt 6.2.1 gestaltet. Der Schaltschrank samt cRIO-basiertem Steuersystem (Steuereinheit) wird in CAD nicht modelliert. In Abschnitt 6.2.2 wird die Fertigung sowie die Montage der Module abschließend vorbereitet.

\subsubsection{Gestaltung der spezifischen Module}

Auf Basis der Modularisierung aus Abschnitt 6.1.4 wurden Abschlussarbeiten (vgl. Übersicht in Anhang F.3) zur Entwicklung des Pulverzuführmoduls [Zha15], Pulverauftragmoduls [Ogo17], Prozessgasmoduls [Lan16] [Lus17] [Ebe18] [Spr18], Lasermoduls [Faß17], IR-Heizmoduls [Möl15] sowie einiger Beschichtereinheiten [Hri15] [Nüc16] vergeben und intensiv betreut. Die Ergebnisse des iterativen Gestaltungsprozesses der modularen La-

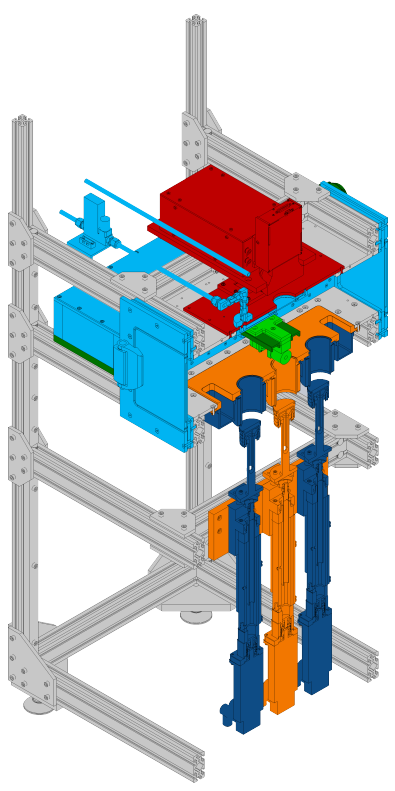

(a) Schnittansicht

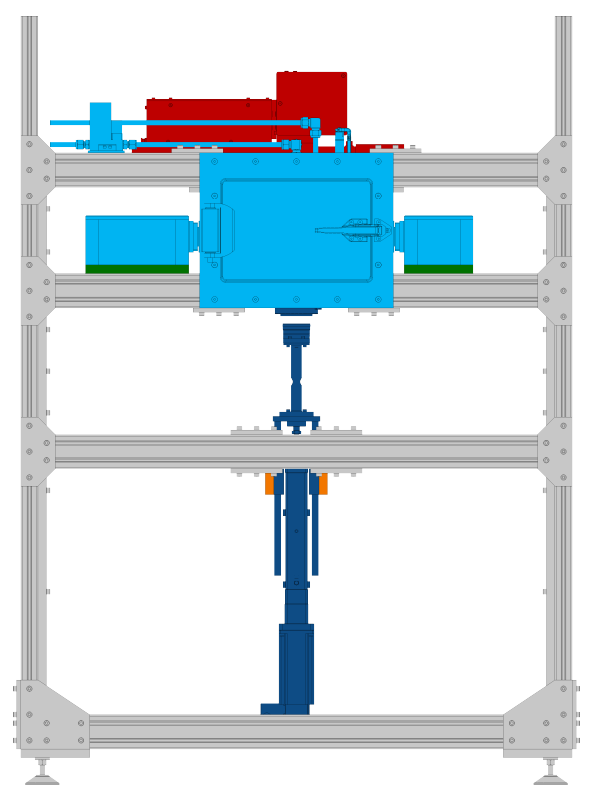

(b) Vorderansicht

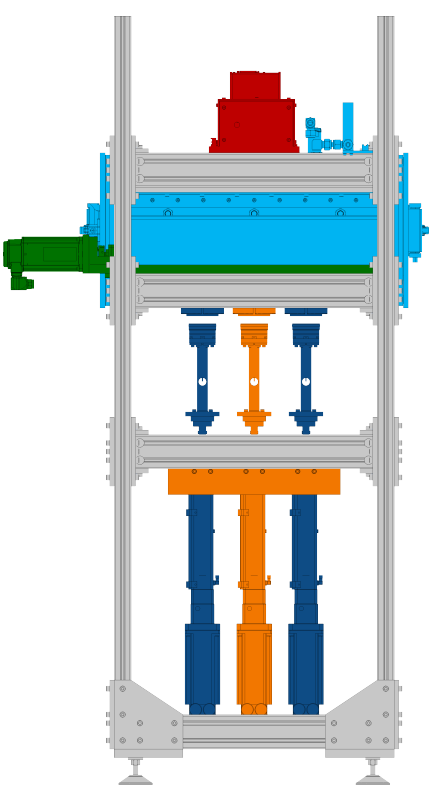

(c) Seitenansicht links

Abbildung 6.6.: Gesamtentwurf der modularen Lasersintermaschine: Maschinengestell

$\begin{array}{lll}\text { Baustempelmodul } & \text { Pulverzuführmodul Pulverauftragsmodul } \\ \text { Beschichtereinheit } & \text { Prozessgasmodul Lasermodul }\end{array}$

sersintermaschine (vgl. Abbildung 6.6) werden im Folgenden dargestellt. Diesbezüglich werden die Baugruppen und Komponenten der jeweiligen Module diskutiert. Die dabei verwendeten Bauteilbezeichnungen sind in Anhang B gesondert visualisiert. 


\section{Maschinengestell}

Das Maschinengestell, dargestellt in Abbildung 6.7, ist symmetrisch (vgl. Anforderung 6.8 in Tabelle A.1) aufgebaut aus Grundrahmen, Antriebsetage, Prozessetage samt Prozessrahmenplatte, Laseretage samt Laserrahmenplatte und Abstandhaltern. Zur Fertigung von Grundrahmen und Etagen werden stranggepresste Aluminiumprofile der Baureihe 8 (itemkompatibel) in schwerer Ausführung (maximales Flächenträgheitsmoment) mit einem quadratischen $(40 \mathrm{~mm} \times 40 \mathrm{~mm})$ oder einem rechteckigen $(80 \mathrm{~mm} \times 40 \mathrm{~mm})$ Querschnitt verwendet. Zum Verbinden der Konstruktionsprofile werden Universal-Verbindungssätze

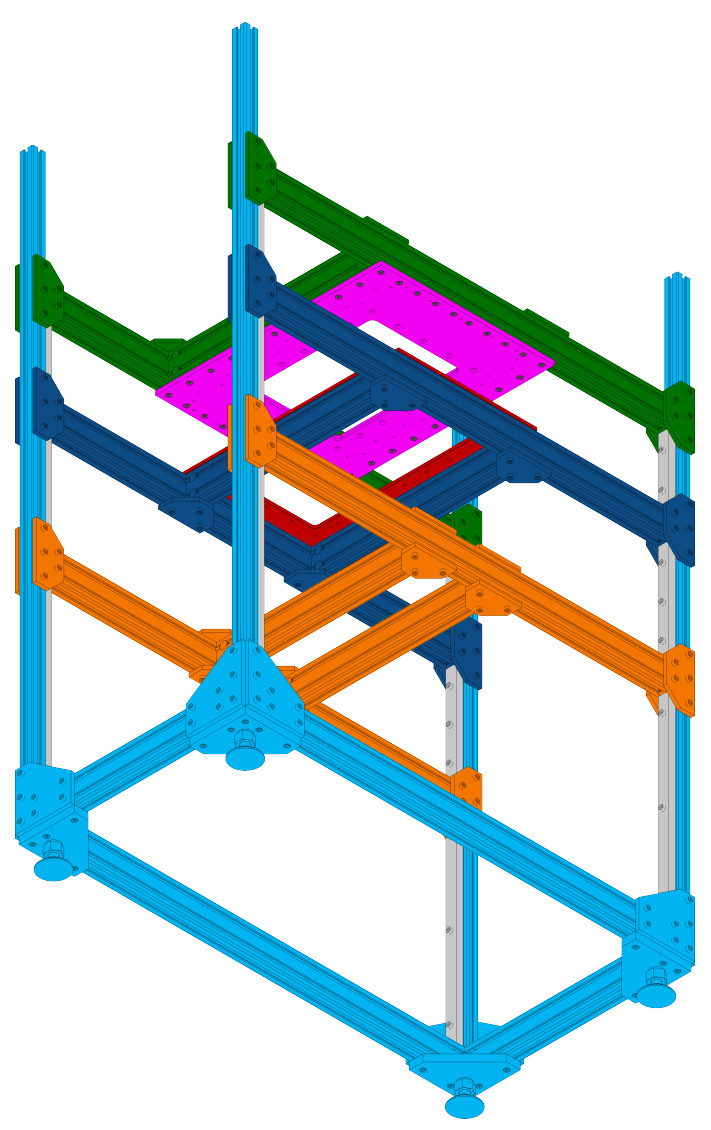

(a) ISO-Ansicht vorne links unten

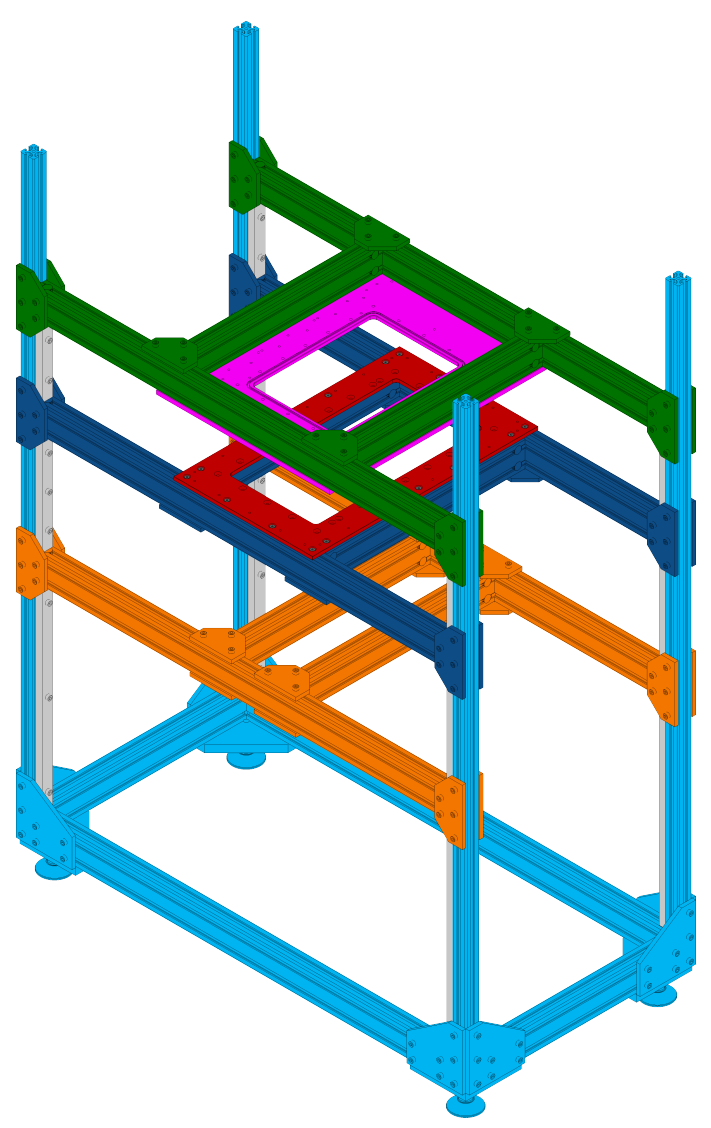

(b) ISO-Ansicht vorne rechts oben

\section{Abbildung 6.7.: Maschinengestell: Grundrahmen \\ Prozessetage

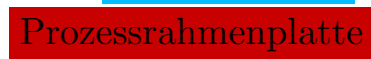 \\ Abstandhalter Antriebsetage Laseretage Laserrahmenplatte}

und gefräste Verbindungsplatten aus $10 \mathrm{~mm}$ (kleine/große Knotenbleche und Sockelversteifungen) bzw. $20 \mathrm{~mm}$ (Fußplatten) Aluminium verwendet. Die modulspezifischen Einbauten werden auf den jeweiligen Etagen (vgl. Konstruktionsdetail in Abbildung B.1) angeordnet und im Grundrahmen verschraubt. Zum Aufbau einer 80x40-Etage sind jeweils zwei 80x40-Profile (Länge $1200 \mathrm{~mm}$ bzw. $570 \mathrm{~mm}$ ), Verbindungssätze und Knotenbleche 
notwendig. Die stabile und verschiebbare Anbindung an den Grundrahmen erfolgt über große Knotenbleche und Verbindungssätze. Zur vertikalen Ausrichtung der Etagen im Grundrahmen werden gefräste Abstandhalter (4er-Sets) eingesetzt, die zwischen der Oberseite der unteren Etage bzw. dem Grundrahmensockel und der Unterseite der oberen Etage aufliegen. Im Folgenden werden die Baugruppen des Maschinengestells beschrieben.

Grundrahmen Der Grundrahmen besteht aus vier $1700 \mathrm{~mm}$ langen 40x40-Profilen, zwei $1200 \mathrm{~mm}$ langen 80x40-Profilen, zwei $570 \mathrm{~mm}$ langen 80x40-Profilen, vier Fußplatten, vier Stellfüßen und acht Sockelversteifungen. Auf einer Fußplatte sind jeweils zwei 80x40-Profile horizontal und ein 40x40-Profil vertikal angeordnet und durch M8 Zylinderschrauben miteinander verschraubt. Die Stellfüße werden in die M12 Gewindebohrungen der Fußplatten eingeschraubt und nach Nivellierung mittels Mutter gekontert. Im Eckbereich des Grundrahmens sind Sockelversteifungen mit jeweils sieben M8 Schrauben verschraubt.

Antriebsetage Die Antriebsetage dient der Anordnung des Hubantriebsbaugruppenpakets (vgl. Anforderung 6.9 in Tabelle A.1) aus dem Baustempel- und Pulverzuführmodul. Der Abstand zwischen den $570 \mathrm{~mm}$ langen 80x40-Profilen beträgt $145 \mathrm{~mm}$. Die Abstandhalter zwischen dem Grundrahmensockel und der Antriebsetage haben eine Länge von $570 \mathrm{~mm}$.

Prozessetage mit Prozessrahmenplatte Die äußeren Sollmaße der Prozessrahmenplatte betragen $648 \mathrm{~mm} \times 398 \mathrm{~mm} \times 10 \mathrm{~mm}$. Bei symmetrischer Montage der Prozessrahmenplatte auf der Prozessetage (vgl. Anforderung 6.10 in Tabelle A.1) ist rundum $1 \mathrm{~mm}$ Abstand zu den Profilaußenflächen. Bei dem Aufbau der Prozessetage werden in die Profilnuten schwere M6 Nutensteine eingeschoben. Die Rahmenplatte wird mittels M6x20 Senkschrauben auf die Prozessetagenoberseite geschraubt. Die über den Umfang verteilten M6 Gewindebohrungen (vgl. Konstruktionsdetail in Abbildung B.2) werden zu einem späteren Zeitpunkt zur Montage eines Prozessgasgehäuses (vgl. Anforderung 6.12 in Tabelle A.1) genutzt. Die Öffnung in der Prozessrahmenplatte beträgt $481 \mathrm{~mm} \times 251 \mathrm{~mm}$ mit Eckradien von $10 \mathrm{~mm}$. Die Positionierung einer mit Zylinderstiften versehenen Prozesseinsatzplatte (Baustempelmodul) geschieht von unten an die Unterseite der Prozessrahmenplatte über $\varnothing 5 \mathrm{H} 7$ Bohrungen. Sämtliche um die Öffnung angeordneten Formsenkbohrungen dienen der Montage der Prozesseinsatzplatte. Die Abstandhalter zwischen der Antriebsetage und der Prozessetage haben eine Länge von $293 \mathrm{~mm}$.

Laseretage mit Laserrahmenplatte Die äußeren Sollmaße der Laserrahmenplatte betragen $648 \mathrm{~mm} \times 498 \mathrm{~mm} \times 12 \mathrm{~mm}$. Bei symmetrischer Montage der Laserrahmenplatte auf der Laseretage (vgl. Anforderung 6.11 in Tabelle A.1) ist rundum $1 \mathrm{~mm} \mathrm{Ab-}$ stand zu den Profilaußenflächen. Bei dem Aufbau der Laseretage werden in die Profilnuten schwere M6 Nutensteine eingeschoben. Die Rahmenplatte wird mittels M6x20 Senkschrauben unter die Laseretagenunterseite geschraubt. Die Öffnung in der Laserrahmenplatte beträgt $350 \mathrm{~mm} \times 250 \mathrm{~mm}$ mit Eckradien von $10 \mathrm{~mm}$. Zwischen der Öffnung und dem M6 Formsenkbohrmuster zur Befestigung der Lasereinsatzplatte (Lasermodul) ist eine Nut (vgl. Konstruktionsdetail in Abbildung B.3) 
für den Einsatz eines nach DIN ISO 3601-1 [DIN ISO 3601-1] genormten O-Rings eingebracht. Die Nutgeometrie ist in Zusammenarbeit mit der Firma COG in Anlehnung an die DIN ISO 3601-2 [DIN ISO 3601-2] auf die Verwendung eines O-Rings (Innendurchmesser $392 \mathrm{~mm}$ / Schnurstärke $4 \mathrm{~mm}$ ) aus Fluorkautschuk (FKM) der Härte $80 \pm 5$ Shore A abgestimmt. Für derzeit noch unbekannte Aufbauten auf der Oberseite der Laserrahmenplatte sind zusätzlich zehn $\varnothing 5 \mathrm{E} 7$ Bohrungen und 14 M6 Gewindebohrungen eingebracht. Die über den Umfang verteilten M6 Gewindebohrungen werden zu einem späteren Zeitpunkt zur Montage eines Prozessgasgehäuses (vgl. Anforderung 6.12 in Tabelle A.1) genutzt. Die Positionierung einer mit Zylinderstiften versehenen Lasereinsatzplatte (Lasermodul) geschieht von oben an die Oberseite der Laserrahmenplatte über $\varnothing 5 \mathrm{E} 7$ Bohrungen. Die Abstandhalter zwischen der Prozessetage und der Laseretage haben eine Länge von $200 \mathrm{~mm}$.

\section{Baustempel- und Pulverzuführmodul}

Das Baustempel- und Pulverzuführmodul ist aufgebaut aus einer Prozesseinsatzplatte samt Anbauteilen (montiert an der Prozessetage - vgl. Abbildung 6.8) und einem Hubantriebsbaugruppenpaket samt Stempelbaugruppen (montiert an der Antriebsetage - vgl. Abbildung 6.9). Im Folgenden werden die Baugruppen des Baustempel- und Pulverzuführmoduls beschrieben.

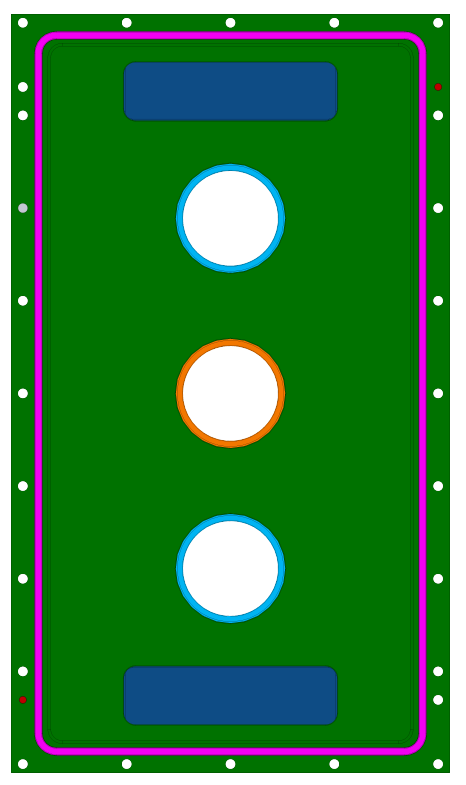

(a) Draufsicht

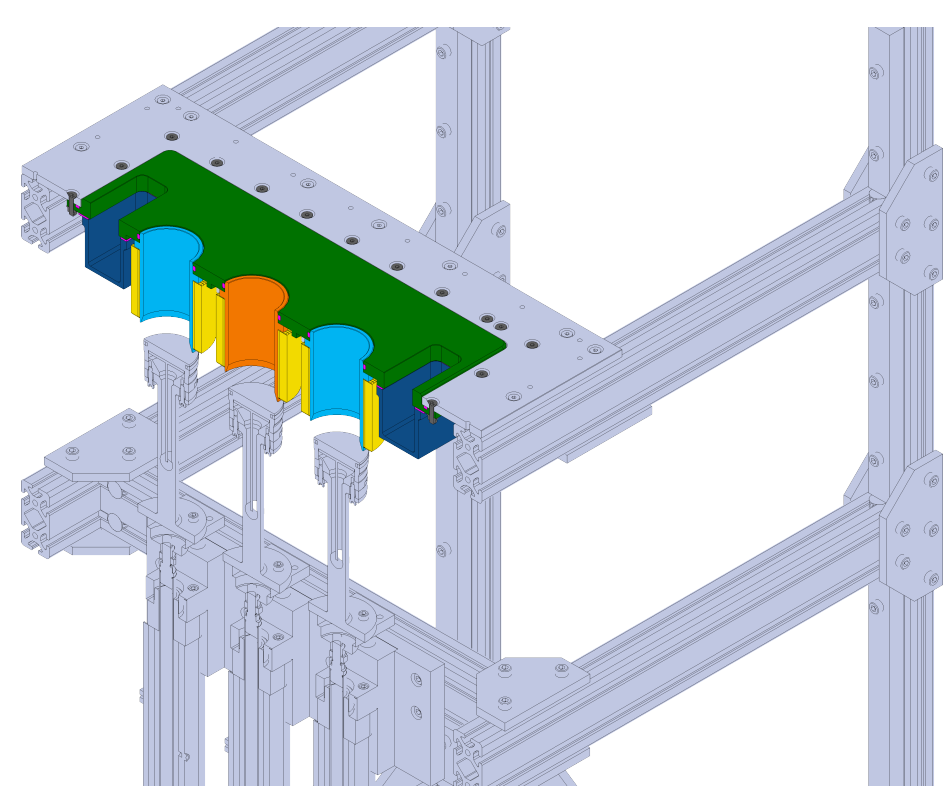

(b) Montage an der Prozessrahmenplatte (Schnittansicht)

Abbildung 6.8.: Prozesseinsatzplatte samt Anbauteilen:

Baustempelgehäuse Pulverzuführgehäuse Keramikheizband
Überlaufbehälter Dichtung Zylinderstift


Prozesseinsatzplatte samt Anbauteilen Die symmetrische Prozesseinsatzplatte samt Anbauteilen (vgl. Konstruktionsdetail in Abbildung B.4) wird von unten an die Unterseite der Prozessrahmenplatte (Maschinengestell) durch die Verwendung von Zylinderstiften positioniert (vgl. Anforderung 7.2 in Tabelle A.1) und mit 26 M6 Senkschrauben verschraubt. Die Prozesseinsatzplatte ist gegenüber der Prozessrahmenplatte durch einen O-Ring (Innendurchmesser $470 \mathrm{~mm}$ / Schnurstärke $4 \mathrm{~mm}$ ) aus FKM der Härte $80 \pm 5$ Shore A gedichtet, dessen Nut in die Prozesseinsatzplatte gefräst ist. Die Gehäuse (Baustempel- und Pulverzuführgehäuse) sind allesamt identisch (vgl. Anforderungen 8.2 / 8.5 in Tabelle A.1), besitzen einen Innendurchmesser von $\varnothing 65 \mathrm{H} 9$, sind $110 \mathrm{~mm}$ hoch, haben einen Mittelpunktabstand von $120 \mathrm{~mm}$ zueinander und werden von der Unterseite mit der Prozesseinsatzplatte verschraubt. Die Gehäuseposition in der Prozesseinsatzplatte ist durch eine Spielpassung zwischen der Innenpassfläche der Bohrung in der Prozesseinsatzplatte $(\varnothing 75 \mathrm{H} 8)$ und der Außenpassfläche des Baustempelgehäuses ( $\varnothing 75 \mathrm{f7})$ bestimmt. Alle Gehäuse sind gegenüber der Prozesseinsatzplatte durch O-Ringe (Innendurchmesser $75 \mathrm{~mm}$ / Schnurstärke 4,5 mm) aus FKM der Härte $80 \pm 5$ Shore A gedichtet, dessen Nuten in die Prozesseinsatzplatte gefräst sind. Die Gehäuse besitzen zur Montage der Dichtungen an der oberen Außenkante $\left(3 \times 20^{\circ}\right)$ und der unteren Innenkante $\left(10 \times 20^{\circ}\right)$ eine Einführschräge. Zur Beheizung der Gehäusemantelflächen (vgl. Anforderungen 7.4 / 8.1 in Tabelle A.1) sind Keramikheizbänder montiert. Die gestiftet und verschraubten Überlaufbehälter (Pulverzuführmodul) sind gegenüber der Prozesseinsatzplatte durch die Verwendung einer $2 \mathrm{~mm}$ Flachdichtung aus FKM gedichtet.

Stempelbaugruppe Eine Stempelbaugruppe (vgl. Konstruktionsdetail in Abbildung B.5) ist aufgebaut aus Abstandshantel, Stempeloberteil, doppeltwirkenden Kolbendichtung, Befestigungsscheibe, zwei Klemmscheiben und Silikonheizmatte. Das Stempeloberteil (Plattform) hat einen Außendurchmesser von $64 \mathrm{~mm}$ und ist durch die Verwendung einer doppeltwirkenden Kolbendichtung gegenüber der Innenwandung der Baustempel- und Pulverzuführgehäuse gedichtet. Die dynamische Dichtung der Firma PTFE-CC (Außendurchmesser $65 \mathrm{~mm} /$ Innendurchmesser $54 \mathrm{~mm}$ / Gleitringhöhe 4,2 $\mathrm{mm}$ ) ist aus einem FDA-konformen PTFE-Gleitring und einem Silikon-O-Ring als Vorspannelement aufgebaut. Die Bau- bzw. Pulverzuführplattform wird durch eine selbstklebende Silikonheizmatte (vgl. Anforderungen 7.14 / 8.1 in Tabelle A.1) beheizt, die auf der Unterseite des Stempeloberteils angebracht ist. Die axiale Zentrierung von Stempeloberteil auf der Befestigungsscheibe ist durch die Fertigung einer Spielpassung zwischen der Innenpassfläche der Bohrung im Stempeloberteil (ø51H7) und der Außenpassfläche der Befestigungsscheibe $(\varnothing 51 \mathrm{~h} 7)$ gewährleistet. Stempeloberteil und Befestigungsscheibe sind miteinander verschraubt. Die Befestigungsscheibe liegt flach auf der Oberseite der $180 \mathrm{~mm}$ langen Abstandshantel auf. Durch das Anziehen der Zylinderschrauben an der geteilten Klemmscheibe entsteht eine kraftschlüssige Verbindung zwischen Befestigungsscheibe und Abstandshantel. Fertigungs- und Montagefehler können zu einem Axialversatz zwischen Stempelbaugruppe (Gesamthöhe $215 \mathrm{~mm}$ ) und 
Baustempel- bzw. Pulverzuführgehäuse führen. Durch die Fertigung von $8 \mathrm{~mm}$ Bohrungen auf der Abstandshanteloberseite kann ein Axialversatz bis maximal 1,5 mm (vgl. Anforderung 7.11 in Tabelle A.1) ausgeglichen werden. Die Stempelbaugruppe wird durch die Hubantriebsbaugruppe in vertikaler Richtung positioniert und auf der Jochplattenoberseite (vgl. Abbildung 6.9) verschraubt.

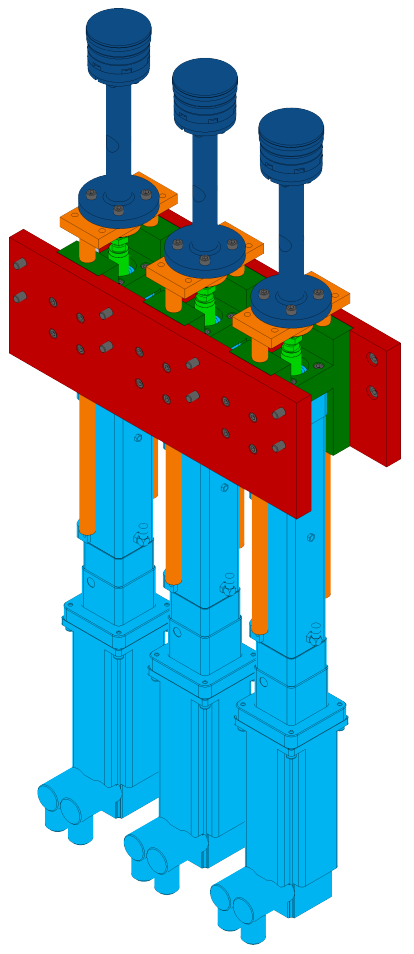

(a) ISO-Ansicht

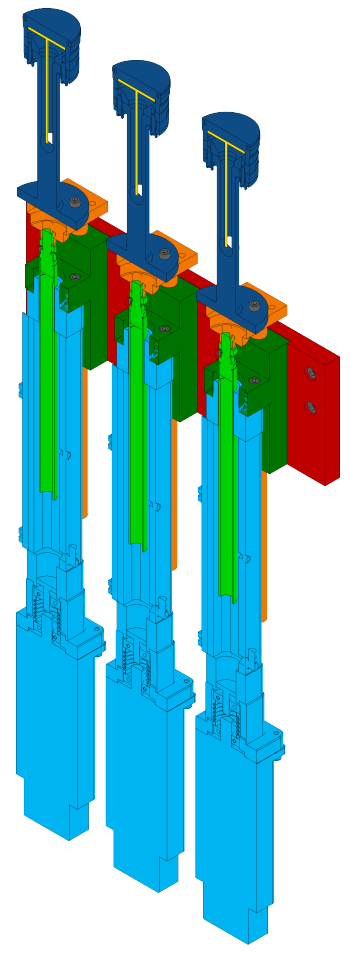

(b) Schnittansicht

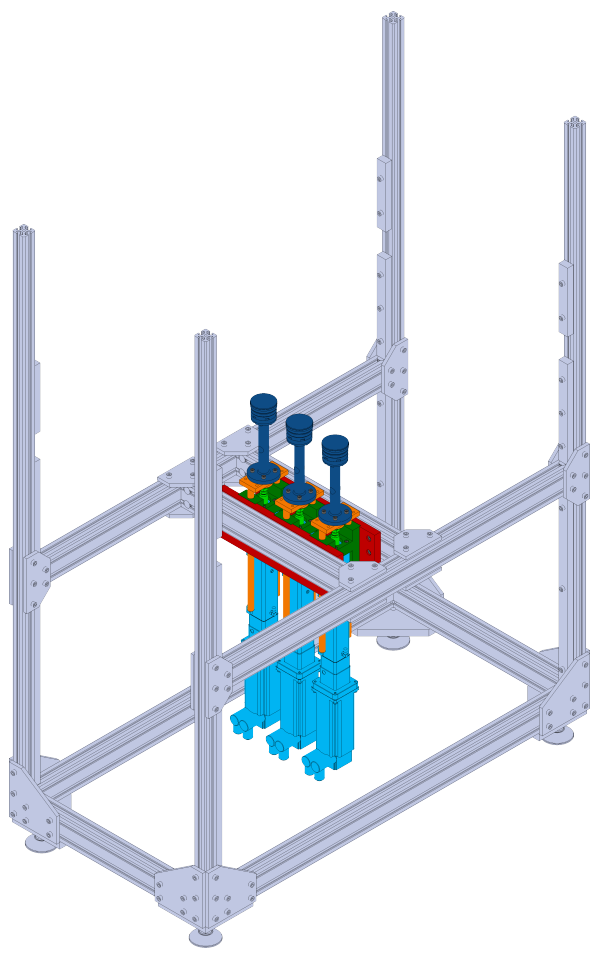

(c) Montage an der Antriebsetage

Abbildung 6.9.: Hubantriebsbaugruppenpaket samt Stempelbaugruppen:

\begin{tabular}{|c|c|c|}
\hline Aufnahmeplatte & Hubantriebsachse & Kolbenstange des EMCs \\
\hline Führungseinheit & Jo & atte mit Führungsstange \\
\hline
\end{tabular}

Hubantriebsbaugruppe (Unterbaugruppe des Hubantriebsbaugruppenpakets) Die

Hubantriebsbaugruppe (vgl. Konstruktionsdetail in Abbildung B.6) ist aus einer Bosch Rexroth Hubantriebsachse (Synchron Servomotor MSK040C-0450 / Motorflansch mit Kupplung / Elektromechanischer Zylinder EMC-040) sowie einer Festo FENG-40-200-KF Führungseinheit [Fes16, S. 3] aufgebaut und dient der Positionierung der Stempelbaugruppe in vertikaler z-Richtung. Die Spezifikationen der aufeinander abgestimmten Antriebskomponenten sind in dem Kapitel zur Inbetriebnahme der Bosch Rexroth Antriebstechnik in Anhang D.1 zusammengefasst. Die rotatorische Bewegung der Motorwelle wird durch einen im elektromechanischen Zylinder gelagerten Gewindetrieb in eine translatorische Bewegung der Kolben- 
stange umgewandelt. Die Führungseinheit (genormt nach DIN ISO 15552 [DIN ISO 15552]) dient der Lagerung der Kolbenstange und als Montageschnittstelle für die Stempelbaugruppe. Die Position der Oberseite der Jochplatte wird indirekt über den Drehgeber am Motor erfasst. Der Servomotor wurde aufgrund des hochpräzisen Gebers „M2" ausgewählt (vgl. Anforderungen 7.7 / 8.1 in Tabelle A.1) und ist in Verlängerung der Achse mittels Flansch und Kupplung direkt (ohne Riemenvorgelege) an den EMC montiert. Der Kugelgewindetrieb hat eine Steigung von $5 \mathrm{~mm}$ und einen effektiven Arbeitshub von ca. $180 \mathrm{~mm}$. Die Fahrbereichsbegrenzung wird durch Magnetsensoren überwacht, die in dem Sensorprofil an der Außenseite des EMCs befestigt sind. Das überdimensionierte Antriebssystem (Maximalkraft $700 \mathrm{~N}$ ) wurde aufgrund der hohen Positioniergenauigkeit und der validierten Schnittstelle zum CompactRIO-Steuersystem (LabVIEW-VI im Lieferumfang enthalten) ausgewählt.

Hubantriebsbaugruppenpaket Das Hubantriebsbaugruppenpaket (vgl. Abbildung 6.9) ist aus drei Hubantriebsbaugruppen sowie zwei Aufnahmeplatten aufgebaut und wird mit der Antriebsetage (vgl. Anforderung 6.9 in Tabelle A.1) verschraubt. Zur Gewährleistung einer parallelen Anordnung der Führungseinheiten der Hubantriebsbaugruppen sind in die Aufnahmeplatten (vgl. Konstruktionsdetail in Abbildung B.7) passgenaue, $5 \mathrm{~mm}$ tiefe Aussparungen zum spielfreien Einschrauben der Führungseinheitkorpusse (vgl. Anforderung 7.10 in Tabelle A.1) gefräst. Die Aufnahmeplatten besitzen die geometrischen Abmessungen von $400 \mathrm{~mm} \times 140 \mathrm{~mm} \times 20 \mathrm{~mm}$. Das montierte Hubantriebsbaugruppenpaket ist $145 \mathrm{~mm}$ breit.

\section{Pulverauftragsmodul}

Das Pulverauftragsmodul, dargestellt in Abbildung 6.10, besteht aus Lagerbaugruppe, Antriebsbaugruppe und Auftragsschlitten (Aufnahme der Beschichtereinheit). Die translatorische Auftragsschlittenbewegung (vgl. Anforderung 9.2 in Tabelle A.1) wird durch einen motorisch angetriebenen Kugelgewindetrieb erzeugt und durch Doppelwagen-Linearführungen geführt. Die Grundplatten der Antriebs- und Lagerbaugruppe werden in einem Abstand von $550 \mathrm{~mm}$ zueinander auf der Oberseite der Prozessetage (vgl. Anforderungen 9.1 / 9.7 / 9.8 in Tabelle A.1) montiert. Bei symmetrischer Ausrichtung des Pulverauftragmoduls an der Prozessrahmenplatte (Breite $498 \mathrm{~mm}$ ) beträgt der Abstand zwischen Prozessrahmenplatte und Grundplatte folglich $26 \mathrm{~mm}$. Im Folgenden werden die Baugruppen des Pulverauftragmoduls beschrieben.

Lagerbaugruppe Die Lagerbaugruppe (vgl. Konstruktionsdetail in Abbildung B.8) ist aufgebaut aus Grundplatte, Doppelwagen-Linearführung und Führungswagenverbinder. Die Grundplatte besitzt die geometrischen Abmessungen von $650 \mathrm{~mm} \times$ $160 \mathrm{~mm} \times 20 \mathrm{~mm}$. Parallel zur Grundplattenlängsseite ist die $580 \mathrm{~mm}$ lange Doppelführungswagen-Profilschienenführung (Artikelnr. SSEL2BLT16-580) der Firma Misumi (vgl. Anforderung 9.6 in Tabelle A.1) über zwei einschraubbare Zentrierstifte mittig auf der Grundplatte positioniert (vgl. Anforderung 9.8 in Tabelle A.1) und mit 13 M3x12 Zylinderschrauben verschraubt. Die zwei gegenüber der Profil- 
schiene leicht vorgespannten Führungswagen, die keinesfalls von der Profilschiene abgezogen werden dürfen, sind über den Führungswagenverbinder miteinander verbunden. Sämtliche M6 Gewindebohrungen, die in den kantennahen Bereichen der Grundplatte verteilt sind, werden zu einem späteren Zeitpunkt für die Montage des Prozessgasgehäuses benötigt.

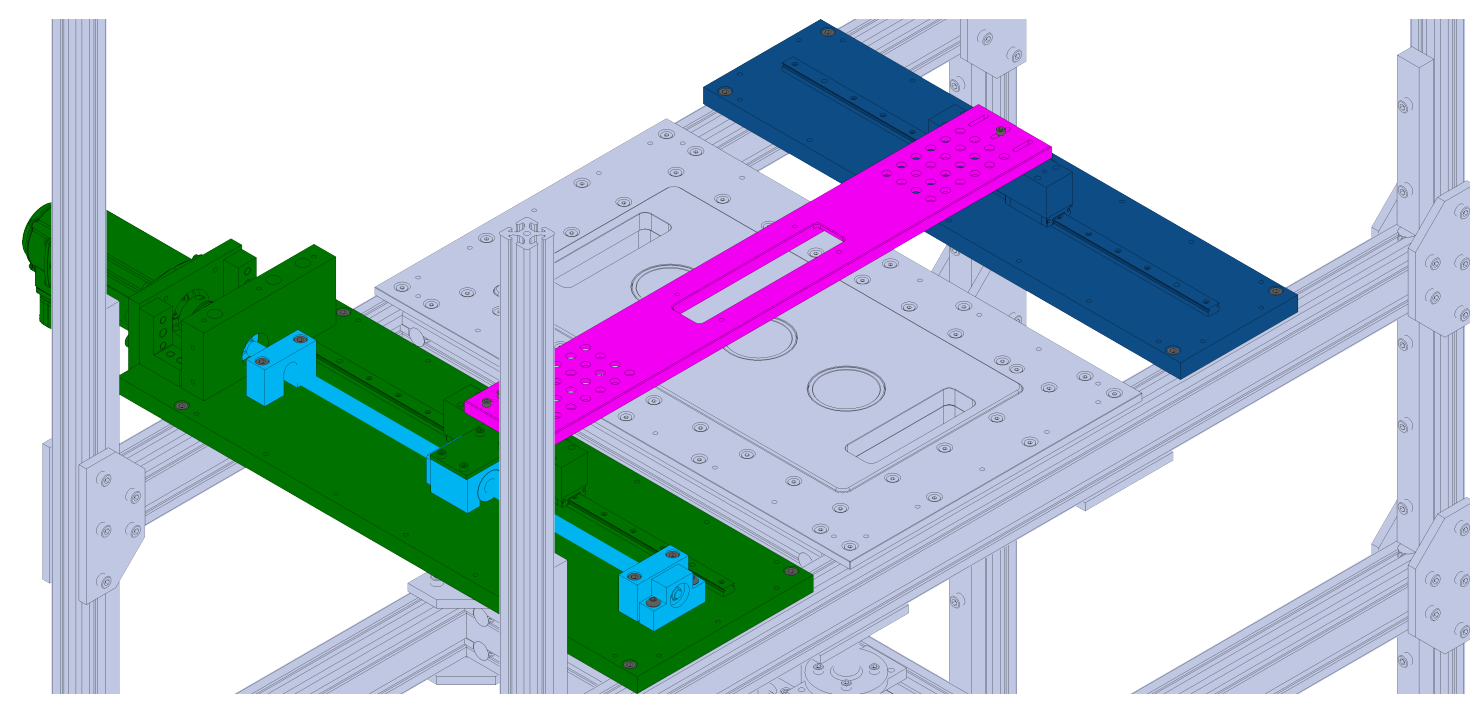

Abbildung 6.10.: Pulverauftragsmodul: Antriebsbaugruppe Kugelgewindetrieb Lagerbaugruppe Auftragsschlitten

Antriebsbaugruppe Die Antriebsbaugruppe (vgl. Konstruktionsdetail in Abbildung B.9) ist aufgebaut aus Grundplatte, Motoraufnahme, Motor, Kugelgewindetrieb, Kupplung, Festlagergehäuse, Doppelwagen-Linearführung, Führungswagenverbinder und einer Gewindetriebmutteranbindung. Die Verwendung der Doppelwagen-Linearführung in Kombination mit dem Führungswagenverbinder entspricht dem in der Lagerbaugruppe (vgl. Anforderung 9.6 in Tabelle A.1) gewählten Aufbau. Die Grundplatte besitzt die geometrischen Abmessungen von $708 \mathrm{~mm} \times 240 \mathrm{~mm} \times 20 \mathrm{~mm}$. Das Festlagergehäuse $(180 \mathrm{~mm} \times 80 \mathrm{~mm} \times 30 \mathrm{~mm})$ dient als Aufnahme $(\varnothing 36 \mathrm{M} 6)$ für das Festlager $(\varnothing 36 \mathrm{~g} 6)$ des Gewindetriebs und ist zugleich eine Wand des Prozessgasgehäuses. Durch die Verwendung von zwei Zylinderstiften wird das Festlagergehäuse vor dem Anziehen der drei M6 Zylinderschrauben auf der Grundplatte positioniert. Der Kugelgewindetrieb, der die rotatorische Bewegung der Motorwelle in eine translatorische Bewegung (vgl. Anforderung 9.3 in Tabelle A.1) der Kugelmutter wandelt, wurde bei der Firma Misumi (Gewindetrieb BSS1520L-640-KLC-K10-S2 mit Kugelmutter / Mutterngehäuse BNFA1520S-23 für die Kugelmutter / Festlager BRWR12 / Loslager BUNR12 / Gummianschläge BSTP12 zur Begrenzung des Verfahrwegs) konfiguriert. Durch die Montage der Gewindetriebmutteranbindung an das Mutterngehäuse des Kugelgewindetriebs wird die Antriebskraft auf den Führungswagenverbinder (vgl. Anforderung 9.7 in Tabelle A.1) über- 
tragen. Das für den Antrieb notwendige Drehmoment wird durch einen Bosch Rexroth Synchron MSK040C-600 Servomotor bereitgestellt und über eine Misumi Scheibenkupplung (Artikelnr. CPDT40-10-14) direkt (vgl. Konstruktionsdetail in Abbildung B.10) auf den Kugelgewindetrieb übertragen. Die absolute Position des Führungswagenverbinders wird aus dem Wert des Multiturn-Motordrehgebers „M1“ und der Gewindetriebsteigung von $20 \mathrm{~mm}$ berechnet. Die Motoraufnahme besteht aus zwei gekürzten Misumi L-Blöcken (Artikelnr. ALB020M) und einer Platte $(190 \mathrm{~mm} \times 140 \mathrm{~mm} \times 15 \mathrm{~mm})$ samt $\varnothing 50 \mathrm{H} 6$ Motorflanschbohrung. Die Positionierung der Motoraufnahmeplatte gegenüber den L-Blöcken bzw. die Motoraufnahme auf der Grundplatte erfolgt durch die Verwendung von insgesamt sechs Zylinderstiften. Die kantennahen M6 Gewindebohrungen werden zu einem späteren Zeitpunkt für die Montage des Prozessgasgehäuses benötigt.

Auftragsschlitten (Aufnahme der Beschichtereinheit) Der außermittig positionierte Antrieb bewirkt ein Drehmoment um die vertikal verlaufende Achse auf den Auftragsschlitten, welches von den auf der Profilschiene laufenden Führungswagen aufgenommen wird. Der Einsatz von zwei Führungswagen pro Profilschiene erhöht das zulässige Moment und gewährleistet ein ruhigeres Führungsverhalten. Die Führungswagen sind über einen Führungswagenverbinder $(160 \mathrm{~mm} \times 36 \mathrm{~mm} \times 37 \mathrm{~mm})$ miteinander verbunden. Der Auftragsschlitten $(700 \mathrm{~mm} \times 100 \mathrm{~mm} \times 15 \mathrm{~mm})$, der auf den Oberseiten der Führungswagenverbinder aufliegt, ist auf dem antriebsseitigen Führungswagenverbinder zweifach gestiftet $(\varnothing 5 \mathrm{~m} 6)$ und mit vier M5x25 Zylinderschrauben verschraubt. Zur Ermöglichung einer ungehinderten Ausdehnung in der Auftragsschlitten-Längsrichtung infolge thermischer Expansion ist die Auflage des Auftragsschlittens auf dem lagerseitigen Führungswagenverbinder konstruktiv als Linearlager (vgl. Konstruktionsdetail in Abbildung B.11) durch die Fertigung von drei $20 \mathrm{~mm}$ Langlöchern ausgeführt. Die Innenflächen der zwei außenliegenden Langlöcher ( $\varnothing 5 \mathrm{~F} 7)$ führen die Auftragsschlitten-Ausdehnungsbewegung bei geringem Spiel in definierter Richtung an den Außenflächen der vier $\varnothing 5 \mathrm{~m} 6$ Zylinderstifte des Führungswagenverbinders auf einem Weg von maximal $\pm 2,5 \mathrm{~mm}$. Zur Montage eines Niederhalters sind zusätzlich drei M5 Gewindebohrungen in den Führungswagenverbinder der Lagerbaugruppe eingebracht. Durch die Freimachungen an der Unterseite des Auftragsschlittens wird das Bauteilgewicht um knapp $50 \%$ verringert. Die Beschichtereinheit wird von oben durch die in der Mitte des Auftragsschlittens befindliche Öffnung $(200 \mathrm{~mm} \times 40 \mathrm{~mm}$ ) eingeführt (vgl. Anforderungen $10.1 / 10.2$ in Tabelle A.1) und mit vier M6 Schrauben befestigt. Der Abstand zwischen der Oberseite des Auftragsschlittens und der Oberseite der Prozesseinsatzplatte beträgt $76 \mathrm{~mm}$.

\section{Beschichtereinheiten (Submodule des Pulverauftragmoduls)}

Zur Durchführung des Pulverauftrags muss eine geeignete Beschichtereinheit ergänzt werden. Zur Montage einer Beschichtereinheit wird die Auftragsschlittenanbindung (vgl. blaues Bauteil der Beschichtereinheit in Abbildung 6.11) auf der Oberseite des Auftragsschlittens positioniert und mit vier M6 Senkschrauben verschraubt. Die Ausrichtung der 
Beschichtereinheit innerhalb der Auftragsschlittenöffnung geschieht geometrisch durch die Formschrägen der Senkbohrungen in der Auftragsschlittenanbindung. Im Folgenden wird die Beschichtereinheit mit starrer Klinge (vgl. (b) Abbildung 6.11), die Beschichtereinheit mit schwingender Klinge (vgl. (c) Abbildung 6.11) und die Beschichtereinheit mit rotierender Rolle (vgl. (d) Abbildung 6.11) beschrieben.

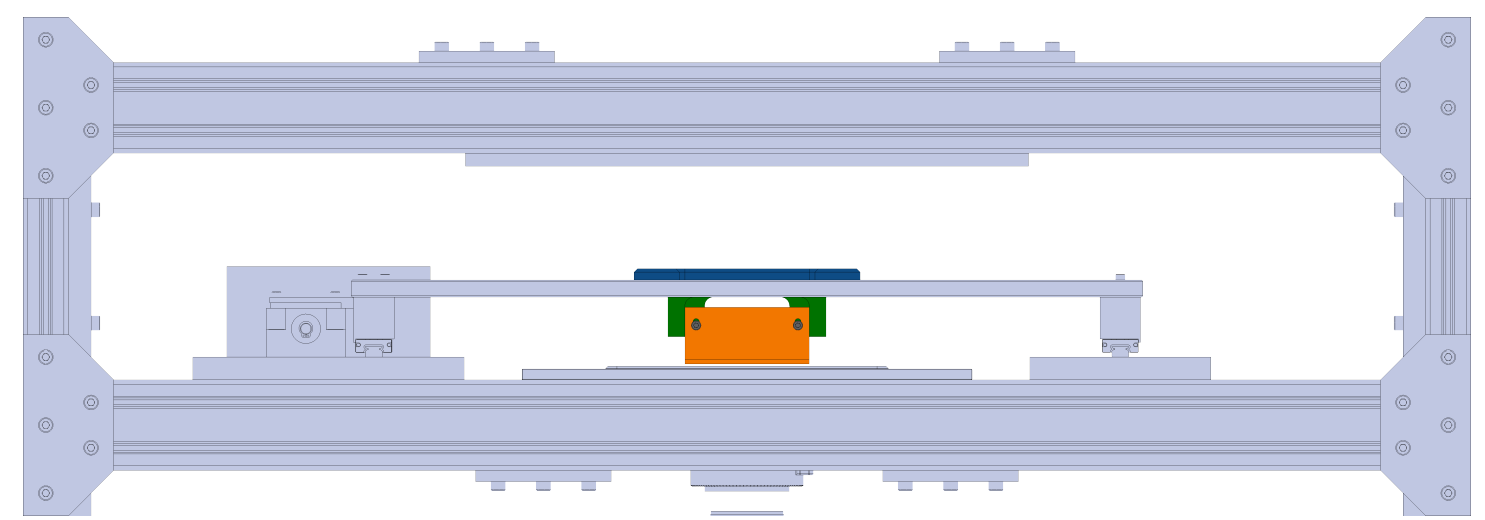

(a) Beschichtereinheit montiert an dem Auftragsschlitten aus dem Pulverauftragsmodul

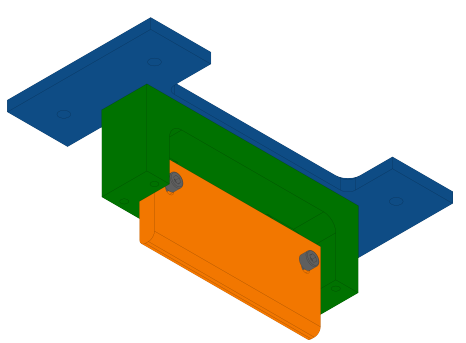

(b) Starre Klinge

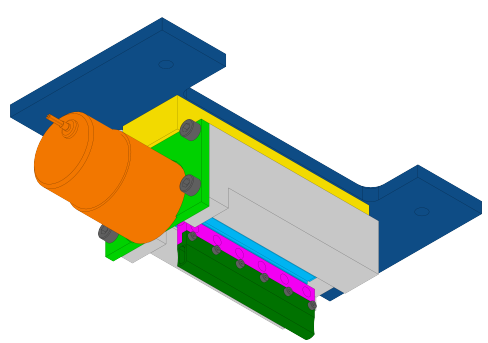

(c) Schwingende Klinge

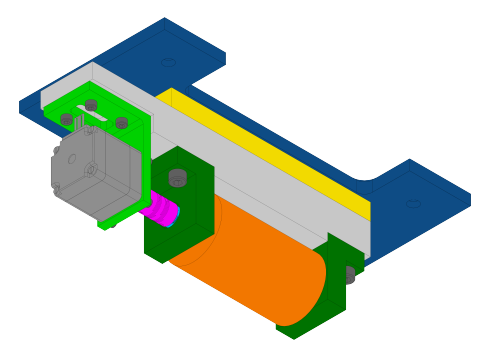

(d) Rotierende Rolle

Abbildung 6.11.: Beschichtereinheiten für das Pulverauftragsmodul

Starre Klinge Die Beschichtereinheit mit starrer Klinge (vgl. Konstruktionsdetail in Abbildung B.12) ist aus Auftragsschlittenanbindung, Klingenaufnahme und einer spezifischen Klinge aufgebaut. Die Klingenaufnahme $(140 \mathrm{~mm} \times 30 \mathrm{~mm} \times 50 \mathrm{~mm})$ ist mit der Auftragsschlittenanbindung zweifach gestiftet und verschraubt. Die Tasche im Bereich der Klinge ist $110 \mathrm{~mm}$ lang, $20 \mathrm{~mm}$ tief, $35 \mathrm{~mm}$ hoch und besitzt Eckradien von $8 \mathrm{~mm}$. Zur Befestigung der Klinge sind zwei M5 Gewindebohrungen in einem Abstand von $90 \mathrm{~mm}$ zueinander bzw. $10 \mathrm{~mm}$ zur Unterseite in die Klingenaufnahme eingebracht. Zur weiteren Gewichtsersparnis ist die Tasche auf einer Länge von $75 \mathrm{~mm}$ über die Höhe von $35 \mathrm{~mm}$ nach hinten geöffnet. Die Klingenkörper $(110 \mathrm{~mm} \times 50 \mathrm{~mm}$ ) sollten aus $10 \mathrm{~mm}$ starken Halbzeugen (vgl. Anforderungen 10.3 / 10.8 in Tabelle A.1) hergestellt werden. Durch die Fertigung von Langlöchern in der Klinge kann der Abstand zur Prozesseinsatzplatte bzw. die aufgetragene Pulverbetthöhe über der Prozesseinsatzplatte bei der Befestigung an der Klingenaufnahme (vgl. Anforderung 10.5 in Tabelle A.1) eingestellt werden. 
Schwingende Klinge Die Beschichtereinheit mit schwingender Klinge (vgl. Konstruktionsdetail in Abbildung B.13) ist aufgebaut aus Auftragsschlittenanbindung, Distanzblock, Fundamentblock, Schwingspulenantrieb, Antriebsaufnahme, Linearführung, Klingenaufnahme und einer Klinge. Die lasergesinterte PA12-Klinge wird durch die Tauchspule quer zur Auftragsrichtung bidirektional (vgl. Anforderung 10.9 in Tabelle A.1) in Bewegung (max. Schwingfrequenz $100 \mathrm{~Hz} /$ max. Amplitude $3 \mathrm{~mm}$ ) versetzt und mit sechs M2x5 Zylinderschrauben an die gefräste Klingenaufnahme geschraubt. Die Miniatur-Linearführung (Artikelnr. MSQ 7-70.58) der Firma Schneeberger ist durch ihre Käfigzwangssteuerung für Beschleunigungen bis $300 \mathrm{~m} / \mathrm{s}^{2}$ geeignet und aus einem Führungswagen mit Wälzkörperleisten und einer Schiene aufgebaut. Zur Befestigung der Klingenaufnahme an die Linearführung sind fünf vertikal verlaufende M2 Gewindebohrungen in die Klingenaufnahme eingebracht. Durch eine Öffnung in dem Führungswagen werden die M2x6 Zylinderschrauben in die Schiene eingebracht, sodass die Oberseite der Klingenaufnahme mit der Unterseite der Linearführungsschiene verschraubt ist. Der Schwingspulenantrieb (Artikelnr. DK-LAS16-23-000A-P01-4E) der Firma Bei Kimco ist an der Antriebsmantelfläche gegenüber der Antriebsaufnahme positioniert und durch zwei zöllige Senkschrauben (8-32 UNCx5/16 Zoll) verschraubt. Das M4 Außengewinde an der Welle des Schwingspulenantriebs wird in das M4 Innengewinde der Klingenaufnahme geklebt und geschraubt. Zur Montage der Beschichtereinheit wird die vormontierte Baugruppe bestehend aus Schwingspulenantrieb, Antriebsaufnahme, Linearführung und Klingenaufnahme an dem Fundamentblock positioniert. In die Oberseite des Fundamentblocks $(106 \mathrm{~mm} \times 60 \mathrm{~mm} \times 40 \mathrm{~mm})$ sind zwölf vertikal verlaufende Formsenkbohrungen eingebracht. Die zwölf M2x16 Zylinderschrauben werden durch den Fundamentblock hindurch in die M2 Gewindebohrungen an der Oberseite des Führungswagens doppelreihig eingeschraubt. Die Antriebsaufnahme wird in horizontaler Richtung durch vier M5x12 Zylinderschrauben mit dem Fundamentblock verbunden. Der Klingenwechsel ist nachträglich (vgl. Anforderung 10.3 in Tabelle A.1) durch eine großzügige Aussparung im Fundamentblock ohne weitere Demontage möglich. Die Gesamthöhe der Beschichtereinheit (vgl. Anforderung 10.5 in Tabelle A.1) wird über die Höhe des Distanzblocks variiert. Die Summe der bewegten Einzelmassen beträgt in etwa $40 \mathrm{~g}$. Ein weiteres Konzept zum Aufbau einer Beschichtereinheit mit einer schwingenden Klinge, zur Umsetzung höherer Schwingfrequenzen bei geringerer Amplitude, basiert auf der Verwendung eines Piezoaktors in Kombination mit einem Dünnblech.

Rotierende Rolle Die Beschichtereinheit mit rotierender Rolle (vgl. Konstruktionsdetail in Abbildung B.14) ist aus Auftragsschlittenanbindung, Distanzblock, Fundamentblock, Schrittmotor, Motoraufnahme, Lagereinheiten, Welle, Kupplung und einer Rolle aufgebaut. Die Beschichtereinheit ist auf einem $34 \mathrm{~mm}$ breiten, 181,5 mm langen und $25 \mathrm{~mm}$ hohen Fundamentblock mit zwei Absätzen $(20 \mathrm{~mm}$ über den Lagereinheiten / $10 \mathrm{~mm}$ über der Motoraufnahme) aufgebaut. Der Fundamentblockbereich über der Rolle ist $74 \mathrm{~mm}$ lang und dient der Ausrichtung der zweifach verschraubten Misumi Lagereinheiten (Artikelnr. BGLKB606ZZ-25). Die Motor- 
aufnahme ist auf einem $50 \mathrm{~mm}$ langen Absatz mit vier M4x12 Zylinderschrauben befestigt. Zur Kabeldurchführung ist sowohl in der Motoraufnahme als auch in dem Fundamentblock ein Langloch eingebracht. Die Absatzlänge auf dem die Lagereinheit im Bereich der Kupplung geschraubt ist, beträgt 39,5 mm. Der Antriebsstrang zur Rotation der Rolle (vgl. Anforderung 10.10 in Tabelle A.1) ist aus einem Nanotec NEMA 11 (Artikelnr. ST2818L1006-A) Schrittmotor, einer Misumi Kupplung (Artikelnr. CPL12-5-6) und einer beidseitig abgesetzten $\varnothing 10 \mathrm{~h} 6$ Welle von Misumi aufgebaut. Der Hybrid-Schrittmotor ist in die Motoraufnahme eingepasst und durch vier M2,5x8 Zylinderschrauben befestigt. Die Rolle wird im Kontaktbereich der $\varnothing 10 \mathrm{H} 7$ Bohrung mit der Welle verklebt, hat einen Außendurchmesser von $38 \mathrm{~mm}$ und ist $68 \mathrm{~mm}$ (vgl. Anforderung 10.3 in Tabelle A.1) lang. Der Fundamentblock ist mit der Auftragsschlittenanbindung (Distanzblock zwischen den beiden Bauteilen) zweifach gestiftet und verschraubt. Die Gesamthöhe der Beschichtereinheit (vgl. Anforderung 10.5 in Tabelle A.1) wird über die Höhe des Distanzblocks variiert.

\section{Prozessgasmodul}

Das Prozessgasmodul ist aus einem Prozessgasgehäuse (vgl. Abbildung 6.12) und einem Prozessgasversorgungssystem samt Sauerstoff-Messsystem (vgl. Abbildung 6.13) aufgebaut. Die beiden Baugruppen werden nacheinander detailliert beschrieben. Das gedichtete Prozessgasgehäuse (vgl. Anforderung 11.2 in Tabelle A.1) ist zwischen der Laser- und Prozessetage montiert und unterteilt sich in türgängige Prozesskammer (bestehend aus Türrahmenplatten, Türbaugruppen und Prozesskammerwandbaugruppen vgl. Konstruktionsdetail in Abbildung B.15), antriebsseitige Nebenkammer, lagerseitige Nebenkammer und zwei Verbindungskammern. Im Folgenden werden die Baugruppen des Prozessgasgehäuses dargestellt.

Türrahmenplatte (Unterbaugruppe der Prozesskammer) Die Türrahmenplatte (vgl. Konstruktionsdetail in Abbildung B.16) besitzt die geometrischen Abmessungen von $398 \mathrm{~mm} \times 356 \mathrm{~mm} \times 10 \mathrm{~mm}$. Die symmetrisch angeordnete Öffnung in der Türrahmenplatte ist $290 \mathrm{~mm}$ breit, $177 \mathrm{~mm}$ hoch und besitzt Eckradien von $10 \mathrm{~mm}$. Die Montage der Türrahmenplatte an das Maschinengestell (vgl. Anforderung 11.4 in Tabelle A.1) geschieht durch das Einschrauben von insgesamt 18 M8 Senkschrauben in die zuvor eingelegten Nutensteine. Die Senkbohrungen sind symmetrisch verteilt und besitzen einen horizontalen Mittelpunktabstand von $45 \mathrm{~mm}$ zueinander. Die insgesamt 20 M6 Gewindebohrungen werden zur Montage der Türbaugruppen (14 Bohrungen) und der Prozesskammerwandbaugruppen benötigt.

Prozesskammerwandbaugruppe (Unterbaugruppe der Prozesskammer) Die Prozesskammerwandbaugruppe (vgl. Konstruktionsdetail in Abbildung B.16) ist aufgebaut aus einer Prozesskammerwand, drei Schaugläsern, zwei $638 \mathrm{~mm}$ langen Winkeln, zwei $168 \mathrm{~mm}$ kurzen Winkeln sowie einer zwischen der Winkelkonstruktion und Wand befindlichen $1 \mathrm{~mm}$ starken Flachdichtung aus Silikon der Härte $40 \pm 5$ Shore A. In die $3 \mathrm{~mm}$ starke Prozesskammerwand $(646 \mathrm{~mm} \times 174 \mathrm{~mm})$ ist eine $540 \mathrm{~mm} \times 35 \mathrm{~mm}$ große Öffnung (Bewegungsbereich des Auftragsschlittens - vgl. Anforderung 11.3 


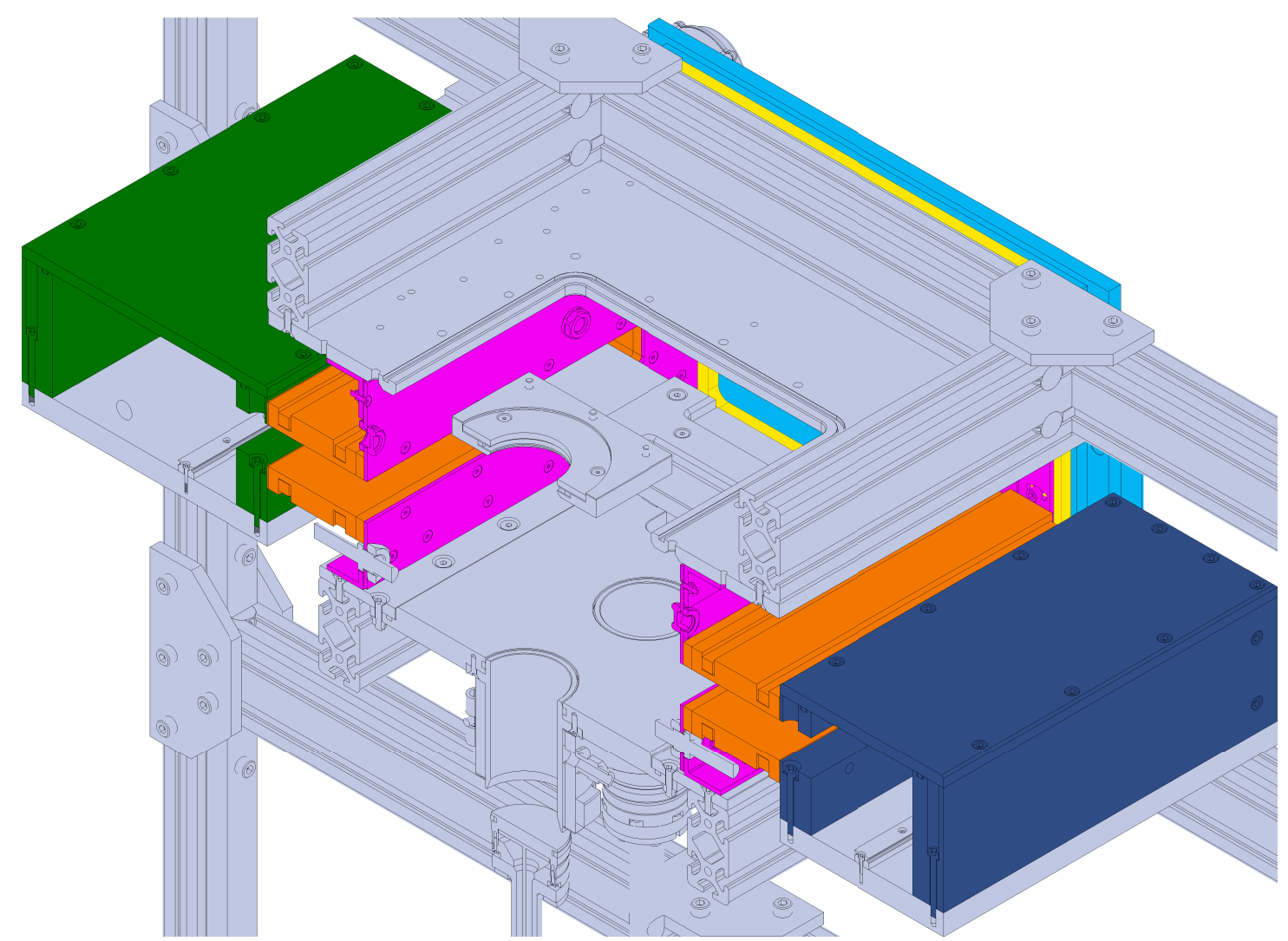

(a) Prozessgasgehäuse montiert zwischen der Laser- und Prozessetage (Schnittansicht)

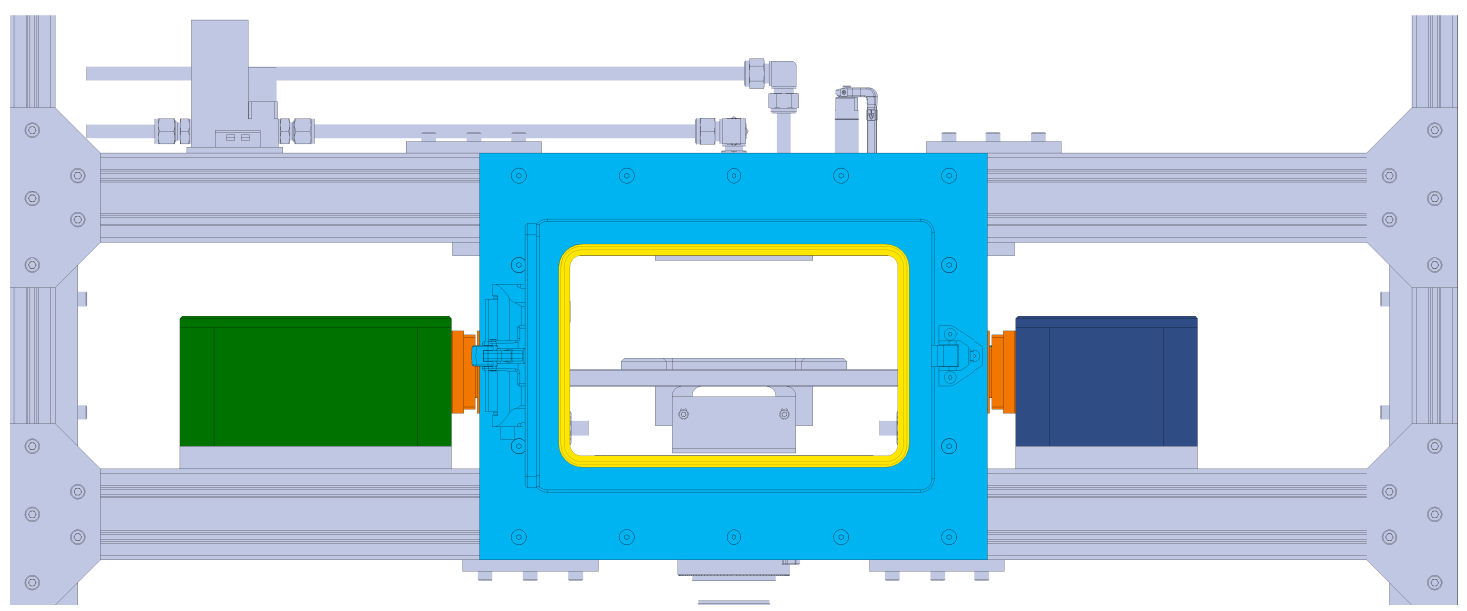

(b) Vorderansicht vom Prozessgasgehäuse mit geöffneten $\left(90^{\circ}\right)$ Prozesskammertüren

Abbildung 6.12.: Prozessgasgehäuse: Türrahmenplatte Antriebsseitige Nebenkammer Verbindungskammer Türbaugruppe Lagerseitige Nebenkammer Prozesskammerwandbaugruppe (ohne Sauerstoffsensoren) 
in Tabelle A.1) und insgesamt $51 \varnothing 4 \mathrm{~mm}$ Senkbohrungen (Anbindung von Verbindungskammer und Winkeln) eingebracht. Die gedichteten Edelstahl-Ölschaugläser (Artikelnr. GN 743.5-11-M16X1,5-B) der Firma Otto Ganter (oberhalb der Prozesskammerwandöffnung) werden durch $\varnothing 16 \mathrm{~mm}$ Bohrungen durchgesteckt und mittels Flachmutter von der Außenseite befestigt. Zur Ausleuchtung des Prozesskammerinnenraums werden kleine LEDs außerhalb der Prozesskammer an der Schauglasaußenseite angebracht. Die Winkel $(35 \mathrm{~mm} \times 35 \mathrm{~mm} \times 4 \mathrm{~mm})$ werden mittels Zylinderschrauben in die dafür vorgesehenen M6 Gewindebohrungen der Prozess-, Laser,- und Türrahmenplatten (vgl. Anforderung 11.5 in Tabelle A.1) eingeschraubt. Die Langlöcher in den Winkeln ermöglichen eine Verschiebung der Prozesskammerwandbaugruppe um maximal $13 \mathrm{~mm}$ in horizontaler Richtung. Die Prozesskammerwand ( $\varnothing 18 \mathrm{~mm}$ Bohrung) und der untere $638 \mathrm{~mm}$ lange Winkel (Freimachung) ist für die Montage eines Sauerstoffsensors vorbereitet.

Türbaugruppe (Unterbaugruppe der Prozesskammer) Eine Türbaugruppe (vgl. Konstruktionsdetail in Abbildung B.17) ist aufgebaut aus Tür, Türinnenblech, Türumrahmung, Schaltscharnier, Türverriegelung, Flachdichtung und 14 Hülsen. Die Türumrahmung $(450 \mathrm{~mm} \times 360 \mathrm{~mm} \times 12 \mathrm{~mm})$ besitzt eine symmetrisch angeordnete $350 \mathrm{~mm} \times 237 \mathrm{~mm}$ (Eckradien $10 \mathrm{~mm}$ ) große Öffnung, in der die $346 \mathrm{~mm} \times 233 \mathrm{~mm} \times$ $10 \mathrm{~mm}$ große Tür (Eckradien $10 \mathrm{~mm}$ ) eingesetzt wird. Tür und Türumrahmung sollen zur Gewichtsreduktion aus einem Aluminiumwerkstoff gefertigt werden. Da bei geschlossener Tür keine Aluminiumoberfläche in den Innenraum der Prozesskammer weisen soll, ist die Tür mit einem Türinnenblech $(344 \mathrm{~mm} \times 231 \mathrm{~mm} \times 3 \mathrm{~mm})$ aus einem hygienegerechten Werkstoff verkleidet. Zur Verringerung der Wärmeübertragung von dem Türinnenblech auf die Tür ist die Auflagefläche im Bereich der Öffnung der Türrahmenplatte durch eine $5 \mathrm{~mm}$ Freimachung in der Tür reduziert. Das Blech (Eckradien $10 \mathrm{~mm}$ ) wird mit M4 Senkschrauben an die Tür geschraubt. Die Sicherheits-Schaltscharniere (Artikelnr. GN 139.5-76-126-B) der Firma Otto Ganter ermöglichen eine durch integrierte Sicherheitsschalter (vgl. Anforderung 11.5 in Tabelle A.1) überwachte Türöffnung. Ab einem zuvor eingestellten Öffnungswinkel werden die insgesamt vier Öffner- und Schließerkontakte in dem Scharnier betätigt, die redundant einen Schutzstromkreis unterbrechen und gleichzeitig ein zusätzliches Signal ausgeben. Das Scharnier ist mit insgesamt sieben M6 Senkschrauben von der Rückseite an Türumrahmung $(4 \times)$ und Tür $(3 \times)$ befestigt. Die Misumi Türverriegelung besteht aus einem Handgriff (Artikelnr. FA-1727) an der Tür und einem Schließblech (Artikelnr. FA-1727S-2) an der Türumrahmung. Beide Bauteile werden mit M5 Senkschrauben an die Außenseite der Türbaugruppe geschraubt. Zur Abdichtung des Türinnenblechs gegenüber der Türrahmenplatte ist zwischen der Türumrahmung und der Türrahmenplatte eine wasserstrahlgeschnittene $10 \mathrm{~mm}$ starke Flachdichtung aus Silikon der Härte $40 \pm 5$ Shore A verbaut. Die Türumrahmung ist durch die Verwendung von 14 gedrehten 10,5 mm hohen Hülsen in einem definierten Abstand zur Türrahmenplatte befestigt. Die Flachdichtung hat eine rechteckige $(410 \mathrm{~mm} \times 350 \mathrm{~mm})$ Außenkontur, eine Öffnung $(310 \mathrm{~mm} \times 197 \mathrm{~mm})$ mit Eckradien von $10 \mathrm{~mm}$ und wird durch ein entsprechendes Bohrmuster an den 
Hülsen positioniert. Wird die Tür mittels Türverriegelung verschlossen, drückt sich das Türinnenblech um 0,5 mm in die nachgiebige Flachdichtung und baut eine dichtende Vorspannkraft auf.

Antriebsseitige Nebenkammer / Lagerseitige Nebenkammer Die Grundplatten der Antriebs- und Lagerbaugruppe des Pulverauftragmoduls sind in einem Abstand von $26 \mathrm{~mm}$ zur Prozessrahmenplatte auf die Prozessetage geschraubt. Sowohl die antriebsseitige (vgl. Konstruktionsdetail in Abbildung B.18) als auch die lagerseitige (vgl. Konstruktionsdetail in Abbildung B.19) Nebenkammer, die jeweils auf die Oberseite der gleichnamigen Grundplatte (vgl. Anforderungen 11.6 / 11.7 in Tabelle A.1) montiert wird, ist aus vier $30 \mathrm{~mm}$ starken Wänden und einem gedichteten $10 \mathrm{~mm}$ starken Deckel aufgebaut. Das integrative Festlagergehäuse der Antriebsbaugruppe dient als $180 \mathrm{~mm}$ breites Wandelement der Nebenkammer. Um die notwendige Gesamthöhe von $105 \mathrm{~mm}$ zum Aufbau der antriebsseitigen Nebenkammer zu erreichen, wird auf das bestehende Festlagergehäuse eine $25 \mathrm{~mm}$ hohe Festlagergehäusewand aufgeschraubt. Die vordere Nebenkammerwand auf der gegenüberliegenden Seite ist $180 \mathrm{~mm}$ breit und $105 \mathrm{~mm}$ hoch. Die Außen- und Innenwände der Kammer sind bei identischer Höhe $650 \mathrm{~mm}$ lang und werden mit je zwei M6 Zylinderschrauben in horizontaler Richtung in die Seiten der kurzen Wandelemente geschraubt. Sowohl die Öffnung in der Innenwand (Bewegungsbereich des Auftragsschlittens - vgl. Anforderung 11.3 in Tabelle A.1) als auch das Bohrmuster (20 Bohrungen) um die Öffnung herum entspricht geometrisch den Spezifikation aus der Prozesskammerwandbaugruppe. Auf den Oberseiten der Wandelemente ist eine durchgängige $3 \mathrm{~mm}$ tiefe und $6 \mathrm{~mm}$ breite Nut zur Verwendung eines $4 \mathrm{~mm}$ Misumi O-Rings (Artikelnr. DFA4-497) eingebracht. Der Deckel $(650 \mathrm{~mm} \times 240 \mathrm{~mm})$ wird mit 20 M6x16 Zylinderschrauben fixiert. Die lagerseitige Nebenkammer ist bis auf wenige Details baugleich zu der antriebsseitigen Nebenkammer. Durch die geringere Breite der vorderen bzw. hinteren Wand von $100 \mathrm{~mm}$ beträgt die Gesamtbreite der Kammer $160 \mathrm{~mm}$. Zur Abdichtung des Deckels $(650 \mathrm{~mm} \times 160 \mathrm{~mm})$ wird ein Misumi O-Ring (Artikelnr. DFA4-446) verwendet.

Verbindungskammer Die symmetrisch aufgebaute Verbindungskammer (vgl. Anforderung 11.8 in Tabelle A.1) besitzt die geometrischen Abmessungen von $578 \mathrm{~mm} \times$ $73 \mathrm{~mm} \times 85 \mathrm{~mm}$ (vgl. Konstruktionsdetail in Abbildung B.20) und wird zur thermischen Entkopplung aus Kunststoff gefräst. Zwischen die Neben- und Verbindungskammer wird eine $1 \mathrm{~mm}$ starke Flachdichtung der Härte $40 \pm 5$ Shore A gelegt. Die $10 \mathrm{~mm}$ starke Flachdichtung auf der gegenüberliegenden Seite dichtet die Verbindungskammer gegenüber der Prozesskammer ab. Die Öffnungen in den Dichtungen und der Verbindungskammer sind identisch (vgl. Anforderung 11.3 in Tabelle A.1) zu den Öffnungen $(540 \mathrm{~mm} \times 35 \mathrm{~mm} /$ Eckradien $5 \mathrm{~mm})$ in der Prozesskammerwand (Prozesskammer) und der Innenwand (Nebenkammer). In einem Abstand von $10 \mathrm{~mm}$ zu den Seitenflächen ist rundum eine $12 \mathrm{~mm}$ breite und $14 \mathrm{~mm}$ tiefe Nut zum Einlegen von Haltespangen eingebracht. Die Haltespangen (Vierkantstangen mit M4 Gewindebohrmuster) werden aus einem Halbzeug mit quadratischem Querschnitt $(10 \mathrm{~mm} \times 10 \mathrm{~mm})$ gefertigt. 
Als Sauerstoff-Messsystem wurde ein aufeinander abgestimmtes System (Zirkoniumdioxid-Sensor XYA5M / Steuerplatine ZBXYAF) der Firma First Sensor ausgewählt. Zur redundanten Messung des Restsauerstoffgehalts innerhalb des Prozessgasgehäuses werden zwei Messsysteme verbaut. Die Sauerstoffsensoren werden an der Prozesskammerwandbaugruppe (vgl. Anforderung 11.11 in Tabelle A.1) befestigt. Das Prozessgasversorgungssystem, dargestellt in Abbildung 6.13, besteht (Benennungsreihenfolge in Strömungsrichtung) aus Gasflasche (nicht dargestellt), Entspannungsstation (nicht dargestellt), Massendurchflussregler, Gaseinlass, Laserglas-Prozessgas-Armatur, Gasauslass und diversen Gasleitungen. Die Baugruppen Gaseinlass, Gasauslass und Laserglas-Prozessgas-Armatur sind an der Lasereinsatzplatte (in Abbildung 6.13 ausgeblendet) aus dem Lasermodul montiert. Im Folgenden werden die Baugruppen des Prozessgasversorgungssystems dargestellt.

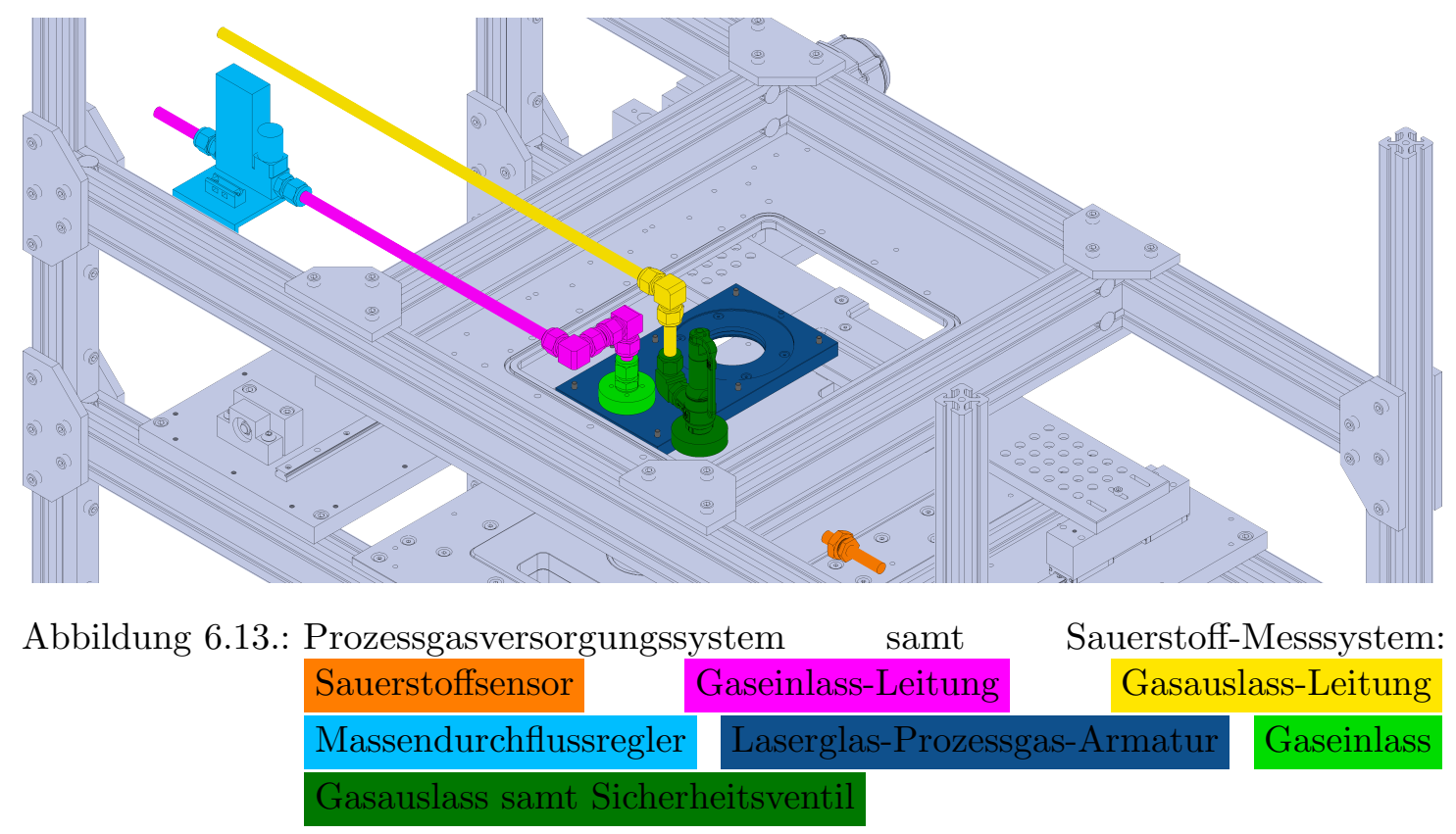

Gasleitungen Für den Aufbau der Gasleitungen werden PFA-Schläuchen (Außendurchmesser $12 \mathrm{~mm}$ ) und Edelstahl-Winkelverschraubungen (Artikelnr. SS-12M0-9) der Firma Swagelok verwendet. Ab der Entspannungsstation sind ausschließlich $12 \mathrm{~mm}$ Rohrverschraubungen (vgl. Anforderung 11.15 in Tabelle A.1) verbaut.

Massendurchflussregler Der Massendurchflussregler (Modell EL-FLOW Prestige / Artikelnr. FG-201CV-RBD-44-K-DA-A1V) der Firma Bronkhorst arbeitet bei einem Vordruck von 5 bar. Das Prozessgas wird massenstromgeregelt in einem Bereich von $0,4 l_{n} / \min$ bis $20 l_{n} /$ min bei einem Nachdruck von 0,3 bar (Überdruck) in die Prozesskammer (vgl. Anforderung 11.14 in Tabelle A.1) eingeleitet. Die Multi-GasFunktion (Kennlinien in der Software hinterlegt) ermöglicht die Verwendung von Stickstoff, Argon oder Helium. Der Massendurchflussregler ist mit 12 mm Klemmringen ausgestattet. Bei der Konfiguration des Reglers wurde die Feldbus-Schnittstelle 
„FLOW-BUS“ zur Kommunikation mit dem cRIO-Steuersystem (LabVIEW-VI im Lieferumfang enthalten) ausgewählt. Der Massendurchflussregler ist über einen Aluminiumwinkel an der Laseretage befestigt.

Gaseinlass / Gasaulass Der Gaseinlass (vgl. Konstruktionsdetail in Abbildung B.21) ist aufgebaut aus Flansch, Dichtscheibe, Einschraubverbindung und einem O-Ring. Der $12 \mathrm{~mm}$ PFA-Schlauch der Zuleitung wird mit der Einschraubverschraubung (Artikelnr. SS-12M0-1-6RS) der Firma Swagelok verbunden. Die gerade Einschraubverschraubung wird mit einem 3/8 Zoll ISO-Außengewinde in den gedrehten Flansch mit entsprechendem $3 / 8$ Zoll ISO-Innengewinde eingeschraubt. Zur Abdichtung der beiden Bauteile gegeneinander wird eine V4A Dichtscheibe mit FKM-Innenring (Artikelnr. SS-6-RSD-2V) der Firma Swagelok verbaut. In den Flansch $(\varnothing 55 \mathrm{~mm} \times 15 \mathrm{~mm})$ sind vier M5 Gewindebohrungen und eine Nut für einen O-Ring eingebracht. Zur Abdichtung gegenüber der Lasereinsatzplatte wird ein Misumi O-Ring (Artikelnr. NPF42) aus FKM verwendet. Der Gasauslass (vgl. Konstruktionsdetail in Abbildung B.22) ist aus Flansch, Dichtscheibe, Sicherheitsventil, Winkeleinschraubverschraubung und einem O-Ring aufgebaut. Flansch, Dichtscheibe und O-Ring sind identisch zum Gaseinlass. Das Sicherheitsventil (Artikelnr. 460tGFL-10-m/f-10/10 FKM) mit manueller Hebelanlüftung der Firma Goetze (vgl. Anforderung 11.18 in Tabelle A.1) öffnet ab einem Überdruck von 0,2 bar. An den Ausgang des Sicherheitsventils ist eine $12 \mathrm{~mm}$ Winkeleinschraubverschraubung (Artikelnr. SS-12M0-2-6PR) der Firma Swagelok (vgl. Anforderung 11.15 in Tabelle A.1) verschraubt.

Laserglas-Prozessgas-Armatur Die Laserglas-Prozessgas-Armatur (vgl. Konstruktionsdetail in Abbildung B.23) ist aufgebaut aus Fundament, Diffusorabdeckung, Laserglas, drei Dichtungen um das Laserglas herum, Flansch und einer Flachdichtung. Die Gasströmung (vgl. Anforderung 11.16 in Tabelle A.1) wird an der Armaturoberseite eingeleitet, innerhalb der Baugruppe um $90^{\circ}$ umgelenkt und durch einen Diffusor hindurch laminar über die Unterseite des $\varnothing 80 \mathrm{~mm} \times 3 \mathrm{~mm}$ großen Laserglases (Lasermodul) geführt. Das Fundament $(248 \mathrm{~mm} \times 140 \mathrm{~mm} \times 15 \mathrm{~mm})$ ist symmetrisch aufgebaut und wird durch Zylinderstifte an der Lasereinsatzplatte positioniert. Zwischen Fundament und Lasereinsatzplatte ist eine $1 \mathrm{~mm}$ starke Flachdichtung aus Silikon eingelegt, die durch das Anziehen der sechs M5x22 Senkschrauben verpresst wird. Unter der Diffusorabdeckung $(122 \mathrm{~mm} \times 85 \mathrm{~mm} \times 4 \mathrm{~mm})$ ist die Kontur des Diffusors mit einer Frästiefe von 0,9 mm eingebracht. Auf einer Länge von 112,5 mm (Abstand zwischen Mittelpunkt Gaseinlass und Austrittskante Diffusorabdeckung) erweitert sich der Strömungsquerschnitt von $10 \mathrm{~mm}$ auf $65 \mathrm{~mm}$ Breite. Das Laserglas wird über die Oberseite der Baugruppe eingesetzt und ist im Kontaktbereich zu anderen Bauteilen rundum mit FKM-Dichtungen der Härte $90 \pm 5$ Shore A von der Firma Misumi (Artikelnr. FRFF1A1-A90-V65 / FRFF1A3-A90-V80 / FRFF1A1-A119-V65) geschützt. Die Fundamentdichtung wird vor dem Einbau C-förmig aufgeschnitten. Durch die Montage des $5 \mathrm{~mm}$ starken Flanschs (Innendurchmesser $65 \mathrm{~mm}$ / Außendurchmesser 119,5 mm) entsteht die dichtende Vorspannkraft am Laserglas. 


\section{Lasermodul}

Das Lasermodul, dargestellt in Abbildung 6.14, besteht aus Lasereinsatzplatte, Lasermodul-Demonstrator (Laser-Scanner-Dummy) samt Halterung und Laserglas. Die Kamera samt Kameraglas-Armatur ist nicht zwangsweise dem Lasermodul zuzuordnen, wird jedoch als Anbauteil im Bereich der Lasereinsatzplatte entsprechend mit dargestellt. Der Laser-Scanner-Dummy kann aufgrund der geringen Leistung des verbauten Pilotlasers nicht zum Aufschmelzen von Kunststoffen verwendet werden. Im Folgenden werden die Baugruppen des Lasermoduls dargestellt.

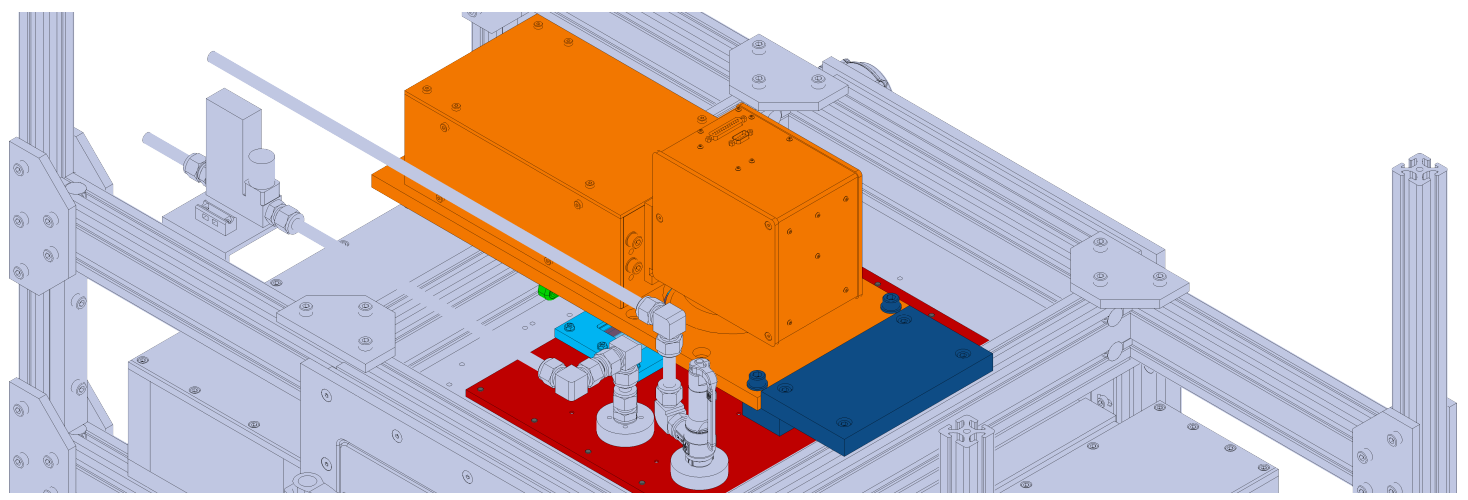

(a) ISO-Ansicht vom Lasermodul montiert an der Laseretage

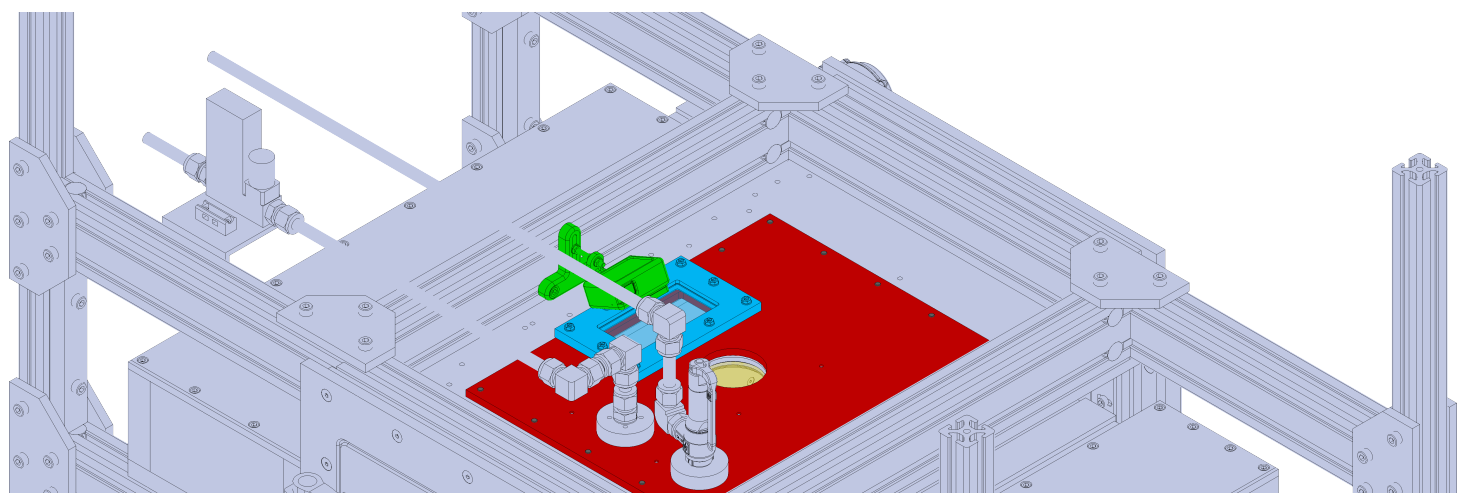

(b) ISO-Ansicht vom Lasermodul bei demontiertem Laser-Scanner-Dummy

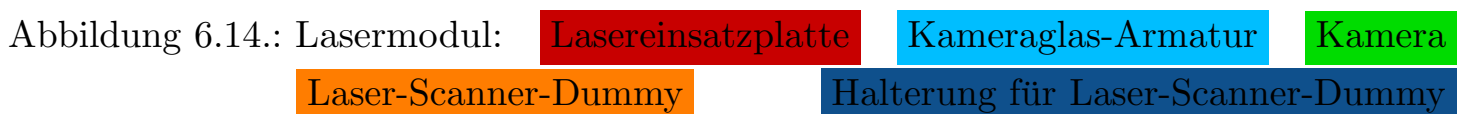
Laserglas

Lasereinsatzplatte Die Lasereinsatzplatte (vgl. Konstruktionsdetail in Abbildung B.24) besitzt die geometrischen Abmessungen von $410 \mathrm{~mm} \times 310 \mathrm{~mm} \times 8 \mathrm{~mm}$, wird von der Oberseite auf die Laserrahmenplatte der Laseretage (vgl. Anforderung 12.1 in Tabelle A.1) aufgelegt, mit bis zu vier $\varnothing 5 \mathrm{~h} 7$ Zylinderstiften gegenüber der Laserrahmenplatte positioniert und mit 20 M6x20 Senkschrauben verschraubt. Auf 
der Oberseite der Lasereinsatzplatte ist der Gaseinlass (Prozessgasmodul), der Gasauslass (Prozessgasmodul) und eine Kameraglas-Armatur befestigt. Auf der Unterseite der Lasereinsatzplatte ist eine Laserglas-Prozessgas-Armatur (Prozessgasmodul) verschraubt. Das Bohrmuster der vier $\varnothing 5 \mathrm{H} 7$ Passbohrungen und der 20 M6 Gewindebohrungen in der Lasereinsatzplatte entspricht dem Bohrmuster der Laserrahmenplatte (Maschinengestell). Beim Anziehen der Senkschraube wird der zuvor eingelegte O-Ring der Rahmenplatte verpresst und dichtet die Bauteile gegeneinander ab. Die $\varnothing 65 \mathrm{~mm}$ Bohrung in der Mitte der Lasereinsatzplatte ist konzentrisch über dem Bauvolumen angeordnet. Zur Befestigung der Laserglas-Prozessgas-Armatur sind sechs durchgängige M5 Gewindebohrungen in die Lasereinsatzplatte eingebracht. Zur Positionierung der beiden Bauteile gegeneinander sind zwei weitere $\varnothing 5 \mathrm{H} 7$ Passbohrungen (Bohrtiefe $6 \mathrm{~mm}$ ) von der Unterseite in die Lasereinsatzplatte eingebracht. Im Bereich der Kameraglas-Armatur ist eine Öffnung $(110 \mathrm{~mm} \times 55 \mathrm{~mm})$ symmetrisch zur Mittellinie in die Lasereinsatzplatte eingebracht. Die zehn M5 Gewindebohrungen (Gewindetiefe $6 \mathrm{~mm}$ ) in der Lasereinsatzplatte dienen zur Befestigung der Kameraglas-Armatur. Zur Ein- und Ausleitung des Prozessgases befinden sich $10 \mathrm{~mm}$ Bohrungen unterhalb von Gaseinlass und Gasauslass. Diese Baugruppen werden von der Unterseite der Lasereinsatzplatte mit jeweils vier M5 Senkschrauben befestigt.

Laserglas Das Laserglas wird in die Laserglas-Prozessgas-Armatur aus dem Prozessgasmodul eingesetzt, hat einen Durchmesser von $80 \mathrm{~mm}$, eine Dicke von $3 \mathrm{~mm}$, ist beidseitig optisch geschliffen und Druckfest bis 0,7 bar Überdruck. Das Fenster aus Zinkselenid der Firma II-VI ist eine Sonderanfertigung und transmittiert durch eine entsprechende Beschichtung elektromagnetische Strahlung einer Wellenlänge von $9 \mu \mathrm{m}$ bis $11 \mu \mathrm{m}$ (Kohlenstoffdioxidlaser - vgl. Anforderungen 12.2 / 12.3 in Tabelle A.1) annähernd verlustfrei.

Laser-Scanner-Dummy samt Halterung Zu Demonstrations- und Lehrzwecken wurde ein ausgesondertes (vgl. Anforderung 12.7 in Tabelle A.1) Lasermarkiersystem in seine Einzelkomponenten zerlegt, geprüft und zu einem funktionsfähigen Laser-Scanner-Dummy rekombiniert. Das Lasermarkiersystem „Mistral“ wurde im Jahre 2008 durch die Firma NWL unter anderem aus den folgenden Komponenten hergestellt:

- Photon Energy Nd:YAG Laserstrahlquelle (defekt) / Typ: DL ARIES HB / $P_{\mathrm{L}}=8 \mathrm{~W} / \lambda=1064 \mathrm{~nm} /$ externe Wasserkühlung

- Pilotlaser (Laserpointer) / sichtbar / $P_{\mathrm{L}}=2 \mathrm{~mW} / \lambda=635 \mathrm{~nm}$ (rot)

- Linos Strahlaufweiter / Artikelnr. 4401-359-000-20 / 2 - 8 fach / $\lambda=1064 \mathrm{~nm}$

- Scanlab Galvanometer-Scanner / Typ: hurrySCAN II $14 / \lambda=1064 \mathrm{~nm}$

- F-Theta-Linse / Brennweite $300 \mathrm{~mm}$

Der Laser-Scanner-Dummy (vgl. Konstruktionsdetail in Abbildung B.25) ist aufgebaut aus (vgl. Anforderung 12.6 in Tabelle A.1) Grundplatte, Scanner, Scanner-Anbindung, Strahlaufweiter samt Justagevorrichtung und einem Pilotlaser samt 
Aufnahme. Die rechteckige Grundplatte besitzt die geometrischen Abmessungen von $520 \mathrm{~mm} \times 210 \mathrm{~mm} \times 15 \mathrm{~mm}$. Im Bereich des Scanners ist eine $\varnothing 130 \mathrm{~mm}$ Bohrung in die Grundplatte eingebracht, dessen Mittelpunkt einen Abstand von 137,85 mm zur vorderen Grundplattenfläche besitzt und um 2,58 mm zur vertikalen Längssymmetrieebene versetzt ist. Die Höhe der optischen Achse oberhalb der Grundplatte beträgt $58 \mathrm{~mm}$ und ist geometrisch bestimmt durch die Wiederverwendung der Justagevorrichtung des einstellbaren Strahlaufweiters. Die Scanner-Anbindung wird auf Strahleintrittsseite an der Stirnplatte des Scannergehäuses befestigt und ist aus einer Platte $(170 \mathrm{~mm} \times 105 \mathrm{~mm} \times 15 \mathrm{~mm})$ sowie zwei Misumi L-Blöcken (Artikelnr. ALB380M) aufgebaut. Zur eindeutigen Positionierung des Scanners samt Scanner-Anbindung gegenüber der Grundplatte sind insgesamt acht $\varnothing 6 \mathrm{~m} 6$ Zylinderstifte verbaut. Die Platte der Anbindung ist zweifach an die Stirnplatte des Scanners gestiftet und mittels M6x25 Zylinderschrauben befestigt. Die L-Blöcke sind vierfach gegenüber der Anbindungsplatte gestiftet und verschraubt (M8x35) bzw. zweifach gegenüber der Grundplatte gestiftet und vierfach verschraubt (M8x25). Der lotrechte Strahlaustrittspunkt aus der F-Theta-Linse liegt ca. $28 \mathrm{~mm}$ unterhalb der Grundplatte im Mittelpunkt der $\varnothing 130 \mathrm{~mm}$ Bohrung. Zur Befestigung der Justagevorrichtung werden zwei M6x50 Zylinderschrauben mit Unterlegscheibe und Sechskantmutter verwendet. Die Aufnahme $(72 \mathrm{~mm} \times 40 \mathrm{~mm} \times 10 \mathrm{~mm})$ für den Pilotlaser mit Aufhängung ist mittels M6x25 Zylinderschrauben von der Grundplattenunterseite auf der Grundplatte befestigt. Zur Montage des Laser-Scanner-Dummys auf die Oberseite der Laseretage (vgl. Anforderung 12.5 in Tabelle A.1) wird eine zusätzliche Halterung benötigt. Bei korrekter Ausrichtung der Halterung befindet sich die Mantelfäche der F-Theta-Linse konzentrisch über dem Bauvolumen. Die Halterung besteht aus einem Anschlag $(200 \mathrm{~mm} \times 112,15 \mathrm{~mm} \times 20 \mathrm{~mm})$ mit Durchgangslöchern und einer Auflage $(200 \mathrm{~mm} \times 50 \mathrm{~mm} \times 20 \mathrm{~mm})$ mit M8 Gewindebohrungen. Ist die Grundplattenvorderseite des Laser-Scanner-Dummys deckungsgleich an Anschlagsrückseite der Halterung ausgerichtet, beträgt der Abstand zwischen der Vorderseite der Halterung und dem lotrechten Strahlaustrittspunkt $250 \mathrm{~mm}$. Der konstruktiv bedingte Versatz von $2,58 \mathrm{~mm}$ zur vertikalen Längssymmetrieebene des Laser-Scanner-Dummys muss bei der Montage der Halterung entsprechend kompensiert werden.

Kamera samt Kameraglas-Armatur Unterhalb des Laser-Scanner-Dummys ist eine GoPro (Artikelnr. HERO5 Black) Kamera (vgl. (b) Abbildung 6.14) an die Profilinnenseite der Laseretage mit einer einstellbaren Halterung montiert. Die Weitwinkelkamera (vgl. Anforderung 12.4 in Tabelle A.1) zeichnet über eine USB 3.0 Schnittstelle den Lasersinterprozess durch die Kameraglas-Armatur hindurch auf. Die Kameraglas-Armatur ist aus Rahmen, Glas und Flachdichtungen aufgebaut. Der Rahmen $(170 \mathrm{~mm} \times 108 \mathrm{~mm} \times 10 \mathrm{~mm})$ ist symmetrisch konstruiert und besitzt eine $110 \mathrm{~mm} \times 58 \mathrm{~mm}$ große Öffnung mit $3 \mathrm{~mm}$ Eckradien. Auf der Rückseite ist eine $6 \mathrm{~mm}$ tiefe Aussparung $(142 \mathrm{~mm} \times 80 \mathrm{~mm})$ eingebracht, um das hitzebeständige Glas (Artikelnr. FGLKH5-138-76) der Firma Misumi samt 1 mm Flachdichtungen einlegen zu können. 


\subsubsection{Fertigungs- und Montagevorbereitung}

Zur Fertigungs- und Montagevorbereitung werden Zeichnungen, Stücklisten und Montageanleitungen der in Abschnitt 6.2.1 dargestellten Bauteile und Baugruppen erstellt. Zur Erfüllung der generellen Anforderungen aus dem medizinischen Gerätebau (3. Anforderungsgruppe aus Tabelle A.1) müssen zur Fertigung der Bauteile hygienegerechte Werkstoffe ausgewählt werden. Eine Beeinflussung der Kosten bei der Fertigung qualitativ hochwertiger Oberflächenbeschaffenheiten ist in der Regel durch die Identifikation geeigneter Halbzeuge möglich. Im Folgenden wird die Auswahl von Werkstoffen und Halbzeugen bzw. die Hinweise zur Fertigung und Montage dargestellt.

\section{Auswahl von Werkstoffen und Halbzeugen}

Aufgrund der Nähe zum Fertigungsprozess und dem damit verbundenen Kontaminationsrisiko der additiv gefertigten Implantatmatrizen ist im Speziellen auf eine hygienegerechte Werkstoffauswahl für sämtliche Bauteile innerhalb und in unmittelbarer Nähe der Prozesskammer zu achten. Aufgrund der Verfügbarkeit, Korrosionsbeständigkeit, Schweißbarkeit und Zerspanbarkeit wird der säurebeständige A4 Edelstahl 1.4404 (X2CrNiMo17-12-2) als geeigneter Konstruktionswerkstoff ausgewählt. Die Prozessrahmenplatte, Prozesseinsatzplatte, Baustempelgehäuse, Pulverzuführgehäuse, Überlaufbehälter, Stempelbaugruppen, Auftragsschlitten, Laserrahmenplatte, Türrahmenplatten, Prozesskammerwände, Türinnenbleche, Gaseinlassflansch und Gasauslassflansch werden entsprechend aus 1.4404 gefertigt. Zur Reduktion des Zerspanvolumens wird für die Herstellung der Baustempel- und Pulverzuführgehäuse ein gewalztes Dickwandrohr (Außendurchmesser $118 \mathrm{~mm}$ / Innendurchmesser $63 \mathrm{~mm}$ ) der Firma Cochius als Halbzeug verwendet. Zur kostengünstigen Fertigung der $3 \mathrm{~mm}$ starken Prozesskammerwände werden geschliffene (240er Korn) und schutzfolierte Edelstahlbleche genutzt. Sämtliche Winkel der Prozesskammerwandbaugruppe werden aufgrund von Lieferschwierigkeiten des präferierten 1.4404 aus einem A2 Edelstahl 1.4301 (X5CrNi18-10) als Alternativwerkstoff gefertigt. Die Protoypen der Beschichtereinheiten werden zur Durchführung erster Pulverauftragsversuche zunächst aus Aluminium bzw. faserverstärktem Kunststoff (Walzen-Auftragskörper) gefertigt. Aufgrund der produktberührten Oberflächen müssen diese Baugruppen vor der Herstellung der Implantatmatrizen aus hygienegerechten Werkstoffen wiederholt gefertigt und ersetzt werden. Die Verbindungskammern werden aufgrund der hervorragenden thermischen Eigenschaften (Dauergebrauchstemperatur ca. $260^{\circ} \mathrm{C}$ ) aus FDA-konformen Polytetrafluorethylen (PTFE) gefertigt. Analog zu den Beschichtereinheiten besitzen die Laserglas-Prozessgas-Armatur und Lasereinsatzplatte einen prototypischen Status und werden aus Kostengründen zunächst aus Aluminium gefertigt. Insbesondere bei der Nachrüstung eines materialspezifischen Lasermoduls wird es zu Anpassungen an der Lasereinsatzplatte kommen. Die Baugruppen innerhalb und in unmittelbarer Nähe der Nebenkammern sowie die Bereiche oberhalb und unterhalb der Prozesskammer können als nicht-produktberührte Oberflächen aus weitaus günstigeren und besser zerspanbaren Konstruktionswerkstoffen hergestellt werden. Diesbezüglich werden feingefräste und schutzfolierte Halbzeuge aus Aluminiumlegierungen der 5000er (Hauptlegierungselement 
Magnesium / mittlere Festigkeit) bzw. der 7000er (Hauptlegierungselement Zink / hohe Festigkeit) Serie verarbeitet [DIN EN 573-3]. Die Tür, Türumrahmung, lagerseitige Nebenkammer, antriebsseitige Nebenkammer, Bauteile des Laser-Scanner-Dummys und die prototypische Lasereinsatzplatte werden aus EN AW-5083 (AlMg4,5Mn) gefertigt. Zum Aufbau des Maschinengestells (Knotenbleche / Sockelversteifungen / Abstandhalter) werden Halbzeuge aus EN AW-7019 (AlZn4Mg2) verwendet. Die Grundplatten der Antriebsund Lagerbaugruppe (Pulverauftragsmodul) werden aus EN AW-7021 (AlZn5,5Mg1,5) gefertigt. Zur Fertigung von Festlagergehäuse (Antriebsbaugruppe), Motoraufnahme (Antriebsbaugruppe), Aufnahmeplatten (Hubantriebsbaugruppenpaket) und der Haltespangen (Verbindungskammer) wird der hochfeste Aluminiumwerkstoff EN AW-7075 (AlZn5,5MgCu) ausgewählt.

\section{Hinweise zur Fertigung und Montage}

Zur Montage der Lasersintermaschine werden fast ausschließlich Schrauben mit Innensechskant aus säurebeständigem A4 Edelstahl verwendet. Zur Gestaltung der verschiedenen Bohrungstypen innerhalb der Bauteile wurden die Normen für Senkschrauben mit Innensechskant nach DIN EN ISO 10642 [DIN EN ISO 10642] (Nachfolgedokument der DIN 7991), Zylinderschrauben mit Innensechskant nach DIN EN ISO 4762 [DIN EN ISO 4762] (Nachfolgedokument der DIN 912), Zylinderschrauben mit niedrigem Kopf mit Innensechskant nach DIN 6912 [DIN 6912] und Schrauben mit abgeflachtem Halbrundkopf (Linsenkopf) mit Innensechskant nach DIN EN ISO 7380 [DIN EN ISO 7380-1] berücksichtigt. Insbesondere bei der Verarbeitung von plattenförmigen Halbzeugen mit einer geringen Wandstärke oder hoher Elastizität wurde das Laser- bzw. Wasserstrahlschneiden zur Herstellung von Prozesskammerwänden (Stärke $3 \mathrm{~mm}$ ) oder Flachdichtungen (Härte 40 bis $80 \pm 5$ Shore A) als geeignetes Fertigungsverfahren identifiziert. Die 51 Formsenkungen für die M4 Senkschrauben in der Prozesskammerwand werden nachträglich mit einem Kegelsenker auf einer Säulenbohrmaschine mit Bohrtiefenabschaltung eingebracht. Die Bauteile sind allesamt dreh- oder fräsgerecht gestaltet. Die Rahmenplatten werden zur Erhöhung der Ebenheit und Parallelität (vgl. DIN EN ISO 1101 [DIN EN ISO 1101]) allseitig spanabhebend und in einer Aufspannung in einer CNC-Fräsmaschine mit entsprechendem Verfahrweg übergefräst. Die Montage der gesamten Lasersintermaschine entspricht der in Abschnitt 6.2.1 dargestellten Reihenfolge, die bei der Gestaltung der spezifischen Module angewendet wurde. Bei dem Sägezuschnitt der stranggepressten Aluminiumprofile für das Maschinengestell sind Längenunterschiede gleicher Profile in jedem Fall zu vermeiden. Der Einbau einer „Übermaßetage“ in den „Untermaßgrundrahmen“ würde zu einer erheblichen Schiefstellung der vertikal angeordneten Aluminiumprofile führen. Profile gleicher Länge müssen daher bei fixiertem Anschlag an der Säge hintereinander zugeschnitten werden. Bei der Fertigung der Abstandhalter (4er-Sets) werden die Halbzeuge nebeneinander in einer CNC-Fräsmaschine aufgespannt, in einem Arbeitsgang gefräst und abschießend mit Bohrungen versehen. Zur Vermeidung von Montagefehlern muss der Zusammenbau des integralen Maschinengestells unter Vorspannung auf einer großen Richtplatte erfolgen. Beim Stapeln der Etagen innerhalb des Grundrahmens sind die Grenzabmaße der Profile zu beachten. Gemäß der Norm für stranggepresste 
Präzisionsprofile [DIN EN 12020-2] sind Höhenabweichungen von $\pm 0,45 \mathrm{~mm}$ (bei $80 \mathrm{~mm}$ hohen Profilen) zulässig, die bei einer Maßkettenrechnung berücksichtigt werden müssen [DIN EN 12020-2, S. 7] [ite16, S. 680] [WMJ+15, S. 36]. Zur Reduktion des Maßkettenfehlers sollte bei der Zusammenstellung der Komponenten für den Etagenbau auf ein möglichst gleichmäßiges Profilgrenzabmaß geachtet werden. Bei der Montage der Stempelbaugruppe auf die Hubantriebsbaugruppe muss zunächst die Abstandshantel auf der Jochplatte der Führungseinheit (axial ausgerichtet am Baustempel- bzw. Pulverzuführgehäuse) fest verschraubt werden. Die Unterbaugruppe aus Stempeloberteil, Kolbendichtung, Silikonheizmatte und Befestigungsscheibe ist montiert und liegt lose auf der Oberseite der Abstandshantel auf. Mit lose angesetzter Klemmscheibe wird die gesamte Stempelbaugruppe in vertikaler Richtung mit geringer Geschwindigkeit durch die Hubantriebsbaugruppe in die Einführschräge der Baustempel- bzw. Pulverzuführgehäuse verfahren. Durch die zunächst konisch verlaufende Gehäuseinnenwand wirkt im Kontaktbereich der Kolbendichtung eine Wandreaktionskraft auf die Stempelunterbaugruppe, durch die eine konzentrische Ausrichtung (Selbstzentriereffekt) der Stempelbaugruppe innerhalb der Baustempel- bzw. Pulverzuführgehäuse erfolgt. Abschließend werden die Zylinderschrauben an der Klemmscheibe angezogen. Bei der Montage des Prozessgasgehäuses müssen alle ungedichteten Fugen der Prozess- und Nebenkammern nachträglich abgedichtet werden. Dafür wird ein hitzebeständiger FDA-konformer Silikonkleber der Firma Wacker Chemie (Artikelnr. Elastosil E43 N) aus einer Kartusche auf die betroffenen Flächen aufgetragen und mit einem Fugenspachtel geglättet. Vor der Erstinbetriebnahme des Laser-Scanner-Dummys müssen Pilotlaser und Strahlaufweiter durch eine Justierung der durch Federringe vorgespannten 3-Punkt-Lagerungen ausgerichtet werden. 


\section{Auswahl der materialspezifischen Laser-Scanner-Einheit am Beispiel PLGA}

Die im Rahmen internationaler Forschung verarbeiteten bioresorbierbaren Werkstoffe zum Lasersintern von Implantatmatrizen sind im Stand der Wissenschaft in Abschnitt 3.3 ausführlich dargestellt. S. Hoeges et al. führten im „Resobone“-Projekt (vgl. Abschnitt 3.3.5) an den Werkstoffen PLA/TCP, Henchglas/TCP, TCP und PLA spektrometische Untersuchungen durch und rüsteten aufgrund der höheren, materialspezifischen Absorptionen

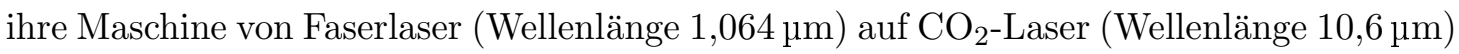
um [Hög10, S. 33-34]. Alle Komponenten einer optischen Bank sind spezifisch für den Betrieb innerhalb eines schmalen Wellenlängenbereichs ausgelegt. Durch den Austausch der Strahlquelle müssen Strahlaufweiter, Galvano-Scanner und Lasereinkoppelfenster ebenfalls getauscht werden. M. Bullemer et al. verarbeiteten PLA/TCP/PCC im darauffolgenden „ActiveBone“-Projekt mit einem $30 \mathrm{~W} \mathrm{CO}_{2}$-Laser (Wellenlänge 10,6 $\mu \mathrm{m}$ ), der ausschließlich im unteren Leistungsbereich betrieben wurde. Da eine Strahlquelle nicht stufenlos regelbar ist, wurde die Verwendung eines $\mathrm{CO}_{2}$-Lasers mit einer maximalen Leistung von $10 \mathrm{~W}$ abschließend als Modifikationsvorschlag genannt [BPL+16, S. 54-55]. Neben der ausschließlich verwendeten Wellenlänge von 10,6 $\mu \mathrm{m}$ (Standard in industriellen Lasersintermaschinen) sind die Kohlenstoffdioxidlaser in der Regel auch mit einer Wel-

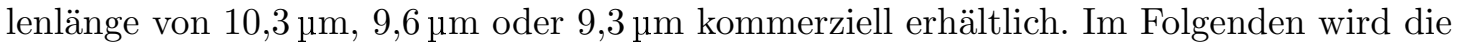
Auswahl einer materialspezifischen Laser-Scanner-Einheit am Beispiel von PLGA, einem bioresorbierbaren Copolymer aus Polymilchsäure (PLA) und Polyglycolsäure (PGA), exemplarisch durchgeführt. Untersucht werden dazu die nachfolgenden, kommerziell erhältlichen Werkstoffe:

Evonik Resomer ${ }^{\circledR}$ RG 755 S ist ein Poly(D,L-Lactide-co-Glycolic Acid) mit einem Molverhältnis PDLLA zu PGA von 75:25. Die logarithmische Viskosität des amorphen Polymers beträgt laut Messprotokoll 0,59 dl/g. Die Zersetzungstemperatur liegt bei $150^{\circ} \mathrm{C}$ [Evo17c] [Evo15] [Evo14].

Corbion Purac Purasorb ${ }^{\circledR}$ PLG 8523 ist ein Poly(L-Lactide-co-Glycolic Acid) mit einem mittleren Molverhältnis PLLA zu PGA von 85:15. Die logarithmische Viskosität des amorphen Polymers beträgt im Mittel 2,3 dl/g [Cor15a].

Corbion Purac Purasorb ${ }^{\circledR}$ PLG 8531 ist ein Poly(L-Lactide-co-Glycolic Acid) mit einem mittleren Molverhältnis PLLA zu PGA von 85:15. Die logarithmische Viskosität des amorphen Polymers beträgt im Mittel 3,1 dl/g [Cor15b].

Die genannten Copolymere sind für den medizintechnischen Einsatz FDA-zertifiziert [Evo17a] [Evo17b] [ES09, S. 358]. Die Werkstoffe sind nicht spezifisch als Ausgangsmaterial 


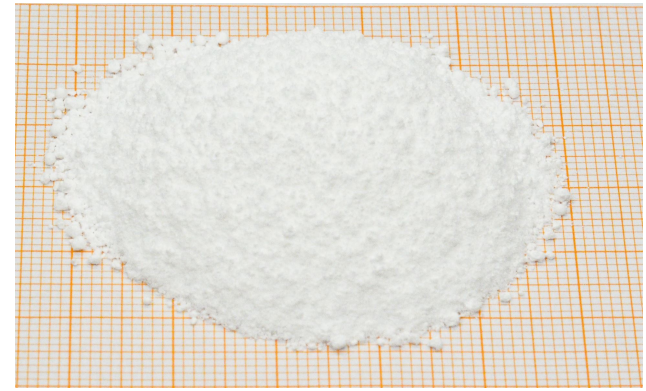

(a) 2 g Resomer ${ }^{\circledR}$ RG $755 \mathrm{~S}$

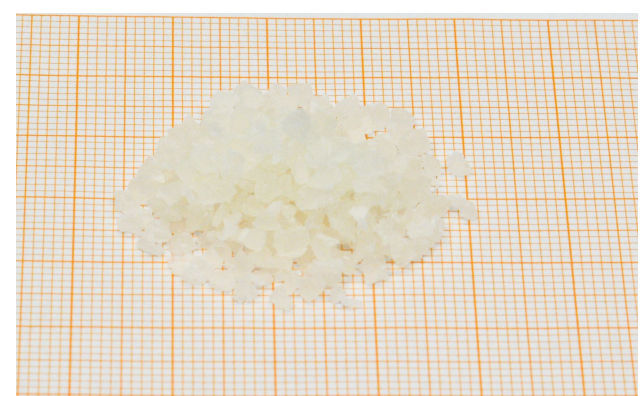

(d) 2 g Purasorb ${ }^{\circledR}$ PLG 8523

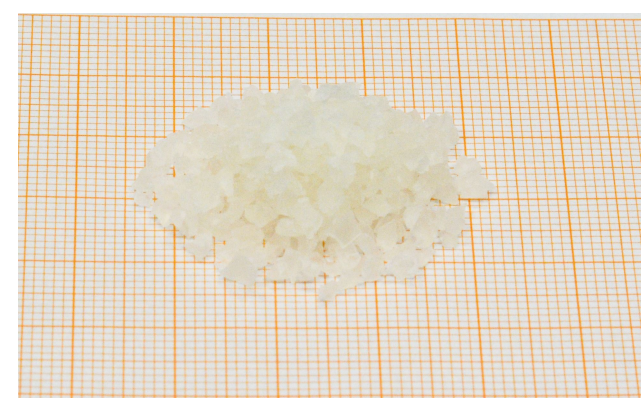

(g) 2 g Purasorb ${ }^{\circledR}$ PLG 8531

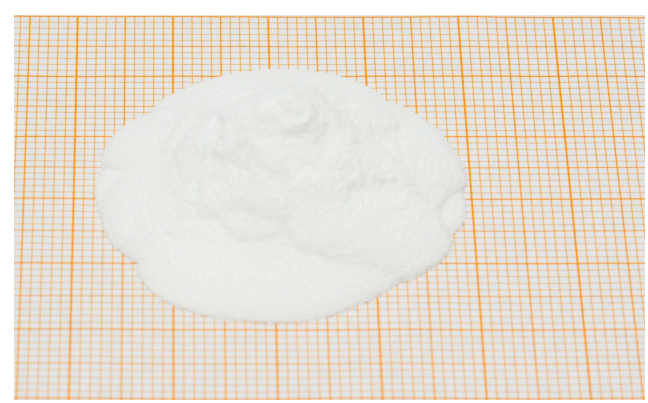

(j) 2 g PA2200 (Referenzmaterial)
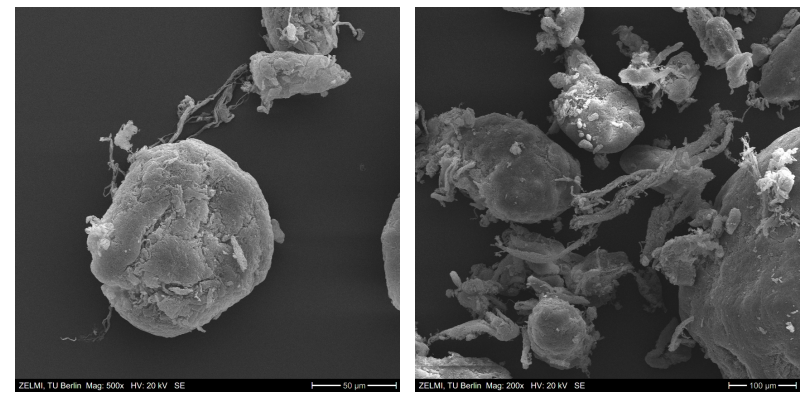

(b) $50 \mu \mathrm{m}$ Maßstabsbalken

(c) $100 \mu \mathrm{m}$ Maßstabsbalken
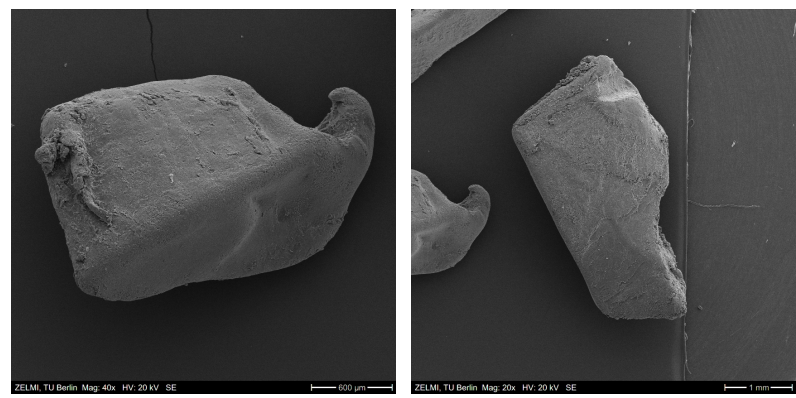

(e) $600 \mu \mathrm{m}$ Maßstabsbalken

(f) $1 \mathrm{~mm}$ Maßstabsbalken

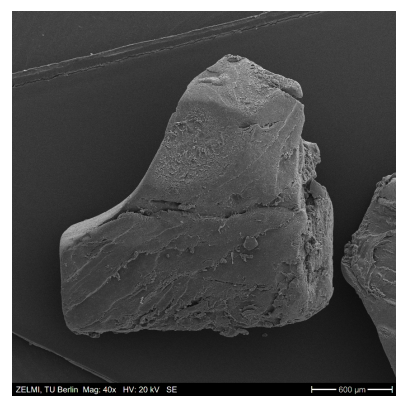

(h) $600 \mu \mathrm{m}$ Maßstabsbalken

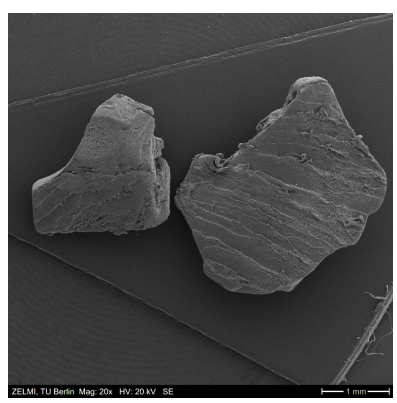

(i) $1 \mathrm{~mm}$ Maßstabsbalken

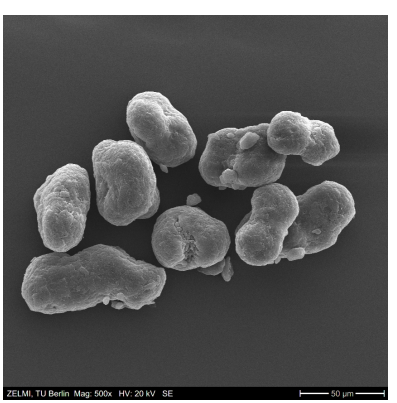

(k) $50 \mu \mathrm{m}$ Maßstabsbalken

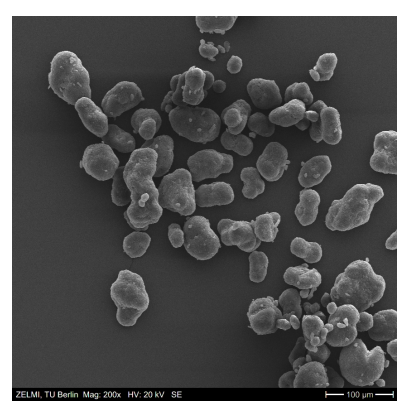

(l) $100 \mu \mathrm{m}$ Maßstabsbalken

Abbildung 7.1.: Materialien im Lieferzustand: Foto und zugehörige REM-Aufnahmen 
für den Lasersinterprozess entwickelt, erfüllen als Thermoplaste jedoch die Grundvoraussetzung für die Verwendung als Lasersintermaterial. Die logarithmische Viskosität korreliert mit der Degradationszeit des Materials. Aus Gründen der Vergleichbarkeit wird zusätzlich das EOS Feinpolyamid PA2200, einem Standardwerkstoff für das Lasersintern, als Referenzmaterial untersucht.

EOS Feinpolyamid PA2200 basiert auf einem Polyamid 12 und ist für die Verarbeitung in den Lasersintermaschinen der Firma EOS entwickelt. Die mittlere Korngröße beträgt $60 \mu \mathrm{m}$. Das teilkristalline Polymer hat einen Schmelzpunkt zwischen $172{ }^{\circ} \mathrm{C}$ und $180^{\circ} \mathrm{C}$ [EOS02]. Das PA12 ist weder bioresorbierbar noch bioaktiv und folglich nicht als Werkstoff für das Tissue Engineering geeignet.

Die Abbildung 7.1 stellt Fotos und zugehörige REM-Aufnahmen der Materialien im Lieferzustand dar. Die Dichte des Schüttguts kann qualitativ anhand der Fotos erfasst werden, da diese bei gleichem Maßstab die Masse von $2 \mathrm{~g}$ des jeweiligen Materials zeigen. Die mittleren Partikelgrößen betragen beim Resomer ca. $120 \mu \mathrm{m}$ und bei den Purasorb-Pulvern ca. $2 \mathrm{~mm}$. Ein generativer Bauteilaufbau mit einer Schichtstärke von $100 \mu \mathrm{m}$ ist ohne Nachbehandlung der PLGA-Materialien dementsprechend nicht möglich. Zur normkonformen [DIN 53733] Analysevorbereitung werden die dargestellten PLGA-Materialien in Abschnitt 7.1 kryogen zermahlen und gesiebt. Nach Durchführung des Aufbereitungsprozesses entspricht die mittlere Partikelgröße der PLGA-Materialien der mittleren Partikelgröße des EOS Referenzmaterials. In Abschnitt 7.2 werden die thermischen Eigenschaften aller vier Materialien mittels DSC-Messverfahren bestimmt. Durch die Auswertung der Messergebnisse lassen sich die materialspezifischen Vorheiztemperaturen und die zum Aufschmelzen der Pulverpartikel notwendige Erhöhung der Pulverbettoberflächentemperatur, hervorgerufen durch den Laserenergieeintrag, identifizieren. Zur Bestimmung der optischen Eigenschaften der PLGA-Materialien werden in Abschnitt 7.3 spektrometrische FTIR-Messungen durchgeführt. Durch die Auswertung der FTIR-Messungen wird eine geeignete Wellenlänge identifiziert. Konzeptionell wurde dieses Thema im Rahmen einer Bachelorarbeit [Bra17] von Herrn Thomas Braun bearbeitet. In Abschnitt 7.4 wird abschließend eine geeignete Laser-Scanner-Einheit zur Verarbeitung von PLGA ausgewählt. Soll im Anschluss an die vorliegende Arbeit ein Lasersinterprozess mit den untersuchten PLGA-Materialien entwickelt werden, kann der in Kapitel 6 entwickelte Laser-Scanner-Demonstrator durch die PLGA-Laser-Scanner-Einheit aus Abschnitt 7.4 ersetzt werden.

\subsection{Mechanische Korngrößenreduktion des Ausgangsmaterials}

Im „Resobone“-Projekt reduzierten M. Lindner et al. die Korngrößen der PLA/TCPPartikel in einem mechanischen Mahl- und Siebprozess für die Versuchsreihen von $S$. Hoeges et al. [LFT10, S. 15-19]. Da die zu untersuchenden PLGA-Werkstoffe zu einem erheblichen Anteil aus PLA bestehen, wird der skizzierte Aufbereitungsprozess entsprechend übernommen. In Abschnitt 7.1.1 wird der an den PLGA-Materialien angewandte Mahlund Siebprozess inklusive verwendeter Geräte detailliert dargestellt. In Abschnitt 7.1.2 werden die zerkleinerten Partikel anhand von REM-Aufnahmen untersucht. 


\subsubsection{Prozess der Pulveraufbereitung durch Mahlen und Sieben}

Zur mechanischen Zerkleinerung von wärmeempfindlichen PLGA-Werkstoffen kann unter anderem ein Stickstoff gekühltes Schwingmühlensystem der Firma Retsch verwendet werden, welches aus der Schwingmühle „CryoMill“ (vgl. (a) Abbildung 7.2) inklusive Mahlbecher und dem Stickstoffbefüllsystem „Dewar 50 l“ (vgl. (b) Abbildung 7.2) besteht [Ret16, S. 40-41]. Zur Vorbereitung der kryogenen Vermahlung werden 501 flüssiger

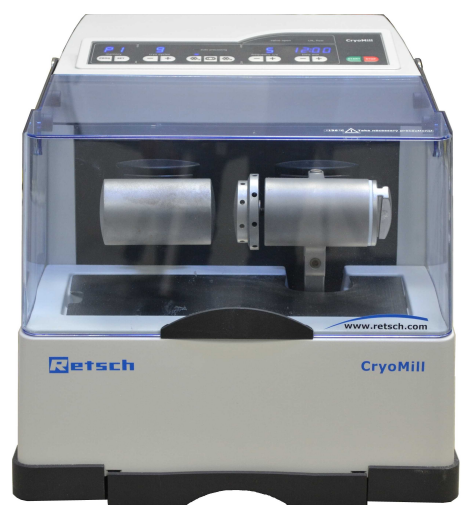

(a) Schwingmühle CryoMill

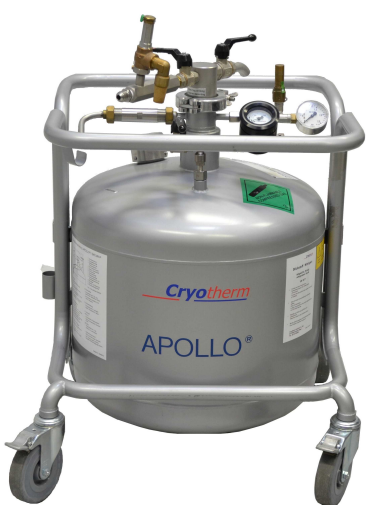

(b) Stickstoffbefüllsystem Dewar

Abbildung 7.2.: Verwendete Produkte zur Kryogenvermahlungen von PLGA

Stickstoff (kryogene Flüssigkeit) in das Stickstoffbefüllsystem „Dewar“ eingefüllt und der Mahlbecher, dargestellt in Abbildung 7.3, mit Mahlgut (PLGA) und Mahlkugel bestückt [Ret12, S. 23-24] [Ret14, S. 33-35]. Das im Mahlbecher befindliche Mahlgut wird durch ein
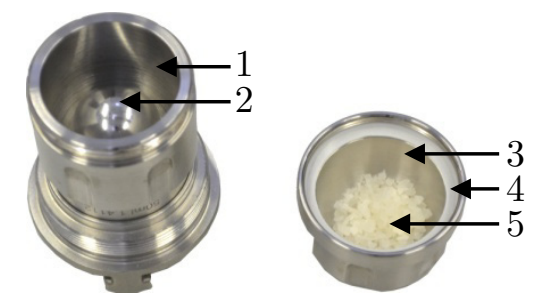

(1) Mahlbecherunterteil

(2) Mahlkugel $\varnothing 25 \mathrm{~mm}$

(3) Mahlbecherverschluss

(4) PTFE-Dichtung

(5) Mahlgut (PLGA)

Abbildung 7.3.: $50 \mathrm{ml}$ Mahlbecher für Retsch CryoMill befüllt mit $2 \mathrm{~g}$ PLGA

integriertes Kühlsystem der Schwingmühle, automatisch befüllt durch das angeschlossene Stickstoffbefüllsystem „Dewar“, auf eine Solltemperatur von $-196{ }^{\circ} \mathrm{C}$ geregelt und versprödet. Führt der Mahlbecher der CryoMill in horizontaler Lage eine kreisbogenförmige Schwingung aus, schlägt die Mahlkugel durch ihre Trägheit auf das Mahlgut auf und zerkleinert es [Ret17, S. 3]. Zur Einrichtung des Mahlprogramms müssen die Parameter Vorkühlzeit, Mahldauer, Zwischenkühlzeit, Zyklenzahl und Mahlfrequenz eingestellt werden [Ret14, S. 39-40]. In Anlehnung an einen durch die Firma Retsch angefertigten Testbericht werden die Parameter zum Zerkleinern von $2 \mathrm{~g}$ PLGA festgelegt. Bei einer Vorkühlzeit von 12 min und einer Zyklenzahl von 12 ist als Mahlergebnis eine mittlere 
Korngröße von $58 \mu \mathrm{m}$ zu erwarten, sofern ein Zyklus aus einer Mahldauer von 4 min bei der maximal möglichen Mahlfrequenz von $30 \mathrm{~Hz}$ mit anschließender Zwischenkühlzeit von $40 \mathrm{sec}$ besteht [Ret13]. Da die mögliche Eingabe der Zyklenzahl auf 9 begrenzt ist, werden die 12 Zyklen auf die Programme „P1“ (Vorkühlzeit 12 min, Zyklenzahl 9) und „P2“ (Vorkühlzeit automatisch, Zyklenzahl 3) aufgeteilt und ohne Verzögerung nacheinander ausgeführt. Der kryogene Mahlprozess ist nach einer durchschnittlichen Mahldauer von 70 min abgeschlossen. Der beschriebene Mahlprozess startet mit dem Beginn der Ausführung von Programm „P1“ und endet mit der Beendigung des Programms „P2“. Nach Reduktion der Prozessnebenzeiten und durch die Entwicklung einer Öffnungshilfe (vgl. Anhang F.1) konnten mit einer 501 Flüssigstickstoffbefüllung drei Mahlprozesse (mit den genannten Parametern) durchgeführt werden. Die Prozessnebenzeit ist jene Zeit, die zwischen den Mahlprozessen benötigt wird, um Vorbereitungsmaßnahmen für den wiederholten Start der Schwingmühle durchzuführen. Neben der Maschineneinrichtung und der Befüllung des Stickstoffbehälters sind die folgenden Prozessschritte notwendig:

1. Mahlbecher aus CryoMill nach Programmende entnehmen

2. Mahlbecher öffnen und zerkleinertes Mahlgut zur Weiterverarbeitung entfernen

3. Mahlbecher erwärmen, reinigen und desinfizieren [Ret14, S. 33]

4. Unzerkleinertes Mahlgut in Mahlbecher einfüllen und verschließen

5. Mahlbecher in CryoMill einsetzen und Programm starten

Zur Ausführung der Prozessschritte 2 bis 4 (Schwingmühle still steht) sind ca. 40 min notwendig. Durch die Beschaffung eines zweiten Mahlbechers wird der vorbereitete Mahlbecher II nach Entnahme von Mahlbecher I eingesetzt, sodass umgehend das Programm gestartet werden kann. Die Mahlprogrammdauer zum Zerkleinern von PLGA-Werkstoffen

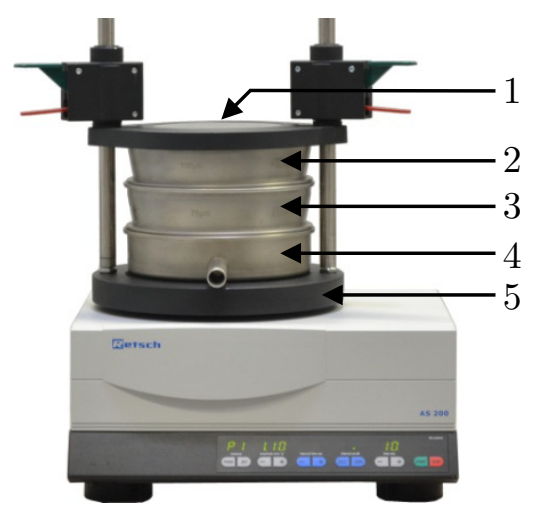

(1) Spanndeckel mit Schnellspanneinheiten

(2) $\varnothing 200 \mathrm{~mm}$ Analysesieb mit Maschenweite $<100 \mu \mathrm{m}$

(3) $\varnothing 200 \mathrm{~mm}$ Analysesieb mit Maschenweite $<75 \mu \mathrm{m}$

(4) Auffangboden mit Auslauf

(5) Siebteller mit eingeschraubten Stativstangen

Abbildung 7.4.: Retsch Vibrationssiebmaschine AS 200 control

betrug in der eigenen Anwendung ca. 70 min. Durch Parallelisierung von Mahl- und Vorbereitungsprozess konnte die Stillstandszeit um $90 \%$ reduziert werden. Die Vibrationssiebmaschine „AS 200 control“ der Firma Retsch führt mittels elektromagnetischem Antrieb eine mit einem Drehimpuls überlagerte, dreidimensionale Wurfbewegung aus. 
Dabei wird das zuvor eingefüllte Schüttgut gleichmäßig über die Siebfläche bewegt und in Abhängigkeit von Korngröße und Siebmaschenweite voneinander getrennt [Ret17]. Durch die Siebanalyse kann die Partikelgrößenverteilung des kryogen zerkleinerten PLGAs bestimmt oder gezielt beeinflusst werden. Die Abbildung 7.4 stellt die Retsch Siebmaschine mit dem verwendeten Siebturmaufbau dar, der sämtliche Partikel aus einem Schüttgut kleiner als $75 \mu \mathrm{m}$ siebt und in dem Auffangboden (vgl. (4) Abbildung 7.4) sammelt. Zur Impulsübertragung vom angetriebenen Siebteller auf den Siebturm, wird eine Vorspannkraft über den Spanndeckel (vgl. (1) Abbildung 7.4) an der Siebturmoberseite aufgebaut. Zur Einrichtung des Siebprogramms müssen die Parameter der Amplitude und Siebzeit, wahlweise im Intervallbetrieb, eingestellt werden [Ret14, S. 31-35]. Der Amplitudenwert der Retsch Vibrationssiebmaschine lässt sich in einem Intervall zwischen $0,20 \mathrm{~mm}\left(\widehat{=} 9,81 \mathrm{~m} / \mathrm{s}^{2}\right)$ und $3,00 \mathrm{~mm}\left(\widehat{=} 250,15 \mathrm{~m} / \mathrm{s}^{2}\right)$ einstellen. Die Siebdauer des ausgeführten Siebprogramms beträgt, bei konstantem Amplitudenwert von 1,1 mm, ca. $10 \mathrm{~min}$. Das Mahlgut wird nach der kryogenen Zerkleinerung ohne Zeitverzögerung in kaltem Zustand aus dem Mahlbecher auf das obere Analysesieb mit einer Maschenweite kleiner als $100 \mu \mathrm{m}$ gegeben. Passieren die Pulverpartikel die zweite Siebstufe und fallen in den Ablageboden beträgt die Partikelgröße einem Wert, der kleiner als $75 \mu \mathrm{m}$ ist. Eine genaue Partikelgrößenverteilung des Siebguts wird nicht bestimmt. Das gesiebte Material wird für die Untersuchungen verwendet.

\subsubsection{Einfluss des Aufbereitungsprozesses auf die Partikelsphärizität}

Jedes der drei PLGA-Materialien wird in zwei Chargen (insgesamt sechs Aufbereitungsprozesse) mit den in Abschnitt 7.1.1 dargestellten Prozessparametern kryogen zermahlen und anschließend gesiebt. Sämtliche Pulverpartikel, die sich nach dem Sieben einer Charge im Ablageboden des Siebturms befinden, werden in ein Gefäß gefüllt und gewogen. Die durchschnittliche Ausbringungsrate, bezogen auf die Schüttgutmasse vor (Mittelwert 2,0065 g, Standardabweichung 0,0045 g) und nach (Mittelwert 0,972 g, Standardabweichung 0,0099g) dem Aufbereitungsprozess, beträgt 48,5\%. Die hohen Verluste scheinen im Zusammenhang mit dem Agglomerationsverhalten des hygroskopischen Materials zu stehen. Bei der kryogenen Zermahlung des PLGAs wird das Schüttgut im Mahlbecher durch die hohe Aufprallenergie der Mahlkugel an der Mahlbecherinnenwand stark komprimiert. Die gemahlenen Pulverpartikel bilden dadurch ein Agglomerat, dessen Verfestigung durch den Siebprozess nicht aufgehoben wird. Die Agglomerate werden aus der ersten Siebstufe heraus entsorgt. Grundsätzlich ist festzustellen, dass das durch die Anwendung des mechanischen Pulveraufbereitungsprozesses die mittleren Partikelgrößen von ca. 120 um (Resomer RG 755 S) bzw. 2 mm (Purasorb PLG 8523 / Purasorb PLG 8531) auf einen Wert unterhalb von $75 \mu \mathrm{m}$ reduziert werden können. Wird eine ausreichende Materialmenge hergestellt, können erste Lasersinterversuche bei einer Schichtstärke von $100 \mu \mathrm{m}$ durchgeführt werden. Anhand der REM-Aufnahmen aus Abbildung 7.5 lässt sich feststellen, dass der Mahlprozess die PLGA-Materialien in poröse, inhomogene Partikel zerkleinert. Weder die Kornform noch die Sphärizität der gemahlenen PLGA-Werkstoffe entspricht dem EOS Referenzmaterial. Aufgrund visueller Begutachtung der aufbereiteten PLGA-Materialien ist davon auszugehen, dass die Verarbeitung in der vorliegenden Form 
auf einer unmodifizierten Lasersintermaschine begrenzt möglich ist. Der Pulverauftrag mit einer Beschichtereinheit mit starrer Klinge würde durch eine mangelnde Fließfähigkeit des Schüttguts zu einem inhomogenen Pulverbett führen. Der Einsatz einer fluidisierenden

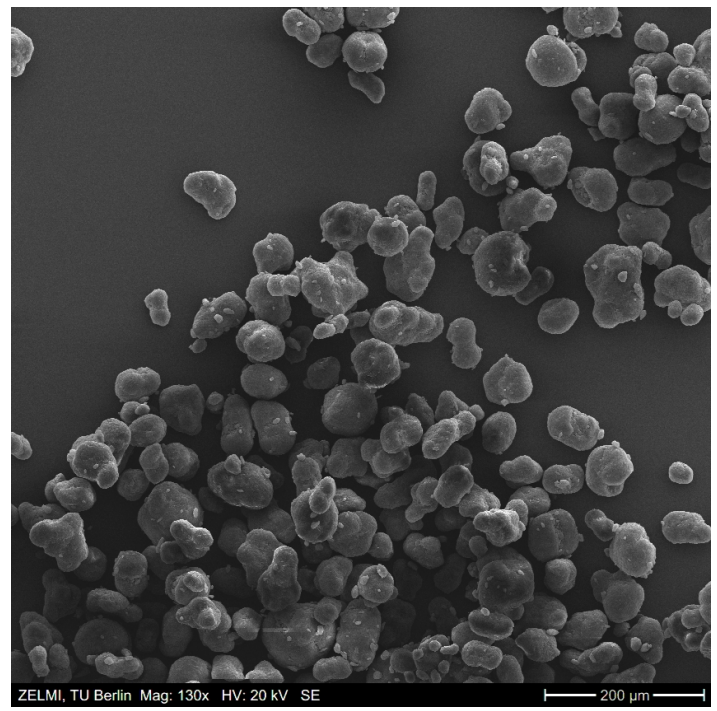

(a) EOS PA2200 / $200 \mu \mathrm{m}$ Maßstabsbalken

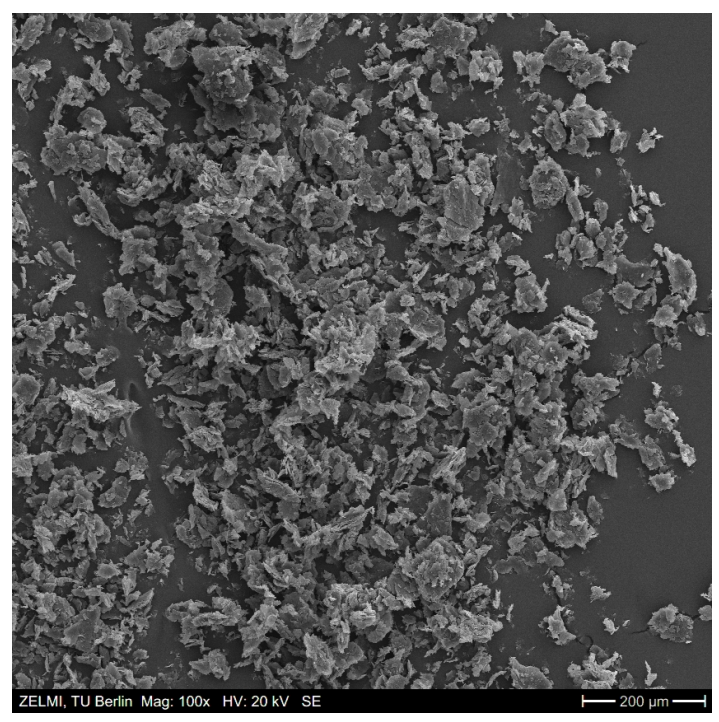

(c) PLG 8523 / $200 \mu \mathrm{m}$ Maßstabsbalken

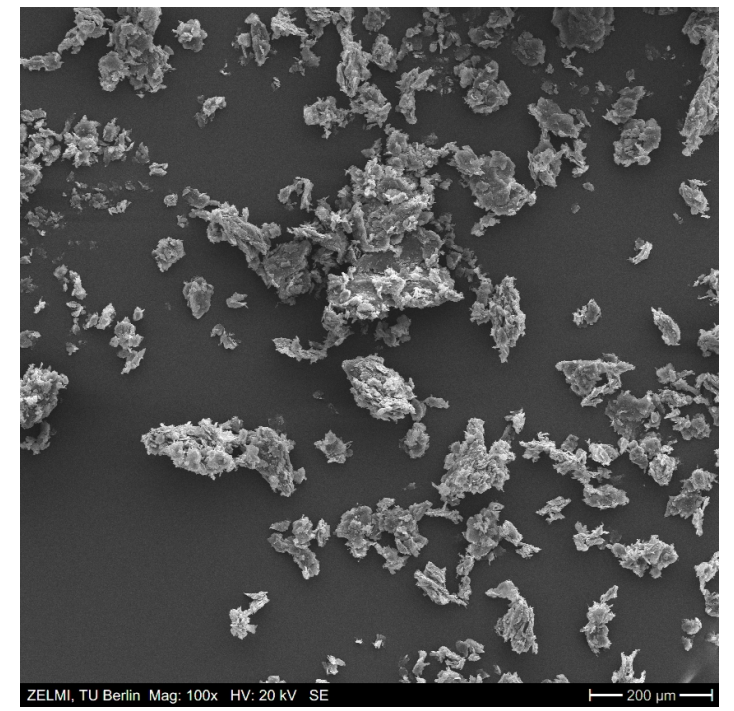

(b) RG $755 \mathrm{~S} / 200 \mu \mathrm{m}$ Maßstabsbalken

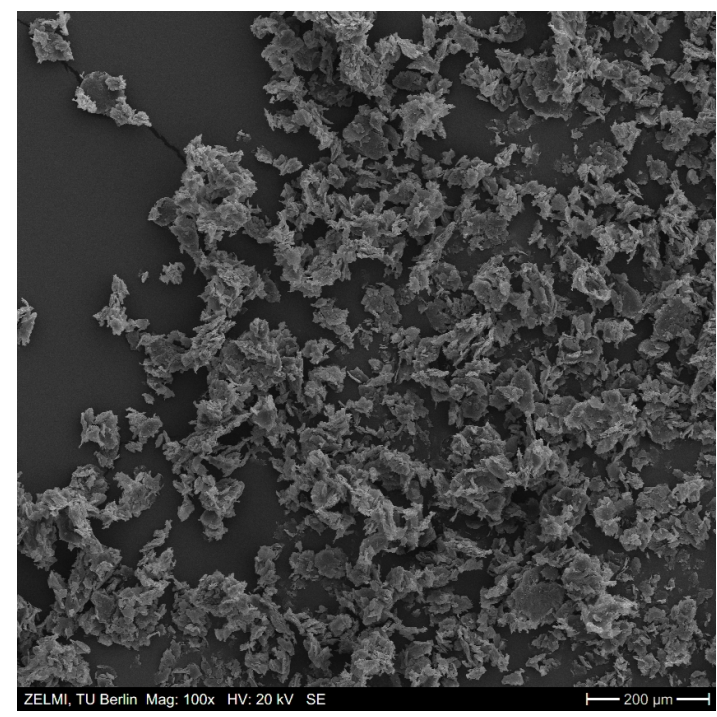

(d) PLG 8531 / $200 \mu \mathrm{m}$ Maßstabsbalken

Abbildung 7.5.: REM-Aufnahmen nach dem Mahl- und Siebprozess

Beschichtereinheit (vgl. Abschnitt 3.3.3) kann zur Kompensation der dargestellten Pulvereigenschaften beitragen. Für entsprechende Pulverauftragsversuche ist die in Kapitel 6 entwickelte Beschichtereinheit mit schwingender Klinge und/oder die Beschichtereinheit mit rotierender Rolle herzustellen. 


\subsection{DSC-Messungen zur Bestimmung thermischer Eigenschaften}

Das DSC-Messverfahren (engl.: „Differential Scanning Calorimetry“) ist ein thermoanalytisches Verfahren zur Messung von aufgenommener (endothermer, positive Wärmestromdifferenz) und abgegebener (exothermer, negative Wärmestromdifferenz) Wärmemenge einer Materialprobe innerhalb eines kontrollierten Temperaturprogramms. Im Kontext des Lasersinterns werden DSC-Messungen unter anderem zur quantitativen Erfassung von Schmelz-, Kristallisations- oder Glasübergangstemperaturen der amorphen oder teilkristallinen Ausgangswerkstoffe verwendet. Für detaillierte Informationen zur Vorgehensweise bei einer DSC-Messung sei auf die 7-teilige DIN EN ISO 11357 [DIN EN ISO 11357-1] Normenreihe verwiesen.

\subsubsection{DSC-Kurvenverläufe von PA12 und PLGA}

Untersucht werden alle drei amorphen PLGA-Werkstoffe und das teilkristalline EOS Referenzmaterial PA2200 mit einem Kalorimeter des Typs „DSC 7“ der Firma PerkinElmer. Die Messungen wurden in einem Temperaturbereich von $25^{\circ} \mathrm{C}$ bis $220^{\circ} \mathrm{C}$ bei einer Heizbzw. Kühlrate von $10^{\circ} \mathrm{C} /$ min durchgeführt. Die Materialproben wurden innerhalb eines Messdurchlaufs nach Temperaturkalibrierung zweifach aufgeheizt und abgekühlt. Die Ergebnisse der Messungen sind grafisch mit identischer Achsskalierung in Abbildung 7.6 dargestellt. Normkonform ist die Energieaufnahme des Materials auf der Ordinate in der Aufwärtsrichtung abgetragen [DIN EN ISO 11357-1, S. 8]. In den DSC-Kurvenverläufen sind für den ersten Aufheiz- und Abkühlvorgang die charakteristischen Temperaturwerte vermerkt. Die Indizes haben dabei die folgenden Bedeutungen:

- $T_{\mathrm{p}, \ldots}$ : Höchsttemperatur (,peak“)

- $T_{\mathrm{i}, \ldots}:$ Anfangstemperatur (,,initial“)

- $T_{\mathrm{f}, \ldots}$ : Endtemperatur (,final“)

- $T_{\ldots, \mathrm{m}}$ : Schmelzen (,melting“)

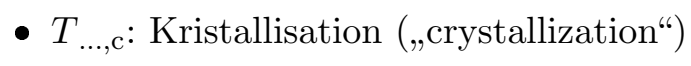

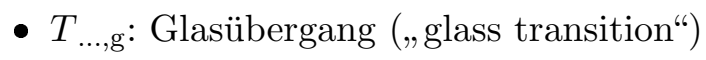

Beim Lasersintern werden die vorgeheizten Polymer-Pulverpartikel mittels Laserenergieeintrag örtlich aufgeschmolzen. Durch die kurzzeitig wirkende Temperaturerhöhung über den Wert von $T_{\mathrm{i}, \mathrm{m}}$ fließen die Pulverpartikel durch die Laser-Pulver-Wechselwirkung ineinander und bilden nach dem Abkühlen den entsprechenden Bauteilbereich aus. Dabei kommt es in Abhängigkeit des Energieeintrags und der Wechselwirkungsdauer zwischen den Partikeln entweder zur Ausbildung von Sinterhälsen (Sintern) oder zu einer vollständigen Koaleszenz (Schmelzen) [Sch15a, S. 10] [GKT16, S. 46-49] [Sch15b, S. 73-74]. Durch das Vorheizen der Pulverpartikel reduziert sich der Wärmebetrag den der Laser zusätzlich zum Aufschmelzen einbringen muss. Markante Schmelzpeaks (Temperaturbereich von $T_{\mathrm{i}, \mathrm{m}}$ bis $\left.T_{\mathrm{f}, \mathrm{m}}\right)$ sind in den DSC-Kurvenverläufen des teilkristallinen 
PA2200 $\left(171^{\circ} \mathrm{C}-185,2^{\circ} \mathrm{C}\right)$ und der amorphen Purasorb-Materialien $\left(125^{\circ} \mathrm{C}-162^{\circ} \mathrm{C}\right.$ bzw. $124{ }^{\circ} \mathrm{C}-163^{\circ} \mathrm{C}$ ) erkennbar. Das amorphe Resomer RG $755 \mathrm{~S}$ hat oberhalb der Erweichungstemperatur hingegen kein ausgeprägtes Schmelzpeak. Die Zersetzung des RG 755 S beginnt laut Datenblatt bei $150^{\circ}$ C. Der Sinter- bzw. Schmelzprozess findet

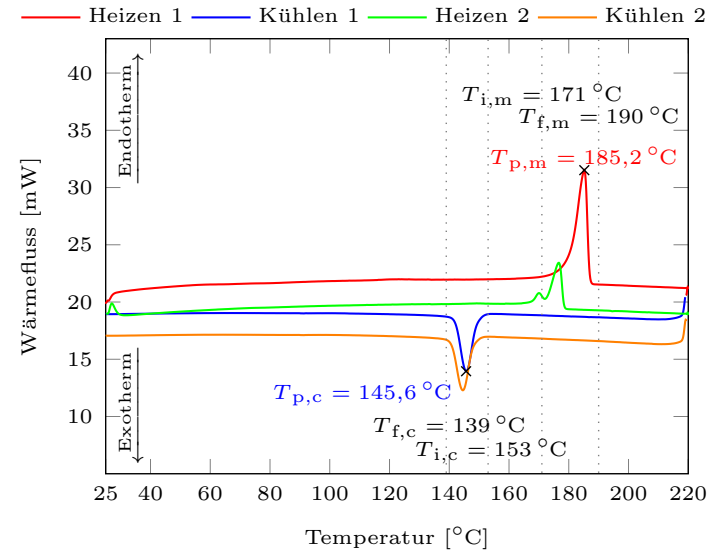

(a) EOS PA2200 (PA12)

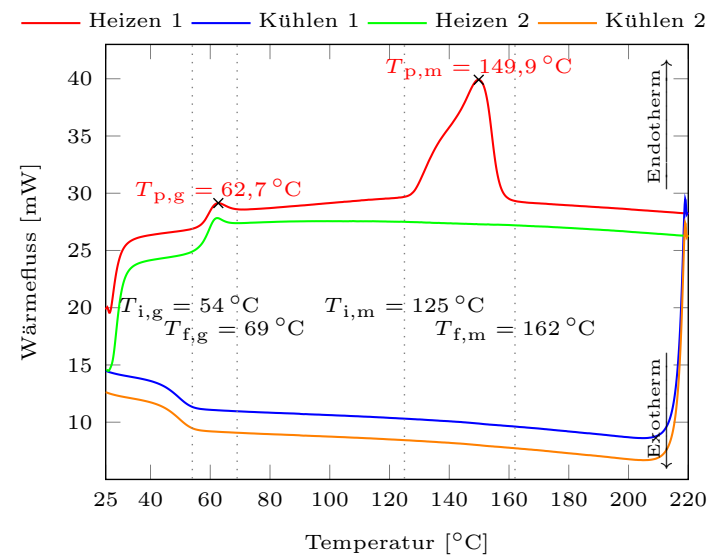

(c) Purasorb PLG 8523 (PLGA)

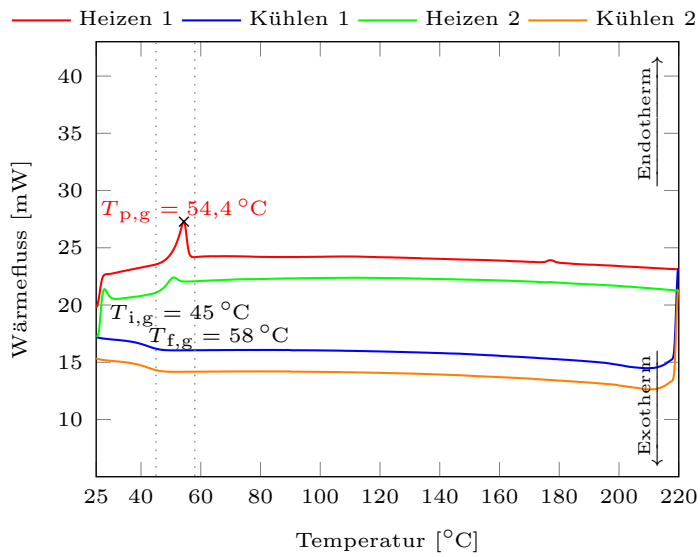

(b) Resomer RG $755 \mathrm{~S}$ (PLGA)

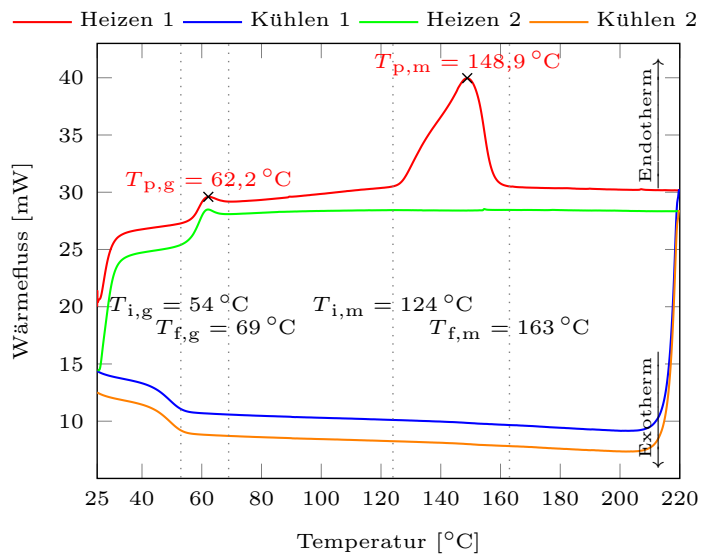

(d) Purasorb PLG 8531 (PLGA)

Abbildung 7.6.: DSC-Kurvenverläufe von PA12 und PLGA bei $10^{\circ} \mathrm{C} / \mathrm{min}$

dementsprechend unterhalb der Zersetzungstemperatur statt, wobei der exakte Wert durch entsprechende Versuche zunächst bestimmt werden muss. Für den Pulverauftrag über der Bauplattform müssen die Partikel in einem festen Aggregatzustand sein. Ist die materialspezifische Vorheiztemperatur zu hoch gewählt, fließen die Partikel bereits ohne zusätzlichen Laserenergieeintrag unbeabsichtigt ineinander [YSH11].

\subsubsection{Lasersintern mit amorphem PLGA}

Die Abbildung 7.7 stellt jeweils einen Aufheiz- und Abkühlvorgang für einen teilkristallinen und einen amorphen Thermoplasten dar. Die Verwendung eines Polyamid 12 für 
das Lasersintern ist seit dem Jahr 1999 patentiert. Das in dem Patent mit der Nummer DE19747309A1 [DE19747309 A1] beschriebene PA12 ist durch eine Schmelztemperatur $T_{\mathrm{m}}=186-188^{\circ} \mathrm{C}$, Schmelzenthalpie $H_{\text {fus }}=100-125 \mathrm{~J} / \mathrm{g}$ und eine Erstarrungstemperatur (Kristallisationstemperatur) $T_{\mathrm{c}}=140-142^{\circ} \mathrm{C}$ gekennzeichnet. Die Ergebnisse der DSC-Messung mit einem EOS PA2200 (vgl. (a) Abbildung 7.7) entsprechen mit geringen Abweichungen den Werten des Patents und bestätigen die Herstellerangaben der Firma EOS. Die Vorheiztemperatur zur Verarbeitung dieses Standardwerkstoffs sollte knapp unter $171^{\circ} \mathrm{C}$ gewählt werden. Thermoplastische Fließvorgänge treten bei teilkristalli-

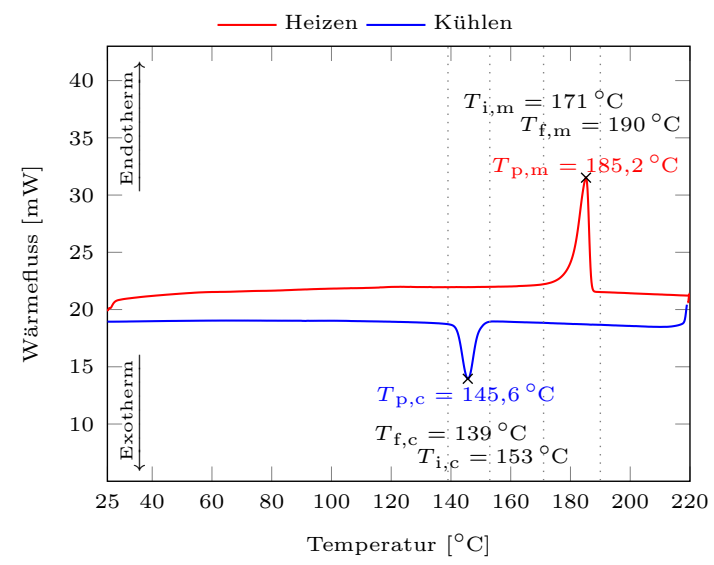

(a) EOS PA2200 (teilkristallines PA12)

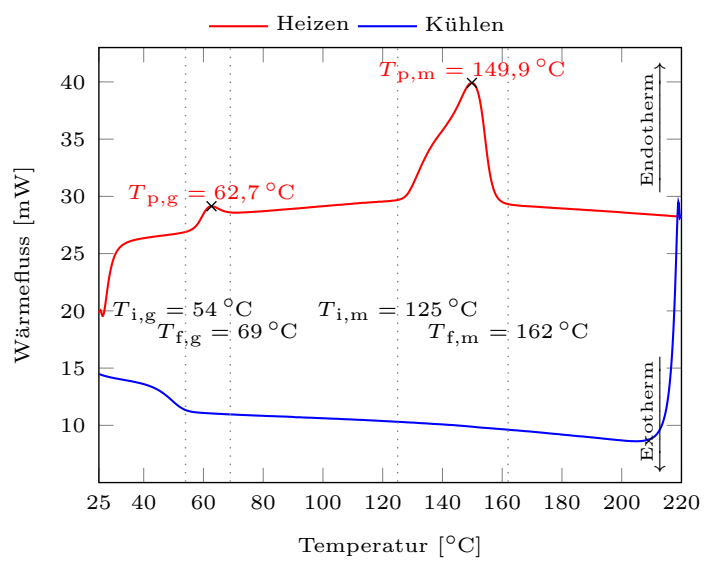

(b) Purasorb PLG 8523 (amorphes PLGA)

Abbildung 7.7.: DSC-Kurvenverläufe von teilkristallinen und amorphen Thermoplasten

nen Thermoplasten schlagartig oberhalb der Kristallitschmelztemperatur $\left(T>T_{\mathrm{i}, \mathrm{m}}\right)$ auf. Zum Aufschmelzen der Partikel muss der Laser dementsprechend nur eine geringe Wärmeenergie in das Pulverbett hinzufügen. Zur Vermeidung unerwünschter Rekristallisationsvorgänge $\left(T<T_{\mathrm{i}, \mathrm{c}}\right)$ darf die Temperatur des Pulverkuchens im Bauprozess den Wert von $153^{\circ} \mathrm{C}$ nicht unterschreiten. Bei der Verwendung von PA12 wird häufig der Begriff des „quasi-isothermen Lasersinterns" verwendet [SFR+08] [Rie11]. Amorphe Thermoplasten besitzen aufgrund der chaotischen Molekülstruktur keine kristallinen Bereiche und folglich keine Kristallitschmelztemperatur. Der Übergang vom thermoelastischen in den thermoplastischen Zustandsbereich geschieht kontinuierlich oberhalb der Glasübergangtemperatur. Für den Pulverauftrag mit festen Partikeln sollte die Vorheiztemperatur unterhalb der materialspezifischen Glasübergangstemperatur gewählt werden. Der Glasübergang des amorphen PLGAs aus Abbildung 7.7 beginnt bei ca. $54^{\circ} \mathrm{C}$. Der Schmelzbereich (thermoplastischer Zustandsbereich) startet laut DSC-Kurvenverlauf bei $125^{\circ} \mathrm{C}$, hat seinen Peak bei $149,9^{\circ} \mathrm{C}$ und endet bei $162^{\circ} \mathrm{C}$. Ist die Vorheiztemperatur beim Lasersintern mit dem Purasorb PLG 8523 auf $54^{\circ} \mathrm{C}$ eingestellt, muss der Laserenergieeintrag zu einer Erhöhung der Pulverbettoberflächentemperatur von $71^{\circ} \mathrm{C}$ führen, um die initiale Schmelztemperatur zu erreichen. Die Temperaturerhöhungsrate durch den Laser im Lasersinterprozess ist im Vergleich zur Heizrate der durchgeführten DSC-Messungen $\left(10^{\circ} \mathrm{C} / \mathrm{min}\right)$ um ein Vielfaches höher und abhängig von den Belichtungsparametern wie die 
Laserleistung, dem Spurabstand und vor allem der Scangeschwindigkeit. Auf Basis der Messergebnisse sollte die Lasersintermaschine bei der Verarbeitung von RG $755 \mathrm{~S}$ auf $45^{\circ} \mathrm{C}$ bzw. von PLG 8523 und PLG 8531 auf $54^{\circ} \mathrm{C}$ vorgeheizt werden. Bei dem Laserenergieeintrag in das PLGA-Pulverbett führt die Wahl einer geringen Scangeschwindigkeit bei entsprechend geringer Laserleistung zu einer erhöhten Laser-Pulver-Wechselwirkungszeit. Zur Erhöhung der Pulverbettoberflächentemperatur um die diskutierte Differenz von $71^{\circ} \mathrm{C}$ kann eine im Vergleich zum PA12 stark verringerte Scangeschwindigkeit ein zielführender Ansatz zur Generierung der bioresorbierbaren Implantatmatrizen sein. Der spezifische Einfluss der gewählten Prozessparameter auf die Qualitätsmerkmale der lasergesinterten Bauteile muss im Rahmen der Prozessentwicklung ermittelt werden.

\subsection{FTIR-Spektroskopie zur Bestimmung optischer Eigenschaften}

Elektromagnetische Strahlung (z. B. Laserstrahlung, Infrarotstrahlung) wird durch die Angabe der Schwingfrequenz oder der Wellenlänge charakterisiert [HS08, S. 1-11]:

$$
\nu=c \cdot \lambda=c \cdot \frac{1}{\tilde{\nu}}
$$

$\nu$ : Schwingfrequenz $[\mathrm{Hz}]$

$\lambda$ : Wellenlänge $[\mu \mathrm{m}]$

$\tilde{\nu}$ : Wellenzahl $[1 / \mathrm{mm}]$

$c$ : Lichtgeschwindigkeit $[\mathrm{m} / \mathrm{s}] \approx 300000000 \mathrm{~m} / \mathrm{s}$

Die Planck-Konstante setzt Schwingfrequenz und Energie eines Photons ins Verhältnis:

$$
E=h \cdot \nu
$$

$E$ : Energie $[\mathrm{J}]$

$h$ : Plancksches Wirkungsquantum $[\mathrm{J} \mathrm{s}] \approx 6,626 \cdot 10^{-34} \mathrm{~J} \mathrm{~s}$

Trifft elektromagnetische Strahlung auf Materie wird diese von der Materie absorbiert (aufgenommen), transmittiert (durchgeleitet) oder reflektiert (zurückgeworfen). Gemäß dem Energieerhaltungssatz gilt der folgende Zusammenhang:

$$
A_{\text {rad }}+T_{\text {rad }}+R_{\text {rad }}=1
$$

$A_{\text {rad }}$ : Absorptionsgrad

$T_{\text {rad }}$ : Transmissionsgrad

$R_{\text {rad }}$ : Reflexionsgrad

Die IR-Spektroskopie beruht auf der Absorption infraroter Strahlung durch die Moleküle des zu untersuchenden Materials. Im Kontext des Lasersinterns führt eine Absorption der vom Laser emittierten elektromagnetischen Strahlung zu einer für den Schmelzvorgang 
notwendigen Energieaufnahme durch das Material. Der IR-Spektralbereich lässt sich unterteilen in nahes Infrarot (NIR: $150001 / \mathrm{cm}-40001 / \mathrm{cm}$ ), mittleres Infrarot (MIR: $40001 / \mathrm{cm}-4001 / \mathrm{cm}$ ) und fernes Infrarot (FIR: $4001 / \mathrm{cm}-51 / \mathrm{cm}$ ) [Lec17, S. 83]. Lasersintermaschinen sind in der Regel mit $\mathrm{CO}_{2}$-Lasern einer Wellenlänge von 10,6 $\mu \mathrm{m}(\tilde{\nu}=9431 / \mathrm{cm})$ ausgerüstet. Zur Bestimmung der optischen Eigenschaften eines Materials wird unter anderem die FTIR-Spektroskopie (Fourier-Transformations-Infrarot-Spektroskopie) angewendet. Durch die Messung der Absorption im infraroten Spektralbereich kann die geeignete Wellenlänge des $\mathrm{CO}_{2}$-Lasers materialspezifisch bestimmt werden [FRW+07].

\subsubsection{FTIR-Spektren von PA12 und PLGA}

Für die Messungen wurde das in Abbildung 7.8 dargestellte „Alpha“ FTIR-Spektrometer mit „Platinum-ATR-Modul“ der Firma Bruker verwendet. Das Messgerät basiert auf einem Michelson-Interferometer und misst mittleres Infrarot. Ein FTIR-Spektrometer ist prinzipiell aus Strahlquelle, Interferometerraum, Probenkammer und Detektorraum aufgebaut. Die von der Strahlquelle emittierte IR-Strahlung wird durch das Interferometer moduliert, passiert die im Probenraum befindliche Materialprobe und wird auf dem Detektor fokussiert. Absorbiert das Material eine spezifische Wellenzahl entsteht eine zugehörige IR-Absorptionsbande. Die Materialproben können bis zu einer Temperatur von $80^{\circ} \mathrm{C}$ vorgeheizt werden. Untersucht wurden die drei PLGA-Werkstoffe und das
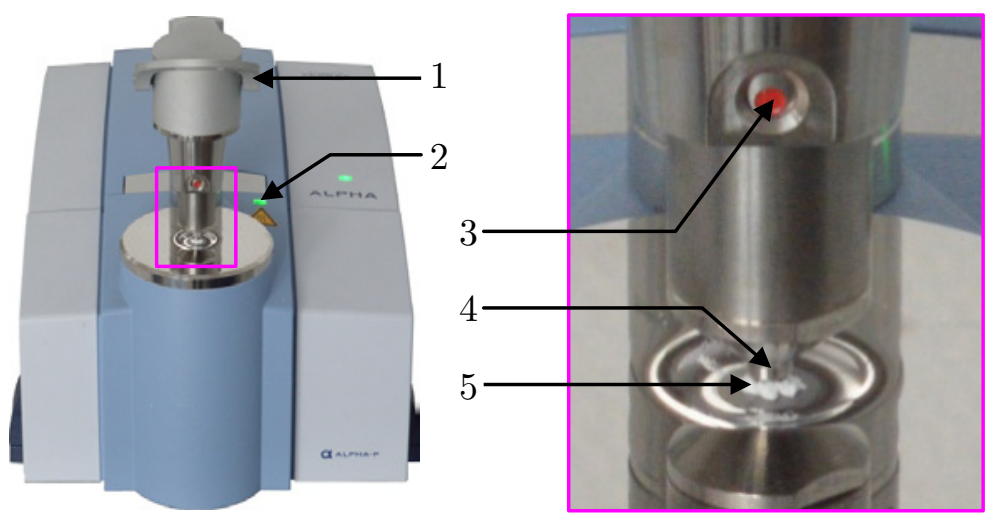

(1) Anpresshebel

(2) Heizkontrollleuchte

(3) Überdruckkontrolle

(4) Anpressstempel

(5) Polymerprobe

Abbildung 7.8.: Bruker Alpha FTIR-Spektrometer mit beheizbarem ATR-Modul

EOS Referenzmaterial PA2200 in dem Wellenzahlbereich von $40001 / \mathrm{cm}$ bis $4001 / \mathrm{cm}$. In der mitgelieferten Spektroskopie-Software „OPUS“ wird die Messauflösung auf 41/cm eingestellt und die Anzahl der Scans pro Probe auf 32 erhöht. Zur Identifikation unbekannter Materialproben kann das gemessene materialspezifische Spektrum mit einer Datenbank abgeglichen werden. Die Spektren der vier verschiedenen Materialien sind grafisch mit identischer Achsskalierung in Abbildung 7.9 dargestellt. Das Referenzmaterial PA2200 wurde sowohl bei Raumtemperatur $\left(23^{\circ} \mathrm{C}\right)$ als auch bei $80^{\circ} \mathrm{C}$ vermessen, mit der Datenbank abgeglichen und durch die Software eindeutig als PA12 identifiziert. Die Messergebnisse für das Referenzmaterial gelten daher als valide. Die PLGA-Copolymere waren zum Zeitpunkt der Messung nicht hinterlegt. Der Wellenzahlbereich zwischen 
$11001 / \mathrm{cm}(\lambda \approx 9,1 \mu \mathrm{m})$ und $900^{1} / \mathrm{cm}(\lambda \approx 11,1 \mu \mathrm{m})$ ist gesondert markiert und im Verlauf der Ergebnisdarstellung zur Kohlenstoffdioxidlaserauswahl in Abschnitt 7.3.2 vergrößert dargestellt. Global betrachtet sind die Spektren der PLGA-Materialien (vgl. (b) - (d) Abbildung 7.9) stark identisch. Die charakteristischen Absorptionsbanden bei den Wellenzahlen 3000 1/cm (,M-Form“), $17501 / \mathrm{cm}$ (1. Peak) und 11001/cm (2. Peak) sind in den jeweiligen Spektren angezeigt. Ein Zusammenhang zwischen der Höhe des Absorptionsgrads und der einstellbaren Vorheiztemperatur konnte aufgrund der geringen Anzahl an durchgeführten Messungen nicht nachgewiesen werden. Das Vorheizen der RG 755 S Materialprobe auf $60^{\circ} \mathrm{C}$ führte zu partiellem Aufschmelzen der Partikel. Die Probenreste konnten nur mit hoher Kraft vom Spektrometer entfernt werden.

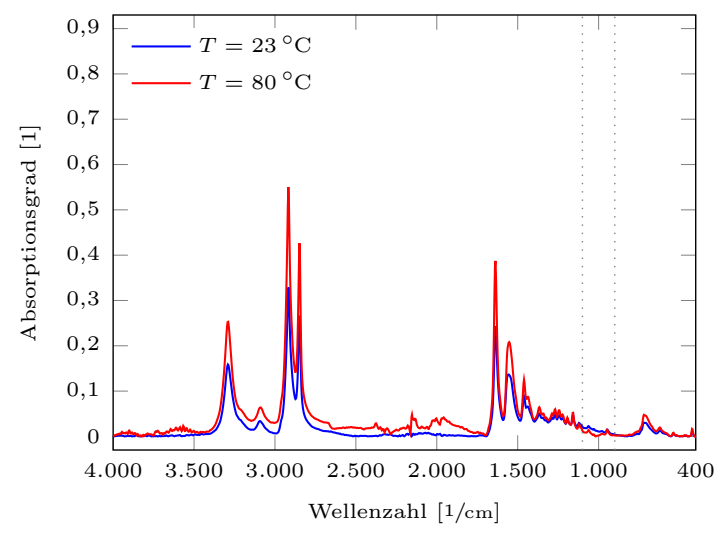

(a) EOS PA2200 (PA12)

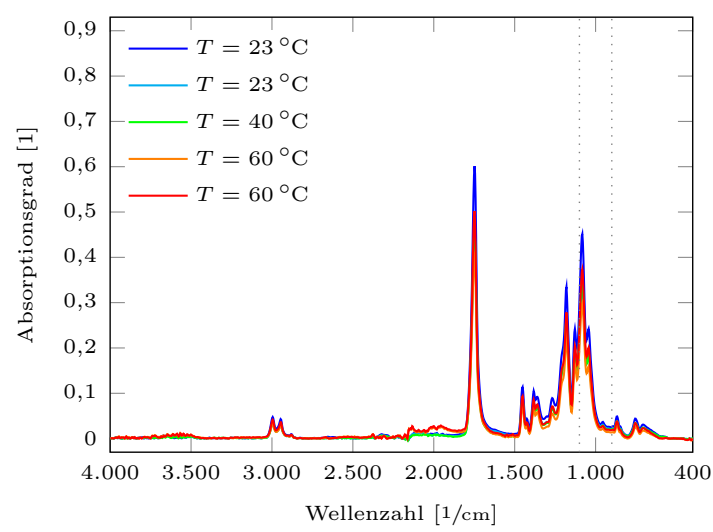

(c) Purasorb PLG 8523 (PLGA)

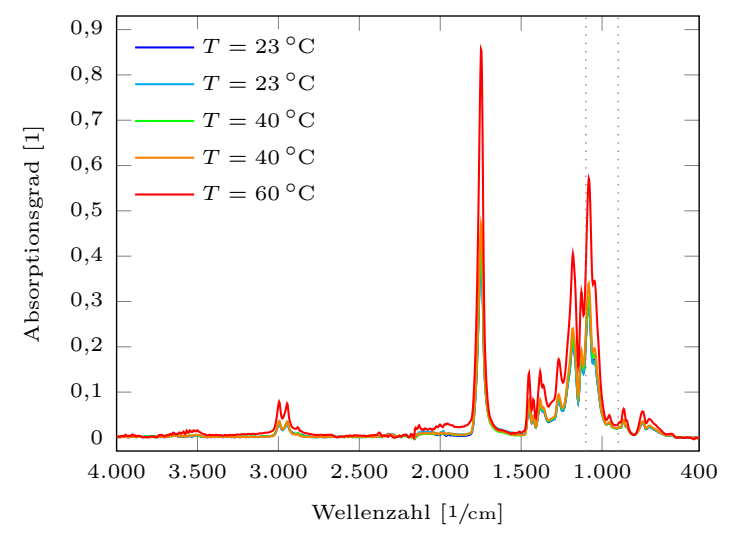

(b) Resomer RG 755 S (PLGA)

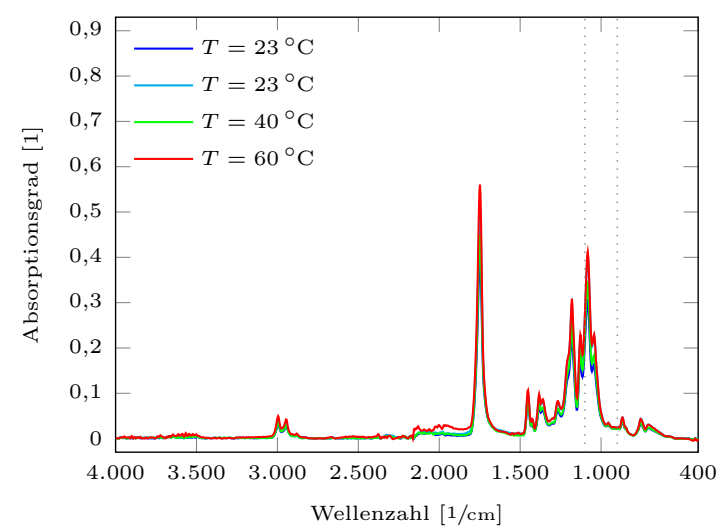

(d) Purasorb PLG 8531 (PLGA)

Abbildung 7.9.: FTIR-Spektren von PA12 und PLGA von 4000 1/cm bis $4001 / \mathrm{cm}$

\subsubsection{Bestimmung der Wellenlänge zum Lasersintern von PLGA}

Kommerziell erhältliche Kohlenstoffdioxidlaser emittieren Strahlung im Bereich 9,3 $\mu \mathrm{m}$ $(\tilde{\nu}=10751 / \mathrm{cm}), 9,6 \mu \mathrm{m}(\tilde{\nu}=10411 / \mathrm{cm}), 10,3 \mu \mathrm{m}(\tilde{\nu}=9701 / \mathrm{cm})$ oder $10,6 \mu \mathrm{m}(\tilde{\nu}=$ 
$9431 / \mathrm{cm})$. Die Spektren der vier verschiedenen Materialien im Wellenzahlbereich von $11001 / \mathrm{cm}(\lambda=9,1 \mu \mathrm{m})$ bis $9001 / \mathrm{cm}(\lambda=11,1 \mu \mathrm{m})$ sind grafisch mit identischer Achsskalierung in Abbildung 7.10 dargestellt. In den Spektren der PLGA-Werkstoffe steigt der Grad der Absorption zu höheren Wellenzahlen (niedrigeren Wellenlängen) stark an. Die arithmetischen Mittelwerte der Absorptionsgrade sind in den jeweiligen Abbildungen vermerkt. Durch die Verwendung eines $\mathrm{CO}_{2}$-Lasers einer Wellenlänge von 9,3 $\mu \mathrm{m}$ $(\tilde{\nu}=10751 / \mathrm{cm})$, anstelle eines $\mathrm{CO}_{2}$-Lasers einer Wellenlänge von 10,6 $\mu \mathrm{m}(\tilde{\nu}=9431 / \mathrm{cm})$, kann die Absorption der elektromagnetischen Strahlung durch das PLGA um den Faktor 10 auf ca. $33 \%$ gesteigert werden. Das im Lasersinterprozess verarbeitete Pulver besteht aus Partikeln und Poren. Durch den geometrisch komplexeren Wechselwirkungswirkungs-

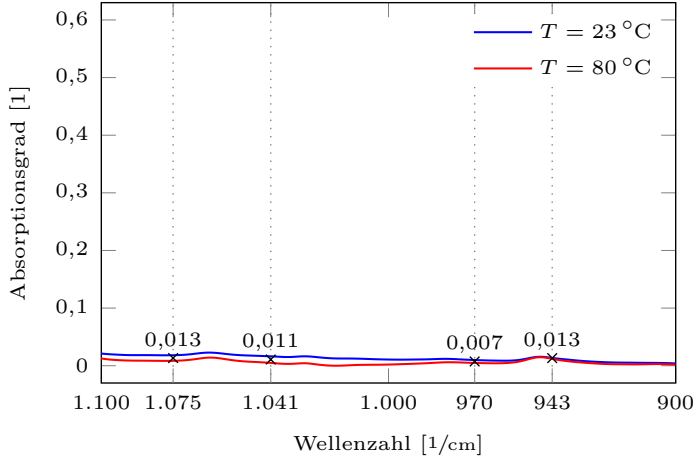

(a) EOS PA2200 (PA12)

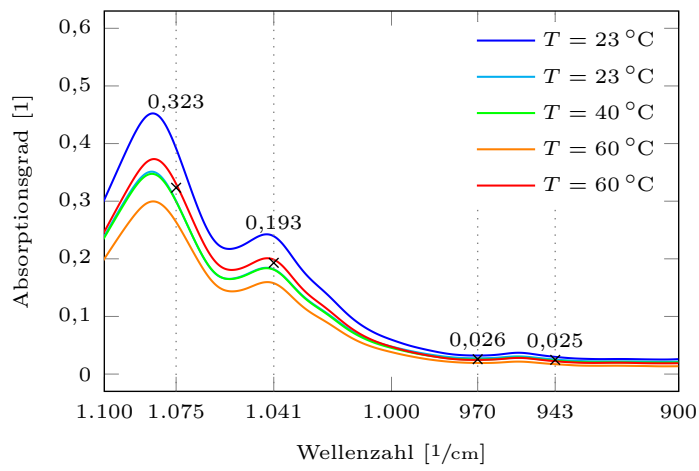

(c) Purasorb PLG 8523 (PLGA)

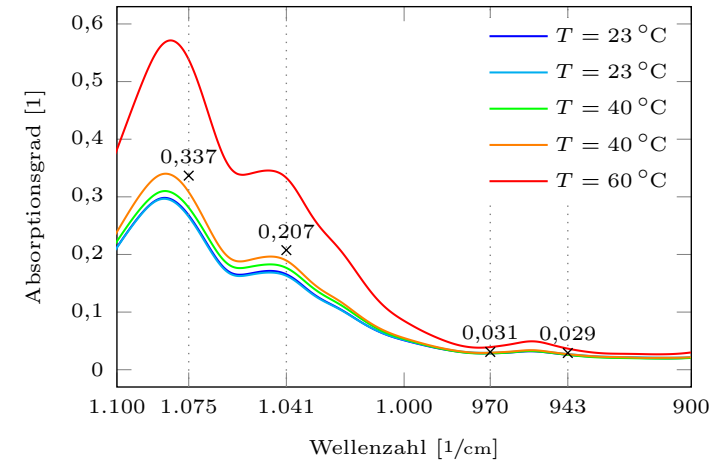

(b) Resomer RG 755 S (PLGA)

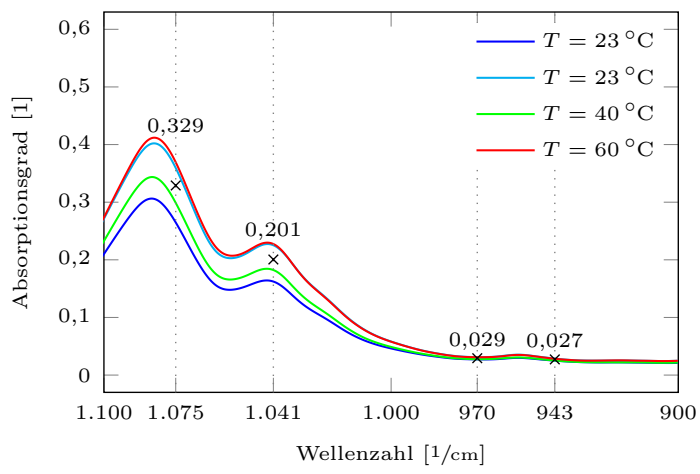

(d) Purasorb PLG 8531 (PLGA)

Abbildung 7.10.: FTIR-Spektren von PA12 und PLGA von 11001/cm bis 9001/cm

prozess von elektromagnetischer Strahlung und den pulverförmigen Werkstoffen wird der Absorptionsgrad der $100 \mu \mathrm{m}$ starken Pulverschicht durch Mehrfachreflexionen zwischen den Partikeln als weitaus höher angenommen. Bei der Laser-Materie-Wechselwirkung dient die transmittierte Strahlung der Erzeugung einer mechanisch belastbaren Schichthaftung mit den bereits generierten Bauteilschichten [Sch15b, S. 91-95]. Zur Bestimmung der Transmission und Reflexion, die im Rahmen der vorliegenden Arbeit nicht durchgeführt werden konnte, wird ein Ulbricht-Kugel-Messaufbau benötigt [LSA+13]. Die Tabelle 7.1 
fasst die Mittelwerte $\left(\bar{x}_{\mathrm{A}_{\mathrm{rad}}}\right)$ und Standardabweichungen $\left(s_{\mathrm{A}_{\mathrm{rad}}}\right)$ der Absorptionsgrade bei den spezifischen Wellenlängen der Materialien zusammen. Die auffallend hohe Standardabweichung für das RG $755 \mathrm{~S}$ ist mit dem Ausreißer der Messreihe bei einer Vorheiztemperatur von $60^{\circ} \mathrm{C}$ zu begründen. Zum Lasersintern mit PLGA sollte folglich ein $\mathrm{CO}_{2}$-Laser mit einer Wellenlänge von 9,3 $\mu \mathrm{m}$ verwendet werden.

Tabelle 7.1.: Absorptionen von PLGA im Wellenlängenbereich der $\mathrm{CO}_{2}$-Laser

\begin{tabular}{|c|c|c|c|c|c|c|c|c|}
\hline \multirow{3}{*}{ Material } & \multicolumn{8}{|c|}{ Absorption bei Wellenzahl bzw. Wellenlänge } \\
\hline & \multicolumn{2}{|c|}{$\begin{array}{l}1075^{1} / \mathrm{cm} \\
9,3 \mu \mathrm{m}\end{array}$} & \multicolumn{2}{|c|}{$\begin{array}{c}1041^{1 / \mathrm{cm}} \\
9,6 \mu \mathrm{m}\end{array}$} & \multicolumn{2}{|c|}{$\begin{array}{l}970^{1} / \mathrm{cm} \\
10,3 \mu \mathrm{m}\end{array}$} & \multicolumn{2}{|c|}{$\begin{array}{l}943^{1} / \mathrm{cm} \\
10,6 \mu \mathrm{m}\end{array}$} \\
\hline & $\bar{x}_{\mathrm{A}_{\mathrm{rad}}}$ & $s_{\mathrm{A}_{\mathrm{rad}}}$ & $\bar{x}_{\mathrm{A}_{\mathrm{rad}}}$ & $s_{\mathrm{A}_{\mathrm{rad}}}$ & $\bar{x}_{\mathrm{A}_{\mathrm{rad}}}$ & $s_{\mathrm{A}_{\mathrm{rad}}}$ & $\bar{x}_{\mathrm{A}_{\mathrm{rad}}}$ & $s_{\mathrm{A}_{\mathrm{rad}}}$ \\
\hline PA2200 & $1,3 \%$ & $\pm 0,7 \%$ & $1,1 \%$ & $\pm 0,8 \%$ & $0,7 \%$ & $\pm 0,4 \%$ & $1,3 \%$ & $\pm 0,1 \%$ \\
\hline RG $755 \mathrm{~S}$ & $33,7 \%$ & $\pm 11,7 \%$ & $20,7 \%$ & $\pm 7,3 \%$ & $3,1 \%$ & $\pm 0,5 \%$ & $2,9 \%$ & $\pm 0,5 \%$ \\
\hline PLG 8523 & $32,3 \%$ & $\pm 4,9 \%$ & $19,3 \%$ & $\pm 3,1 \%$ & $2,6 \%$ & $\pm 0,5 \%$ & $2,5 \%$ & $\pm 0,5 \%$ \\
\hline PLG 8531 & $32,9 \%$ & $\pm 5 \%$ & $20,1 \%$ & $\pm 3,2 \%$ & $2,9 \%$ & $\pm 0,2 \%$ & $2,7 \%$ & $\pm 0,2 \%$ \\
\hline
\end{tabular}

\subsection{Laser-Scanner-Einheit zur Verarbeitung von PLGA}

Soll die in Kapitel 6 entwickelte Lasersintermaschine zukünftig zur Herstellung von bioresorbierbaren Implantatmatrizen aus PLGA verwendet werden, muss das Lasermodul um eine $10 \mathrm{~W}$ Laser-Scanner-Einheit mit einer Sonderwellenlänge von 9,3 $\mu \mathrm{m}$ ergänzt werden. Die in Abschnitt 7.4.1 dargestellte spezifische Anforderungsliste an die PLGA-Laser-Scanner-Einheit dient diesbezüglich als mögliche Grundlage zur Identifikation eines geeignetes Teilsystems. In Abschnitt 7.4.2 wird ein konkreter Systemvorschlag verfasst.

\subsubsection{Spezifische Anforderungsliste}

Gemäß der in Abschnitt 6.1.4 durchgeführten Modularisierung ist die Laser-ScannerEinheit eine Baugruppe des Lasermoduls. Zur Bestimmung einer geeigneten Brennweite für die am Strahlausgang des Scanners befindliche F-Theta-Linse (Planfeldlinse) fragen die Hersteller zur Auslegung des optischen Systems in der Regel den Arbeitsabstand ab. Der Arbeitsabstand ist definiert als der vertikale Abstand zwischen dem Strahleintritt am Scanner und der Fokussierebene (Pulverbettoberfläche) oberhalb der Bauplattform. Die Abbildung 7.11 stellt diesbezüglich die Einbausituation des Laser-Scanner-Demonstrators mit einem Arbeitsabstand von 338,5 $\pm 2,5 \mathrm{~mm}$ beispielhaft dar. Der Variable Anteil weist auf den Einfluss der aufgetragenen Schichtstärke auf die Verortung der Fokussierebene hin. Gemäß der spezifischen Anforderungsliste der modularen Lasersintermaschine ist die aufgetragene Pulverbetthöhe über der Prozesseinsatzplatte (vgl. Anforderung 10.5 in Tabelle A.1) von $0 \mathrm{~mm}$ bis maximal $5 \mathrm{~mm}$ einstellbar. Der Abstand zwischen der Oberseite der Prozesseinsatzplatte und der Oberseite der Laseretage (Auflage der Laser-ScannerEinheit) beträgt $268 \mathrm{~mm}$. Der vertikale Abstand zwischen Strahleintritt am Scanner und der Unterseite der Grundplatte des Laser-Scanner-Dummys, maßgeblich durch die Positionierung der Strahlquelle innerhalb der Baugruppe beeinflusst, beträgt in dieser 
Kapitel 7. Auswahl der materialspezifischen Laser-Scanner-Einheit am Beispiel PLGA

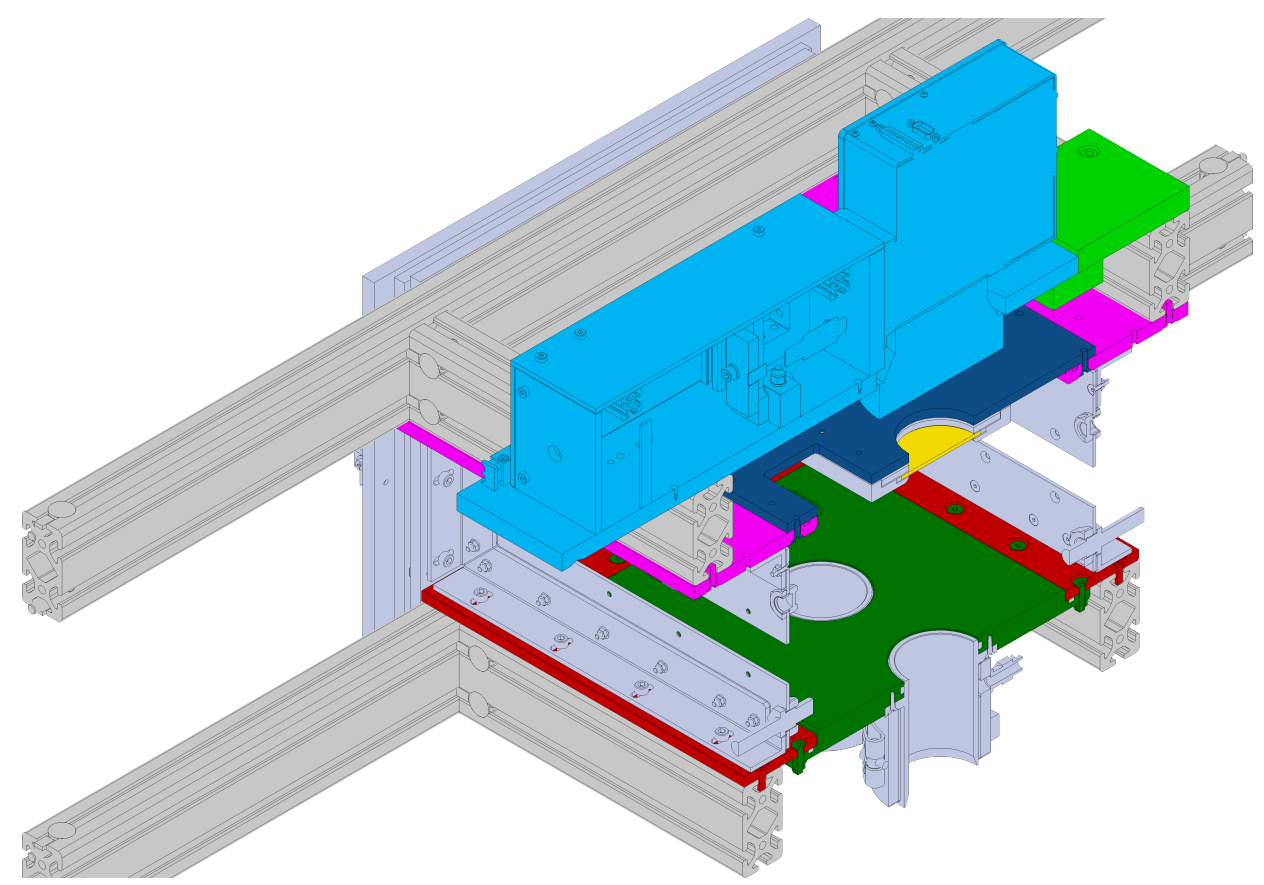

(a) ISO-Ansicht

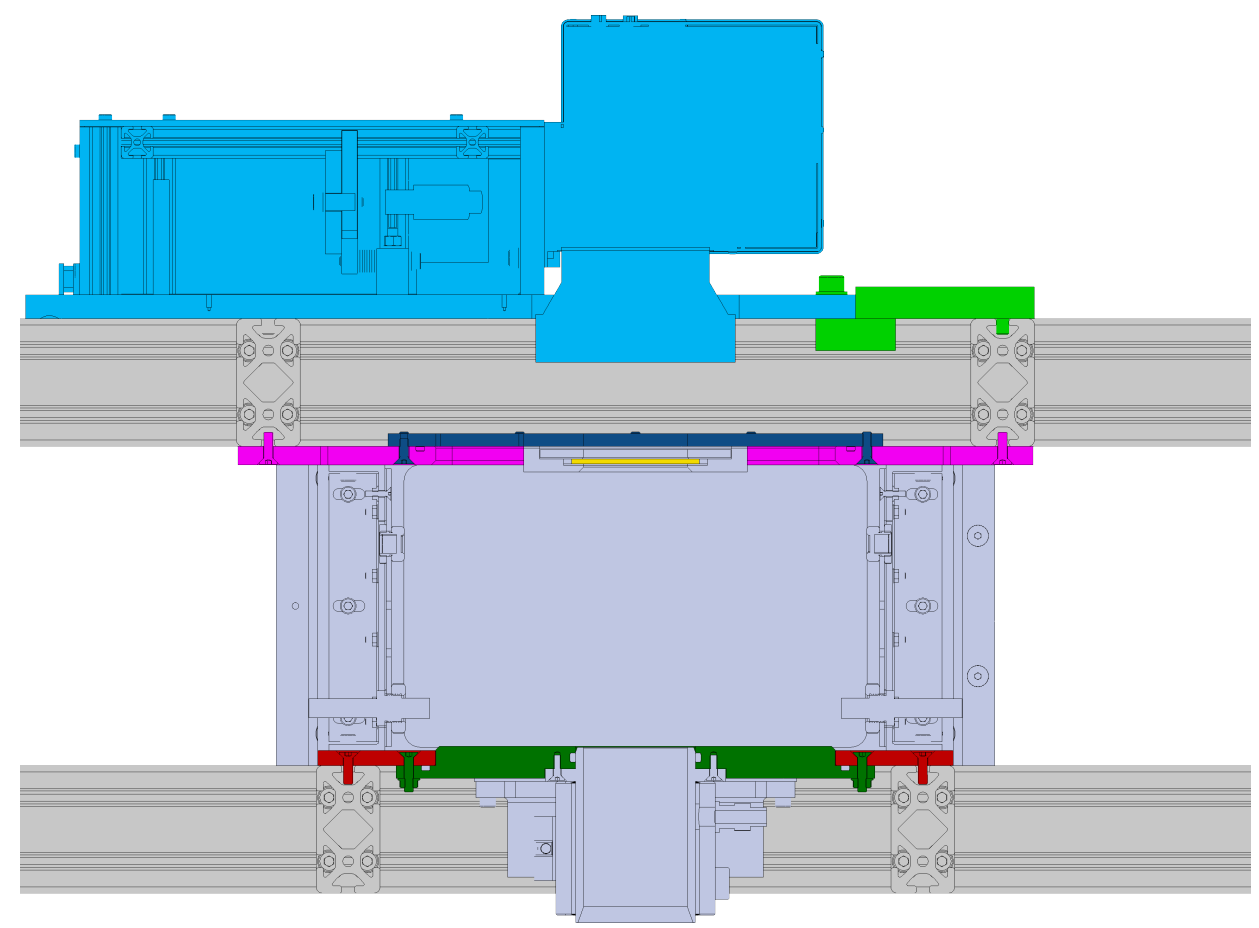

(b) Vorderansicht

Abbildung 7.11.: Schnittansicht der Prozesskammer: Alu-Konstruktionsprofile

\begin{tabular}{l} 
Prozessrahmenplatte Prozesseinsatzplatte Laserrahmenplatte \\
\hline Lasereinsatzplatte Laserglas Laser-Scanner-Dummy Halterung
\end{tabular}


spezifischen Einbausituation $73 \mathrm{~mm}$. Die Tabelle 7.2 stellt die spezifische Anforderungsliste zur Beschaffung einer PLGA-Laser-Scanner-Einheit dar. Die Anforderungsnummerierung impliziert die Erweiterung der in Abschnitt 6.1.1 dargestellten spezifischen Anforderungsliste der modularen Lasersintermaschine. Die Anforderung „Übergangsweiser Einsatz eines Laser-Scanner-Demonstrators als Dummy-Baugruppe" (vgl. Anforderung 12.7 in Tabelle A.1) wird entsprechend gestrichen.

Tabelle 7.2.: Spezifische Anforderungsliste der PLGA-Laser-Scanner-Einheit

\begin{tabular}{|c|c|c|}
\hline $\mathbf{F} / \mathbf{W}$ & \multicolumn{2}{|r|}{10} \\
\hline \multicolumn{3}{|r|}{ Spezifische Anforderungsliste der modularen Lasersintermaschine vgl. Abschnitt 6.1.1 } \\
\hline & 12. & Weitere Anforderungen an das bzw. aus dem Lasermodul \\
\hline W & 12.10 & Data Logging der optischen Laserleistung während der Bauteilschichtgenerierung \\
\hline $\mathrm{W}$ & 12.11 & Data Logging der Scangeschwindigkeit \\
\hline $\mathrm{W}$ & 12.12 & Data Logging des Scanabstands \\
\hline W & 12.13 & Integration eines „On-Axis"-Schmelzbadüberwachungssystems \\
\hline $\mathrm{F}$ & 12.14 & Einsatz einer $\mathrm{CO}_{2}$-Strahlquelle \\
\hline \multirow{16}{*}{$\mathrm{F}$} & $\hookrightarrow$ & Wellenlänge $9,3 \mu \mathrm{m}$ \\
\hline & $\hookrightarrow$ & Maximale Leistung $10 \mathrm{~W}$ \\
\hline & $\hookrightarrow$ & Gaußförmige Intensitätsverteilung \\
\hline & $\hookrightarrow$ & Temperaturstabilisierung durch den Einsatz einer Wasserkühlung \\
\hline & $\hookrightarrow$ & Digitaler PWM-Controller zur Steuerung der Laserleistung \\
\hline & $\hookrightarrow$ & Montage eines Sicherheits-Shutters am Strahlausgang (Sicherheitsaspekt) \\
\hline & 12.15 & Einsatz eines 2-achsigen Scan-Systems samt F-Theta-Linse (Planfeldlinse) \\
\hline & $\hookrightarrow$ & Maximaler Arbeitsbereich (Scanfeld): $70 \mathrm{~mm} \times 70 \mathrm{~mm}$ \\
\hline & $\hookrightarrow$ & Geometrische Abmessungen der zu scannenden Muster: $65 \mathrm{~mm} \times 65 \mathrm{~mm}$ \\
\hline & $\hookrightarrow$ & Art der zu scannenden Muster: interkonnektierende Porenstrukturen \\
\hline & $\hookrightarrow$ & Spiegel-Breitbandbeschichtung für Reflexion von Wellenlängen $9,3 \mu \mathrm{m}$ bis $10,6 \mu \mathrm{m}$ \\
\hline & $\hookrightarrow$ & Digitaler Positionsdetektor mit einer Auflösung von 20 Bit \\
\hline & $\hookrightarrow$ & Temperaturstabilisierung durch den Einsatz einer Wasserkühlung \\
\hline & $\hookrightarrow$ & Digitale PCI-Express-Reglerkarte samt zugehöriger Software \\
\hline & $\hookrightarrow$ & 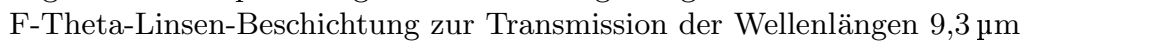 \\
\hline & $\hookrightarrow$ & Arbeitsabstand muss in Zusammenarbeit mit dem Hersteller definiert werden \\
\hline
\end{tabular}

\subsubsection{Auswahl eines geeigneten Teilsystems für das Lasermodul}

Ausgehend von den in Abschnitt 7.4.1 definierten Anforderungen an die PLGA-LaserScanner-Einheit wurde eine Strahlquelle der Firma Synrad in Kombination mit einem Galvanometer-Scanner der Firma Scanlab als geeignetes Teilsystem identifiziert. Die Anforderung „Einsatz einer $\mathrm{CO}_{2}$-Strahlquelle“ (vgl. Anforderung 12.14 in Tabelle 7.2) wird durch die Beschaffung der folgenden Komponenten erfüllt:

- Synrad $\mathrm{CO}_{2}$-Laser 48-1W / $8 \mathrm{~W} @ 9,3 \mu \mathrm{m} /$ wassergekühlte Version

- Netzteil für den Kohlenstoffdioxidlaser

- MCA Laser-Controller LCT 3001

- APEX LASER Shutter ELS11-A10 samt Shutter-Controller SLCU13DN

Die Strahlquelle besitzt in der Wellenlängenversion 10,6 $\mathrm{\mu m}$ eine maximale Ausgangsleistung von $10 \mathrm{~W}$. Der Laserstrahl tritt auf einer Höhe von ca. $80 \mathrm{~mm}$ aus dem Gehäuse der 
Strahlquelle aus. Wird die Strahlquelle analog zum Laser-Scanner-Dummy aus Abbildung 7.11 auf einer $15 \mathrm{~mm}$ starken Grundplatte angeordnet, kann der Arbeitsabstand von mindestens $363 \mathrm{~mm}(268 \mathrm{~mm}+80 \mathrm{~mm}+15 \mathrm{~mm})$ zur groben Auslegung der F-Theta-Linse genutzt werden. Die Anforderung „Einsatz eines 2-achsigen Scan-Systems samt F-ThetaLinse (Planfeldlinse)“ (vgl. Anforderung 12.15 in Tabelle 7.2) wird durch die Beschaffung der folgenden Komponenten erfüllt:

- Scanlab excelliSCAN 14 mit SCANahead Regelungstechnik und digitalen Encodern

- Netzteil für den Galvanometer-Scanner

- RTC6 Karte zur Scanneransteuerung durch das SL2-100 Übertragungsprotokoll

- laserDESK Software zur Zuweisung der Scanparameter

- F-Theta-Ojektiv mit einer Brennweite von $360 \mathrm{~mm}$ @ 9,3 $\mu \mathrm{m}$ samt Objektivhalter

Bei der Konstruktion der PLGA-Laser-Scanner-Einheit ist in Kombination mit der genannten Planfeldlinse ein Arbeitsabstand von $391 \mathrm{~mm}$ zu realisieren. Das Scan-System erfüllt, aufgrund der Möglichkeit zur echtzeitfähigen Erfassung von Spiegel-Position und Spiegel-Geschwindigkeit, die technisch anspruchsvollen Anforderungen „Data Logging der Scangeschwindigkeit" und „Data Logging des Scanabstands“ (vgl. Anforderungen 12.11 und 12.12 in Tabelle 7.2). Laut Scanlab ist die Integration eines „On-Axis"-Schmelzbadüberwachungssystems (vgl. Anforderung 12.13 in Tabelle 7.2) durch den Einsatz eines Scanlab Kameraadapters in Kombination mit $\mathrm{CO}_{2}$-Laser typischen Wellenlängen möglich. 


\section{Montage, Inbetriebnahme und Erprobung der Lasersintermaschine}

Die VDI-Richtlinie 2206 [VDI 2206] ist betitelt als „Entwicklungsmethodik für mechatronische Systeme“, ist vom VDI-Ausschuss A127 offiziell als Ergänzung zu der in Kapitel 6 angewendeten VDI-Richtlinie 2221 positioniert [VDI 2206, S. 8] und „besteht aus einem dreiteiligen Vorgehensmodell (Mikrozyklus, Makrozyklus, Prozessbausteine)“ [VDI 2206, S. 9]. Die Anwendung des Vorgehensmodells auf der Makroebene („V-Modell“) wird insbesondere bei der Erprobung der Lasersintermaschine zur Validierung des modularen Konzepts als zielführend bewertet. Bei dem V-Modell bilden die "Anforderungen“ den Ausgangspunkt und das „Produkt" das Ergebnis des durchlaufenden Makrozyklus, wobei das Durchlaufen mehrerer Makrozyklen in der Regel zu einer Steigerung der Produktreife beiträgt. Die „Eigenschaftsabsicherung“ innerhalb eines Zyklus stellt, durch den Abgleich von tatsächlichen und gewünschten Systemeigenschaften, einen elementaren Kontrollschritt dar [PBF+13, S. 18]. Die in Kapitel 6 entwickelte Lasersintermaschine wurde plangemäß hergestellt und in Betrieb genommen. In Abschnitt 8.1 ist das mechatronische Gesamtsystem nach der Montage dargestellt. In Abschnitt 8.2 wird die Funktionsfähigkeit der mechatronischen Teilsysteme der Lasersintermaschine überprüft und zur abschließenden Eigenschaftsabsicherung mit der in Abschnitt 6.1.1 definierten spezifischen Anforderungsliste der modularen Lasersintermaschine abgeglichen. 


\subsection{Mechatronisches Gesamtsystem}

Die modulare Lasersintermaschine samt Steuereinheit, dargestellt in Abbildung 8.1, ist im Labor für Maschinensysteme an der Technischen Universität Berlin aufgebaut. Das Gas für die Inertisierung der Prozesskammer wird aus einer 501 / 200 bar Gasflasche entnommen, die links neben dem Fenster mit einem Stahlflaschenständer gesichert ist. Der

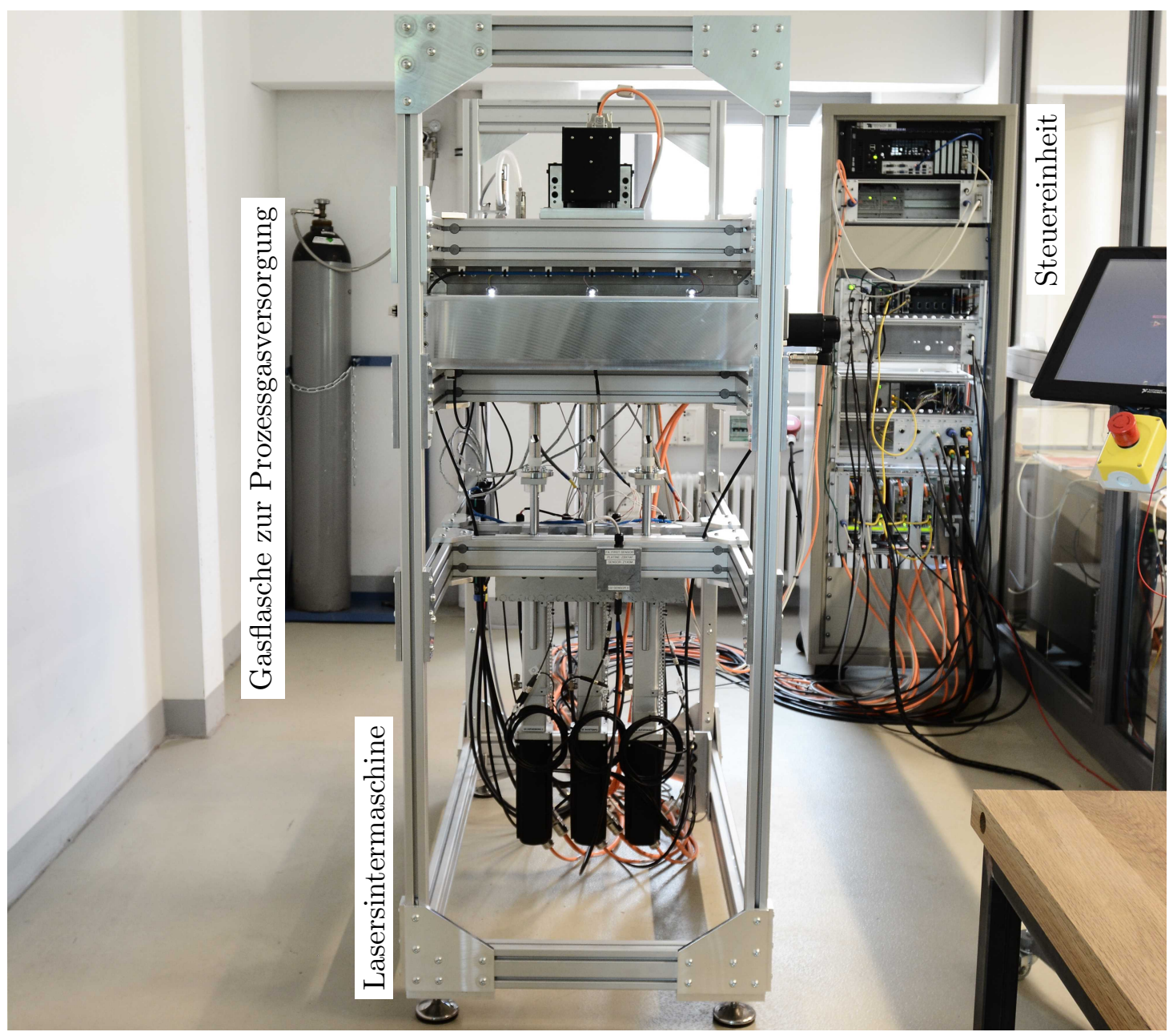

Abbildung 8.1.: Aufstellung der modularen Lasersintermaschine in Laborumgebung

Flaschendruck von maximal 210 bar wird über eine 2-stufige Entspannungsstation (Wandmontage rechts oberhalb der Flasche) auf einen Druck von 0 bar bis 7 bar reduziert. Der Ausgang der Entspannungsstation und der Eingang des Massendurchflussreglers an der Lasersintermaschine ist mit einer $12 \mathrm{~mm}$ Klemmringverschraubung ausgestattet und über einen PFA-Schlauch miteinander verbunden. Im Folgenden wird die Lasersintermaschine (Abschnitt 8.1.1) und die zugehörige Steuereinheit (Abschnitt 8.1.2) dargestellt. 


\subsubsection{Lasersintermaschine}

Durch den annähernd symmetrischen Aufbau der modularen Lasersintermaschine lässt sich die Prozesskammer sowohl von der Vorderseite als auch von der Rückseite über eine Tür öffnen. Die linke bzw. rechte Seite der Maschine ist definiert durch die "glatte“ Vorderseite (vgl. (a) / (b) Abbildung 8.2) der Lasersintermaschine. Der Servomotor des Pulverauftragmoduls (Q2) befindet sich als charakteristisches Bauteil auf der Rückseite (vgl. (c) / (d) Abbildung 8.2) der Maschine und kann zur Orientierung entsprechend genutzt werden. In der Vorderansicht ist die antriebsseitige Nebenkammer links bzw. die

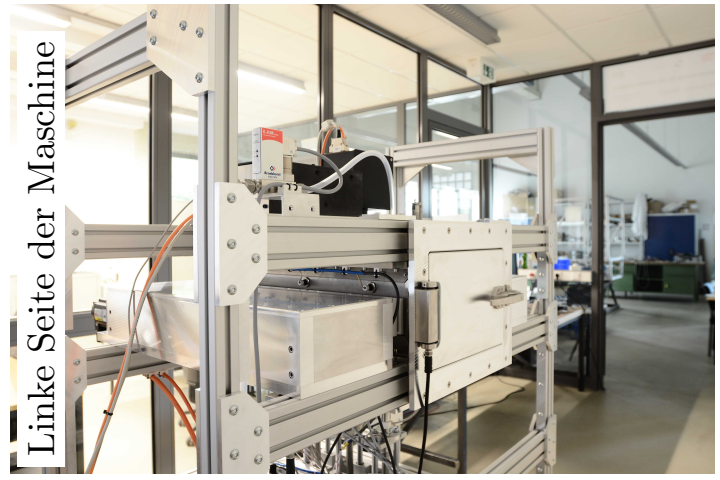

(a) Vorderansicht schräg Richtung Eingangstür

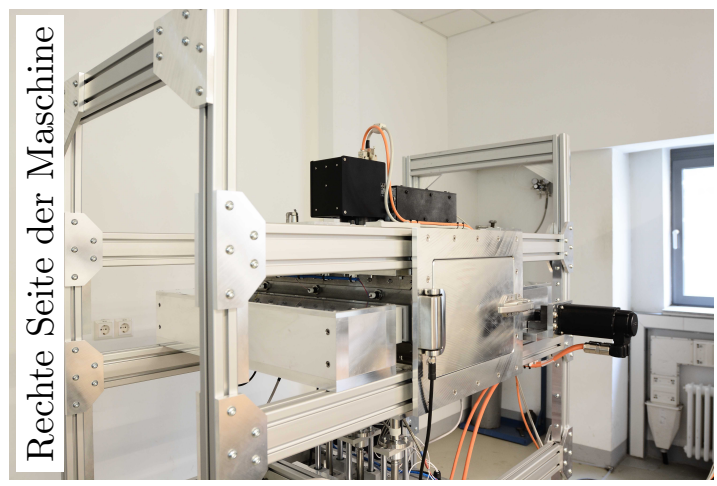

(c) Rückansicht schräg Richtung Fenster

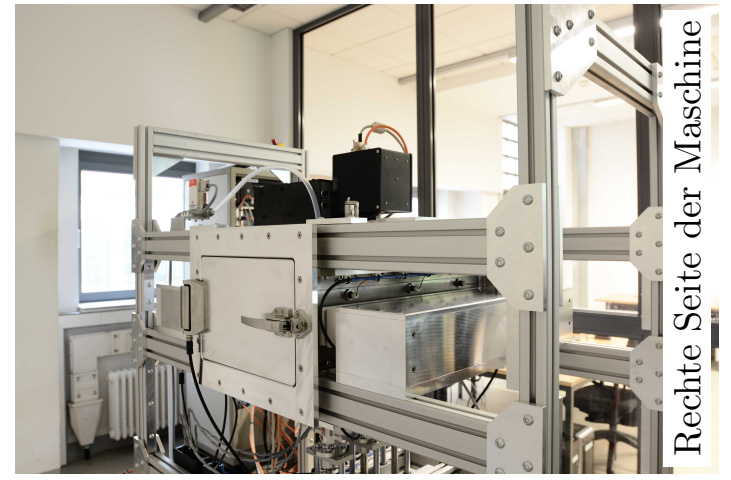

(b) Vorderansicht schräg Richtung Fenster

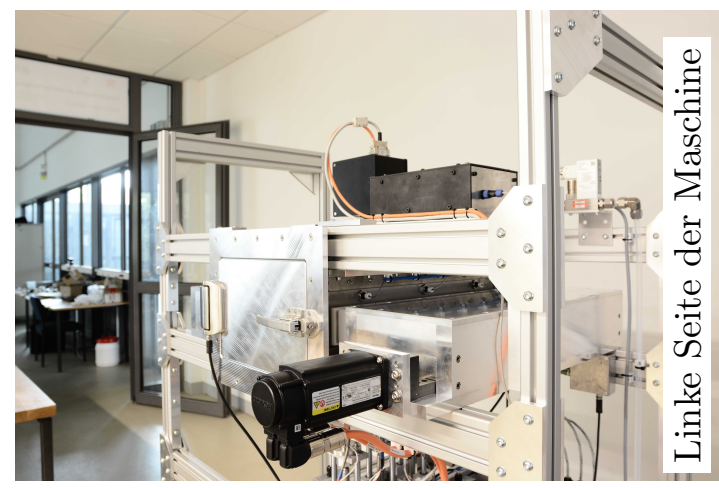

(d) Rückansicht schräg Richtung Eingangstür

Abbildung 8.2.: Definition von Vorder- und Rückseite der Lasersintermaschine

lagerseitige Nebenkammer rechts von der Prozesskammer angeordnet. Die Anordnung von Antriebsetage (unten), Prozessetage (mittig) und Laseretage (oben) ist in der Abbildung 8.2 dargestellt. Die Hubantriebsbaugruppe aus dem Baustempelmodul (Q1) und die zwei weiteren Hubantriebsbaugruppen aus dem Pulverzuführmodul (Q3 / Q4) sind als Hubantriebsbaugruppenpaket, dargestellt in Abbildung 8.3, an der Antriebsetage befestigt. Der Pulverzuführantrieb I (Q3) ist im Bereich der Rückseite der Lasermaschine, in der Nähe des Servomotors aus dem Pulverzuführmodul (Q2), montiert. Zur vertikalen Ausrichtung der Etagen im Grundrahmen werden Abstandhalter verwendet. Die Abbil- 
dung 8.3 (a) stellt die Abstandhalter zwischen Grundrahmen und Antriebsetage ( $570 \mathrm{~mm}$ ) bzw. Antriebsetage und Prozessetage $(293 \mathrm{~mm})$ sowie sämtliche Knotenbleche an den Enden der Aluminiumprofile dar. Die Abbildung 8.3 (b) stellt die Aufnahmeplatten und

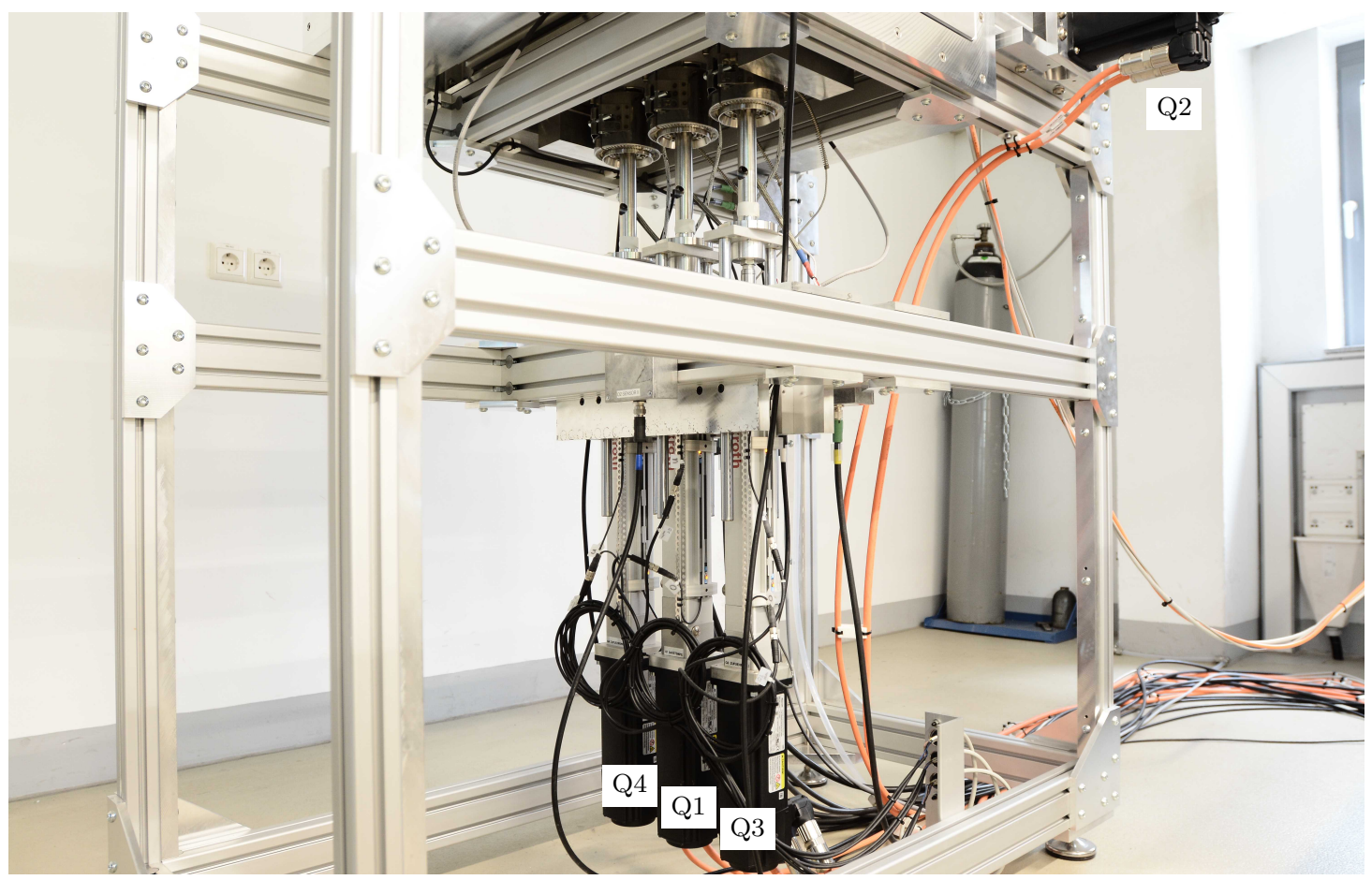

(a) Antriebsetage samt Hubantriebsbaugruppenpaket und Stempelbaugruppen

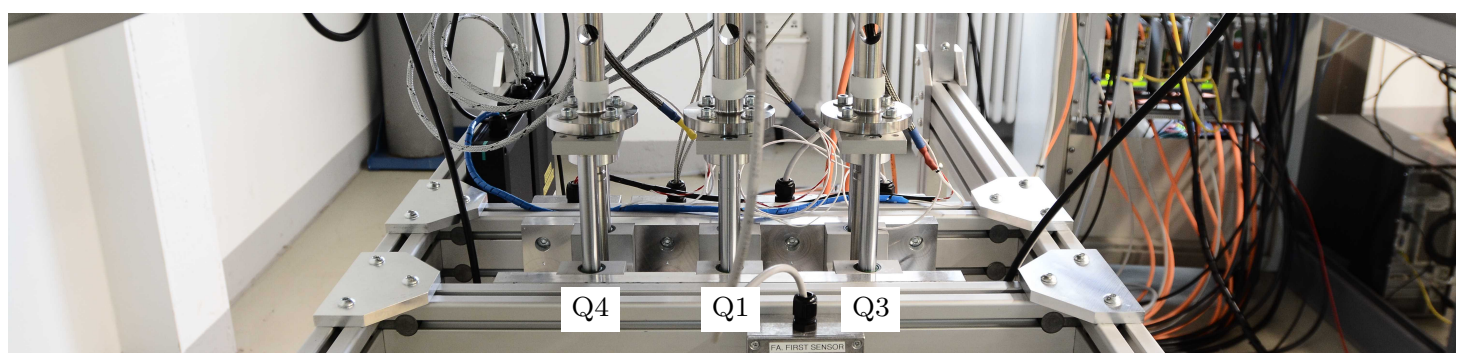

(b) Anbindung von Etage/Hubantriebsbaugruppenpaket bzw. Jochplatte/Stempelbaugruppe

Abbildung 8.3.: Hubantriebsbaugruppen aus dem Baustempel- und Pulverzuführmodul

die H-Führungen der Firma Festo des Hubantriebsbaugruppenpakets vergrößert dar. Zur Gewährleistung der parallelen Anordnung der drei Führungseinheitkorpusse sind in die Aufnahmeplatten passgenaue Aussparungen gefräst. Im Rahmen der Inbetriebnahme wurden die zweiteiligen Ausgleichskupplungen an den Führungseinheiten zur Reduktion des Umkehrspiels (vgl. Anhang D.5) durch eine starre Kupplung ersetzt. Die Stempelbaugruppen (Pulverzuführstempel Q4 / Baustempel Q1 / Pulverzuführstempel Q3) sind mit den Jochplatten der H-Führungen verschraubt. Die Abbildung 8.4 stellt das geregelte 6-Kanal-Heizsystem der Lasersintermaschine dar. Unterhalb der Prozesseinsatzplatte 
ist das Baustempelgehäuse (mittig), die zwei Pulverzuführgehäuse (jeweils rechts und links vom Baustempelgehäuse) und die zwei Überlaufbehälter (außen) angebracht. Drei Keramikheizbänder (abgekürzt mit „HG“) besitzen eine Leistung von jeweils $950 \mathrm{~W}$ und beheizen die Mantelflächen der Baustempel- und Pulverzuführgehäuse. Eine Stempelbaugruppe ist aus einer Abstandshantel und einer Stempelunterbaugruppe aufgebaut. In

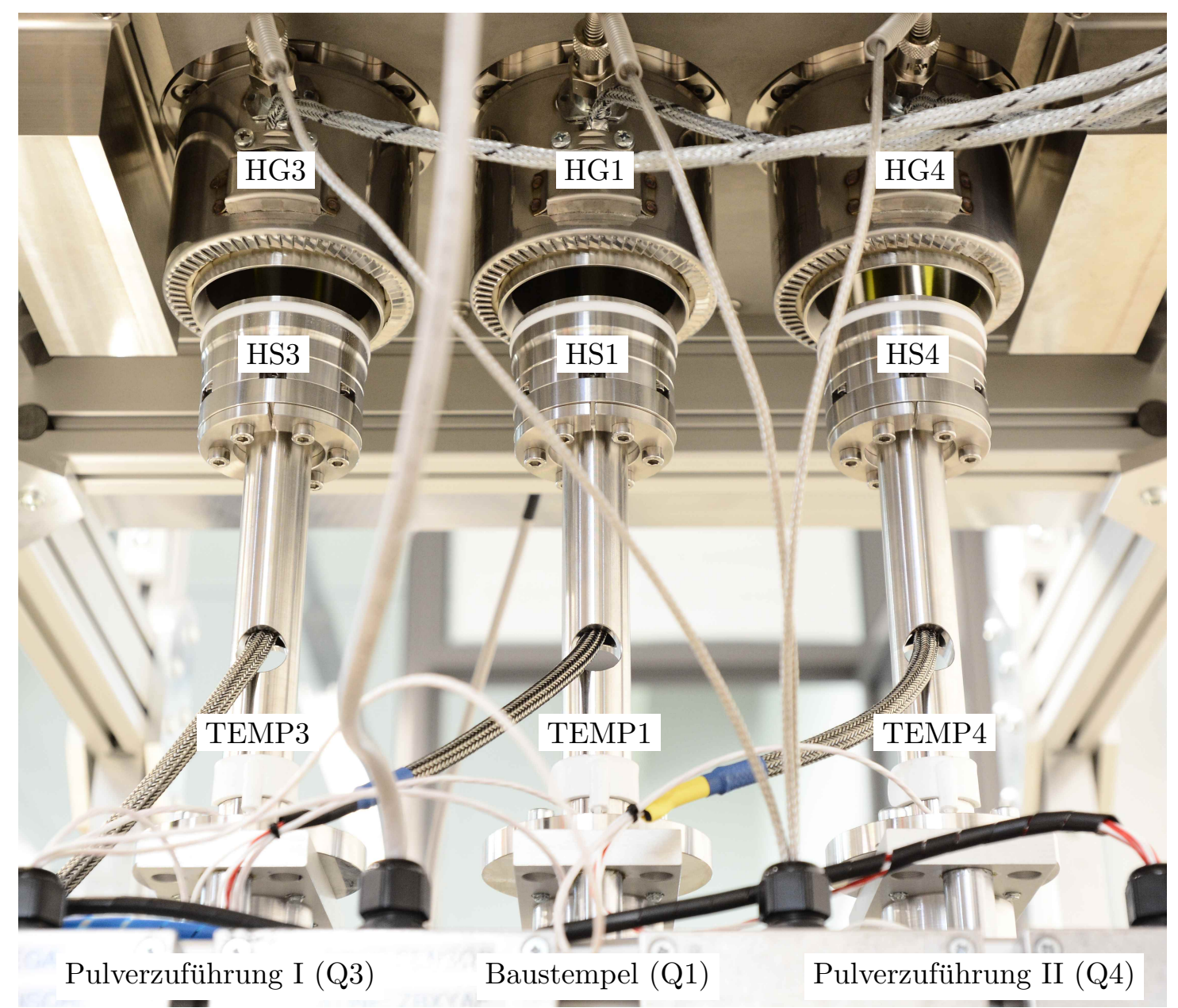

Abbildung 8.4.: 6-Kanal-Heizsystem unterhalb der Prozesseinsatzplatte

der Stempelunterbaugruppe ist auf der Unterseite des Stempeloberteils eine Silikonheizmatte (abgekürzt mit „HS“) verbaut, die zur Beheizung der Plattform genutzt wird. Zur Temperaturüberwachung sind PT100-Klebefühler an den Abstandshanteln (abgekürzt mit „TEMP“) angebracht. Die Nummerierung der Komponente richtet sich nach der Bezeichnung der Hubantriebsachse. Die im Stempeloberteil befindliche doppeltwirkende Kolbendichtung (Gleitring PTFE / Vorspannelement Silikon) dichtet die Plattform gegenüber der Gehäuseinnenwand ab. Zum mechanischen Schutz der Kolbendichtung wird die Stempelbaugruppe über die Einführschräge an der Gehäuseunterseite in das Gehäuse verfahren. Zur Reinigung/Desinfektion der produktberührten Oberflächen werden die 
Stempelbaugruppen in die in Abbildung 8.4 dargestellte Wartungsposition bewegt. Die Abbildung 8.5 stellt die Draufsicht (von schräg vorne) der Prozessetage nach erfolgter Montage der Prozessrahmenplatte (Maschinengestell), der Prozesseinsatzplatte mit Anbauteilen (Baustempelmodul) und dem Pulverauftragsmodul dar. Zum Zeitpunkt der Aufnahme sind Beschichtereinheit, Prozessgasmodul, Lasermodul sowie Laseretage samt Laserrahmenplatte (Maschinengestell) nicht montiert. Die wechselbare Beschichtereinheit wird in den oberhalb der Prozessebene befindlichen Auftragsschlitten eingeschraubt. Die

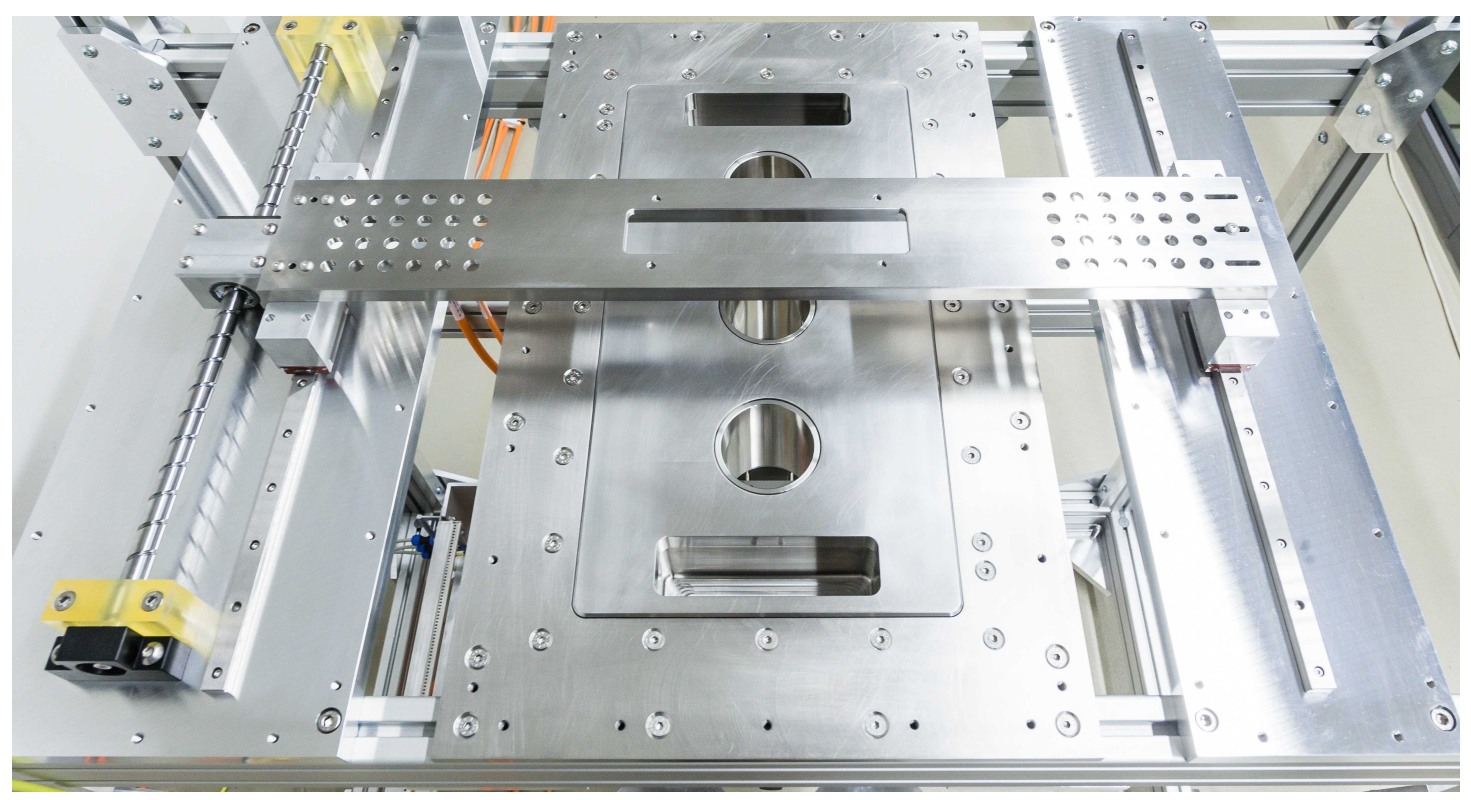

Abbildung 8.5.: Prozessrahmenplatte, Prozesseinsatzplatte und Pulverauftragsmodul

Langlöcher auf der rechten Seite des Auftragsschlittens ermöglichen eine ungehinderte Ausdehnung in der Auftragsschlitten-Längsrichtung infolge thermischer Expansion. Der Servomotor aus dem Pulverauftragsmodul (Q2) befindet sich in axialer Richtung zum Kugelgewindetrieb hinten links außerhalb der Abbildung. Die Gewindebohrmuster in den randnahen Bereichen der Prozessrahmenplatte (mittig), antriebsseitigen Grundplatte (links) und lagerseitigen Grundplatte (rechts) werden (mit Ausnahme einiger Bohrungen in der Prozessrahmenplatte) zur Montage des Prozessgasgehäuses (Prozessgasmodul) verwendet. Die Prozessrahmenplatte, die Prozesseinsatzplatte, alle metallischen Anbauteile der Prozesseinsatzplatte sowie der Auftragsschlitten sind aufgrund der Nähe zum Fertigungsprozess aus dem A4 Edelstahl 1.4404 hergestellt. Zum Ausbau der wechselbaren Prozesseinsatzplatte wird die Einsatzplatte nach dem Lösen aller Senkschrauben von der Unterseite der Prozessrahmenplatte in vertikaler Richtung nach unten weg bewegt und unterhalb der Prozessetage entnommen. Soll das runde Bauvolumen $(\varnothing 65 \mathrm{~mm} \times 80 \mathrm{~mm})$ zu einem späteren Zeitpunkt verkleinert oder gegen ein eckiges Bauvolumen getauscht werden, kann die in Abbildung 8.6 dargestellte Prozesseinsatzplatte ausgetauscht werden. Die Mantelflächen der Baustempel- und Pulverzuführgehäuse (vgl. (b) Abbildung 8.6) besitzen einen Außendurchmesser von $80 \mathrm{~mm}$, an denen die Keramikheizbänder des Heiz- 
systems unterhalb der Prozesseinsatzplatte (vgl. Abbildung 8.4) befestigt werden. Die gedichteten Überlaufvolumina werden nach Abschluss des Lasersinterprozesses von der Prozesseinsatzplatte abgeschraubt und unterhalb der Prozessetage entnommen. Ist die

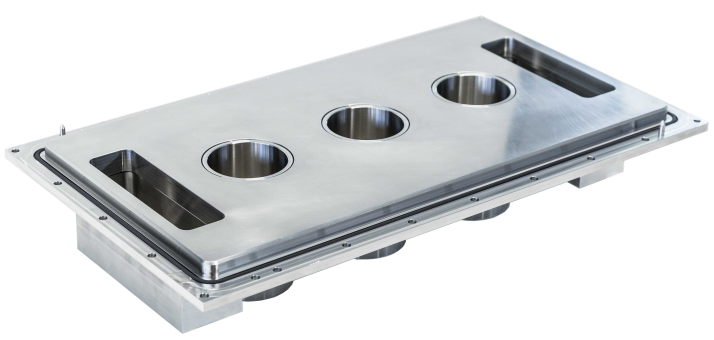

(a) Oberseite der gesamten Baugruppe

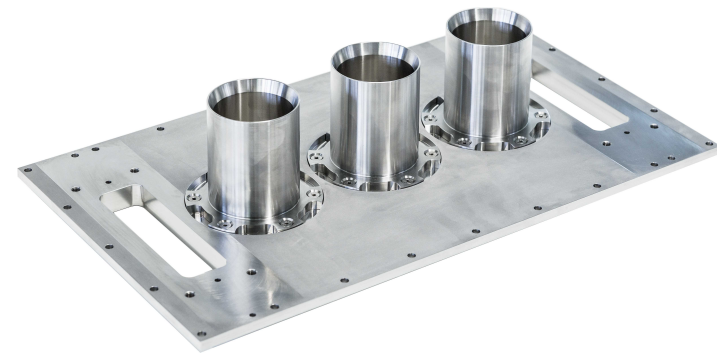

(b) Unterseite bei demontierten Überlaufbehältern

Abbildung 8.6.: Symmetrische Prozesseinsatzplatte samt Anbauteilen

Laseretage samt Laserrahmenplatte in dem Grundrahmen (Maschinengestell) angeordnet, kann die Montage des Prozessgasgehäuses (Prozessgasmodul) in spezifischer Reihenfolge durchgeführt werden. Sind die Wände der lagerseitigen bzw. antriebsseitigen Nebenkammer aufgestellt, werden die Türrahmenplatten an die Stirnseiten der Prozess- und Laseretage geschraubt. Die auf der Türrahmenplatte montierte Türbaugruppe ist in Abbildung 8.7 dargestellt. Auf der Außenseite der Türbaugruppe ist das Sicherheits-

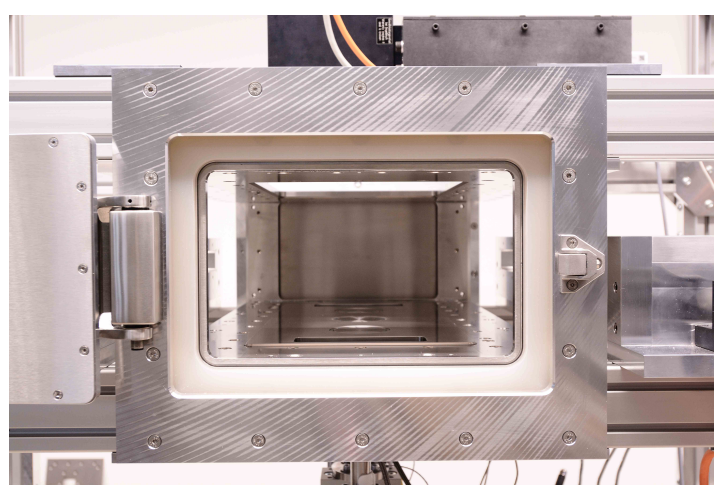

(a) Geöffnete Türbaugruppe

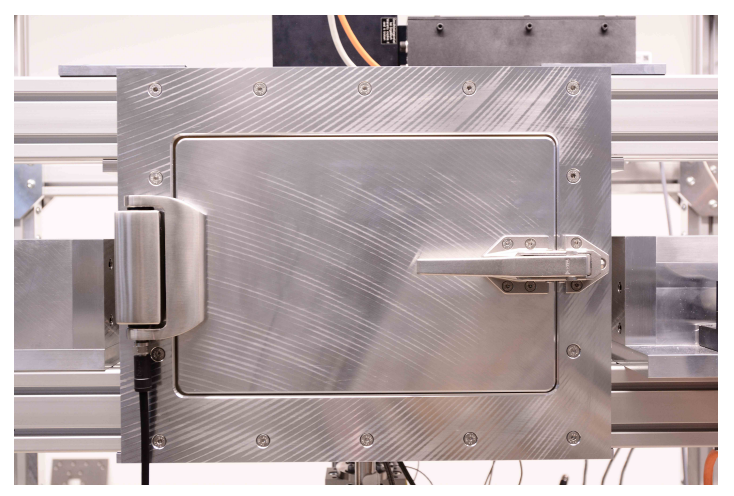

(b) Geschlossene Türbaugruppe

Abbildung 8.7.: Rückseitige Türbaugruppe der Prozesskammer

Schaltscharnier (vgl. (b) Abbildung 8.7) mit integrierten Öffner- und Schließerkontakten verschraubt. Ist die Tür nur minimal geöffnet, sind sämtliche mechatronischen Teilsysteme der Lasersintermaschine still gesetzt. Vor der Montage der Prozesskammerwandbaugruppe innerhalb der Prozesskammer müssen die PTFE-Verbindungskammern an die Innenseiten der lagerseitigen und antriebsseitigen Nebenkammern geschraubt sein. An einer Prozesskammerwand sind drei Schaugläser und ein Sauerstoffsensor angeordnet. Die Kammerbeleuchtung ist aufgebaut aus insgesamt sechs $5 \mathrm{~mm}$ LEDs (Abstrahlwinkel 
$75^{\circ} /$ Lichtstärke $14000 \mathrm{mcd}$ ). Diese werden von der Außenseite der Prozesskammer in lasergesinterten Halterungen an den Schaugläsern befestigt. Die Sauerstoffsensoren (vgl. (b) Abbildung 8.8) sind in unmittelbarer Nähe zum Bauvolumen platziert und messen den Restsauerstoffgehalt in der Prozesskammer. Ist der Auftragsschlitten des Pulverauftragmoduls über die antriebsseitige Nebenkammer in die Prozesskammer eingeführt und remontiert, kann die wechselbare Beschichtereinheit aufgeschraubt werden. Die Abbildung 8.8 stellt sowohl die Beschichtereinheit mit starrer Klinge als auch mit rotierender Rolle dar. Die Abbildung 8.9 stellt die Lasereinsatzplatte mit sämtlichen Anbauteilen dar.

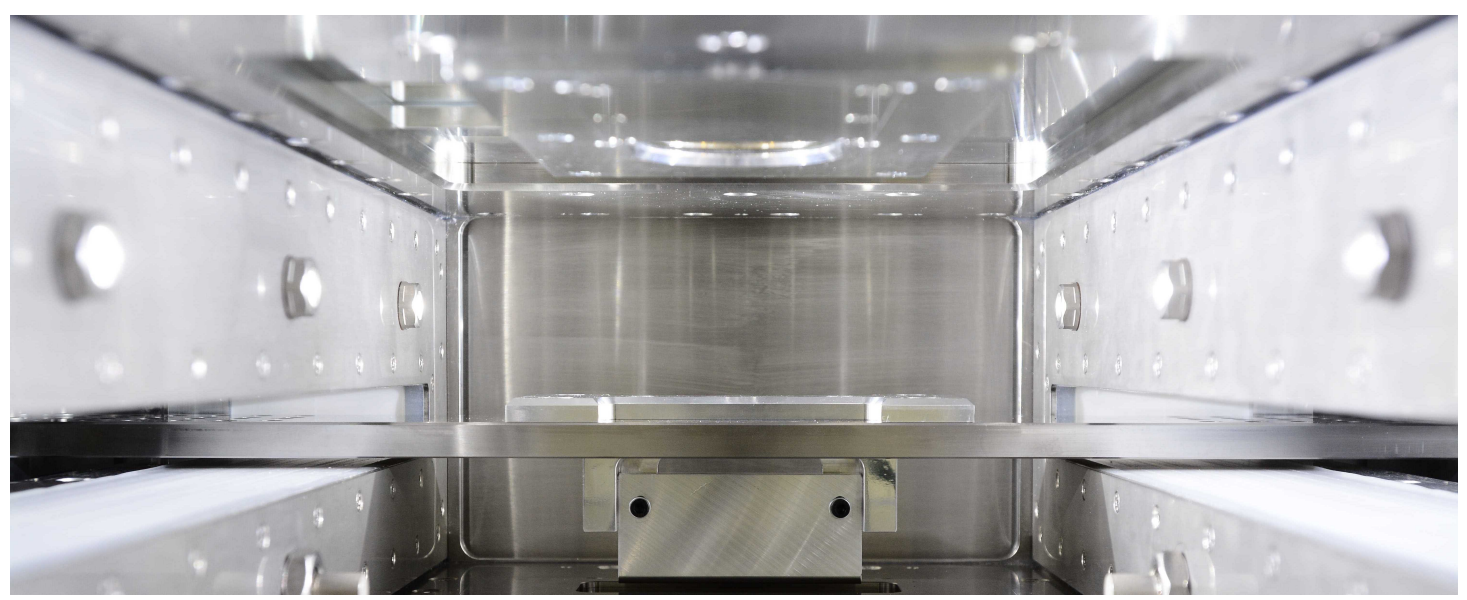

(a) Beschichtereinheit mit starrer Klinge \& Lasereinsatzplatte an der Laserrahmenplatte

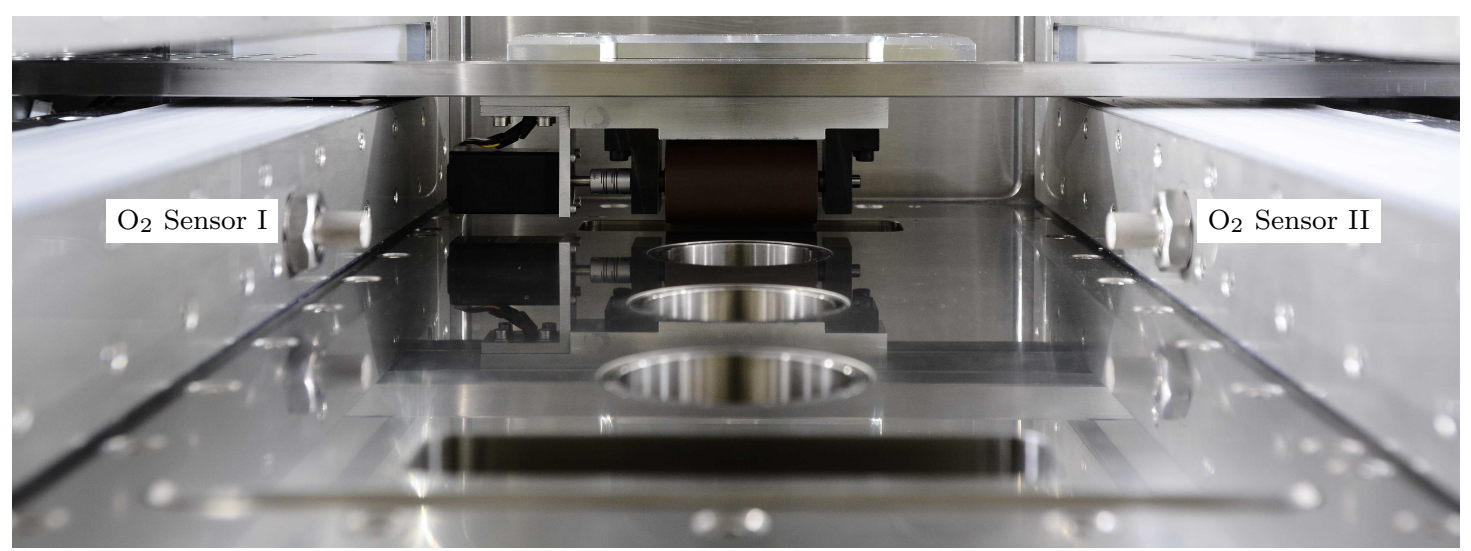

(b) Beschichtereinheit mit rotierender Rolle \& Prozesseinsatzplatte an der Prozessrahmenplatte

Abbildung 8.8.: Wechselbare Beschichtereinheiten in der Prozesskammer

Das Prozessgas wird durch den Bronkhorst Massendurchflussregler von der Oberseite der Lasereinsatzplatte durch den Gaseinlass in die Laserglas-Prozessgas-Armatur eingeleitet, innerhalb der Baugruppe um $90^{\circ}$ umgelenkt und durch einen Diffusor hindurch laminar über die Unterseite des Laserglases geführt. Durch eine konstante Gaseinleitung wird die betriebsbedingte Verschmutzung des Laserglases reduziert. Durch das Überdruckventil am Gasauslass kann der Prozesskammerinnendruck einen Wert von 0,2 bar nicht übersteigen. 
Die Abbildung 8.10 stellt die Laseretage mit montierter Lasereinsatzplatte, den Bronkhorst Massendurchflussregler und den Laser-Scanner-Demonstrator von schräg oben dar.

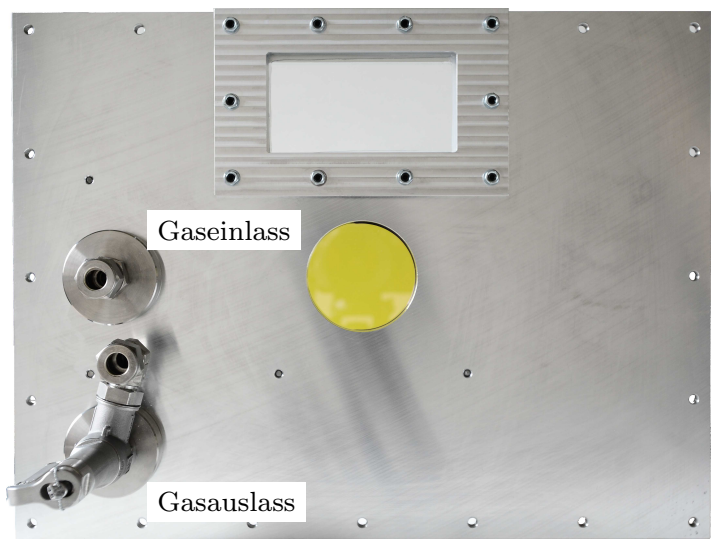

(a) Draufsicht

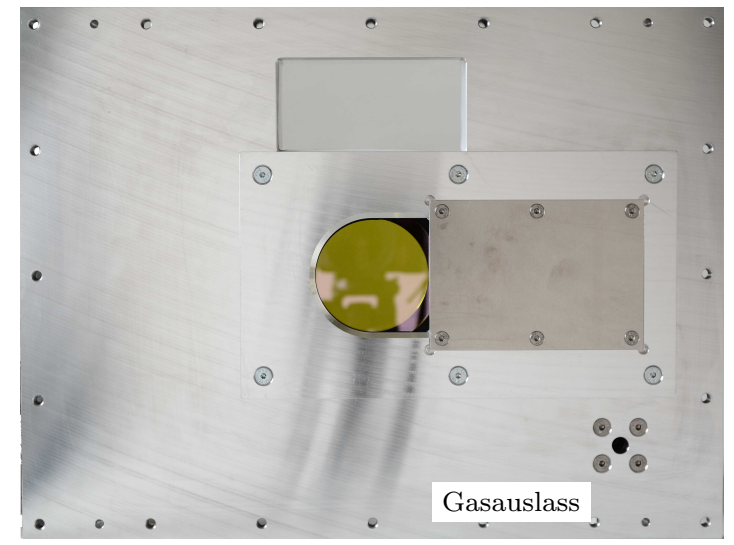

(b) Untersicht

Abbildung 8.9.: Lasereinsatzplatte samt Anbauteilen

Der durch den Pilotlaser emittierte Laserstrahl $\left(P_{\mathrm{L}}=2 \mathrm{~mW} / \lambda=635 \mathrm{~nm}\right)$ wird durch den Galvano-Scanner (für $\lambda=1064 \mathrm{~nm}$ ) in Richtung der Bauplattform umgelenkt und mittels koordinierter Spiegeldrehung in der x-y-Ebene positioniert. Zur Herstellung von bioresorbierbaren Implantatmatrizen aus PLGA würde der Laser-Scanner-Demonstrator durch die in Abschnitt 7.4.2 skizzierte PLGA-Laser-Scanner-Einheit ersetzt werden müssen.

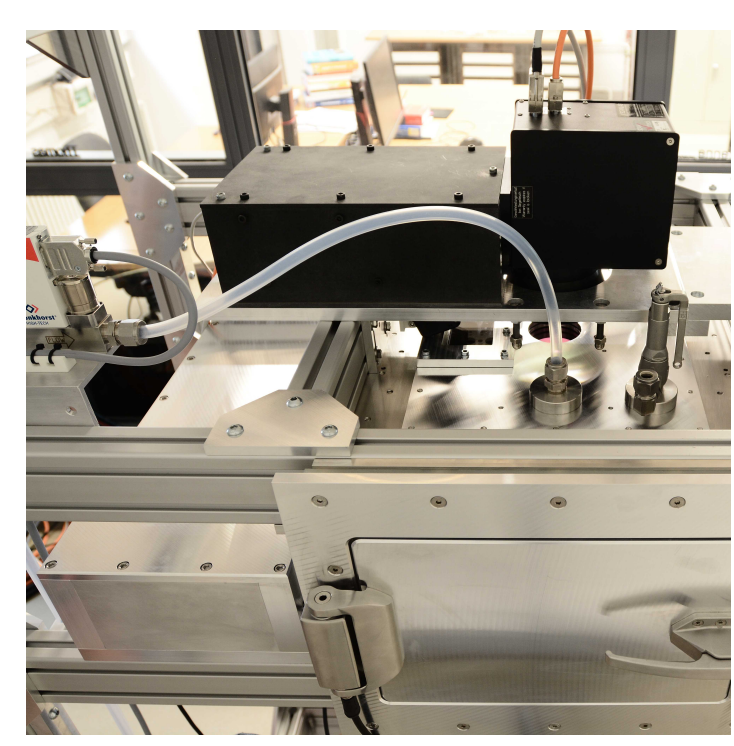

(a) Vorderansicht der Lasersintermaschine

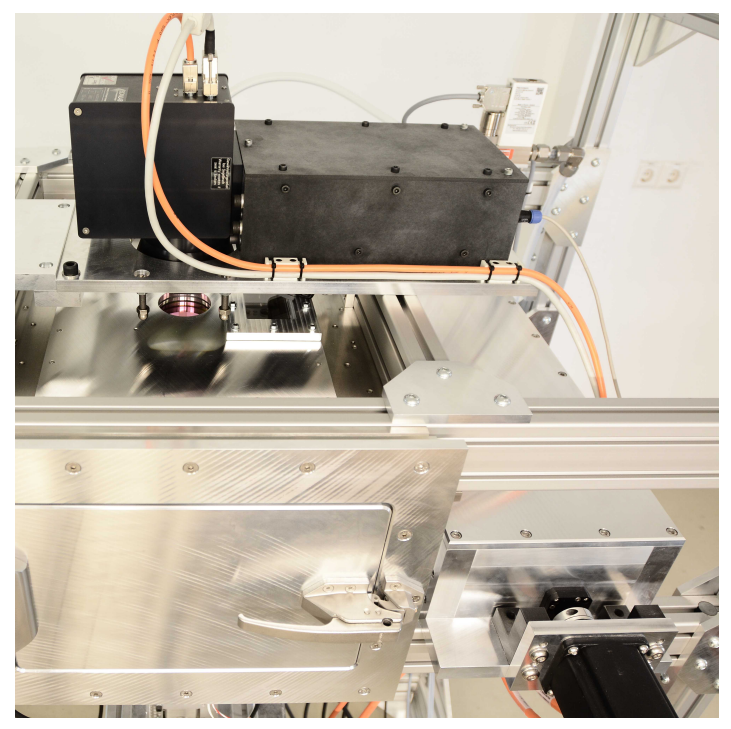

(b) Rückansicht der Lasersintermaschine

Abbildung 8.10.: Laseretage samt Prozessgasversorgung und Laser-Scanner-Dummy 


\subsubsection{Steuereinheit der Lasersintermaschine}

Die Steuereinheit der modularen Lasersintermaschine, dargestellt in Abbildung 8.11, ist in einem 19" Schroff Eurorack Schaltschrank (Gesamthöhe 38U) der Firma Pentair aufgebaut. Der CompactRIO-Controller 9035 in Kombination mit dem CompactRIO-Erweiterungschassis 9144 bilden das Steuersystem. Das cRIO-basierte Steu-

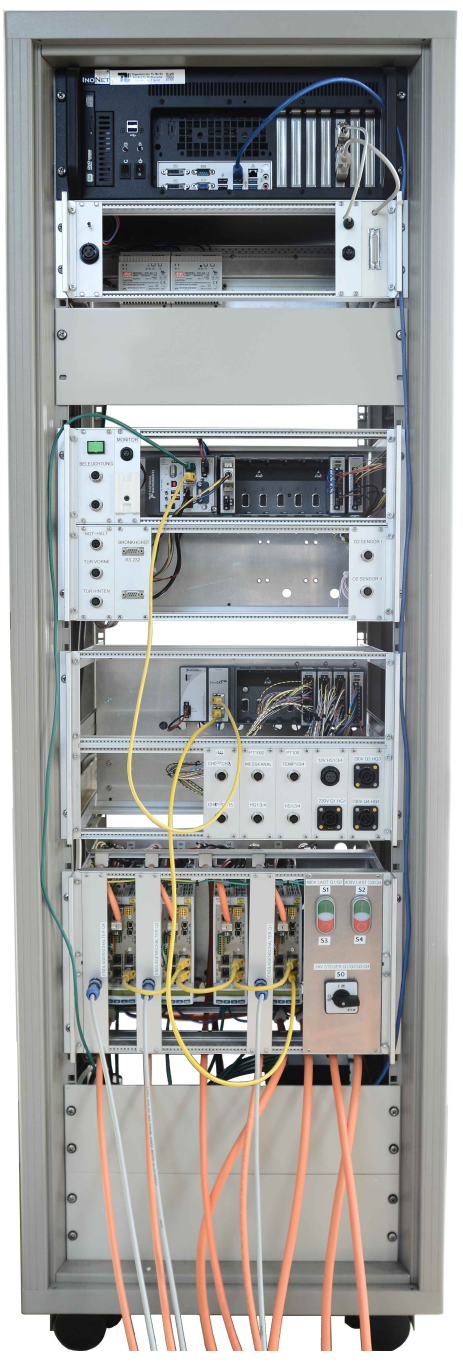

(a) Vorderansicht
Steuercomputer Laser-Scanner-Dummy

Baugruppenträger Laser-Scanner-Dummy

Baugruppenträger cRIO-Controller 9035

Baugruppenträger cRIO-Chassis 9144

Baugruppenträger der Bosch Rexroth Antriebsregelgeräte

Ethernet Switch Stromversorgung

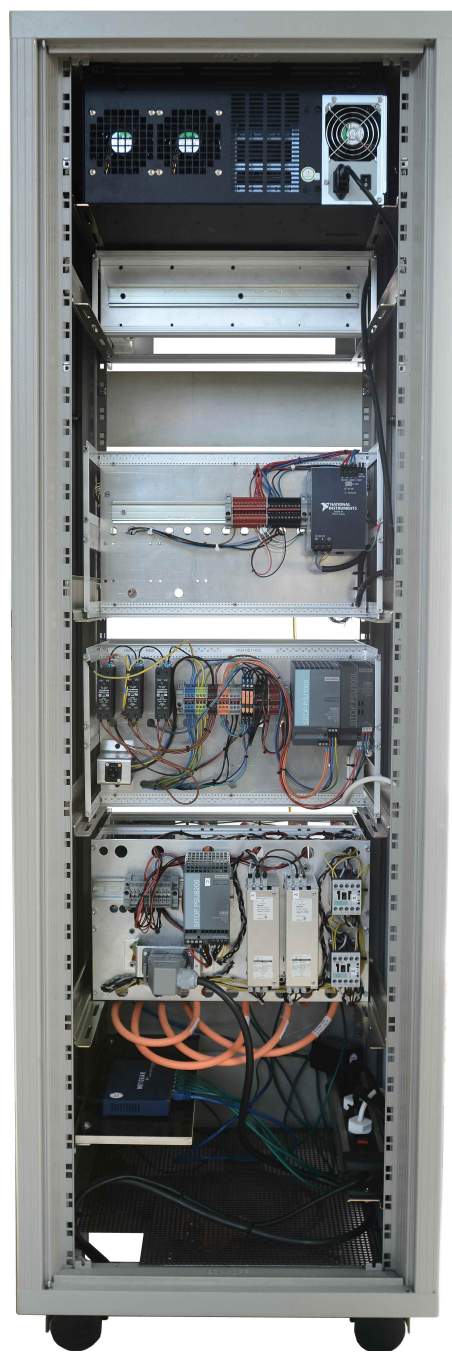

(b) Rückansicht

Abbildung 8.11.: Steuereinheit der Lasersintermaschine

ersystem, der Touchscreen-Monitor und der Schaltschrank sind Komponenten des Maschinengestells. Detaillierte Informationen zur verwendeten Schaltschranktechnik (vgl. Anhang C.1) und dem CompactRIO-Controller (vgl. Anhang C.2) sind in den entsprechenden Abschnitten ergänzend dargestellt. Die Elektronik von Baustempelmodul, Pulverzuführmodul, Pulverauftragsmodul, Prozessgasmodul und Lasermodul ist 
in insgesamt vier Baugruppenträgern angeordnet. Im oberen Schaltschrankbereich ist ein Computer zur Steuerung des Laser-Scanner-Demonstrators eingeschoben. Der detaillierte Aufbau der Einschübe sowie die zur Erweiterung des CompactRIO-basierten Steuersystems verwendeten NI C-Module sind in den entsprechenden Anhängen der Baugruppenträger ergänzend dargestellt. Die elektrischen Verbindungen zwischen der Lasersintermaschine und dem Schaltschrank sind gemäß dem Verkabelungskonzept aus Anhang C.3 trennbar. Für die Netzwerkkommunikation und Stromversorgung ist im unteren Schaltschrankbereich ein Ethernet Switch mit 8 Anschlüssen (Netgear ProSAFE FS108), ein 230 V Einphasenwechselstrom-Anschluss (CEE 7/3 Mehrfachsteckdosenleiste) und ein $400 \mathrm{~V}$ Dreiphasenwechselstrom-Anschluss (Harting Han 6B Tüllengehäuse) angeordnet. Die modulspezifischen Teilsysteme der Lasersintermaschine werden an die jeweiligen Baugruppenträger wie folgt angeschlossen:

Baugruppenträger des NI cRIO-Controllers 9035 (Anhang C.4)

- Bedienelemente der Lasersintermaschine (Maschinengestell)

- Touchscreen-Monitor mit grafischer Benutzeroberfläche $\rightarrow$ MONITOR

- Not-Halt-Pilztaster-Einheit $\rightarrow$ NOT-HALT

- Submodul des Pulverauftragmoduls (Beschichtereinheit)

- Beschichtereinheit mit rotierender Rolle $\rightarrow$ ROLLE

- Beleuchtung und Türüberwachung der Prozesskammer (Prozessgasmodul)

- Beleuchtung der Prozesskammer $\rightarrow$ BELEUCHTUNG

- Sicherheits-Schaltscharnier der vorderen Türbaugruppe $\rightarrow$ TÜR VORNE

- Sicherheits-Schaltscharnier der hinteren Türbaugruppe $\rightarrow$ TÜR HINTEN

- Prozessgasversorgungssystem und Sauerstoff-Messsysteme (Prozessgasmodul)

- Massendurchflussregelventil $\rightarrow$ BRONKHORST

- Sauerstoff-Messsystem I $\rightarrow O_{2}$ SENSOR I

- Sauerstoff-Messsystem II $\rightarrow \mathrm{O}_{2}$ SENSOR II

Baugruppenträger des NI cRIO-Erweiterungschassis 9144 (Anhang C.5)

- Heizsystem für das Bauvolumen (Baustempelmodul)

- Keramikheizband am Baustempelgehäuse $\rightarrow$ Q1.HG1

- Temperatursensor am Baustempelgehäuse $\rightarrow$ PT1000.HG1

- Silikonheizmatte im Baustempel $\rightarrow$ Q1.HS1

- Temperatursensor im Baustempel $\rightarrow$ PT100.HS1

- Temperatursensor an der Abstandshantel $\rightarrow$ TEMP1

- Heizsystem für das Pulvervorratsvolumen I (Pulverzuführmodul)

- Keramikheizband am Pulverzuführgehäuse I $\rightarrow$ Q3.HG3 
- Temperatursensor am Pulverzuführgehäuse I $\rightarrow$ PT1000.HG3

- Silikonheizmatte im Pulverzuführstempel I $\rightarrow$ Q3.HS3

- Temperatursensor im Pulverzuführstempel I $\rightarrow$ PT100.HS3

- Temperatursensor an der Abstandshantel $\rightarrow$ TEMP3

- Heizsystem für das Pulvervorratsvolumen II (Pulverzuführmodul)

- Keramikheizband am Pulverzuführgehäuse II $\rightarrow$ Q4.HG4

- Temperatursensor am Pulverzuführgehäuse II $\rightarrow$ PT1000.HG4

- Silikonheizmatte im Pulverzuführstempel II $\rightarrow$ Q4.HS4

- Temperatursensor im Pulverzuführstempel II $\rightarrow$ PT100.HS4

- Temperatursensor an der Abstandshantel $\rightarrow$ TEMP4

Baugruppenträger der Bosch Rexroth Antriebsregelgeräte (Anhang C.6)

- Hubantriebsachse zur Positionierung der Bauplattform (Baustempelmodul)

- Leistungskabel für Servomotor Q1 $\rightarrow Q 1$

- Geberkabel für Servomotor Q1 $\rightarrow$ Q1D

- Fahrbereichsgrenzschalter des EMCs $\rightarrow$ ENDLAGENSCHALTER Q1

- Antriebsachse zur Bewegung der Beschichtereinheit (Pulverauftragsmodul)

- Leistungskabel für Servomotor Q2 $\rightarrow$ Q2

- Geberkabel für Servomotor Q2 $\rightarrow$ Q2D

- Hubantriebsachse zur Positionierung der Zuführplattform I (Pulverzuführmodul)

- Leistungskabel für Servomotor Q3 $\rightarrow$ Q3

- Geberkabel für Servomotor Q3 $\rightarrow$ Q3D

- Fahrbereichsgrenzschalter des EMCs $\rightarrow$ ENDLAGENSCHALTER Q3

- Hubantriebsachse zur Positionierung der Zuführplattform II (Pulverzuführmodul)

- Leistungskabel für Servomotor Q4 $\rightarrow$ Q4

- Geberkabel für Servomotor Q4 $\rightarrow Q 4 D$

- Fahrbereichsgrenzschalter des EMCs $\rightarrow$ ENDLAGENSCHALTER Q4

Baugruppenträger und Steuercomputer des Laser-Scanner-Dummys (Anhang C.7)

- Laser-Scanner-Demonstrator (Lasermodul)

- Leistungskabel für Galvano-Scanner $\rightarrow$ SCANNER

- Datenkabel für Galvano-Scanner $\rightarrow D A T A$

- Pilotlaser $\rightarrow$ LASER 


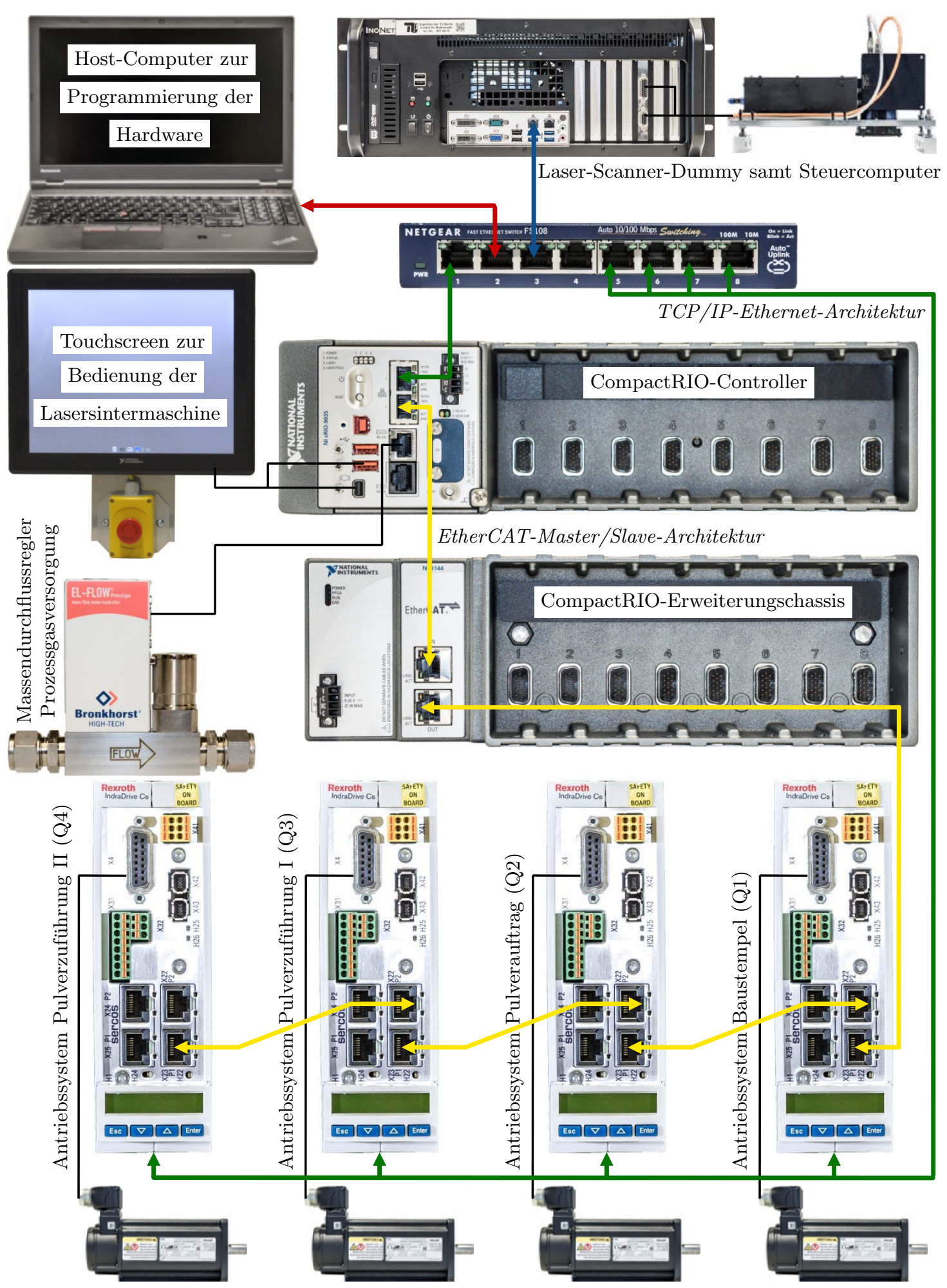

Abbildung 8.12.: Datenverarbeitung mit dem cRIO-basierten Steuersystem 
Die Abbildung 8.12 stellt die Datenverarbeitung mit dem CompactRIO-basierten Steuersystem dar. Die Einzelkomponenten sind über farbige RJ-45 Patchkabel in einem Netzwerk miteinander verbunden. Die Farbkodierung (vgl. farbige Linien in Abbildung 8.12) weist auf die Verwendung eines spezifischen Kommunikationsprotokolls hin:

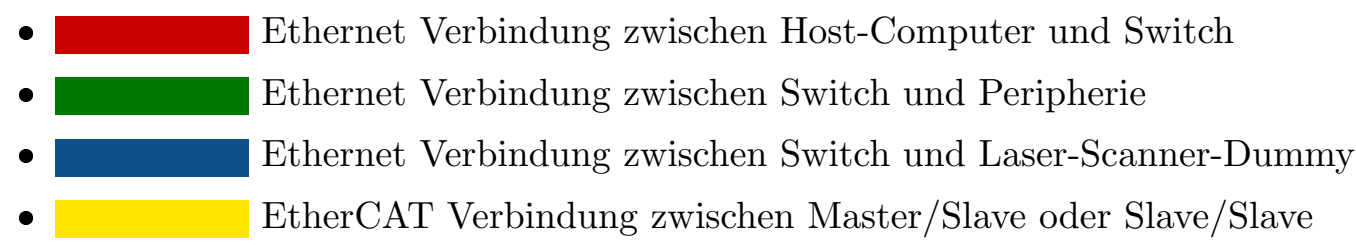

Auf dem Host-Computer (Betriebssystem Windows 7 64bit) ist die National Instruments Software „LabVIEW“ und die Bosch Rexroth Software „IndraWorks“ installiert. Zur Inbetriebnahme der Bosch Rexroth Antriebstechnik wird der Host-Computer via Ethernet mit dem jeweiligen Umrichter verbunden. Sind die in Anhang D dargestellten Arbeitsschritte durchgeführt, muss zur Vorbereitung auf die EtherCAT-Führungskommunikation das Protokoll CoE (CAN application protocol over EtherCAT) in den Antriebsregelgeräten ausgewählt werden. Die für den Betrieb der mechatronischen Teilsysteme der Lasersintermaschine notwendige Steuersoftware wird auf dem Host-Computer in LabVIEW programmiert und via Ethernet auf den cRIO-Controller 9035 übertragen. Das LabVIEW-Steuerprogramm ist gemäß der Modularisierung aus Abschnitt 6.1.4 in spezifische Unterprogramme (Sub-VIs) aufgeteilt und wird über eine grafische Benutzeroberfläche auf dem Touchscreen-Monitor bedient. Zur Kommunikation zwischen dem cRIO-Controller, dem cRIO-Erweiterungschassis und den insgesamt vier Bosch Rexroth Antriebsregelgeräten wird das echtzeitfähige Ethernet-Protokoll „EtherCAT" verwendet [Nat12]. Ausgehend vom cRIO-Controller 9035 (EtherCAT-Master) ist das Erweiterungschassis als EtherCAT-Slave I und die Antriebsregelgeräte als EtherCAT-Slave II bis EtherCAT-Slave V in einer Reihenschaltung miteinander verbunden [Nat16d]. Soll beispielsweise die Bauplattform um eine Schichtstärke abgesenkt werden, sendet der cRIO-Controller 9035 einen entsprechenden Steuerbefehl (z. B. Positionssollwert) via EtherCAT an das Antriebsregelgerät Q1. Die geregelte Anpassung vom Lageistwert auf den Lagesollwert der Hubantriebsachse (Prozesszustand „running“) übernimmt der adressierte Umrichter aus dem Baustempelmodul und meldet nach dessen Ausführung den Zustand „terminated“ an das CompactRIO zurück. Während des Prozessdurchlaufs können sämtliche achsspezifischen Ausgabewerte (Position / Geschwindigkeit / Antriebsmoment / Motortemperatur) zusätzlich ausgelesen und abgespeichert (Data Logging) werden. Das in Abbildung 8.12 dargestellte Massendurchflussregelventil der Firma Bronkhorst ist an die RS-232 Buchse des cRIO-Controllers angeschlossen und übermittelt während der Inertisierung der Prozesskammer Informationen bezüglich des Volumenstroms und der Gastemperatur. Die Steuerung des Laser-Scanner-Dummys wird durch einen separaten Computer durchgeführt. Soll der Prozessschritt „Bauteilschichtgenerierung“ ausgeführt werden, sendet das cRIO einen entsprechenden Steuerbefehl über die nicht echtzeitfähige Ethernet-Verbindung an die statische IP-Adresse des Steuercomputers des Laser-Scanner-Dummys. Sind die Befehle zur Belichtung der Bauteilschicht ausgeführt wird der Zustand "terminated" an den CompactRIO-Controller zurückgemeldet. 


\subsection{Funktionsabsicherung der mechatronischen Teilsysteme}

Im Folgenden wird die Funktionsfähigkeit der mechatronischen Teilsysteme der modularen Lasersintermaschine anhand von Systemtests überprüft und zur abschließenden Eigenschaftsabsicherung mit den in Abschnitt 6.1.1 definierten Anforderungen abgeglichen. Der Begriff „Eigenschaftsabsicherung“ subsumiert die aus dem Qualitätsmanagement stammenden Begriffe „Verifizierung“ und „Validierung“ [VDI 2206, S. 38]. Gemäß der DIN EN ISO 9000 [DIN EN ISO 9000] ist die Verifizierung als „Bestätigung durch Bereitstellung eines objektiven Nachweises, dass festgelegte Anforderungen erfüllt worden sind [DIN EN ISO 9000, S. 49]“ bzw. die Validierung als „Bestätigung durch Bereitstellung eines objektiven Nachweises, dass die Anforderungen für einen spezifischen beabsichtigten Gebrauch oder eine spezifische beabsichtigte Anwendung erfüllt worden sind [DIN EN ISO 9000, S. 50]“ definiert. Der objektive Nachweis, definiert als „Daten, welche die Existenz oder Wahrheit von etwas bestätigen“, kann durch „Beobachtung, Messung, Test oder anderen Mitteln erbracht werden [DIN EN ISO 9000, S. 46]“. Die Sicherheitseinrichtungen (Abschnitt 8.2.1), alle vier Bosch Rexroth Antriebsachsen (Abschnitt 8.2.2), das 6-Kanal-Heizsystem unterhalb der Prozesseinsatzplatte (Abschnitt 8.2.3), das Prozessgasversorgungssystem samt Sauerstoff-Messsystemen (Abschnitt 8.2.4) sowie der Laser-Scanner-Demonstrator und die Weitwinkelkamera im Bereich der Laseretage (Abschnitt 8.2.5) werden diesbezüglich überprüft. In Abschnitt 8.2.6 werden die Ergebnisse zur Funktionsabsicherung abschließend kritisch diskutiert.

\subsubsection{Sicherheitseinrichtungen}

Zum Schutz vor Arbeitsunfällen besitzt die Lasersintermaschine bzw. der Raum, in dem die Maschine aufgestellt ist, derzeit die folgenden Sicherheitseinrichtungen:

- Not-Halt-Pilztaster-Einheit

- Sicherheits-Schaltscharnier an der Türbaugruppe auf der Maschinenvorderseite

- Sicherheits-Schaltscharnier an der Türbaugruppe auf der Maschinenrückseite

- Sauerstoffmangel-Gaswarnanlage zur Überwachung der Umgebung

- Ventil des Massendurchflussreglers im unbestromten Zustand geschlossen

Die insgesamt sechs Öffnerkontakte aus dem Not-Halt-Pilztaster und den zwei Schaltscharnieren des $24 \mathrm{~V}$ Sicherheitsschaltkreises sind an die digitalen Eingänge des C-Moduls NI-9411 am cRIO-Controller 9035 angeschlossen. Wird der Not-Halt-Pilztaster betätigt, eine Tür geöffnet oder einer der genannten Komponenten aus dem Sicherheitsschaltkreis entfernt, interpretiert dies der jeweilige Kanal des C-Moduls als „False“. Die Nutzung der mechatronischen Teilsysteme (6-Kanal-Heizsystem / Antriebsachsen / Prozessgasversorgung und Sauerstoffsensorik / Laser-Scanner-Dummy) der Lasersintermaschine ist nur möglich, wenn jeder Kanal des C-Moduls NI-9411 die Variable „True“ ausgibt. Wechselt der boolesche Wert der Schleife im Betrieb der Lasersintermaschine von "True" auf „False" werden die mechatronischen Teilsysteme mit sofortiger Wirkung still gesetzt. In dem LabVIEW-Steuerprogramm wird die Schleife (Default-Wert „False“) zum Abfragen 
der digitalen Eingänge alle $10 \mathrm{~ms}$ durchlaufen. Das Prozessgas für die Inertisierung der Prozesskammer wird aus einer Gasflasche entnommen. Stickstoff ist farblos, geruchslos, geschmackslos und verdrängt die im Raum befindliche Atemluft. Vor der Inbetriebnahme des Prozessgasversorgungssystems wurde diesbezüglich eine entsprechende Warneinrichtung zur Überwachung des Sauerstoffgehalts im Raum installiert. Die Gaswarnanlage der Firma Dräger besteht aus einem stationären „Polytron 7000“ Gaswarngerät samt wechselbarer Sauerstoff-Sensorkapsel, einer „Regard 2400“ Auswerteeinheit und einer Blitzlichthupe. Die Konfiguration und Inbetriebnahme der Warneinrichtung wurde durch die Firma Dräger durchgeführt. Die modulspezifischen Sicherheitsanforderungen (vgl. Anforderungen 6.14 / 11.13 / 11.14 in Tabelle A.1) sind allesamt erfüllt. Für den Betrieb des Laser-Scanner-Demonstrators gelten, aufgrund der geringen Leistung des Pilotlasers, keine besonderen Sicherheitsvorschriften.

\subsubsection{Antriebsachsen}

Die Lasersintermaschine ist mit vier Antriebsachsen $(3 \times$ Hubantriebsachse / $1 \times$ Pulverauftragsachse) ausgestattet. Die Hubantriebsachse aus dem Baustempelmodul (Q1) positioniert die Bauplattform in der vertikalen z-Richtung innerhalb des Baustempelgehäuses. Die zwei weiteren Hubantriebsachsen aus dem Pulverzuführmodul (Q3 / Q4) positionieren die Zuführplattformen in der vertikalen z-Richtung innerhalb der Pulverzuführgehäuse. Die Antriebsachse aus dem Pulverauftragsmodul (Q2) bewegt die Beschichtereinheit-Aufnahme (Auftragsschlitten) in der horizontalen Richtung oberhalb der Prozesseinsatzplatte. Die zur Inbetriebnahme der Bosch Rexroth Antriebstechnik notwendigen Schritte sind in Anhang D detailliert dargestellt und lauten wie folgt:

1. Erstinbetriebnahme und Reglerparametrierung (alle Achsen)

2. Begrenzung des Fahrbereichs (alle Achsen)

3. Kompensation von Steigungsabweichungen der Kugelgewindetriebe (Q1/Q3/Q4)

4. Umbau der Kupplungen an den Festo Führungseinheiten (Q1/Q3/Q4)

5. Maschinenreferenzierte Drehgeberwertausgabe (alle Achsen)

Die Position der jeweiligen Achse (Lageistwert) wird durch den am Servomotor befindlichen Multiturn-Absolutwertgeber ermittelt. Die Zuordnung zwischen dem achsspezifischen Drehgeberwert und dem Koordinatenursprung der modularen Lasersintermaschine ist in der maschinenreferenzierten Drehgeberwertausgabe in Anhang D.6 dargestellt. Sowohl die horizontale Bewegung der Beschichtereinheit-Aufnahme als auch die vertikale Positionierung einer Plattform basiert auf einer Änderung des Drehgeberwerts der zu bewegenden Achse. Durch die Verwendung des „Straight-Line Move“-Funktionsblocks (NI SoftMotion Module) berechnet das LabVIEW-Steuerprogramm auf Basis der Eingangsparameter "Positionsstartwert" (Lageistwert), „Positionszielwert" (Lagesollwert), „Geschwindigkeit" und „Smoothing Factor" das symmetrische Weg-Geschwindigkeits-Profil zur Positionierung der spezifischen Antriebsachse. Der "Smoothing Factor" wird im Intervall von 0 (hohe Beschleunigungen) bis 1 (niedrige Beschleunigungen) eingestellt, korreliert mit dem Bereich konstanter Geschwindigkeit anteilig am Verfahrweg und beeinflusst die 


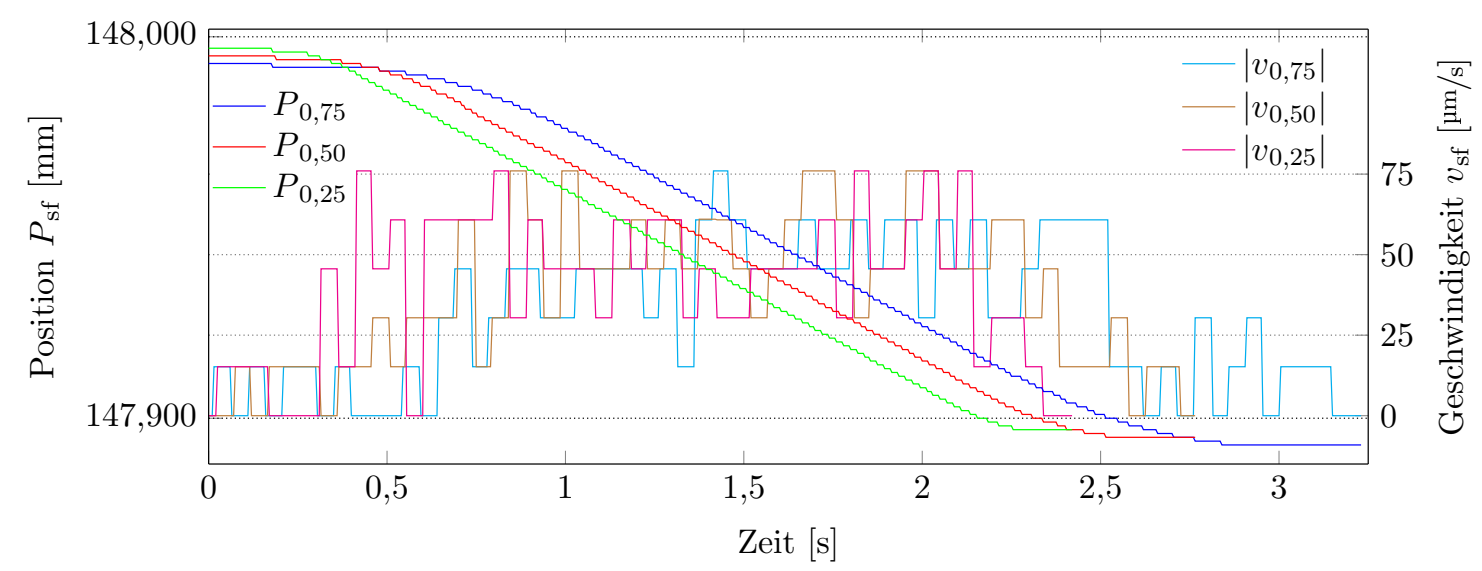

(a) Variation des Beschleunigungsprofils $\left(v_{\mathrm{sf}}=50 \mu \mathrm{m} / \mathrm{s}\right)$ bei der Positionierung von Q1 $\downarrow$ um $100 \mu \mathrm{m}$

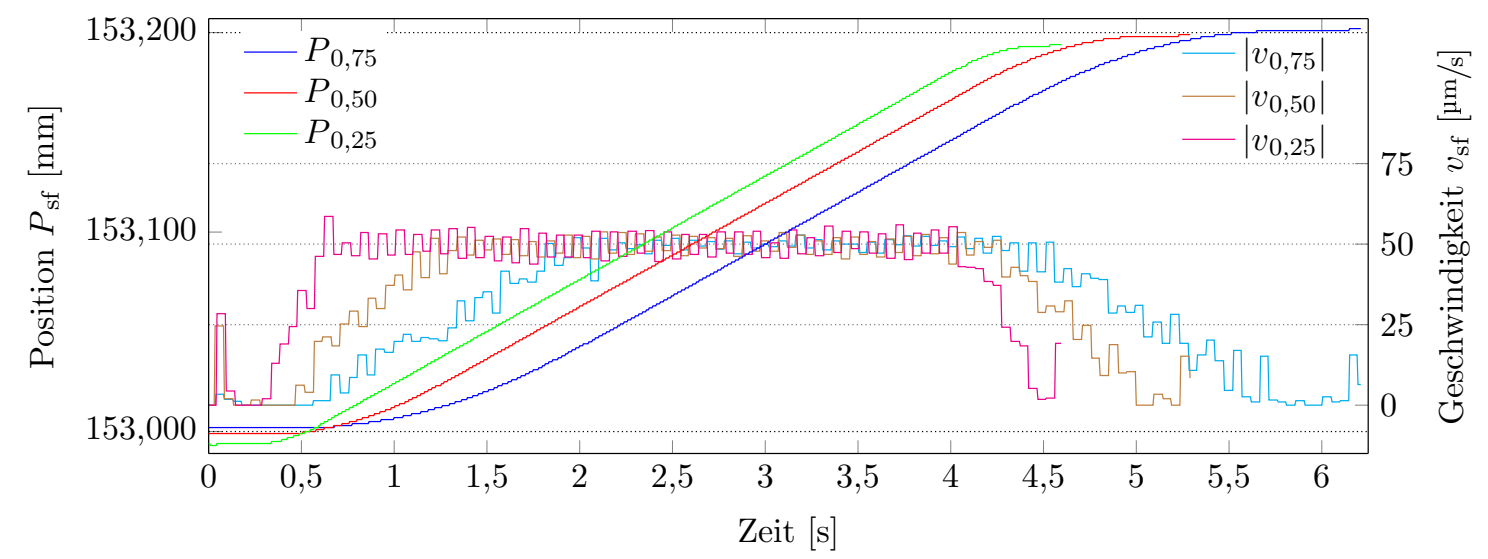

(b) Variation des Beschleunigungsprofils $\left(v_{\mathrm{sf}}=50 \mu \mathrm{m} / \mathrm{s}\right)$ bei der Positionierung von Q3 $\uparrow$ um $200 \mu \mathrm{m}$

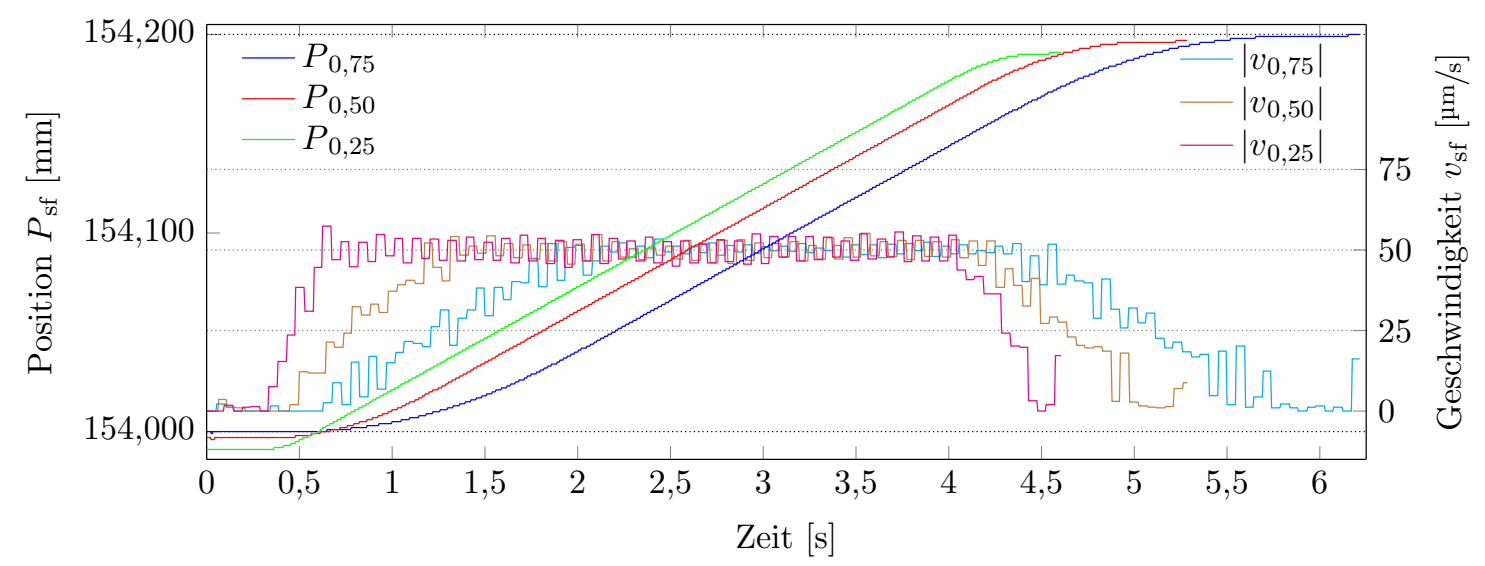

(c) Variation des Beschleunigungsprofils $\left(v_{\mathrm{sf}}=50 \mathrm{\mu m} / \mathrm{s}\right)$ bei der Positionierung von Q4 $\uparrow$ um $200 \mu \mathrm{m}$

Abbildung 8.13.: Prüfung der Hubantriebsachsen: Variation der Beschleunigungsprofile 
Kapitel 8. Montage, Inbetriebnahme und Erprobung der Lasersintermaschine

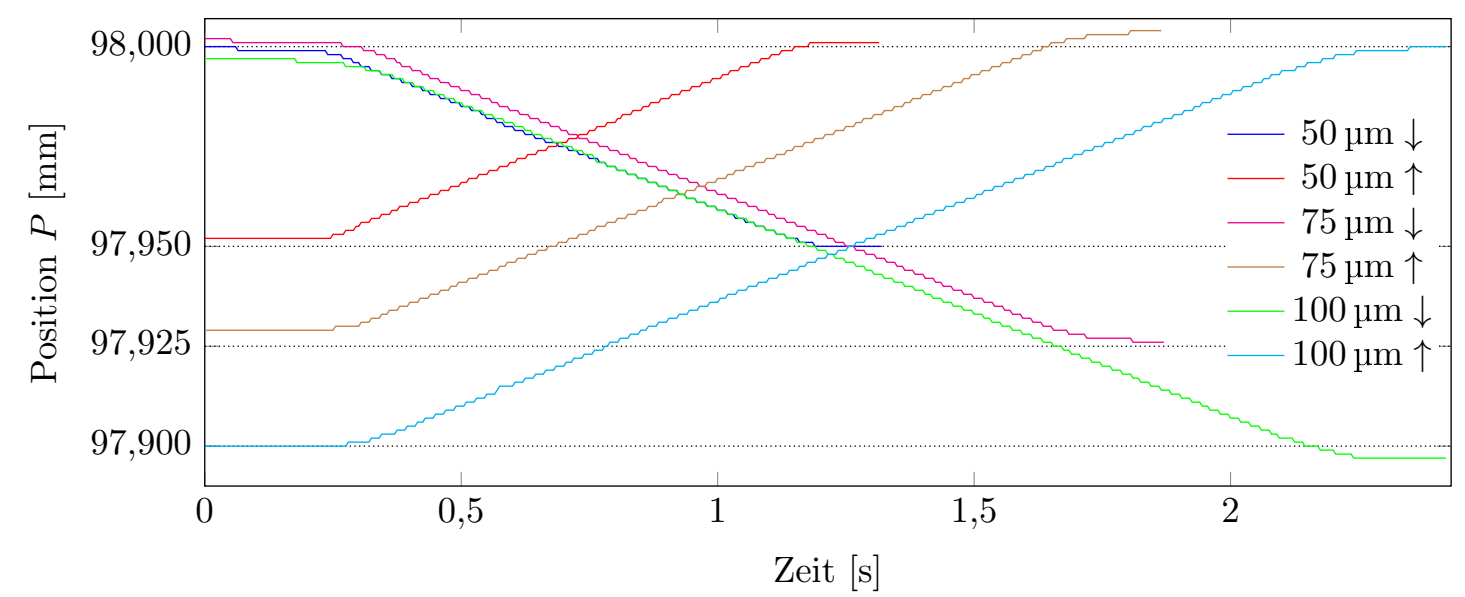

(a) Variation der Wegstrecken bei der schrittweisen Positionierung von Q1 mit $v_{0,25}=50 \mu \mathrm{m} / \mathrm{s}$

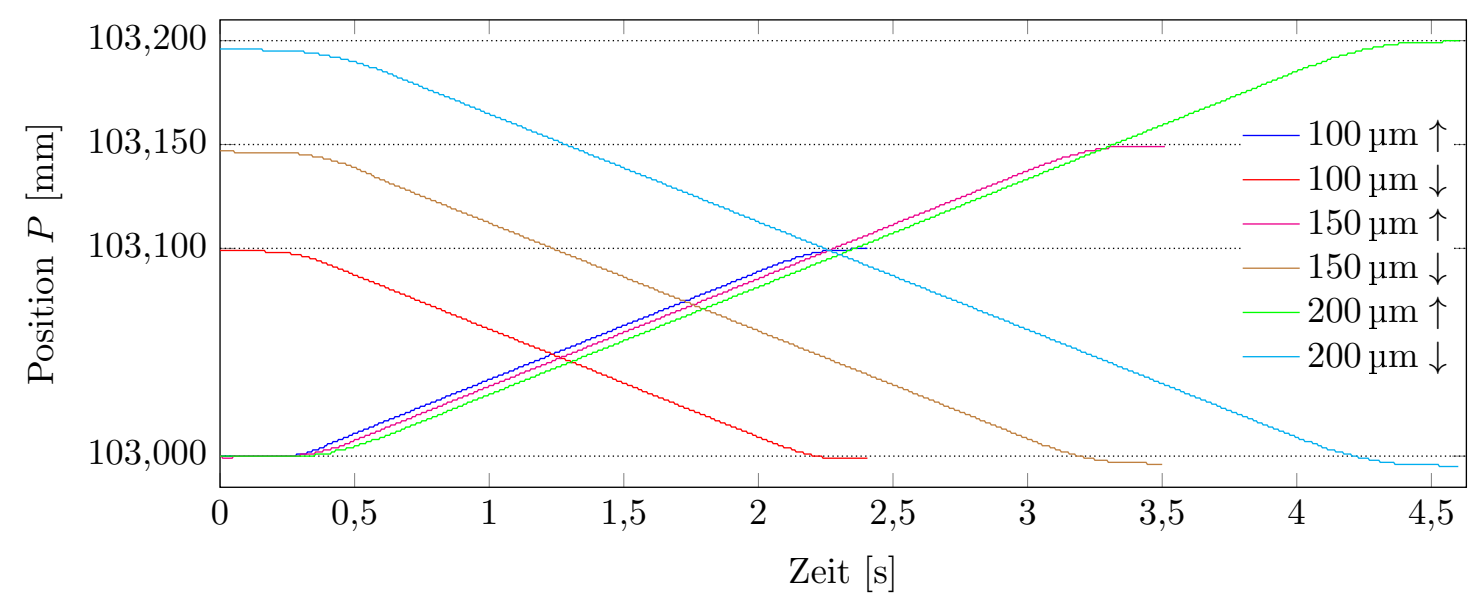

(b) Variation der Wegstrecken bei der schrittweisen Positionierung von Q3 mit $v_{0,25}=50 \mu \mathrm{m} / \mathrm{s}$

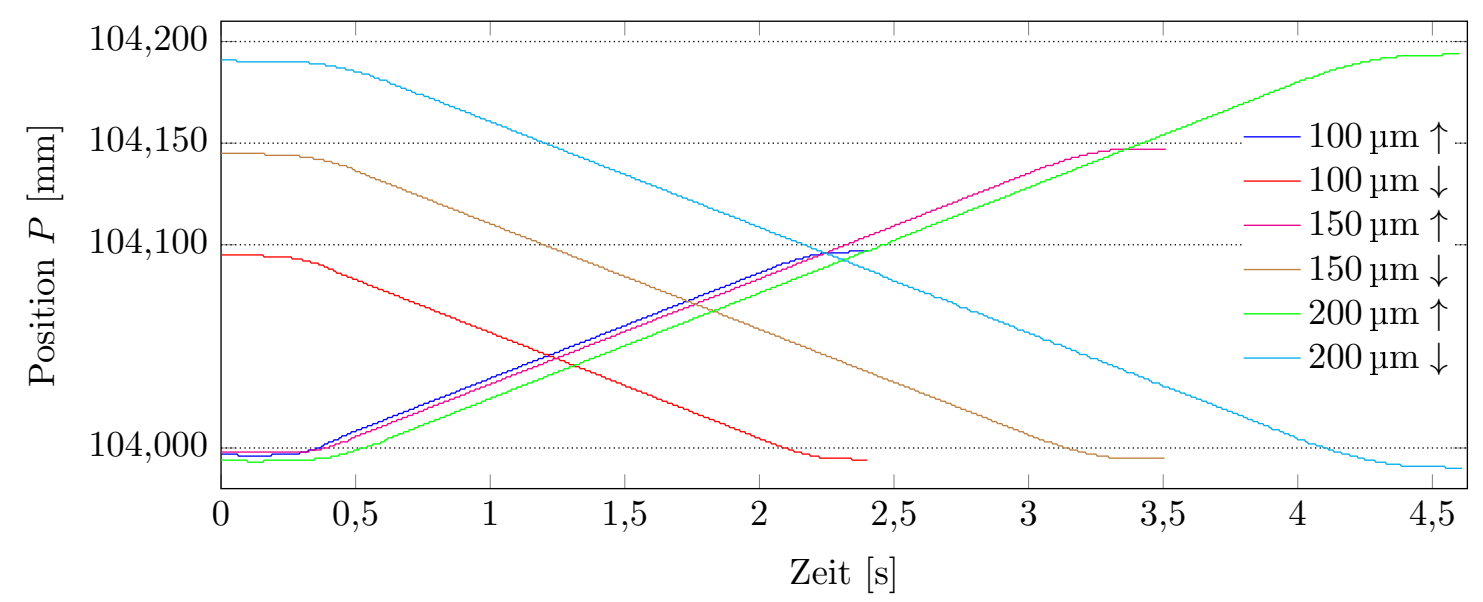

(c) Variation der Wegstrecken bei der schrittweisen Positionierung von Q4 mit $v_{0,25}=50 \mathrm{~mm} / \mathrm{s}$

Abbildung 8.14.: Prüfung der Hubantriebsachsen: Variation der Verfahrwege 
zur Ausführung der Bewegung notwendige Zeit. Zur Prüfung der Hubantriebsachsen (vgl. Abbildungen 8.13 und 8.14) wurden Beschleunigungsprofile und Verfahrwege bei gleicher Geschwindigkeit variiert. Das Inkrement, um das die Bauplattform der $\mathrm{Hu}-$ bantriebsachse Q1 während des Lasersinterprozesses abgesenkt wird, entspricht der Schichtstärke zur Bauteilgenerierung. Das Inkrement, um das die Zuführplattform I der Hubantriebsachse Q3 bzw. die Zuführplattform II der Hubantriebsachse Q4 während des Lasersinterprozesses angehoben wird, beeinflusst das für den Pulverauftragsprozess bereitgestellte Pulvervolumen. In Abbildung 8.13 wird die Bauplattform der Hubantriebsachse Q1 um $100 \mu \mathrm{m}$ abwärts und die Zuführplattformen der Hubantriebsachsen Q3 bzw. Q4 um $200 \mu \mathrm{m}$ aufwärts bei einer Geschwindigkeit von $50 \mu \mathrm{m} / \mathrm{s}$ positioniert. Die Prüfung wird bei der Vorgabe eines „Smoothing Factors“ von $0,25\left(v_{0,25}=50 \mathrm{\mu m} / \mathrm{s}\right)$, $0,5\left(v_{0,5}=50 \mathrm{\mu m} / \mathrm{s}\right)$ und $0,75\left(v_{0,75}=50 \mathrm{\mu m} / \mathrm{s}\right)$ wiederholt durchgeführt. Zur grafischen Darstellung der Prüfergebnisse wurden alle $5 \mathrm{~ms}$ die Werte der Achsposition $\left(P_{\mathrm{sf}}\right)$ und der Achsgeschwindigkeit $\left(v_{\mathrm{sf}}\right)$ aus dem jeweiligen Antriebsregelgerät via EtherCAT an den cRIO-Controller übertragen. Die Positionsänderung um einen Verfahrweg von $100 \mu \mathrm{m}$ ist in Abhängigkeit des gewählten Beschleunigungsprofils nach einer Zeit (vgl. (a) Abbildung 8.13$)$ von $2,42 \mathrm{~s}\left(v_{0,25}=50 \mu \mathrm{m} / \mathrm{s}\right), 2,76 \mathrm{~s}\left(v_{0,5}=50 \mu \mathrm{m} / \mathrm{s}\right)$ bzw. $3,23 \mathrm{~s}\left(v_{0,75}=50 \mu \mathrm{m} / \mathrm{s}\right)$ abgeschlossen. Wird der Verfahrweg auf $200 \mu \mathrm{m}$ verdoppelt, verlängert sich die zur Positionsänderung notwendige Zeit (vgl. (a) / (b) Abbildung 8.13) auf 4,59 $\mathrm{s}\left(v_{0,25}=50 \mathrm{~mm} / \mathrm{s}\right)$, $5,29 \mathrm{~s}\left(v_{0,5}=50 \mu \mathrm{m} / \mathrm{s}\right)$ bzw. $6,21 \mathrm{~s}\left(v_{0,75}=50 \mu \mathrm{m} / \mathrm{s}\right)$. In Kombination mit der geringen Geschwindigkeit von $50 \mathrm{\mu m} / \mathrm{s}$ hatte die Änderung des „Smoothing Factors“ keinen Einfluss auf die Positionierbarkeit der Hubantriebsachsen. Die Prüfergebnisse waren allesamt reproduzierbar. In Abbildung 8.14 werden die Plattformen der Hubantriebsachsen bei einer Geschwindigkeit von $v_{0,25}=50 \mathrm{\mu m} / \mathrm{s}$ (bei einem „Smoothing Factor" von 0,25) in alternierender Richtung bei vorgegebenem Inkrement positioniert. Die Prüfung wird bei der Vorgabe des Verfahrwegs von $50 \mu \mathrm{m}, 75 \mu \mathrm{m}$ und $100 \mu \mathrm{m}$ für die Bauplattform bzw. $100 \mu \mathrm{m}, 150 \mu \mathrm{m}$ und $200 \mu \mathrm{m}$ für die Zuführplattformen wiederholt durchgeführt. Zur grafischen Darstellung der Prüfergebnisse wurden alle $5 \mathrm{~ms}$ die Werte der Achsposition $\left(P_{\mathrm{sf}}\right)$ und der Achsgeschwindigkeit (nicht dargestellt) aus dem jeweiligen Antriebsregelgerät via EtherCAT an den cRIO-Controller übertragen. Die Positionierung der Hubantriebsachsen ist fehlerfrei möglich. Die Anforderung „Positions-Sollwertvorgabe (relative \& absolute Werte) zur Achspositionierung“" (vgl. Anforderungen 7.8 / 8.6 in Tabelle A.1) ist demnach erfüllt. Zusätzlich zum Data Logging der vom Umrichter ausgegebenen Achsinformationen wurden die Positioniergenauigkeiten der Hubantriebsachsen mit einem Laser-Wegmesssystem LC-2400 (Messbereich $\pm 3 \mathrm{~mm} /$ Auflösung 0,2 $\mu \mathrm{m}$ ) der Firma Keyence gemessen. Die Ergebnisse der Messreihen sind in Anhang E dargestellt. Im Hinblick auf die in Anhang E.2 erzielten Messergebnisse bezüglich der Positioniergenauigkeit der Bauplattform der Hubantriebsachse Q1 gilt die Anforderung „Positioniergenauigkeit des Baustempels $< \pm 5 \mu \mathrm{m}$ bei $100 \mu \mathrm{m}$ Schichtstärke" (vgl. Anforderung 7.12 in Tabelle A.1) als erfüllt. Die Pulverauftragsachse (Q2) aus dem Pulverauftragsmodul wird während des Lasersinterprozesses zwischen den Drehgeberwerten 11,731 mm (hinterer Überlaufbehälter) und 411,731 mm (vorderer Überlaufbehälter) auf einem Verfahrweg von $400 \mathrm{~mm}$ in alternierender Richtung bewegt. Zur Prüfung der Pulverauftragsachse (vgl. Abbildung 8.15) wurde das Beschleunigungsprofil und die Geschwindigkeit bei gleichem 
Kapitel 8. Montage, Inbetriebnahme und Erprobung der Lasersintermaschine

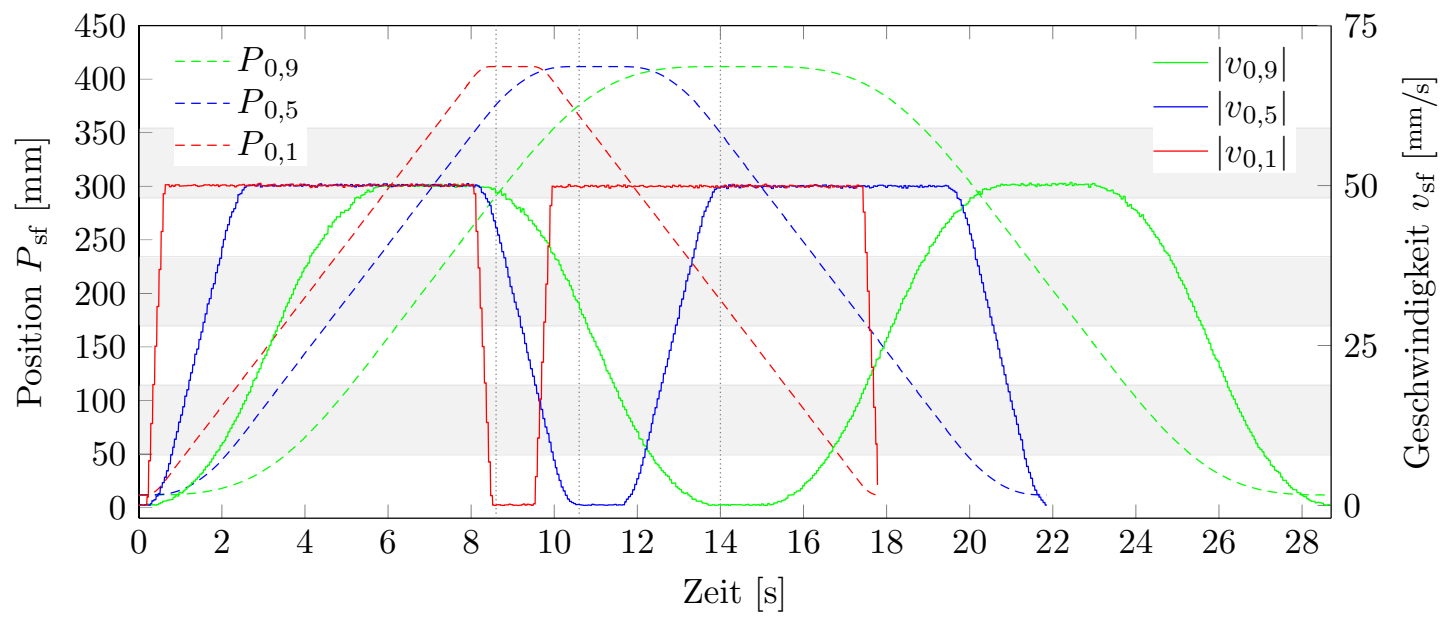

(a) Variation des Beschleunigungsprofils bei konstanter Beschichtergeschwindigkeit

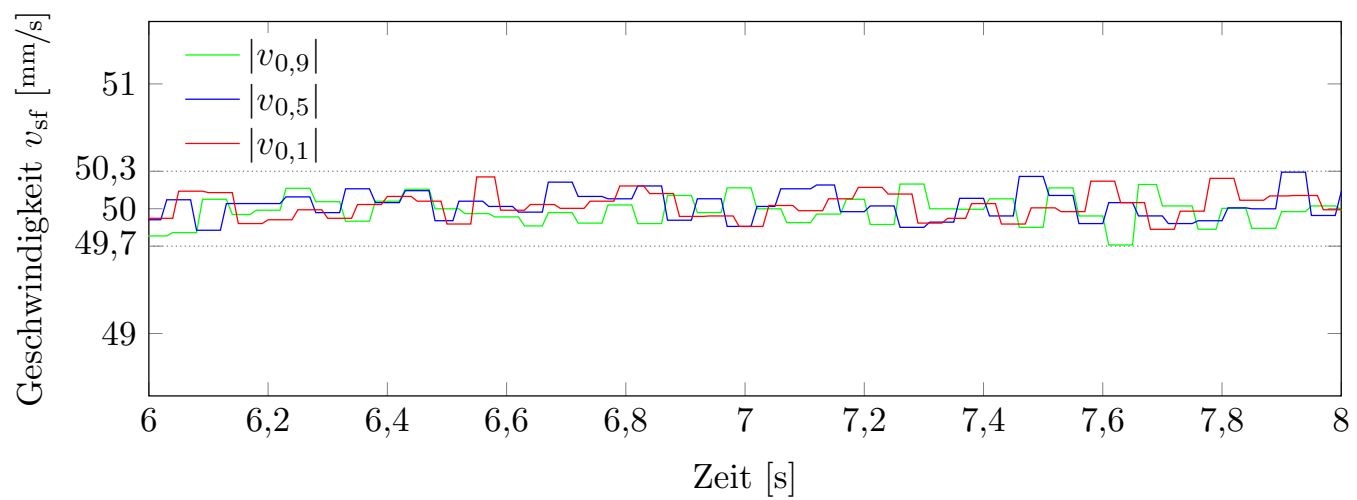

(b) Istgeschwindigkeit des Beschichters bei einer Sollwertvorgabe von $50 \mathrm{~mm} / \mathrm{s}$

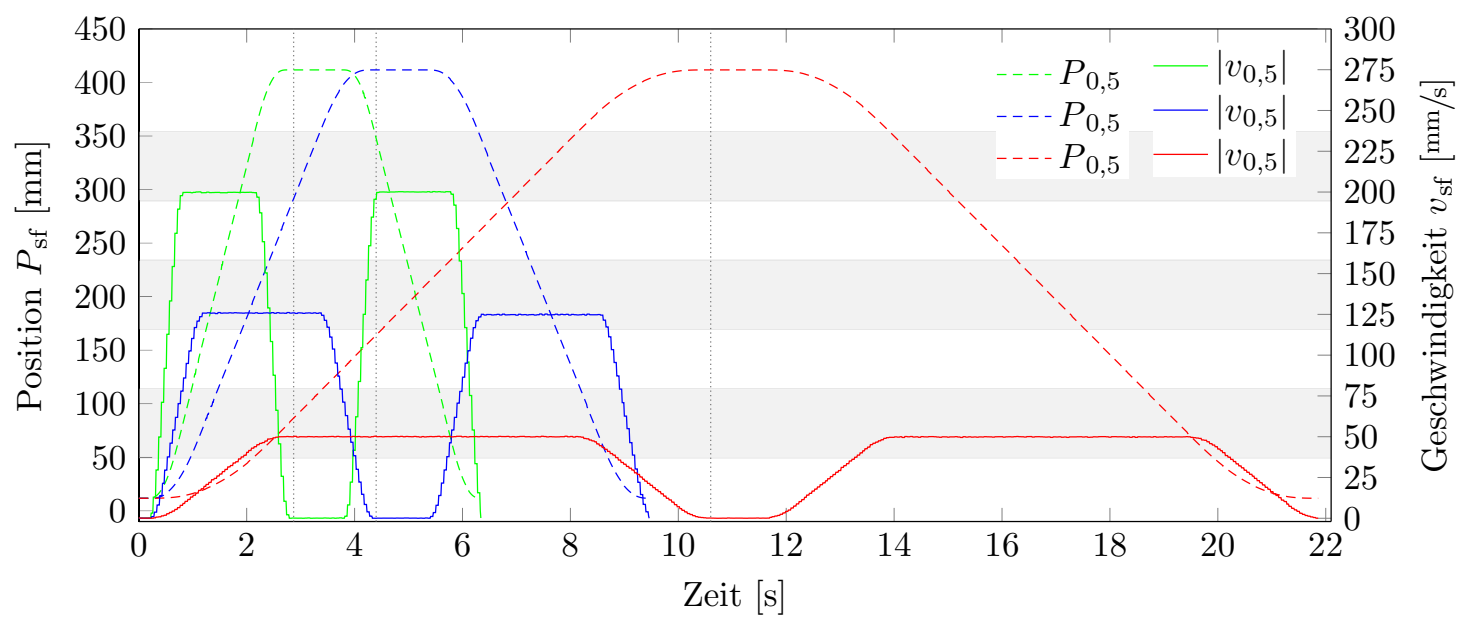

(c) Variation der Beschichtergeschwindigkeit bei konstantem Beschleunigungsprofil

Abbildung 8.15.: Prüfungen der Pulverauftragsachse 
Verfahrweg variiert. Die in Abbildung 8.15 (a) bzw. (c) ausgegrauten Positionsintervalle markieren die Positionen der Bohrungen in den Baustempel- und Pulverzuführgehäusen auf Basis der maschinenreferenzierten Drehgeberwertausgabe. Zur Erfüllung der Anforderungen „Geschwindigkeits-Sollwertvorgabe für Beschichtereinheit-Aufnahme bis $200 \mathrm{~mm} / \mathrm{s}^{\text {" }}$ und „Konstante Pulverauftragskörper-Dynamik bei Auftragsbewegung über Bauvolumen“ (vgl. Anforderung 9.4 / 10.4 in Tabelle A.1) muss die Geschwindigkeit der Bewegung im Positionsintervall von 179,231 mm bis 244,231 mm (vgl. Abbildung D.11) einen konstanten Betrag besitzen. In Abbildung 8.15 (a) wird die Pulverauftragsachse zunächst von der Maschinenrückseite zur Maschinenvorderseite und anschließend von der Maschinenvorderseite zur Maschinenrückseite bei einer Geschwindigkeit von $50 \mathrm{~mm} / \mathrm{s}$ bewegt. Zwischen den zwei Pulverauftragsbewegungen ist eine Wartezeit von $1 \mathrm{~s}$ eingestellt. Die Prüfung wird bei der Vorgabe eines „Smoothing Factors“ von $0,1\left(v_{0,1}=50 \mathrm{~mm} / \mathrm{s}\right), 0,5\left(v_{0,5}=50 \mathrm{~mm} / \mathrm{s}\right)$ und 0,9 $\left(v_{0,9}=50 \mathrm{~mm} / \mathrm{s}\right)$ wiederholt durchgeführt. Zur grafischen Darstellung der Prüfergebnisse wurden alle $10 \mathrm{~ms}$ die Werte der Achsposition $\left(P_{\mathrm{sf}}\right)$ und der Achsgeschwindigkeit $\left(v_{\mathrm{sf}}\right)$ aus dem Antriebsregelgerät Q2 via EtherCAT an den cRIO-Controller übertragen. Die Positionsänderung auf dem Verfahrweg von $400 \mathrm{~mm}$ ist in Abhängigkeit des gewählten Beschleunigungsprofils nach einer Zeit von $8,6 \mathrm{~s}\left(v_{0,1}=50 \mathrm{~mm} / \mathrm{s}\right), 10,6 \mathrm{~s}\left(v_{0,5}=50 \mathrm{~mm} / \mathrm{s}\right)$ bzw. $14 \mathrm{~s}\left(v_{0,9}=50 \mathrm{~mm} / \mathrm{s}\right)$ abgeschlossen. Die Wahl eines "Smoothing Factors“ von 0,9 führt zu unerwünschten Beschleunigungen im Bereich des Bauvolumens. Durch die Vorgabe eines „Smoothing Factors“ von 0,1 ist die Beschleunigung der Pulverauftragsachse auf eine Geschwindigkeit von $v_{0,1}=50 \mathrm{~mm} / \mathrm{s}$ bereits nach einer Zeit von $0,64 \mathrm{~s}$ abgeschlossen. Im Hinblick auf die Lebensdauer der Kugelmutter des Kugelgewindetriebs wird ein mittlerer „Smoothing Factor" von 0,5 für den weiteren Betrieb der Pulverauftragsachse gewählt. Der positionsgeregelte Betrieb der Pulverauftragsachse (vgl. Abbildung 8.15 (b)) führt zu einer tolerierten Streuung von $\pm 0,3 \mathrm{~mm} / \mathrm{s}$ der Geschwindigkeits-Istwerte um den vorgegebenen Geschwindigkeits-Sollwert von $v_{\mathrm{sf}}=50 \mathrm{~mm} / \mathrm{s}$. In Abbildung 8.15 (c) wird die bereits diskutierte Pulverauftragsbewegung bei den Geschwindigkeiten von $v_{0,5}=50 \mathrm{~mm} / \mathrm{s}, v_{0,5}=125 \mathrm{~mm} / \mathrm{s}$ und $v_{0,5}=200 \mathrm{~mm} / \mathrm{s}$ dargestellt. Die Anforderungen gelten, nach dem Umbau (vgl. Detaillierte Darstellung der Motoraufhängung in Abbildung B.10) der Antriebsbaugruppe aus dem Pulverzuführmodul, als erfüllt.

\subsubsection{6-Kanal-Heizsystem}

Zur Verarbeitung von bioresorbierbaren Polymeren muss das 6-Kanal-Heizsystem unterhalb der Prozesseinsatzplatte (vgl. Abbildung 8.4) die Lasersintermaschine auf eine maximale Temperatur von $80^{\circ} \mathrm{C}$ vorheizen können. Die Anforderungen an die Heizelemente (HG1 / HS1) aus dem Baustempelmodul „Vorheiztemperatur-Sollwertvorgabe für Gehäuseheizung „Off" bzw. $30^{\circ} \mathrm{C}-80^{\circ} \mathrm{C}$ " und „Vorheiztemperatur-Sollwertvorgabe für Plattformheizung „Off“ bzw. $30^{\circ} \mathrm{C}-80^{\circ} \mathrm{C}^{\circ}$ (vgl. Anforderungen 7.5 / 7.15 in Tabelle A.1) wurden auf die Heizelemente (HG3 / HS3 / HG4 / HS4) aus dem Pulverzuführmodul (vgl. Anforderungen 8.3 / 8.9 in Tabelle A.1) übertragen. Durch die Verwendung einer „PID-PWM“-Funktionsblockkombination regelt das LabVIEW-Steuerprogramm jeden der sechs Heizkanäle einzeln. Auf Basis der in Abschnitt 7.2 durchgeführten DSC-Messungen an den PLGA-Materialien wurden die Glieder der PID-Regler für die Gehäuse- und 
Kapitel 8. Montage, Inbetriebnahme und Erprobung der Lasersintermaschine

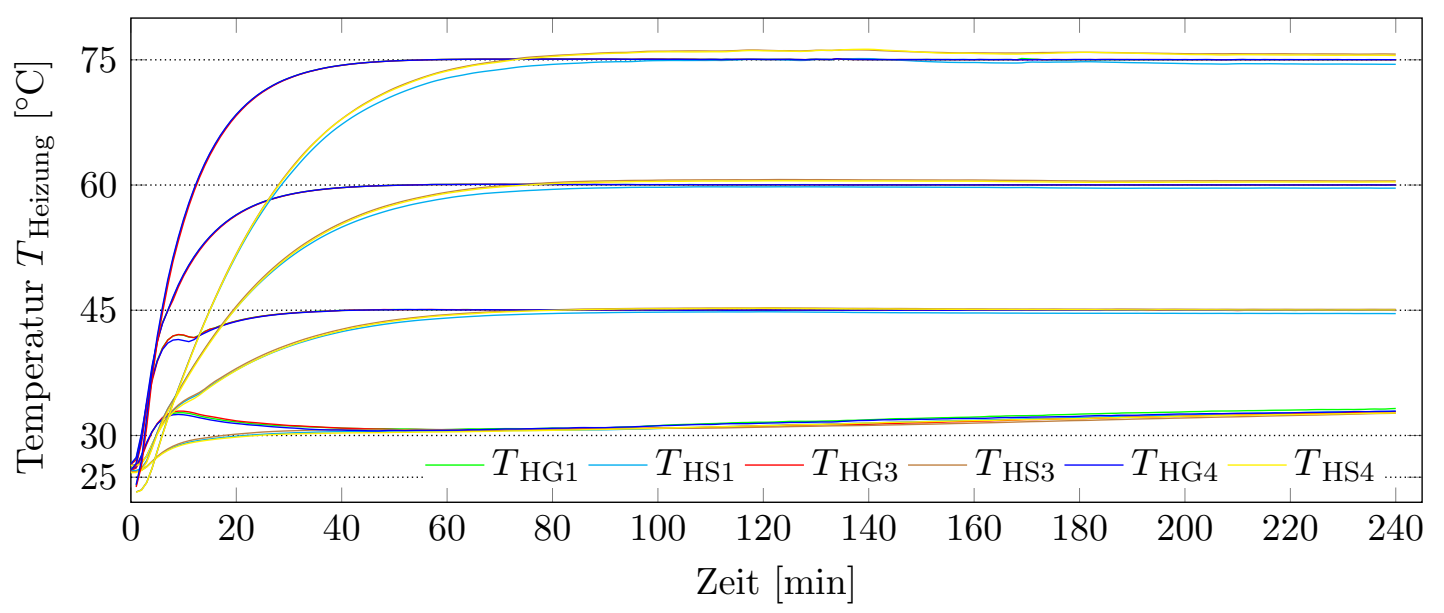

(a) Aufheizkurven bei einer Temperatur-Sollwertvorgabe von $30^{\circ} \mathrm{C}, 45^{\circ} \mathrm{C}, 60^{\circ} \mathrm{C}$ und $75^{\circ} \mathrm{C}$
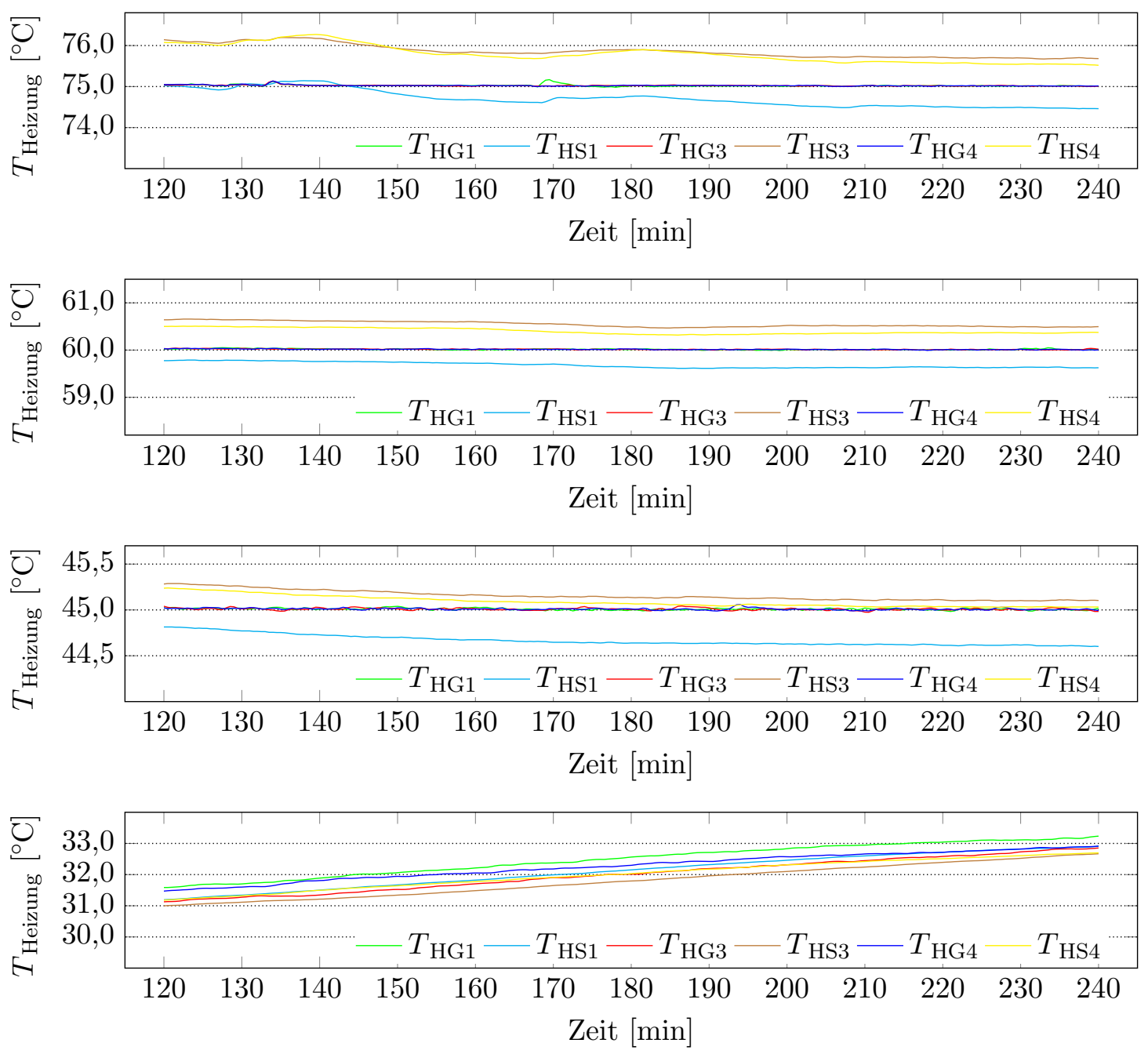

(b) Vergrößerung der Aufheizkurven: Regelverhalten für 120 min nach einer Vorhheizzeit von 120 min Abbildung 8.16.: Prüfung des 6-Kanal-Heizsystems: Variation der Vorheiztemperatur 
Plattformheizungen experimentell für den Betrieb bei $45^{\circ} \mathrm{C}$ (Vorheiztemperatur Evonik Resomer RG 755 S) ermittelt. Zur Untersuchung des Regelverhaltens wurden dem 6-Kanal-Heizsystem (ohne weitere Anpassung der Reglerparameter) die Temperatur-Sollwerte von $30^{\circ} \mathrm{C}, 45^{\circ} \mathrm{C}, 60^{\circ} \mathrm{C}$ bzw. $75^{\circ} \mathrm{C}$ vorgegeben. Zur grafischen Darstellung der Prüfergebnisse wurden alle $10 \mathrm{~s}$ die Temperaturwerte der federbelasteten PT1000-Bajonettfühler $\left(T_{\mathrm{HG} 1} / T_{\mathrm{HG} 3} / T_{\mathrm{HG} 4}\right)$ an den Gehäusen und den integrierten PT100-Temperaturfühlern $\left(T_{\mathrm{HS} 1} / T_{\mathrm{HS} 3} / T_{\mathrm{HS} 4}\right)$ der geklebten Silikonheizmatten über eine Zeit von 240 min ausgelesen. Die in Abbildung 8.4 dargestellten Aufheizkurven der Lasersintermaschine sind bei ausgeschalteten Plattformheizungen (HS1 / HS3 / HS4) entstanden. Bei den Messreihen waren die drei Plattformen innerhalb der Gehäuse auf einem z-Wert von $40 \mathrm{~mm}$ positioniert. Das Heizsystem ist nach einer Einschwingzeit (vgl. (a) Abbildung 8.4) von ca. 120 min auf den gewünschten Temperatur-Sollwert vorgeheizt. Der Regler kann für den Betrieb (vgl. (b) Abbildung 8.4) bei einer Vorheiztemperatur von $45^{\circ} \mathrm{C}, 60^{\circ} \mathrm{C}$ und $75^{\circ} \mathrm{C}$ verwendet werden. Die zur Verarbeitung der PLGA-Materialien Corbion Purac Purasorb PLG 8523 und PLG 8531 erforderliche Vorheiztemperatur von $54^{\circ} \mathrm{C}$ kann folglich eingestellt werden. Die Anwendung der Reglerparameter auf das Regelziel von $30^{\circ} \mathrm{C}$ führt zu einem nicht tolerierbaren Überschwingverhalten. Als Ursache der Temperaturabweichungen der integrierten PT100-Fühler $\left(T_{\mathrm{HS} 1} / T_{\mathrm{HS} 3} / T_{\mathrm{HS} 4}\right)$ werden schwankende Haftfestigkeiten der Klebeverbindungen zwischen den Silikonheizmatten und den Stempeloberteilen vermutet. Die Anforderungen gelten, in Verbindung mit dem Hinweis zur Umgestaltung der Plattformheizungen, als erfüllt.

\subsubsection{Prozessgasversorgungssystem und Sauerstoff-Messsysteme}

Nach dem gegenwärtigen Stand der Wissenschaft sollte der Lasersinterprozess in einer Atmosphäre mit einem maximalen Restsauerstoffgehalt [Weg15, S. 113] von 0,5\% vol durchgeführt werden. Ist die Bronkhorst „Flow-Bus“-Treiberbibliothek in dem LabVIEW-Steuerprogramm implementiert, kann das Massendurchflussregelventil zur Inertisierung der Prozesskammer (Regelbereich: 0,4 $\mathrm{l}_{\mathrm{n}} / \mathrm{min}$ bis $20 \mathrm{l}_{\mathrm{n}} / \mathrm{min}$ ) verwendet werden. Das Gesamtvolumen des Prozessgasgehäuses beträgt in etwa 581 und ergibt sich aus der Summe der Volumina von Prozesskammer (36 l), Verbindungskammern $(2 \times 2,5 \mathrm{l})$ und Nebenkammern $(61+111)$. Die kontinuierliche Gaseinleitung von 2,79 $\mathrm{l}_{\mathrm{n}} / \mathrm{min}$ in die Laserglas-Prozessgas-Armatur des Prozessgasmoduls [Spr18, S. 46] führt zur Bildung eines Gasvorhangs an der zu reinigenden Laserglasoberfläche. Während des Regelventilbetriebs wird der tatsächliche Volumenstrom und die Temperatur des eingeleiteten Prozessgases überwacht. Vorab wurde die Funktion des Massendurchflussreglers über den gesamten Regelbereich geprüft und die Sauerstoff-Messsysteme der Firma First Sensor kalibriert. Zur Prüfung der Systeme zur Prozessgasversorgung und Sauerstoffmessung wurde das Prozessgasgehäuse wiederholt mit Stickstoff inertisiert und auf Dichtheit geprüft. Die Abbildung 8.17 (a) stellt die Inertisierung bis zu einem Restsauerstoffgehalt von $0,5 \%$ bei einem Volumenstrom $(\dot{V}) 5 l_{\mathrm{n}} / \mathrm{min}, 10 \mathrm{l}_{\mathrm{n}} / \mathrm{min}, 15 \mathrm{l}_{\mathrm{n}} / \mathrm{min}$ bzw. $20 \mathrm{l}_{\mathrm{n}} / \mathrm{min}$ dar. Zur grafischen Darstellung der Prüfergebnisse wurden die Sauerstoffmesswerte der $\mathrm{O}_{2}$ Sensoren I $\left(\mathrm{O}_{2(\mathrm{~S} 1)}\right)$ bzw. II $\left(\mathrm{O}_{2(\mathrm{~S} 2)}\right)$ im Bereich des Bauvolumens alle $5 \mathrm{~s}$ ausgelesen. In Abhängigkeit des eingestellten Volumenstroms ist die Inertisierung des Prozessgasgehäuses 
nach $48,5 \min \left(\dot{V}=5 \mathrm{l}_{\mathrm{n}} / \min \right), 21,58 \min \left(\dot{V}=10 \mathrm{l}_{\mathrm{n}} / \min \right), 13,92 \min \left(\dot{V}=15 \mathrm{l}_{\mathrm{n}} / \mathrm{min}\right)$ bzw. 10,58 $\min \left(\dot{V}=20 \mathrm{l}_{\mathrm{n}} / \mathrm{min}\right)$ abgeschlossen. Durch die angewendete Spülmethode ist ein 4-facher Volumenwechsel zur Herstellung der inerten Atmosphäre notwendig. Die Temperatur des eingeleiteten Stickstoffs war über die gesamte Öffnungszeit des Ventils, unabhängig vom eingestellten Volumenstrom, gleich der Raumtemperatur. Der Regler folgte der Sollwertvorgabe ohne nennenswerte Abweichungen. Zur Prüfung der

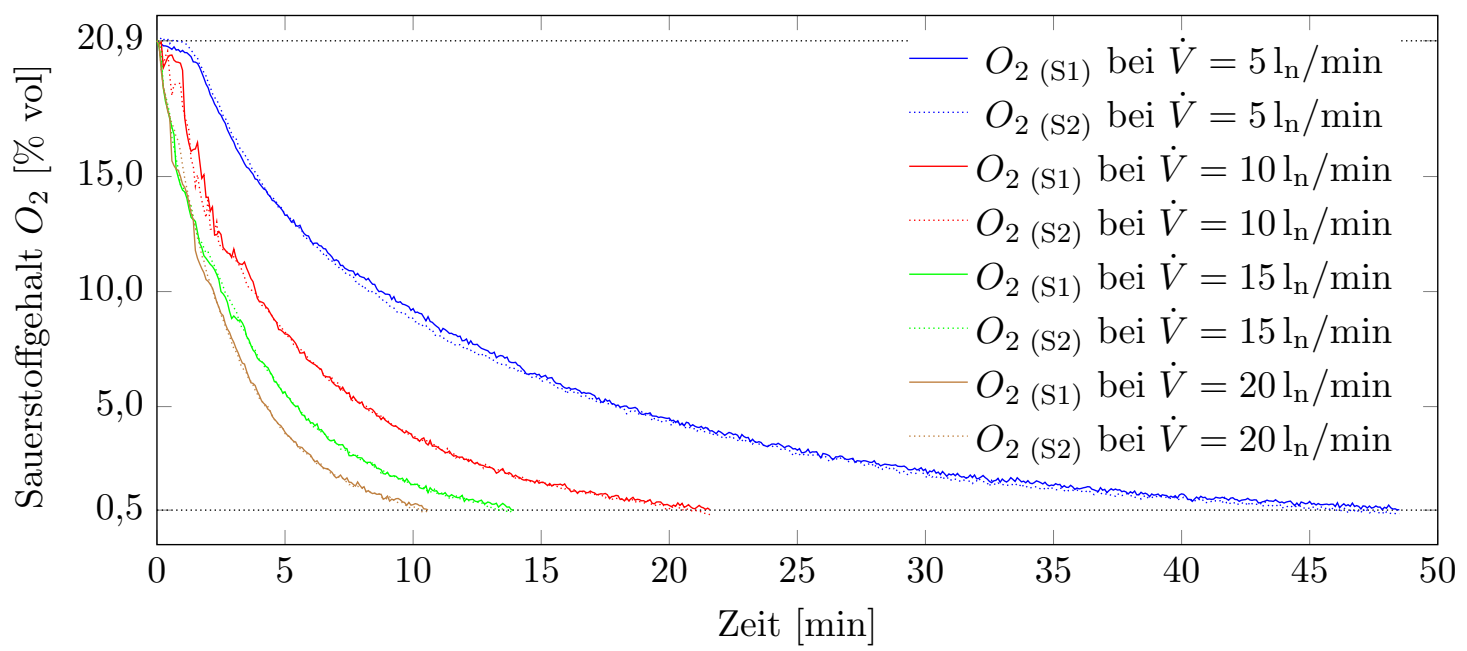

(a) Inertisierung der geschlossenen Prozesskammer bis zu einem Restsauerstoffgehalt von 0,5\% vol

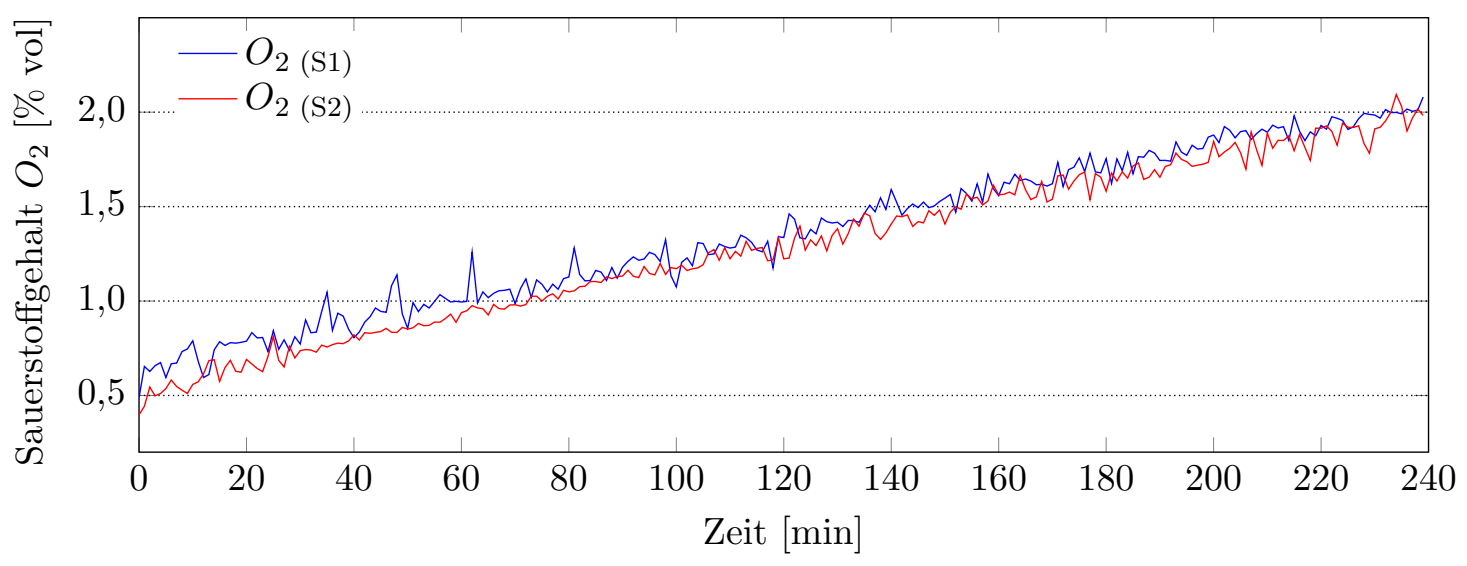

(b) Dichtheitsprüfung des Prozessgasgehäuses ab einem Restsauerstoffgehalt von $0,5 \%$ vol für 240 min

Abbildung 8.17.: Prüfung der Systeme zur Prozessgasversorgung und Sauerstoffmessung

Dichtheit des Prozessgasgehäuses (vgl. (b) Abbildung 8.17) wurde das Prozessgasgehäuse bis zu einem Restsauerstoffgehalt von $0,5 \%$ inertisiert, das Massendurchflussregelventil geschlossen $\left(\dot{V}=0 \mathrm{l}_{\mathrm{n}} / \mathrm{min}\right)$ und die Sauerstoffmesswerte mit einer Abtastfrequenz von $11 /$ min über eine Messdauer von 240 min ausgelesen. Der Sauerstoffgehalt innerhalb der Prozesskammer steigt annähernd linear um 0,375 \% vol pro Stunde an. Die Anforderungen aus dem Prozessgasmodul gelten folglich als erfüllt. 


\subsubsection{Laser-Scanner-Demonstrator und Weitwinkelkamera}

Die unterhalb des Laser-Scanner-Demonstrators montierte Weitwinkelkamera zeichnet den gesamten Bewegungsbereich der Beschichtereinheit (vgl. Abbildung 8.18) auf. Durch die Verwendung des linearen Sichtfeldmodus wird die konvexe Bildverzerrung, hervorgerufen durch das Fischaugenobjektiv der GoPro Kamera, weitestgehend beseitigt. Zur

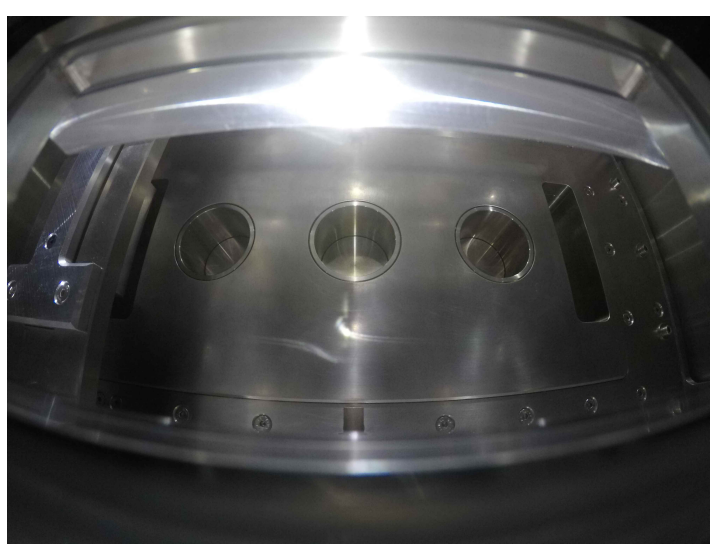

(a) Sichtfeldmodus „Wide“

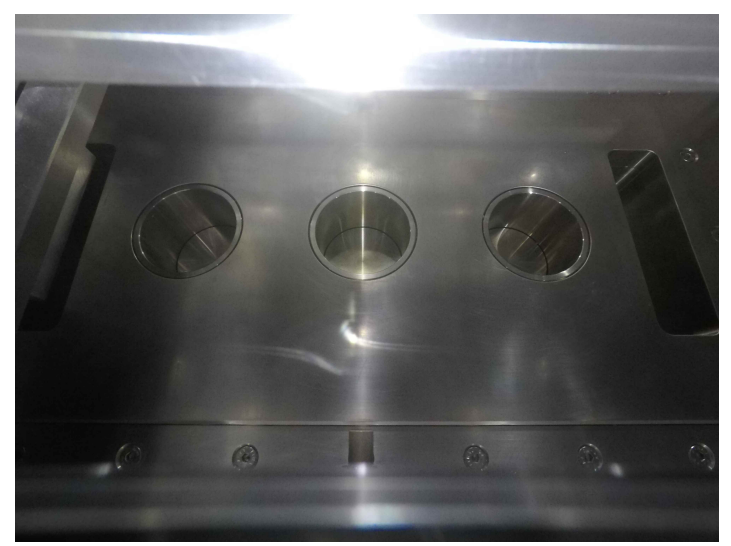

(b) Sichtfeldmodus „Linear"

Abbildung 8.18.: Prüfung der Live-Video-Weitwinkelkamera

Prüfung des Laser-Scanner-Demonstrators (vgl. Abbildung 8.19) wird die Bauteilschichtgenerierung eines spezifischen Bauteils durch den in der Baugruppe befindlichen Pilotlaser simuliert. Auf Basis der Eingangsparameter „Füllmuster" und „Fülldichte“ generiert die Slicer-Software „Slic3er“ (Freeware) die schichtspezifischen Belichtungspfade zum Lasersintern des zylinderförmigen Körpers $(\varnothing 50 \mathrm{~mm} \times 50 \mathrm{~mm})$ mit symmetrisch angeordneter Öffnung $(40 \mathrm{~mm} \times 10 \mathrm{~mm})$. Die im LabVIEW-Steuerprogramm implementierten Funktionsblöcke wurden im Rahmen einer Masterarbeit [Faß17] von Herrn Tim Helge Faß entwickelt, lesen den nach ISO 6983-1 [ISO 6983-1] genormten G-Code ein, initialisieren die RTC5 Ansteuerkarte im zugehörigen Steuercomputer und bieten die Möglichkeit zur Steuerung des Laser-Scanner-Dummys. Die in Abbildung 8.19 dargestellten Langzeitbelichtungen der Laserenergieeinträge wurden bei reduzierter Scangeschwindigkeit von $666 \mathrm{~mm} / \mathrm{s}$ und geöffneter Prozesskammer (Sicherheits-Schaltscharnier überbrückt) mit einer Nikon „D7100“ Spiegelreflexkamera mit einem Nikon „AF-S Zoom-Nikkor 17-35mm“ Objektiv aufgenommen. Das zylinderförmige Probebauteil wurde nach Vorgabe der folgenden Eingangsparameter wiederholt geslicet:

- Füllmuster „Rectilinear“ mit 50\% Fülldichte

- Füllmuster „Octagram Spiral“ mit 40\% Fülldichte

- Füllmuster „Concentric“ mit $60 \%$ Fülldichte

Die Bewertung der Funktionsfähigkeit des Laser-Scanner-Dummys basiert auf einem visuellen Abgleich (vgl. (a) / (b) / (c) in Abbildung 8.19) zwischen geplanten (vom 


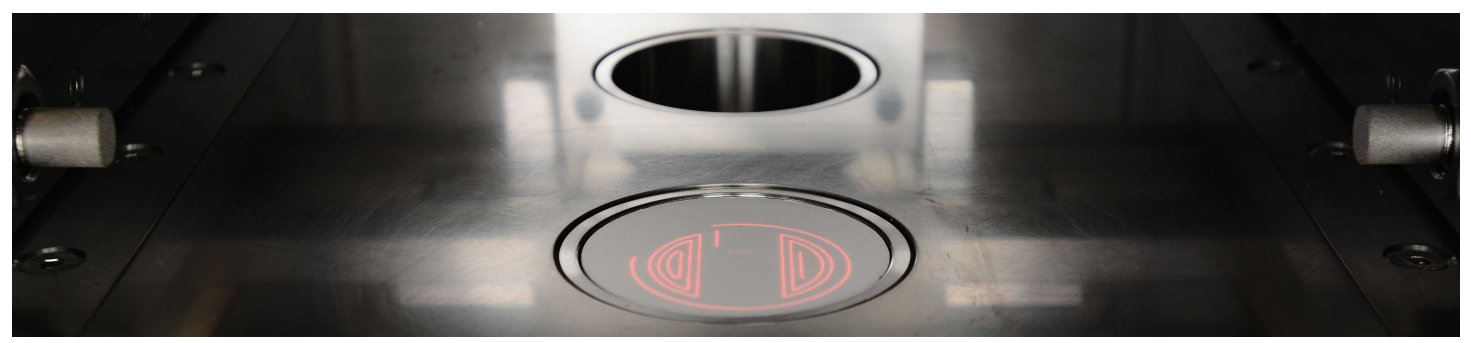

(a) Langzeitbelichtung eines Laserenergieeintrags durch den Laser-Scanner-Dummy
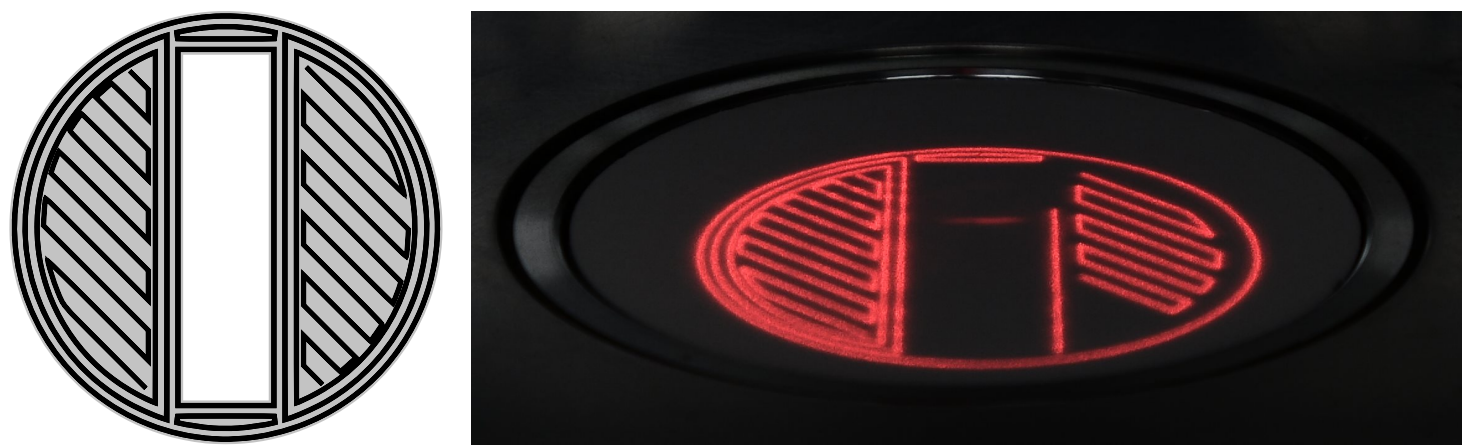

(b) Belichtungspfad des Füllmusters „Rectilinear" mit 50\% Fülldichte
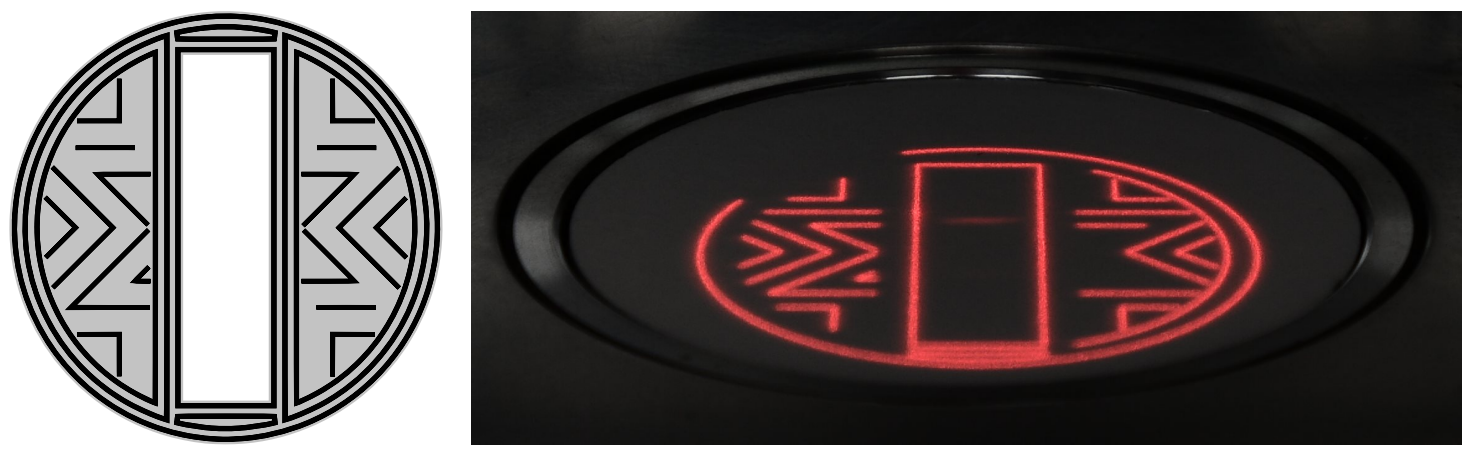

(c) Belichtungspfad des Füllmusters „Octagram Spiral“ mit 40\% Fülldichte
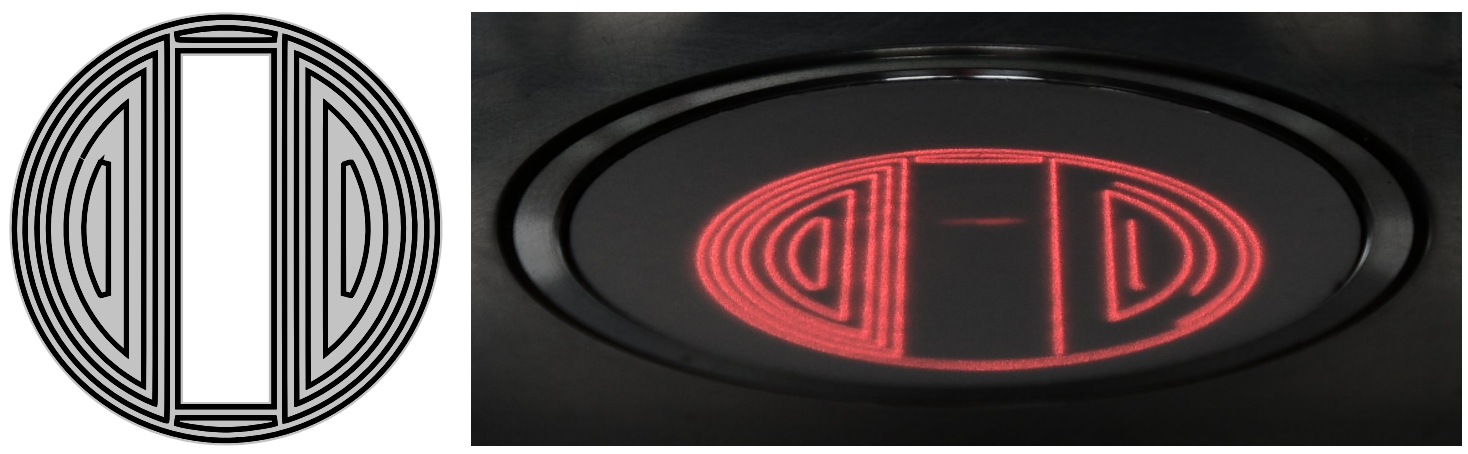

(d) Belichtungspfad des Füllmusters „Concentric“ mit 60\% Fülldichte

Abbildung 8.19.: Prüfung des Laser-Scanner-Demonstrators 
Slicer berechneter Pfad) und tatsächlichen (langzeitbelichtetes Foto) Belichtungspfaden. Da die Laserbearbeitungszeit der spezifischen Bauteilschicht größer als die eingestellte Verschlusszeit der Spiegelreflexkamera war, stellen die langzeitbelichteten Bilder lediglich einen Zwischenstand bei der Abarbeitung der numerischen Steuerbefehle des G-Codes dar. Auf Basis der vorliegenden Prüfergebnisse ist sowohl die Positionierung des Laserstrahls als auch die Koordination des Laser-Logikpegels („Laser On“ bzw. „Laser Off“) augenscheinlich möglich. Die Anforderungen an das Lasermodul gelten als erfüllt.

\subsubsection{Diskussion zur Funktionsabsicherung}

Im Hinblick auf die in den Abschnitten 8.2.1 bis 8.2.6 erzielten Prüfergebnisse gilt die Funktionsfähigkeit der mechatronischen Teilsysteme unter Berücksichtigung der in Abschnitt 6.1.1 definierten Anforderungen als erwiesen. Die Lasersintermaschine kann in der derzeitigen Ausbaustufe zur Durchführung der Prozessschritte (vgl. Grundlagen in Abschnitt 2.3.3) „Inertisierung“, „Aufheizvorgang“, „Pulverzuführung“, „Pulverauftrag“" und „Abkühlvorgang“ verwendet werden. Die zur materialspezifischen „Bauteilschichtgenerierung" notwendige Umrüstung des Lasermoduls ist in Abschnitt 7.4.2 am Beispiel von PLGA dargestellt. Die Übertragung der Entwicklungsergebnisse von dem Laser-ScannerDemonstrator (Scanlab hurrySCAN II 14 / Scanlab RTC5 / Pilotlaser mit $P_{\mathrm{L}}=2 \mathrm{~mW}$ bei $\lambda=635 \mathrm{~nm}$ ) auf die PLGA-Laser-Scanner-Einheit (Scanlab excelliSCAN 14 / Scanlab RTC6 / $\mathrm{CO}_{2}$-Laser mit $P_{\mathrm{L}}=8 \mathrm{~W}$ bei $\lambda=9,3 \mu \mathrm{m}$ ) ist mit wenigen Anpassungen ohne weiteres technisches Risiko möglich. Nichtsdestotrotz kann die modulare Lasersintermaschine, aufgrund der geringen Leistung des in dem Laser-Scanner-Demonstrator verbauten Pilotlasers, derzeitig nicht zur Herstellung von bioresorbierbaren Implantatmatrizen verwendet werden. Die nachfolgenden Diskussionspunkte der Funktionsabsicherung beziehen sich auf den Aufbau bzw. die softwareseitige Implementierung des jeweiligen mechatronischen Teilsystems oder die angewendete Methode zur Bereitstellung bzw. die Aussagekraft des objektiven Nachweises.

Sicherheitseinrichtungen Im Hinblick auf die hohen Erwartungen an die Sicherheit der modularen Lasersintermaschine (vgl. allgemeine Gestaltungsleitsätze nach DIN EN ISO 12100 [DIN EN ISO 12100]) muss die Wirksamkeit der Sicherheitseinrichtungen aufgrund fehlender Sicherheitsnachweise als kritisch bewertet werden. Da die Funktionen der sicherheitsbezogenen Teilsysteme derzeit einzig und allein auf der Zuverlässigkeit des C-Moduls NI-9411 bzw. der softwareseitigen Implementierung in dem LabVIEW-Steuerprogramm beruhen, muss für diesen Teil des programmierbaren Steuersystems (vgl. [DIN EN ISO 13849-1]) die funktionale Sicherheit gewährleistet sein. Da insbesondere die Sicherheitsanforderungsstufe (engl. „Safety Integrity Level“ (SIL)) (vgl. [DIN EN 61508-1]) des digitalen Eingangsmoduls nicht für den Betrieb einer materialspezifischen Laser-Scanner-Einheit genügt, wird eine entsprechende Neubewertung des Gesamtsystems hinsichtlich arbeitssicherheitlicher Kriterien notwendig sein. In diesem Zusammenhang sei auf die entsprechende Literatur (vgl. [DIN EN ISO 13849-1] [DIN EN 61508-1] [DIN EN 61511-1] [DIN EN 62061]) verwiesen. Zusätzlich wird der Austausch des C-Moduls NI-9411 gegen 
das Sicherheits-C-Modul NI-9350 (behördlich geprüftes Sicherheits-Integritätslevel) empfohlen.

Hubantriebsachsen Die Position der Plattform einer Hubantriebsachse wird indirekt über den achsreferenzierten Multiturn-Absolutwert-Drehgeber am Servomotor erfasst. Durch die drehstarre Kupplung des Servomotors an den elektromechanischen Zylinder (EMC) ist die erreichbare Positioniergenauigkeit der Achse abhängig von der Auflösung des verwendeten Drehgebers (vgl. Anhang D.1), der Fertigungsgenauigkeit des Kugelgewindetriebs im Steigungswinkel (vgl. Anhang D.4) und der Leistungsfähigkeit des Reglers. Die Auflösung $\left( \pm 20^{\prime \prime} \widehat{=} \pm 0,0056^{\circ}\right.$ vgl. [Bos13, S. 26]) des „M2“-Drehgebers führt in Kombination mit der Steigung ( $5 \mathrm{~mm}$ ) des Kugelgewindetriebs zu einer Abweichung von bis zu $\pm 0,7778 \mu \mathrm{m}$. Die Fertigungstoleranzklasse des Kugelgewindetriebs von T7 (zulässige Wegschwankung: $52 \mu \mathrm{m}$ pro $300 \mathrm{~mm}$ Verfahrweg vgl. [DIN ISO 3408-3, S. 14]) führt in Abhängigkeit des Inkrements zu einer zusätzlichen Abweichung von $\pm 0,0087 \mu \mathrm{m}$ (50 $\mu \mathrm{m}$ Verfahrweg),

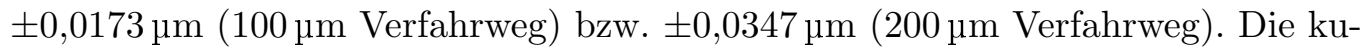
mulierte Abweichung, bezogen auf ein Inkrement von $100 \mu \mathrm{m}$ beträgt demnach bis $\mathrm{zu} \pm 0,8 \mu \mathrm{m}$. Spezifische Kennwerte bezüglich der Leistungsfähigkeit des Reglers sind nicht bekannt. Bei dem Betrieb einer derartig integrativ aufgebauten Hubantriebsachse können Umkehrspiele in axialer Richtung, von der Abtriebswelle des Servomotors bis hoch zur Oberseite der Plattform, vom Motordrehgeber schlichtweg nicht erfasst werden. Im Hinblick auf die durchgeführten Messungen zur Bestimmung der Positioniergenauigkeiten der Plattformen (vgl. Anhang E.2) erreichte die Bauplattform oberhalb der Hubantriebsbaugruppe Q1 eine Positioniergenauigkeit von $\pm 2,8 \mu \mathrm{m}$ bei einem Verfahrweg von $100 \mu \mathrm{m}$ (vgl. Ergebnisse der Messreihe "4-Q1+ST-100“ in Tabelle E.4). Eine intensive Nutzung der Lasersintermaschine führt unweigerlich zu einer Verschlechterung der Positioniergenauigkeit. Die Erfüllung der Anforderung „Positioniergenauigkeit des Baustempels $< \pm 5 \mu \mathrm{m}$ bei $100 \mu \mathrm{m}$ Schichtstärke" (vgl. Anforderung 7.12 in Tabelle A.1) sollte daher in diskreten Abständen überprüft werden. Sollte eine weitere Verbesserung der absoluten Positioniergenauigkeit (bezogen auf den gesamten Verfahrweg der Achse) gefordert sein, ist zu einem Austausch des Bosch Rexroth EMCs (Wechsel von Toleranzklasse $\mathrm{T} 7$ auf beispielsweise T1) angeraten.

Pulverauftragsachse Die Momentangeschwindigkeit der Beschichtereinheit-Aufnahme, in einem spezifischen Punkt oberhalb der Prozesseinsatzplatte, wird indirekt über den achsreferenzierten Multiturn-Absolutwert-Drehgeber am Servomotor erfasst. Durch die direkte Kupplung des Servomotors an den Kugelgewindetrieb ist die erreichbare Gleichmäßigkeit des Geschwindigkeitsprofils der Pulverauftragsachse abhängig von der Auflösung des verwendeten Drehgebers (vgl. Anhang D.1), der Fertigungsgenauigkeit des Kugelgewindetriebs im Steigungswinkel und der Leistungsfähigkeit des Reglers. Die Auflösung ( $\pm 120^{\prime \prime} \widehat{=} \pm 0,0333^{\circ}$ vgl. [Bos13, S. 26]) des „M1“-Drehgebers führt in Kombination mit der Steigung $(20 \mathrm{~mm})$ des Kugelgewindetriebs zu einer Abweichung von bis zu $\pm 1,85 \mu \mathrm{m}$. Die Fertigungstoleranzklasse des Kugelgewindetriebs von T5 (zulässige Wegschwankung: $23 \mu \mathrm{m}$ pro $300 \mathrm{~mm}$ 
Verfahrweg vgl. [DIN ISO 3408-3, S. 14]) führt pro Umdrehung zusätzlich zu einer Wegschwankung von $\pm 1,5333 \mu \mathrm{m}$. Führt die Motorwelle eine Drehbewegung mit einer Umdrehung pro Sekunde aus, beträgt die Momentangeschwindigkeit der Beschichtereinheit-Aufnahme ohne Abweichungen $20 \mathrm{~mm} / \mathrm{s}$. Die Geschwindigkeitsabweichung bezogen auf eine Umdrehung pro Sekunde $\left(\frac{(1,85 \mu \mathrm{m}+1,5333 \mu \mathrm{m}) \times 100 \%}{20 \mathrm{~mm}}\right)$ beträgt ca. $\pm 0,017 \%$. Bei einer Geschwindigkeits-Sollwertvorgabe für die Beschichtereinheit-Aufnahme von $50 \mathrm{~mm} / \mathrm{s}$ beträgt die rechnerische Abweichung $\pm 0,0213 \mathrm{~mm} / \mathrm{s}$. Wird die Geschwindigkeits-Sollwertvorgabe auf den geforderten Höchstwert (vgl. Anforderung 9.4 in Tabelle A.1) von $200 \mathrm{~mm} / \mathrm{s}$ erhöht, steigt die Abweichung auf $\pm 0,34 \mathrm{~mm} / \mathrm{s}$. Spezifische Kennwerte bezüglich der Leistungsfähigkeit des Reglers sind nicht bekannt. Aufgrund der Anordnung des Motordrehgebers können die Geschwindigkeitsabweichungen, hervorgerufen durch den Spindelsteigungsfehler des Kugelgewindetriebs, nicht erfasst werden. Eine experimentelle Untersuchung der Geschwindigkeitsabweichung, zur Verifizierung der aus dem Antriebsregelgerät ausgelesenen Geschwindigkeitswerte, wurde derzeit nicht vorgenommen. Sollte eine weitere Verbesserung der Gleichmäßigkeit des Geschwindigkeitsprofils erforderlich sein, ist die Antriebsachse geschwindigkeitsgeregelt zu betreiben. In diesem Betriebsmodus ist die simple Vorgabe der Parameter „Positionsstartwert“ (Lageistwert) und „Positionszielwert“ (Lagesollwert) jedoch nicht ohne Weiteres möglich.

6-Kanal-Heizsystem Die erreichbare Temperatur-Regelgenauigkeit eines Heizkanals ist abhängig von der Genauigkeit der verwendeten Temperatursensorik und der Leistungsfähigkeit des in LabVIEW programmierten PID-Reglers. Der federbelastete PT1000-Bajonettfühler der Gehäuseheizung (vgl. Anforderung 7.4 in Tabelle A.1) ist vom Hersteller mit der Genauigkeitsklasse „B“ (Grenzabweichung $\pm\left(0,3^{\circ} \mathrm{C}+0,005 \times\left|T_{\text {Heizung }}\right|\right)$ vgl. [DIN EN 60751, S. 13] $)$ klassifiziert, wird durch das C-Modul NI-9226 (Grenzabweichung $\pm 0,5^{\circ} \mathrm{C}$ vgl. [Nat16k, S. 5]) ausgelesen und misst die Temperatur an der Mantelfläche des jeweiligen Gehäuses. Die kumulierte Abweichung beträgt demnach $\pm 0,95^{\circ} \mathrm{C}\left(T_{\text {Heizung }}=30^{\circ} \mathrm{C}\right), \pm 1,025^{\circ} \mathrm{C}$ $\left(T_{\text {Heizung }}=45^{\circ} \mathrm{C}\right), \pm 1,1{ }^{\circ} \mathrm{C}\left(T_{\text {Heizung }}=60^{\circ} \mathrm{C}\right)$ bzw. $\pm 1,175^{\circ} \mathrm{C}\left(T_{\text {Heizung }}=75^{\circ} \mathrm{C}\right)$. Der in der Silikonheizmatte befindliche PT100-Fühler der Plattformheizung (vgl. Anforderung 7.14 in Tabelle A.1) ist ebenfalls mit der Genauigkeitsklasse „B“ klassifiziert, wird durch das C-Modul NI-9216 (Grenzabweichung $\pm 0,4{ }^{\circ} \mathrm{C}$ vgl. [Nat16j, S. 5]) ausgelesen und misst die Temperatur der Silikonheizmatte. Die auf die Vorheiztemperatur-Sollwertvorgabe bezogene kumulierte Abweichung ist im Vergleich zur Temperatursensorik der Gehäuseheizung um $\pm 0,1^{\circ} \mathrm{C}$ geringer. Da ausschließlich die Temperatur der zu beheizenden Oberfläche für die Bewertung der Funktionsfähigkeit des jeweiligen Heizkanals relevant ist, muss der Oberflächenkontakt des Temperatursensors stets gewährleistet sein. Würde sich die Silikonheizmatte vom Stempeloberteil innerhalb der Stempelbaugruppe lösen, führt dies unweigerlich zu einer (ggf. unentdeckten) Fehlfunktion. Die experimentelle Verifizierung der aus den RTD-Messkanälen ausgelesenen Temperaturmesswerte wurde bis dato nicht durchgeführt. Sollte eine weitere Verbesserung der Regelgenauigkeit erforderlich sein, ist ein Austausch der Platin-Messwiderstände (Wechsel von Genauigkeits- 
klasse „B“ auf beispielsweise „AA“), die Anpassung des Reglers, die Nutzung des NI-Kalibrierdienstes und/oder der Neuaufbau der jeweiligen Heizkanäle empfohlen. Die Verwendung mehrerer Messfühler pro Heizkanal wird in diesem Zusammenhang als zielführend bewertet.

Prozessgasversorgungssystem Die Genauigkeit des Massendurchflussreglers der Firma Bronkhorst [Bro17, S. 2] ist mit $\pm\left(0,005 \times \dot{V}+0,02 \mathrm{l}_{\mathrm{n}} / \mathrm{min}\right)$ angegeben. Die Grenzabweichung beträgt, in Abhängigkeit des eingestellten Volumenstroms, zwischen $\pm 0,022 \mathrm{l}_{\mathrm{n}} / \min \left(\dot{V}=0,4 \mathrm{l}_{\mathrm{n}} / \mathrm{min}\right)$ und $\pm 0,12 \mathrm{l}_{\mathrm{n}} / \min \left(\dot{V}=20 \mathrm{l}_{\mathrm{n}} / \mathrm{min}\right)$. Im Hinblick auf die bisherige Betriebserfahrung besteht insbesondere für dieses Teilsystem kein weiterer Handlungsbedarf bezüglich einer Optimierung.

Sauerstoff-Messsysteme Die erreichbare Sauerstoffmessgenauigkeit im Bereich des Bauvolumens ist abhängig von der Genauigkeit des Sauerstoff-Messsystems (Steuerplatine mit Zirkoniumdioxid-Sensor) und der Auslesegenauigkeit des analogen Spannungseingangsmoduls $( \pm 10 \mathrm{~V})$ NI-9201. Nach entsprechender Kalibrierung misst der Sensor eine Sauerstoffkonzentration von $0,1 \%$ vol $(0,04 \mathrm{~V})$ bis $25 \%$ vol $(10 \mathrm{~V})$, wobei insbesondere die Sauerstoffkonzentrationswerte unterhalb von 0,5\% vol $(0,2 \mathrm{~V})$ relevant sind. Wird der Sensor in einer reduzierten Atmosphäre unterhalb einer Sauerstoffkonzentration von $0,1 \%$ vol betrieben, führt dies zu einer Beschädigung des Zirkoniumdioxid-Elements [Fir18a, S. 10]. Die Genauigkeit des Sauerstoff-Messsystems der Firma First Sensor [Fir18b, S. 2] ist mit $\pm 0,275 \%$ vol angegeben. Die durch das C-Modul NI-9201 [Nat16i, S. 6] zusätzlich erzeugte Abweichung, bezogen auf Messwerte kleiner als 0,5\% vol, beträgt $\pm 0,122 \%$ vol. Die kumulierte Abweichung beträgt demnach bis zu $\pm 0,4 \%$ vol. Im Hinblick auf die mangelnde Messgenauigkeit ist für den schadensfreien Betrieb des Messsystems eine Abschaltung unterhalb einer Sauerstoffkonzentration von 0,5\% vol obligatorisch, wodurch die Überwachung des Prozessgasatmosphäre während des Lasersinterns nicht möglich ist. Die Platzierung der Zirkoniumdioxid-Sensoren im Bereich des Bauvolumens (vgl. Anforderung 11.11 in Tabelle A.1) kann, durch eine erhöhte Staubbelastung innerhalb der Prozesskammer, zu einer stark verkürzten Sensorlebensdauer führen. Ist das Volumen des Prozessgasgehäuses mit einem 4-fachen Volumenwechsel durch den Bronkhorst Massendurchflussregler gespült, die Laserglas-Prozessgas-Armatur über die gesamte Dauer der Bauteilgenerierung kontinuierlich mit einem Volumenstrom von $2,79 \mathrm{l}_{\mathrm{n}} / \mathrm{min}$ versorgt, könnte auf Grundlage der bisherigen Betriebserfahrung auf eine Sauerstoffmessung verzichtet werden.

Live-Video-Kamerasystem Trotz grundsätzlicher Funktionsfähigkeit (vgl. Anforderung 12.4 in Tabelle A.1) wird zu einem Kamerasystemwechsel (Flächenkamera: Basler „acA1920-150um“ / Objektiv: Kowa „LM16JC1MS“/ Arbeitsabstand: 250 mm) angeraten. Der Bildausschnitt von $135 \mathrm{~mm} \times 84 \mathrm{~mm}$ (lotrechte Angabe bei $250 \mathrm{~mm}$ Arbeitsabstand) in Kombination mit der hohen Auflösung der Basler Kamera (1920× 1200 mit einer Pixelgröße von 4,8 $\mu \mathrm{m} \times 4,8 \mu \mathrm{m}$ ) kann zur visuellen Begutachtung der aufgetragenen Pulverschichten über der Bauplattform verwendet werden. Zur Optimierung des Kamera-Blickfeldes sollte die Anpassung des Fundaments (vgl. Abbildung 8.18) der Laserglas-Prozessgas-Armatur in Betracht gezogen werden. 
Bei der Neukonstruktion der Kameraglas-Armatur empfiehlt sich der Zukauf eines entspiegelten Glases.

Laser-Scanner-Demonstrator Da der Laser-Scanner-Dummy ausschließlich zu Demonstrations- und Lehrzwecken aufgebaut wurde und zukünftig durch eine materialspezifische Laser-Scanner-Einheit ersetzt wird, wird an dieser Stelle auf eine Diskussion zur Funktionsabsicherung verzichtet.

Bei der Umsetzung der diskutierten Verbesserungen sollten die folgenden Modifikationen, gemäß der dargestellten Reihenfolge, entsprechend priorisiert werden:

1. Erhöhung der funktionalen Sicherheit der Sicherheitseinrichtung

2. Umbau des Lasermoduls auf eine materialspezifische Laser-Scanner-Einheit

3. Durchführung des Kamerasystemwechsels

4. Umbau der Heizkanäle in den Stempelbaugruppen 



\section{Zusammenfassung und Ausblick}

Im Rahmen der vorliegenden Arbeit wurde eine modulare Lasersintermaschine zur Herstellung von bioresorbierbaren Implantatmatrizen methodisch entwickelt, montiert und in Betrieb genommen. In Abschnitt 9.1 werden die Ergebnisse der jeweiligen Kapitel nacheinander zusammengefasst. Nach Abschluss des Produktentstehungsprozesses erfolgt die eigentliche Nutzung des Produkts. In Abschnitt 9.2 werden diesbezüglich weiterführende Forschungsarbeiten an und mit der Lasersintermaschine dargestellt. 


\subsection{Zusammenfassung}

Eine aus dem Bereich der regenerativen Medizin stammende visionäre Anwendung der AM-Technologie, einleitend in Kapitel 1 dargestellt, ist die Fertigung von individuell angepassten Implantaten und Organen. Werden zur Herstellung von Implantatmatrizen, dem Gerüst zum TE-Gewebeaufbau, bioresorbierbare Werkstoffe mittels Lasersintern verarbeitet, verbleibt das erzeugte Implantat nach der Transplantation im Körper des Patienten und wird dort durch biologische Prozesse in natürliches Gewebe umgesetzt. Die Grundlagen zu den Themen Additive Manufacturing (AM), Tissue Engineering (TE) und Lasersintern (LS) wurden in Kapitel 2 zusammengefasst. Bioresorbierbare Polymere wie PLA (Poly(Lactic Acid)), PGA (Poly(Glycolic Acid)), PLGA (Poly(Lactic-co-Glycolic Acid)) oder PCL (Polycaprolacton) gelten im Tissue Engineering Kontext als „Standardwerkstoffe" und sind als Thermoplaste grundsätzlich für das Lasersintern geeignet. In Kapitel 3 wurden kommerzielle Lasersintermaschinen samt kommerzieller Lasersintermaterialien (Stand der Technik) und die im Rahmen der Forschung eingesetzten Lasersintermaschinen samt bioresorbierbarer Labormaterialien (Stand der Wissenschaft) gegenübergestellt. Zur optimierten Verarbeitung eines bioresorbierbaren Werkstoffs in einer kommerziellen Lasersintermaschine müssten aufgrund der spezifischen Werkstoffcharakteristik, die erheblich von den kommerziellen Lasersintermaterialien abweicht, sowohl das Bauvolumen, die Beschichtereinheit, das Heizsystem als auch die Laser-ScannerEinheit modifiziert werden. Die Verwendung einer vollumfänglich modifizierten Lasersintermaschine zur Verarbeitung von bioresorbierbaren Materialien ist allerdings nicht bekannt. Um einen Beitrag zur zukünftigen Fertigung individuell angepasster Implantate und Organe mittels Lasersintern zu leisten, wurde im Rahmen der vorliegenden Arbeit eine spezifische Lasersintermaschine zur Herstellung von bioresorbierbaren Implantatmatrizen neuentwickelt. In Kapitel 4 wurden diesbezüglich der Forschungsbedarf sowie der Ansatz zur methodischen Entwicklung der modularen Lasersintermaschine dargestellt.

Das methodische Vorgehen bei der Entwicklung des mechatronischen Gesamtsystems orientierte sich an den VDI-Richtlinien 2221 [VDI 2221] und 2206 [VDI 2206]. Als Entwicklungsgrundlage wurden in Kapitel $\mathbf{5}$ generelle Anforderungen an Lasersintermaschinen zur Implantatherstellung erhoben und den folgenden Gruppen zugeordnet:

- Generelle Anforderungen an die Prozessführung

- z. B. Großer Einstellbereich der Prozessparameter

- z. B. Möglichkeit zur Integration zusätzlicher Messtechnik

- Generelle Anforderungen an die Produktarchitektur

- z. B. Hohes Maß an Modularität

- z. B. Kleines Bauvolumen zur wirtschaftlichen Fertigung filigraner Strukturen

- Generelle Anforderungen aus dem medizinischen Gerätebau

- z. B. Bevorzugte Verwendung von hygienegerechten Werkstoffen

- z. B. Reinigungsgerechte Gestaltung sämtlicher Bauteilgeometrien 
Das Kapitel 6 stellt die methodische Entwicklung der modularen Lasersintermaschine dar. Die grundlagenforschungstaugliche Maschine wurde explizit für die Anwendung im Bereich der Forschung konzipiert. Sowohl bei der Qualifizierung von bioresorbierbaren Sonderwerkstoffen für das Lasersintern als auch bei der Verarbeitung von Kleinstmengen spezifischer Materialchargen (Materialherstellung im Labormaßstab) wird es im Betriebsablauf der Forschungsmaschine häufig zu einem Materialwechsel kommen. Da insbesondere die Teilprozessschritte „Pulverauftrag" und „Bauteilschichtgenerierung" zur Fertigung von geometrisch und mechanisch geeigneten Implantatmatrizen von großer Bedeutung sind, wurde der modulare Charakter der Lasersintermaschine im Bereich der Beschichtereinheit und Laser-Scanner-Einheit betont ausgeprägt. Beim „Planen und Konzipieren" des mechatronischen Gesamtsystems wurde eine spezifische Anforderungsliste erstellt, eine Funktionsstruktur erfasst, prinzipielle Lösungen zur Erfüllung dieser Funktionen identifiziert und eine Modularisierung der Lasersintermaschine in die Module „Maschinengestell“, „Baustempelmodul“, „Pulverzuführmodul“, „Pulverauftragsmodul“, „Beschichtereinheit" (Submodul des Pulverauftragmoduls), „Prozessgasmodul“, „IR-Heizmodul" und „Lasermodul" durchgeführt. Die spezifische Anforderungsliste bestand zunächst aus den generellen Anforderungen aus Kapitel 5, Aufstellbedingungen für die Lasermaschine sowie Anforderungen an die Fertigung der Komponenten und wurde in den Phasen „Entwerfen und Ausarbeiten“ iterativ durch modulspezifische Anforderungen ergänzt. Sämtliche Baugruppen der Module sind auf horizontal verlaufenden Etagen (Antriebsetage unten / Prozessetage mittig / Laseretage oben) im Maschinengestell angeordnet. Auf der Oberseite der Prozessetage und der Unterseite der Laseretage ist jeweils eine Rahmenplatte (Prozessrahmenplatte / Laserrahmenplatte) mit spezifischem Bohrmuster montiert. Zur Umsetzung des Baustempel- und Pulverzuführmoduls sind eine Prozesseinsatzplatte samt Anbauteilen (Montage an Prozessrahmenplatte) und insgesamt drei Hubantriebsbaugruppen samt Stempelbaugruppen (Montage an Antriebsetage) ergänzt. Das Bauvolumen beträgt $\varnothing 65 \mathrm{~mm} \times 80 \mathrm{~mm}$ und wird sowohl über die Mantelfäche als auch über die Plattform elektrisch bis zu einer Vorheiztemperatur von $80^{\circ} \mathrm{C}$ beheizt. Die bioresorbierbaren Labormaterialien werden gemäß dem bewährten „DTM-Konzept“ aus zwei Pulvervorratsvolumina (baugleich zum Bauvolumen) in der vertikalen z-Richtung zugeführt und durch das Pulverauftragsmodul samt Beschichtereinheit in einer translatorischen Bewegung alternierend über der Bauplattform aufgetragen. Der Auftragsschlitten des Pulverauftragmoduls ist beidseitig (Fest-Los-Lagerung) gelagert, über einen Kugelgewindetrieb in horizontaler Richtung bewegt und dient als Aufnahme für die wechselbare Beschichtereinheit (starre Klinge / rotierende Rolle / schwingende Klinge). Das geschraubt und gedichtete Prozessgasgehäuse, bestehend aus einer beidseitig türgängigen Prozesskammer, zwei Nebenkammern und zwei Verbindungskammern, wird durch ein Massenstromregelventil mit Stickstoff inertisiert. Das Prozessgas wird auf der Oberseite einer Laserglas-Prozessgas-Armatur eingeleitet, innerhalb der Baugruppe um $90^{\circ}$ umgelenkt und durch einen Diffusor hindurch laminar über die Unterseite des Laserglases geführt. Die Armatur ist innerhalb der Prozesskammer an der Lasereinsatzplatte (Montage an Laserrahmenplatte) befestigt. Der Laser-Scanner-Demonstrator, der lediglich zu Demonstrations- und Lehrzwecken aufgebaut wurde, ist eine Baugruppe des Lasermoduls und ist modifikationsfreundlich auf der Laseretage befestigt. Alle 
mechatronischen Teilsysteme der modularen Lasersintermaschine werden durch den echtzeitfähigen und beliebig erweiterbaren CompactRIO-Controller der Firma National Instruments gesteuert oder geregelt. Die zur Prozessführung notwendigen Mess-, Steuerungs-, Regelungs- und Überwachungsanwendungen können für den Zweck der Forschung frei in LabVIEW programmiert und angepasst werden. Das Konzept zur Entwicklung der modularen Lasersintermaschine wurde schrittweise ausgearbeitet, detailliert dokumentiert und kann insbesondere von anderen Forschungsinstituten als Vorlage zur Realisierung vergleichbarer Entwicklungsprojekte genutzt werden.

Bei der Auslegung einer Laser-Scanner-Einheit für eine Lasersintermaschine ist neben der Laserleistung vor allem die Wellenlänge der Strahlquelle von großer Bedeutung. Aufgrund des materialspezifischen Absorptionsspektrums muss die zur Generierung der bioresorbierbaren Implantatmatrizen verwendete Laserwellenlänge auf das zu verarbeitende Material abgestimmt sein. Da zum Zeitpunkt der Systementwicklung die Auswahl eines spezifischen bioresorbierbaren Polymers nicht erfolgt war, wurde in Kapitel $\mathbf{7}$ die Auswahl einer materialspezifischen Laser-Scanner-Einheit auf Basis entsprechender Materialuntersuchungen beispielhaft an PLGA durchgeführt. Diesbezüglich wurden insgesamt drei medizinisch zertifizierte PLGA-Werkstoffe der Firmen Evonik und Corbion Purac untersucht. Die kommerziellen PLGA-Materialien sind aufgrund ihrer mittleren Partikelgröße (Evonik $>120 \mu \mathrm{m} /$ Corbion Purac $>2 \mathrm{~mm}$ ) nicht ohne weitere Nachbehandlung zum Lasersintern geeignet und werden zur normkonformen Analysevorbereitung kryogen gemahlen und gesiebt. Im ersten Schritt wurden die thermischen Eigenschaften der amorphen Polymere mittels DSC-Messverfahren ermittelt. Die beim Lasersintern einzustellende Vorheiztemperatur (Evonik $45^{\circ} \mathrm{C} /$ Corbion Purac $54^{\circ} \mathrm{C}$ ) muss, im Hinblick auf den Pulverauftrag mit festen Partikeln, unterhalb der materialspezifischen Glasübergangstemperatur liegen. Der Übergang vom thermoelastischen in den thermoplastischen Zustandsbereich geschieht bei den amorphen Polymeren oberhalb der Glasübergangstemperatur. Die Corbion Purac Materialien (Evonik Material ohne ausgeprägtes Schmelzpeak) hatten Schmelzbereiche zwischen $124^{\circ} \mathrm{C}$ und $163^{\circ} \mathrm{C}$. Der Laserenergieeintrag in das PLGA-Pulverbett muss folglich zu einer Erhöhung der Pulverbettoberflächentemperatur um mehr als $70^{\circ} \mathrm{C}$ führen. Bei der Verarbeitung eines teilkristallinen PA12 beträgt die notwendige Temperaturerhöhung hingegen weitaus weniger als $10^{\circ} \mathrm{C}$ („quasi-isothermes Lasersintern“). Im zweiten Schritt wurden die optischen Eigenschaften der PLGA-Materialien mittels FTIR-Spektroskopie untersucht. Ein FTIR-Spektrometer misst die vom Material absorbierte elektromagnetische Strahlung, die im Kontext des Lasersinterns zu einer für den Schmelzvorgang notwendigen Energieaufnahmen durch das Material führt. Die in den kommerziellen Lasersintermaschinen eingesetzten $\mathrm{CO}_{2}$-Laser emittieren ausschließlich eine Wellenlänge von 10,6 $\mathrm{m}$. Kommerzielle $\mathrm{CO}_{2}$-Laser sind hingegen auch mit den Wellenlängen von

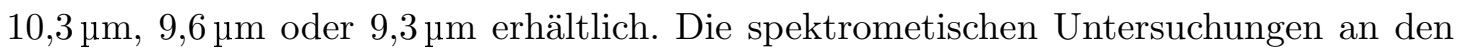
drei PLGA-Materialien ergaben einheitlich, dass durch die Verwendung eines $\mathrm{CO}_{2}$-Lasers mit einer Wellenlänge von $9,3 \mu \mathrm{m}$, anstelle eines $\mathrm{CO}_{2}$-Lasers mit einer Wellenlänge von 10,6 $\mu \mathrm{m}$, die Absorption der elektromagnetischen Strahlung durch das PLGA um den Faktor 10 auf ca. $33 \%$ gesteigert werden kann. Der Ansatz zur materialspezifischen 
Auswahl der Laserwellenlänge vor der Verarbeitung eines bioresorbierbaren Polymers ist bis dato nicht bekannt. Diesbezüglich wurde ein konkreter Systemvorschlag für eine PLGA-Laser-Scanner-Einheit mit einer maximalen Leistung von $8 \mathrm{~W}$ und einer Wellenlänge von 9,3 um als möglicher Ersatz für den Laser-Scanner-Demonstrator aus dem Lasermodul der modularen Lasersintermaschine erarbeitet. Sowohl die in Kapitel 5 erarbeiteten Anforderungen als auch die in Kapitel 7 diskutierten Überlegungen zur Laserwellenlänge können bei der Weiterentwicklung kommerzieller Lasersintermaschinen zur Verarbeitung bioresorbierbarer Polymere übertragen werden.

Das Kapitel 8 stellt die modulare Lasersintermaschine nach der Montage und Inbetriebnahme abschließend dar. Zur Erprobung des Gesamtsystems wurde die Funktionsfähigkeit der mechatronischen Teilsysteme „Sicherheitseinrichtungen“, „Hubantriebsachsen“, „Pulverauftragsachse“, „6-Kanal-Heizsystem“, „Prozessgasversorgungssystem“, „SauerstoffMesssysteme“, „Live-Video-Kamerasystem“ sowie „Laser-Scanner-Demonstrator“ überprüft und gemäß dem V-Modell der VDI-Richtlinie 2206 zur Eigenschaftsabsicherung mit den eingangs definierten Anforderungen an die bzw. aus den spezifischen Modulen abgeglichen. Im Hinblick auf die erzielten Prüfergebnisse wurde die Funktionsfähigkeit jedes einzelnen mechatronischen Teilsystems erwiesen.

\subsection{Ausblick}

Die modulare Lasersintermaschine kann in der derzeitigen Ausbaustufe zur Durchführung der Prozessschritte „Inertisierung“, „Aufheizvorgang“, „Pulverzuführung“, „Pulverauftrag“ und „Abkühlvorgang“ verwendet werden. Die „Bauteilschichtgenerierung“ kann aufgrund der geringen Leistung des in dem Laser-Scanner-Demonstrator (vgl. schwarze Baugruppe oberhalb der Laseretage in Abbildung 9.1) verbauten Pilotlasers nicht realisiert werden.

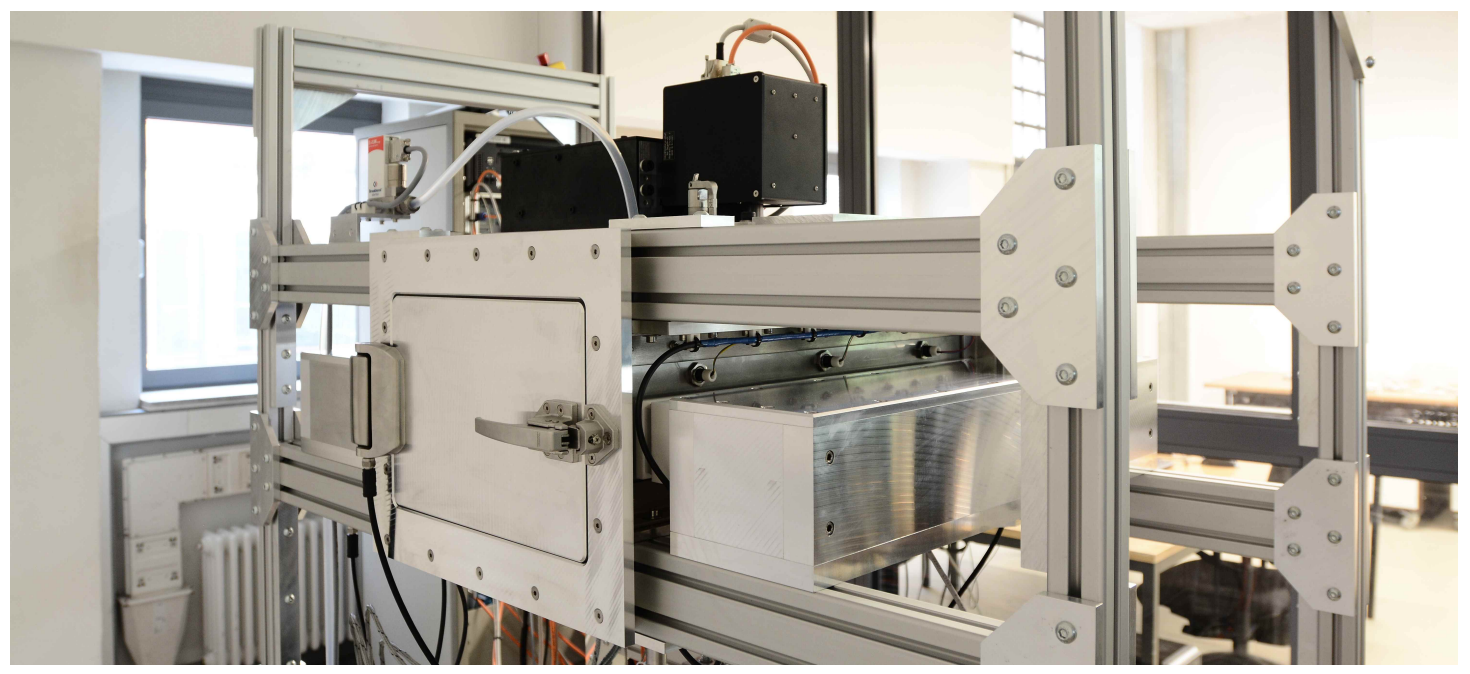

Abbildung 9.1.: Laser-Scanner-Demonstrator der modularen Lasersintermaschine 
Zur Nutzung der Lasersintermaschine muss der Laser-Scanner-Demonstrator zunächst durch eine materialspezifische Laser-Scanner-Einheit ersetzt werden. Sollen zur Herstellung der bioresorbierbaren Implantatmatrizen entweder PLA oder das in Kapitel 7 untersuchte PLGA verarbeitet werden, kann die in Abschnitt 7.4.2 ausgewählte PLGALaser-Scanner-Einheit verwendet werden. Soll eine gänzlich andere Materialklasse (z. B. PCL) eingesetzt werden, müssen die spektrometrischen Untersuchungen entsprechend wiederholt werden. Trotz grundsätzlicher Funktionsfähigkeit des Gesamtsystems kann der Produktreifegrad der Maschine gesteigert werden. Ein konkreter Maßnahmenkatalog ist diesbezüglich in Abschnitt 8.2.6 erfasst.

Die durch das Additive Manufacturing erzeugte Bauteilqualität ist das Ergebnis einer komplexen Wechselwirkung aus Material, Maschine und Prozess. Bei der additiven Fertigung von bioresorbierbaren Implantatmatrizen für das Tissue Engineering erhöht sich die Komplexität der Wechselwirkung zusätzlich durch die spezifischen Qualitätsmerkmale des Tissue Engineerings. Die Motivation zur Entwicklung der modularen Lasersintermaschine zielt letztendlich auf eine Steigerung der erzeugten Bauteilqualität durch die Nutzung des im Rahmen der vorliegenden Arbeit entwickelten Gesamtsystems ab. Ist ein spezifisches bioresorbierbares Material ausgewählt, welches im Idealfall bereits in vergangenen Forschungsprojekten verarbeitet wurde, muss zunächst ein geeigneter Prozess mit der modularen Lasersintermaschine entwickelt werden. Gelingt es die spezifischen Qualitätsmerkmale der lasergesinterten Implantatmatrizen (Biokompatibilität / Biodegradierbarkeit / Bioaktivität / mechanische Eigenschaften / geometrische Eigenschaften) durch den erweiterten Prozessparameterbereich der modularen Lasersintermaschine zu steigern, wurde ein Beitrag zur zukünftigen Fertigung individuell angepasster Implantate und Organe mittels Lasersintern geleistet. 
Anhang 



\section{A. Spezifische Anforderungsliste der Lasersintermaschine}

Tabelle A.1.: Spezifische Anforderungsliste der modularen Lasersintermaschine

\begin{tabular}{|c|c|c|}
\hline $\mathbf{F} / \mathbf{W}$ & & Anforderungen \\
\hline \multicolumn{3}{|r|}{$\downarrow$ Initiale Anforderungen aus der Planungs- und Konzipierungsphase $\downarrow$} \\
\hline & 1. & Generelle Anforderungen an die Prozessführung \\
\hline $\mathrm{F}$ & 1.1 & Großer Einstellbereich der Prozessparameter \\
\hline $\mathrm{F}$ & 1.2 & Möglichkeit der Regelung zielführender Prozessparameter \\
\hline $\mathrm{F}$ & 1.3 & Kenntnis über die parameterspezifische Leistungsfähigkeit der Teilsysteme \\
\hline $\mathrm{F}$ & 1.4 & Möglichkeit zur vorübergehenden Integration zusätzlicher Messtechnik \\
\hline $\mathrm{W}$ & 1.5 & Data Logging sämtlicher Prozessparameter \\
\hline \multirow[t]{2}{*}{$\mathrm{F}$} & 1.6 & Möglichkeit zur Anpassung der Steuersoftware \\
\hline & 2. & Generelle Anforderungen an die Produktarchitektur \\
\hline $\mathrm{F}$ & 2.1 & Hohes Maß an Modularität \\
\hline $\mathrm{F}$ & 2.2 & Modifikationsfreundliche Produktstruktur \\
\hline $\mathrm{F}$ & 2.3 & Erweiterbarkeit des Steuersystems \\
\hline $\mathrm{F}$ & 2.4 & Kleines Bauvolumen zur wirtschaftlichen Fertigung filigraner Strukturen \\
\hline $\mathrm{F}$ & 2.5 & Bevorzugte Verwendung von multifunktionalen Teilsystemen \\
\hline $\mathrm{F}$ & 2.6 & Bevorzugte Verwendung von geregelten Teilsystemen \\
\hline $\mathrm{F}$ & 2.7 & Einsatz spezifischer Sensorik \\
\hline \multirow[t]{2}{*}{$\mathrm{F}$} & 2.8 & Kenntnis über die komponentenspezifische Leistungsfähigkeit der Teilsysteme \\
\hline & 3. & Generelle Anforderungen aus dem medizinischen Gerätebau \\
\hline $\mathrm{F}$ & 3.1 & Bevorzugte Verwendung von hygienegerechten Werkstoffen \\
\hline $\mathrm{W}$ & 3.2 & Reinigungsgerechte Gestaltung sämtlicher Bauteilgeometrien \\
\hline $\mathrm{W}$ & 3.3 & Hygienegerechte Gestaltung von Bauteilverbindungen \\
\hline $\mathrm{W}$ & 3.4 & Vermeidung von Toträumen in Baugruppen \\
\hline $\mathrm{W}$ & 3.5 & Fertigung qualitativ hochwertiger Oberflächenbeschaffenheiten \\
\hline $\mathrm{F}$ & 3.6 & Bevorzugte Verwendung von hygienekonformen Zukaufteilen \\
\hline \multirow[t]{2}{*}{$\mathrm{F}$} & 3.7 & Einsatz einer medizinischen Gasversorgung zur Inertisierung \\
\hline & 4. & Aufstellbedingungen für die Lasersintermaschine \\
\hline $\mathrm{F}$ & 4.1 & Spannungsversorgung $230 \mathrm{~V} \& 400 \mathrm{~V}$ \\
\hline $\mathrm{F}$ & 4.2 & Autarkes System zur Verwendung in Räumen ohne Druckluft- oder Gasanschluss \\
\hline $\mathrm{F}$ & 4.3 & Transport der montierten Maschine muss durch eine $1 \mathrm{~m} \times 2,2 \mathrm{~m}$ Tür möglich sein \\
\hline \multirow[t]{2}{*}{$\mathrm{F}$} & 4.4 & Ergonomische Bedienung gemäß DIN 33402-2 [DIN 33402-2] bei Bodenaufstellung \\
\hline & 5. & Anforderungen an die Fertigung der Komponenten \\
\hline $\mathrm{W}$ & 5.1 & Primär die institutseigene DMU 50 Eco CNC-Fräsmaschine nutzen \\
\hline $\mathrm{W}$ & 5.2 & Institutseigene konventionelle substraktive Fertigungsmöglichkeiten nutzen \\
\hline \multicolumn{3}{|r|}{$\downarrow$ Iterativ ergänzte Anforderungen aus der Entwurfs- und Ausarbeitungsphase $\downarrow$} \\
\hline & 6. & Anforderungen an das bzw. aus dem Maschinengestell \\
\hline $\mathrm{F}$ & 6.1 & Kompatibilität zum Steuersystem NI CompactRIO 9035 / Erweiterungschassis 9144 \\
\hline
\end{tabular}




\begin{tabular}{|c|c|c|}
\hline $\mathrm{F}$ & 6.2 & Programmierung der Steuersoftware in der Entwicklungsumgebung NI LabVIEW \\
\hline W & 6.3 & Zukauf von mechatronischen Teilsystemen mit validierten LabVIEW-Sub-VIs \\
\hline W & 6.4 & Integration mechatronischer Zukauf-Teilsysteme in das EtherCAT-Netzwerk \\
\hline W & 6.5 & Einbau der Elektronik in einen 19" Schaltschrank neben der Lasersintermaschine \\
\hline $\mathrm{F}$ & 6.6 & Anordnung der Schaltschrankelektronik in modularen 19" Baugruppenträgern \\
\hline W & 6.7 & Elektrische Verbindungen trennbar gemäß einheitlichem Verkabelungskonzept \\
\hline \multirow[t]{6}{*}{$\mathrm{F}$} & 6.8 & Einsatz eines symmetrischen Maschinengestells aus Alu-Konstruktionsprofilen \\
\hline & $\hookrightarrow$ & Verwendung von Maschinenfüßen zum Ausgleich von Bodenunebenheiten \\
\hline & $\hookrightarrow$ & Verwendung von Verbindungsplatten zur Erhöhung der Ecksteifigkeit \\
\hline & $\hookrightarrow$ & Vertikale Alu-Konstruktionsprofile: Profil $840 \times 40$ schwer / item-kompatibel \\
\hline & $\hookrightarrow$ & Horizontale Alu-Konstruktionsprofile: Profil $880 \times 40$ schwer / item-kompatibel \\
\hline & $\hookrightarrow$ & Geometrische Abmessungen einer Etage: $1200 \mathrm{~mm} \times 650 \mathrm{~mm} \times 80 \mathrm{~mm}$ \\
\hline $\mathrm{F}$ & 6.9 & Montage aller Hubantriebsachsen an der Antriebsetage \\
\hline \multirow[t]{6}{*}{$\mathrm{F}$} & 6.10 & Montage einer Prozessrahmenplatte auf die Oberseite der Prozessetage \\
\hline & $\hookrightarrow$ & Einbringung Bohrmuster (M6 Senkschrauben) für Montage an Etage \\
\hline & $\hookrightarrow$ & Montagerichtung Prozesseinsatzplatte: von unten an Prozessrahmenplatte \\
\hline & $\hookrightarrow$ & Einbringung Bohrmuster (M6 Senkschrauben) zur Befestigung der Einsatzplatte \\
\hline & $\hookrightarrow$ & Einbringung von Passbohrungen zur Positionierung der Einsatzplatte \\
\hline & $\hookrightarrow$ & Einbringung M6 Gewindebohrmuster für Montage Prozesskammerwandbaugruppe \\
\hline \multirow[t]{8}{*}{$\mathrm{F}$} & 6.11 & Montage einer Laserrahmenplatte unter die Unterseite der Laseretage \\
\hline & $\hookrightarrow$ & Einbringung Bohrmuster (M6 Senkschrauben) für Montage an Etage \\
\hline & $\hookrightarrow$ & Montagerichtung Lasereinsatzplatte: von oben auf Laserrahmenplatte \\
\hline & $\hookrightarrow$ & Einbringung Bohrmuster (M6 Senkschrauben) zur Befestigung der Einsatzplatte \\
\hline & $\hookrightarrow$ & Einbringung von Passbohrungen zur Positionierung von Einsatzplatte \& Aufbauten \\
\hline & $\hookrightarrow$ & Einbringung M6 Gewindebohrmuster für Montage von Aufbauten \\
\hline & $\hookrightarrow$ & Einbringung einer O-Ring-Dichtnut auf Oberseite der Laserrahmenplatte \\
\hline & $\hookrightarrow$ & Einbringung M6 Gewindebohrmuster für Montage Prozesskammerwandbaugruppe \\
\hline $\mathrm{F}$ & 6.12 & Montage des Prozessgasgehäuses zwischen Prozessetage \& Laseretage \\
\hline W & 6.13 & Data Logging von Datum \& Uhrzeit über den gesamten Betrieb \\
\hline \multirow[t]{2}{*}{$\mathrm{F}$} & 6.14 & Implementierung einer Not-Halt-Funktion (Sicherheitsaspekt) \\
\hline & 7. & Anforderungen an das bzw. aus dem Baustempelmodul \\
\hline $\mathrm{F}$ & 7.1 & Geometrie des nicht wechselbaren Bauvolumens: $\varnothing 65 \mathrm{~mm} \times 80 \mathrm{~mm}(\widehat{=} \mathrm{ca} .265 \mathrm{ml})$ \\
\hline \multirow[t]{9}{*}{$\mathrm{F}$} & 7.2 & Einsatz von symmetrischer Prozesseinsatzplatte (Montage an Prozessrahmenplatte) \\
\hline & $\hookrightarrow$ & Übertragung der Bohrmuster von Prozessrahmenplatte auf Prozesseinsatzplatte \\
\hline & $\hookrightarrow$ & Einbringung einer O-Ring-Dichtnut zur Abdichtung gegen Prozessrahmenplatte \\
\hline & $\hookrightarrow$ & Montage aller Anbauteile von der Unterseite an die Prozesseinsatzplatte \\
\hline & $\hookrightarrow$ & Baustempelgehäuse mit Bund $\left(d_{\mathrm{i}}\right) 65 \mathrm{~mm} \times\left(d_{\mathrm{a}}\right) 75 \mathrm{~mm} \times(h) 110 \mathrm{~mm}$ \\
\hline & $\hookrightarrow$ & Einbringung Passbohrung für Baustempelgehäuse mittig in Prozesseinsatzplatte \\
\hline & $\hookrightarrow$ & Einbringung einer O-Ring-Dichtnut zur Abdichtung gegen Baustempelgehäuse \\
\hline & $\hookrightarrow$ & Ergänzung einer Dichtungs-Einführschräge am Baustempelgehäuse (oben außen) \\
\hline & $\hookrightarrow$ & Berücksichtigung der Ergänzungen/Modifikationen aus dem Pulverzuführmodul \\
\hline $\mathrm{W}$ & 7.3 & Data Logging Raumtemperatur (Umgebungsbedingung) \\
\hline \multirow[t]{3}{*}{$\mathrm{F}$} & 7.4 & Einsatz eines geregelten Heizsystems an Baustempelgehäuse-Mantelfläche \\
\hline & $\hookrightarrow$ & $\begin{array}{l}\text { Schraubbare Heizmanschette }(230 \mathrm{~V}) \text { : Anschlussmaß } \varnothing 75 \mathrm{~mm} \times 88 \mathrm{~mm} / \text { Kabelarma- } \\
\text { tur } 12 \mathrm{Uhr} / \text { Verspannung } 6 \mathrm{Uhr} / \text { Bohrung Thermofühler } 3 \mathrm{Uhr}\end{array}$ \\
\hline & $\hookrightarrow$ & PT1000-Bajonettfühler / $120^{\circ}$ Messspitze / 4-Leiter / Genauigkeitsklasse min. B \\
\hline $\mathrm{F}$ & 7.5 & Vorheiztemperatur-Sollwertvorgabe für Gehäuseheizung $30^{\circ} \mathrm{C}-80^{\circ} \mathrm{C}$ bzw. „Off“ \\
\hline W & 7.6 & Data Logging der Baustempelgehäuse-Temperaturmesswerte \\
\hline \multirow[t]{4}{*}{$\mathrm{F}$} & 7.7 & Einsatz einer geregelten Antriebsachse mit effektivem Arbeitshub von $180 \mathrm{~mm}$ \\
\hline & $\hookrightarrow$ & Antrieb durch Servomotor mit Multiturn-Absolutwert-Drehgeber (Auflösung $\pm 20^{\prime \prime}$ ) \\
\hline & $\hookrightarrow$ & Direkte Übertragung (ohne Getriebe) des Antriebsmoments auf Kugelgewindetrieb \\
\hline & $\hookrightarrow$ & $\begin{array}{l}\text { Kugelgewindetrieb mit } 2 \% \text { Vorspannung / Toleranzklasse min. T7 / Steigung } 5 \mathrm{~mm} \\
\text { / Dokumentation über die Steigungsabweichung der Spindel }\end{array}$ \\
\hline
\end{tabular}




\begin{tabular}{|c|c|c|}
\hline & $\hookrightarrow$ & Data Logging der Motortemperatur \\
\hline $\mathrm{F}$ & 7.8 & Positions-Sollwertvorgabe (relative \& absolute Werte) zur Achspositionierung \\
\hline \multirow[t]{4}{*}{$\mathrm{F}$} & 7.9 & Einsatz einer Führungseinheit zur Lagerung der Hubantriebsachsen-Kolbenstange \\
\hline & $\hookrightarrow$ & 200 mm Führungsstangen der Jochplatte gelagert durch Kugelumlaufführung \\
\hline & $\hookrightarrow$ & Jochplatte mit M6 Gewindebohrungen zur Montage der Stempelbaugruppe \\
\hline & $\hookrightarrow$ & Umkehrspiel in axialer Richtung $=0 \mu \mathrm{m}$ (Kupplung) \\
\hline $\mathrm{F}$ & 7.10 & Befestigung der Führungseinheit an der Antriebsetage über Aufnahmeplatten \\
\hline \multirow[t]{7}{*}{$\mathrm{F}$} & 7.11 & Einsatz einer wechselbaren $215 \mathrm{~mm}$ hohen Stempelbaugruppe \\
\hline & $\hookrightarrow$ & Montage der Stempelbaugruppe auf der Jochplattenoberseite der Führungseinheit \\
\hline & $\hookrightarrow$ & Ausgleich eines Axialversatzes von max. 1,5 mm durch die Stempelbaugruppe \\
\hline & $\hookrightarrow$ & Durchmesser der wechselbaren Bauplattform (Baustempel) $\varnothing 64 \mathrm{~mm}$ \\
\hline & $\hookrightarrow$ & Verwendung einer Kolbendichtung aus PTFE trotz Stick-Slip-Gefahr \\
\hline & $\hookrightarrow$ & Einbringung einer Dichtnut in Stempel zur Abdichtung gegen Baustempelgehäuse \\
\hline & $\hookrightarrow$ & Ergänzung einer Dichtungs-Einführschräge am Baustempelgehäuse (unten innen) \\
\hline $\mathrm{F}$ & 7.12 & Positioniergenauigkeit des Baustempels $< \pm 5 \mu \mathrm{m}$ bei $100 \mu \mathrm{m}$ Schichtstärke \\
\hline $\mathrm{W}$ & 7.13 & Data Logging der Schichtstärken (Achskontrolle in vertikaler (abwärts) z-Richtung) \\
\hline \multirow[t]{2}{*}{$\mathrm{F}$} & 7.14 & Einsatz eines geregelten Heizsystems integriert im Baustempel \\
\hline & $\hookrightarrow$ & $\begin{array}{l}\text { Selbstklebende Silikonheizmatte }(12 \mathrm{~V}) \text { : Anschlussmaß } \varnothing 50 \mathrm{~mm} \times 3 \mathrm{~mm} / \text { integrierter } \\
\text { PT-Fühler (Genauigkeitsklasse min. B) / Kabelpatch mittig auf Unterseite }\end{array}$ \\
\hline $\mathrm{F}$ & 7.15 & Vorheiztemperatur-Sollwertvorgabe für Plattformheizung $30^{\circ} \mathrm{C}-80^{\circ} \mathrm{C}$ bzw. „Off“ \\
\hline W & 7.16 & Data Logging der Baustempel-Temperaturmesswerte \\
\hline W & 7.17 & Data Logging der Temperatur an der Abstandshantel nahe Führungseinheit \\
\hline \multirow[t]{2}{*}{$\mathrm{W}$} & 7.18 & Data Logging Anlagen-Vorwärmzeit / Schicht-Vorheizzeit / Bauteil-Abkühlzeit \\
\hline & 8. & Anforderungen an das bzw. aus dem Pulverzuführmodul \\
\hline $\mathrm{F}$ & 8.1 & Umsetzung des Pulverzuführmoduls mit Komponenten des Baustempelmoduls \\
\hline \multirow[t]{5}{*}{$\mathrm{F}$} & 8.2 & Ergänzung der Prozesseinsatzplatte mit Anbauteilen aus dem Pulverzuführmodul \\
\hline & $\hookrightarrow$ & Anordnung nach robustem DTM-Konzept \\
\hline & $\hookrightarrow$ & Einsatz von zwei weiteren (nicht wechselbaren) Gehäusen (Pulverzuführgehäusen) \\
\hline & $\hookrightarrow$ & Einsatz von zwei weiteren Heizsystemen an den Gehäuse-Mantelflächen \\
\hline & $\hookrightarrow$ & Ergänzung von zwei Überlaufbehältern ( $\widehat{=}$ ca. $700 \mathrm{ml})$ \\
\hline $\mathrm{F}$ & 8.3 & Vorheiztemperatur-Sollwertvorgabe für Gehäuseheizungen $30^{\circ} \mathrm{C}-80^{\circ} \mathrm{C}$ bzw. „Off“ \\
\hline $\mathrm{W}$ & 8.4 & Data Logging der Pulverzuführgehäuse-Temperaturmesswerte \\
\hline \multirow[t]{5}{*}{$\mathrm{F}$} & 8.5 & Ergänzung der Antriebsetage mit Anbauteilen aus dem Pulverzuführmodul \\
\hline & $\hookrightarrow$ & Einsatz von zwei weiteren Antriebsachsen \\
\hline & $\hookrightarrow$ & Einsatz von zwei weiteren Führungseinheiten \\
\hline & $\hookrightarrow$ & Einsatz von zwei weiteren Stempelbaugruppen \\
\hline & $\hookrightarrow$ & Einsatz von zwei weiteren Heizsystemen integriert in den Pulverzuführstempeln \\
\hline $\mathrm{F}$ & 8.6 & Positions-Sollwertvorgabe (relative \& absolute Werte) zur Achspositionierung \\
\hline $\mathrm{W}$ & 8.7 & Umschaltbarer Betrieb zur Verwendung einer Zuführung bzw. beider Zuführungen \\
\hline $\mathrm{W}$ & 8.8 & Data Logging der Feedrates (Achskontrolle in vertikaler (aufwärts) z-Richtung) \\
\hline $\mathrm{F}$ & 8.9 & Vorheiztemperatur-Sollwertvorgabe für Plattformheizungen $30^{\circ} \mathrm{C}-80^{\circ} \mathrm{C}$ bzw. „Off“ \\
\hline W & 8.10 & Data Logging der Pulverzuführstempel-Temperaturmesswerte \\
\hline \multirow[t]{2}{*}{ W } & 8.11 & Data Logging der Temperatur an den Abstandshanteln nahe Führungseinheit \\
\hline & 9. & Anforderungen an das bzw. aus dem Pulverauftragsmodul \\
\hline $\mathrm{F}$ & 9.1 & Montage des Pulverauftragmoduls auf der Oberseite der Prozessetage \\
\hline \multirow[t]{3}{*}{$\mathrm{F}$} & 9.2 & Bewegung der Beschichtereinheit-Aufnahme in translatorischer Richtung \\
\hline & $\hookrightarrow$ & Möglichkeit zur Montage einer Beschichtereinheit $(l) 180 \mathrm{~mm} \times(b) 40 \mathrm{~mm} \times(h) 75 \mathrm{~mm}$ \\
\hline & $\hookrightarrow$ & Schlittenaufnahme einseitig angetrieben / beidseitig gelagert (Fest-Los-Lagerung) \\
\hline \multirow[t]{4}{*}{$\mathrm{F}$} & 9.3 & Einsatz einer geregelten Antriebsachse mit effektivem Verfahrweg von $420 \mathrm{~mm}$ \\
\hline & $\hookrightarrow$ & Antrieb durch Servomotor mit Multiturn-Absolutwert-Drehgeber (Auflösung $\pm 120^{\prime \prime}$ ) \\
\hline & $\hookrightarrow$ & Direkte Übertragung (ohne Getriebe) des Antriebsmoments auf Kugelgewindetrieb \\
\hline & $\hookrightarrow$ & $\begin{array}{l}\text { Kugelgewindetrieb mit Vorspannung / Toleranzklasse min. T5 / Steigung } 20 \mathrm{~mm} / \\
\text { hohe Staubbeständigkeit / Dauergebrauchstemperatur } 100^{\circ} \mathrm{C}\end{array}$ \\
\hline
\end{tabular}




\begin{tabular}{|c|c|c|}
\hline & $\hookrightarrow$ & Data Logging der Motortemperatur \\
\hline $\mathrm{F}$ & 9.4 & Geschwindigkeits-Sollwertvorgabe für Beschichtereinheit-Aufnahme bis 200 mm/s \\
\hline $\mathrm{W}$ & 9.5 & Data Logging der Schicht-Auftragszeit \\
\hline \multirow[t]{4}{*}{$\mathrm{F}$} & 9.6 & Einsatz von Linearführungen zur Lagerung der Beschichtereinheit-Aufnahme \\
\hline & $\hookrightarrow$ & Festlagerung auf der angetriebenen Seite (Antriebsbaugruppe) \\
\hline & $\hookrightarrow$ & Loslagerung auf der nicht angetriebenen Seite (Lagerbaugruppe) \\
\hline & $\hookrightarrow$ & $\begin{array}{l}\text { Linearführungen mit Vorspannung / belastungsgerechte Tragzahlen / hohe Staubbe- } \\
\text { ständigkeit / Dauergebrauchstemperatur } 100^{\circ} \mathrm{C} / \text { ausreichende Führungslänge }\end{array}$ \\
\hline \multirow[t]{10}{*}{$\mathrm{F}$} & 9.7 & Anordnung der Antriebsbaugruppe links neben der Prozessrahmenplatte \\
\hline & $\hookrightarrow$ & Montage der antriebsseitigen Grundplatte auf der Oberseite der Prozessetage \\
\hline & $\hookrightarrow$ & Anordnung einer Linearführung (gestiftet \& geschraubt) auf der Grundplatte \\
\hline & $\hookrightarrow$ & Anordnung der Antriebsachse auf der Grundplatte fern der Prozessrahmenplatte \\
\hline & $\hookrightarrow$ & Montage Servomotor in axialer Richtung zum Gewindetrieb auf Maschinenrückseite \\
\hline & $\hookrightarrow$ & Kugelgewindetrieb innerhalb Nebenkammer / Servomotor außerhalb Nebenkammer \\
\hline & $\hookrightarrow$ & Integration des Kugelgewindetrieb-Festlagers in die Wand der Nebenkammer \\
\hline & $\hookrightarrow$ & Übertragung der Antriebskraft auf die Führungswagen der Linearführung \\
\hline & $\hookrightarrow$ & Einbringung M6 Gewindebohrmuster in Grundplatte für Montage Nebenkammer \\
\hline & $\hookrightarrow$ & Ergänzung M6 Gewindebohrmuster in Festlagerwand für Montage Nebenkammer \\
\hline \multirow[t]{4}{*}{$\mathrm{F}$} & 9.8 & Anordnung der Lagerbaugruppe rechts neben der Prozessrahmenplatte \\
\hline & $\hookrightarrow$ & Montage der lagerseitigen Grundplatte auf der Oberseite der Prozessetage \\
\hline & $\hookrightarrow$ & Anordnung einer Linearführung (gestiftet \& geschraubt) auf der Grundplatte \\
\hline & $\hookrightarrow$ & Einbringung M6 Gewindebohrmuster in Grundplatte für Montage Nebenkammer \\
\hline \multirow[t]{2}{*}{ W } & 9.9 & Kontrolle der Qualität des Pulverauftrags für jede Schicht \\
\hline & 10. & Anforderungen an das bzw. aus dem Submodul Beschichtereinheit \\
\hline $\mathrm{F}$ & 10.1 & Verwendung einer einheitlichen Auftragsschlittenanbindung als Schnittstelle \\
\hline $\mathrm{F}$ & 10.2 & Symmetrische Anordnung des Pulverauftragkörpers an Auftragsschlittenanbindung \\
\hline $\mathrm{F}$ & 10.3 & Breite Auftragskörper $\geq 68 \mathrm{~mm}$ für Pulverauftrag über $\varnothing 65 \mathrm{~mm}$ Bauvolumen \\
\hline $\mathrm{F}$ & 10.4 & Konstante Pulverauftragskörper-Dynamik bei Auftragsbewegung über Bauvolumen \\
\hline $\mathrm{F}$ & 10.5 & Aufgetragene Pulverbetthöhe über Prozesseinsatzplatte bis max. $5 \mathrm{~mm}$ einstellbar \\
\hline $\mathrm{F}$ & 10.6 & Vorgabe spezifischer Dynamik-Sollwerte für die fluidisierenden Beschichtereinheiten \\
\hline $\mathrm{W}$ & 10.7 & Data Logging spezifischer Dynamik-Istwerte der fluidisierenden Beschichtereinheiten \\
\hline \multirow[t]{5}{*}{$\mathrm{F}$} & 10.8 & Submodul I: Beschichtereinheit mit starrer Klinge \\
\hline & $\hookrightarrow$ & Wechselbare Auftragsklinge \\
\hline & $\hookrightarrow$ & Pulverbetthöhe einstellbar durch die Fertigung von Langlöchern in der Klinge \\
\hline & $\hookrightarrow$ & Halbzeug zur Fertigung Klinge $110 \mathrm{~mm} \times 50 \mathrm{~mm} \times 10 \mathrm{~mm}$ (Achsreferenzierung) \\
\hline & $\hookrightarrow$ & Bei Klingendicke $<10 \mathrm{~mm}$ entsprechendes „Offset" in Achsposition berücksichtigen \\
\hline \multirow[t]{7}{*}{$\mathrm{F}$} & 10.9 & Submodul II: Beschichtereinheit mit schwingender Klinge \\
\hline & $\hookrightarrow$ & Dynamik der Klinge: max. Schwingfrequenz $100 \mathrm{~Hz} /$ max. Amplitude $3 \mathrm{~mm}$ \\
\hline & $\hookrightarrow$ & Verwendung eines geregelten (Frequenz \& Amplitude) Schwingspulenantriebs \\
\hline & $\hookrightarrow$ & Bewegung der Klinge: quer zur Auftragsrichtung / hohe Steifigkeit in z-Richtung \\
\hline & $\hookrightarrow$ & Verwendung einer Miniatur-Linearführung (keine Gleitlagerung) \\
\hline & $\hookrightarrow$ & Leichtbauweise für alle bewegten Bauteile \\
\hline & $\hookrightarrow$ & Wechselbare Auftragsklinge aus Polyamid 12 (Herstellung mittels Lasersintern) \\
\hline \multirow[t]{5}{*}{$\mathrm{F}$} & 10.10 & Submodul III: Beschichtereinheit mit rotierender Rolle \\
\hline & $\hookrightarrow$ & Dynamik der Rolle: Drehzahl (Gleichlauf \& Gegenlauf) max. $240^{1 / \min }$ \\
\hline & $\hookrightarrow$ & Verwendung eines NEMA 11 Schrittmotors mit einer Auflösung von 200 Schritten \\
\hline & $\hookrightarrow$ & Walzendurchmesser max. $38 \mathrm{~mm}$ \\
\hline & 11. & Anforderungen an das bzw. aus dem Prozessgasmodul \\
\hline $\mathrm{W}$ & 11.1 & Trennung zwischen produktberührten \& nicht-produktberührten Bereichen \\
\hline $\mathrm{F}$ & 11.2 & Einsatz eines gasdichten Prozessgasgehäuses (5-Kammer-Bauweise) \\
\hline $\mathrm{F}$ & 11.3 & Demontage/Montage der Beschichtereinheit-Aufnahme nachträglich möglich \\
\hline \multirow[t]{2}{*}{$\mathrm{F}$} & 11.4 & Montage von Türrahmenplatten an die Außenseiten der Prozess- \& Laseretage \\
\hline & $\hookrightarrow$ & Einbringung Bohrmuster (M8 Senkschrauben) für Montage an Etagen \\
\hline
\end{tabular}




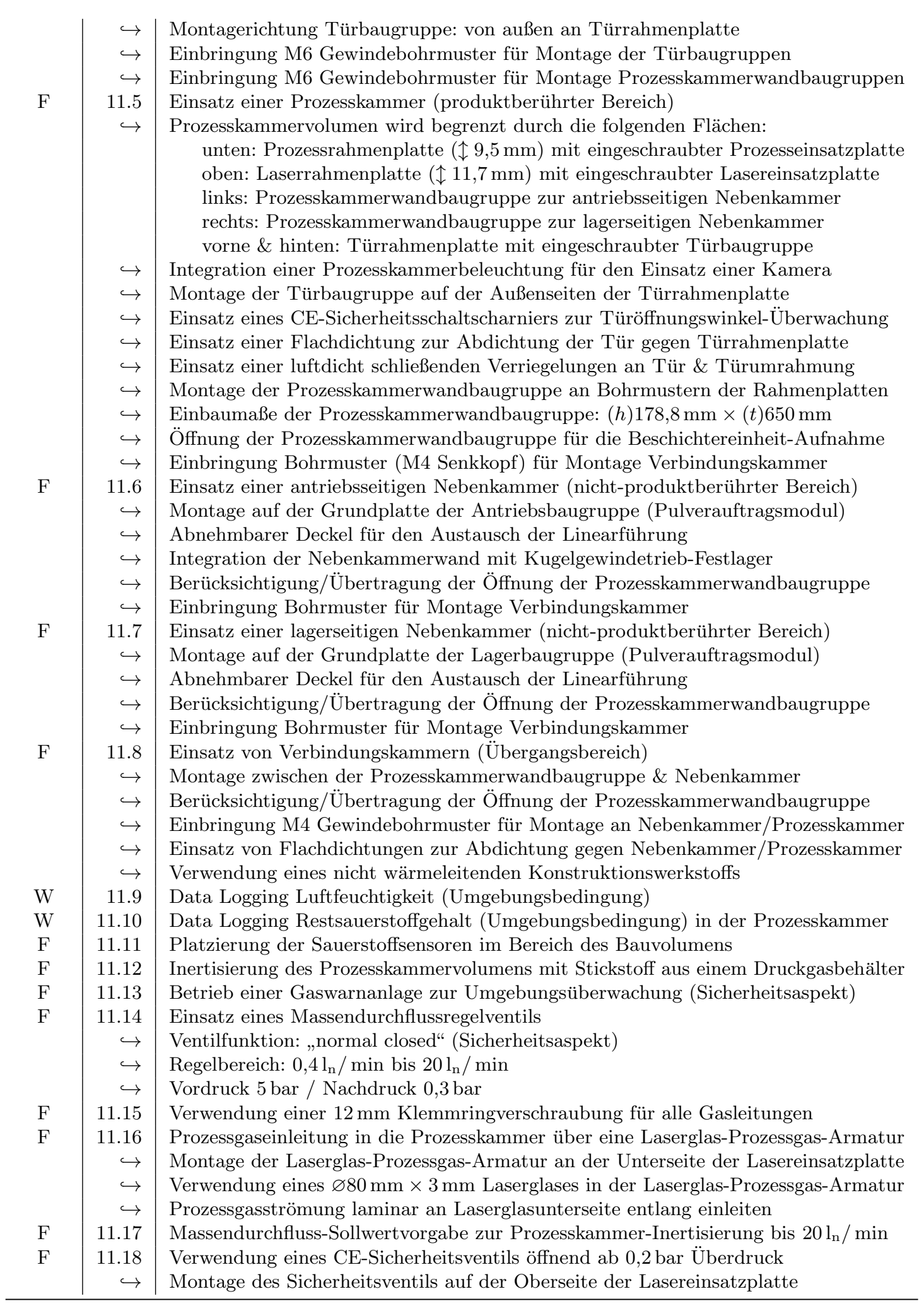




\begin{tabular}{c|r|l} 
& \multicolumn{1}{|c}{12.} & Anforderungen an das bzw. aus dem Lasermodul \\
& 12.1 & Einsatz einer Lasereinsatzplatte (Montage an Laserrahmenplatte) \\
& $\hookrightarrow$ & Übertragung der Bohrmuster von Laserrahmenplatte auf Lasereinsatzplatte \\
& $\hookrightarrow$ & Einbringung einer $\varnothing 65$ mm Bohrung in der Mitte der Einsatzplatte \\
& $\hookrightarrow$ & Konzentrische Anordnung des Laserglases unterhalb der $\varnothing 65$ mm Bohrung \\
& $\hookrightarrow$ & Übertragung des Bohrmusters der Laserglas-Prozessgas-Armatur \\
& $\hookrightarrow$ & Einbringung einer Öffnung für den Einsatz einer Kamera (Live-Video) \\
F & 12.2 & Anordnung von Gaseinlass \& Gasauslass auf der Oberseite der Lasereinsatzplatte \\
F & 12.3 & Verwender optischen Bank in Kombination mit einem CO ${ }_{2}$-Laser \\
& $\hookrightarrow$ & Minimale Brechungsindex-Variation innerhalb des Fensters (richtungsunabhängig) \\
& $\hookrightarrow$ & Breitbandbeschichtung zur Transmission von Wellenlängen 9 pm bis 11 pm \\
& $\hookrightarrow$ & Mechanische Druckbeständigkeit bis 0,5 bar Überdruck \\
F & 12.4 & Einsatz einer Weitwinkelkamera zur Erfassung der Pulverauftragsbewegung \\
F & 12.5 & Montage der Laser-Scanner-Einheit auf der Oberseite der Laseretage \\
F & 12.6 & Komponenten der optischen Bank innerhalb einer wechselbaren Baugruppe anordnen \\
F & 12.7 & Übergangsweiser Einsatz eines Laser-Scanner-Demonstrators als Dummy-Baugruppe \\
& $\hookrightarrow$ & Verwendung von Komponenten eines ausgesonderten Lasermarkiersystems \\
& $\hookrightarrow$ & Demonstration der Schichtgenerierung durch Ablenkung eines Pilotlaser-Laserstrahls \\
W & 12.8 & Data Logging der schichtspezifischen Bearbeitungszeit mit dem Laser \\
F & 12.9 & Einstellbare Wartezeit vor \& nach dem Laserenergieeintrag \\
\hline
\end{tabular}

Wird der Laser-Scanner-Demonstrator (vgl. Anforderung 12.7 in Tabelle A.1) durch eine PLGA-Laser-Scanner-Einheit ersetzt, wird die Anforderung 12.7 in Tabelle A.1 gestrichen und die spezifische Anforderungsliste der modularen Lasersintermaschine durch die Anforderungen aus Tabelle A.2 erweitert.

Tabelle A.2.: Spezifische Anforderungsliste der PLGA-Laser-Scanner-Einheit

\begin{tabular}{|c|c|c|}
\hline \multirow{2}{*}{$\frac{\mathbf{F} / \mathbf{W}}{\mathrm{W}}$} & \multicolumn{2}{|r|}{ Anforderungen } \\
\hline & 12.10 & Data Logging der optischen Laserleistung während der Bauteilschichtgenerierung \\
\hline W & 12.11 & Data Logging der Scangeschwindigkeit \\
\hline W & 12.12 & Data Logging des Scanabstands \\
\hline W & 12.13 & Integration eines „On-Axis“-Schmelzbadüberwachungssystems \\
\hline $\mathrm{F}$ & 12.14 & Einsatz einer $\mathrm{CO}_{2}$-Strahlquelle \\
\hline \multirow{16}{*}{$\mathrm{F}$} & $\hookrightarrow$ & Wellenlänge $9,3 \mu \mathrm{m}$ \\
\hline & $\hookrightarrow$ & Maximale Leistung $10 \mathrm{~W}$ \\
\hline & $\hookrightarrow$ & Gaußförmige Intensitätsverteilung \\
\hline & $\hookrightarrow$ & Temperaturstabilisierung durch den Einsatz einer Wasserkühlung \\
\hline & $\hookrightarrow$ & Digitaler PWM-Controller zur Steuerung der Laserleistung \\
\hline & $\hookrightarrow$ & Montage eines Sicherheits-Shutters am Strahlausgang (Sicherheitsaspekt) \\
\hline & 12.15 & Einsatz eines 2-achsigen Scan-Systems samt F-Theta-Linse (Planfeldlinse) \\
\hline & $\hookrightarrow$ & Maximaler Arbeitsbereich (Scanfeld): $70 \mathrm{~mm} \times 70 \mathrm{~mm}$ \\
\hline & $\hookrightarrow$ & Geometrische Abmessungen der zu scannenden Muster: $65 \mathrm{~mm} \times 65 \mathrm{~mm}$ \\
\hline & $\hookrightarrow$ & Art der zu scannenden Muster: interkonnektierende Porenstrukturen \\
\hline & $\hookrightarrow$ & Spiegel-Breitbandbeschichtung für Reflexion von Wellenlängen $9,3 \mu \mathrm{m}$ bis $10,6 \mu \mathrm{m}$ \\
\hline & $\hookrightarrow$ & Digitaler Positionsdetektor mit einer Auflösung von 20Bit \\
\hline & $\hookrightarrow$ & Temperaturstabilisierung durch den Einsatz einer Wasserkühlung \\
\hline & $\hookrightarrow$ & Digitale PCI-Express-Reglerkarte samt zugehöriger Software \\
\hline & $\hookrightarrow$ & F-Theta-Linsen-Beschichtung zur Transmission der Wellenlängen 9,3 um \\
\hline & $\hookrightarrow$ & Arbeitsabstand muss in Zusammenarbeit mit dem Hersteller definiert werden \\
\hline
\end{tabular}




\section{B. Detaillierte Darstellung spezifischer Baugruppen}

Im Folgenden werden die in der Entwurfsphase konstruierten Baugruppen detailliert dargestellt. Jede Baugruppe ist aus mehreren Bauteilen aufgebaut. Die im Rahmen der vorliegenden Arbeit verwendeten Bauteilbezeichnungen sind in der Abbildungsbeschriftung der jeweiligen Baugruppe vermerkt. Zur Zuordnung zwischen Bauteil und Bauteilbezeichnung wird eine farbliche Kodierung verwendet. 


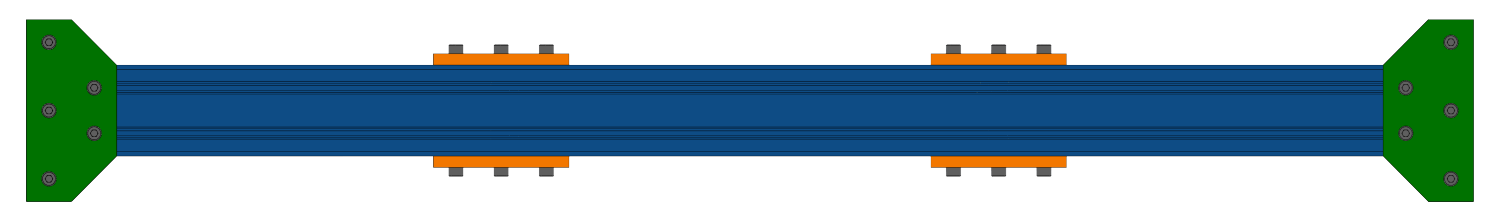

(a) Vorderansicht

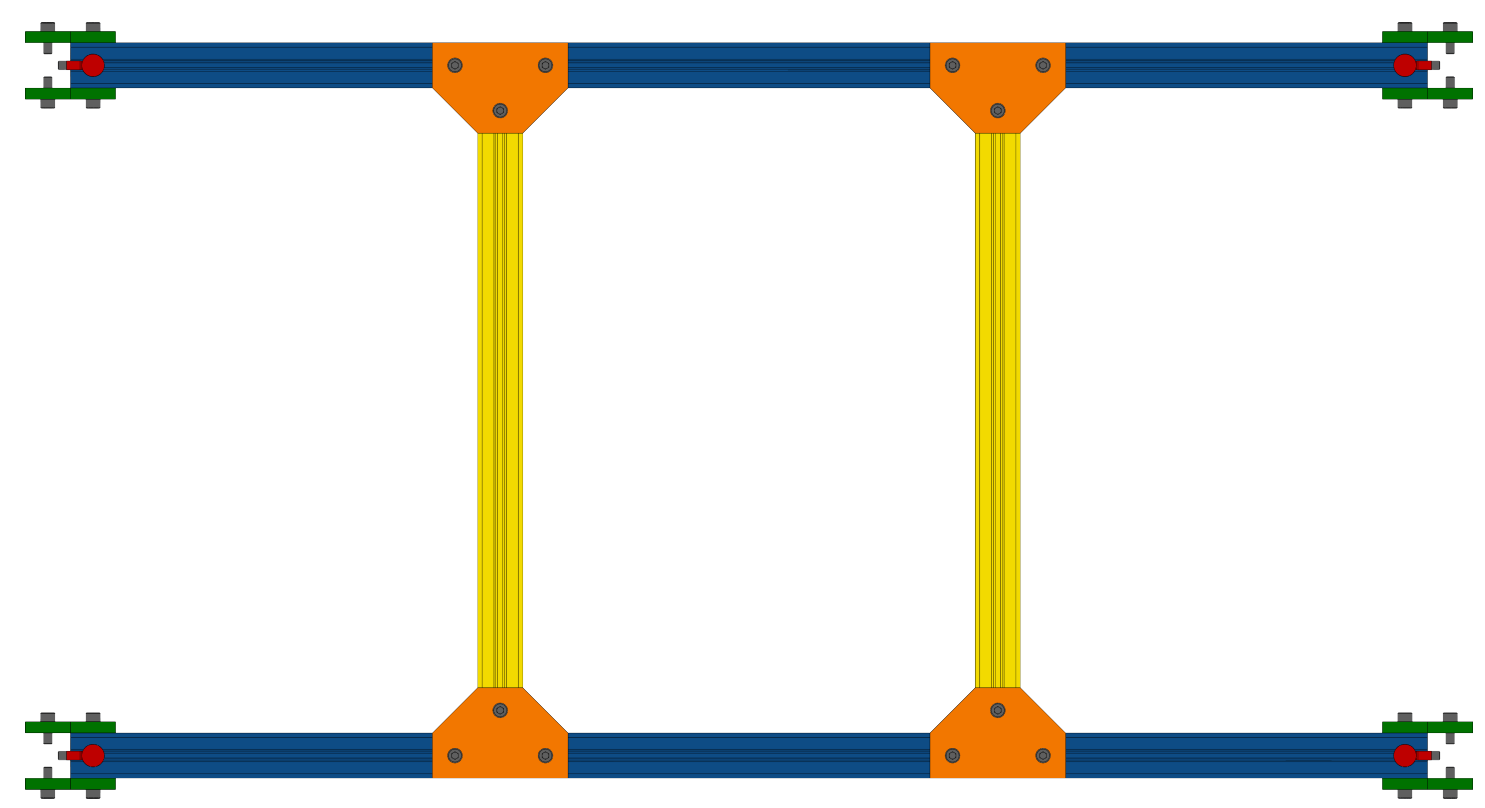

(b) Draufsicht

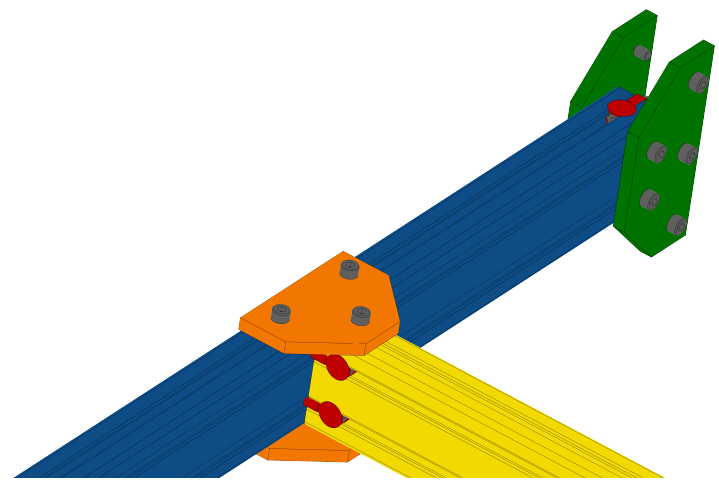

(c) Detailansicht Knotenbleche

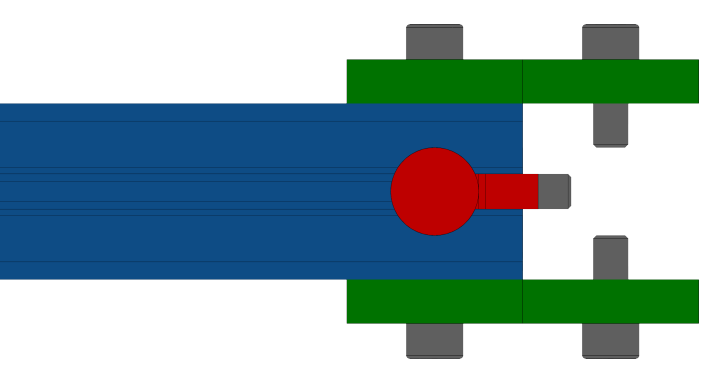

(d) Anbindung Grundrahmen

Abbildung B.1.: 80x40-Etage:

80x40-Profil $1200 \mathrm{~mm}$ 80x40-Profil $570 \mathrm{~mm}$ Knotenblech klein 


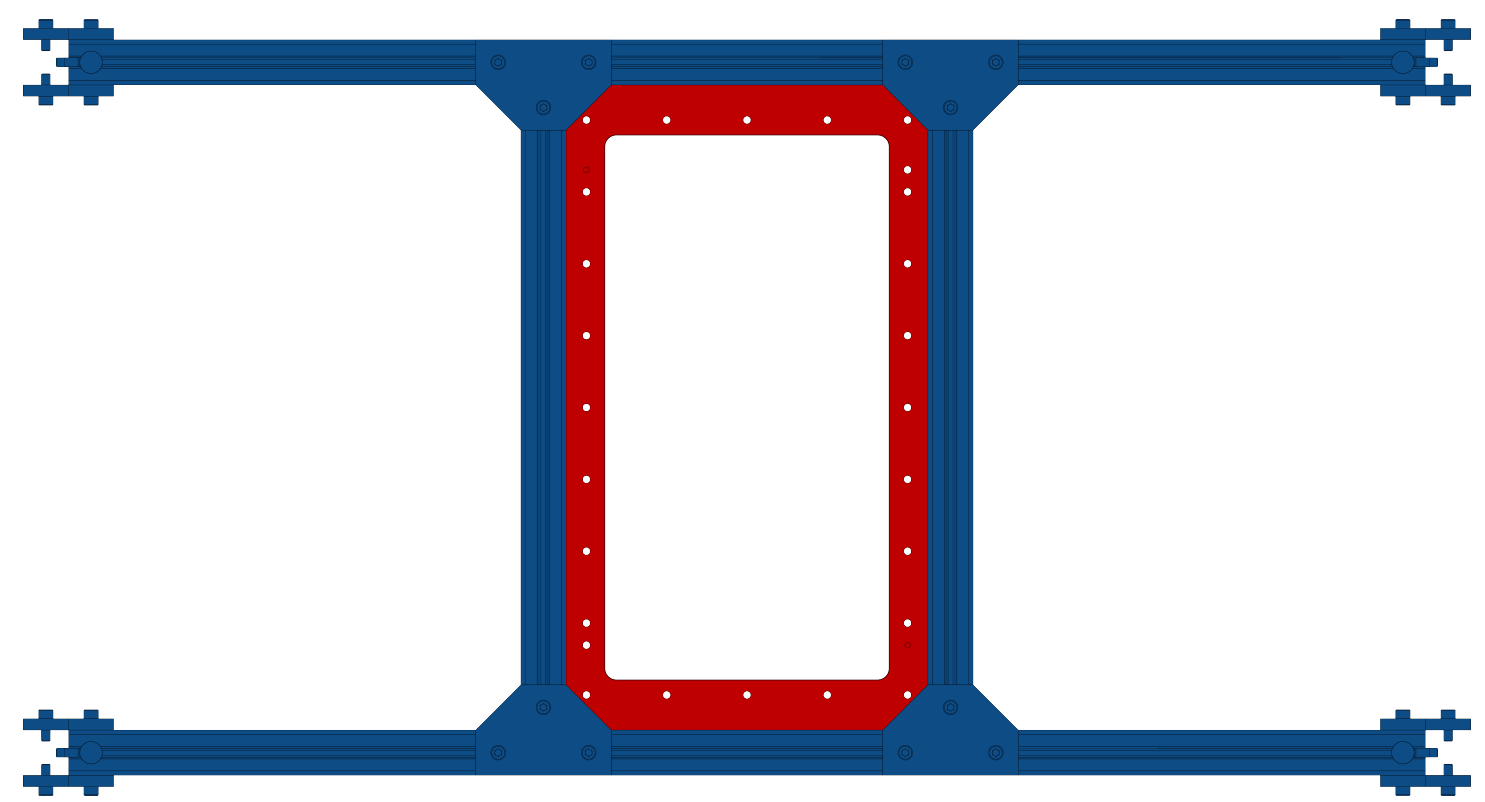

(a) Untersicht

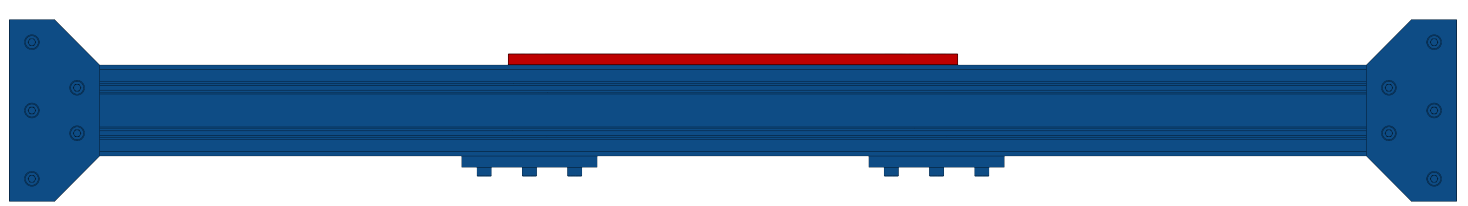

(b) Vorderansicht

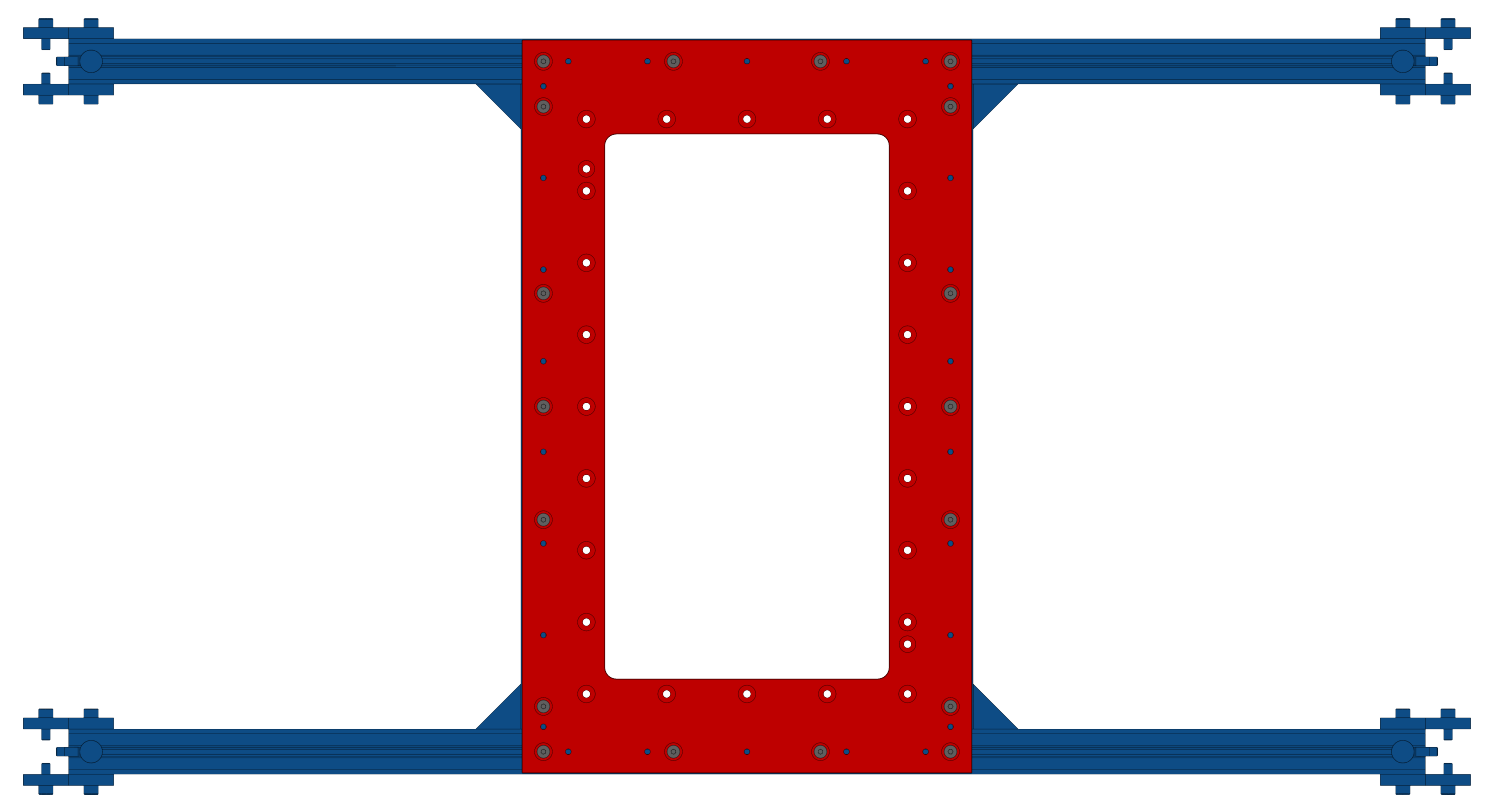

(c) Draufsicht

Abbildung B.2.: Prozessetage samt Prozessrahmenplatte 


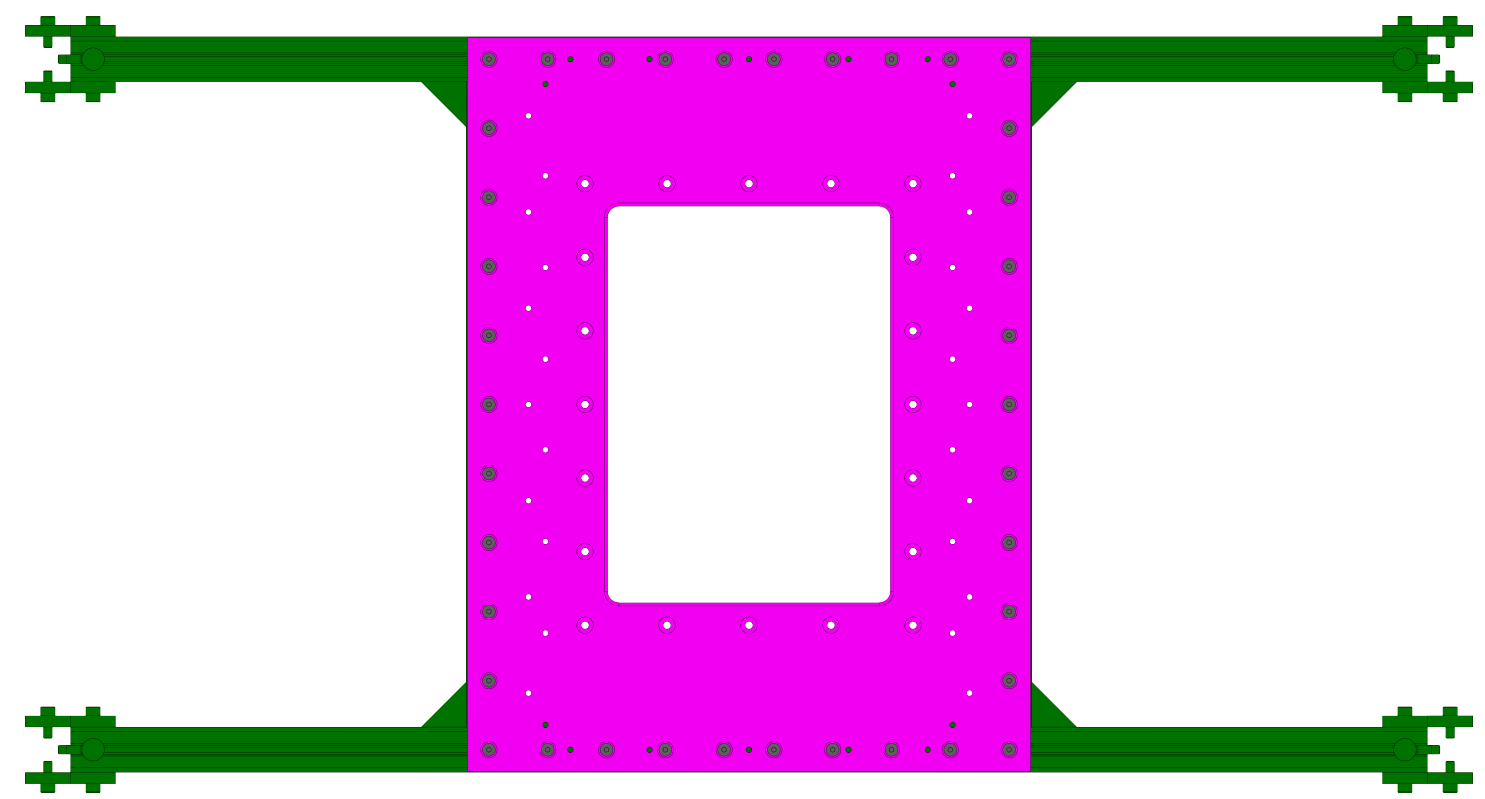

(a) Untersicht

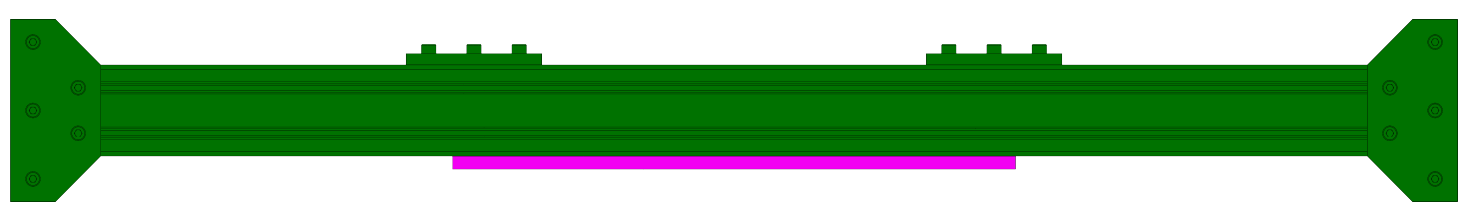

(b) Vorderansicht

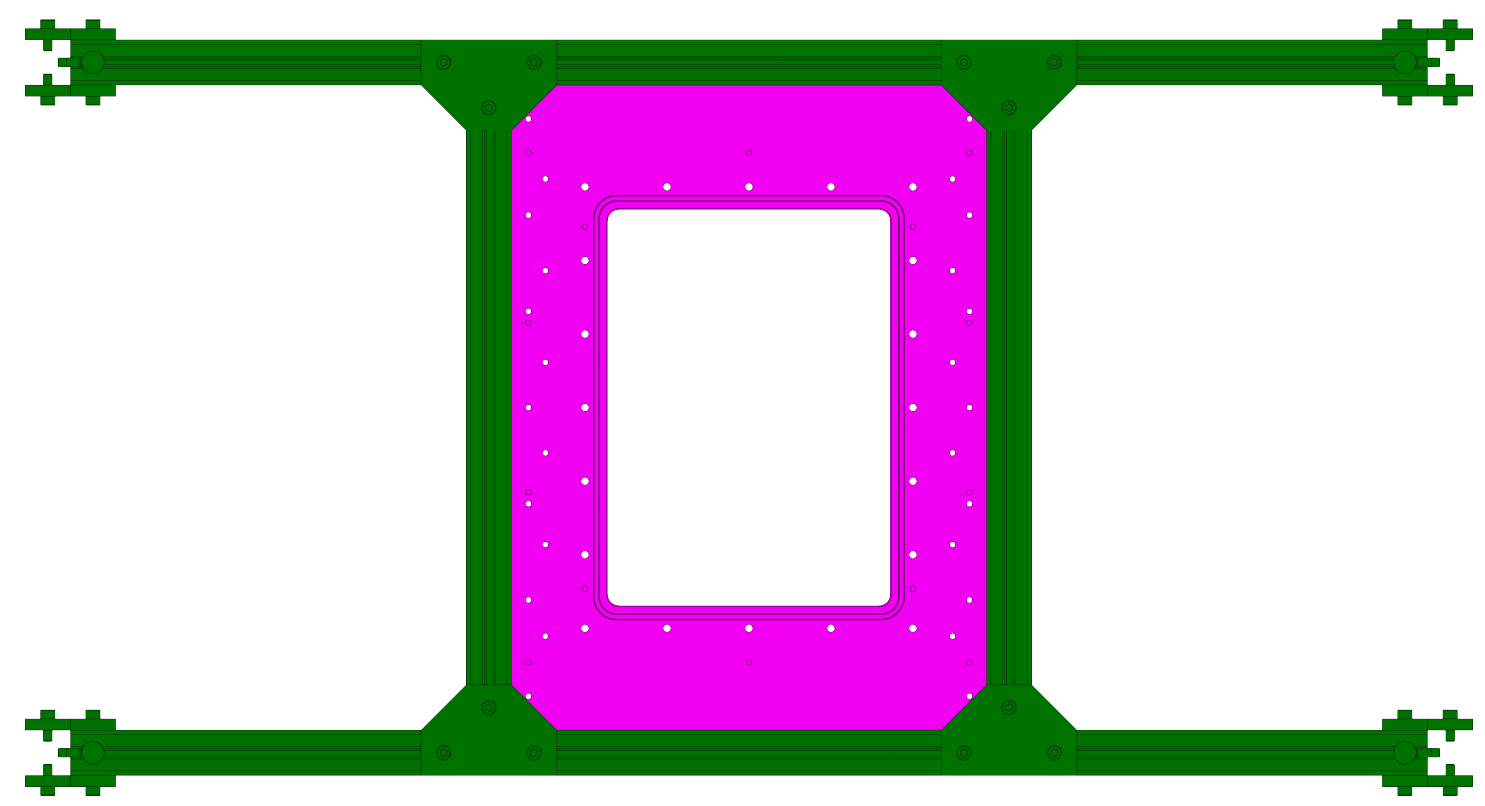

(c) Draufsicht

Abbildung B.3.: Laseretage samt Laserrahmenplatte 


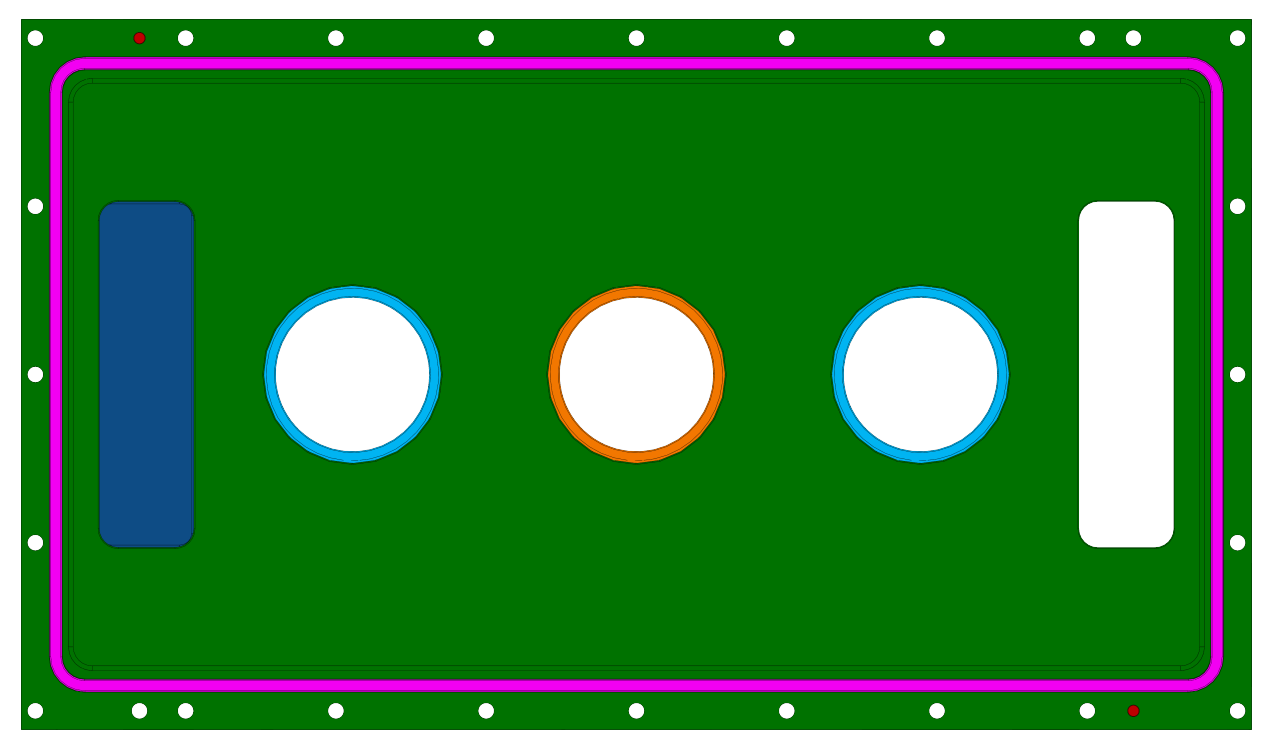

(a) Draufsicht

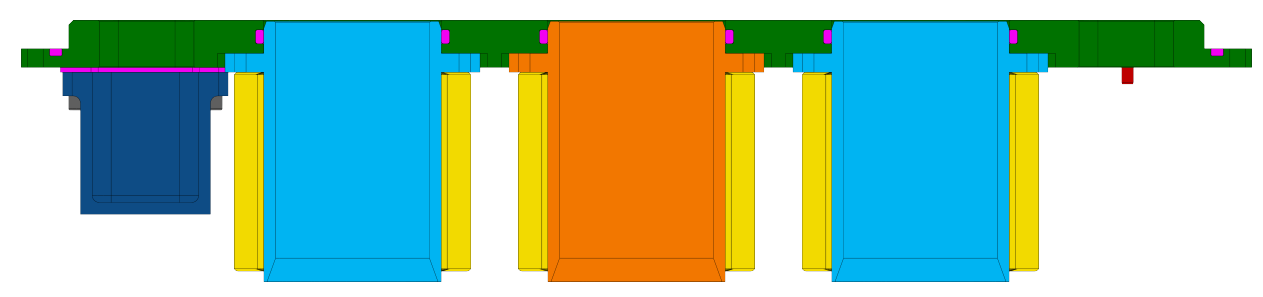

(b) Schnittansicht

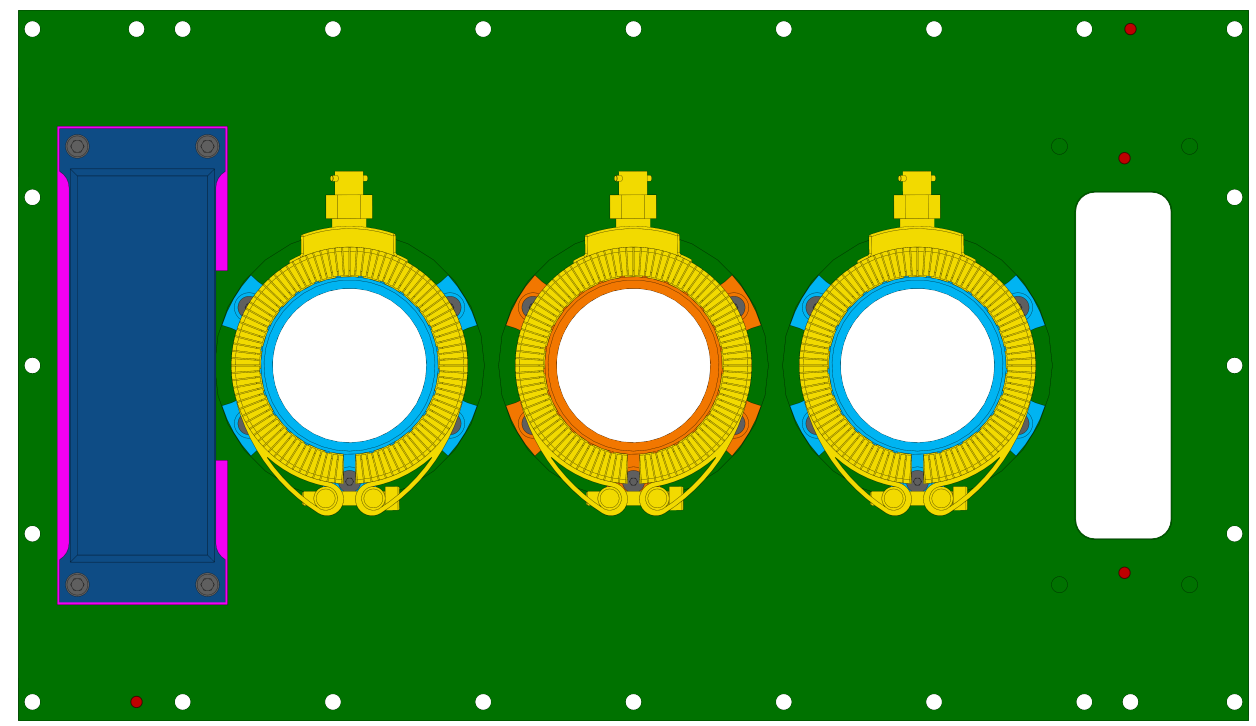

(c) Untersicht

Abbildung B.4.: Prozesseinsatzplatte samt Anbauteilen: Baustempelgehäuse Pulverzuführgehäuse Keramikheizband Überlaufbehälter Dichtung Zylinderstift 


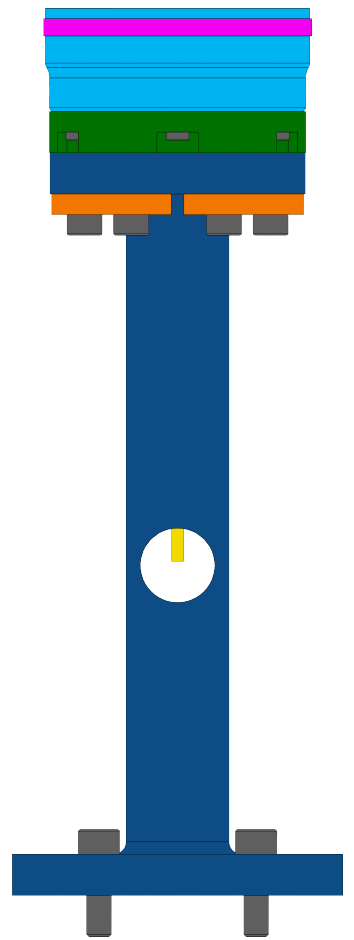

(a) Seitenansicht

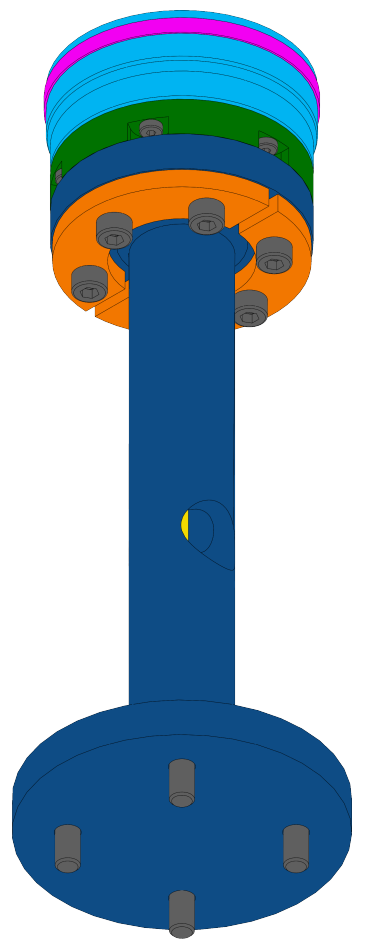

(b) ISO-Ansicht

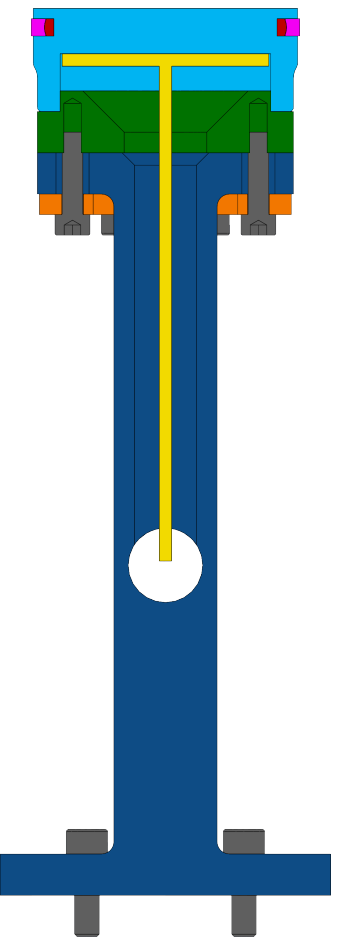

(c) Schnittansicht

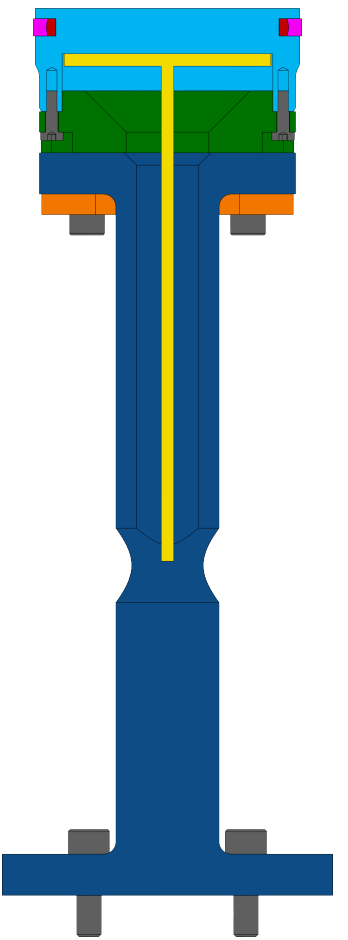

(d) Schnittansicht

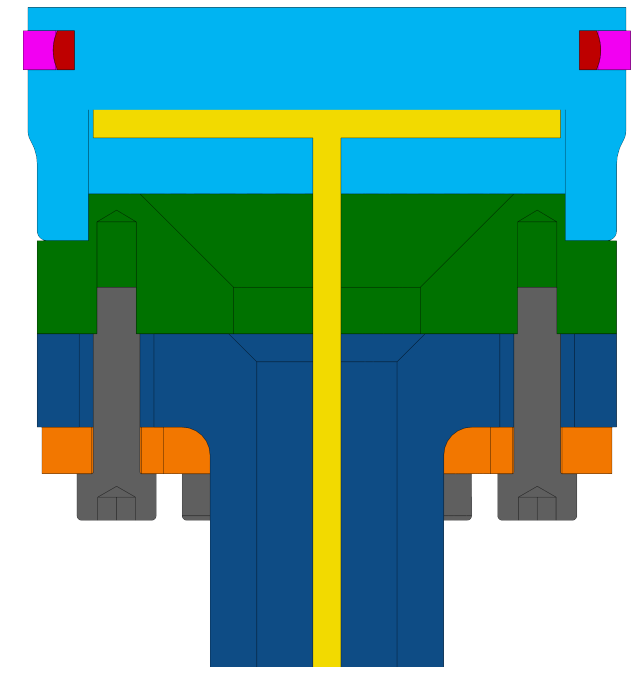

(e) Axialversatz von $0 \mathrm{~mm}$

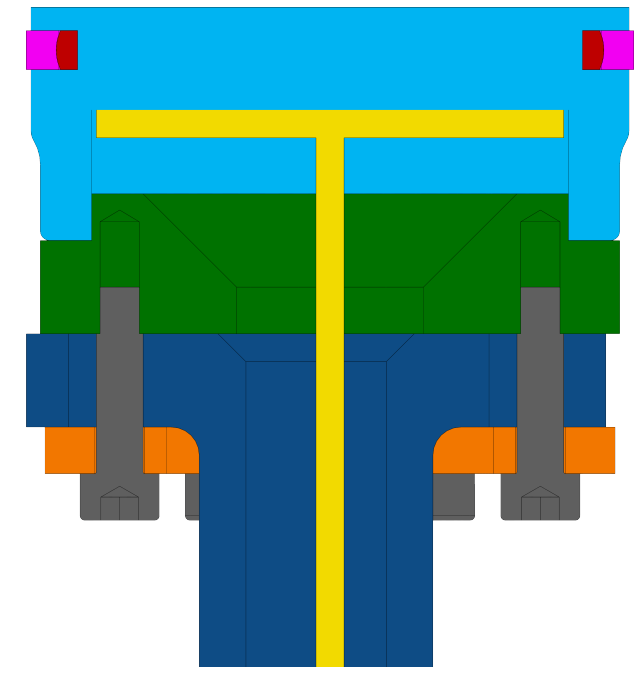

(f) Axialversatz von 1,5 mm

Abbildung B.5.: Stempelbaugruppe:

\begin{tabular}{|c|c|c|}
\hline $\mathrm{Abs}$ & & Stempeloberteil \\
\hline Klemmscheibe & Gleitring & Torspannelement \\
\hline
\end{tabular}

Befestigungsscheib

Silikonheizmatte 


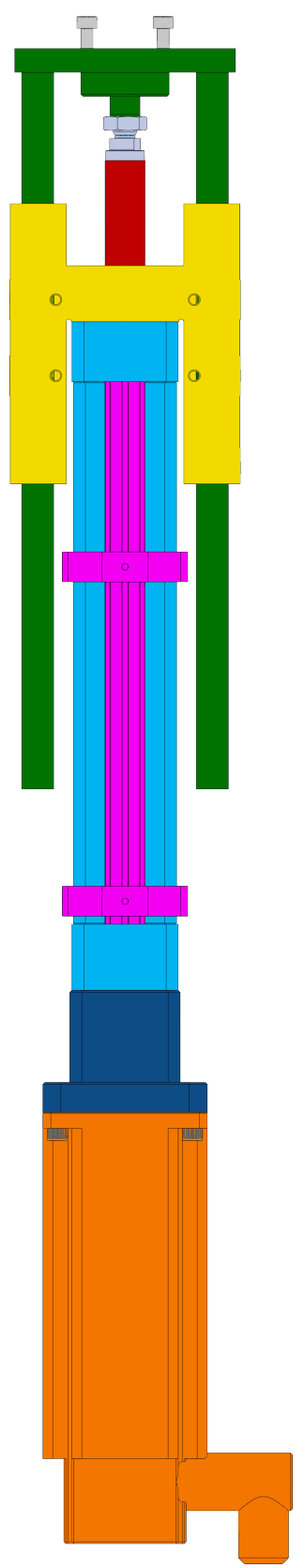

(a) Rückansicht

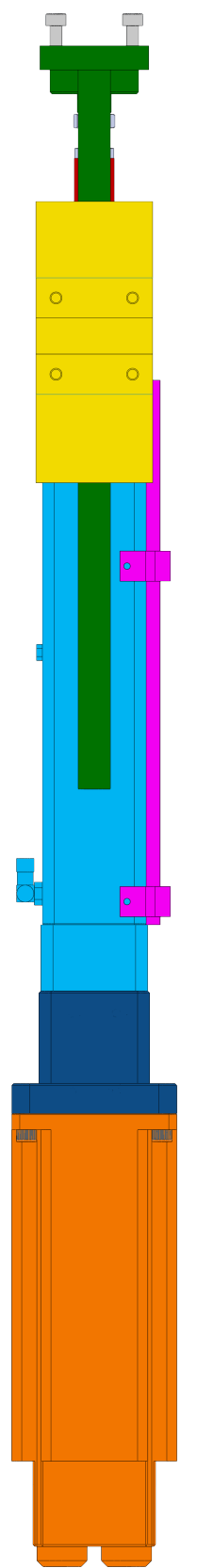

(b) Seitenansicht

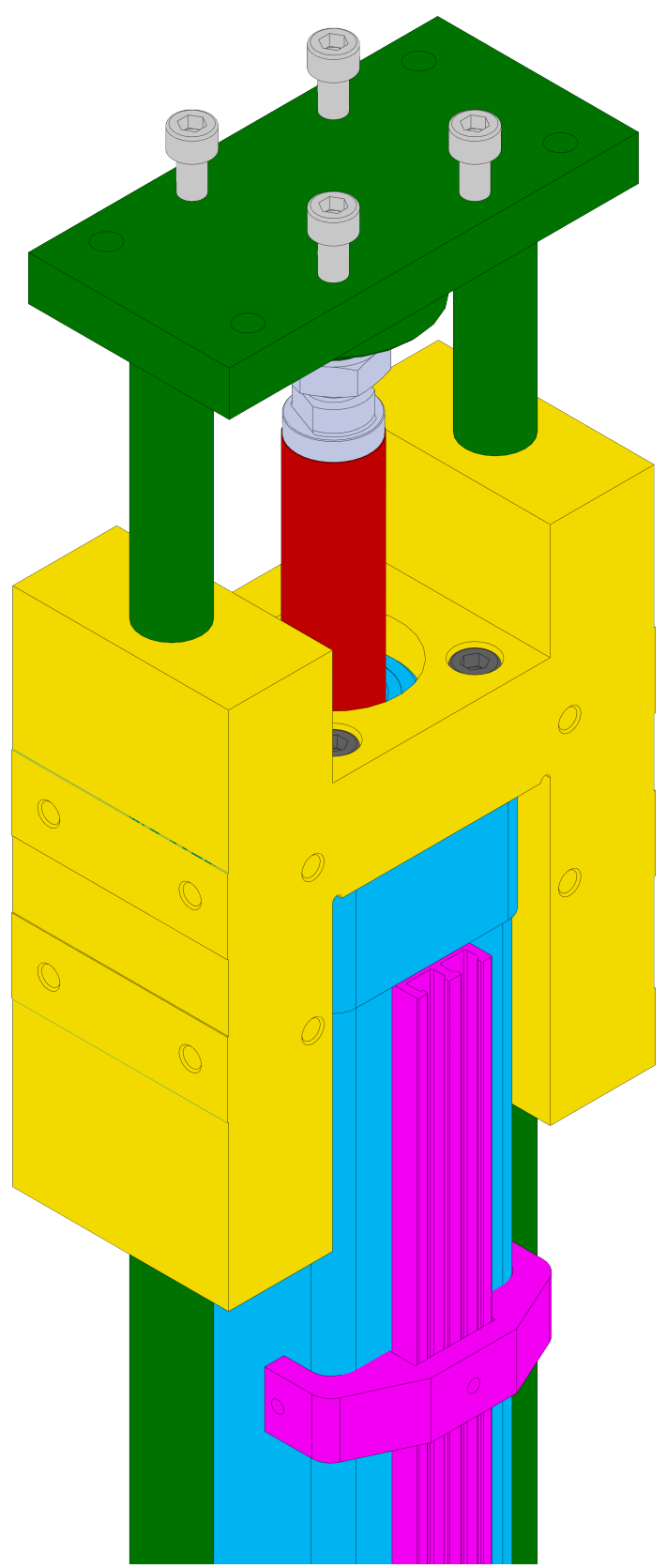

(c) ISO-Ansicht von oben

Abbildung B.6.: Hubantriebsbaugruppe: Bosch Rexroth Synchron Servomotor MSK040C Motorflansch mit Kupplung Elektromechanischer Zylinder EMC-040 Sensorprofil mit Haltebügeln Festo FENG-40 Führungseinheitkorpus Kolbenstange des EMCs Jochplatte mit Führungsstangen 


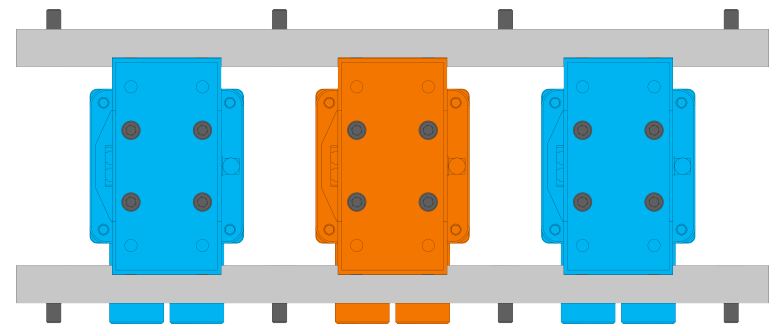

(a) Draufsicht

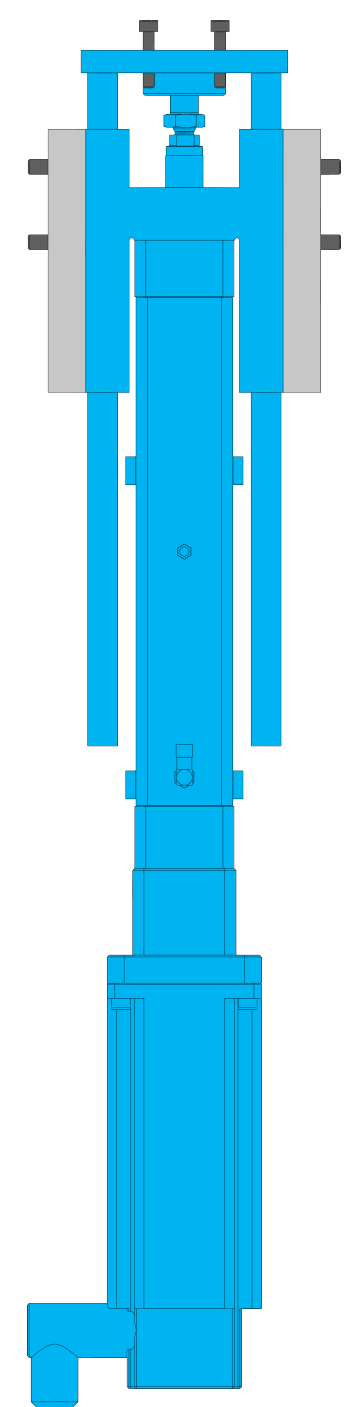

(b) Vorderansicht

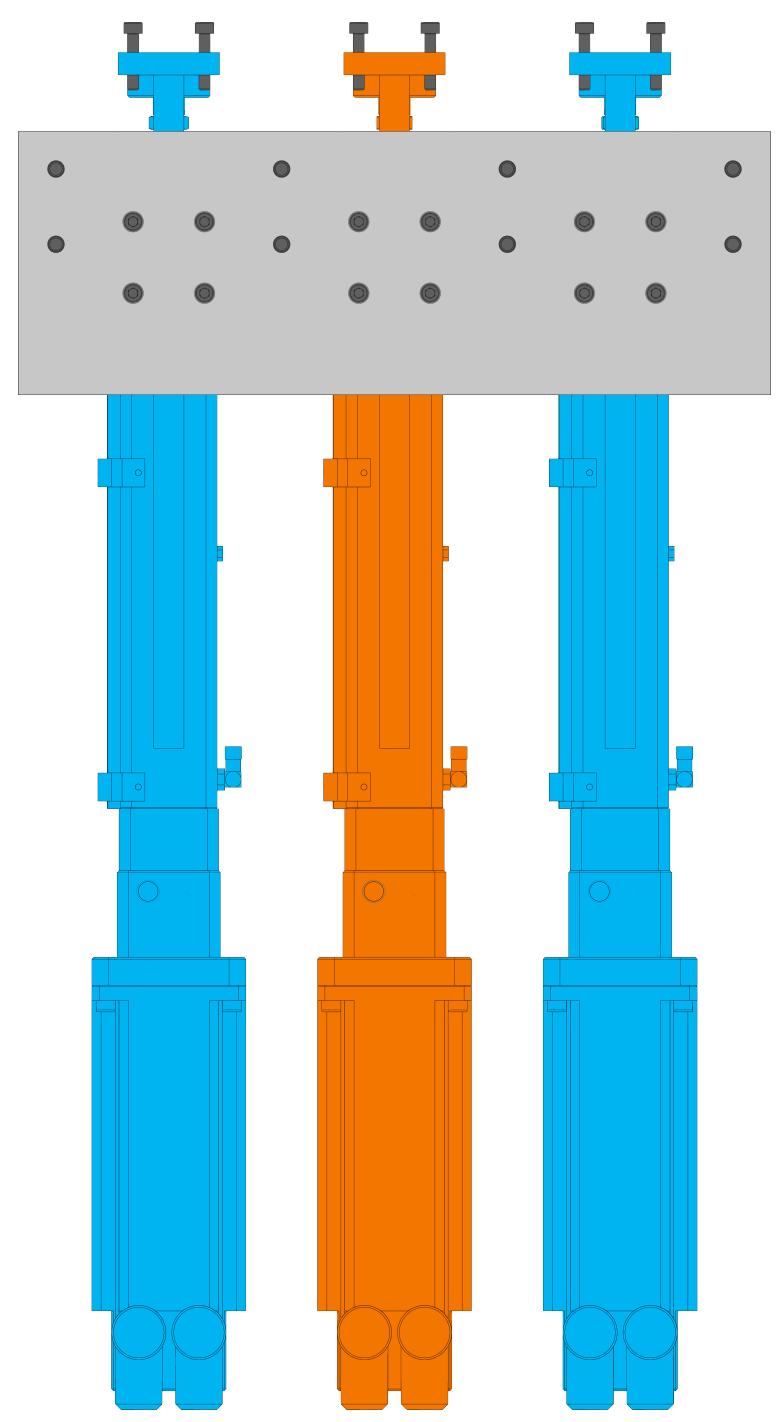

(c) Seitenansicht

Abbildung B.7.: Hubantriebsbaugruppenpaket:

Aufnahmeplatte

Hubantriebsbaugruppe aus dem Pulverzuführmodul

Hubantriebsbaugruppe aus dem Baustempelmodul 


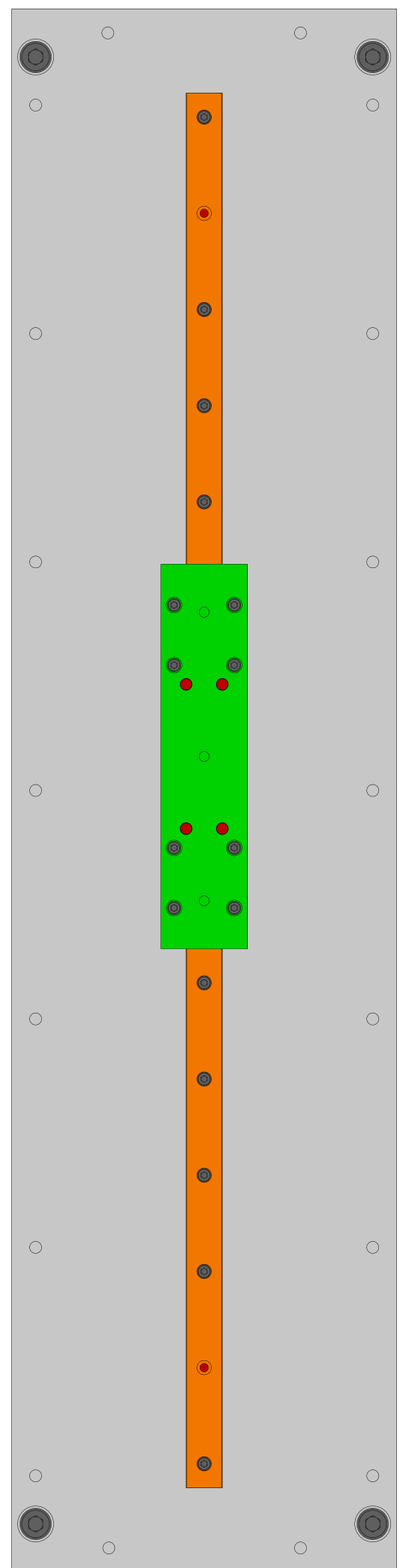

(a) Draufsicht

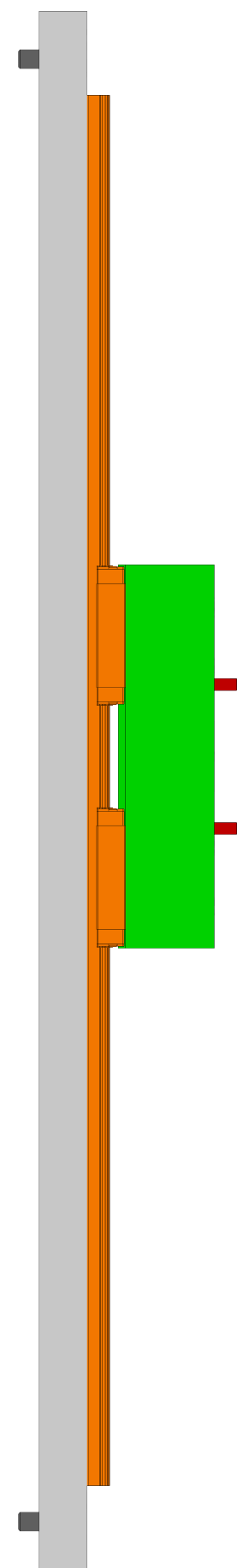

(b) Seitenansicht

Abbildung B.8.: Lagerbaugruppe des Pulverauftragmoduls: Führungswagenverbinder Grundplatte Doppelwagen-Linearführung 


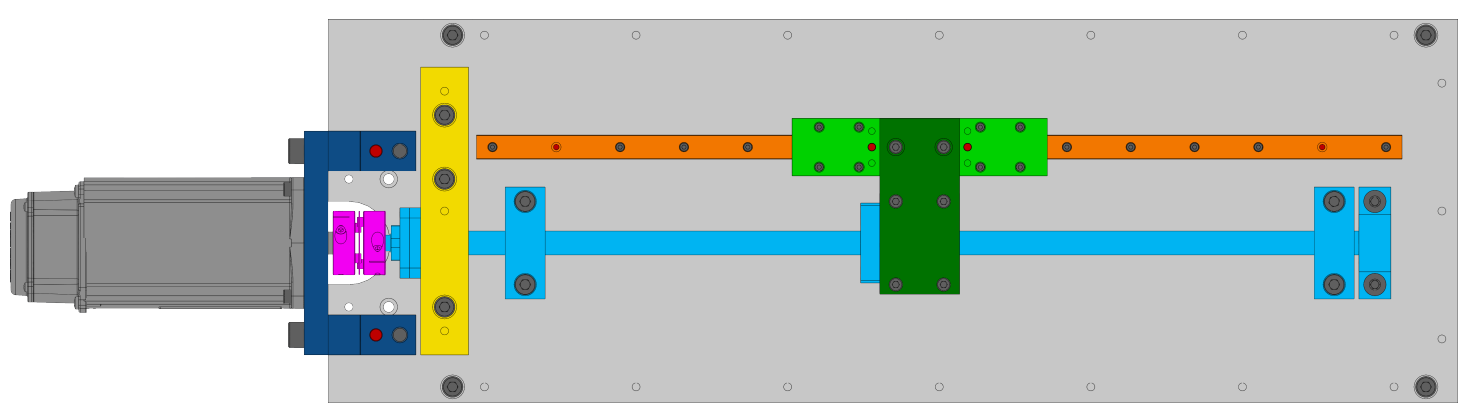

(a) Draufsicht

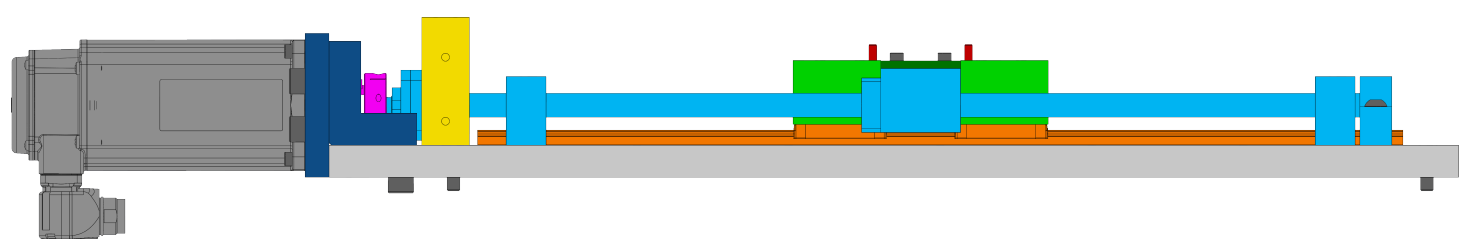

(b) Seitenansicht

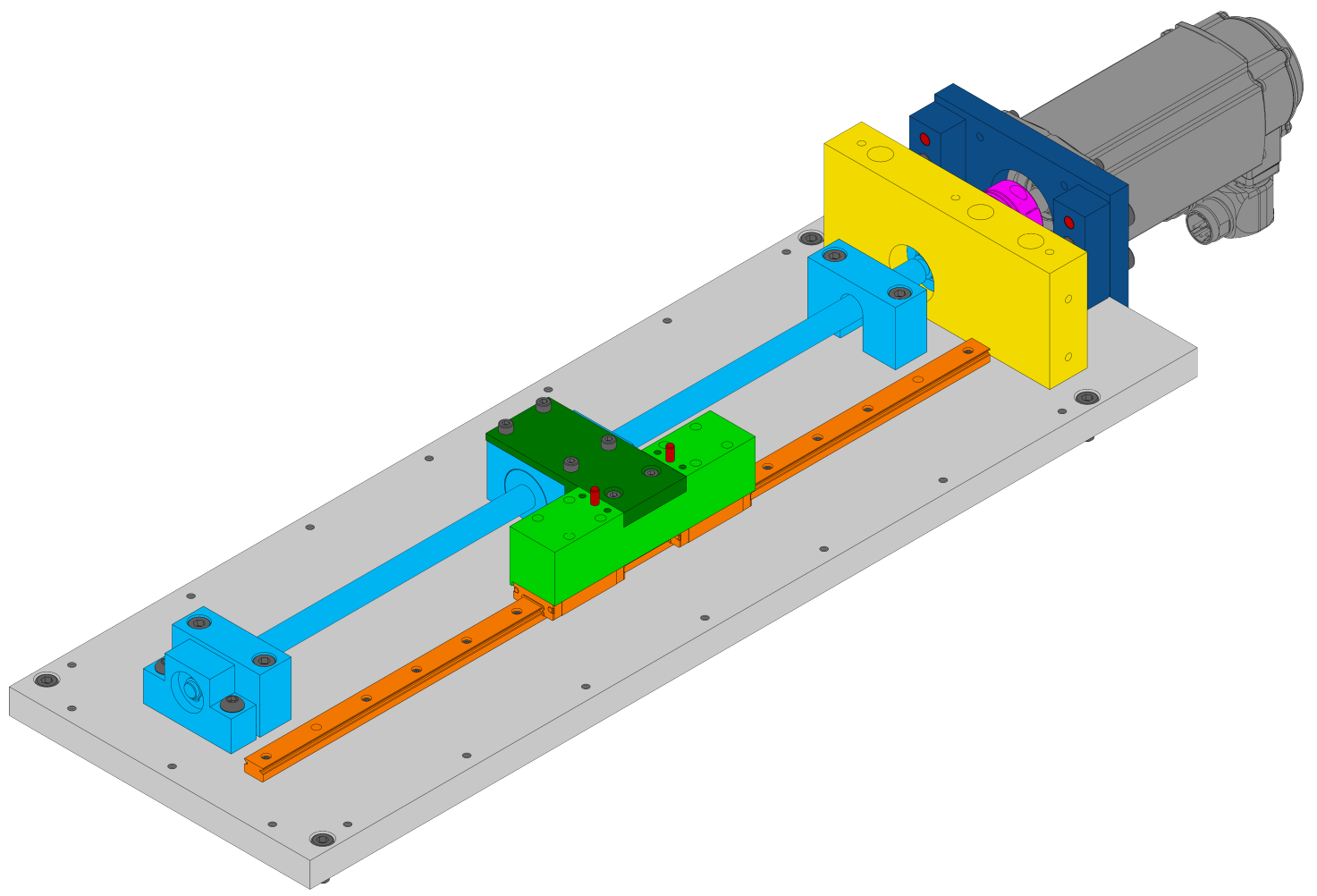

(c) ISO-Ansicht von oben

Abbildung B.9.: Antriebsbaugruppe des Pulverauftragmoduls: Motor

Motoraufnahme

\begin{tabular}{ll|l|l|} 
Grundplatte Kupplung & Kugelgewindetrieb Festlagergehäuse \\
\hline Doppelwagen-Linearführung & Zylinderstift & Führungswagenverbinder \\
\hline Gewindetriebmutteranbindung &
\end{tabular}




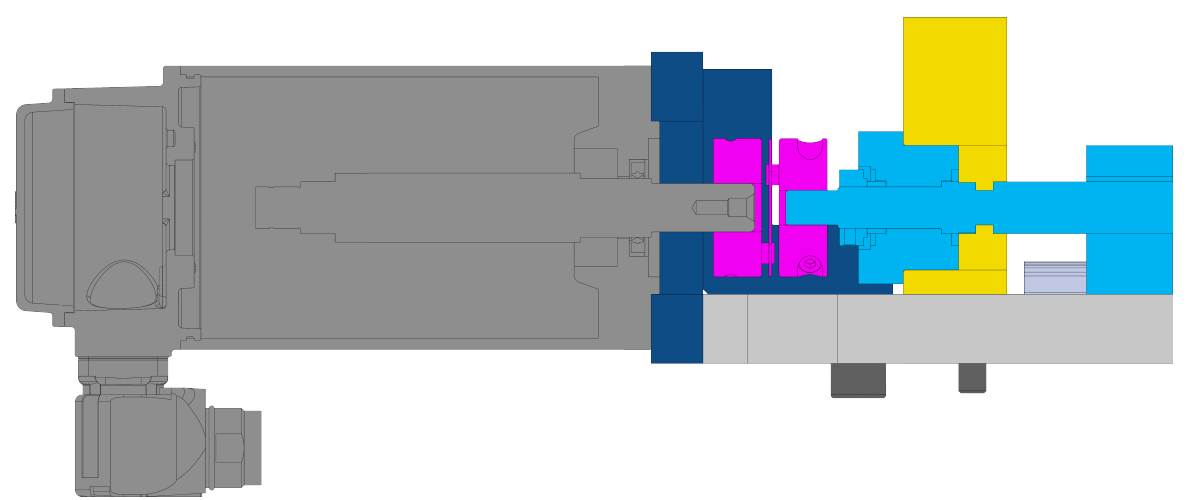

(a) Aktuell verwendetes Konzept

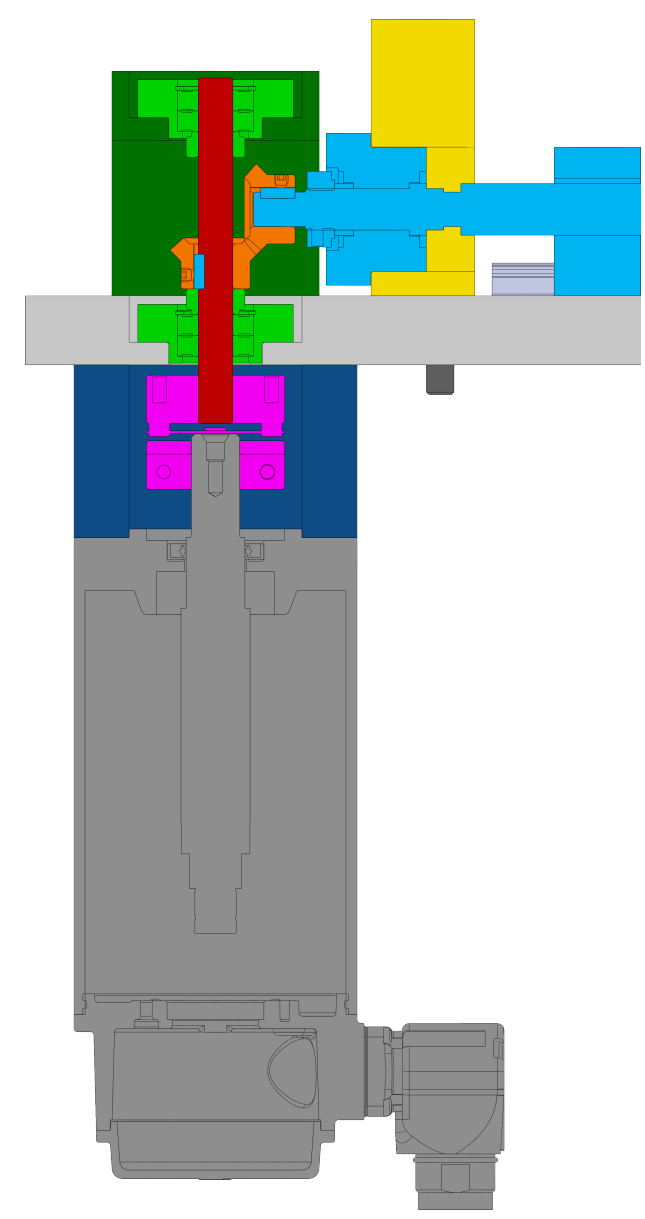

(b) Verworfenes Konzept

Abbildung B.10.: Einleitung Antriebsmoment: Motor Motoraufnahme Grundplatte Kupplung Kugelgewindetrieb Festlagergehäuse Zwischenwelle Doppelloslager Doppelloslagergehäuse Kegelzahnrad 


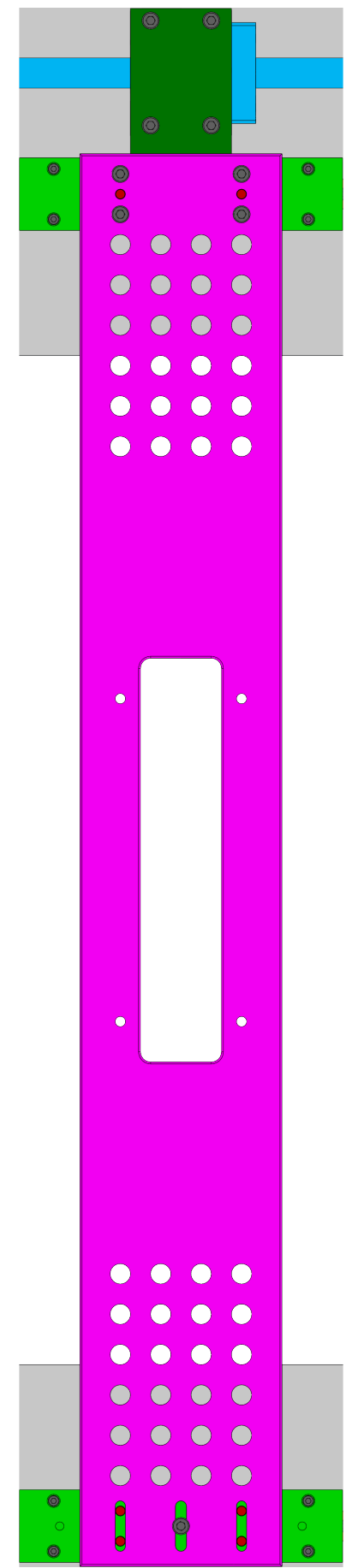

(a) Draufsicht

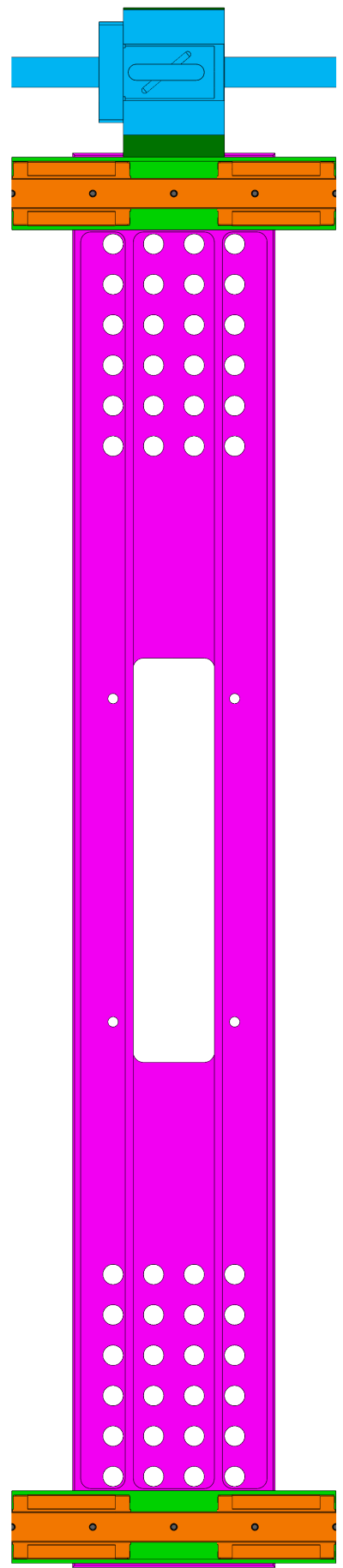

(b) Untersicht

Abbildung B.11.: Anbindung des Auftragsschlittens: Auftragsschlitten Kugelgewindetrieb Doppelwagen-Linearführung 


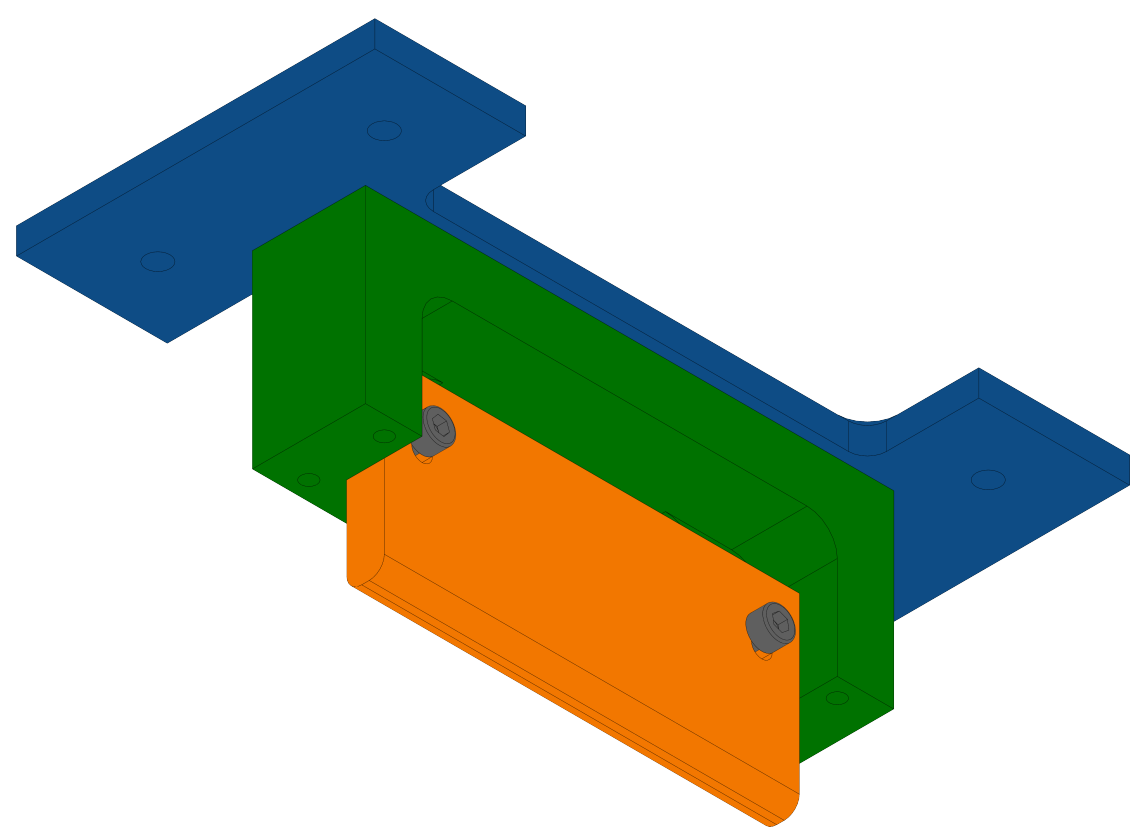

(a) ISO-Ansicht von unten

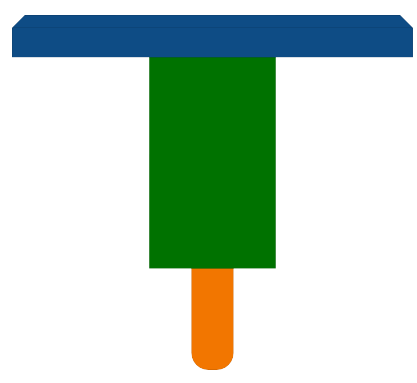

(b) Seitenansicht

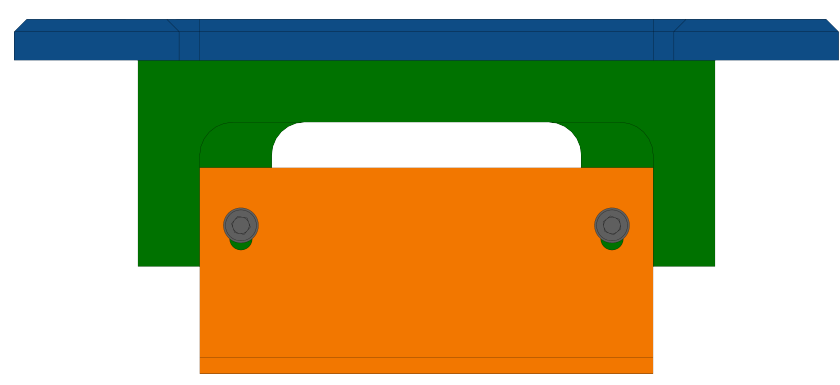

(c) Vorderansicht

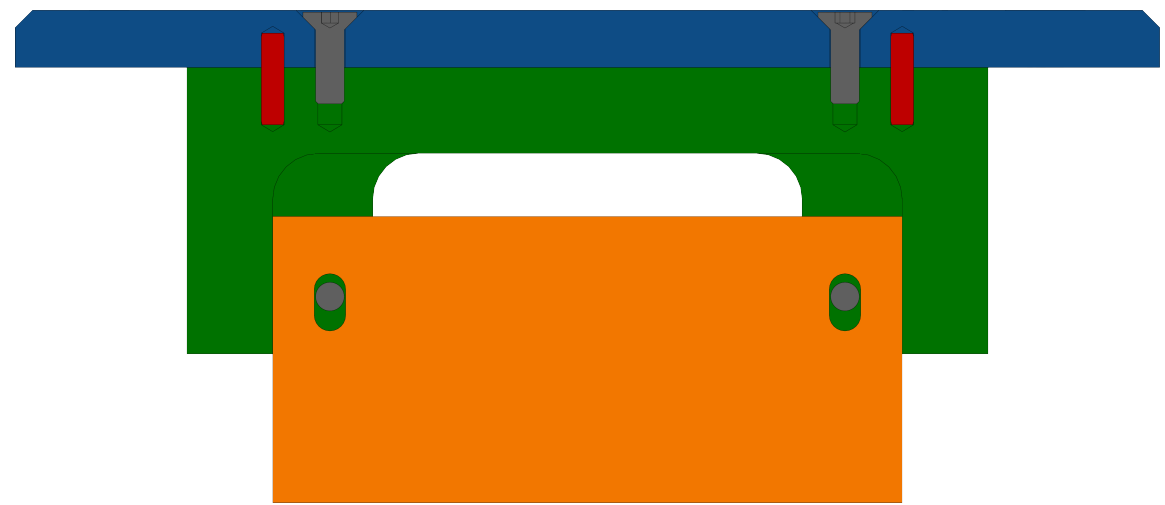

(d) Schnittansicht

Abbildung B.12.: Beschichtereinheit mit starrer Klinge: Auftragsschlittenanbindung Klingenaufnahme Klinge Zylinderstift 


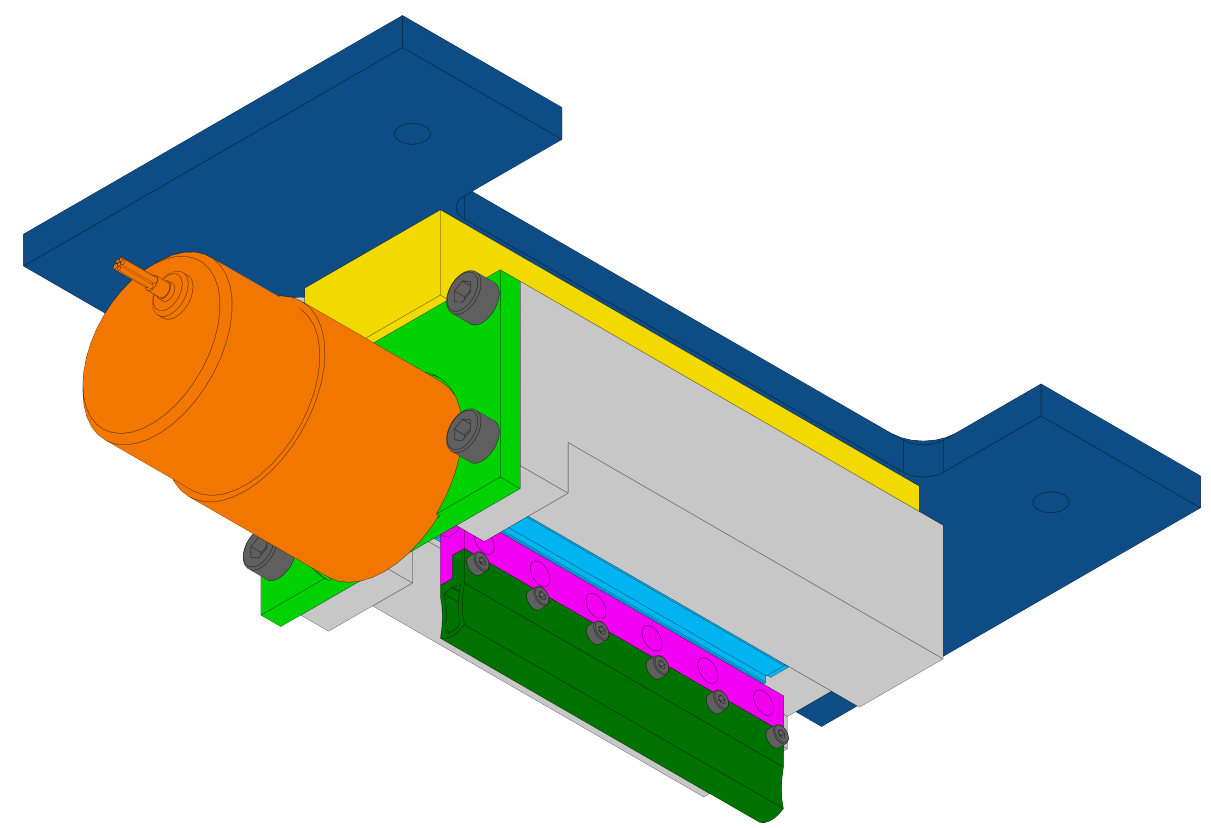

(a) ISO-Ansicht von unten

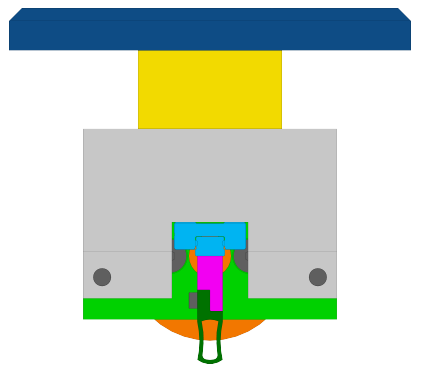

(b) Seitenansicht

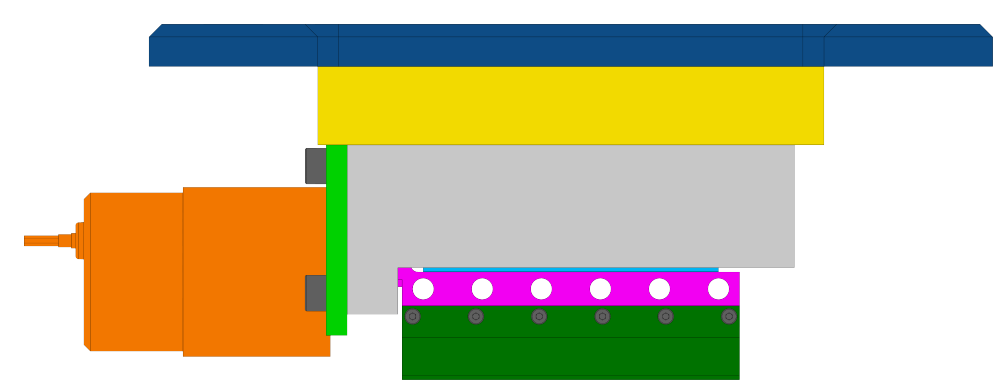

(c) Vorderansicht

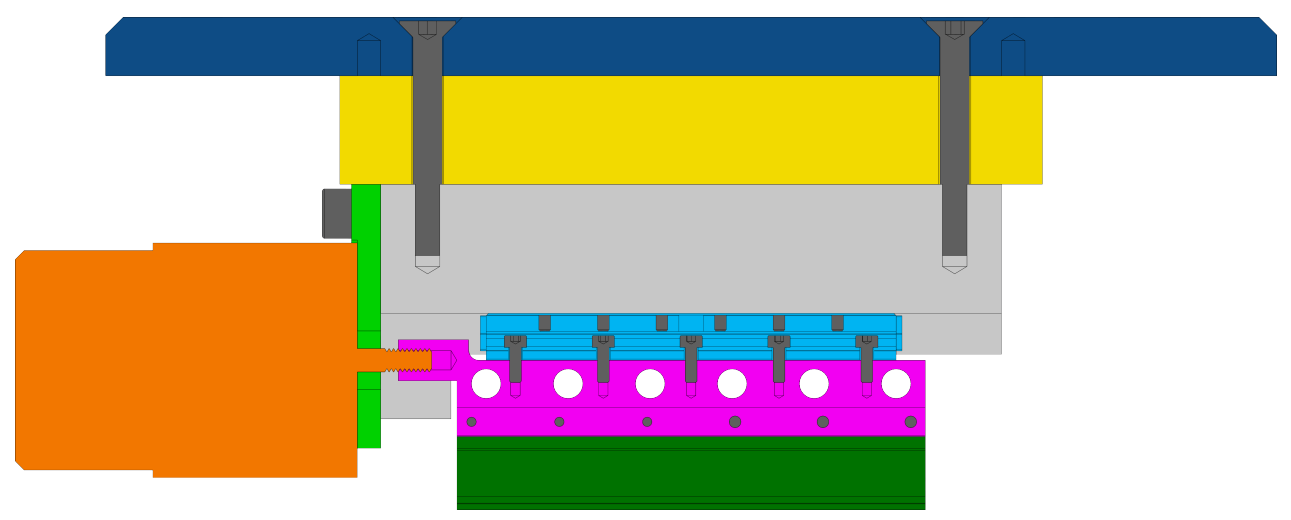

(d) Schnittansicht

Abbildung B.13.: Beschichtereinheit mit schwingender Klinge: Schwingspulenantrieb Auftragsschlittenanbindung Distanzblock Fundamentblock Antriebsaufnahme Linearführung Klingenaufnahme Klinge 


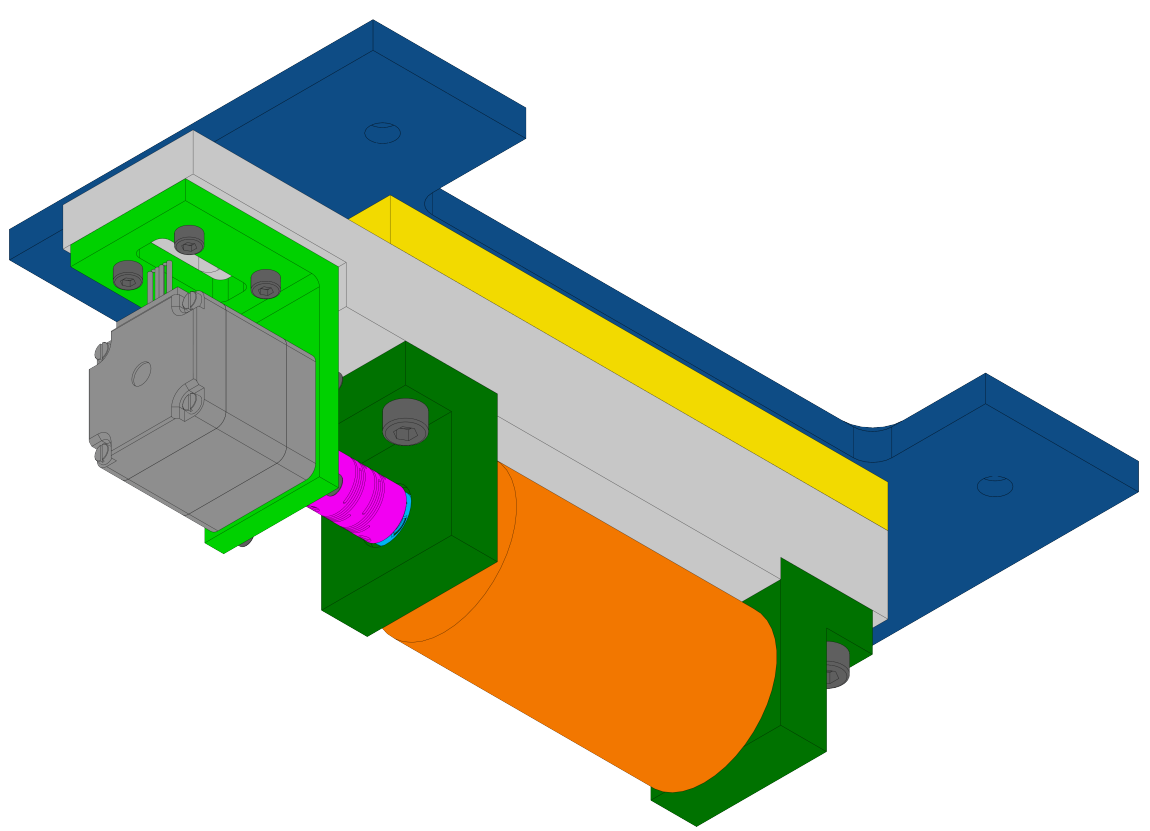

(a) ISO-Ansicht von unten

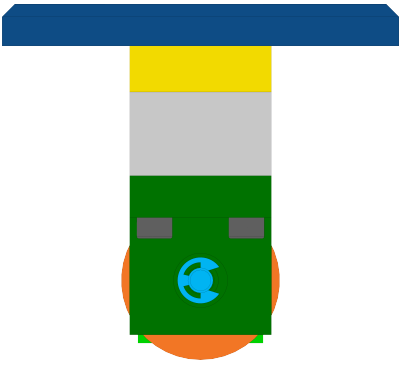

(b) Seitenansicht

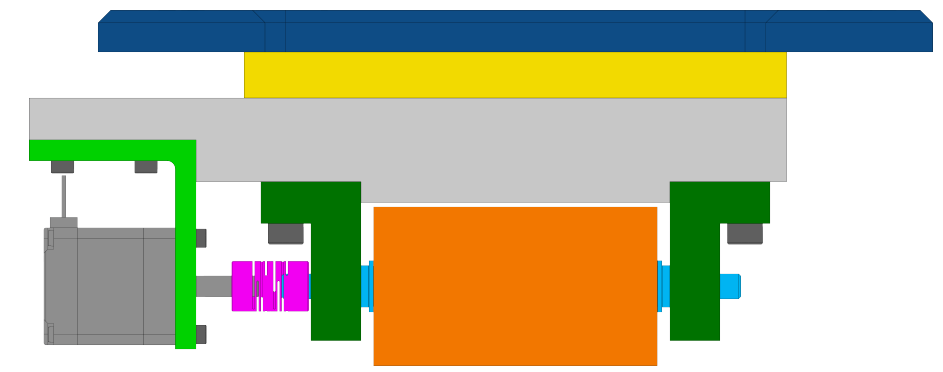

(c) Vorderansicht

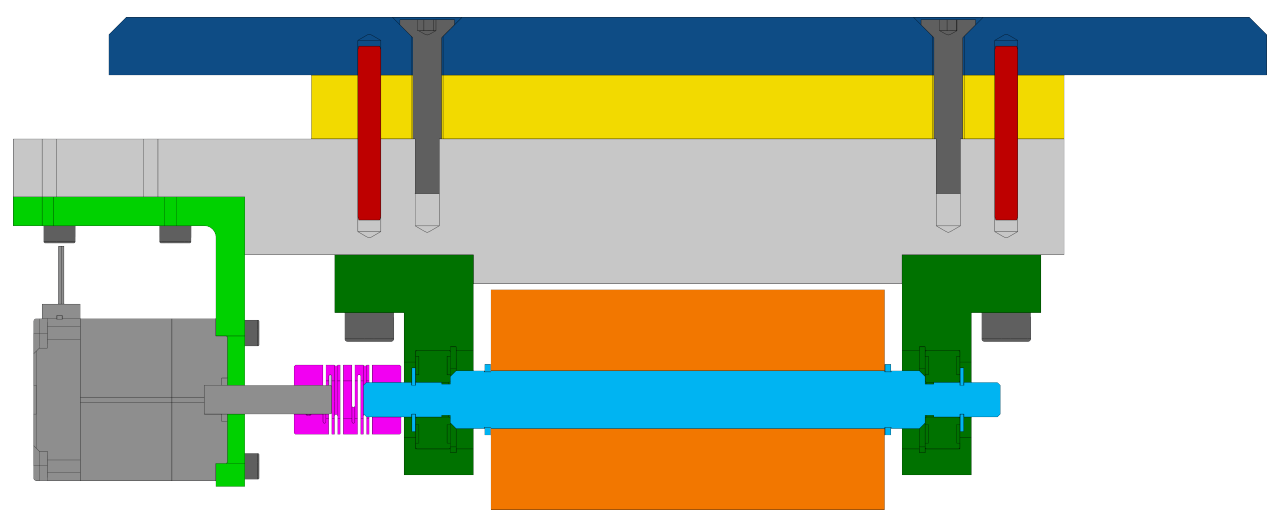

(d) Schnittansicht

Abbildung B.14.: Beschichtereinheit mit rotierender Rolle: Auftragsschlittenanbindung Distanzblock Fundamentblock Motoraufnahme Lagereinheit Schrittmotor Kupplung Welle Rolle Zylinderstift 


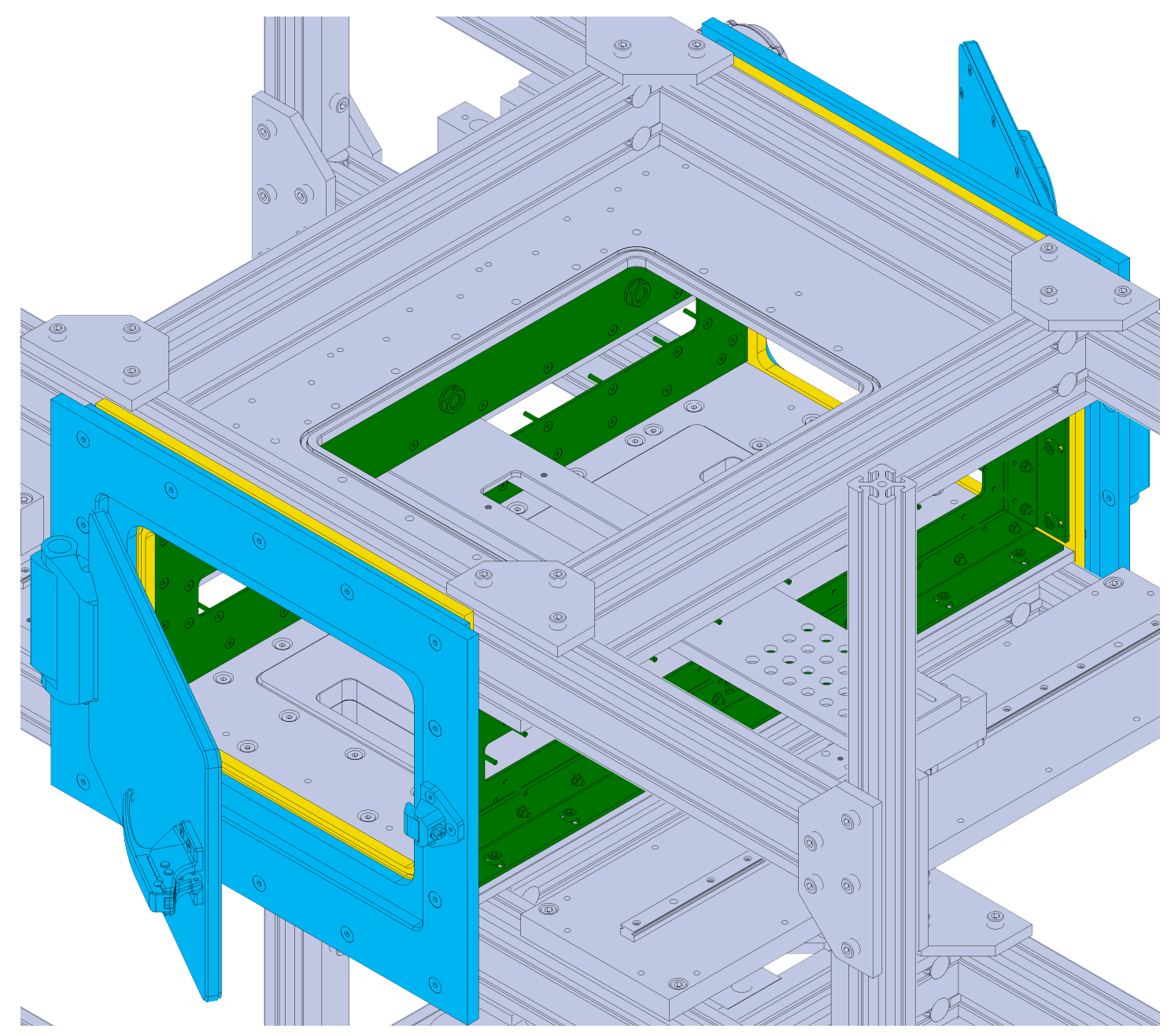

Abbildung B.15.: Türgängige Prozesskammer: Türrahmenplatte Türbaugruppe Prozesskammerwandbaugruppe 


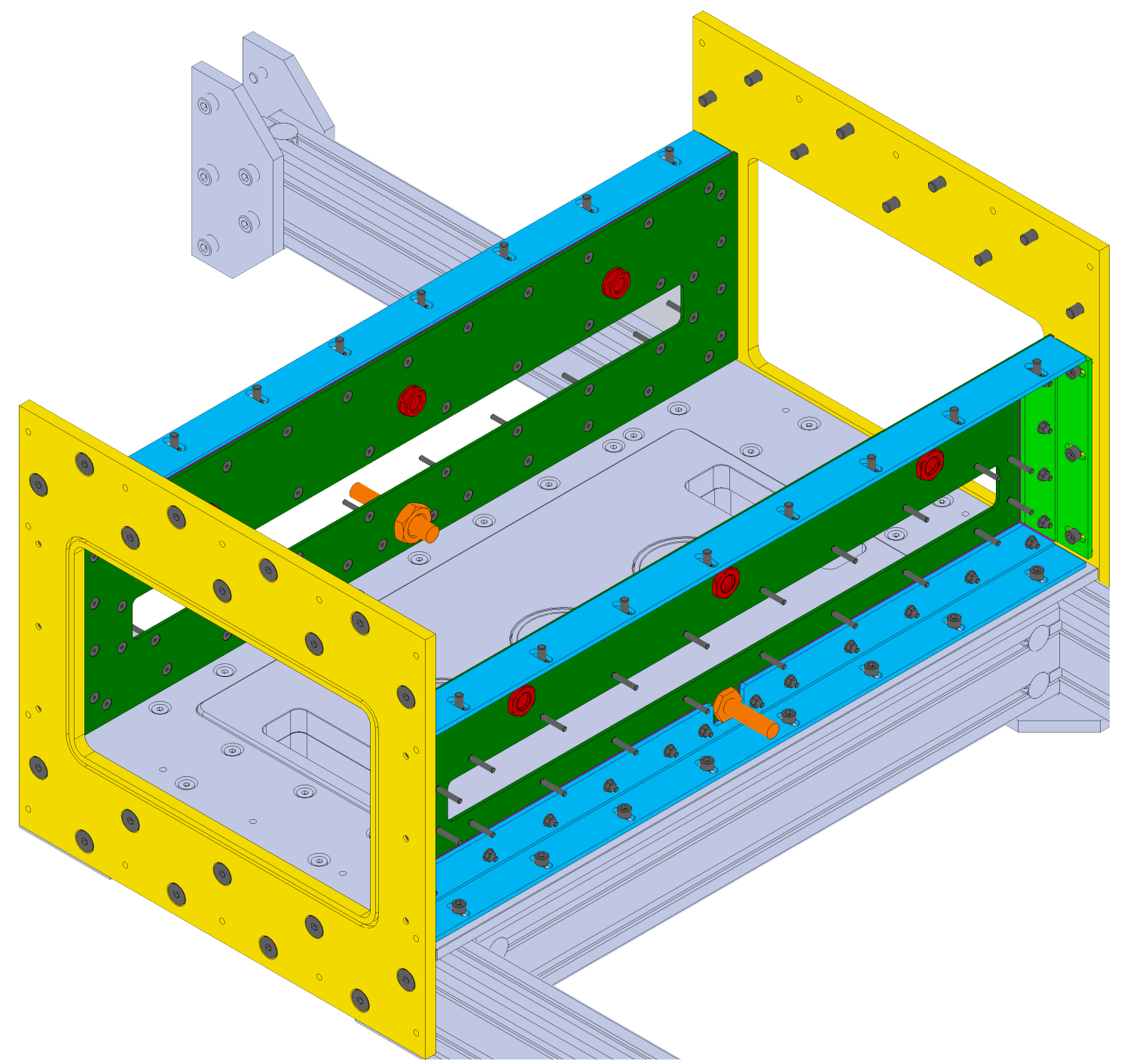

Abbildung B.16.: Türrahmenplatte

und

Prozesskammerwandbaugruppe: $638 \mathrm{~mm}$ Winkel $168 \mathrm{~mm}$ Winkel Prozesskammerwand Schauglas Sauerstoffsensor 


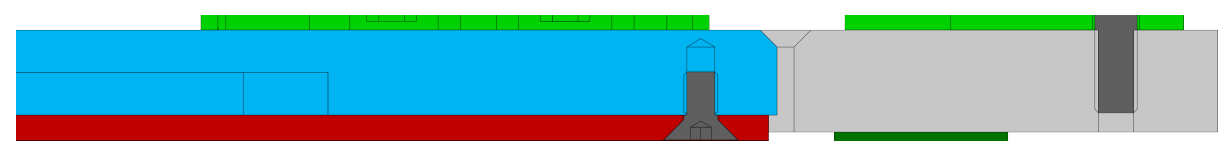

(a) $1 \mathrm{~mm}$ Versatz zwischen Türinnenblecht und Türumrahmung

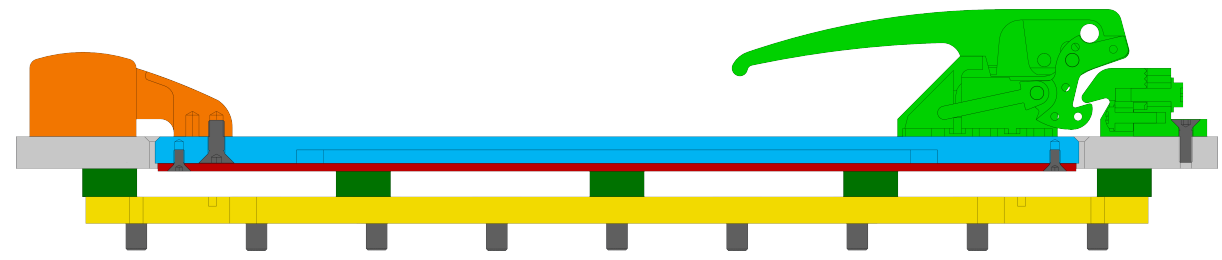

(b) Schnittansicht ohne Flachdichtung

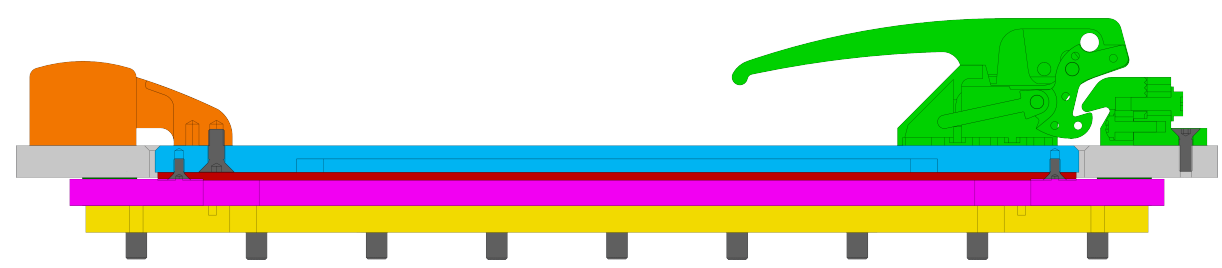

(c) Schnittansicht

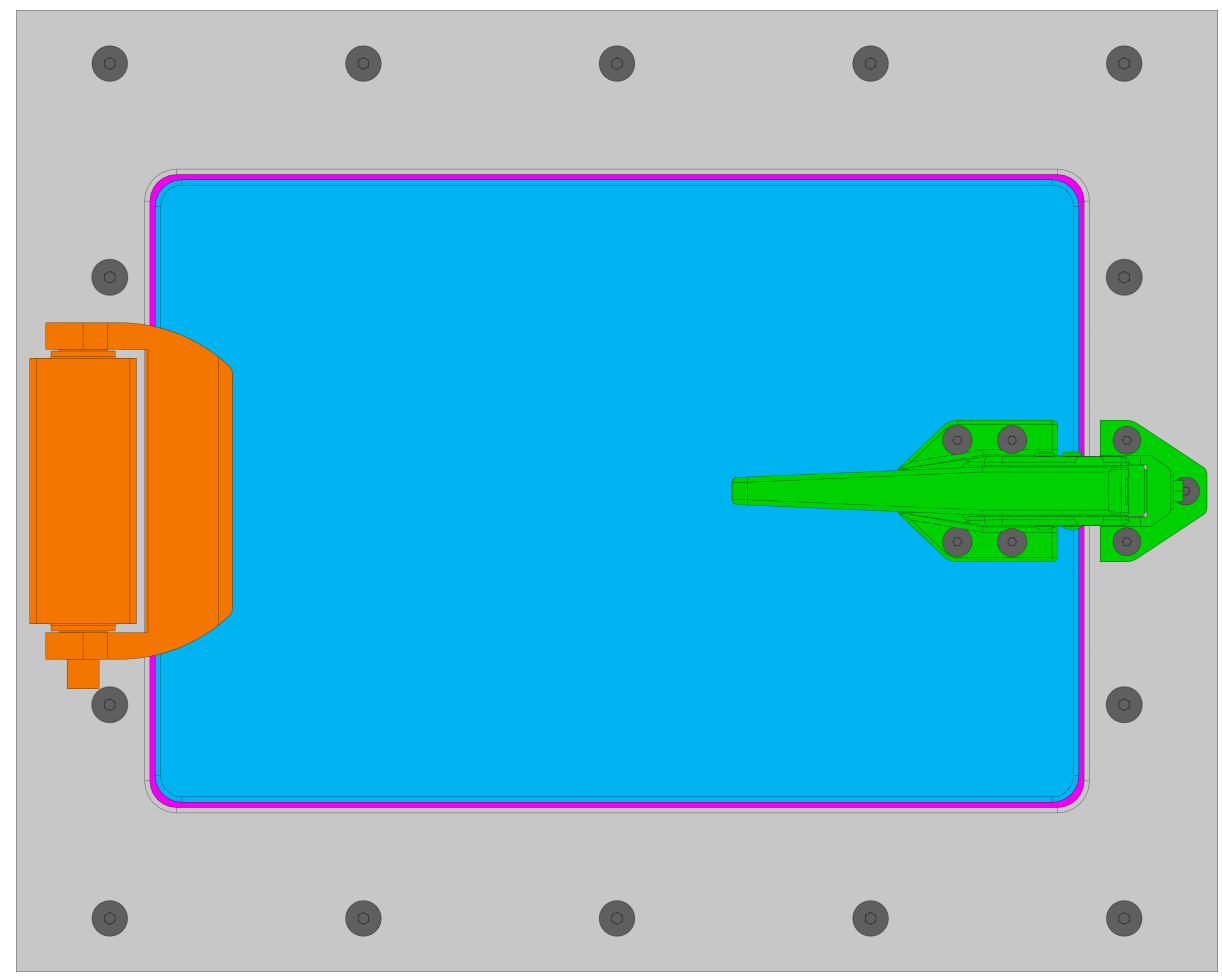

(d) Vorderansicht

Abbildung B.17.: Türbaugruppe und Türrahmenplatte : \begin{tabular}{c|c|c|} 
Türumrahmung & Tür Türinnenblech \\
Türverriegelung & $10 \mathrm{~mm}$ Flachdichtung
\end{tabular}

$\varnothing 20,5 \mathrm{~mm} \times 10,5 \mathrm{~mm}$ Hülse Sicherheits-Schaltscharnier 


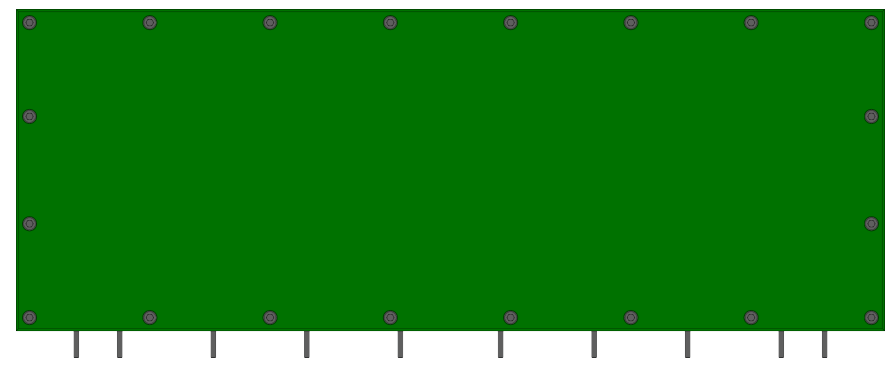

(a) Draufsicht

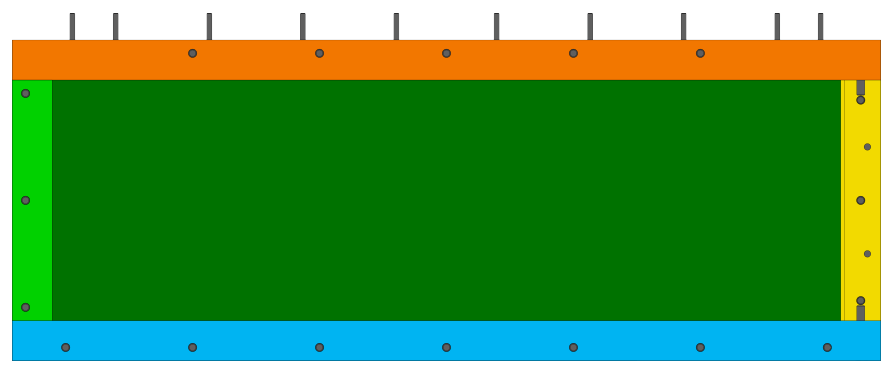

(b) Untersicht

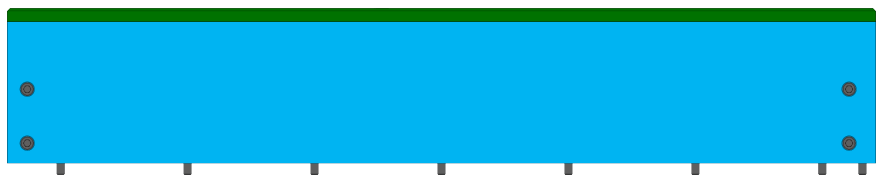

(c) Seitenansicht links

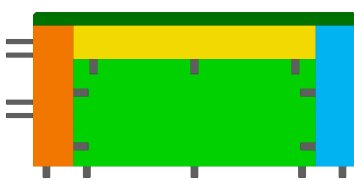

(d) Rückansicht

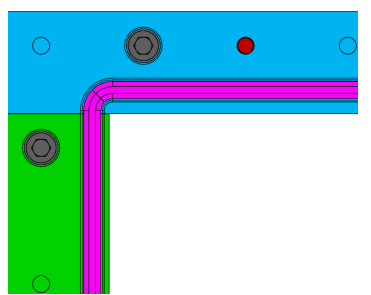

(f) Detailansicht

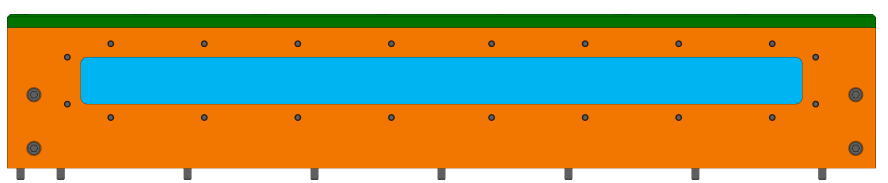

(e) Seitenansicht rechts

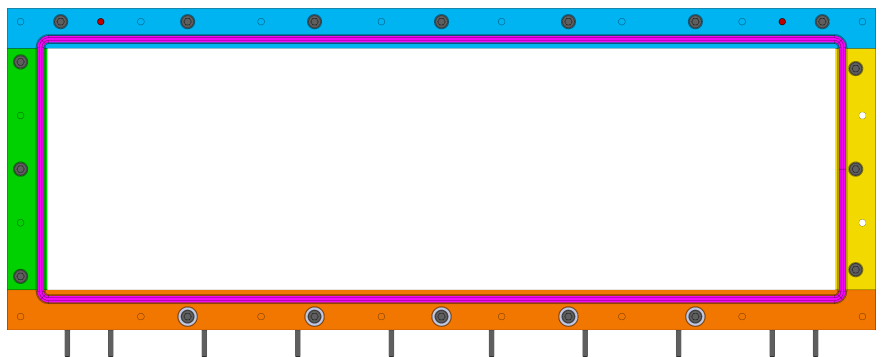

(g) Draufsicht ohne Deckel

Abbildung B.18.: Antriebsseitige Nebenkammer: Deckel Außenwand Innenwand Festlagergehäusewand vordere Wand Dichtscheibe Zylinderstift O-Ring 


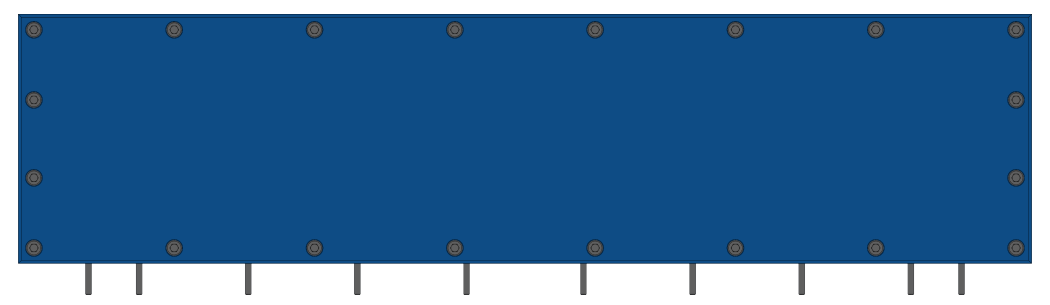

(a) Draufsicht

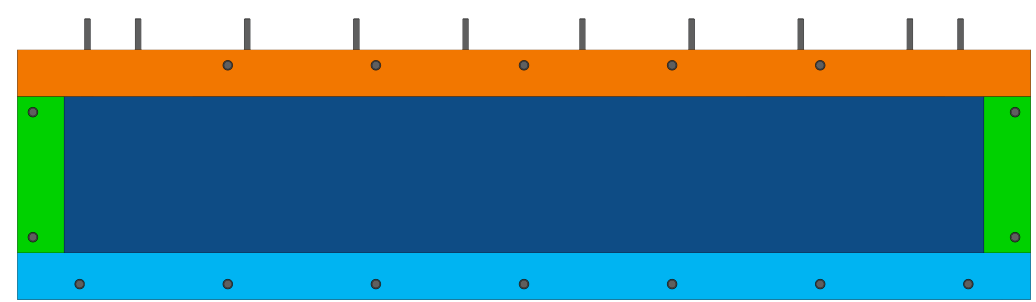

(b) Untersicht

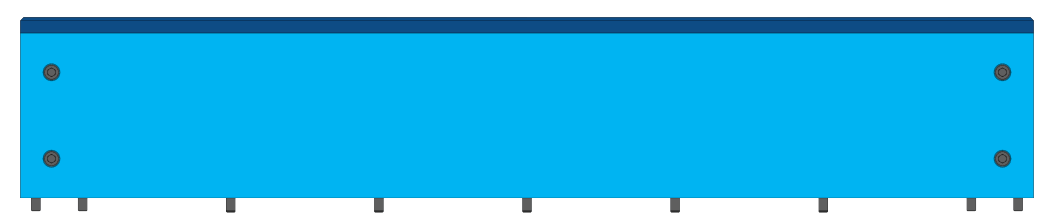

(c) Seitenansicht rechts

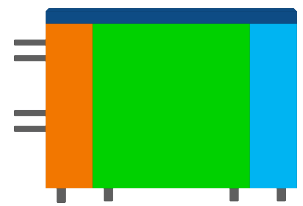

(d) Vorderansicht

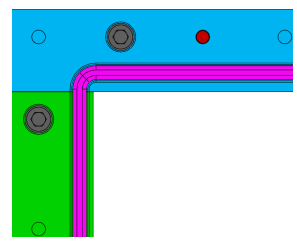

(f) Detailansicht

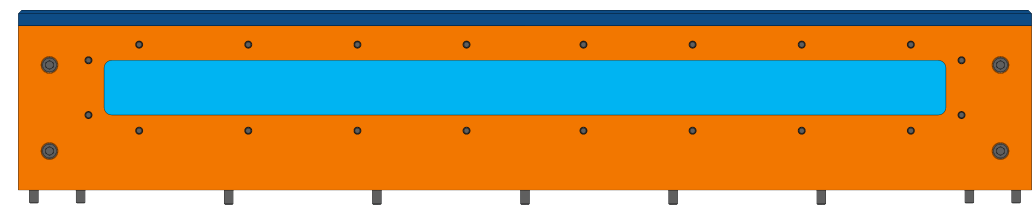

(e) Seitenansicht links

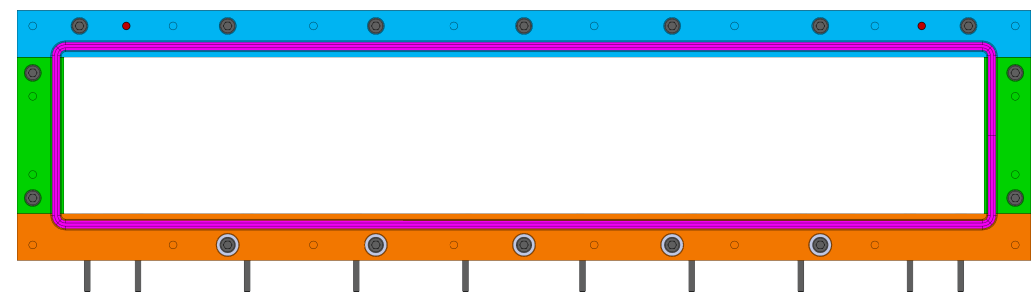

(g) Draufsicht ohne Deckel

Abbildung B.19.: Lagerseitige Nebenkammer: Deckel Außenwand Innenwand vordere bzw. hintere Wand Dichtscheibe Zylinderstift O-Ring 


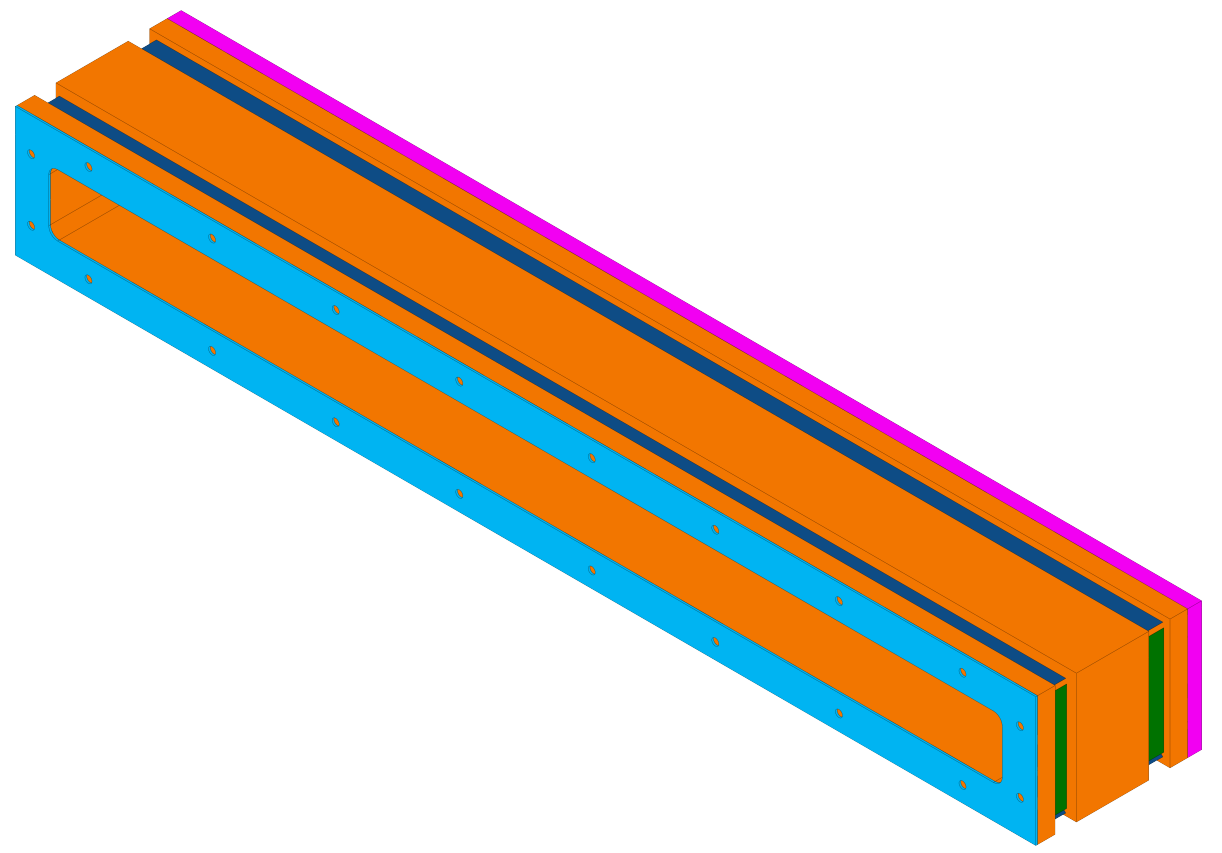

(a) ISO-Ansicht

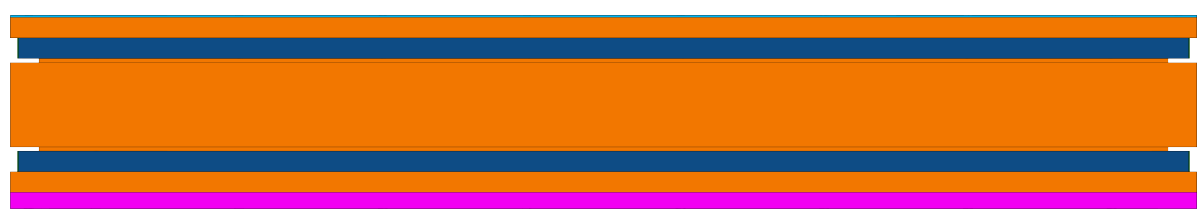

(b) Draufsicht

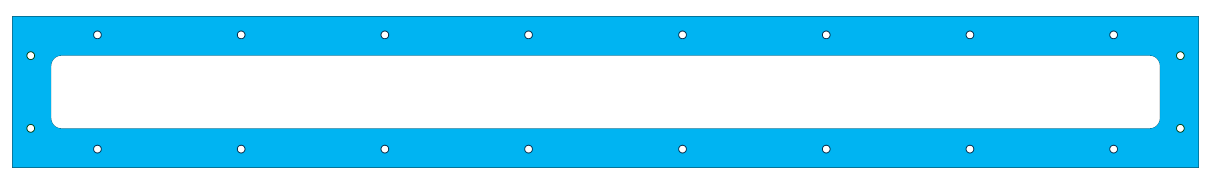

(c) Seitenansicht

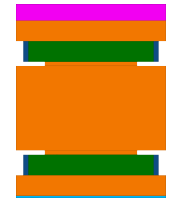

(d)

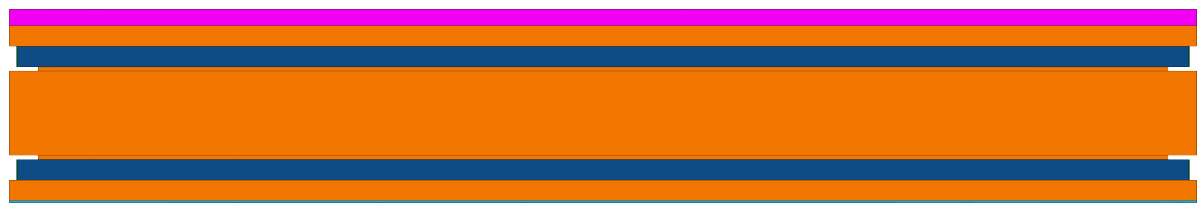

(e) Untersicht

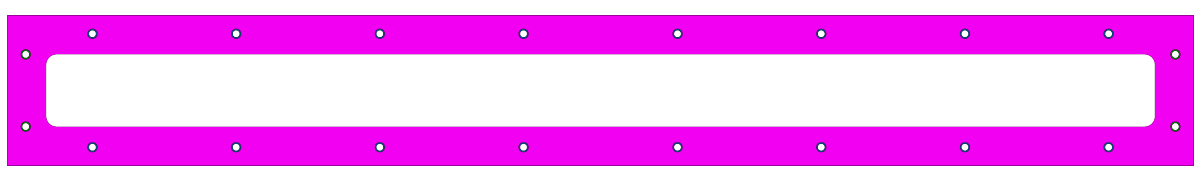

(f) Seitenansicht

Abbildung B.20.: Verbindungskammer: Verbindungskammer lange Haltespange kurze Haltespange $1 \mathrm{~mm}$ Flachdichtung $10 \mathrm{~mm}$ Flachdichtung 


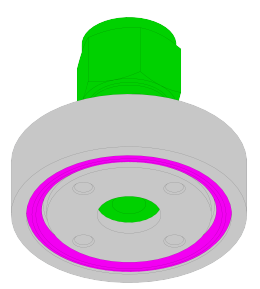

(a) ISO-Ansicht

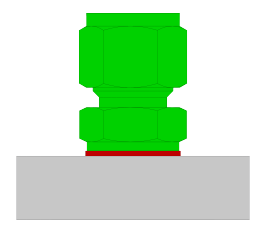

(b) Seitenansicht

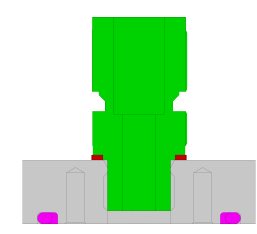

(c) Schnittansicht

\section{Abbildung B.21.: Gaseinlass: \\ Flansch \\ Dichtscheibe \\ Einschraubverschraubung O-Ring}

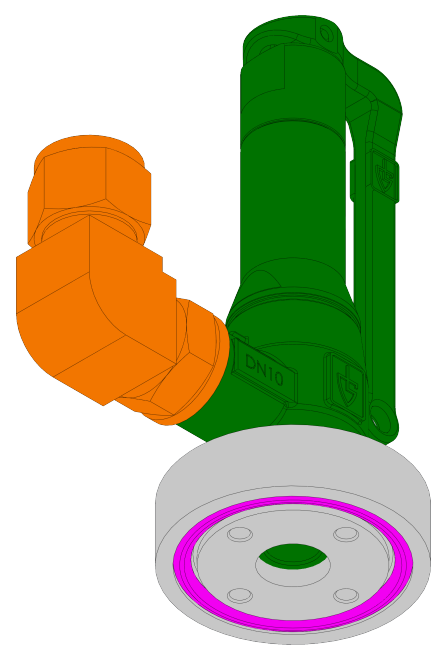

(a) ISO-Ansicht

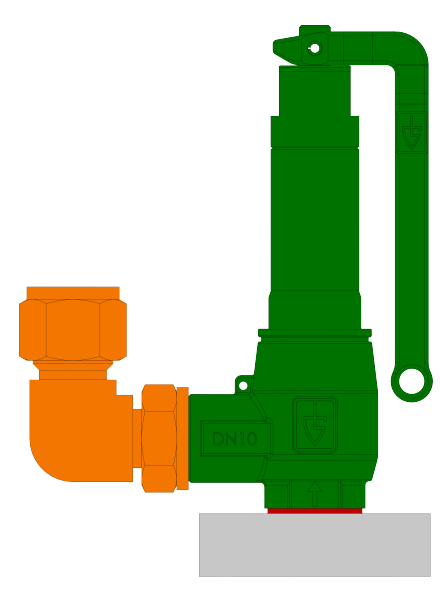

(b) Seitenansicht

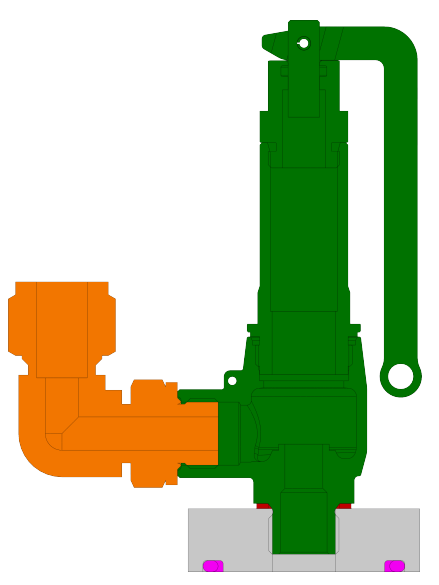

(c) Schnittansicht

Abbildung B.22.: Gasauslass:

Flansch Dichtscheibe

Sicherheitsventil 


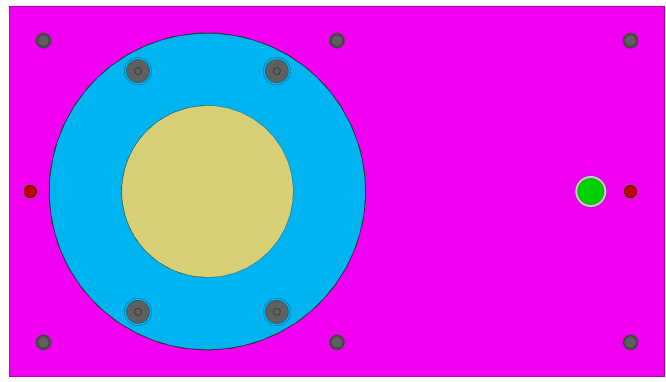

(a) Draufsicht

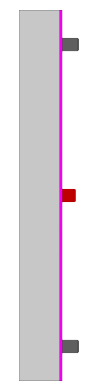

(b)

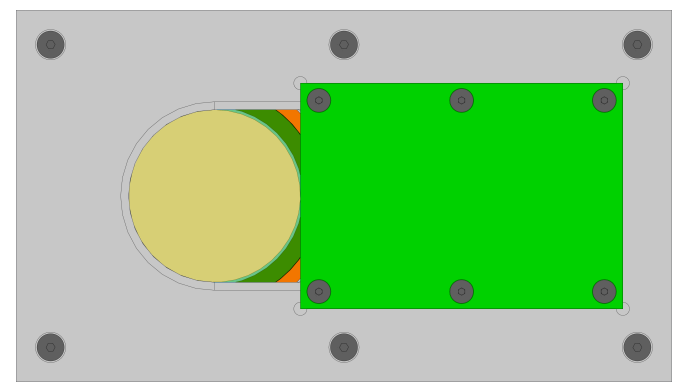

(c) Untersicht

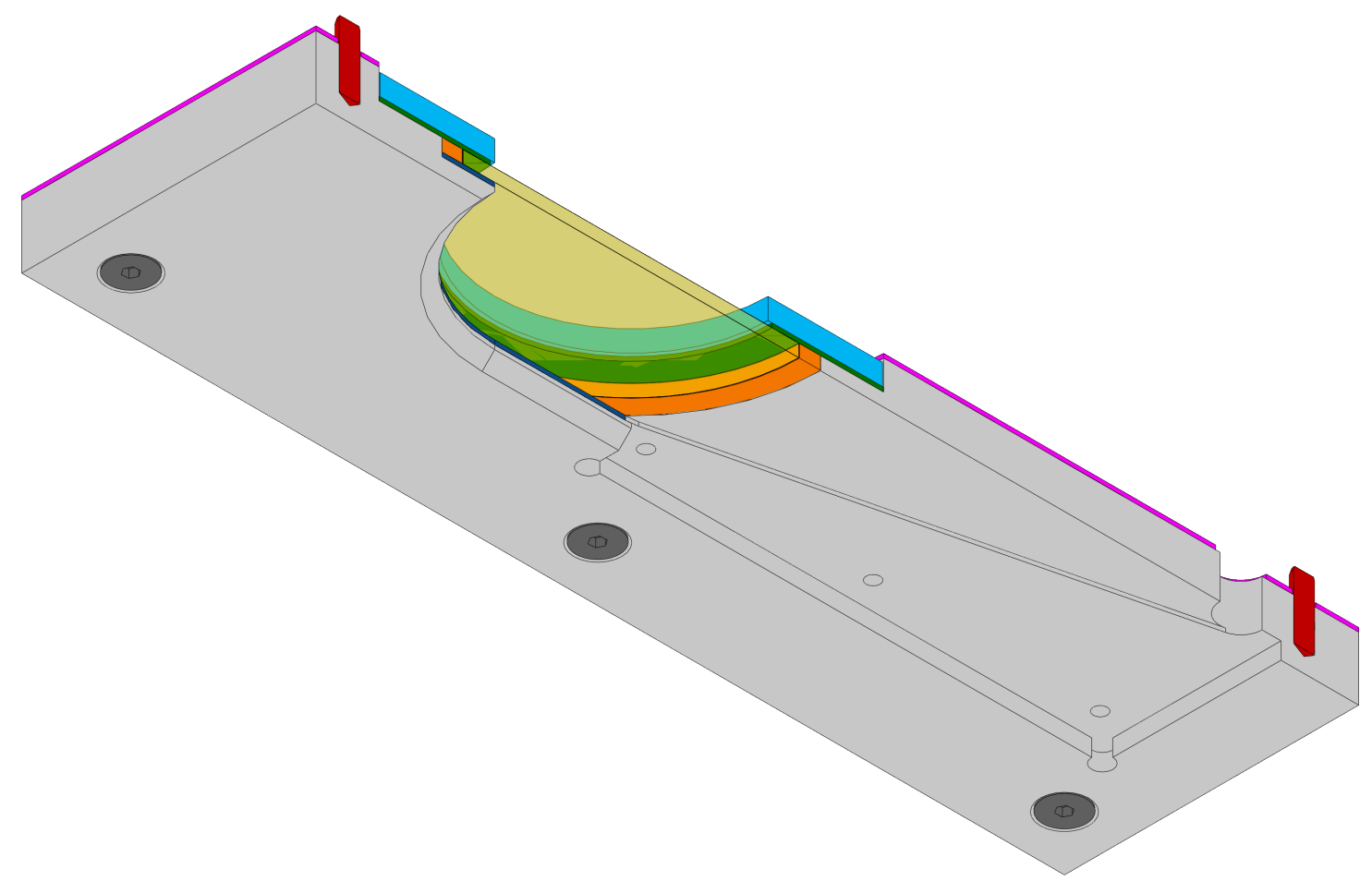

(d) Schnittansicht von unten ohne Diffusorabdeckung

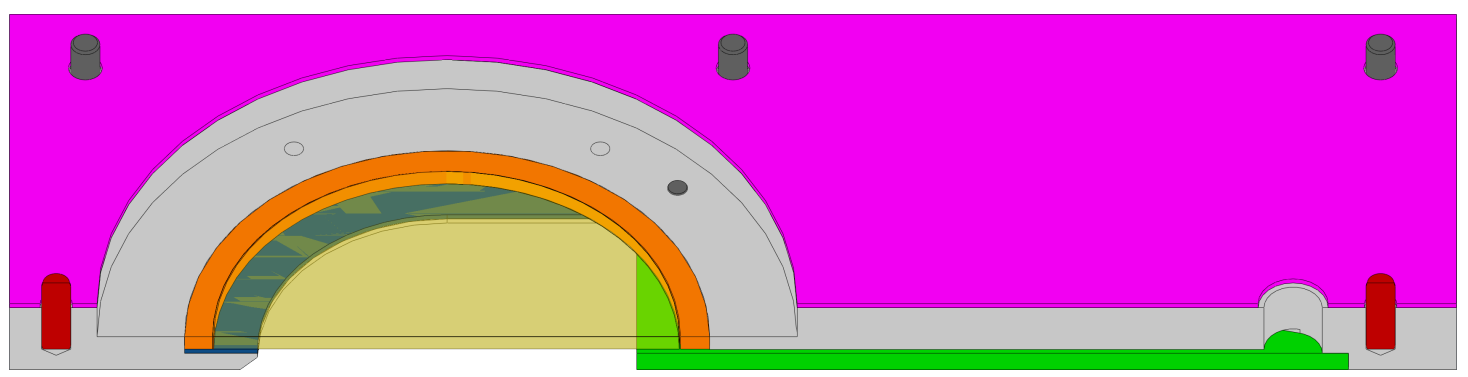

(e) Schnittansicht von oben ohne Flansch und Flanschdichtung

Abbildung B.23.: Laserglas-Prozessgas-Armatur: Fundament Diffusorabdeckung Flansch Flanschdichtung ZnSe-Laserglas Manteldichtung

Fundamentdichtung Flachdichtung Zylinderstift




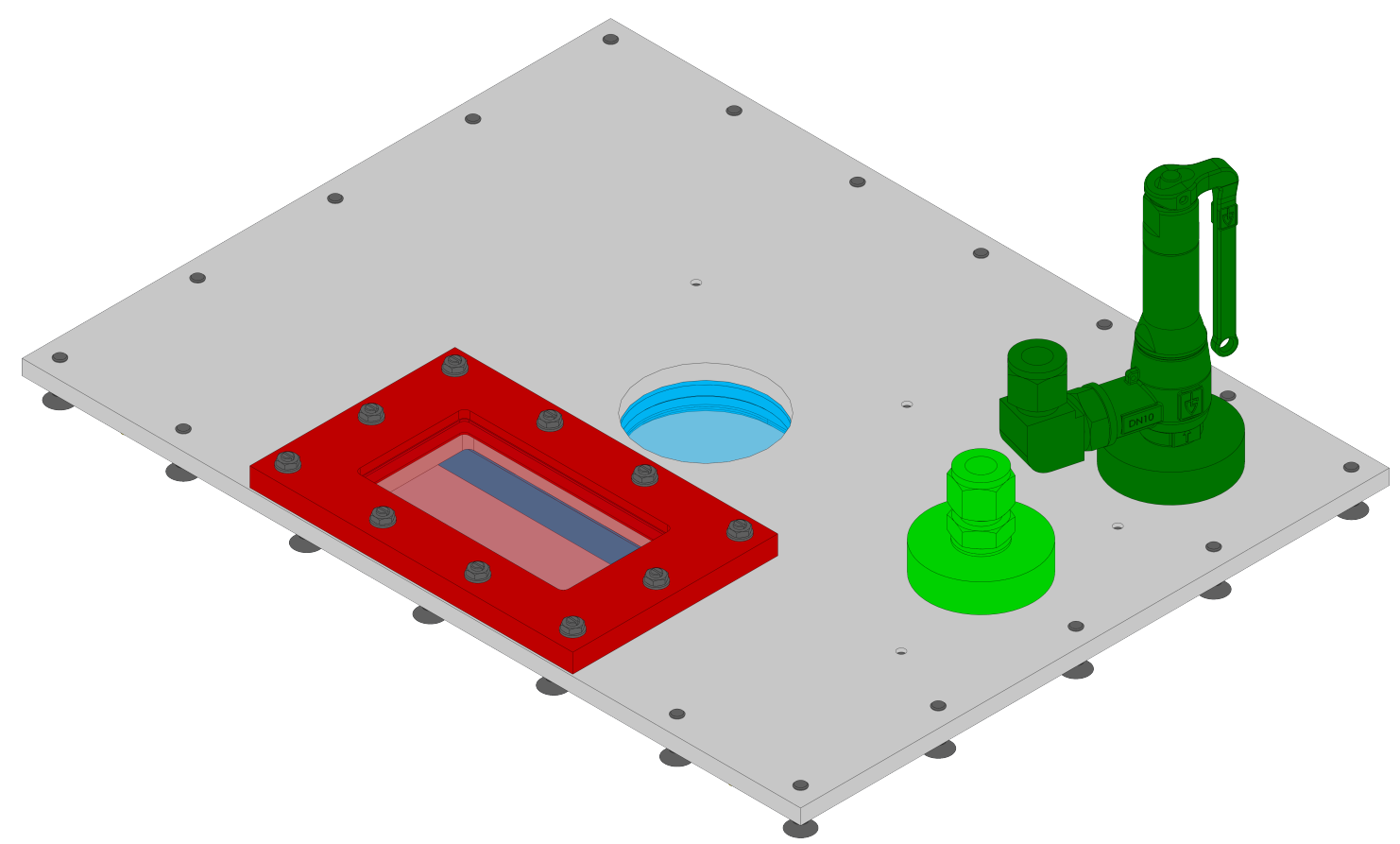

(a) ISO-Ansicht von oben

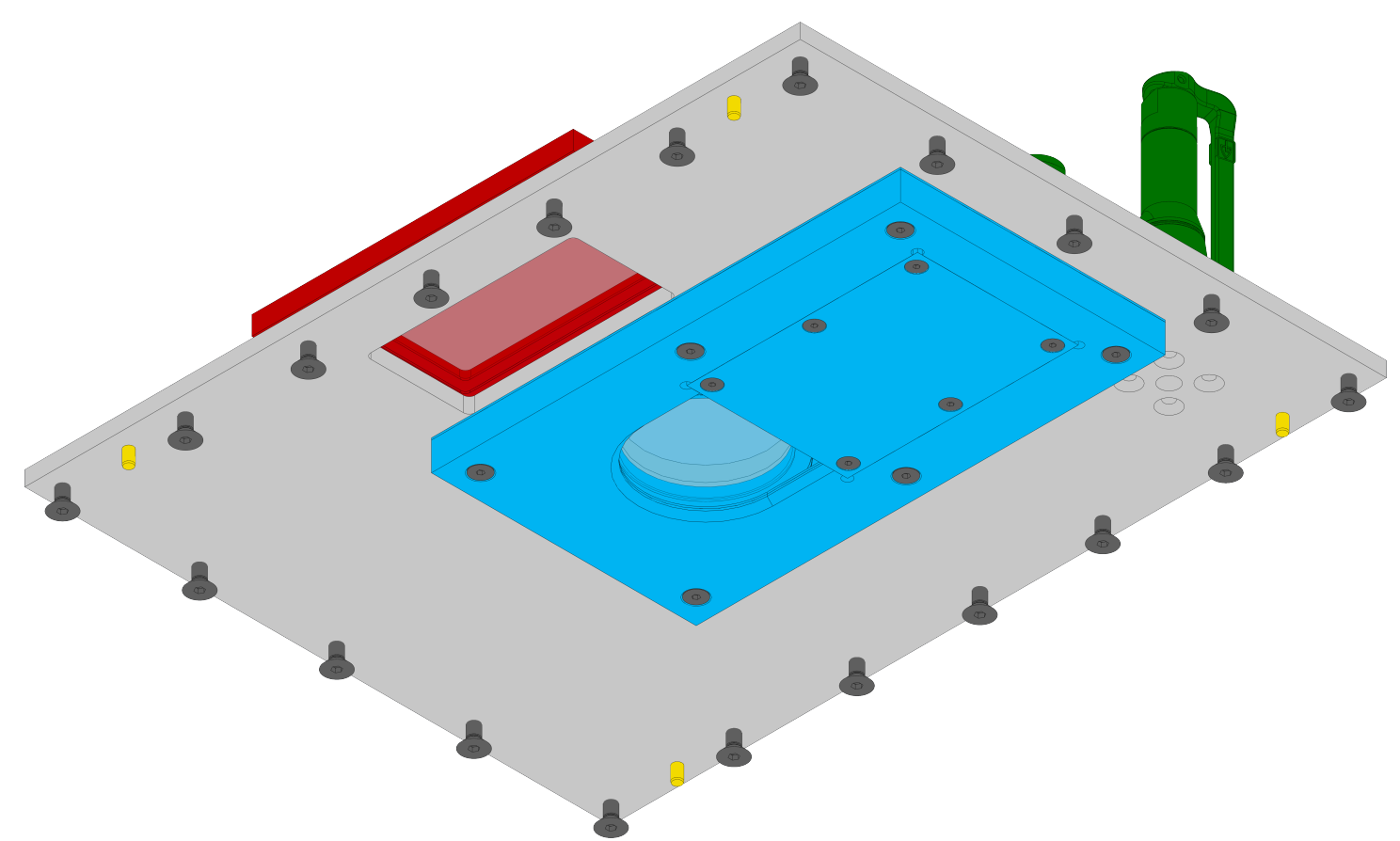

(b) ISO-Ansicht von unten

Abbildung B.24.: Lasereinsatzplatte samt Anbauteilen: Kameraglas-Armatur \begin{tabular}{lll} 
Laserglas-Prozessgas-Armatur $\quad$ Gaseinlass & Gasauslass \\
\hline Zylinderstift &
\end{tabular} 


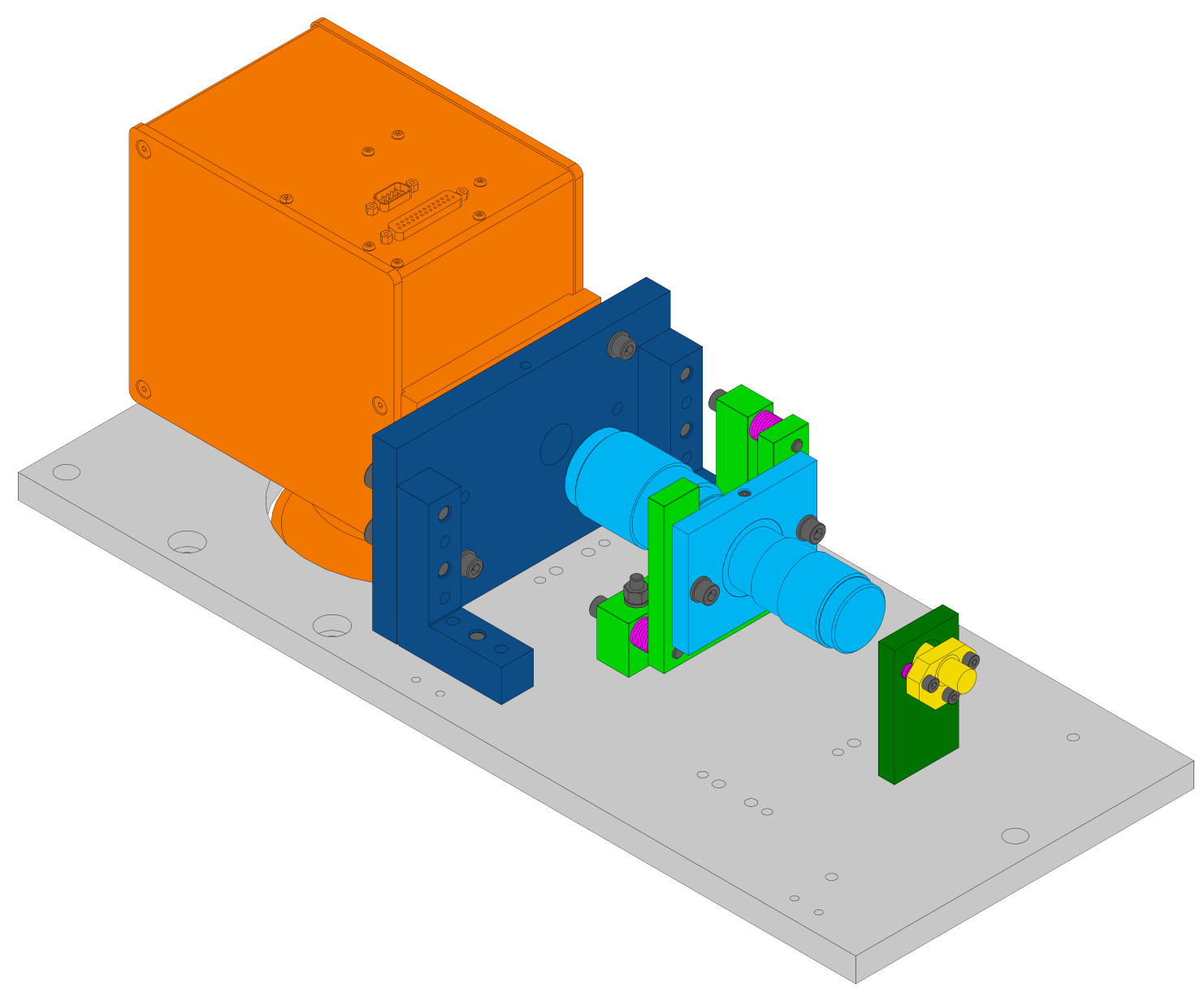

(a) ISO-Ansicht von oben

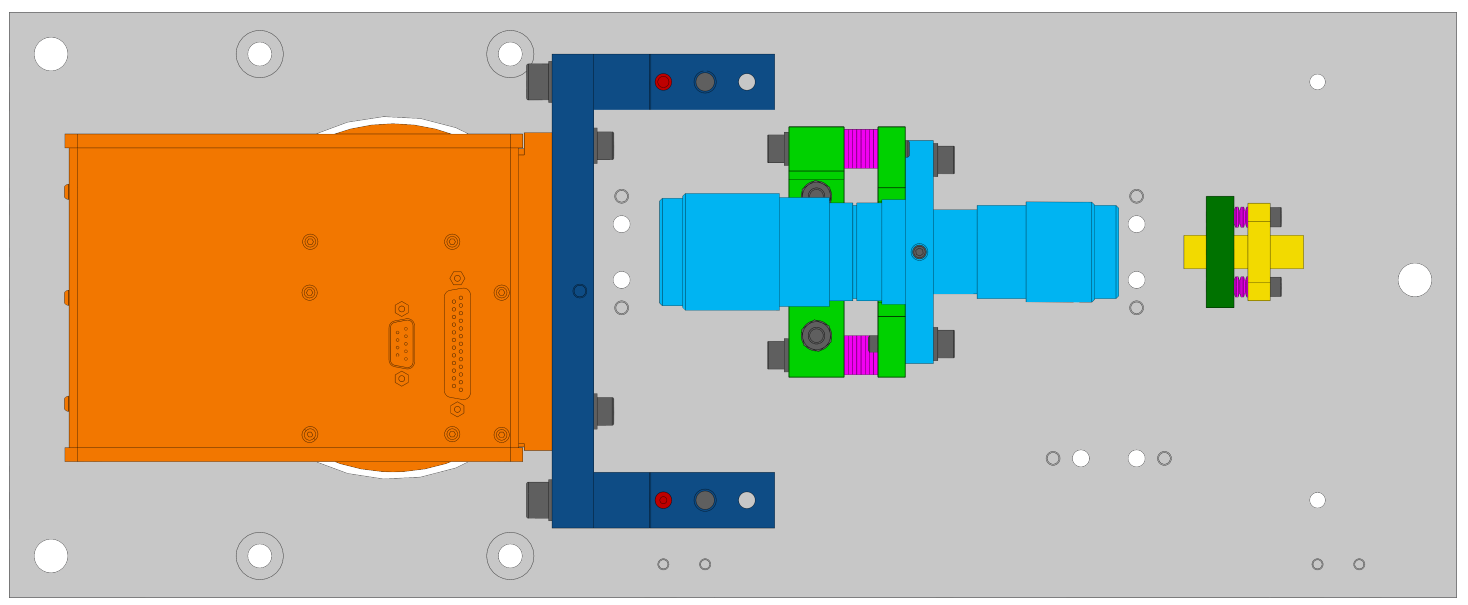

(b) Draufsicht

Abbildung B.25.: Laser-Scanner-Dummy ohne Abdeckung: Grundplatte Scanner Scanner-Anbindung Strahlaufweiter Justagevorrichtung Pilotlaser mit Aufhängung Aufnahme Federring Zylinderstift 



\section{Detaillierte Darstellung der Steuereinheit}

Im Folgenden wird die Steuereinheit der modularen Lasersintermaschine detailliert dargestellt. Das Steuersystem und die Elektronik der mechatronischen Teilsysteme sind in insgesamt vier Baugruppenträgern in einem 19" Schaltschrank angeordnet. Die Grundlagen der Schaltschranktechnik werden diesbezüglich in Anhang C.1 dargestellt. Das Steuersystem setzt sich aus einem cRIO-Controller, einem cRIO-Erweiterungschassis und einem Touchscreen-Monitor zusammen. Die Anschlussmöglichkeiten und Funktionen des CompactRIO-Controllers 9035 werden in Anhang C.2 beschrieben. Das Verkabelungskonzept zwischen der Lasersintermaschine und dem Schaltschrank ist in Anhang C.3 dargestellt. Abschließend werden die folgenden Einschübe beschrieben:

- Baugruppenträger des NI cRIO-Controllers 9035 (Anhang C.4)

- Baugruppenträger des NI cRIO-Erweiterungschassis 9144 (Anhang C.5)

- Baugruppenträger der Bosch Rexroth Antriebsregelgeräte (Anhang C.6)

- Baugruppenträger und Steuercomputer des Laser-Scanner-Dummys (Anhang C.7) 


\section{C.1. Verwendete Schaltschranktechnik}

Die Abbildung C.1 stellt den verwendeten, nach DIN EN 60297-3-100 [DIN EN 60297-3-100] genormten, 19" Schroff Eurorack Schaltschrank (Gesamthöhe 38U) der Firma Pentair mit Anbauteilen dar. Das Schaltschrankgestell ist mit vertikalen Monta-
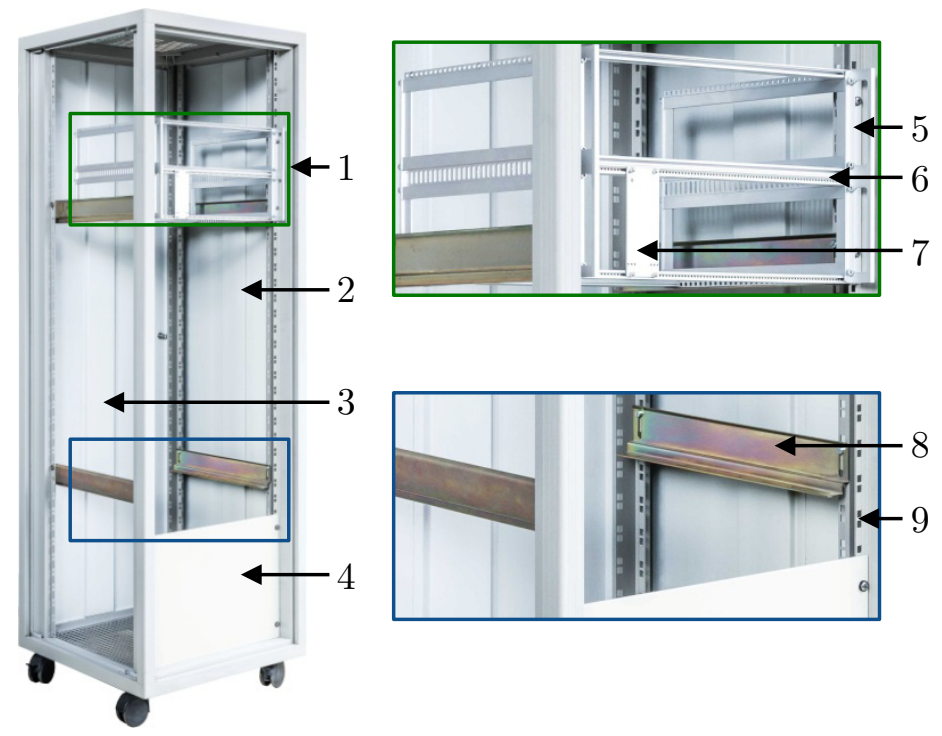

(1) Baugruppenträger

(2) Seitenwand

(3) Tür

(4) Frontplatte

(5) 19" Haltewinkel

(6) Modulschiene

(7) Teilfrontplatte

(8) Gleitschiene

(9) Vertikale Montageschiene

Abbildung C.1.: Benennung der Komponenten eines 19" Schaltschranks

geschienen ausgestattet an denen Frontplatten, Baugruppenträger oder Einschübe der Breite 19" (482,6 mm) befestigt werden können. Das Höhenmaß von Frontplatte und Baugruppenträger ist gemäß DIN EN 60297-3-100 [DIN EN 60297-3-100, S. 4] definiert als:

$$
1 \mathrm{U}=44,45 \mathrm{~mm}=1,75 "=1 \mathrm{HE}
$$

Die normspezifische Einheit „U“ wird von der Marke Schroff als „HE“ (Höheneinheit) geführt [Pen15]. Die Baugruppenträger und Einschübe werden in der vertikalen Richtung durch zuvor montierte Gleitschienen gelagert. Ein Baugruppenträger ist aufgebaut aus Seitenwänden, Haltewinkeln und Modulschienen [Pen16a, S. 14]. Die Breitenangabe von 19" bezieht sich auf das äußere Abmaß der gesamten Baugruppe mit montierten Haltewinkeln. Die zur Montage von Teilfrontplatten nutzbare Breite des Baugruppenträgers entspricht der Länge der Modulschienen. Die Norm DIN EN 60297-3-101 [DIN EN 60297-3-101] führt zur Breitenangabe von Modulschienen die Angabe von horizontalen Teilungen „HP“ (Horizontal Pitches) ein [DIN EN 60297-3-101, S. 22]:

$$
1 \mathrm{HP}=5,08 \mathrm{~mm}=0,2 "=1 \mathrm{TE}
$$

Die normspezifische Einheit „HP“ wird von der Marke Schroff als „TE“ (Teilungseinheit) geführt [Pen16a]. Die Modulschienen sind 84HP (426,72 mm) lang [Pen16b]. 


\section{C.2. National Instruments CompactRIO-Controller 9035}

Als Komponente des Steuersystems ist der in Abbildung C.2 dargestellte cRIO-Controller 9035 ausgewählt. Im linken Teil des Controllers befinden sich der zwei Kern Intel Prozessor mit einer Taktfrequenz von 1,33 GHz, der rekonfigurierbare FPGA (Field Programmable Gate Array) und ein Anschlussfeld. Der rechte Teil des Chassis ist für den Anschluss von bis zu acht C-Modulen bestimmt [Nat15b] [Nat15d]. Der leistungsfähige Embedded-

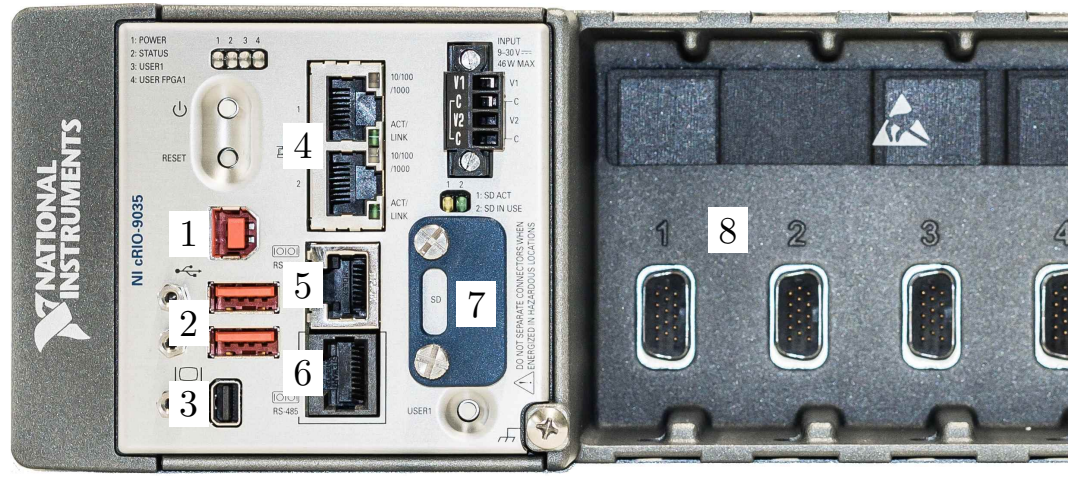

(1) USB Device

(2) USB Host

(3) Mini DisplayPort

(4) RJ-45 Ethernet

(5) RS-232

(6) RS-485/422

(7) SD Karte

(8) C-Modul

Abbildung C.2.: Anschlussmöglichkeiten des NI CompactRIO-Controllers 9035

Controller wird durch National Instruments mit hoher Funktionsvielfalt aus insgesamt acht Bereichen beworben und wird im Folgenden vorgestellt [Nat16c]:

Integrierte Software Das CompactRIO ist mit einem durch NI validierten Echtzeitbetriebssystem ausgestattet. Über die Software LabVIEW werden sämtliche Funktionalitäten rekonfigurierbar aus Bibliotheken zusammengestellt [Nat16c]. Um den Funktionsumfang zu erhöhen, lässt sich LabVIEW durch anwendungsspezifische Softwaremodule erweitern [SS07, S. 26-30].

Motorsteuerung Elektromotorische Antriebe werden in mechatronischen Systemen unter anderem zur Erzeugung von Bewegungen verwendet [Rod12, S. 200]. Moderne Antriebssysteme kommunizieren mit dem cRIO-Controller digital über eine Feldbusschnittstelle [Pro11, S. 1-9] [Bos15c].

Industrielle Kommunikation „Kommunikation ist der Austausch von Informationen nach bestimmten Regeln [MBW10, S. 1]." Damit Sender und Empfänger miteinander kommunizieren können, sind genormte Kommunikationsregeln [ISO IEC 7498-1] einzuhalten, die in einem Protokoll definiert sind. Das cRIO unterstützt annähernd 20 industrielle Kommunikationsprotokolle und kann damit flexibel zur Einbindung von Sensoren und Aktoren eingesetzt werden [Nat16b] [Nat16a].

Analog \& Digital Inputs/Outputs Zur Verarbeitung von analogen und digitalen Signalen bietet NI mehr als 150 I/O Module an [Nat16e]. Die sogenannten C-Module werden in den Controllerkörper (vgl. (8) Abbildung C.2) eingesteckt [Nat15c, S. 6]. Die nachgerüsteten Kanäle werden in LabVIEW angezeigt und können dort softwaretechnisch in den Prozess eingebunden werden. Sollte die Anzahl der Steckplätze 
des Controllers nicht ausreichen, können cRIO-Erweiterungschassis als EtherCAT-Slaves eingebunden werden [Nat16d].

Anzeigen und Datendarstellung Über eine Benutzeroberfläche, häufig als „User Interface“ (UI) oder „Human Machine Interface“ (HMI) bezeichnet, kann der Nutzer vor dem Prozessstart die Jobdaten laden und Verarbeitungsparameter anpassen. Im laufenden Fertigungsprozess werden über die Anzeige Statusdaten ausgegeben. Die Benutzeroberfläche von LabVIEW wird als „Frontpanel“ bezeichnet. An den CompactRIO-Controller 9035 können Touchpanels direkt angeschlossen werden. Inhalte aus dem Frontpanel können über das Touchpanel angezeigt und bedient werden [Nat15a].

Protokollierung und Überwachung Um Beschädigungen an Bauteilen vorzubeugen, werden Temperatursensoren in spezifischen Bereichen der Maschine installiert. Sofern die überwachenden Sensoren eine Überschreitung einer voreingestellten Grenztemperatur messen, wird die Maschine zur Überprüfung abgeschaltet. Eine Speicherung der Zustandsmesswerte ist wahlweise auf einer SD-Speicherkarte (vgl. (7) Abbildung C.2) im cRIO oder einem Host-Computer möglich [Nat16f].

Verarbeitung und Analyse Durch eine ausführliche Messwertanalyse sollen, nach direkter oder indirekter Messung einer Messgröße, robuste Prozessparameter des additiven Fertigungsprozesses identifiziert werden [DIN 1319-3] [DIN 1319-4] [PK11, S. 3]. Zur Messdatenanalyse kann die NI Software DIAdem verwendet werden [Nat16h] [Par16, S. 237-265] [Nat11].

Industrielle Bildverarbeitung Der Anschluss von Bildverarbeitungssystemen an das cRIO ist nativ möglich [Nat16g]. Durch die Integration eines „Off-Axis" angeordneten IR-Kamerasystems lassen sich im Rahmen einer robusten Prozessentwicklung Temperatur-Zeit-Verläufe auf der Pulverbettoberfläche messen [WW15, S. 79-90].

\section{C.3. Verkabelungskonzept zwischen Maschine und Schaltschrank}

Gemäß dem definierten Verkabelungskonzept werden auf der Seite der elektrischen Energiequelle ausschließlich Buchsen (weiblicher Teil: Kontaktöffnungen weisen nach innen) verbaut. Auf Verbraucherseite werden dementsprechend Stecker (männlicher Teil: Kontaktstifte weisen nach außen) verwendet. Die Gerätebuchse im Schaltschrank und der Gerätestecker an der Lasersintermaschine sind durch ein Verlängerungskabel miteinander verbunden. Die Gerätebuchsen sind an Teilfrontplatten (Zugentlastung zwischen NI C-Modul und Verlängerungskabel) befestigt und an die jeweilige Baugruppenträgerfront geschraubt. Die Fertigung der Teilfrontplatten kann mit der Software „Frontplattendesigner" der Firma Schaeffer geplant und in Auftrag gegeben werden. Zur Abdeckung von elektrischen Verbindungen im Bereich der Lasersintermaschine werden entweder Kunststoffgehäuse der Firma Phoenix Contact (Serie UCS) oder Aluminiumgehäuse (Typ 70009) der Firma Hammond verwendet. Die Verbindungskabel werden in die Gerätestecker an den Gehäuseunterseiten eingesteckt. Über die Oberseite der Gehäuse werden 
Kabel und Litzen durch Kabelverschraubungen eingeführt. Sämtliche Bohrungen für Kabelverschraubungen oder Gerätestecker/Gerätebuchsen werden mit Hilfe eines Stufenbohrers an einer Standbohrmaschine eingebracht. Die beschrifteten Gehäuse sind mittels M5 Schrauben an der Maschine befestigt. Die Abbildung C.3 zeigt drei verschiedene Typen von Kabelbuchsen in den Farben gelb (Neutrik), blau (Weipu) und grün (Phoenix Contact). Zum Aufbau der elektrischen Verbindungen werden konfektionierte (bevorzugt)

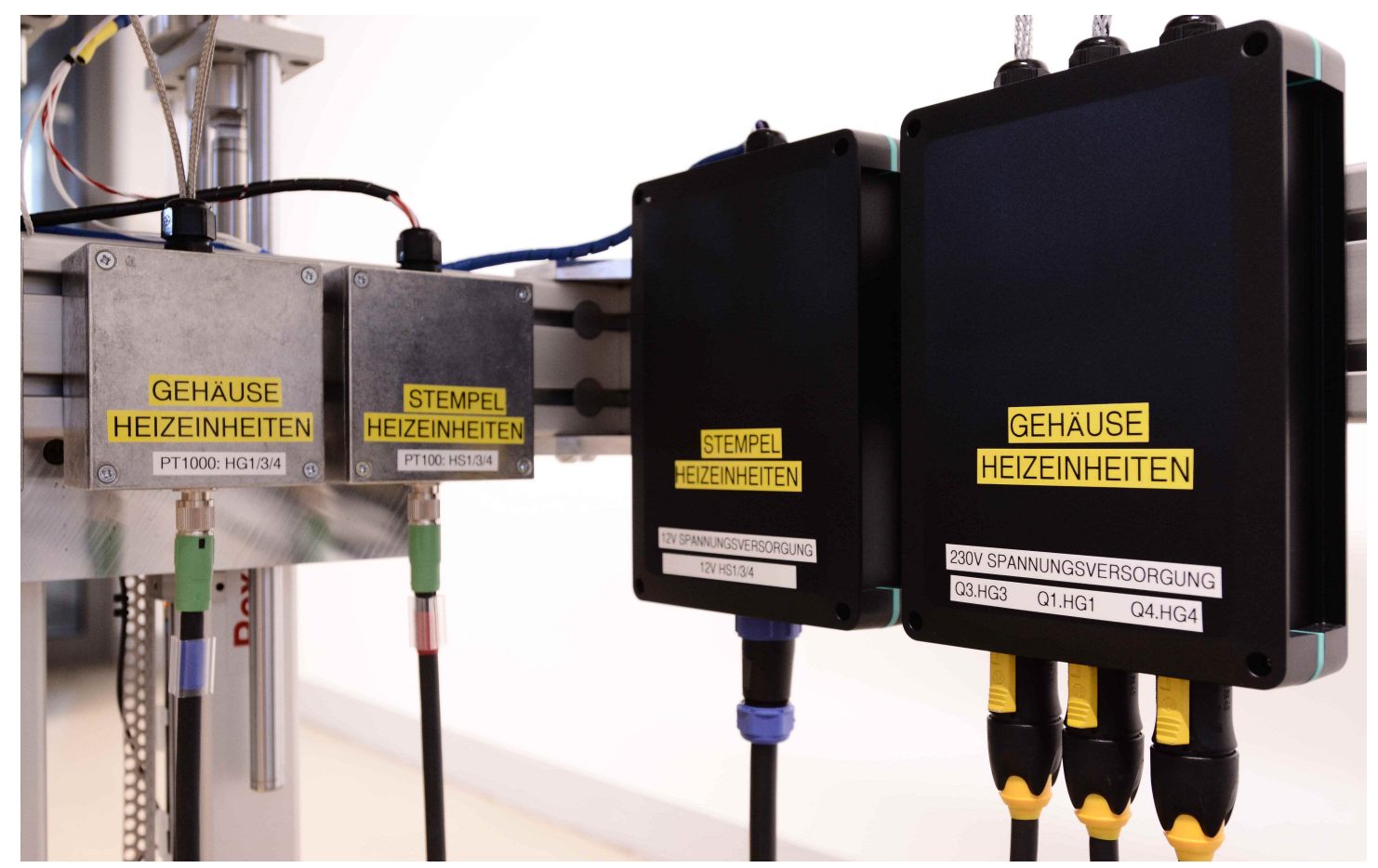

Abbildung C.3.: Gehäuse zur Abdeckung der elektrischen Verbindungen

oder unkonfektionierte Bauteilkombinationen verwendet. Die konfektionierte Verbindung von Sensoren/Aktoren wird entweder mittels Sensor-Aktor-Kabel-Kombinationen für geringe Ströme der Firma Phoenix Contact oder durch eine Stromkabel-Kombination für hohe Ströme der Firma Neutrik aus den folgenden Bauteilen hergestellt:

\section{7-polige Sensor-Aktor-Kabel-Kombination (geschirmt) von Phoenix Contact}

- 17-polige Gerätebuchse: SACC-E-FS-17CON-M16/0,5 SCO

- Flachmutter mit M16 Gewinde (2x): SACC-E-MU-M16

- 17-poliges Verlängerungskabel: SAC-17P-MS/5,0-35T/FS SH SCO

- 17-poliger Gerätestecker: SACC-E-MS-17CON-M16/0,5 SCO

8-polige Sensor-Aktor-Kabel-Kombination (geschirmt) von Phoenix Contact

- 8-polige Gerätebuchse: SACC-E-M12FS-8CON-PG9/0,5 
- Flachmutter mit PG9 Gewinde (2x): SACC-E-MU-PG9

- 8-poliges Verlängerungskabel: SAC-8P-M12MS/5,0-28X/M12FSSHOD

- 8-poliger Gerätestecker: SACC-E-M12MS-8CON-PG9/0,5

4-polige Sensor-Aktor-Kabel-Kombination (ungeschirmt) von Phoenix Contact

- 4-polige Gerätebuchse: SACC-E-M12FS-4CON-PG9/0,5

- Flachmutter mit PG9 Gewinde (2x): SACC-E-MU-PG9

- 4-poliges Verlängerungskabel: SAC-4P-M12MS/5,0-28X/M12FS OD

- 4-poliger Gerätestecker: SACC-E-M12MS-4CON-PG9/0,5

3-polige Stromkabel-Kombination (bis max. 16 A) von Neutrik und Adam Hall

- 3-polige Neutrik powerCON Gerätebuchse: NAC3FPX-ST (unkonfektioniert)

- 3-poliges Adam Hall Verlängerungskabel: PowerCON TRUE1 8101 TCONL 0500

- 3-poliger Neutrik powerCON Gerätestecker: NAC3MPX (unkonfektioniert)

3-polige Netzanschluss-Kombination (bis max. 16 A) von Neutrik und Cordial

- 3-poliger Neutrik powerCON Gerätestecker: NAC3MPX (unkonfektioniert)

- 3-polige Cordial powerCON Netzleitung: CFCA 3 S-TRUE1

Alle Litzen der Phoenix Contact Gerätestecker/Gerätebuchsen sind farblich gekennzeichnet, im Bereich der Verschraubung vergossen und haben eine Länge von 0,5 m. Verbaut werden ausschließlich A-kodierte Kabel, die in der Regel geschirmt sind. Der Leiterquerschnitt der 4-poligen $\left(4 \mathrm{x} 0,5 \mathrm{~mm}^{2}\right)$, 8-poligen $\left(8 \mathrm{x} 0,25 \mathrm{~mm}^{2}\right)$ oder 17 -poligen $\left(17 \mathrm{x} 0,14 \mathrm{~mm}^{2}\right)$ Verlängerungskabel nimmt mit steigender Anzahl an Signalleitungen ab. Die Litzen der Neutrik-Verbindungen haben allesamt einen Leiterquerschnitt von $1,5 \mathrm{~mm}^{2}$. Die Verlängerungskabel sind farblich gekennzeichnet. Durch die verwendete Standardisierung der elektrischen Verbindungselemente ist ein Vertauschen bei gleicher Polzahl möglich. Zu Projektbeginn wurden unkonfektionierte Buchsen und Stecker der Firma Weipu (für niedrige Ströme die Serie „SP13“ bzw. für hohe Ströme die größere Serie „SP21“) verwendet. Verbaute Kombinationen lauten wie folgt:

6/7-polige SP 13 Stecker-Buchsen-Kombination (unkonfektioniert) von Weipu

- 7-polige Gerätebuchse: SP1312 / S7

- 7-poliger Kabelstecker: SP1310 / P7 II

- 6-polige Kabelbuchse: SP1310 / S6 II

- 6-poliger Gerätestecker: SP1312 / P6

3-polige SP 13 Stecker-Buchsen-Kombination (unkonfektioniert) von Weipu

- 3-polige Gerätebuchse: SP1312 / S3 
- 3-poliger Kabelstecker: SP1310 / P3 I

7-polige SP 21 Stecker-Buchsen-Kombination (unkonfektioniert) von Weipu

- 7-polige Gerätebuchse: SP2112 / S7

- 7-poliger Kabelstecker: SP2110 / P7 II

- 7-polige Kabelbuchse: SP2110 / S7 II

- 7-poliger Gerätestecker: SP2112 / P7

3-polige SP 21 Stecker-Buchsen-Kombination (unkonfektioniert) von Weipu

- 3-polige Gerätebuchse: SP2112 / S3

- 3-poliger Kabelstecker: SP2110 / P3 I

Die Weipu-Kombinationen sind von Hand gelötet. Im Fall eines Defekts ist zu einem Neuaufbau mit konfektionierten Bauteilen der Firma Phoenix Contact angeraten.

\section{C.4. Baugruppenträger des NI cRIO-Controllers 9035}

Die Abbildung C.4 stellt den Baugruppenträger des CompactRIO-Controllers 9035 mit einer Gesamthöhe von $6 \mathrm{U}$ dar. Zwischen den hinteren Modulschienen ist ein stabiles Aluminiumblech zur Aufnahme von nach DIN EN 60715 [DIN EN 60715, S. 5] genormten Hutschienen der Größe TH35 geschraubt. Das cRIO ist mittels passendem Montagesatz auf der Hutschiene montiert. Auf der zur Schaltschrankrückseite gewandten Hutschiene ist ein National Instruments PS-17 Gleichspannungsnetzteil (Spannung 24 V / Stromstärke max. 20 A) zur Stromversorgung von Controller und weiterer Peripherie montiert. Der Netzteilanschluss an das $230 \mathrm{~V}$ Niederspannungsnetz erfolgt über ein festes Anschlusskabel mit CEE 7/4 Schutzkontaktstecker, der in die fest installierte CEE 7/3 Mehrfachsteckdosenleiste des Schaltschranks eingesteckt wird. Das Anschlusskabel ist mit Kabelbindern an einer lasergesinterten Zugentlastung befestigt. Zur Entlastung der Federklemmenanschlüsse am Netzteil wird die maximale Ausgangsleistung von $480 \mathrm{~W}$ auf fest gebrückte Durchgangsklemmen mit Schraubanschluss (Phoenix Contact / Artikelnummer UT 2,5) geführt. Zur Stromversorgung des Baugruppenträgers sind 20 Schraubanschlüsse (Pluspol rot / Masse schwarz) vorgesehen. In den Controllerkörper sind die folgenden NI C-Module eingesteckt:

- NI-9411: 6 Ch Digital Input / \pm 5 V - 24 V / Differential/Single-Ended / $500 \mathrm{~ns}$

- NI-9201: 8 Ch Analog Input / $\pm 10 \mathrm{~V} / 12 \mathrm{Bit} / 500 \mathrm{kS} / \mathrm{s}$

- NI-9474: 8 Ch Digital Output / 5 V - 30 V / Sourcing / $1 \mu \mathrm{s}$

- NI-9503 (nicht dargestellt): 1 Ch PWM Stepper Motor Drive / 9 V - 30 V / 3 A

Auf der Baugruppenträgervorderseite sind beschriftete Teilfrontplatten angebracht. Die Anschlussmöglichkeiten samt verwendeter C-Module werden im Folgenden dargestellt. 


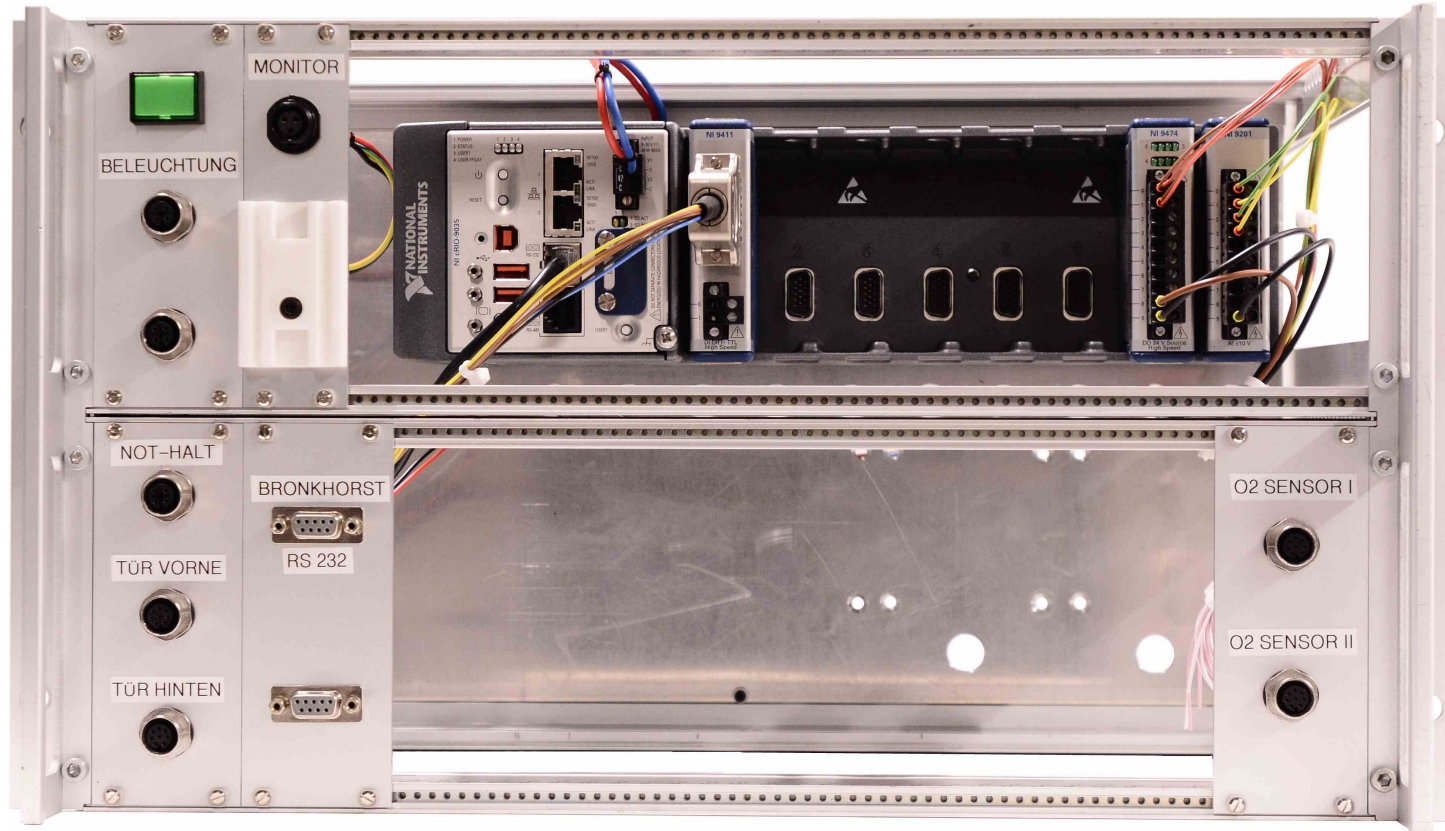

(a) Vorderansicht

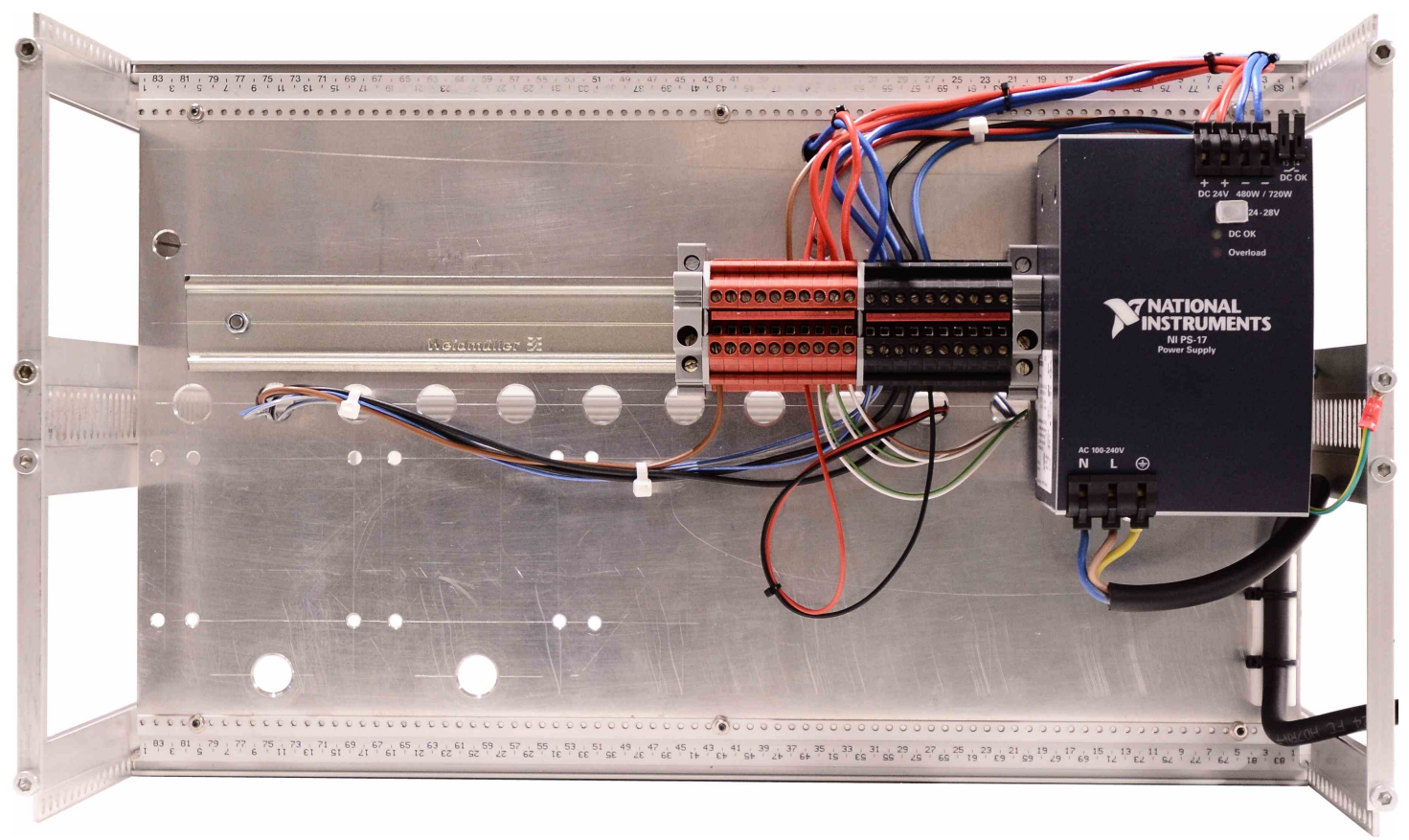

(b) Rückansicht

Abbildung C.4.: Baugruppenträger des NI cRIO-Controllers 9035 
BELEUCHTUNG Wird der grüne Druckschalter auf der Teilfrontplatte mit der Aufschrift „BELEUCHTUNG“ auf Höhe des CompactRIOs betätigt, liegt eine 24 V Spannung an der oberen 4-poligen Gerätebuchse (Pluspol braun+schwarz / Masse blau+weiß) an und die LED in dem Druckschalter beginnt zu leuchten. Die Spannung wird an den Durchgangsklemmen auf der Rückseite des Baugruppenträgers abgegriffen. An die Gerätebuchse wird die LED-Beleuchtung der Prozesskammer angeschlossen. Die untere 4-polige Gerätebuchse ist nicht beschriftet und derzeit nicht verkabelt.

MONITOR Die Teilfrontplatte mit der Aufschrift „MONITOR“ auf Höhe des CompactRIOs dient dem Anschluss des in Abbildung C.5 dargestellten 17" TouchscreenMonitors. Über die 3-polige Gerätebuchse (Weipu) wird der Monitor mit Strom versorgt. Die $24 \mathrm{~V}$ Versorgungsspannung wird an den Durchgangsklemmen auf der Rückseite des Baugruppenträgers abgegriffen. Die lasergesinterte Zugentlastung auf der Teilfrontplatte dient der Aufnahme von USB-Kabel und Mini DisplayPort-Kabel. Der Monitor ist auf einer Aluminiumplatte montiert. Unterhalb des Monitors ist

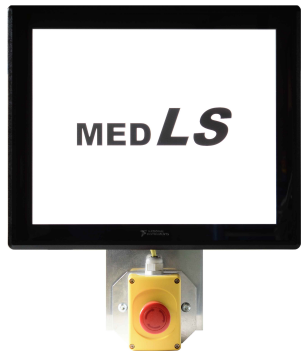

(a) Vorderansicht

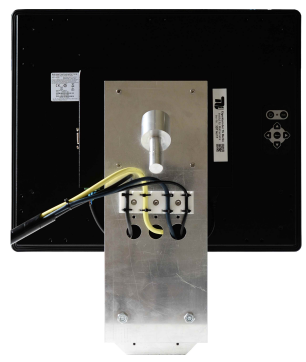

(b) Rückansicht

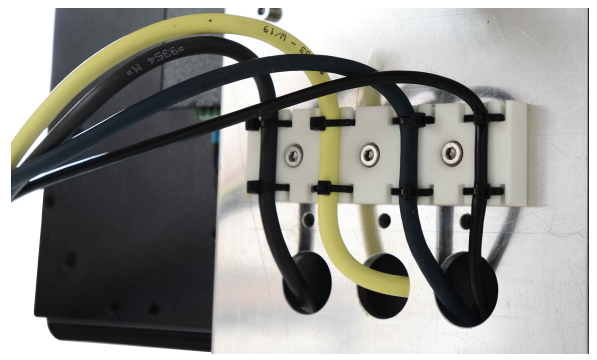

(c) Zugentlastungen

Abbildung C.5.: Touchscreen-Monitor mit Not-Halt-Pilztaster-Einheit

eine feste Not-Halt-Pilztaster-Einheit (vgl. [DIN EN ISO 13850]) angebracht. Das USB-Kabel und Mini DisplayPort-Kabel werden an das Anschlussfeld des CompactRIOs angeschlossen. Zur Verwendung der festen Not-Halt-Pilztaster-Einheit muss das Anschlusskabel in die 4-polige Gerätebuchse auf der Teilfrontplatte mit der Aufschrift „Not-Halt" eingesteckt werden.

NOT-HALT / TÜR VORNE / TÜR HINTEN Die Teilfrontplatte mit der Aufschrift „NOT-HALT / TÜR VORNE / TÜR HINTEN" dient dem Anschluss der in Abbildung C.6 dargestellten Sicherheits-Schaltscharniere und einer Not-Halt-Pilztaster-Einheit. Eine Not-Halt-Pilztaster-Einheit besitzt zwei Öffnerkontakte zur redundanten Absicherung (vgl. [DIN EN ISO 13849-1]) der Sicherheitsfunktion. Je nach Bedarf kann entweder die portable (vgl. (a) Abbildung C.6) oder die feste (vgl. (a) Abbildung C.5) Not-Halt-Pilztaster-Einheit verwendet werden. Das Anschlusskabel der Not-Halt-Pilztaster-Einheit wird in die 4-polige Gerätebuchse mit der Beschriftung „Not-Halt" eingesteckt. Die Sicherheits-Schaltscharniere sind in den Türbaugruppen des Prozessgasgehäuses verbaut und überwachen dort den Türöffnungswinkel. In den Scharnieren sind zwei Öffnerkontakte und zwei Schließerkontakte zur redundanten Absicherung der Sicherheitsfunktion integriert. Die 
Schaltscharniere und die 8-poligen Gerätebuchsen mit den Beschriftungen „Tür vorne" und „Tür hinten“ werden mittels 8-poligem Verlängerungskabel miteinander verbunden. Zur Funktionsintegration in das LabVIEW-Steuerprogramm ist das C-Modul NI-9411 in den 1. Steckplatz des Controllerkörpers eingesteckt. Der $24 \mathrm{~V}$ Spannungspegel wird an den Durchgangsklemmen auf der Rückseite

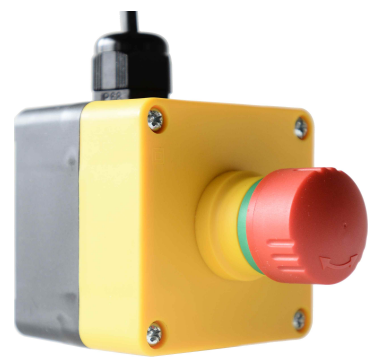

(a) Not-Halt

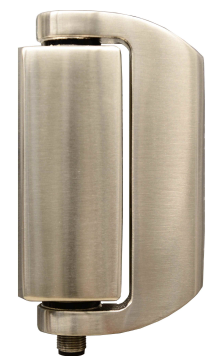

(b) Schaltscharnier

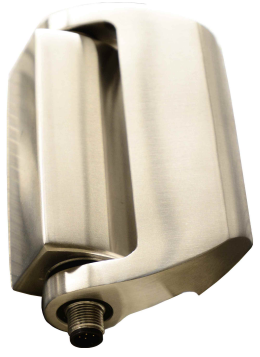

(c) Anschluss

Abbildung C.6.: Sicherheits-Schaltscharnier und Not-Halt-Pilztaster-Einheit

des Baugruppenträgers abgegriffen. Die insgesamt sechs Öffnerkontakte der zwei Schaltscharniere und einer Not-Halt-Pilztaster-Einheit sind an die sechs Kanäle des C-Moduls angeschlossen. Die Schließerkontakte der Schaltscharniere sind derzeit nicht integriert.

BRONKHORST Die Teilfrontplatte mit der Aufschrift „BRONKHORST“ dient dem Anschluss des in Abbildung C.7 dargestellten Massendurchflussreglers „EL-FLOW Prestige" zur Prozessgasversorgung. Der Bronkhorst Regler ist an der Laseretage der Maschine befestigt. Der Massendurchflussregler und die 9-polige Sub-D-Geräte-

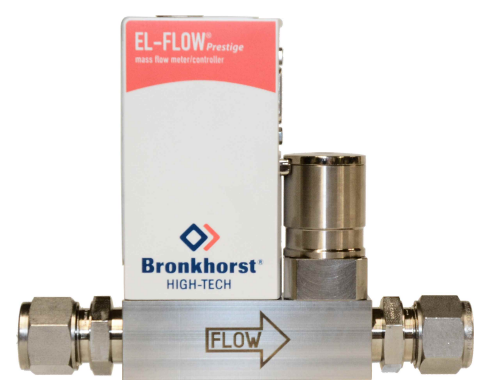

(a) Vorderansicht

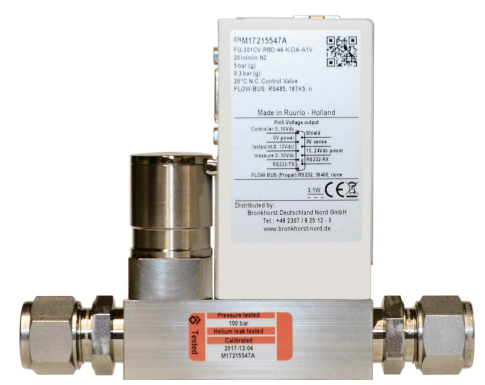

(b) Rückansicht

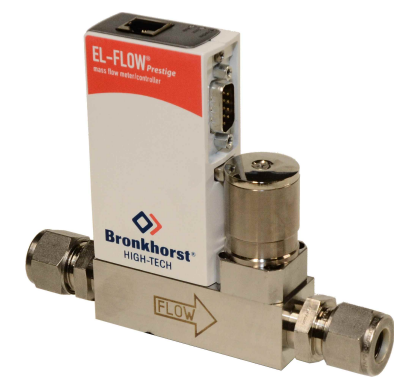

(c) Anschlüsse

Abbildung C.7.: Bronkhorst Massendurchflussregler EL-FLOW Prestige

buchse an der Teilfrontplatte werden mittels geschirmten Sub-D-Verlängerungskabel (RM Computertechnik GmbH / Artikelnummer 17995 / 9x 0,25 mm² / Belegung 1:1 / Kabellänge $7 \mathrm{~m}$ ) miteinander verbunden. An die Sub-D-Gerätebuchse sind zwei Litzen zur 24 V Spannungsversorgung und ein RJ-45 Patchkabel zur Datenübertragung angelötet. Die Versorgungsspannung wird an den Durchgangsklemmen 
auf der Rückseite des Baugruppenträgers abgegriffen. Das Patchkabel ist in die RS-232 Buchse am Anschlussfeld des CompactRIOs eingesteckt. Das Ventil ist in unbestromten Zustand geschlossen. Die untere Sub-D-Gerätebuchse (nicht beschriftet) ist derzeit nicht verkabelt. Ein validiertes Sub-VI zur Implementierung in das LabVIEW-Steuerprogramm war Teil des Lieferumfangs.

$\mathbf{O}_{2}$ SENSOR I / $\mathbf{O}_{2}$ SENSOR II Die Teilfrontplatte mit der Aufschrift „ $\mathrm{O}_{2}$ SENSOR I $/ \mathrm{O}_{2}$ SENSOR II“ dient dem Anschluss von zwei Sauerstoff-Messsystemen. Zwischen dem Zirkoniumdioxid-Sensor (vgl. (b) Abbildung C.8) und der 8-poligen Gerätebuchse auf der Teilfrontplatte ist eine Platine (vgl. (c) Abbildung C.8) zur Steuerung und Auswertung der Sauerstoffmessung geschaltet, die in einem Aluminiumgehäuse an die Maschine geschraubt ist. Zur Funktionsintegration in das LabVIEW-Steuerprogramm ist das C-Modul NI-9201 (Auswertung Sensorsignal) in den 8. Steckplatz und das C-Modul NI-9474 (Spannungsversorgung Messsystem) in den 7. Steckplatz des Controllerkörpers eingesetzt. Die Steuerplatine

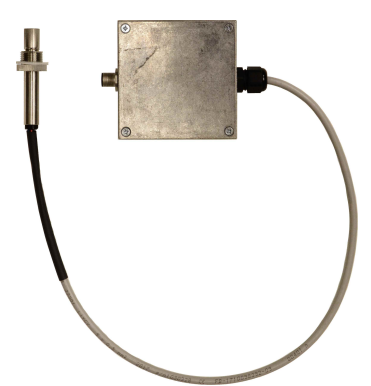

(a) Gesamtansicht

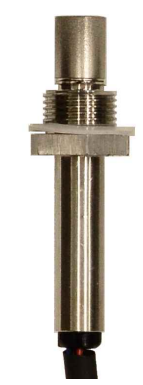

(b) XYA5M-Sensor

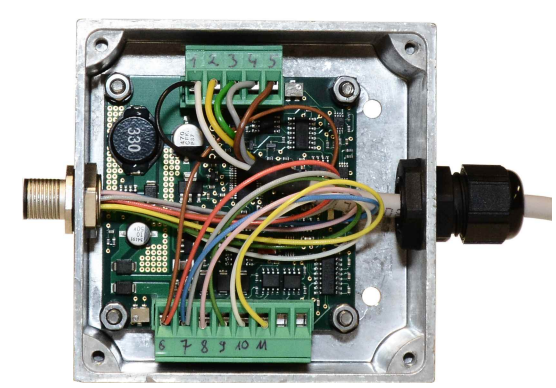

(c) ZBXYAF-Platine

Abbildung C.8.: First Sensor Sauerstoffsensor XYA mit Steuerplatine

und die 8-polige Gerätebuchse an der Teilfrontplatte werden mittels 8-poligem Verlängerungskabel miteinander verbunden. Erhält das C-Modul NI-9474 ein entsprechendes Steuersignal, liegt die $24 \mathrm{~V}$ Versorgungsspannung an der steckbaren Reihenklemme der Platine (Pin 6 (Pluspol) braun+rot / Pin 7 (Masse) grau+blau) an und das Heizelement im Sensor wird mit Strom versorgt. Hat das Heizelement seine Betriebstemperatur erreicht, liegt ein digitales 3,3 V Signal (Betriebszustand) auf Pin 11 (Cycle / gelbe Litze) und ein analoges $0 \mathrm{~V}$ bis $10 \mathrm{~V}$ Gleichspannungssignal (Sauerstoffkonzentration) auf Pin 9 (grüne Litze) an. Die Spannungssignale (Betriebszustand / Sauerstoffkonzentration) werden von dem C-Modul NI-9201 interpretiert. Der Sensor misst eine Sauerstoffkonzentration von $0,1 \%$ vol $(0,04 \mathrm{~V})$ bis $25 \%$ vol $(10 \mathrm{~V})$ und ist nach einer Aufheizzeit von $10 \mathrm{~min}$ betriebsbereit.

ROLLE Die Teilfrontplatte mit der Aufschrift „ROLLE“ (nicht dargestellt) dient dem Anschluss der Beschichtereinheit mit rotierender Rolle. Zur Funktionsintegration des Steppers in das LabVIEW-Steuerprogramm ist das C-Modul NI-9503 in den 6. Steckplatz des Controllerkörpers eingesteckt. 


\section{C.5. Baugruppenträger des NI cRIO-Erweiterungschassis 9144}

Die Abbildung C.9 stellt den Baugruppenträger des CompactRIO-Erweiterungschassis 9144 mit einer Gesamthöhe von 6U dar. Zwischen den hinteren Modulschienen ist ein stabiles Aluminiumblech zur Aufnahme von Hutschienen der Größe TH35 geschraubt. Das Erweiterungschassis ist mittels passendem Montagesatz auf der Hutschiene montiert. An den Baugruppenträger wird die 6-Kanal-Heizanlage der Maschine angeschlossen. Auf der zur Schaltschrankrückseite gewandten Hutschiene sind zwei Gleichspannungsnetzteile montiert. Das schwarze 24 V Netzteil (Siemens SITOP PSU100L / Stromstärke max. 5 A) dient der Stromversorgung des Chassis und weiterer Peripherien. Der Netzteilanschluss an das $230 \mathrm{~V}$ Niederspannungsnetz erfolgt über ein festes Anschlusskabel mit CEE 7/4 Schutzkontaktstecker, der in die fest installierte CEE 7/3 Mehrfachsteckdosenleiste des Schaltschranks eingesteckt wird. Das Anschlusskabel ist mit Kabelbindern an einer lasergesinterten Zugentlastung befestigt. Zur Entlastung der Federklemmenanschlüsse am Netzteil wird die maximale Ausgangsleistung von $120 \mathrm{~W}$ auf fest gebrückte Durchgangsklemmen mit Schraubanschluss (Phoenix Contact / Artikelnummer UT 2,5) in den Farben rot (24 V Pluspol) und schwarz (24 V Masse) geführt. Das hellblaue 12 V Netzteil (Siemens SITOP PSU100S / Stromstärke max. 14 A) dient der Stromversorgung der Silikonheizmatten in den Stempelbaugruppen. Zur Entlastung der Federklemmenanschlüsse am Netzteil wird die maximale Ausgangsleistung von $168 \mathrm{~W}$ auf fest gebrückte Durchgangsklemmen mit Schraubanschluss in den Farben orange (12 V Pluspol) und grau (12 V Masse) geführt. Der $230 \mathrm{~V}$ Netzteilanschluss ist an die gebrückten Durchgangsklemmen mit den Farben gelb/grün (Schutzleiter PE), blau (Neutralleiter N) und braun (Phase L) angeschlossen. Der Anschluss dieser Durchgangsklemmen an das 230 V Niederspannungsnetz erfolgt durch die 3-polige Netzanschluss-Kombination von Neutrik und Cordial. Der Neutrik Gerätestecker ist auf einem gebogenen Blech unten links (vgl. (b) Abbildung C.9) befestigt. Die Cordial powerCON Netzleitung wird aufgrund der hohen Leistung der Keramikheizbänder in eine gesonderte CEE $7 / 3$ Steckdose außerhalb des Schaltschranks eingesteckt. Die $230 \mathrm{~V}$ Keramikheizbänder werden durch die Halbleiterrelais (Crydom CKRD2420 / Nullspannungsschaltend / Schaltspannung bis $280 \mathrm{~V} \mathrm{AC} \mathrm{/} \mathrm{Schaltstrom} \mathrm{bis}$ $20 \mathrm{~A} /$ Steuerspannung bis $32 \mathrm{~V} \mathrm{DC}$ ) geschaltet, die oberhalb des powerCON Gerätesteckers auf die Aluminiumplatte geschraubt sind. Die $12 \mathrm{~V}$ Silikonheizmatten werden durch die Optokopplerrelais (Weidmüller TOS 24VDC/24VDC 4A / Schaltspannung bis 33 V DC / Schaltstrom bis 4 A / Steuerspannung 24 V DC) geschaltet, die zwischen den Durchgangsklemmen auf der Hutschiene angeordnet sind. In den Controllerkörper sind die folgenden NI C-Module eingesteckt:

- NI-9474: 8 Ch Digital Output / $5 \mathrm{~V}$ - 30 V / Sourcing / $1 \mu \mathrm{s}$

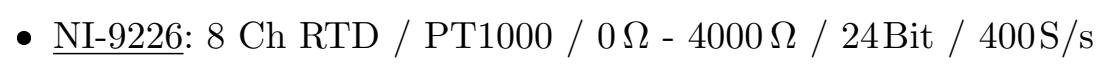

- NI-9216: 8 Ch RTD / PT100 / $0 \Omega-400 \Omega$ / 24Bit / 400S/s

- NI-9213: $16 \mathrm{Ch}$ TC / Thermoelement / $\pm 78 \mathrm{mV} / 24 \mathrm{Bit} / 75 \mathrm{~S} / \mathrm{s}$

Auf der Baugruppenträgervorderseite sind beschriftete Teilfrontplatten angebracht. Die Anschlussmöglichkeiten samt verwendeter C-Module werden im Folgenden dargestellt. 


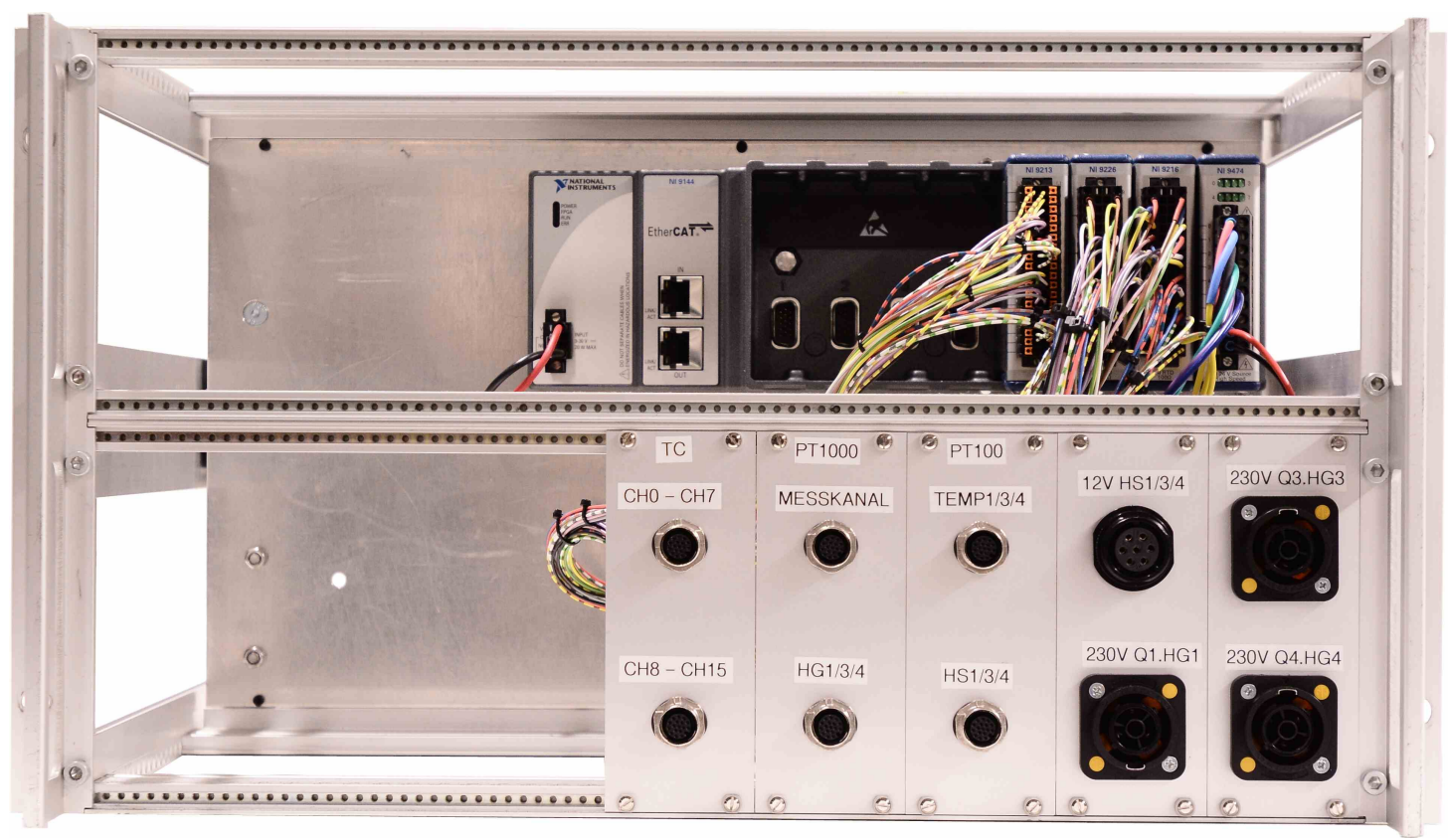

(a) Vorderansicht

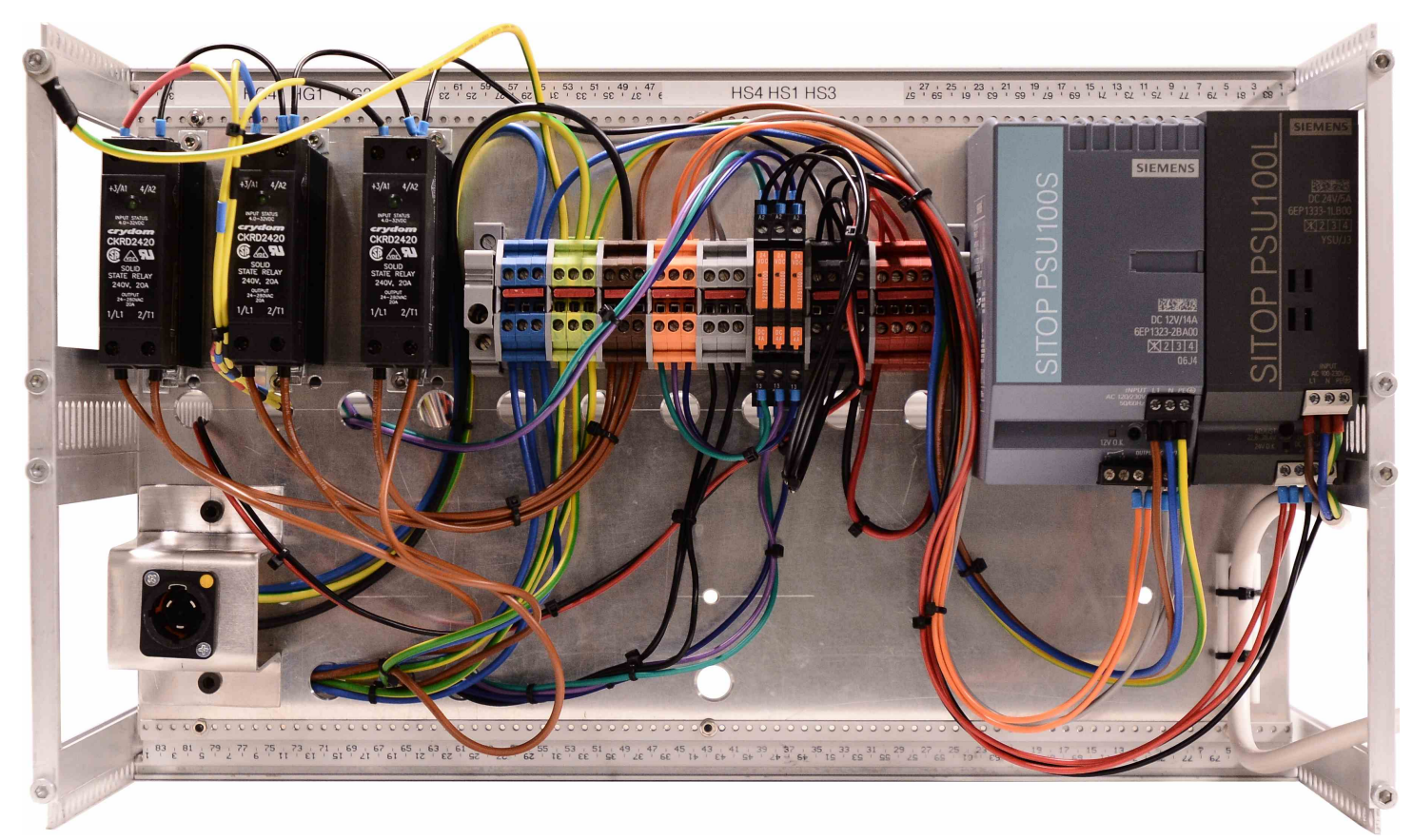

(b) Rückansicht

Abbildung C.9.: Baugruppenträger des NI cRIO-Erweiterungschassis 9144 
230V Q3.HG3 / 230V Q4.HG4 Die Teilfrontplatte mit der Aufschrift „230V Q3.HG3 / 230V Q4.HG4“ dient dem Anschluss von zwei Keramikheizbändern zur Beheizung der beiden Pulverzuführgehäuse. Die Bezeichnung „230V Q3.HG3“ weist auf die Beheizung des Gehäuses „HG3“ im Bereich der Hubantriebsbaugruppe der Pulverzuführung „Q3“ hin. Das Keramikheizband (vgl. Abbildung C.10) und die powerCON Gerätebuchse an der Teilfrontplatte wird mittels Adam Hall Verlängerungskabel miteinander verbunden. Zur Funktionsintegration in das LabVIEW-Steuerprogramm ist das C-Modul NI-9474 in den 8. Steckplatz des Controllerkörpers eingesteckt. Die $24 \mathrm{~V}$ Schaltspannung wird an den Durchgangsklemmen auf der Rückseite des Baugruppenträgers abgegriffen. Wird der jeweilige Kanal des C-Moduls aktiviert, liegt eine $24 \mathrm{~V}$ Steuerspannung (Steuerstromkreis) an dem Crydom Halbleiterrelais (vgl. (c) Abbildung C.10) an. Dieser Steuerimpuls schließt die Arbeitskontakte im

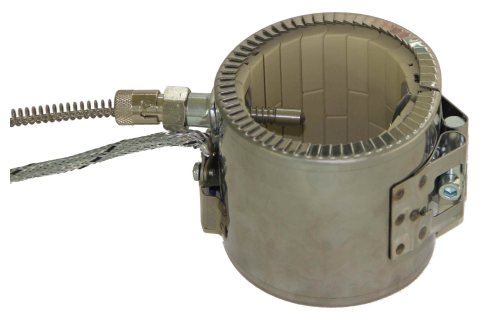

(a) Heizmanschette

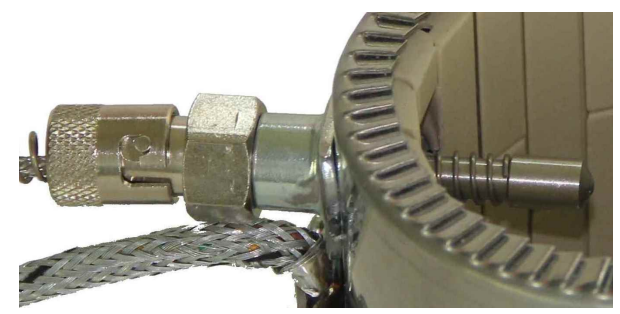

(b) PT1000-Bajonettfühler

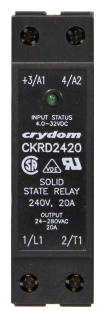

(c) Relais

Abbildung C.10.: Keramikheizband mit PT1000-Bajonettfühler

Halbleiterrelais, sodass die $230 \mathrm{~V}$ Netzspannung an dem jeweiligen Keramikheizband anliegt und der fließende Strom (Laststromkreis) in Wärme umgesetzt wird. Die gelben $1,5 \mathrm{~mm}^{2}$ Litzen zwischen Halbleiterrelais und dem C-Modul NI-9474 sind mit einem schwarzen (230V Q3.HG3), roten (230V Q4.HG4) oder blauen (230V Q1.HG1) Schrumpfschlauch zur Zuordnung markiert.

PT1000 / MESSKANAL / HG1/3/4 Die Teilfrontplatte mit der Aufschrift „PT1000 / MESSKANAL / HG1/3/4" dient dem Anschluss der PT1000-Bajonettfühler in den Keramikheizbändern zum Aufbau einer Temperaturregelung. Die Spitze des 4-Draht-Temperaturfühlers (Genauigkeitsklasse B) (vgl. (b) Abbildung C.10) wird federbelastet an die Mantelfläche der Baustempel- oder Pulverzuführgehäuse angepresst und misst die Wandtemperatur des Hohlzylinders. Zur Funktionsintegration in das LabVIEW-Steuerprogramm ist das C-Modul NI-9226 in den 6. Steckplatz des Controllerkörpers eingesteckt. Pro Kanal verfügt die Steckkarte über vier Federklemmenanschlüsse. Da für den Anschluss von vier 4-Draht-Temperaturfühlern 16 Litzen notwendig sind, werden pro C-Modul NI-9226 (8 Kanäle) zwei 17-polige Sensor-Aktor-Kabel-Kombinationen der Firma Phoenix Contact verwendet. Die Kanäle „HG1“, „HG2“ und „HG3“ werden zum Auslesen der PT1000-Bajonettfühler in den jeweiligen Keramikheizbändern verwendet. Die verbleibenden Kanäle an der Gerätebuchse mit der Aufschrift „MESSKANAL" sind derzeit nicht belegt.

12V HS1/3/4 / 230V Q1.HG1 Die Teilfrontplatte mit der Aufschrift „12V HS1/3/4 
/ 230V Q1.HG1" dient dem Anschluss der Stromversorgungen aller Silikonheizmatten in den Stempelbaugruppen und dem Keramikheizband (230V Q1.HG1) am Baustempelgehäuse. Die Silikonheizmatte, dargestellt in Abbildung C.11, wird auf die Unterseite des Stempeloberteils aufgeklebt und ist mit einem integrierten PT100-Temperaturfühler ausgestattet. Die Bezeichnung „12 V HS1“ weist auf die Beheizung des Stempels über der Hubantriebsbaugruppe „Q1“ hin. Die Heizmatten (7-poliger SP 21 Weipu Gerätestecker am Gehäuse) und die 7-polige Gerätebuchse an der Teilfrontplatte werden durch ein Verbindungskabel miteinander verbunden. Zur Funktionsintegration in das LabVIEW-Steuerprogramm ist das C-Modul NI9474 in den 8. Steckplatz des Controllerkörpers eingesteckt. Liefert der jeweilige

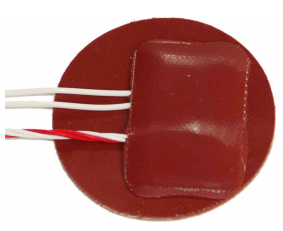

(a) Heizmatte

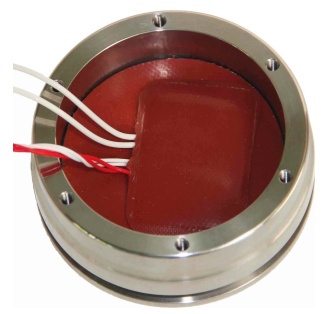

(b) Stempeloberteil

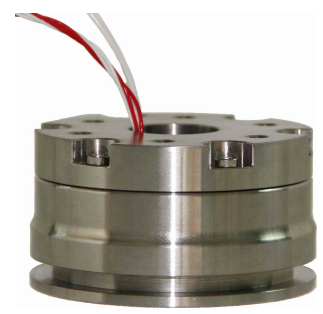

(c) Seitenansicht

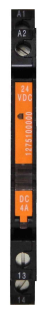

(d) Optokoppler

Abbildung C.11.: Silikonheizmatte mit PT100 in der Stempelbaugruppe

Kanal der Steckkarte einen Steuerimpuls an das Weidmüller Optokoppler (vgl. (d) Abbildung C.11) schließen die Arbeitskontakte des Optokopplers, sodass die $12 \mathrm{~V}$ Netzteilspannung an der Heizmatte anliegt. Die weißen $0,75 \mathrm{~mm}^{2}$ Litzen sind farblich in hellgrün (12V HS4), lila (12V HS1) oder blau (12V HS3) kodiert. Die Silikonheizmatten können bis zu einer Temperatur von $80^{\circ} \mathrm{C}$ aufgeheizt werden.

PT100 / TEMP1/3/4 / HS1/3/4 Die Teilfrontplatte mit der Aufschrift „PT100 / TEMP1/3/4 / HS1/3/4" dient dem Anschluss der PT100-Fühler in den Silikonheizmatten zum Aufbau einer Temperaturregelung und weiterer PT-100-Klebefühler zur Zustandsüberwachung der Maschine. Der 4-Draht-Temperaturfühler (Genauigkeitsklasse B) ist auf der Unterseite der Heizmatte integriert (vgl. (a) Abbildung C.11) und misst die Temperatur des vergossenen Heizdrahts innerhalb der Matte. Zur Funktionsintegration in das LabVIEW-Steuerprogramm ist das C-Modul NI9216 in den 7. Steckplatz des Controllerkörpers eingesteckt. Pro Kanal verfügt die Steckkarte über vier Federklemmenanschlüsse. Da für den Anschluss von vier 4-Draht-Temperaturfühlern 16 Litzen notwendig sind, werden pro C-Modul NI-9216 (8 Kanäle) zwei 17-polige Sensor-Aktor-Kabel-Kombinationen der Firma Phoenix Contact verwendet. Die Kanäle „HS1“, „HS3“ und „HS4“ werden zum Auslesen der PT100-Fühler in den Heizmatten verwendet. Die Kanäle „TEMP1“, „TEMP3“ und "TEMP4" werden zum Auslesen der 4-Draht-Fühler (Omega Engineering GmbH / SA2C-RTD-3-100-A-1M / Genauigkeitsklasse A / Temperatur bis $200{ }^{\circ} \mathrm{C}$ ) an den Abstandshanteln der Stempelbaugruppen genutzt.

TC / CH0-CH7 / CH8-CH15 Die Teilfrontplatte mit der Aufschrift „TC / CH0-CH7 
/ CH8-CH15" dient dem Anschluss von Thermoelementen zur Zustandsüberwachung der Maschine. Die Teilfrontplatte ist mit zwei 17-poligen Gerätebuchsen der Firma Phoenix Contact bestückt. Zur Funktionsintegration in das LabVIEW-Steuerprogramm ist das C-Modul NI-9213 in den 5. Steckplatz des Controllerkörpers eingesteckt. Die Kanäle sind derzeit nicht belegt.

\section{C.6. Baugruppenträger der Bosch Rexroth Antriebsregelgeräte}

Die Antriebsregelgeräte der vier Motoren von Baustempel-, Pulverzuführ- und Pulverauftragsmodul sind in einem Baugruppenträger der Höhe 6U verbaut. Jeder Motor besitzt einen eigenen Umrichter. Ein elektrischer Anschlussplan und sämtliche Anschlussstellen der Antriebsregelgeräte sind in der Rexroth IndraDrive Cs Projektionsbeschreibung dokumentiert [Bos15d, S. 124,127]. Die Benennung der Umrichter erfolgt, bezogen auf die Vorderansicht (vgl. (a) Abbildung C.12), von rechts nach links:

- Q1: Antriebsregelgerät für Motor aus dem Baustempelmodul

- Q2: Antriebsregelgerät für Motor aus dem Pulverauftragsmodul

- Q3: Antriebsregelgerät für Motor I aus dem Pulverzuführmodul

- Q4: Antriebsregelgerät für Motor II aus dem Pulverzuführmodul

Sämtliche Komponenten sind auf einer stabilen Aluminiumplatte verschraubt. Auf der Vorderseite des Baugruppenträgers (vgl. (a) Abbildung C.12) sind die folgende Komponenten angeordnet:

- 4x Rexroth Antriebsregelgeräte HCS01.1E-W0008-A-03-A-CC-EC-ET-S4-NN-FW

- 1x Rexroth Sicherheitszonenmodul HSZ01.1-D08-D04-NNNN

- 2x Eaton Doppeldrucktaster (Öffner / Schließer / LED) M22-DDL-GR-X1/X0

- 1x Eaton Nockenschalter T0-2-15679/E

- 10x Phoenix Contact Durchgangsklemmen (24V) UK 5 N

Auf der Rückseite des Baugruppenträgers (vgl. (a) Abbildung C.13) sind die folgende Komponenten angeordnet:

- 1x Harting Gerätestecker für Dreiphasenwechselstrom-Anschluss Han 6B

- 1x Siemens Netzteil 3AC 400 V / DC 24 V SITOP PSU8200

- 2x Rexroth Netzfilter NFD03.1-480-007

- 2x Siemens Hilfsschütz 3RH1140-1BB40

- 10x Phoenix Contact Durchgangsklemmen (24V) UK 5 N

Wird der Nockenschalter an der Baugruppenträgervorderseite betätigt, liegt eine $400 \mathrm{~V}$ Spannung am Siemens Netzteil an. Die $24 \mathrm{~V}$ Netzteilausgangsspannung wird auf die 


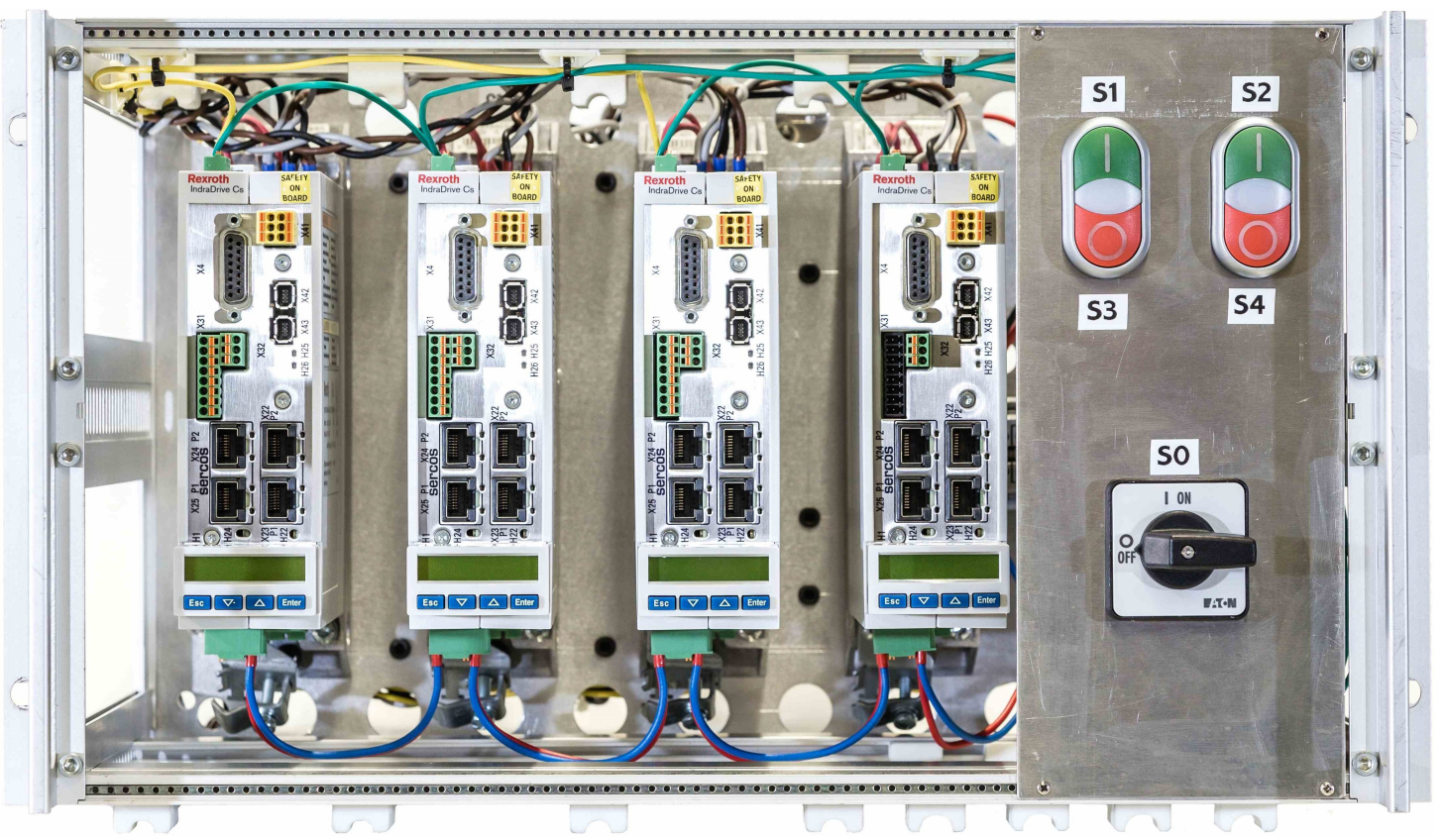

(a) Vorderansicht

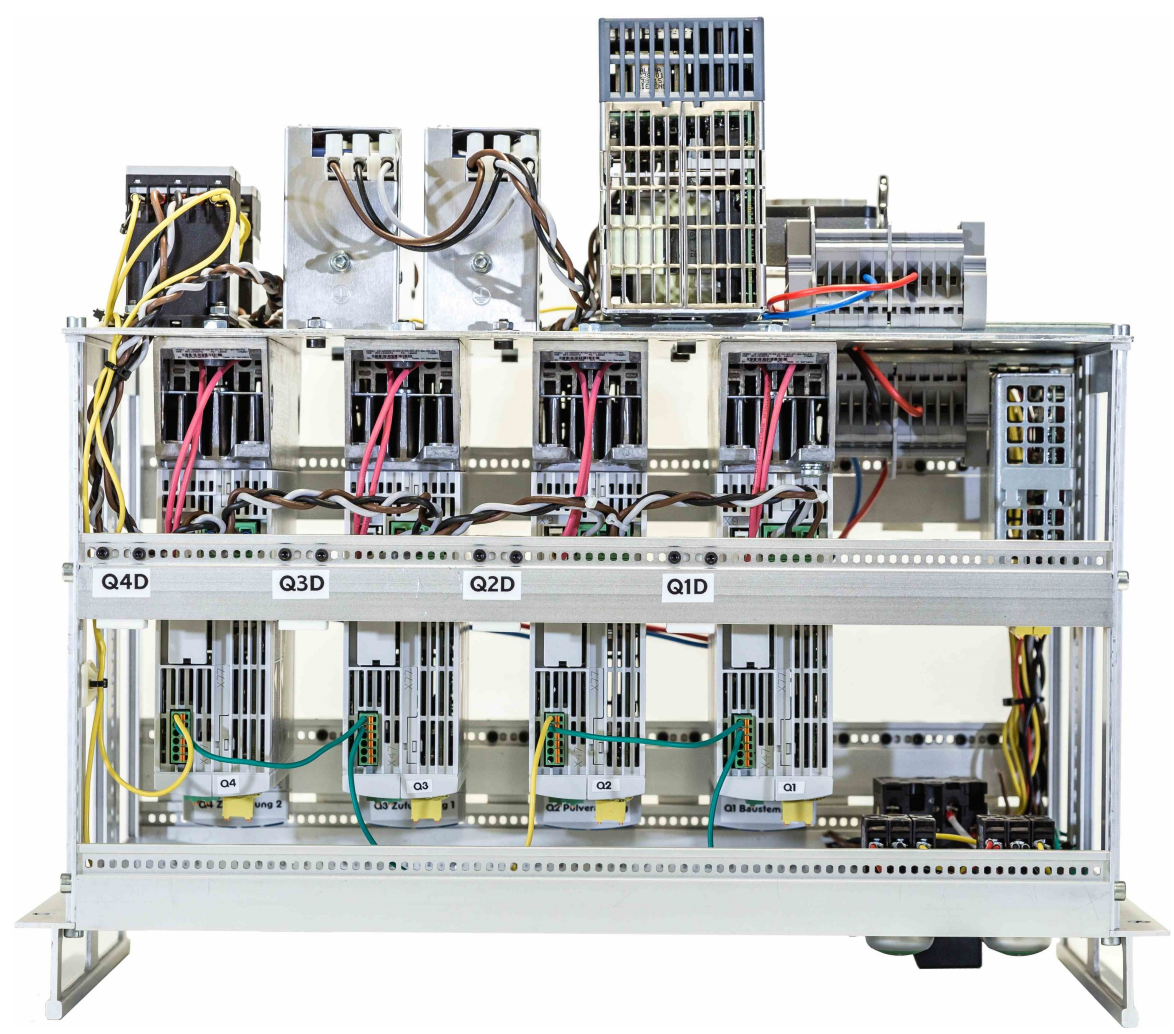

(b) Draufsicht

Abbildung C.12.: Baugruppenträger der Bosch Rexroth Antriebsregelgeräte 


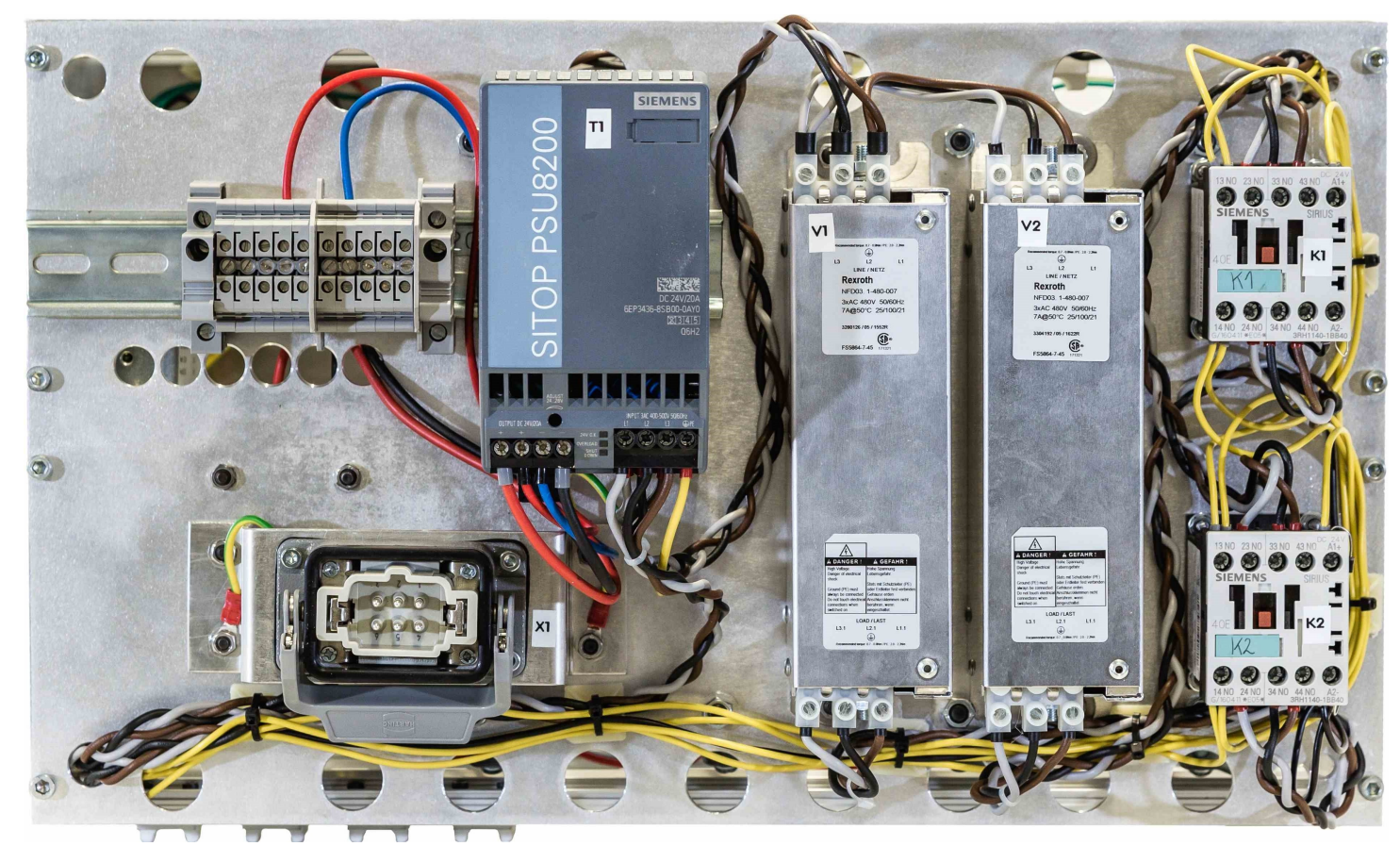

(a) Rückansicht

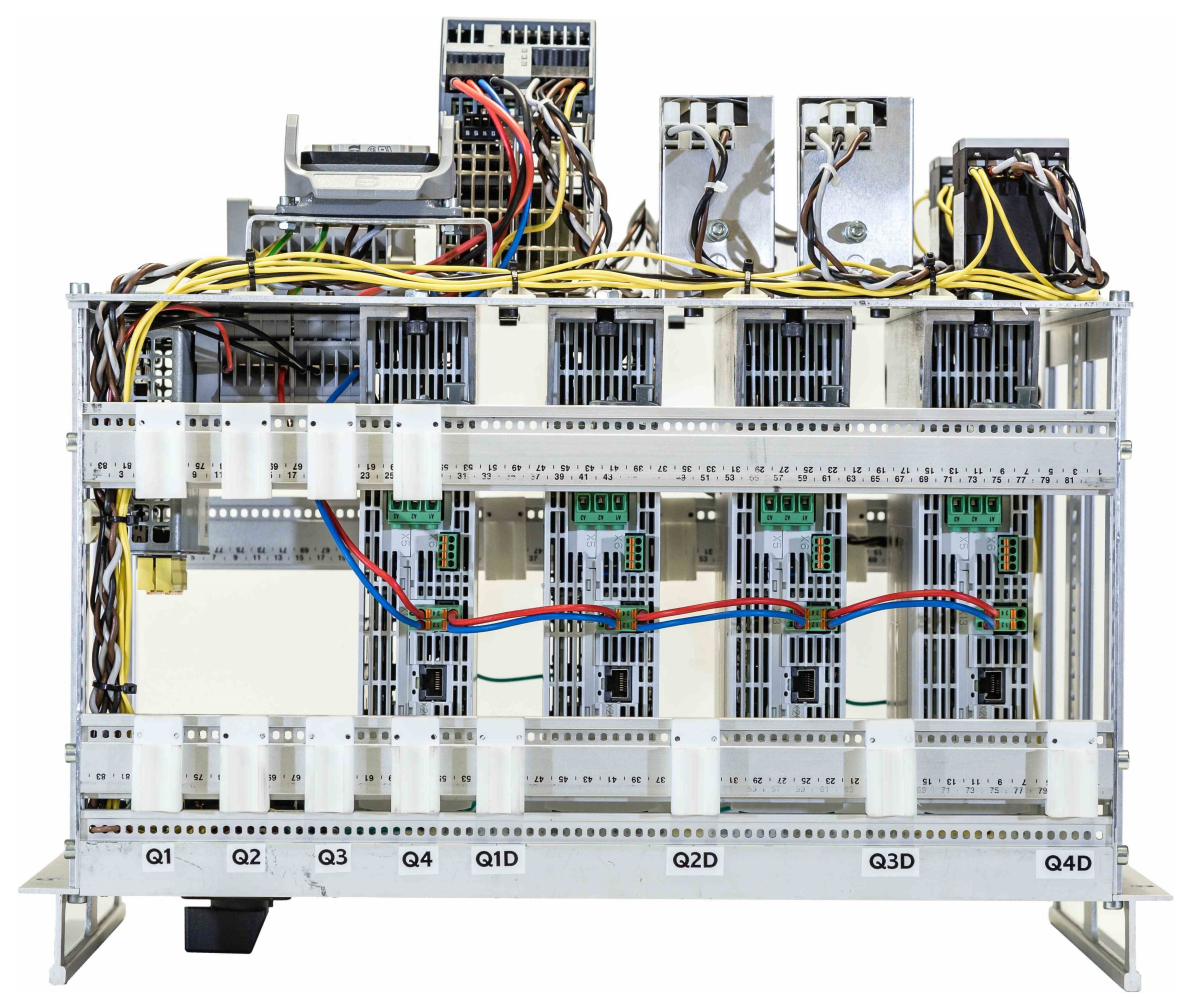

(b) Untersicht

Abbildung C.13.: Baugruppenträger der Bosch Rexroth Antriebsregelgeräte 
Anschlüsse X13 an der Unterseite der vier Antriebsregelgeräte geführt (vgl. (b) Abbildung C.13 Litzen blau / rot), um den Steuerstromkreis (24 V Gleichspannung) zu speisen. Die Displays der Antriebsregelgeräte zeigen den Boot-Vorgang der Firmware an. Sind die Antriebsregelgeräte hochgefahren und betriebsbereit, wird an den Anschlüssen X47 an der Oberseite der Antriebsregelgeräte (vgl. (b) Abbildung C.12 Litzen grün / gelb) durch einen internen Kontakt die $24 \mathrm{~V}$ Gleichspannung vom Siemens Netzteil durchgeschaltet. Nun liegt die zur Betätigung notwendige $24 \mathrm{~V}$ Gleichspannung an den Schließern der Doppeldrucktaster an. Die Antriebsregelgeräte sind paarweise auf ein Hilfsschütz (vgl. (a) Abbildung C.13 rechts) geführt:

- Antriebsregelgeräte Q1 und Q2 auf Hilfsschütz K1

- Antriebsregelgeräte Q3 und Q4 auf Hilfsschütz K2

Erst nachdem die Antriebsregelgeräte die Betriebsbereitschaft gemeldet haben, kann die 400 V Spannung an die Anschlüsse X3 an der Oberseite der Antriebsregelgeräte (vgl. (b) Abbildung C.12 geflochtene Litzen braun / grau / schwarz), durch die Betätigung der Doppeldrucktaster auf der Baugruppenträgervorderseite, angelegt werden. Die zeitliche Abfolge bei der Schaltung von $24 \mathrm{~V}$ Steuerspannung vor der Beaufschlagung mit $400 \mathrm{~V}$ Spannung muss zwingend eingehalten werden [Bos15d, S. 78]. Jedes der beiden Schütze kann über seinen eigenen Doppeldrucktaster geöffnet oder geschlossen werden:

- Taster S1/S3 schaltet Hilfsschütz K1 ein/aus: 400 V/0 V an Q1 und Q2 anliegend

- Taster S2/S4 schaltet Hilfsschütz K2 ein/aus: 400 V/0 V an Q3 und Q4 anliegend

Liegt die $400 \mathrm{~V}$ Spannung an den Antriebsregelgeräten an, sind die Antriebssysteme betriebsbereit und können über Steuerbefehle vom CompactRIO 9035 in Bewegung gesetzt werden. Die Netzfilter dienen der Entstörung der Antriebsregelgeräte und zur Reduktion von Netzrückwirkungen [Bos14b, S. 31]. Der Anschluss der Motoren an die Antriebsregelgeräte geschieht jeweils über ein vorkonfektioniertes Leistungskabel (Artikelnummer RLS1101-INK0653-RLS0745) und ein Geberkabel (Artikelnummer RGS1001-INK0448-INS0760). Das Geberkabel wird über einen nach DIN 41652-1 [DIN 41652-1] genormten 15 poligen D-Sub-Stecker in den Anschluss X4 auf der Vorderseite des Antriebsregelgeräts eingesteckt und verschraubt. Der umrichterseitige Motorkabelanschluss ist zweigeteilt und wird in die Anschlüsse X5 (Stromversorgung) und X6 (Motortemperaturfeedback) auf der Unterseite des Antriebsregelgeräts (vgl. (b) Abbildung C.13 zwei grüne Stecker) eingesteckt. Auf der Unterseite des Baugruppenträgers sind lasergesinterte Zugentlastungen zur Führung von Leistungs- und Geberkabeln auf den Modulschienen montiert. Im Zuge der Inbetriebnahme wurden Endlagenschalter zur Absicherung der Hubantriebsbaugruppen nachgerüstet. Die Fahrbereichsgrenzschalter werden über eine 6/7-polige SP 13 Stecker-Buchsen-Kombination (Weipu) mit der jeweiligen Frontplatte verbunden. Ein validiertes Sub-VI zur Implementierung in das LabVIEW-Steuerprogramm war Teil des Lieferumfangs. 


\section{C.7. Baugruppenträger und Steuercomputer des Laser-Scanner-Dummys}

Der Laser-Scanner-Demonstrator, dargestellt in Abbildung C.14, ist aus Komponenten eines ausgesonderten Lasermarkiersystems rekombiniert. Der hurrySCAN II 14 Scanner der Firma Scanlab lenkt zu Demonstrationszwecken einen sichtbaren Pilotlaser über der Bauplattform ab. Der Galvano-Scanner besitzt ein XY2-100-Interface mit getrennten

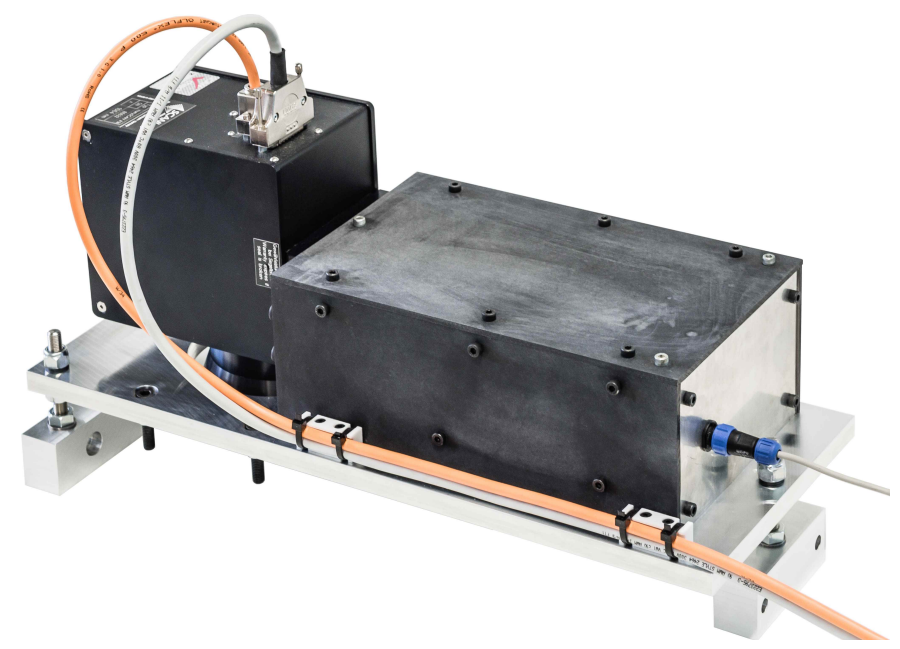

(a) Laser-Scanner-Dummy mit Abdeckung und Kabeln

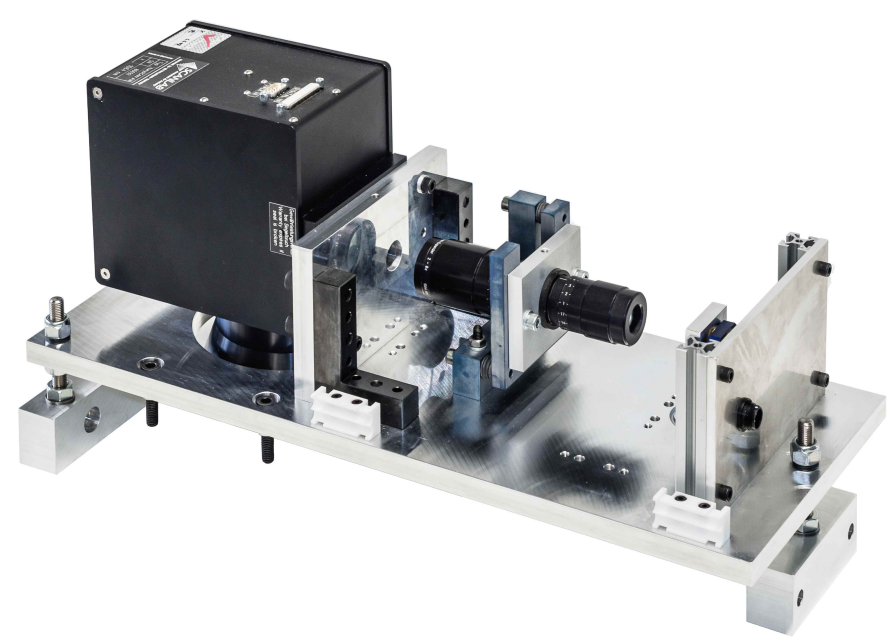

(b) Laser-Scanner-Dummy ohne Abdeckung

Abbildung C.14.: Laser-Scanner-Demonstrator mit hurrySCAN II 14 Scanner

Anschlüssen für die Daten- und Stromversorgung. Das orangefarbene Kabel ist scannerseitig mit einer 9-poligen (je 3 Litzen zur Vergrößerung des Querschnitts im Scanner zusammengeführt) Sub-D-Kabelbuchse und baugruppenträgerseitig mit einem 3-poligen SP 21 Weipu Kabelstecker zur Stromversorgung konfektioniert. Das benachbarte, graue 
Verlängerungskabel besitzt zur digitalen Datenübertragung beidseitig 25-polige Sub-DKabelstecker. Die Scanner-Kabel werden durch zwei lasergesinterten Kabelführungen auf die Rückseite des Dummys geführt. In die Rückwand im Bereich der Abdeckung ist ein 3-poliger SP 13 Weipu Gerätestecker eingebaut, über den der Pilotlaser durch den Anschluss eines Verlängerungskabels mit Strom versorgt wird. Alle drei Kabel werden in den Baugruppenträger eingesteckt. Die Abbildung C.15 stellt den Baugruppenträger zum

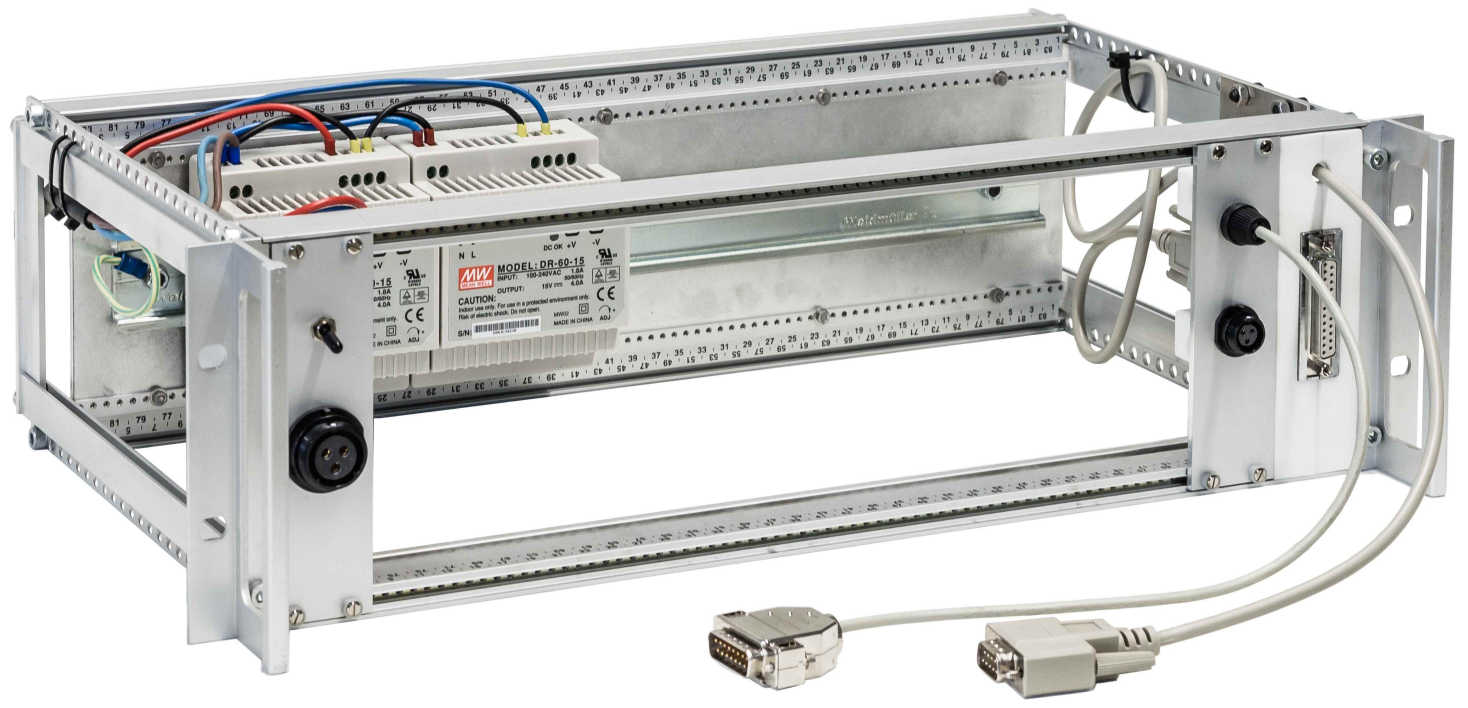

(a) Baugruppenträger

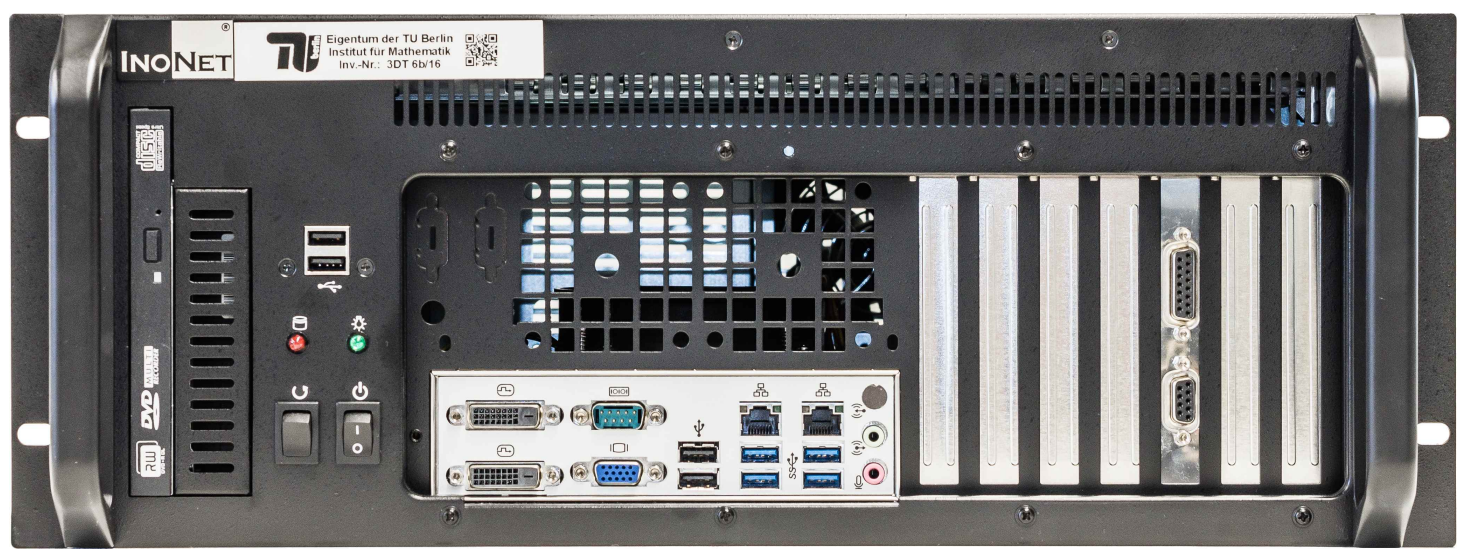

(b) Steuercomputer mit Scanlab RTC5 Karte

Abbildung C.15.: Baugruppenträger und Steuercomputer des Laser-Scanner-Dummys

Anschluss des Laser-Scanner-Dummys mit einer Gesamthöhe von 3U dar. Zwischen den hinteren Modulschienen ist ein stabiles Aluminiumblech zur Aufnahme von Hutschienen der Größe TH35 geschraubt. Auf der zur Schaltschrankvorderseite gewandten Hutschiene sind zwei Mean Well Netzteile (DR-60-15 / Ausgangsspannung 15 V DC / Stromstärke max. 4A) montiert, wobei eines eine Spannung von $+15 \mathrm{~V}$ und das andere eine Span- 
nung von $-15 \mathrm{~V}$ zur Scanner-Stromversorgung erzeugt. In die linke Teilfrontplatte ist eine 3-polige SP 21 Weipu Gerätebuchse (+15 V / -15 V / Masse) und ein Kippschalter eingebracht. Die Teilfrontplatten auf der rechten Seite des Baugruppenträgers dienen dem Durchschleifen der Anschlüsse der RTC5 Ansteuerkarte, die in dem Steuercomputer als PCI-Express-Karte eingebaut ist. Der Steuercomputer (Intel Core i5-6500 Prozessor mit 3,4 GHz, 8GB DDR4 Ram, 1TB SATA-600 HD, Windows 7) aus Abbildung C.15 besitzt ein 19" breites Gehäuse mit einer Höhe von 4U. Die Scanlab RTC5 PCI-Express-Ansteuerkarte besitzt eine 15-polige Sub-D-Buchse zur Lasersteuerung und eine 9-polige Sub-D-Buchse zur Scannersteuerung. Zur Kommunikation mit dem Scanner verwendet die RTC5 Karte ein SL2-100 Übertragungsprotokoll. Da der verwendete hurrySCAN II Scanner ein XY2-100-Interface besitzt, muss ein Konverter (9-polig Sub-D-Stecker auf 25-polig Sub-D-Buchse) verwendet werden, der hinter der rechten, lasergesinterten Teilfrontplatte des Baugruppenträgers fest eingebaut ist. Der Konverter wird mittels 9-poligem Sub-D-Verlängerungskabel an die Ansteuerkarte angeschlossen. Die Stromversorgung des Pilotlasers geschieht durch drei Pins der 15-poligen Lasersteuerungsbuchse. An der entsprechenden Teilfrontplatte ist ein 3-poliges Kabel mittels Kabelverschraubung befestigt, an die 3-polige SP 13 Weipu Gerätebuchse angelötet und mit einem 15-poligen Sub-D-Gerätestecker konfektioniert. Der Steuercomputer ist mittels Patch-Kabel in das lokale Netzwerk integriert. 


\section{Inbetriebnahme der Bosch Rexroth Antriebstechnik}

Die Lasersintermaschine ist mit vier Antriebsachsen $(3 \times$ Hubantriebsachsen $/ 1 \times$ Pulverauftragsachse) ausgestattet. Die Hubantriebsachse aus dem Baustempelmodul (Q1) positioniert die Bauplattform in der vertikalen z-Richtung innerhalb des Baustempelgehäuses. Die Hubantriebsachsen aus dem Pulverzuführmodul (Q3 und Q4) positionieren die Zuführplattformen in der vertikalen z-Richtung innerhalb der Pulverzuführgehäuse. Die Hubantriebsbaugruppen aller drei Hubantriebsachsen sind aus identischen Komponenten (Servomotor / Umrichter / Kugelgewindetrieb) der Firma Bosch Rexroth aufgebaut. Die Antriebsachse aus dem Pulverauftragsmodul (Q2) bewegt die Beschichtereinheit-Aufnahme in der horizontalen Richtung oberhalb der Prozesseinsatzplatte. Der Kugelgewindetrieb der Pulverauftragsachse wird ebenfalls durch einen Bosch Rexroth Servomotor samt Umrichter angetrieben. Die verwendeten Bosch Rexroth Antriebskomponenten werden in Anhang D.1 dargestellt. Sind die Fahrbereichsgrenzschalter zum mechanischen Schutz der Hubantriebsbaugruppen angebracht, alle Antriebsachsen der Lasersintermaschine montiert und sämtliche Komponenten korrekt verkabelt, können die zur Inbetriebnahme der Bosch Rexroth Antriebstechnik notwendigen Schritte nacheinander durchgeführt werden:

1. Erstinbetriebnahme und Reglerparametrierung (Anhang D.2): Dabei werden die Umrichter in das Netzwerk eingebunden, sämtliche Basisparameter der Antriebskomponenten geladen und der Maßbezug für das Gebersystem achsreferenziert gesetzt. Der ausgegebene Drehgeber-Lageistwert entspricht nun der Achsposition.

2. Begrenzung des Fahrbereichs (Anhang D.3): Um die Antriebsachsen vor der Bewegung in die mechanischen Endanschläge zu schützen, wird die Lagegrenzwertüberwachung und eine Fahrbereichsgrenzschalterüberwachung eingerichtet.

3. Kompensation von Steigungsabweichungen der Kugelgewindetriebe (Anhang D.4): Zur Erhöhung der Positioniergenauigkeit der Hubantriebsbaugruppen wird die Steigungsabweichung der Kugelgewindetriebe softwareseitig auf Basis von zuvor erstellten Messprotokollen (Iststeigung der Kugelgewindespindel) kompensiert.

4. Umbau der Kupplungen an den Festo Führungseinheiten (Anhang D.5): Zur Eliminierung des nicht tolerierbaren Umkehrspiels von ca. $170 \mu \mathrm{m}$ wird die Ausgleichskupplung der Festo Führungseinheit gegen eine starre Kupplung ausgetauscht.

5. Maschinenreferenzierte Drehgeberwertausgabe (Anhang D.6): Abschließend werden die Drehgeberwertausgaben der achsreferenzierten Antriebe in ein einheitliches Koordinatensystem auf Basis zuvor bestimmter Offsetwerte umgerechnet. 


\section{D.1. Verwendete Bosch Rexroth Antriebskomponenten}

Die Lasersintermaschine ist mit vier Antriebssystemen $(3 \times$ Hubantriebsachse $/ 1 \times$ Pulverauftragsachse) der Firma Bosch Rexroth ausgestattet. Die drei baugleichen Hubantriebsbaugruppen aus Baustempel- und Pulverzuführmodul positionieren die jeweilige Plattform (Stempelbaugruppe) innerhalb der Baustempel- und Pulverzuführgehäuse. Die Achse einer Hubantriebsbaugruppe ist aus den folgenden Komponenten aufgebaut:

- Bosch Rexroth Motor: MSK040C-0450-NN-M2-UG1-NNNN

- Bosch Rexroth Umrichter: HCS01.1E-W0008-A-03-A-CC-EC-ET-S4-NN-FW

- Bosch Rexroth Electromechanical Cylinder (EMC): EMC-040-NN-2

- Festo Führungseinheit: FENG-40-200-KF

Das Antriebssystem aus dem Pulverauftragsmodul treibt den Auftragsschlitten samt eingeschraubter Beschichtereinheit über einen Kugelgewindetrieb der Firma Misumi (Steigung $20 \mathrm{~mm}$ / Toleranzklasse T5) an. Die Achse des Pulverauftragmoduls ist aus den folgenden Bosch Rexroth Komponenten aufgebaut:

- Bosch Rexroth Motor: MSK040C-0600-NN-M1-UG0-NNNN

- Bosch Rexroth Umrichter: HCS01.1E-W0008-A-03-A-CC-EC-ET-S4-NN-FW

Die Position der Plattformen und die Geschwindigkeit der Beschichtereinheit wird indirekt über die achsreferenzierten Motordrehgeber erfasst. Die Einheit der Winkelsekunde wird zur Angabe kleiner Winkel verwendet, dient der Beschreibung der Systemgenauigkeit von Drehgebern und entspricht dem folgenden Wert in SI-Einheiten [Phy07, S. 116]:

$$
1^{\prime \prime}=\frac{\pi}{648000} \cdot \operatorname{rad}=0,0002 \overline{7}^{\circ}
$$

Im Folgenden werden die Bosch Rexroth Systemkomponenten detailliert beschrieben:

Servomotor MSK040C-0450 Die eindeutige Beschreibung des Synchron Servomotors geschieht durch die Angabe des Typenschlüssels „MSK040C-0450-NN-M2-UG1-NNNN“. Bei der Motorvariante handelt es sich um einen Servomotor der Baureihe "MSK", Baugröße „040“, Baulänge „C“, Wicklung „450“, Kühlart „NN“ (natürliche Konvektion), Geber „M2“ (optischer Multiturn-Absolutwertgeber mit 2048 Signalperioden), elektrischer Anschluss „U“ (drehbare Kabelstecker), Welle „G“ (glatte Welle), Haltebremse "1" (elektrische lösend bei $4 \mathrm{~N} \mathrm{~m}$ ) ohne weitere Sonderausführungen „NNNN“ [Bos13, S. 162]. Als weitere technische Daten seien genannt: Stillstandsdauerdrehmoment $60 \mathrm{~K}$ (empfohlener Projektierungswert gemäß [Bos13, S. 21]) $\mathrm{M}_{0 \_60}$ $=2,7 \mathrm{Nm}$, Maximaldrehmoment $\mathrm{M}_{\max }=8,1 \mathrm{Nm}$ und die Maximaldrehzahl $\mathrm{n}_{\max }=$ 6000 1/min [Bos13, S. 32]. Der Multiturn-Absolutwertgeber ermöglicht eine indirekte Positionserfassung innerhalb 4096 mechanischen Motorwellenumdrehungen. Die absolute Achsposition ist bei dieser Gebervariante auch nach einer Spannungsabschaltung auslesbar, wodurch Referenzpunktfahrten entfallen. Der „M2“-Encoder (präziseste Bosch Rexroth Konfigurationsmöglichkeit) kommuniziert über eine 
EnDat 2.1 Schnittstelle und verwendet eine Teilung von 2048 Signalperioden, bei angegebener Systemgenauigkeit von $\pm 20^{\prime \prime} \widehat{=} \pm 0,0056^{\circ}$, pro Motorwellenumdrehung [Bos13, S. 26]. Die Geberauflösung, die Einfluss auf die Positionsauflösung des Antriebssystems hat, ist abhängig vom verwendeten Antriebsregelgerät.

Servomotor MSK040C-0600 Die eindeutige Beschreibung des Synchron Servomotors geschieht durch die Angabe des Typenschlüssels „MSK040C-0600-NN-M1-UG0-NNNN“. Bei der Motorvariante handelt es sich um einen Servomotor der Baureihe „MSK“, Baugröße „040“, Baulänge „C“, Wicklung „600“, Kühlart „NN“ (natürliche Konvektion), Geber „M1“ (optischer Multiturn-Absolutwertgeber mit 128 Signalperioden), elektrischer Anschluss „U“ (drehbare Kabelstecker), Welle „G“ (glatte Welle), ohne Haltebremse „0" und ohne weitere Sonderausführungen „NNNN“ [Bos13, S. 162]. Als weitere technische Daten seien genannt: Stillstandsdauerdrehmoment $60 \mathrm{~K}$ (empfohlener Projektierungswert gemäß [Bos13, S. 21]) $\mathrm{M}_{0 \_60}=2,7 \mathrm{~N} \mathrm{~m}$, Maximaldrehmoment $\mathrm{M}_{\max }=8,1 \mathrm{~N} \mathrm{~m}$ und die Maximaldrehzahl $\mathrm{n}_{\max }=7500^{1} / \min [\operatorname{Bos} 13$, S. 32]. Der Multiturn-Absolutwertgeber ermöglicht eine indirekte Positionserfassung des Auftragsschlittens im Pulverauftragsmodul innerhalb 4096 mechanischen Motorwellenumdrehungen. Die absolute Achsposition ist bei dieser Gebervariante auch nach einer Spannungsabschaltung auslesbar, wodurch Referenzpunktfahrten entfallen. Der „M1“-Encoder kommuniziert über eine Hiperface Schnittstelle und verwendet eine Teilung von 128 Signalperioden, bei angegebener Systemgenauigkeit von $\pm 120^{\prime \prime} \widehat{=} \pm 0,0333^{\circ}$, pro Motorwellenumdrehung [Bos13, S. 26]. Die Geberauflösung, die Einfluss auf die Positionsauflösung des Antriebssystems hat, ist abhängig vom verwendeten Antriebsregelgerät.

Antriebsregelgerät HCS01 Zum Betrieb der MSK040C Servormotoren ist jeweils ein Antriebsregelgerät notwendig. Verwendet werden insgesamt vier Bosch Rexroth Kompaktumrichter mit dem Typenschlüssel „HCS01.1E-W0008-A-03-A-CC-EC-ET-S4-NN-FW“. Bei der Antriebsreglervariante handelt es sich um das Produkt „HCS“ (Kompaktumrichter), Baureihe „01“, Ausführung „1“, Netzteil „E“ (einspeisend), Kühlart „W" (Luft, intern), Maximalstrom „0008“ ( $\left.\mathrm{I}_{\max }=8 \mathrm{~A}\right)$, Schutzart „A“ (IP20), Netzanschluss „03“ (3 x AC 200 ... 500 V), Ausführung Steuerteil „A“ (Advanced), Kommunikation „CC“ (sercos 3 Master für Querkommunikation), Schnittstelle 1 „EC“ (Multigeberschnittstelle), Schnittstelle 2 „ET“ (Multi-Ethernet), Schnittstelle 3 „S4“ (Safe Motion), Sonstige Ausführung „NN“ (keine) mit Firmware „FW“ (mit Bedienteil: Advanced mit Speicherkartenslot, Firmware: FWA-INDRV*-MPC-20VRS-D5-1-NNN-NN) [Bos15d, S. 17-19]. Die bei der Motorbeschreibung genannte Geberauflösung des Antriebsregelgeräts beträgt 13bit [Bos15d, S. 229]. Die Motoren werden jeweils über ein Leistungs- und ein Geberkabel an die Umrichter angeschlossen. In der Projektierungsphase der Antriebe war die Möglichkeit der „Plug \& Play“ Ansteuerung über das CompactRIO Steuersystem von zentraler Bedeutung. Als Ergebnis intensiver Zusammenarbeit mit Mitarbeitern der National Instruments Germany GmbH und der Bosch Rexroth AG wurden die Antriebsregelgeräte mit der Firmware FWA-INDRV*-MPC-20VRS-D5-1-NNN-NN ausgeliefert. Zum Zeitpunkt der ersten Beschaffung befand sich die 20er Firmware 
unter Kundenschutz und benötigte eine manuelle Freigabe von Bosch Rexroth im Bestellprozess. Die Steuerbefehle vom CompactRIO zu den Antrieben werden mittels echtzeitfähigem EtherCAT Protokoll übertragen. Die Datenübertragungsfunktion CoE (CAN application protocol over EtherCAT) ist in den Bosch Rexroth Antrieben erst ab einer Firmware Version 20 implementiert [Bos16]. Zur Nutzung des Funktionsumfangs müssen nach der Erstinbetriebnahme die Antriebsregelgeräte auf die EtherCAT-Führungskommunikation eingestellt werden.

Elektromechanischer Zylinder EMC-040 Der MSK040C-0450 Motor einer Hubantriebsbaugruppe ist in Verlängerung der Achse mittels Flansch und Kupplung ohne Riemenvorgelege an den EMC montiert. Die Kennzeichnung EMC-040-NN-2 beschreibt das Bosch Rexroth Produkt „EMC“ (Electro Mechanical Cylinder), Größe „40“, Ausführung „NN“ (Normalausführung) der aktuellen Generation „2“ [Bos15a, S. 2]. Der Kugelgewindetrieb hat einen Nenndurchmesser von $16 \mathrm{~mm}$, eine Steigung von $5 \mathrm{~mm}$ und einen maximalen Verfahrweg von $200 \mathrm{~mm}$ (Länge des Gewindetriebs ca. $330 \mathrm{~mm}$ ). Die Fertigungstoleranzklasse des Kugelgewindetriebs ist angegeben mit T7 (zulässige Wegschwankung: $52 \mu \mathrm{m}$ pro $300 \mathrm{~mm}$ Verfahrweg). Zur Kompensation des Steigungsfehlers ist die Erstellung eines Steigungsabweichungsprotokolls durch Bosch Rexroth in Auftrag gegeben, das bei der Inbetriebnahme softwareseitig eingepflegt wird [Bos15a, S. 79]. Zur Reduktion des Spiels zwischen Gewindetrieb und Gewindetrieb-Mutter ist der Aufbau um $2 \%$ vorgespannt. Das Gehäuse des EMCs ist nach Schutzart IP65 gemäß DIN EN 60529 [DIN EN 60529] klassifiziert. Der Gewindetrieb ist ab Werk mit Dynalub 510 befettet (Schmierfett der NLGI Klasse 2 nach DIN 51818 [DIN 51818]). Der maximale Verfahrweg von $\mathrm{s}_{\max }=$ $200 \mathrm{~mm}$ wird beidseitig um einen Überlauf von jeweils $\mathrm{s}_{\mathrm{e}}=10 \mathrm{~mm}$ (zwei Spindelumdrehungen) begrenzt, sodass ein effektiver Arbeitshub von $s_{\text {eff }}=180 \mathrm{~mm}$ in der Anwendung genutzt werden kann [Bos15a, S. 43]. Die Fahrbereichsbegrenzung wird durch Magnetsensoren überwacht, die in einem Sensorprofil an der Außenseite des EMCs befestigt sind. Die Fahrbereichsgrenzschalter (Endlagenschalter) sind PNP/Öffner, werden von der Sick AG hergestellt und haben die exakte Bezeichnung „MZT8-03VPO-KRDS14“ [Bos15a, S. 63] [SIC16]. Wird versehentlich ein solcher Endlagenschalter überfahren, so wird zum mechanischen Schutz des EMCs der gesamte Antrieb still gesetzt.

Die Tabelle D.1 stellt die achsspezifischen Identifikationsnummern (Seriennummern „SN" / Kundeninformationsnummern „CS“) der einzelnen Komponenten dar.

Tabelle D.1.: Identifikationsnummern der Antriebskomponenten

\begin{tabular}{l|c|c|c|c}
\hline \multicolumn{1}{c|}{ Antrieb } & MSK040C SN & HCS01 SN & EMC CS & Spindel \\
\hline Q1 Baustempel & 7260406282272 & 7260406209369 & 1009553990090001 & 68303 \\
\hline Q2 Pulverauftrag & 7260406942142 & 7260407071022 & & \\
\hline Q3 Zuführung I & 7260407564346 & 7260407460802 & 1009968636010002 & $27612-1$ \\
\hline Q4 Zuführung II & 7260407564348 & 7260407460797 & 1009968636010001 & $27612-2$ \\
\hline
\end{tabular}




\section{D.2. Erstinbetriebnahme und Reglerparametrierung}

Die Erstinbetriebnahme der Antriebssysteme wird mit Hilfe der Bosch Rexroth Software „IndraWorks“ durchgeführt. Alle eingesetzten Antriebsregelgeräte verfügen auf der Geräteunterseite über RJ-45 Netzwerkanschlüsse (Engineering Port / Anschluss X26), die über den Ethernet Switch mit dem Host-Computer verbunden sind. Nach der Zuweisung unterschiedlicher IP-Adressen über die Bedienteile der Kompaktumrichter kann der Host-Computer eine Netzwerkverbindung mit den Antriebsregelgeräten aufbauen. Die IP-Adressen der Umrichter sind in Tabelle D.2 zusammengefasst.

Tabelle D.2.: IP-Adressen und Firmware-Versionen der Antriebsregelgeräte

\begin{tabular}{l|c|c|c|c}
\hline \multicolumn{1}{c|}{ Antrieb } & MSK040C SN & HCS01 SN & IP-Adresse & Firmware \\
\hline Q1 Baustempel & 7260406282272 & 7260406209369 & 169.254 .0 .1 & MPC-20V06 \\
\hline Q2 Pulverauftrag & 7260406942142 & 7260407071022 & 169.254 .2 .1 & MPC-20V10 \\
\hline Q3 Zuführung I & 7260407564346 & 7260407460802 & 169.254 .3 .1 & MPC-20V10 \\
\hline Q4 Zuführung II & 7260407564348 & 7260407460797 & 169.254 .4 .1 & MPC-20V10 \\
\hline
\end{tabular}

Der Erstanlauf geschieht im „Easy-Startup“-Modus [Bos14a, S. 1167-1177]. Die Servomotoren verfügen über einen Geberdatenspeicher, in dem sämtliche Basisparameter über Motor, Messsystem und Motorhaltebremse gespeichert sind. Beim ersten Einschalten des Antriebssystems erkennt der Kompaktumrichter, dass ein unbekannter Motor angeschlossen ist und gibt eine entsprechende Fehlermeldung aus. Beim Zurücksetzen des Fehlers werden die motorspezifischen Regelkreisparameterwerte in das Regelgerät geladen [Bos14a, S. 203-204]. Ist die reglerintegrierte Sicherheitstechnik „Safe Motion“ deaktiviert [Bos14a, S. 851-854], wechselt der Antrieb aus dem Parametriermodus in den Betriebsmodus [Bos14a, S. 1179], sodass die Motorwelle zur funktionalen Prüfung im Tippbetrieb [Bos14a, S. 608-609] bewegt werden kann. Die an den Motoren befindlichen optischen Multiturn-Drehgeber senden digitale Gebersignale zur Auswertung an die Antriebsregelgeräte [DR 15b, S. 13]. Zur korrekten Nutzung des absolut auswertbaren Messsystems muss die Signalausgabe des jeweiligen Drehgebers zunächst an die Einbausituation angepasst werden [DR 15a, S. 12-15] [Bos14a, S. 262]. Zur Einrichtung der achsbezogenen Lageistwertausgabe wird die Achse in eine sogenannte "markante“ Achsposition verfahren. Die Kolbenstange einer Hubantriebsbaugruppe wird dazu kraftfrei bei geringer Tippgeschwindigkeit von $0,01 \mathrm{~mm} / \mathrm{s}$ vollständig bis in den unteren mechanischen Endanschlag eingefahren [Bos15b, S. 41] [Bos14a, S. 288]. Ist über IndraWorks die Achsmechanik, sowie die Wichtung der physikalischen Daten auf eine lineare Bewegung eingestellt, kann das Absolutmaß gesetzt werden [Bos14a, S. 336-250]. Der vom Geber ausgegebene Lageistwert ist gleich 0,000 $\mathrm{mm}$ und entspricht dabei der Achsposition im unteren mechanischen Endanschlag [Bos14a, S. 288]. Die Abbildung D.1 stellt die Antriebsbaugruppe des Pulverauftragmoduls samt Nebenkammer bei demontiertem Deckel dar. Der Antriebsmotor "Q2" ist links außerhalb der Nebenkammer montiert. Der Verfahrweg des Spindelantriebs ist beidseitig durch Gummianschläge begrenzt. Zur Anpassung der Drehgebersignalausgabe an die Einbausituation wird der Antrieb in den hinteren Gummianschlag (vgl. (a) Abbildung D.1) im Bereich des Motors verfahren und 
das Absolutmaß auf 0,000 mm gesetzt. Im Normalbetrieb darf keines der Antriebssysteme in die mechanischen Endanschläge gefahren werden. Die Begrenzung des Fahrbereichs wird diesbezüglich in Anhang D.3 dargestellt.

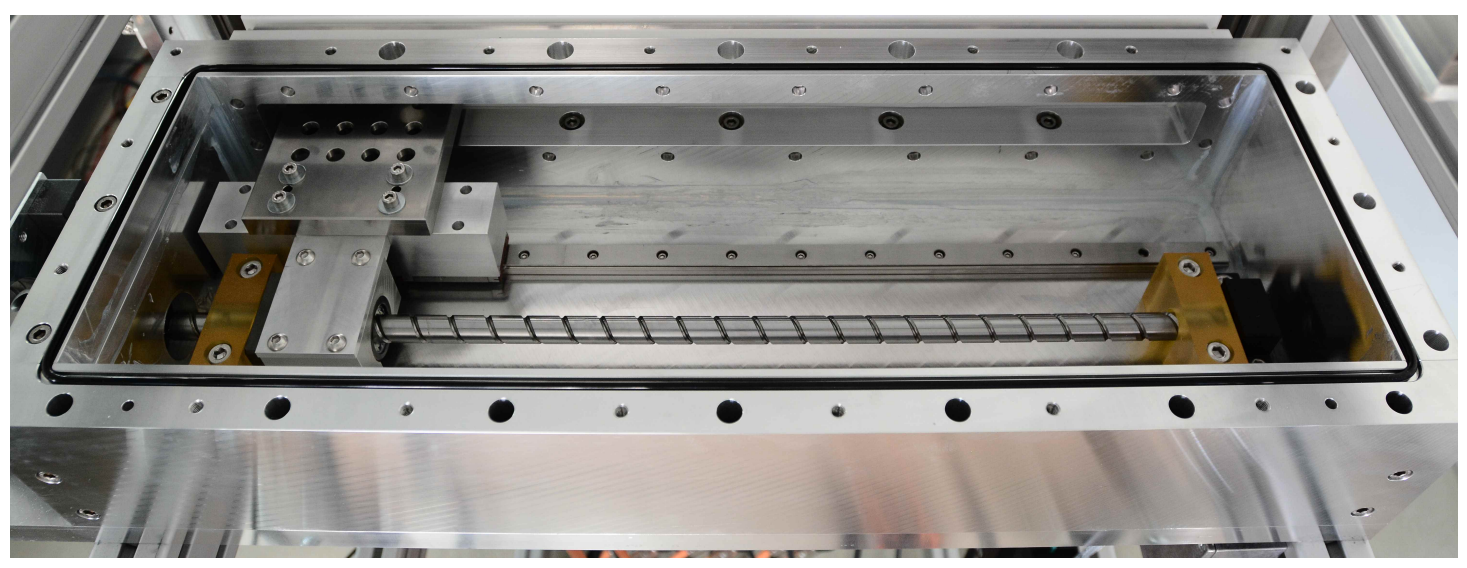

(a) 1. Markante Achsposition / Absolutmaß gesetzt (Lageistwert 0,000 mm)

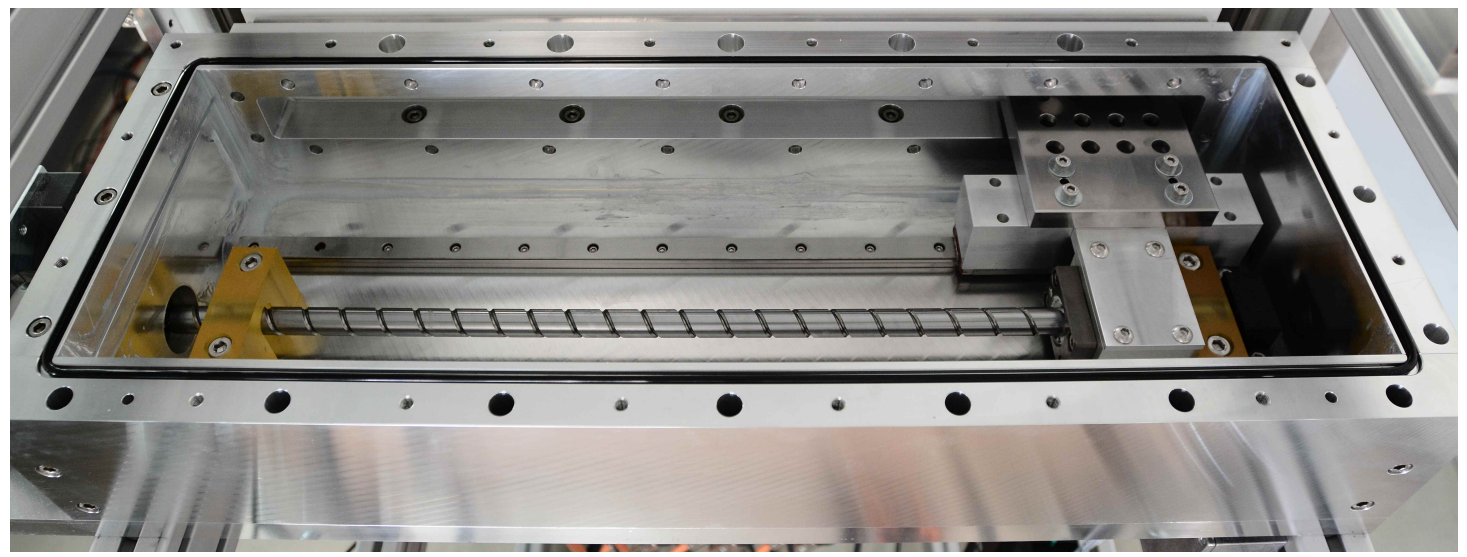

(b) 2. Markante Achsposition / Bewegungsgrenze bei Lageistwert 421,553 mm

Abbildung D.1.: Anpassung der Drehgebersignalausgabe an die Einbausituation

\section{D.3. Begrenzung des Fahrbereichs}

Um die Achsen an der Fahrt in die mechanischen Endanschläge zu hindern, wird eine Fahrbereichsbegrenzung eingestellt. Die folgenden zwei Methoden werden genutzt:

Lagegrenzwertüberwachung Der Lageistwert der Achse, der sich aus dem Feedback des Absolutwert-Motordrehgebers berechnet, wird in Echtzeit mit den zuvor eingestellten Lagegrenzwerten verglichen. Ist der Lageistwert größer oder gleich dem zuvor eingestellten Grenzwert, wird der Antrieb mit sofortiger Wirkung still gesetzt. Die Lagegrenzwertüberwachung basiert auf dem im Rahmen der Inbetriebnahme gesetztem Absolutwert und ist ein reiner Software-Parameter. 
Fahrbereichsgrenzschalterüberwachung Zur Steigerung der Funktionssicherheit der mechatronischen Achsen können zusätzlich Näherungsschalter verbaut werden. Detektiert einer der Näherungsschalter eine Bewegung in einem Sperrbereich, wird nach entsprechender Signalverarbeitung durch das Antriebsregelgerät der Antrieb mit sofortiger Wirkung still gesetzt.

Die Achse des Pulverauftragmoduls ist lediglich über eine Überwachung der Lagegrenzwerte abgesichert. In den drei Achsen der Hubantriebsbaugruppen sind die Fahrbereiche redundant durch Fahrbereichsgrenzschalter und Lagegrenzwerte überwacht. Alle Drehgeber wurden im Rahmen der Erstinbetriebnahme in einem der beiden achsspezifischen Endanschläge parametriert, sodass diese Achsposition einem Lageistwert von 0,000 mm entspricht. Das Vorzeichen des Lageistwerts im zweiten achsspezifischen, mechanischen Endanschlag ist positiv. Zur Begrenzung des Fahrbereichs einer Achse muss zunächst der Drehgeberwert im zweiten mechanischen Endanschlag $(>0,000 \mathrm{~mm}$ ) identifiziert werden, um die Begrenzung des Fahrbereichs durchführen zu können. Die Abbildung D.1 stellt die Antriebsbaugruppe des Pulverauftragmoduls in beiden markanten Achspositionen dar. Die vom Drehgeber ausgegebenen Lageistwerte in den mechanischen Endanschlägen betragen 0,000 mm hinten (vgl. (a) Abbildung D.1) und 421,553 mm vorne (vgl. (b) Abbildung D.1). Die Fahrbereichsgrenzwerte aus Tabelle D.3 für die Achse aus dem Pulverauftragsmodul werden in IndraWorks unter dem Reiter der "Bewegungsgrenzwerte“ eingetragen und auf das Antriebsregelgerät übertragen.

Tabelle D.3.: Fahrbereichsbegrenzung der Achse aus dem Pulverauftragsmodul

\begin{tabular}{l|r}
\hline \multicolumn{2}{c}{ Achse aus dem Pulverauftragsmodul: Q2 } \\
\hline \multicolumn{2}{c}{ Drehgeberwert } \\
\hline Mechanischer Endanschlag hinten (im Bereich des Motors) & $0,000 \mathrm{~mm}$ \\
\hline Mechanischer Endanschlag vorne & $421,553 \mathrm{~mm}$ \\
\hline IndraWorks-interner Fahrbereichsgrenzwert hinten & $4,000 \mathrm{~mm}$ \\
\hline IndraWorks-interner Fahrbereichsgrenzwert vorne & $416,000 \mathrm{~mm}$ \\
\hline
\end{tabular}

Vor der Erstinbetriebnahme der Hubantriebsbaugruppen wurden alle Achsen zusätzlich mit Magnetsensoren ausgestattet. An der Außenseite des elektromechanischen Zylinders ist ein Sensorprofil über zwei Haltebügel angebracht, in das die Fahrbereichsgrenzschalter eingeschoben werden. Die verwendeten elektromechanischen Zylinder haben jeweils einen maximalen Verfahrweg $\left(s_{\max }\right)$ von $200 \mathrm{~mm}$, der beidseitig um einen Überlauf $\left(s_{\mathrm{e}}\right)$ von $10 \mathrm{~mm}$ zum mechanischen Schutz der Achse begrenzt wird. Der effektive Arbeitshub $\left(s_{\text {eff }}\right)$ des EMCs von $180 \mathrm{~mm}$ berechnet sich aus dem maximalen Verfahrweg abzüglich der Überläufe und wird durch eine entsprechende Positionierung der Magnetsensoren innerhalb der Sensorleiste überwacht. [Bos15a, S. 43]. Die Abbildung D.2 stellt die drei Hubantriebsbaugruppen samt Sensorleiste und Fahrbereichsgrenzschalter unterhalb der Antriebsetage der Lasersintermaschine dar. Zur Fahrbereichsbegrenzung eines Antriebs werden zwei Sensoren mit der Artikelnummer „MZT8-03VPO-KRDS14“ der Firma Sick verwendet. Die zum Betrieb der Magnetsensoren notwendige $24 \mathrm{~V}$ Versorgungsspannung wird an den Durchgangsklemmen auf der Rückseite des Baugruppenträgers der Bosch Rexroth 
Antriebsregelgeräte (vgl. Anhang C.6) abgegriffen und dient als Bezugspotenzial für die digitalen Eingänge. Die Öffner der Fahrbereichsgrenzschalter sind über die Anschlussstelle

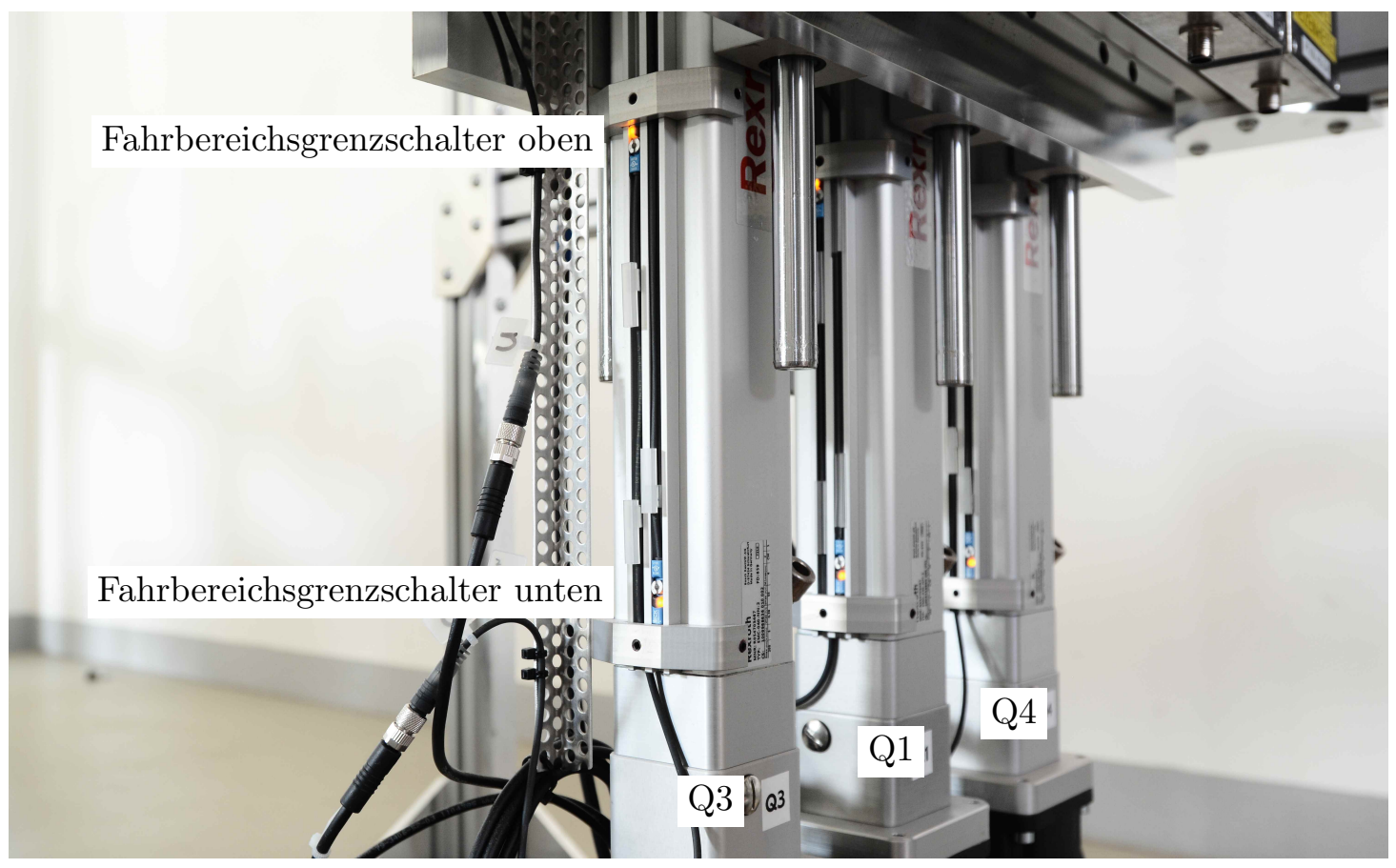

Abbildung D.2.: Fahrbereichsgrenzschalter an den Hubantriebsbaugruppen

X31 (Pin 4 und 5) mit dem jeweiligen Antriebsregelgerät verbunden [Bos15d, S. 148]. Die Überwachung durch die Fahrbereichsgrenzschalter wird in IndraWorks unter dem Reiter der „Bewegungsgrenzwerte“ aktiviert. Unter dem Reiter „Lokale I/Os“ sind die Pins

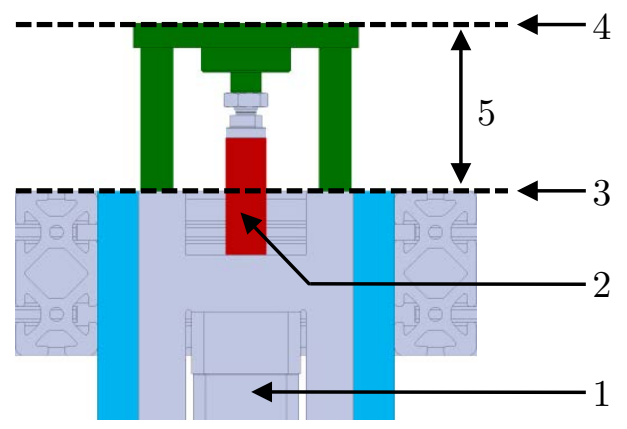

(1) Elektromechanischer Zylinder „EMC“

(2) Kolbenstange des EMCs

(3) Jochplatte Oberseite „JP“

(4) Führungseinheitkorpus Oberseite „FK“

(5) Abstand zw. (3) und (4): $d(J P, F K)$

Abbildung D.3.: Bezugsabstand einer Hubantriebsbaugruppe

X31/4 bzw. X31/5 auf ein Signal der Fahrbereichsgrenzschalter-Eingänge einzustellen. Die Jochplatte der Festo Führungseinheit ist an der Kolbenstange des elektromechanischen Zylinders befestigt. Im Zuge der Einrichtung der Fahrbereichsbegrenzung wurde der Abstand (vgl. Abbildung D.3) zwischen den Oberseiten von Jochplatte und Füh- 
rungseinheitkorpus als $d(J P, F K)$ definiert. Zur Ermittlung der Fahrbereichsgrenzwerte werden die Hubantriebsbaugruppen jeweils kraftfrei (bei deaktivierter Überwachung der Fahrbereichsgrenzschalter) mit sehr geringer Geschwindigkeit in den oberen mechanischen Endanschlag bewegt. Der Abstand $d(J P, F K)$ wird mit einem Stahllineal gemessen und zusammen mit dem entsprechenden Lageistwert notiert. Zur Ermittlung der Kolbenstangenposition, die zum Auslösen der Fahrbereichsgrenzschalter führen, wird der Antrieb (bei aktivierter Überwachung der Fahrbereichsgrenzschalter) kraftfrei mit sehr geringer Geschwindigkeit aus dem Bereich des Arbeitshubs kommend in Richtung der mechanischen Endanschläge bewegt, bis dieser durch den Umrichter still gesetzt wird. Nach jeder Antriebsstillsetzung wird der vom Drehgeber ausgegebene Lageistwert notiert und der Abstand $d(J P, F K)$ gemessen. Abschließend werden die Achsen jeweils in Richtung der mechanischen Endanschläge bewegt, bis der Antrieb durch die Überwachung der Lagegrenzwerte still gesetzt wird. Der Abstand $d(J P, F K)$ wird gemessen und notiert. Die Messergebnisse sind in Tabelle D.4 zusammengefasst. Die oberen IndraWorks-internen Fahrbereichsgrenzwerte werden nach Montage der Stempelbaugruppen (vgl. Anhang D.6) nochmals angepasst.

Tabelle D.4.: Fahrbereichsbegrenzung der Hubantriebe ohne Stempelbaugruppe

Achse der Hubantriebsbaugruppe aus dem Baustempelmodul: Q1

\begin{tabular}{l|r|r}
\hline & Drehgeberwert & $\boldsymbol{d}(\boldsymbol{J P}, \boldsymbol{F K})$ \\
\hline Mechanischer Endanschlag unten & $0,000 \mathrm{~mm}$ & $19 \mathrm{~mm}$ \\
\hline Mechanischer Endanschlag oben & $199,031 \mathrm{~mm}$ & $218 \mathrm{~mm}$ \\
\hline Fahrbereichsgrenzschalter unten & $10,102 \mathrm{~mm}$ & $30 \mathrm{~mm}$ \\
\hline Fahrbereichsgrenzschalter oben & $189,970 \mathrm{~mm}$ & $209 \mathrm{~mm}$ \\
\hline IndraWorks-interner Fahrbereichsgrenzwert unten & $15,000 \mathrm{~mm}$ & $34 \mathrm{~mm}$ \\
\hline IndraWorks-interner Fahrbereichsgrenzwert oben* & $189,000 \mathrm{~mm}$ & $208 \mathrm{~mm}$ \\
\hline
\end{tabular}

\begin{tabular}{l|r|r}
\multicolumn{2}{c}{ Achse der Hubantriebsbaugruppe aus dem Pulverzuführmodul I: Q3 } \\
\hline Mechanischer Endanschlag unten & Drehgeberwert & $\boldsymbol{d}(\boldsymbol{J P}, \boldsymbol{F K})$ \\
\hline Mechanischer Endanschlag oben & $0,000 \mathrm{~mm}$ & $14 \mathrm{~mm}$ \\
\hline Fahrbereichsgrenzschalter unten & $210,891 \mathrm{~mm}$ & $225 \mathrm{~mm}$ \\
\hline Fahrbereichsgrenzschalter oben & $13,300 \mathrm{~mm}$ & $27 \mathrm{~mm}$ \\
\hline IndraWorks-interner Fahrbereichsgrenzwert unten & $193,773 \mathrm{~mm}$ & $208 \mathrm{~mm}$ \\
\hline IndraWorks-interner Fahrbereichsgrenzwert oben* & $15,000 \mathrm{~mm}$ & $29 \mathrm{~mm}$ \\
\hline
\end{tabular}

\begin{tabular}{|c|c|c|}
\hline \multicolumn{3}{|c|}{ Achse der Hubantriebsbaugruppe aus dem Pulverzuführmodul II: Q4 } \\
\hline & Drehgeberwert & $d(J P, F K)$ \\
\hline Mechanischer Endanschlag unten & $0,000 \mathrm{~mm}$ & $14 \mathrm{~mm}$ \\
\hline Mechanischer Endanschlag oben & $210,950 \mathrm{~mm}$ & $225 \mathrm{~mm}$ \\
\hline Fahrbereichsgrenzschalter unten & $14,060 \mathrm{~mm}$ & $28 \mathrm{~mm}$ \\
\hline Fahrbereichsgrenzschalter oben & $194,521 \mathrm{~mm}$ & $209 \mathrm{~mm}$ \\
\hline IndraWorks-interner Fahrbereichsgrenzwert unten & $15,000 \mathrm{~mm}$ & $29 \mathrm{~mm}$ \\
\hline IndraWorks-interner Fahrbereichsgrenzwert oben* & $189,000 \mathrm{~mm}$ & $203 \mathrm{~mm}$ \\
\hline
\end{tabular}

*: Werte werden nach Einbau der Stempelbaugruppe angepasst 


\section{D.4. Kompensation von Steigungsabweichungen der Kugelgewindetriebe}

Kugelgewindetriebe wandeln eine rotatorische in translatorische Bewegung um. Diese mechanische Standardkomponente ist aus Kugelgewindespindel, Kugelgewindemutter(n) sowie Kugeln aufgebaut und nach DIN ISO 3408 [DIN ISO 3408-1] genormt. Bauteile, die an der Kugelgewindemutter befestigt sind, werden bei einer Drehbewegung der Kugelgewindespindel linear bewegt. Zur Klassifizierung von Kugelgewindetrieben werden Prüfungen in insgesamt sechs Toleranzklassen in Übereinstimmung mit der geometrischen Prüfinspektionsnorm für Bohrungen und Wellen DIN EN ISO 286-2 [DIN EN ISO 286-2] durchgeführt. Toleranzen für Sollwerte sind häufig mit einem Index „p“ (engl.: „permiss“) versehen. Der Index „a“ (engl.: „actual“) weist auf einen Messwert hin. Die zulässigen Abweichungen aller Toleranzklassen steigen in Abhängigkeit vom Nutzweg $\left(l_{\mathrm{u}}\right)$ des Kugelgewindetriebs. Die Tabelle D.5 stellt zulässige Toleranzwerte für Kugelgewindetriebe mit einem Nutzweg bis zu $315 \mathrm{~mm}$ dar.

Tabelle D.5.: Toleranzwerte für Kugelgewindetriebe bis $l_{\mathrm{u}}=315 \mathrm{~mm}$ [DIN ISO 3408-3]

\begin{tabular}{r|r|r|r|r|r|r|r}
\hline & \multicolumn{7}{|c}{ Toleranzklasse } \\
& $\mathbf{0}$ & $\mathbf{1}$ & $\mathbf{3}$ & $\mathbf{5}$ & $\mathbf{7}$ & $\mathbf{1 0}$ \\
\hline Toleranzwerte für Sollweg: $e_{\mathrm{p}}$ & $4 \mu \mathrm{m}$ & $6 \mu \mathrm{m}$ & $12 \mu \mathrm{m}$ & $23 \mu \mathrm{m}$ & $52 \mu \mathrm{m}$ & $210 \mu \mathrm{m}$ \\
\hline Zul. Wegschwankung: $\nu_{300 \mathrm{p}}$ & $3,5 \mu \mathrm{m}$ & $6 \mu \mathrm{m}$ & $12 \mu \mathrm{m}$ & $23 \mu \mathrm{m}$ & $52 \mu \mathrm{m}$ & $210 \mu \mathrm{m}$ \\
\hline
\end{tabular}

In Abhängigkeit der Toleranzklasse werden die Kugellaufbahnen der Kugelgewindespindeln durch die Fertigungsverfahren Rollen, Wirbeln oder Schleifen hergestellt [Nad14, S. 4]. Die höchsten Anforderung an Genauigkeit und Funktion wird an einen Kugelgewindetrieb der Toleranzklasse 0 gestellt [DIN ISO 3408-1, S. 5]. Die Mechanik des elektromechanischen Zylinders aus den Hubantriebsbaugruppen der Firma Bosch Rexroth basiert auf einem Kugelgewindetrieb [Bos15a, S. 4]. Der vom Motordrehgeber gelieferte Lageistwert kann vom tatsächlichen Lageistwert der Achse durch Ungenauigkeiten des Drehgebers, Übertragungsungenauigkeiten der mechanischen Übertragungselemente und der thermischen Dehnung von Bauteilen im Antriebsstrang abweichen [Bos14a, S. 760]. Zur Kompensation der genannten Fehlübertragungsverhalten können Achsfehlerkorrekturen softwareseitig über die Antriebsregelgeräte durchgeführt werden [Bos14a, S. 760-776]. Fertigungsbedingt weicht die Iststeigung der Kugelgewindespindel stets von der Nennsteigung ab, die zu Schwankungen in der linearen Ein- oder Ausfahrbewegung (Wegabweichung) der Kolbenstange führen. Der maximale Verfahrweg $\left(s_{\max }\right)$ der elektromechanischen Zylinder der Hubantriebsbaugruppen beträgt $200 \mathrm{~mm}$. Verbaut sind gerollte, vorgespannte Kugelgewindetriebe der Toleranzklasse 7 mit dokumentierter Steigungsabweichung. Bosch Rexroth führte an allen drei Kugelgewindetrieben Prüfungen (Zusatzdienstleistung) zur Bestimmung der Toleranz des Sollwegs $\left(e_{\mathrm{a}}\right)$ und der Wegschwankung über $300 \mathrm{~mm}$ Weg $\left(\nu_{300 \mathrm{a}}\right)$ durch. Die Messprotokolle der Hubantriebsbaugruppe „Q1“ (vgl. Abbildung D.4), Hubantriebsbaugruppe „Q3“ (vgl. Abbildung D.5) und der Hubantriebsbaugruppe "Q4“ (vgl. Abbildung D.6) sind in den entsprechenden 
Abbildungen dargestellt. Die Prüfergebnisse (Index „a“ für „actual“) der Firma Bosch Rexroth sind in Tabelle D.6 zusammengefasst. Bezogen auf die durchgeführten Prüfungen erfüllen alle Kugelgewindetriebe die Kriterien der höherwertigen Toleranzklasse 5.

Tabelle D.6.: Messdaten der Kugelgewindetriebe aus den Hubantriebsbaugruppen

\begin{tabular}{r|r|r|r}
\hline & \multicolumn{3}{|c}{ Messdaten der Spindelnummer } \\
& Q1: 68303 & Q3: 27612-1 & Q4: 27612-2 \\
\hline Nutzweg: $l_{\mathrm{u}}$ & $230 \mathrm{~mm}$ & $250 \mathrm{~mm}$ & $250 \mathrm{~mm}$ \\
\hline Wegschwankung: $\nu_{300 \mathrm{a}}$ & $3,8 \mu \mathrm{m}$ & $11,5 \mu \mathrm{m}$ & $3,5 \mu \mathrm{m}$ \\
\hline Kompensierte Steigung: $P_{\mathrm{a}}$ & $5,000444 \mathrm{~mm}$ & $4,999971 \mathrm{~mm}$ & $4,999874 \mathrm{~mm}$ \\
\hline Wegabweichung: $e_{\mathrm{a}}$ & $20,4 \mu \mathrm{m}$ & $-1,5 \mu \mathrm{m}$ & $-6,3 \mu \mathrm{m}$ \\
\hline
\end{tabular}

Zur Kompensation der nichtlinearen, fertigungsbedingten Spindelsteigungsfehler bietet das Antriebsregelgerät unter anderem die Funktion der „Präzisionsachsfehlerkorrektur" [Bos14a, S. 760]. Der „unkorrigierte Lageistwert“ des Gebers wird durch lage- und bewegungsrichtungsabhängige Korrekturwerte zu einem "korrigierten Lageistwert" revidiert. Die Nutzlängen der Spindeln $\left(l_{\mathrm{u}}\right)$ aus den Hubantriebsbaugruppen, zusammengefasst in Tabelle D.6, entsprechen dem maximal möglichen Korrekturbereich der Achsfehlerkompensation. Die durch Bosch Rexroth gemessenen Abweichungen von der Sollposition sind in Tabelle D.7 dargestellt. Wird die Funktionalität der Präzisionsachsfehlerkorrektur nicht genutzt, der Hubantrieb Q1 von Lageistwert $0 \mathrm{~mm}$ auf $50 \mathrm{~mm}$ (unkorrigierter Lageistwert) verfahren, befindet er sich bereits auf 50,0077 mm. Die Abweichung von 7,7 $\mathrm{mm}$, um die der Lageistwert korrigiert werden muss, ist ein sogenannter Korrekturstützpunkt, der innerhalb des Korrekturbereichs liegt. In IndraWorks kann lediglich ein konstanter Stützpunktabstand definiert werden, der in der vorliegenden Anwendung $50 \mathrm{~mm}$ beträgt. Die Werte der Abweichung aus Tabelle D.7 bilden für Q1 bis $200 \mathrm{~mm}$ bzw. für Q3 und Q4 bis $250 \mathrm{~mm}$ die Achskorrekturtabelle. Zwischen den eingegebenen Korrekturstützpunkten werden alle weiteren Korrekturwerte durch Interpolation berechnet [Bos14a, S. 765]. Zur Vermeidung von Unstetigkeiten bei der Interpolation, muss ein fiktiver Korrekturwert von $0 \mathrm{~mm}$ an Tabellenanfang und Tabellenende gesetzt werden [Bos14a, S. 766]. Die Steigungsabweichung des Kugelgewindetriebs aus der Achse des Pulverauftragmoduls der Firma Misumi (Toleranzklasse 5) ist nicht gemessen.

Tabelle D.7.: Abweichungen von der Sollposition der Hubantriebsspindeln

\begin{tabular}{r|r|r|r}
\hline \multirow{2}{*}{ Sollposition } & \multicolumn{3}{|c}{ Positionsabweichung der Spindelnummer } \\
& Q1: 68303 & Q3: 27612-1 & Q4: 27612-2 \\
\hline $0 \mathrm{~mm}$ & $0 \mu \mathrm{m}$ & $0 \mu \mathrm{m}$ & $0 \mu \mathrm{m}$ \\
\hline $50 \mathrm{~mm}$ & $7,7 \mu \mathrm{m}$ & $7,5 \mu \mathrm{m}$ & $1,5 \mu \mathrm{m}$ \\
\hline $100 \mathrm{~mm}$ & $12,3 \mu \mathrm{m}$ & $11,0 \mu \mathrm{m}$ & $1,0 \mu \mathrm{m}$ \\
\hline $150 \mathrm{~mm}$ & $17,0 \mu \mathrm{m}$ & $4,4 \mu \mathrm{m}$ & $-1,6 \mu \mathrm{m}$ \\
\hline $200 \mathrm{~mm}$ & $17,6 \mu \mathrm{m}$ & $3,9 \mu \mathrm{m}$ & $-3,1 \mu \mathrm{m}$ \\
\hline $230 \mathrm{~mm}$ & $22,4 \mu \mathrm{m}$ & & \\
\hline $250 \mathrm{~mm}$ & & $1,4 \mu \mathrm{m}$ & $-5,6 \mu \mathrm{m}$ \\
\hline
\end{tabular}


Anhang D. Inbetriebnahme der Bosch Rexroth Antriebstechnik
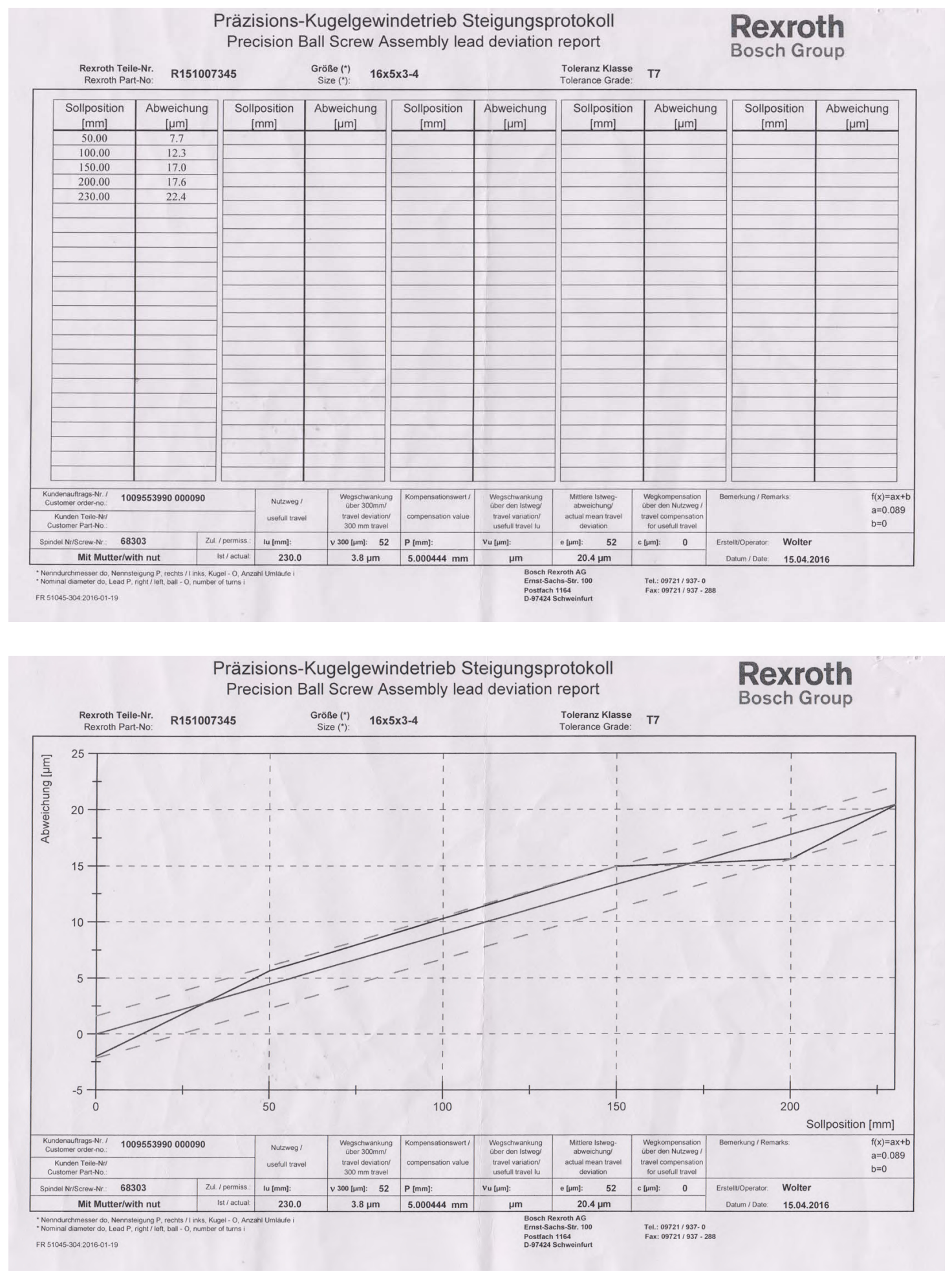

Abbildung D.4.: Messprotokoll des EMCs aus der Hubantriebsbaugruppe Q1 


\section{D.4. Kompensation von Steigungsabweichungen der Kugelgewindetriebe}
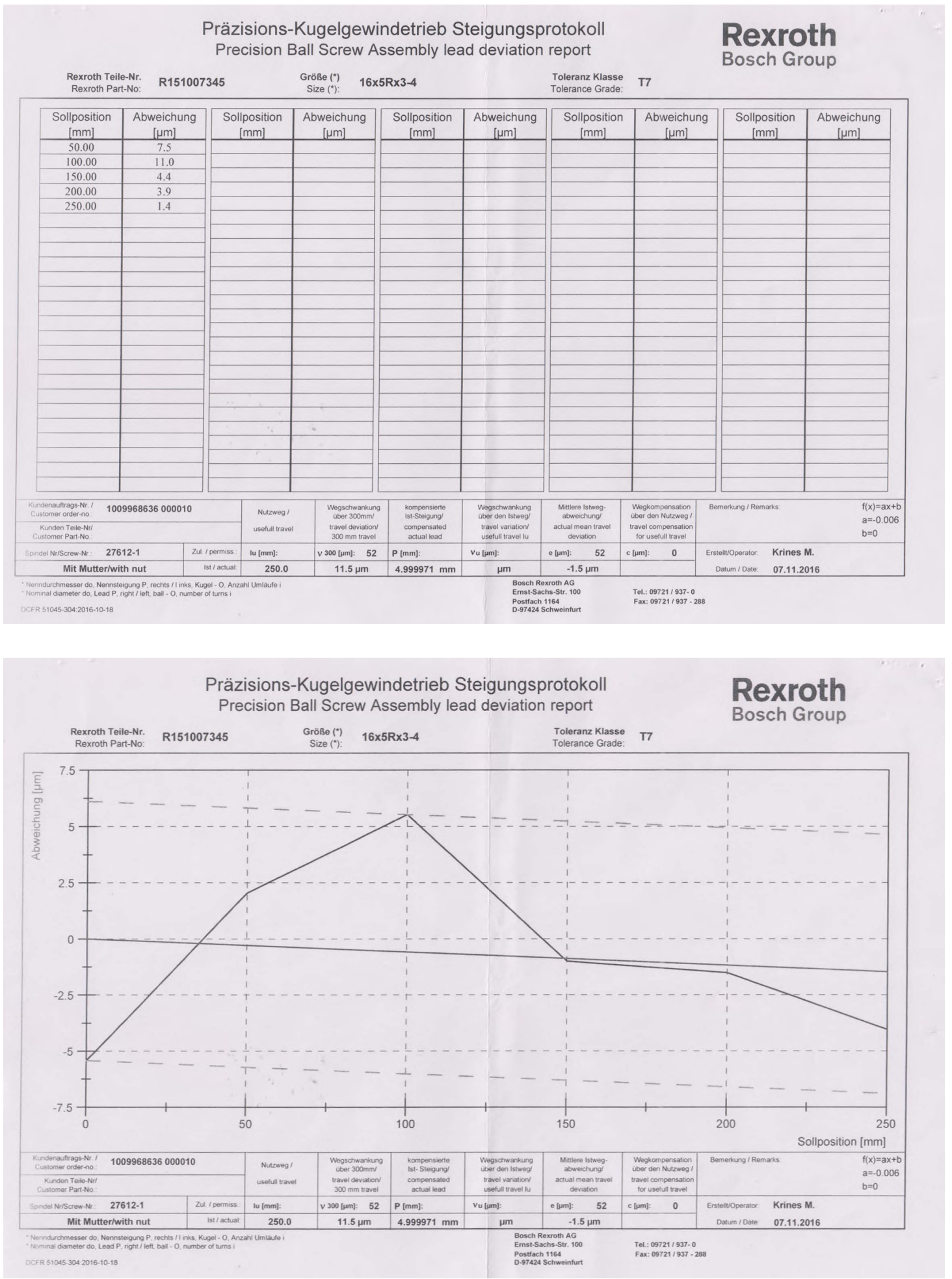

Abbildung D.5.: Messprotokoll des EMCs aus der Hubantriebsbaugruppe Q3 
Anhang D. Inbetriebnahme der Bosch Rexroth Antriebstechnik
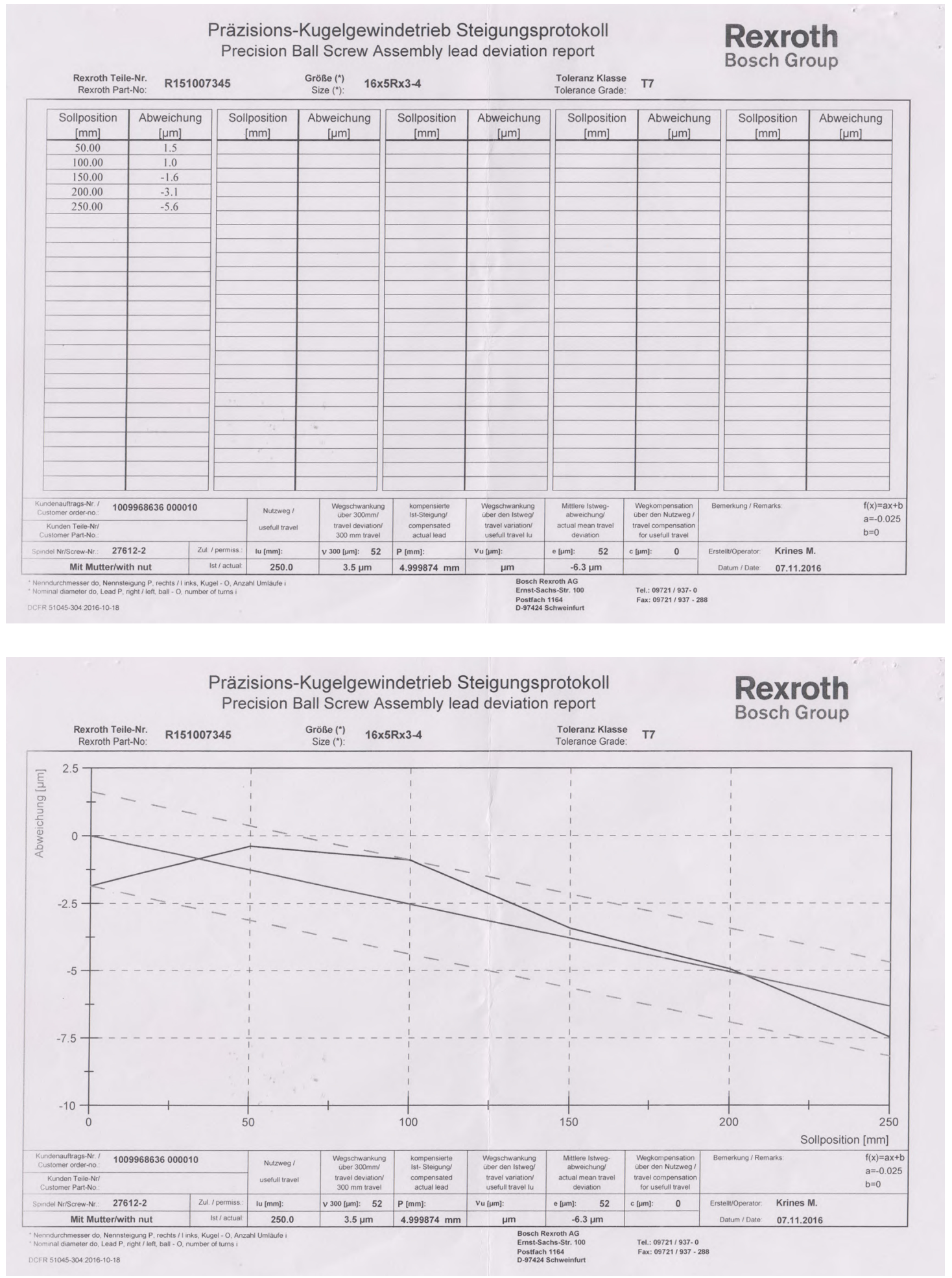

Abbildung D.6.: Messprotokoll des EMCs aus der Hubantriebsbaugruppe Q4 


\section{D.5. Umbau der Kupplungen an den Festo Führungseinheiten}

Die Abbildung D.7 stellt den Messaufbau zur Bestimmung des Axialspiels der Hubantriebsbaugruppen am Beispiel von „Q1“ dar. Der Messkopf des Laser-Wegmesssystems der Firma Keyence (vgl. Anhang F.2) ist auf einer Traverse an der Prozessrahmenplatte oberhalb der Bauplattform befestigt. Die Stempelbaugruppenoberseite, beklebt mit einem

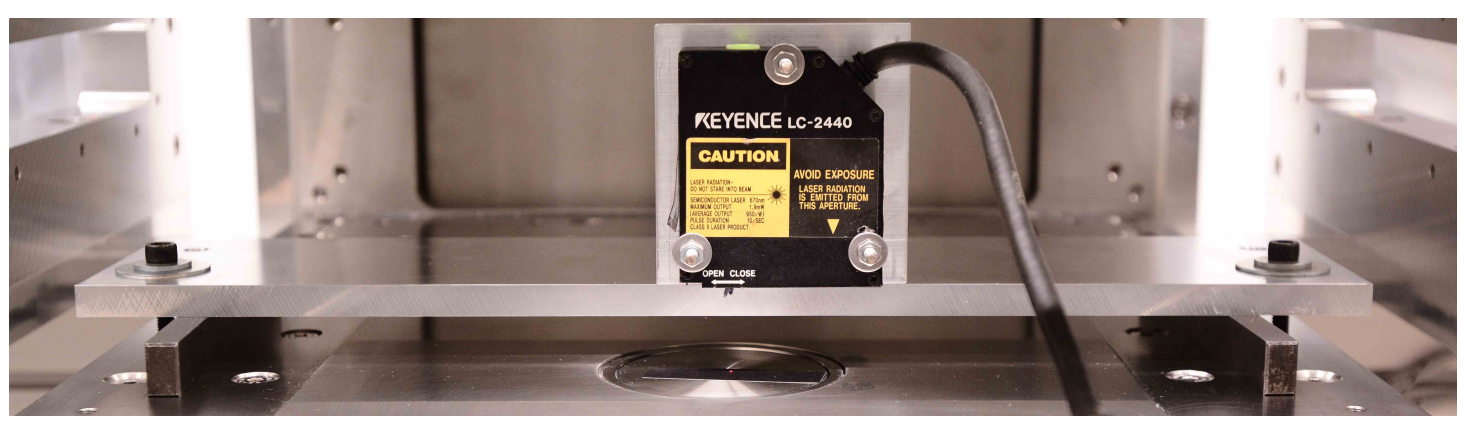

Abbildung D.7.: Messaufbau zur Bestimmung des Axialspiels

Emissionsklebeband, ist in dem Verschiebungsbereich des Messkopfs auf den Lageistwert (Drehgeberwert) von 147,500 mm positioniert. Nach Einrichtung der Höhenmessung wird die Messwertausgabe am Regler auf Null gesetzt. Der Lageistwert (Drehgeberwert) der Stempeloberfläche wird bei vorgegebenem Wert (Betrag der Relativbewegung) in alternierender Richtung (Vorzeichen der Relativbewegung) variiert, der Messwert abgelesen und in die Tabelle D.8 eingetragen.

Tabelle D.8.: Axialspielmessung bei montierter Stempelbaugruppe vor dem Umbau

\begin{tabular}{|c|c|c|c|c|}
\hline Hubantrieb & Relativbewegung & Drehgeberwert & Messwert & Axialspiel \\
\hline Q1 & $\begin{array}{r}0,500 \mathrm{~mm} \\
-0,500 \mathrm{~mm} \\
0,500 \mathrm{~mm} \\
-0,500 \mathrm{~mm} \\
0,750 \mathrm{~mm} \\
-0,750 \mathrm{~mm} \\
0,750 \mathrm{~mm} \\
-0,750 \mathrm{~mm} \\
1,000 \mathrm{~mm} \\
-1,000 \mathrm{~mm} \\
1,000 \mathrm{~mm} \\
-1,000 \mathrm{~mm}\end{array}$ & $\begin{array}{l}147,450 \mathrm{~mm} \\
147,950 \mathrm{~mm} \\
147,450 \mathrm{~mm} \\
147,950 \mathrm{~mm} \\
147,450 \mathrm{~mm} \\
148,200 \mathrm{~mm} \\
147,450 \mathrm{~mm} \\
148,200 \mathrm{~mm} \\
147,450 \mathrm{~mm} \\
148,450 \mathrm{~mm} \\
147,450 \mathrm{~mm} \\
148,450 \mathrm{~mm} \\
147,450 \mathrm{~mm}\end{array}$ & $\begin{array}{l}0,000 \mathrm{~mm} \\
0,338 \mathrm{~mm} \\
0,001 \mathrm{~mm} \\
0,338 \mathrm{~mm} \\
0,002 \mathrm{~mm} \\
0,588 \mathrm{~mm} \\
0,000 \mathrm{~mm} \\
0,588 \mathrm{~mm} \\
0,000 \mathrm{~mm} \\
0,840 \mathrm{~mm} \\
0,004 \mathrm{~mm} \\
0,840 \mathrm{~mm} \\
0,001 \mathrm{~mm}\end{array}$ & $\begin{array}{l}0,162 \mathrm{~mm} \\
0,162 \mathrm{~mm} \\
0,162 \mathrm{~mm} \\
0,162 \mathrm{~mm} \\
0,160 \mathrm{~mm} \\
0,160 \mathrm{~mm}\end{array}$ \\
\hline
\end{tabular}

Das Axialspiel einer Achse samt montierter Stempelbaugruppe entspricht der Differenz aus Relativbewegung und dem abgelesenem Messwert. Die Messung wurde an allen Achsen mit einer Hubantriebsbaugruppe wiederholt und ein Axialspiel von durchschnittlich $170 \mu \mathrm{m}$ festgestellt. Ursache des Umkehrspiels ist die Ausgleichskupplung (vgl. (a) 
Abbildung D.8) auf der Unterseite der Jochplatte der Festo „FENG“ Führungseinheit. Die zweiteilige Ausgleichskupplung wurde durch eine einteilige starre Kupplung (vgl. (b) Abbildung D.8) ersetzt. Die starre Kupplung muss bei demontierter Stempelbaugruppe

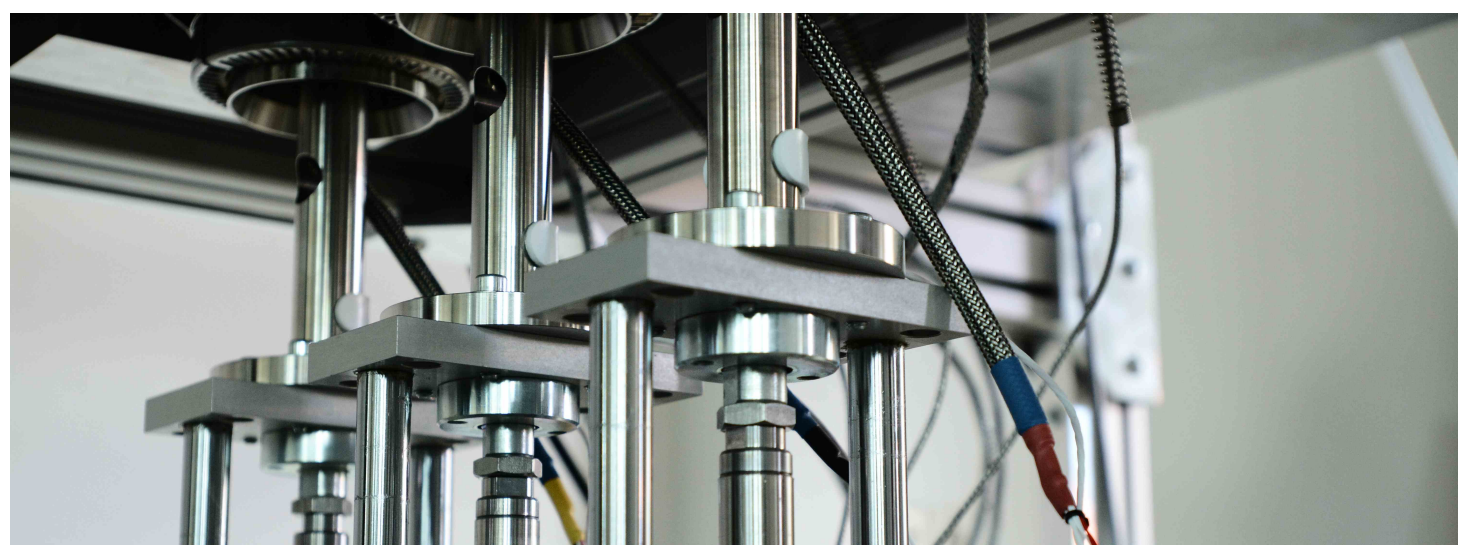

(a) Vor Umbau: Jochplatte mit originaler Ausgleichskupplung: Axiales Umkehrspiel ca. $170 \mu \mathrm{m}$

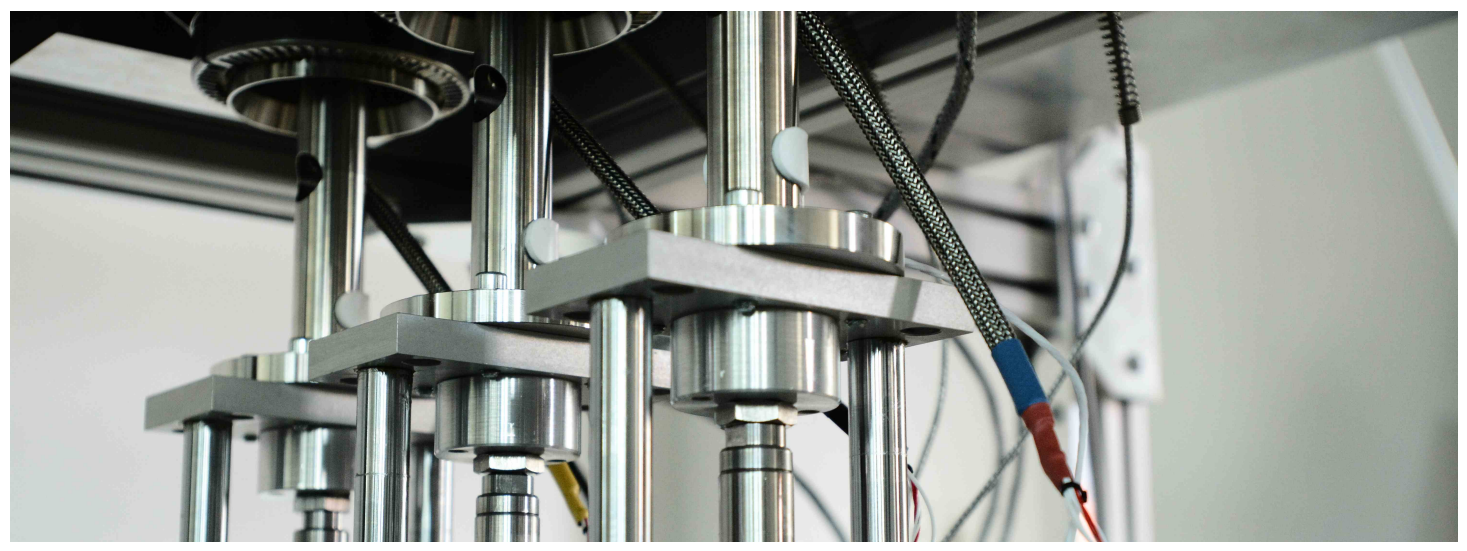

(b) Nach Umbau: Jochplatte mit starrer Kupplung: Axiales Umkehrspiel ca. $0 \mu \mathrm{m}$

Abbildung D.8.: Kupplungsumbau an den Festo Führungseinheiten FENG

auf das M12x1,5 Außengewinde der Kolbenstangen aufgeschraubt werden und von der Oberseite der Jochplatte mittels zwei M6x20 Schrauben an die Jochplatte geschraubt werden. Abschließend kann die Kontermutter an der Kolbenstange angezogen und die Stempelbaugruppe montiert werden. Nach Umbau der Kupplungen wurden erneute Messungen zur Bestimmung des Axialspiels an allen Achsen durchgeführt. Das Axialspiel konnte annähernd eliminiert werden.

\section{D.6. Maschinenreferenzierte Drehgeberwertausgabe}

Zum Aufbau eines intuitiv zu bedienenden LabVIEW-Steuerprogramms müssen die Drehgeberwertausgaben der achsreferenzierten Antriebe in einheitliche Koordinaten um- 
gerechnet werden. Ausgehend von der Lasersintermaschine als Referenz müssen dazu achsspezifische Offsetwerte bestimmt werden, die für eine Korrektur zum Lageistwert hinzugerechnet oder vom Lageistwert abgezogen werden. Zur Referenzierung der drei Hubantriebsachsen wird der Messaufbau aus Abbildung D.9 verwendet. Der Nullpunkt $(\mathrm{z}=$ $0,000 \mathrm{~mm}$ ) der vertikalen z-Richtung (Hubbewegung der Plattformen innerhalb der Gehäuse) entspricht der Gehäuseoberseite knapp unterhalb der Prozesseinsatzplattenoberfläche. Zur Identifikation des achsspezifischen Lageistwerts, an dem die Plattformoberfläche planar zu der Gehäuseoberseite ausgerichtet ist, wird auf die Oberseite der Gehäuse ein Aluminiumstreifen aufgelegt. Der Messkopf des Laser-Wegmesssystems der Firma

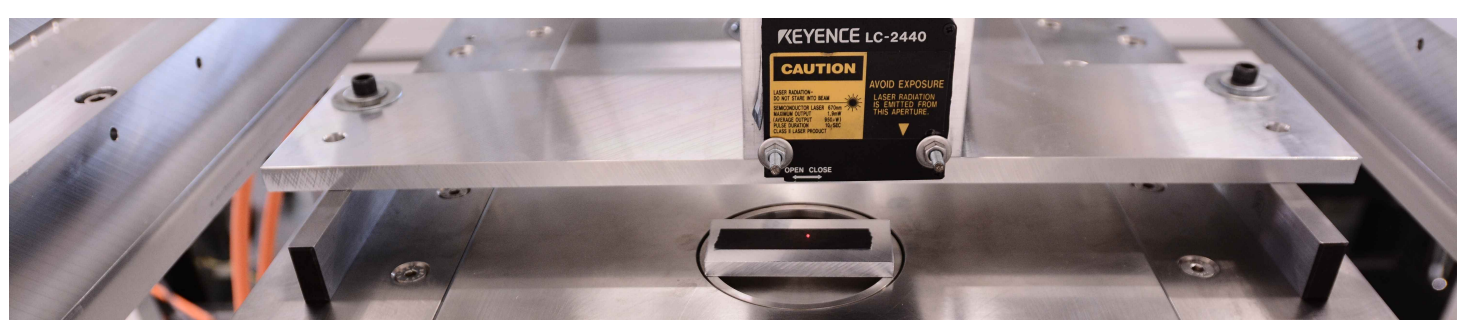

Abbildung D.9.: Messaufbau zur Drehgeberwertreferenzierung: Hubantriebsachse

Keyence (vgl. Anhang F.2) ist auf einer Traverse an der Prozessrahmenplatte befestigt und misst die vertikale Position des Aluminiumstreifens. Die Stempelbaugruppe nähert sich anschließend positionsgeregelt in einer Aufwärtsfahrt dem Aluminiumstreifen. Zeigt der Regler des Messgeräts einen Messwert unwesentlich größer als 0,000 mm an, hat die Plattformoberfläche Kontakt zur Unterseite des Aluminiumstreifens. Der zugehörige Lageistwert des Erstkontakts entspricht dem gesuchten Referenzwert.

Tabelle D.9.: Maschinenreferenzierte Drehgeberwertausgabe in z-Richtung

\begin{tabular}{l|r|r}
\hline Hubantriebsbaugruppe / Plattform & Drehgeberwert & z-Position \\
\hline Q1 Baustempel / Bauplattform & $149,835 \mathrm{~mm}$ & $0,000 \mathrm{~mm}$ \\
\hline Q3 Pulverzuführung I / Pulverzuführplattform I & $155,355 \mathrm{~mm}$ & $0,000 \mathrm{~mm}$ \\
\hline Q4 Pulverzuführung II / Pulverzuführplattform II & $155,285 \mathrm{~mm}$ & $0,000 \mathrm{~mm}$ \\
\hline
\end{tabular}

Die Messung wird für alle Hubantriebsbaugruppen wiederholt. Die Ergebnisse sind in Tabelle D.9 zusammengefasst. Bei weiterer Erhöhung der Drehgeberwerte werden die jeweiligen Stempelbaugruppen über die Oberfläche der Prozesseinsatzplatte bewegt. Um die Achsen an der Fahrt über die angegebenen Lageistwerte hinaus zu hindern, wird die Lagegrenzwertüberwachung aus Anhang D.3 angepasst. Die oberen IndraWorks-internen Fahrbereichsgrenzwerte (ohne montierte Stempelbaugruppe) aus Tabelle D.4 werden achsspezifisch entsprechend der neuen Einbausituation verändert. Weiterhin soll die Eingabemöglichkeit der Lagesollwertvorgabe in dem LabVIEW-Steuerprogramm programmatisch eingeschränkt werden. Das LabVIEW-interne Eingabeintervall muss innerhalb des achsspezifischen IndraWorks-internen Fahrbereichs liegen. Die Fahrbereichsgrenzwerte der Achsen mit montierter Stempelbaugruppe sind in Tabelle D.10 
zusammengefasst. Die Überwachung durch die Fahrbereichsgrenzschalter bleibt unverändert. Zur Reinigung der Gehäuse oder Stempeloberflächen werden die Achsen in die unteren LabVIEW-internen Fahrbereichsgrenzwerte gefahren.

Tabelle D.10.: Fahrbereichsbegrenzung der Hubantriebsachsen nach Referenzierung

\begin{tabular}{|c|c|c|}
\hline \multicolumn{3}{|c|}{ Hubantriebsachse aus dem Baustempelmodul: Q1 } \\
\hline & Drehgeberwert & z-Position \\
\hline Nullposition / Referenzposition & $149,835 \mathrm{~mm}$ & $0,000 \mathrm{~mm}$ \\
\hline IndraWorks-interner Fahrbereichsgrenzwert unten & $15,000 \mathrm{~mm}$ & $134,835 \mathrm{~mm}$ \\
\hline IndraWorks-interner Fahrbereichsgrenzwert oben & $150,000 \mathrm{~mm}$ & $-0,165 \mathrm{~mm}$ \\
\hline LabVIEW-interner Fahrbereichsgrenzwert unten & $19,835 \mathrm{~mm}$ & $130,000 \mathrm{~mm}$ \\
\hline LabVIEW-interner Fahrbereichsgrenzwert oben & $149,900 \mathrm{~mm}$ & $-0,065 \mathrm{~mm}$ \\
\hline \multicolumn{3}{|c|}{ Hubantriebsachse aus dem Pulverzuführmodul I: Q3 } \\
\hline & Drehgeberwert & z-Position \\
\hline Nullposition / Referenzposition & $155,355 \mathrm{~mm}$ & $0,000 \mathrm{~mm}$ \\
\hline IndraWorks-interner Fahrbereichsgrenzwert unten & $15,000 \mathrm{~mm}$ & $140,355 \mathrm{~mm}$ \\
\hline IndraWorks-interner Fahrbereichsgrenzwert oben & $155,500 \mathrm{~mm}$ & $-0,145 \mathrm{~mm}$ \\
\hline LabVIEW-interner Fahrbereichsgrenzwert unten & $25,355 \mathrm{~mm}$ & $130,000 \mathrm{~mm}$ \\
\hline LabVIEW-interner Fahrbereichsgrenzwert oben & $155,400 \mathrm{~mm}$ & $-0,045 \mathrm{~mm}$ \\
\hline \multicolumn{3}{|c|}{ Hubantriebsachse aus dem Pulverzuführmodul II: Q4 } \\
\hline & Drehgeberwert & z-Position \\
\hline Nullposition / Referenzposition & $155,285 \mathrm{~mm}$ & $0,000 \mathrm{~mm}$ \\
\hline IndraWorks-interner Fahrbereichsgrenzwert unten & $15,000 \mathrm{~mm}$ & $140,285 \mathrm{~mm}$ \\
\hline IndraWorks-interner Fahrbereichsgrenzwert oben & $155,400 \mathrm{~mm}$ & $-0,115 \mathrm{~mm}$ \\
\hline LabVIEW-interner Fahrbereichsgrenzwert unten & $25,285 \mathrm{~mm}$ & $130,000 \mathrm{~mm}$ \\
\hline LabVIEW-interner Fahrbereichsgrenzwert oben & $155,350 \mathrm{~mm}$ & $-0,065 \mathrm{~mm}$ \\
\hline
\end{tabular}

Zur Referenzierung der Achse des Pulverauftragmoduls wird der in Abbildung D.10 dargestellte Messaufbau genutzt. Da die Prozesseinsatzplatte der Lasersintermaschine symmetrisch aufgebaut ist, wird der Mittelpunkt der Bauplattform als Referenzpunkt für die Pulverauftragsbewegung (x-Richtung oder y-Richtung) definiert. Ist das Antriebsregelgerät „Q2“ bestromt und der Antriebsmotor auf „Standby“, kann die Spindel des Kugelgewindetriebs der Antriebsbaugruppe per Hand gedreht werden. Der Lageistwert (Drehwinkel der Motorwelle) der Achse kann in IndraWorks abgelesen werden. Der Auftragsschlitten (Beschichtereinheit-Aufnahme) wird auf die Rückseite der Maschine bewegt, mittels Schlosserwinkel deckungsgleich (vgl. (a) Abbildung D.10) an der Überlauföffnung ausgerichtet und der entsprechende Lageistwert $(74,175 \mathrm{~mm}$ ) abgelesen. Die Ausrichtung wird an der vorderen Überlauföffnung (vgl. (b) Abbildung D.10) wiederholt und der entsprechende Lageistwert $(349,287 \mathrm{~mm})$ abgelesen. Der Mittelwert der beiden Lageistwerte entspricht dem Referenzpunkt der Pulverauftragsbewegung aus Tabelle D.11. Die Beschichtereinheit wird auf die Oberseite des Auftragsschlittens (Beschichtereinheit-Aufnahme) montiert und durch die Formschrägen der verwendeten Senkschrauben mittig ausgerichtet. Die Abbildung D.10 (c) stellt die Beschichtereinheit mit starrer Klinge auf 


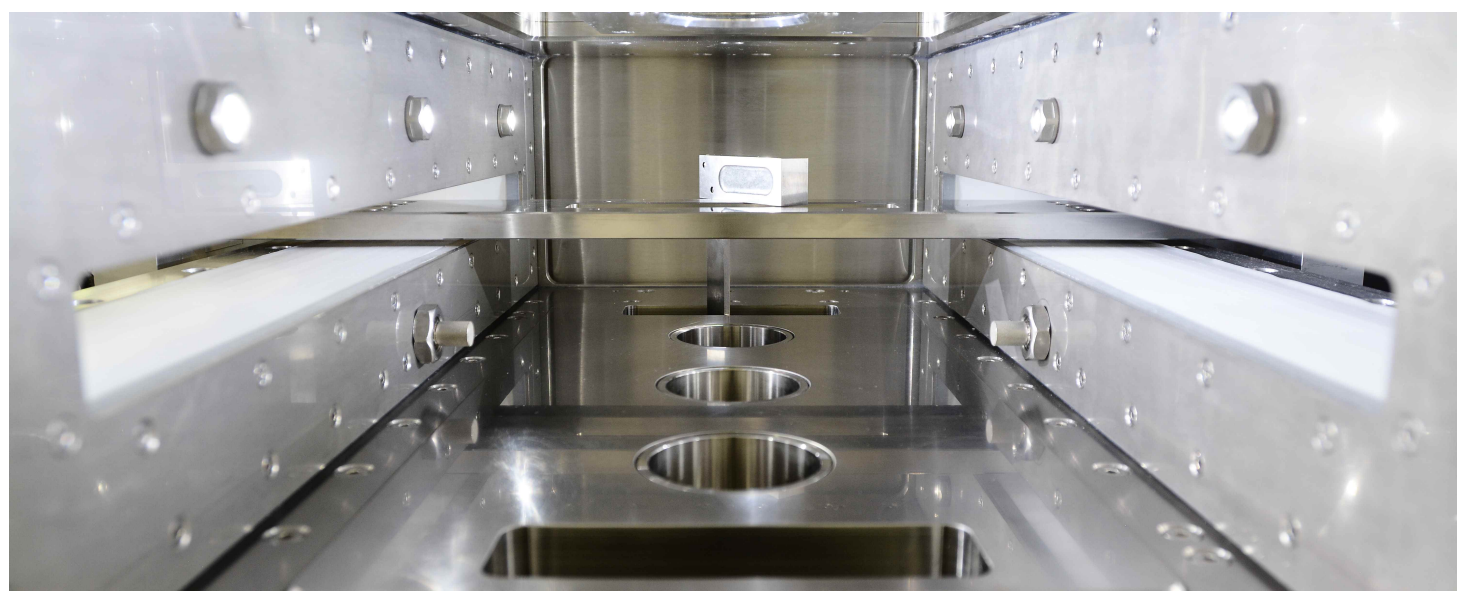

(a) Hintere Ausrichtung des Auftragsschlittens (Lageistwert 74,175 mm)

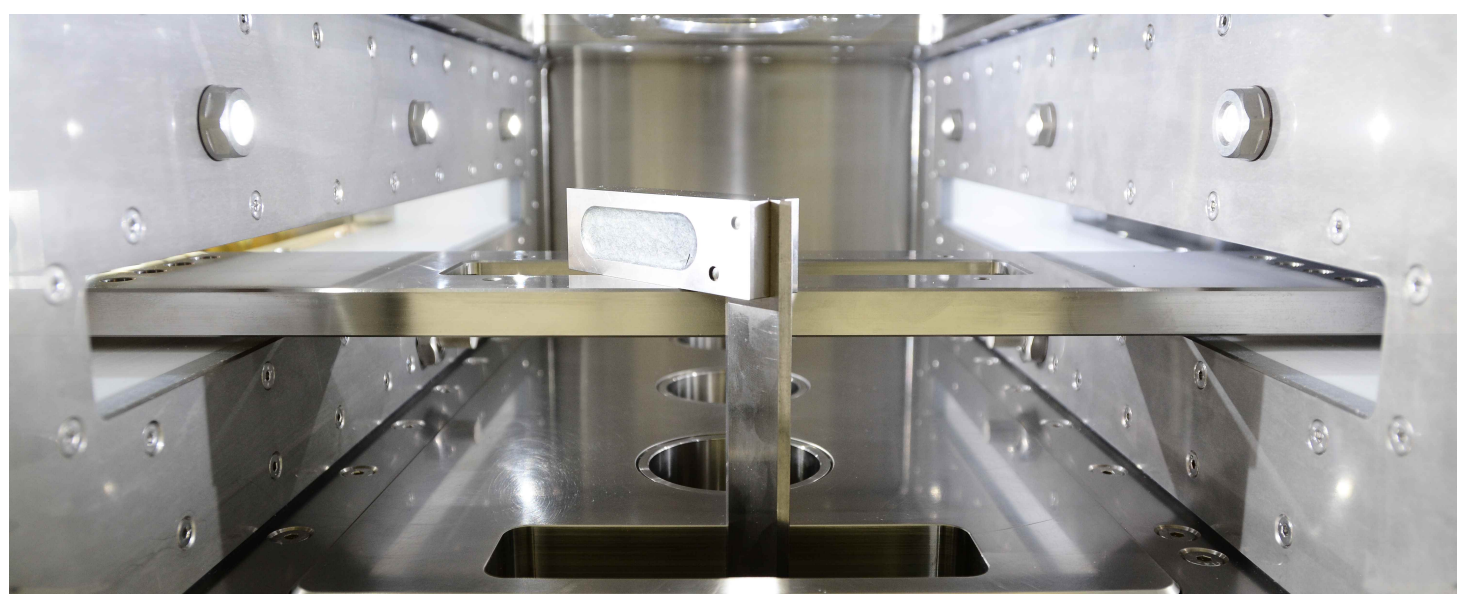

(b) Vordere Ausrichtung des Auftragsschlittens (Lageistwert 349,287 mm)

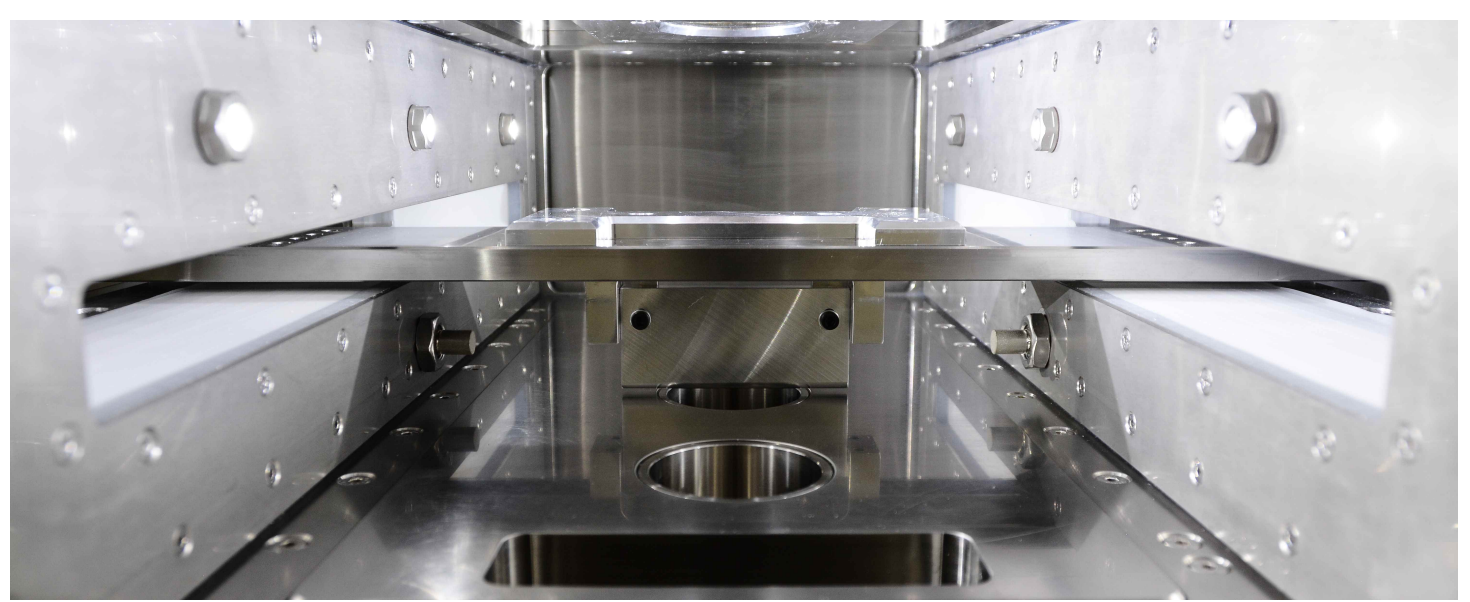

(c) Mittig positionierter Auftragsschlitten samt Beschichtereinheit (Lageistwert 211,731 mm)

Abbildung D.10.: Messaufbau zur Drehgeberwertreferenzierung: Pulverauftragsachse 
dem Auftragsschlitten im Lageistwert von 211,731 mm dar. Bewegt sich die Beschichtereinheit um jeweils $200 \mathrm{~mm}$ in alternierender Richtung um die Referenzposition, kann das überschüssige Pulver in die Überläufe transportiert werden. Die LabVIEW-internen Fahrbereichsgrenzwerte sind gemäß Tabelle D.12 einzustellen.

Tabelle D.11.: Maschinenreferenzierte Drehgeberwertausgabe in $\mathrm{x}$-/y-Richtung

\begin{tabular}{l|r|r}
\hline Achse des Pulverauftragmoduls & Drehgeberwert & x-/y-Position \\
\hline Q2 Pulverauftrag / Mitte Auftragsschlitten & $211,731 \mathrm{~mm}$ & $0,000 \mathrm{~mm}$ \\
\hline
\end{tabular}

Tabelle D.12.: Fahrbereichsbegrenzung der Pulverauftragsachse nach Referenzierung

\begin{tabular}{l|r|r}
\hline \multicolumn{3}{c}{ Antriebsachse aus dem Pulverauftragsmodul: Q2 } \\
\hline Nullposition / Referenzposition & Drehgeberwert & $\mid \mathbf{x}$-/y-Position \\
\hline IndraWorks-interner Fahrbereichsgrenzwert hinten & $211,731 \mathrm{~mm}$ & $0,000 \mathrm{~mm}$ \\
\hline IndraWorks-interner Fahrbereichsgrenzwert vorne & $4,000 \mathrm{~mm}$ & $207,731 \mathrm{~mm}$ \\
\hline LabVIEW-interner Fahrbereichsgrenzwert hinten & $116,000 \mathrm{~mm}$ & $204,269 \mathrm{~mm}$ \\
\hline LabVIEW-interner Fahrbereichsgrenzwert vorne & $411,731 \mathrm{~mm}$ & $200,000 \mathrm{~mm}$ \\
\hline
\end{tabular}

Die Abbildung D.11 stellt die vom Drehgeber ausgegebenen Lageistwerte der Pulverauftragsachse bezogen auf die Anbauteile an der Prozesseinsatzplatte dar. Ist der Pulverauftragskörper symmetrisch an der Beschichtereinheit-Aufnahme (Auftragsschlitten) angeordnet, entspricht der Lageistwert der Pulverauftragsachse dem Lageistwert der Beschichtereinheit.

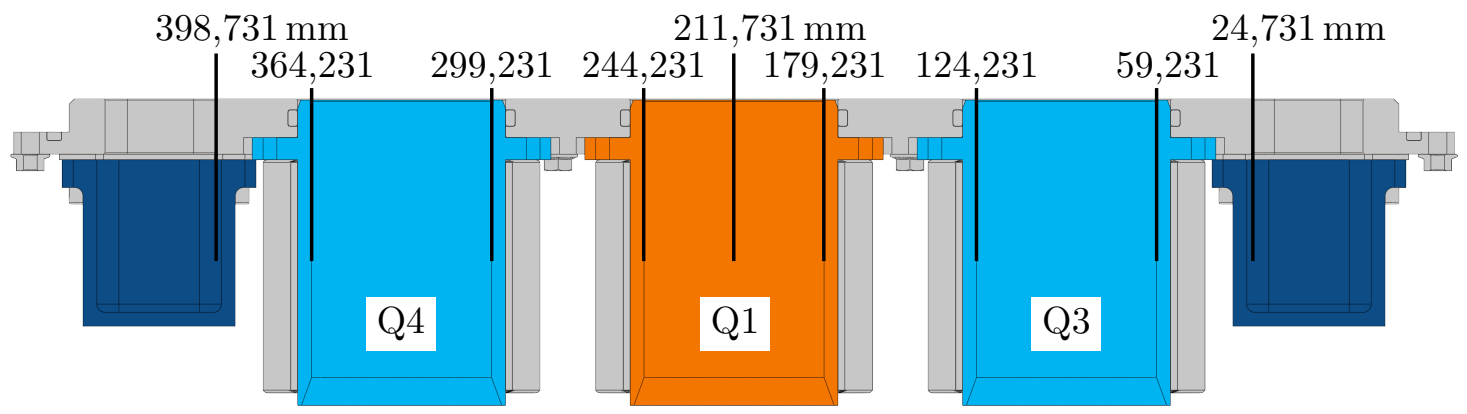

Abbildung D.11.: Drehgeberwertausgabe der Pulverauftragsachse nach Referenzierung 


\section{E. Messung der Positioniergenauigkeiten der Hubantriebsachsen}

Die Lasersintermaschine ist mit insgesamt drei Hubantriebsachsen ausgestattet. Die Hubantriebsachse aus dem Baustempelmodul (Q1) positioniert die Bauplattform in der vertikalen z-Richtung innerhalb des Baustempelgehäuses. Das Inkrement, um das die Bauplattform während des Lasersinterprozesses abgesenkt wird, entspricht der Schichtstärke. Die Hubantriebsachsen aus dem Pulverzuführmodul (Q3 und Q4) positionieren die Zuführplattformen in der vertikalen z-Richtung innerhalb der Pulverzuführgehäuse. Das Inkrement, um das der Pulverzuführstempel während des Lasersinterprozesses angehoben wird, beeinflusst das für den Pulverauftragsprozess bereitgestellte Pulvervolumen. Die Positioniergenauigkeiten der Hubantriebsachsen wurden im Rahmen der Inbetriebnahme der Lasersintermaschine mit dem in Anhang F.2 dargestellten Laser-Wegmesssystem LC-2400 (Messbereich $\pm 3 \mathrm{~mm} /$ Auflösung 0,2 $\mu \mathrm{m}$ ) der Firma Keyence wiederholt gemessen. In Anhang E.1 ist die Messung der Positioniergenauigkeiten der Hubantriebsbaugruppen auf einem Verfahrweg von ca. $80 \mathrm{~mm}$ (Länge der z-Achse der Lasersintermaschine) dargestellt. Das Messobjekt ist die Oberseite der Jochplatte (Montageschnittstelle der Stempelbaugruppe) der Führungseinheit. Die Messungen erfolgten vor dem Kupplungsumbau an den Festo Führungseinheiten (vgl. Anhang D.5) bei demontierten Stempelbaugruppen. In Anhang E.2 ist die Messung der Positioniergenauigkeiten der Plattformen auf einem Verfahrweg von ca. $17 \mathrm{~mm}$ (ab der Nullposition der z-Achse der Lasersintermaschine) dargestellt. Das Messobjekt ist die Oberseite der Stempelbaugruppe innerhalb des Gehäuses. Die Messungen erfolgten nach dem Kupplungsumbau an den Festo Führungseinheiten bei montierten Stempelbaugruppen. 


\section{E.1. Positioniergenauigkeiten der Hubantriebsbaugruppen}

Die Abbildung E.1 stellt den Messaufbau zur Bestimmung der Positioniergenauigkeit einer Hubantriebsbaugruppe auf einem Verfahrbereich von $5 \mathrm{~mm}$ dar. Der Messkopf ist über einen Aluminiumwinkel auf der Jochplattenoberseite der Führungseinheit des Zuführantriebs I (Q3) befestigt. Das Messobjekt, das während der Messreihe im Verschiebungsbereich unterhalb des Messkopfs positioniert wird, ist die Jochplattenoberseite der Hubantriebsbaugruppe aus dem Baustempelmodul (Q1). Da die Rauheit der Jochplattenoberfläche zu hoch für eine Laserabstandsmessung ist, wird eine feingefräste Aluminiumplatte samt diffus reflektierendem Emissionsklebeband aufgeschraubt. Zur

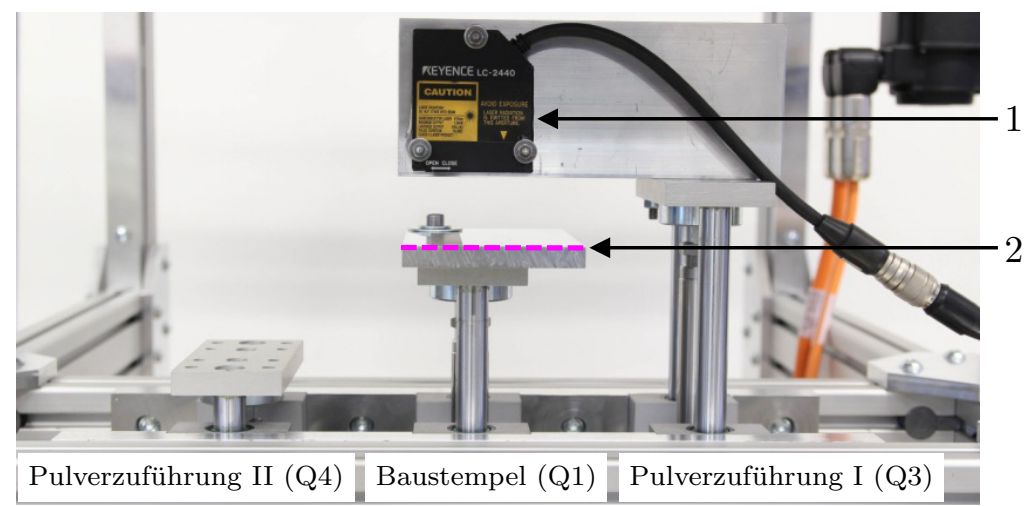

(1) Messkopf

(2) Messobjektebene

(a) Vorderansicht des Messaufbaus: Führungseinheit der Hubantriebsbaugruppe als Messobjekt
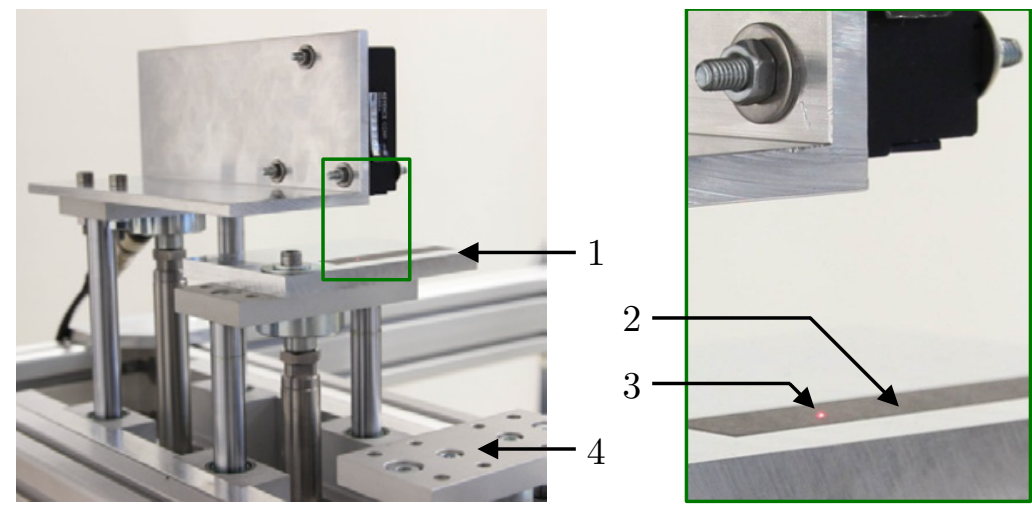

(1) Aluplatte

(2) Emissionsklebeband

(3) Lasermesspunkt

(4) FENG Jochplatte

(b) Anbindung von Messkopf, Messkopfhalterung und der Messobjektoberfläche

Abbildung E.1.: Messaufbau zur Bestimmung der Positioniergenauigkeit der Hubantriebsbaugruppen / Messobjekt: Führungseinheit Q1

Durchführung einer Messreihe bei einem Inkrement von $100 \mu \mathrm{m}$ sind 50 Einzelmessungen notwendig. Zur Bewegung zwischen den jeweiligen Drehgeberwerten wird die Geschwindigkeit von $v_{0,25}=0,05 \mathrm{~mm} / \mathrm{s}$ (bei einem „Smoothing Factor" von 0,25) gewählt. Ist die Messreihe abgeschlossen, werden die Hubantriebsbaugruppen Q1 (Messobjekt) und Q3 (Messkopf) um $5 \mathrm{~mm}$ verfahren, das Messsystem neu kalibriert und die nächste Mess- 
reihe gestartet. Zur Messung der Positioniergenauigkeit des Zuführantriebs I (Q3) bzw. II (Q4) wird die Messkopfhalterung samt Messkopf auf der Jochplattenoberseite der Hubantriebsbaugruppe aus dem Baustempelmodul befestigt. Die Aluminiumplatte samt Emissionsklebeband wird entsprechend auf die Jochplattenoberseite des Zuführantriebs I (Q3) bzw. II (Q4) geschraubt. Die Tabelle E.1 stellt die Ergebnisse der Messreihe im Drehgeberwertintervall von $158,500 \mathrm{~mm}$ bis $153,500 \mathrm{~mm}$ (Verfahrbereich $5 \mathrm{~mm}$ ) bei einem Inkrement von $100 \mu \mathrm{m}$ (Bewegungsrichtung abwärts) der Hubantriebsbaugruppe aus dem Baustempelmodul (Q1) dar. Die Abweichung der 1. Messung ( $-0,2 \mu \mathrm{m})$ berechnet sich aus der Differenz des 2. und 1. Messwerts $(0,0998 \mu \mathrm{m}-0,000 \mu \mathrm{m})$ abzüglich des Inkrements $(100 \mu \mathrm{m})$ der Positionierung. Aus den Absolutwerten der Abweichungen wird der Mittelwert $\left(\bar{x}_{|\mathrm{Abw}|}\right)$ und die Standardabweichung $\left(s_{|\mathrm{Abw}|}\right)$ bestimmt.

Tabelle E.1.: Positioniergenauigkeit der Hubantriebsbaugruppe Q1: Messreihe 1-Q1-100

\begin{tabular}{|c|c|c|c|c|c|}
\hline Messung & Drehgeberwert & Inkrement & Messwert & Abweichung & |Abweichung| \\
\hline 1 & $158,500 \mathrm{~mm}$ & $100 \mu \mathrm{m}$ & $0,0000 \mathrm{~mm}$ & $-0,2 \mu \mathrm{m}$ & $0,2 \mu \mathrm{m}$ \\
\hline 2 & $158,400 \mathrm{~mm}$ & $100 \mu \mathrm{m}$ & $0,0998 \mathrm{~mm}$ & $-0,6 \mu \mathrm{m}$ & $0,6 \mu \mathrm{m}$ \\
\hline 3 & $158,300 \mathrm{~mm}$ & $100 \mu \mathrm{m}$ & $0,1992 \mathrm{~mm}$ & $1,2 \mu \mathrm{m}$ & $1,2 \mu \mathrm{m}$ \\
\hline 4 & $158,200 \mathrm{~mm}$ & $100 \mu \mathrm{m}$ & $0,3004 \mathrm{~mm}$ & $-1,8 \mu \mathrm{m}$ & $1,8 \mu \mathrm{m}$ \\
\hline 5 & $158,100 \mathrm{~mm}$ & $100 \mu \mathrm{m}$ & $0,3986 \mathrm{~mm}$ & $1,8 \mu \mathrm{m}$ & $1,8 \mu \mathrm{m}$ \\
\hline 6 & $158,000 \mathrm{~mm}$ & $100 \mu \mathrm{m}$ & $0,5004 \mathrm{~mm}$ & $1,2 \mu \mathrm{m}$ & $1,2 \mu \mathrm{m}$ \\
\hline 7 & $157,900 \mathrm{~mm}$ & $100 \mu \mathrm{m}$ & $0,6016 \mathrm{~mm}$ & $1,4 \mu \mathrm{m}$ & $1,4 \mu \mathrm{m}$ \\
\hline 8 & $157,800 \mathrm{~mm}$ & $100 \mu \mathrm{m}$ & $0,7030 \mathrm{~mm}$ & $0,0 \mu \mathrm{m}$ & $0,0 \mu \mathrm{m}$ \\
\hline 9 & $157,700 \mathrm{~mm}$ & $100 \mu \mathrm{m}$ & $0,8030 \mathrm{~mm}$ & $1,8 \mu \mathrm{m}$ & $1,8 \mu \mathrm{m}$ \\
\hline 10 & $157,600 \mathrm{~mm}$ & $100 \mu \mathrm{m}$ & $0,9048 \mathrm{~mm}$ & $-2,8 \mu \mathrm{m}$ & $2,8 \mu \mathrm{m}$ \\
\hline 11 & $157,500 \mathrm{~mm}$ & $100 \mu \mathrm{m}$ & $1,0020 \mathrm{~mm}$ & $-2,0 \mu \mathrm{m}$ & $2,0 \mu \mathrm{m}$ \\
\hline 12 & $157,400 \mathrm{~mm}$ & $100 \mu \mathrm{m}$ & $1,1000 \mathrm{~mm}$ & $-0,4 \mu \mathrm{m}$ & $0,4 \mu \mathrm{m}$ \\
\hline 13 & $157,300 \mathrm{~mm}$ & $100 \mu \mathrm{m}$ & $1,1996 \mathrm{~mm}$ & $0,6 \mu \mathrm{m}$ & $0,6 \mu \mathrm{m}$ \\
\hline 14 & $157,200 \mathrm{~mm}$ & $100 \mu \mathrm{m}$ & $1,3002 \mathrm{~mm}$ & $0,4 \mu \mathrm{m}$ & $0,4 \mu \mathrm{m}$ \\
\hline 15 & $157,100 \mathrm{~mm}$ & $100 \mu \mathrm{m}$ & $1,4006 \mathrm{~mm}$ & $0,8 \mu \mathrm{m}$ & $0,8 \mu \mathrm{m}$ \\
\hline 16 & $157,000 \mathrm{~mm}$ & $100 \mu \mathrm{m}$ & $1,5014 \mathrm{~mm}$ & $-0,6 \mu \mathrm{m}$ & $0,6 \mu \mathrm{m}$ \\
\hline 17 & $156,900 \mathrm{~mm}$ & $100 \mu \mathrm{m}$ & $1,6008 \mathrm{~mm}$ & $-1,6 \mu \mathrm{m}$ & $1,6 \mu \mathrm{m}$ \\
\hline 18 & $156,800 \mathrm{~mm}$ & $100 \mu \mathrm{m}$ & $1,6992 \mathrm{~mm}$ & $-0,6 \mu \mathrm{m}$ & $0,6 \mu \mathrm{m}$ \\
\hline 19 & $156,700 \mathrm{~mm}$ & $100 \mu \mathrm{m}$ & $1,7986 \mathrm{~mm}$ & $-0,6 \mu \mathrm{m}$ & $0,6 \mu \mathrm{m}$ \\
\hline 20 & $156,600 \mathrm{~mm}$ & $100 \mu \mathrm{m}$ & $1,8980 \mathrm{~mm}$ & $0,2 \mu \mathrm{m}$ & $0,2 \mu \mathrm{m}$ \\
\hline 21 & $156,500 \mathrm{~mm}$ & $100 \mu \mathrm{m}$ & $1,9982 \mathrm{~mm}$ & $0,6 \mu \mathrm{m}$ & $0,6 \mu \mathrm{m}$ \\
\hline 22 & $156,400 \mathrm{~mm}$ & $100 \mu \mathrm{m}$ & $2,0988 \mathrm{~mm}$ & $0,4 \mu \mathrm{m}$ & $0,4 \mu \mathrm{m}$ \\
\hline 23 & $156,300 \mathrm{~mm}$ & $100 \mu \mathrm{m}$ & $2,1992 \mathrm{~mm}$ & $1,0 \mu \mathrm{m}$ & $1,0 \mu \mathrm{m}$ \\
\hline 24 & $156,200 \mathrm{~mm}$ & $100 \mu \mathrm{m}$ & $2,3002 \mathrm{~mm}$ & $1,4 \mu \mathrm{m}$ & $1,4 \mu \mathrm{m}$ \\
\hline 25 & $156,100 \mathrm{~mm}$ & $100 \mu \mathrm{m}$ & $2,4016 \mathrm{~mm}$ & $2,2 \mu \mathrm{m}$ & $2,2 \mu \mathrm{m}$ \\
\hline 26 & $156,000 \mathrm{~mm}$ & $100 \mu \mathrm{m}$ & $2,5038 \mathrm{~mm}$ & $1,0 \mu \mathrm{m}$ & $1,0 \mu \mathrm{m}$ \\
\hline 27 & $155,900 \mathrm{~mm}$ & $100 \mu \mathrm{m}$ & $2,6048 \mathrm{~mm}$ & $-0,2 \mu \mathrm{m}$ & $0,2 \mu \mathrm{m}$ \\
\hline 28 & $155,800 \mathrm{~mm}$ & $100 \mu \mathrm{m}$ & $2,7046 \mathrm{~mm}$ & $-1,6 \mu \mathrm{m}$ & $1,6 \mu \mathrm{m}$ \\
\hline 29 & $155,700 \mathrm{~mm}$ & $100 \mu \mathrm{m}$ & $2,8030 \mathrm{~mm}$ & $0,2 \mu \mathrm{m}$ & $0,2 \mu \mathrm{m}$ \\
\hline 30 & $155,600 \mathrm{~mm}$ & $100 \mu \mathrm{m}$ & $2,9032 \mathrm{~mm}$ & $-0,4 \mu \mathrm{m}$ & $0,4 \mu \mathrm{m}$ \\
\hline 31 & $155,500 \mathrm{~mm}$ & $100 \mu \mathrm{m}$ & $3,0028 \mathrm{~mm}$ & $-0,2 \mu \mathrm{m}$ & $0,2 \mu \mathrm{m}$ \\
\hline 32 & $155,400 \mathrm{~mm}$ & $100 \mu \mathrm{m}$ & $3,1026 \mathrm{~mm}$ & $0,4 \mu \mathrm{m}$ & $0,4 \mu \mathrm{m}$ \\
\hline 33 & $155,300 \mathrm{~mm}$ & $100 \mu \mathrm{m}$ & $3,2030 \mathrm{~mm}$ & $0,8 \mu \mathrm{m}$ & $0,8 \mu \mathrm{m}$ \\
\hline 34 & $155,200 \mathrm{~mm}$ & $100 \mu \mathrm{m}$ & $3,3038 \mathrm{~mm}$ & $1,2 \mu \mathrm{m}$ & $1,2 \mu \mathrm{m}$ \\
\hline 35 & $155,100 \mathrm{~mm}$ & $100 \mu \mathrm{m}$ & $3,4050 \mathrm{~mm}$ & $0,6 \mu \mathrm{m}$ & $0,6 \mu \mathrm{m}$ \\
\hline 36 & $155,000 \mathrm{~mm}$ & $100 \mu \mathrm{m}$ & $3,5056 \mathrm{~mm}$ & $1,2 \mu \mathrm{m}$ & $1,2 \mu \mathrm{m}$ \\
\hline
\end{tabular}


Anhang E. Messung der Positioniergenauigkeiten der Hubantriebsachsen

\begin{tabular}{|c|c|c|c|c|c|}
\hline 37 & $154,900 \mathrm{~mm}$ & $100 \mu \mathrm{m}$ & $3,6068 \mathrm{~mm}$ & $1,2 \mu \mathrm{m}$ & $1,2 \mu \mathrm{m}$ \\
\hline 38 & $154,800 \mathrm{~mm}$ & $100 \mu \mathrm{m}$ & $3,7080 \mathrm{~mm}$ & $0,6 \mu \mathrm{m}$ & $0,6 \mu \mathrm{m}$ \\
\hline 39 & $154,700 \mathrm{~mm}$ & $100 \mu \mathrm{m}$ & $3,8086 \mathrm{~mm}$ & $0,2 \mu \mathrm{m}$ & $0,2 \mu \mathrm{m}$ \\
\hline 40 & $154,600 \mathrm{~mm}$ & $100 \mu \mathrm{m}$ & $3,9088 \mathrm{~mm}$ & $0,0 \mu \mathrm{m}$ & $0,0 \mu \mathrm{m}$ \\
\hline 41 & $154,500 \mathrm{~mm}$ & $100 \mu \mathrm{m}$ & $4,0088 \mathrm{~mm}$ & $0,2 \mu \mathrm{m}$ & $0,2 \mu \mathrm{m}$ \\
\hline 42 & $154,400 \mathrm{~mm}$ & $100 \mu \mathrm{m}$ & $4,1090 \mathrm{~mm}$ & $-0,4 \mu \mathrm{m}$ & $0,4 \mu \mathrm{m}$ \\
\hline 43 & $154,300 \mathrm{~mm}$ & $100 \mu \mathrm{m}$ & $4,2086 \mathrm{~mm}$ & $-0,8 \mu \mathrm{m}$ & $0,8 \mu \mathrm{m}$ \\
\hline 44 & $154,200 \mathrm{~mm}$ & $100 \mu \mathrm{m}$ & $4,3078 \mathrm{~mm}$ & $0,0 \mu \mathrm{m}$ & $0,0 \mu \mathrm{m}$ \\
\hline 45 & $154,100 \mathrm{~mm}$ & $100 \mu \mathrm{m}$ & $4,4078 \mathrm{~mm}$ & $-0,4 \mu \mathrm{m}$ & $0,4 \mu \mathrm{m}$ \\
\hline 46 & $154,000 \mathrm{~mm}$ & $100 \mu \mathrm{m}$ & $4,5074 \mathrm{~mm}$ & $-0,2 \mu \mathrm{m}$ & $0,2 \mu \mathrm{m}$ \\
\hline 47 & $153,900 \mathrm{~mm}$ & $100 \mu \mathrm{m}$ & $4,6072 \mathrm{~mm}$ & $0,0 \mu \mathrm{m}$ & $0,0 \mu \mathrm{m}$ \\
\hline 48 & $153,800 \mathrm{~mm}$ & $100 \mu \mathrm{m}$ & $4,7072 \mathrm{~mm}$ & $-0,4 \mu \mathrm{m}$ & $0,4 \mu \mathrm{m}$ \\
\hline 49 & $153,700 \mathrm{~mm}$ & $100 \mu \mathrm{m}$ & $4,8068 \mathrm{~mm}$ & $0,0 \mu \mathrm{m}$ & $0,0 \mu \mathrm{m}$ \\
\hline \multirow[t]{2}{*}{50} & $153,600 \mathrm{~mm}$ & $100 \mu \mathrm{m}$ & $4,9068 \mathrm{~mm}$ & $0,2 \mu \mathrm{m}$ & $0,2 \mu \mathrm{m}$ \\
\hline & $153,500 \mathrm{~mm}$ & $100 \mu \mathrm{m}$ & $5,0070 \mathrm{~mm}$ & & \\
\hline & 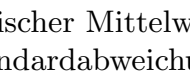 & . & (2) & eichung & $\begin{array}{l}0,8 \mu \mathrm{m} \\
0,7 \mu \mathrm{m}\end{array}$ \\
\hline
\end{tabular}

Pro Hubantriebsbaugruppe werden jeweils 17 Messreihen (850 Einzelmessungen bei einem Inkrement von $100 \mu \mathrm{m}$ ) zur Bestimmung der Positioniergenauigkeit auf ca. $80 \mathrm{~mm}$ Verfahrweg durchgeführt. Das Ergebnis der Auswertung $\left(\bar{x}_{|\mathrm{Abw}|} / s_{|\mathrm{Abw}|}\right)$ der jeweiligen Messreihe wird in die achsspezifischen Übersichtstabellen (vgl. Tabelle E.2) überführt.

Tabelle E.2.: Positioniergenauigkeiten der Hubantriebsbaugruppen Q1 / Q3 / Q4

Hubantriebsbaugruppe aus dem Baustempelmodul: Q1

\begin{tabular}{r|r|r|r|r|l}
\hline Messreihe & Drehgeber-Startwert & Drehgeber-Endwert & Inkrement & $\bar{x}_{|\mathrm{Abw}|}$ & $s_{|\mathrm{Abw}|}$ \\
\hline 1-Q1-100 & $158,500 \mathrm{~mm}$ & $153,500 \mathrm{~mm}$ & $100 \mu \mathrm{m}$ & $0,8 \mu \mathrm{m}$ & $0,7 \mu \mathrm{m}$ \\
2-Q1-100 & $153,600 \mathrm{~mm}$ & $148,600 \mathrm{~mm}$ & $100 \mu \mathrm{m}$ & $1,0 \mu \mathrm{m}$ & $0,8 \mu \mathrm{m}$ \\
3-Q1-100 & $148,700 \mathrm{~mm}$ & $143,700 \mathrm{~mm}$ & $100 \mu \mathrm{m}$ & $1,0 \mu \mathrm{m}$ & $1,6 \mu \mathrm{m}$ \\
4-Q1-100 & $143,800 \mathrm{~mm}$ & $138,800 \mathrm{~mm}$ & $100 \mu \mathrm{m}$ & $0,9 \mu \mathrm{m}$ & $0,7 \mu \mathrm{m}$ \\
5-Q1-100 & $138,900 \mathrm{~mm}$ & $133,900 \mathrm{~mm}$ & $100 \mu \mathrm{m}$ & $1,2 \mu \mathrm{m}$ & $0,9 \mu \mathrm{m}$ \\
6-Q1-100 & $134,000 \mathrm{~mm}$ & $129,000 \mathrm{~mm}$ & $100 \mu \mathrm{m}$ & $0,9 \mu \mathrm{m}$ & $1,4 \mu \mathrm{m}$ \\
7-Q1-100 & $129,100 \mathrm{~mm}$ & $124,100 \mathrm{~mm}$ & $100 \mu \mathrm{m}$ & $1,3 \mu \mathrm{m}$ & $1,4 \mu \mathrm{m}$ \\
8-Q1-100 & $124,200 \mathrm{~mm}$ & $119,200 \mathrm{~mm}$ & $100 \mu \mathrm{m}$ & $1,0 \mu \mathrm{m}$ & $1,5 \mu \mathrm{m}$ \\
9-Q1-100 & $119,300 \mathrm{~mm}$ & $114,300 \mathrm{~mm}$ & $100 \mu \mathrm{m}$ & $1,4 \mu \mathrm{m}$ & $1,0 \mu \mathrm{m}$ \\
10-Q1-100 & $114,400 \mathrm{~mm}$ & $109,400 \mathrm{~mm}$ & $100 \mu \mathrm{m}$ & $1,2 \mu \mathrm{m}$ & $0,9 \mu \mathrm{m}$ \\
11-Q1-100 & $109,500 \mathrm{~mm}$ & $104,500 \mathrm{~mm}$ & $100 \mu \mathrm{m}$ & $1,3 \mu \mathrm{m}$ & $1,1 \mu \mathrm{m}$ \\
12-Q1-100 & $104,600 \mathrm{~mm}$ & $99,600 \mathrm{~mm}$ & $100 \mu \mathrm{m}$ & $1,2 \mu \mathrm{m}$ & $1,2 \mu \mathrm{m}$ \\
13-Q1-100 & $99,700 \mathrm{~mm}$ & $94,700 \mathrm{~mm}$ & $100 \mu \mathrm{m}$ & $1,2 \mu \mathrm{m}$ & $0,9 \mu \mathrm{m}$ \\
14-Q1-100 & $94,800 \mathrm{~mm}$ & $89,800 \mathrm{~mm}$ & $100 \mu \mathrm{m}$ & $0,9 \mu \mathrm{m}$ & $1,0 \mu \mathrm{m}$ \\
15-Q1-100 & $89,900 \mathrm{~mm}$ & $84,900 \mathrm{~mm}$ & $100 \mu \mathrm{m}$ & $1,0 \mu \mathrm{m}$ & $0,9 \mu \mathrm{m}$ \\
16-Q1-100 & $85,000 \mathrm{~mm}$ & $80,000 \mathrm{~mm}$ & $100 \mu \mathrm{m}$ & $1,2 \mu \mathrm{m}$ & $0,9 \mu \mathrm{m}$ \\
17-Q1-100 & $80,100 \mathrm{~mm}$ & $75,100 \mathrm{~mm}$ & $100 \mu \mathrm{m}$ & $1,3 \mu \mathrm{m}$ & $1,0 \mu \mathrm{m}$ \\
\hline 1-Q1-50 & $158,500 \mathrm{~mm}$ & $153,500 \mathrm{~mm}$ & $50 \mu \mathrm{m}$ & $0,7 \mu \mathrm{m}$ & $0,8 \mu \mathrm{m}$ \\
2-Q1-50 & $153,550 \mathrm{~mm}$ & $148,550 \mathrm{~mm}$ & $50 \mu \mathrm{m}$ & $0,7 \mu \mathrm{m}$ & $0,6 \mu \mathrm{m}$ \\
3-Q1-50 & $148,600 \mathrm{~mm}$ & $143,600 \mathrm{~mm}$ & $50 \mu \mathrm{m}$ & $0,9 \mu \mathrm{m}$ & $0,7 \mu \mathrm{m}$ \\
4-Q1-50 & $143,650 \mathrm{~mm}$ & $138,650 \mathrm{~mm}$ & $50 \mu \mathrm{m}$ & $0,8 \mu \mathrm{m}$ & $0,8 \mu \mathrm{m}$ \\
5-Q1-50 & $138,700 \mathrm{~mm}$ & $133,700 \mathrm{~mm}$ & $50 \mu \mathrm{m}$ & $0,8 \mu \mathrm{m}$ & $0,8 \mu \mathrm{m}$ \\
6-Q1-50 & $133,750 \mathrm{~mm}$ & $128,750 \mathrm{~mm}$ & $50 \mu \mathrm{m}$ & $0,8 \mu \mathrm{m}$ & $0,7 \mu \mathrm{m}$ \\
7-Q1-50 & $128,800 \mathrm{~mm}$ & $123,800 \mathrm{~mm}$ & $50 \mu \mathrm{m}$ & $0,8 \mu \mathrm{m}$ & $0,7 \mu \mathrm{m}$
\end{tabular}


E.1. Positioniergenauigkeiten der Hubantriebsbaugruppen

\begin{tabular}{|c|c|c|c|c|c|}
\hline 8-Q1-50 & $123,850 \mathrm{~mm}$ & $118,850 \mathrm{~mm}$ & $50 \mu \mathrm{m}$ & $0,8 \mu \mathrm{m}$ & $0,7 \mu \mathrm{m}$ \\
\hline $9-\mathrm{Q} 1-50$ & $118,900 \mathrm{~mm}$ & $113,900 \mathrm{~mm}$ & $50 \mu \mathrm{m}$ & $0,7 \mu \mathrm{m}$ & $0,8 \mu \mathrm{m}$ \\
\hline 10-Q1-50 & $113,950 \mathrm{~mm}$ & $108,950 \mathrm{~mm}$ & $50 \mu \mathrm{m}$ & $0,8 \mu \mathrm{m}$ & $0,9 \mu \mathrm{m}$ \\
\hline 11-Q1-50 & $109,000 \mathrm{~mm}$ & $104,000 \mathrm{~mm}$ & $50 \mu \mathrm{m}$ & $0,9 \mu \mathrm{m}$ & $0,9 \mu \mathrm{m}$ \\
\hline $12-\mathrm{Q} 1-50$ & $104,050 \mathrm{~mm}$ & $99,050 \mathrm{~mm}$ & $50 \mu \mathrm{m}$ & $0,8 \mu \mathrm{m}$ & $0,7 \mu \mathrm{m}$ \\
\hline 13-Q1-50 & $99,100 \mathrm{~mm}$ & $94,100 \mathrm{~mm}$ & $50 \mu \mathrm{m}$ & $0,6 \mu \mathrm{m}$ & $0,6 \mu \mathrm{m}$ \\
\hline 14-Q1-50 & $94,150 \mathrm{~mm}$ & $89,150 \mathrm{~mm}$ & $50 \mu \mathrm{m}$ & $0,7 \mu \mathrm{m}$ & $0,8 \mu \mathrm{m}$ \\
\hline $15-\mathrm{Q} 1-50$ & $89,200 \mathrm{~mm}$ & $84,200 \mathrm{~mm}$ & $50 \mu \mathrm{m}$ & $0,7 \mu \mathrm{m}$ & $0,7 \mu \mathrm{m}$ \\
\hline $16-\mathrm{Q} 1-50$ & $84,250 \mathrm{~mm}$ & $79,250 \mathrm{~mm}$ & $50 \mu \mathrm{m}$ & $0,8 \mu \mathrm{m}$ & $0,7 \mu \mathrm{m}$ \\
\hline $17-Q 1-50$ & $79,300 \mathrm{~mm}$ & $74,300 \mathrm{~mm}$ & $50 \mu \mathrm{m}$ & $0,9 \mu \mathrm{m}$ & $0,9 \mu \mathrm{m}$ \\
\hline
\end{tabular}

Hubantriebsbaugruppe aus dem Pulverzuführmodul I: Q3

\begin{tabular}{r|r|r|r|r|r}
\hline Messreihe & Drehgeber-Startwert & Drehgeber-Endwert & Inkrement & $\bar{x}_{|\mathrm{Abw}|}$ & $s_{|\mathrm{Abw}|}$ \\
\hline 1-Q3-200 & $75,100 \mathrm{~mm}$ & $80,100 \mathrm{~mm}$ & $200 \mu \mathrm{m}$ & $2,9 \mu \mathrm{m}$ & $3,0 \mu \mathrm{m}$ \\
2-Q3-200 & $79,900 \mathrm{~mm}$ & $84,900 \mathrm{~mm}$ & $200 \mu \mathrm{m}$ & $2,8 \mu \mathrm{m}$ & $1,8 \mu \mathrm{m}$ \\
3-Q3-200 & $84,700 \mathrm{~mm}$ & $89,700 \mathrm{~mm}$ & $200 \mu \mathrm{m}$ & $2,3 \mu \mathrm{m}$ & $2,3 \mu \mathrm{m}$ \\
4-Q3-200 & $89,500 \mathrm{~mm}$ & $94,500 \mathrm{~mm}$ & $200 \mu \mathrm{m}$ & $3,2 \mu \mathrm{m}$ & $2,5 \mu \mathrm{m}$ \\
5-Q3-200 & $94,300 \mathrm{~mm}$ & $99,300 \mathrm{~mm}$ & $200 \mu \mathrm{m}$ & $3,0 \mu \mathrm{m}$ & $1,9 \mu \mathrm{m}$ \\
6-Q3-200 & $99,100 \mathrm{~mm}$ & $104,100 \mathrm{~mm}$ & $200 \mu \mathrm{m}$ & $3,1 \mu \mathrm{m}$ & $2,1 \mu \mathrm{m}$ \\
7-Q3-200 & $103,900 \mathrm{~mm}$ & $108,900 \mathrm{~mm}$ & $200 \mu \mathrm{m}$ & $2,1 \mu \mathrm{m}$ & $1,9 \mu \mathrm{m}$ \\
8-Q3-200 & $108,700 \mathrm{~mm}$ & $113,700 \mathrm{~mm}$ & $200 \mu \mathrm{m}$ & $2,3 \mu \mathrm{m}$ & $2,1 \mu \mathrm{m}$ \\
9-Q3-200 & $113,500 \mathrm{~mm}$ & $118,500 \mathrm{~mm}$ & $200 \mu \mathrm{m}$ & $1,7 \mu \mathrm{m}$ & $1,9 \mu \mathrm{m}$ \\
10-Q3-200 & $118,300 \mathrm{~mm}$ & $123,300 \mathrm{~mm}$ & $200 \mu \mathrm{m}$ & $2,2 \mu \mathrm{m}$ & $1,8 \mu \mathrm{m}$ \\
11-Q3-200 & $123,100 \mathrm{~mm}$ & $128,100 \mathrm{~mm}$ & $200 \mu \mathrm{m}$ & $2,3 \mu \mathrm{m}$ & $1,9 \mu \mathrm{m}$ \\
12-Q3-200 & $127,900 \mathrm{~mm}$ & $132,900 \mathrm{~mm}$ & $200 \mu \mathrm{m}$ & $3,8 \mu \mathrm{m}$ & $3,1 \mu \mathrm{m}$ \\
13-Q3-200 & $132,700 \mathrm{~mm}$ & $137,700 \mathrm{~mm}$ & $200 \mu \mathrm{m}$ & $3,1 \mu \mathrm{m}$ & $2,7 \mu \mathrm{m}$ \\
14-Q3-200 & $137,500 \mathrm{~mm}$ & $142,500 \mathrm{~mm}$ & $200 \mu \mathrm{m}$ & $2,4 \mu \mathrm{m}$ & $2,2 \mu \mathrm{m}$ \\
15-Q3-200 & $142,300 \mathrm{~mm}$ & $147,300 \mathrm{~mm}$ & $200 \mu \mathrm{m}$ & $2,2 \mu \mathrm{m}$ & $2,0 \mu \mathrm{m}$ \\
16-Q3-200 & $147,100 \mathrm{~mm}$ & $152,100 \mathrm{~mm}$ & $200 \mu \mathrm{m}$ & $2,0 \mu \mathrm{m}$ & $1,9 \mu \mathrm{m}$ \\
17-Q3-200 & $151,900 \mathrm{~mm}$ & $156,900 \mathrm{~mm}$ & $200 \mu \mathrm{m}$ & $2,1 \mu \mathrm{m}$ & $1,8 \mu \mathrm{m}$ \\
\hline
\end{tabular}

Hubantriebsbaugruppe aus dem Pulverzuführmodul II: Q4

\begin{tabular}{r|r|r|r|r|r}
\hline Messreihe & Drehgeber-Startwert & Drehgeber-Endwert & Inkrement & $\bar{x}_{|\mathrm{Abw}|}$ & $s_{|\mathrm{Abw}|}$ \\
\hline 1-Q4-200 & $75,100 \mathrm{~mm}$ & $80,100 \mathrm{~mm}$ & $200 \mu \mathrm{m}$ & $2,9 \mu \mathrm{m}$ & $2,5 \mu \mathrm{m}$ \\
2-Q4-200 & $79,900 \mathrm{~mm}$ & $84,900 \mathrm{~mm}$ & $200 \mu \mathrm{m}$ & $2,3 \mu \mathrm{m}$ & $2,1 \mu \mathrm{m}$ \\
3-Q4-200 & $84,700 \mathrm{~mm}$ & $89,700 \mathrm{~mm}$ & $200 \mu \mathrm{m}$ & $2,1 \mu \mathrm{m}$ & $2,4 \mu \mathrm{m}$ \\
4-Q4-200 & $89,500 \mathrm{~mm}$ & $94,500 \mathrm{~mm}$ & $200 \mu \mathrm{m}$ & $2,0 \mu \mathrm{m}$ & $2,2 \mu \mathrm{m}$ \\
5-Q4-200 & $94,300 \mathrm{~mm}$ & $99,300 \mathrm{~mm}$ & $200 \mu \mathrm{m}$ & $2,3 \mu \mathrm{m}$ & $2,0 \mu \mathrm{m}$ \\
6-Q4-200 & $99,100 \mathrm{~mm}$ & $104,100 \mathrm{~mm}$ & $200 \mu \mathrm{m}$ & $2,2 \mu \mathrm{m}$ & $2,5 \mu \mathrm{m}$ \\
7-Q4-200 & $103,900 \mathrm{~mm}$ & $108,900 \mathrm{~mm}$ & $200 \mu \mathrm{m}$ & $2,7 \mu \mathrm{m}$ & $2,3 \mu \mathrm{m}$ \\
8-Q4-200 & $108,700 \mathrm{~mm}$ & $113,700 \mathrm{~mm}$ & $200 \mu \mathrm{m}$ & $2,3 \mu \mathrm{m}$ & $2,0 \mu \mathrm{m}$ \\
9-Q4-200 & $113,500 \mathrm{~mm}$ & $118,500 \mathrm{~mm}$ & $200 \mu \mathrm{m}$ & $2,2 \mu \mathrm{m}$ & $2,1 \mu \mathrm{m}$ \\
10-Q4-200 & $118,300 \mathrm{~mm}$ & $123,300 \mathrm{~mm}$ & $200 \mu \mathrm{m}$ & $2,4 \mu \mathrm{m}$ & $1,6 \mu \mathrm{m}$ \\
11-Q4-200 & $123,100 \mathrm{~mm}$ & $128,100 \mathrm{~mm}$ & $200 \mu \mathrm{m}$ & $2,1 \mu \mathrm{m}$ & $1,7 \mu \mathrm{m}$ \\
12-Q4-200 & $127,900 \mathrm{~mm}$ & $132,900 \mathrm{~mm}$ & $200 \mu \mathrm{m}$ & $2,2 \mu \mathrm{m}$ & $2,0 \mu \mathrm{m}$ \\
13-Q4-200 & $132,700 \mathrm{~mm}$ & $137,700 \mathrm{~mm}$ & $200 \mu \mathrm{m}$ & $2,2 \mu \mathrm{m}$ & $1,8 \mu \mathrm{m}$ \\
14-Q4-200 & $137,500 \mathrm{~mm}$ & $142,500 \mathrm{~mm}$ & $200 \mu \mathrm{m}$ & $3,0 \mu \mathrm{m}$ & $2,2 \mu \mathrm{m}$ \\
15-Q4-200 & $142,300 \mathrm{~mm}$ & $147,300 \mathrm{~mm}$ & $200 \mu \mathrm{m}$ & $2,8 \mu \mathrm{m}$ & $2,5 \mu \mathrm{m}$ \\
16-Q4-200 & $147,100 \mathrm{~mm}$ & $152,100 \mathrm{~mm}$ & $200 \mu \mathrm{m}$ & $1,8 \mu \mathrm{m}$ & $2,3 \mu \mathrm{m}$ \\
17-Q4-200 & $151,900 \mathrm{~mm}$ & $156,900 \mathrm{~mm}$ & $200 \mu \mathrm{m}$ & $2,1 \mu \mathrm{m}$ & $1,9 \mu \mathrm{m}$ \\
\hline
\end{tabular}




\section{E.2. Positioniergenauigkeiten der Plattformen}

Die Abbildung E.2 stellt den Messaufbau zur Bestimmung der Positioniergenauigkeit einer Stempelbaugruppe (montiert auf der Jochplatte der Führungseinheit einer Hubantriebsbaugruppe) auf einem Verfahrbereich von $5 \mathrm{~mm}$ dar. Der Messkopf ist auf einer Traverse an der Prozessrahmenplatte oberhalb der zu vermessenden Plattform befestigt. Zwischen Traverse und Prozessrahmenplatte sind geschliffene Parallelendmaße $(16 \mathrm{~mm} / 11,66 \mathrm{~mm}$ / 7,78 mm / 3,74 mm) eingesetzt. Das Messobjekt, das während der Messreihe im Verschiebungsbereich unterhalb des Messkopfs positioniert wird, ist die Stempelbaugruppe (Bauplattform) aus dem Baustempelmodul (Q1). Auf die Plattformoberseite ist ein diffus reflektierendes Emissionsklebeband aufgebracht. Zur Bewegung zwischen den jeweiligen

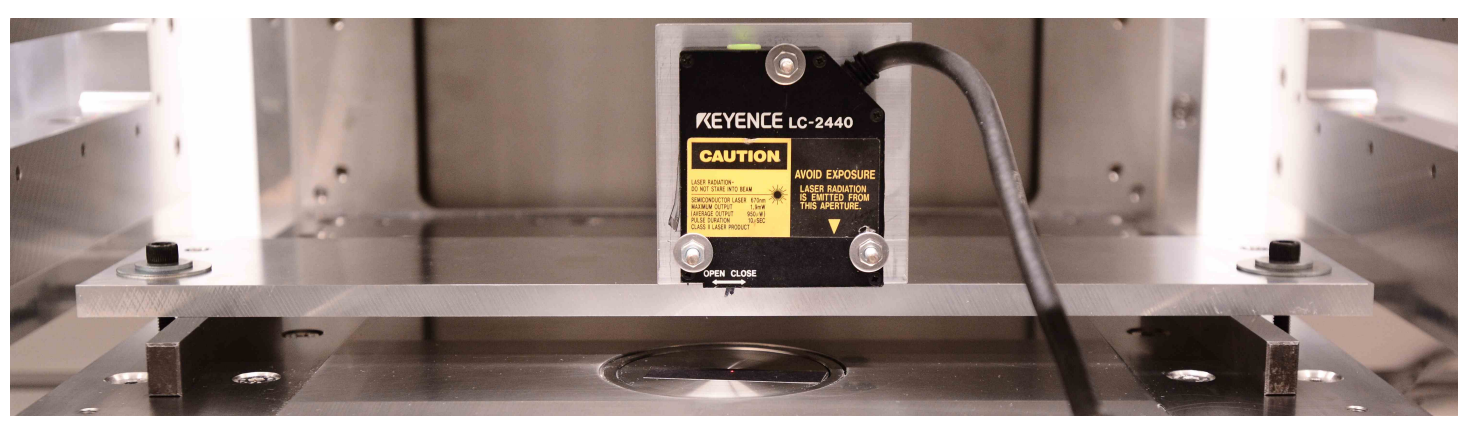

Abbildung E.2.: Messaufbau zur Bestimmung der Positioniergenauigkeit der Plattformen / Messobjekt: Stempelbaugruppe Q1

Drehgeberwerten wird die Geschwindigkeit von $v_{0,25}=0,05 \mathrm{~mm} / \mathrm{s}$ (bei einem „Smoothing Factor" von 0,25) gewählt. Ist die Messreihe abgeschlossen, wird die Höhe der Traverse gegenüber der Prozesseinsatzplatte durch den Wechsel der Parallelendmaße verändert, das Messgerät neu kalibriert und die nächste Messreihe gestartet. Zur Messung der Positioniergenauigkeiten der Zuführplattform I (Q3) bzw. II (Q4) wird die Traverse samt Messkopf oberhalb der jeweiligen Plattform befestigt. Die Tabelle E.3 stellt die Ergebnisse der Messreihe im Drehgeberwertintervall von 149,890 mm bis 144,890 mm (Verfahrbereich $5 \mathrm{~mm}$ ) bei einem Inkrement von $100 \mu \mathrm{m}$ (Bewegungsrichtung abwärts) der Hubantriebsbaugruppe Q1 samt Stempelbaugruppe (Bauplattform) aus dem Baustempelmodul dar. Analog zu Anhang E.1 wird der Mittelwert $\left(\bar{x}_{|\mathrm{Abw}|}\right)$ und die Standardabweichung $\left(s_{|\mathrm{Abw}|}\right)$ für die Messreihe bestimmt.

Tabelle E.3.: Positioniergenauigkeit der Bauplattform Q1: Messreihe 1-Q1+ST-100

\begin{tabular}{c|r|r|r|r|r}
\hline Messung & Drehgeberwert & Inkrement & Messwert & Abweichung & |Abweichung \\
\hline 1 & $149,890 \mathrm{~mm}$ & $100 \mu \mathrm{m}$ & $0,0000 \mathrm{~mm}$ & $-2,6 \mu \mathrm{m}$ & $2,6 \mu \mathrm{m}$ \\
2 & $149,790 \mathrm{~mm}$ & $100 \mu \mathrm{m}$ & $0,0998 \mathrm{~mm}$ & $-0,2 \mu \mathrm{m}$ & $0,2 \mu \mathrm{m}$ \\
3 & $149,690 \mathrm{~mm}$ & $100 \mu \mathrm{m}$ & $0,1992 \mathrm{~mm}$ & $-0,2 \mu \mathrm{m}$ & $0,2 \mu \mathrm{m}$ \\
4 & $149,590 \mathrm{~mm}$ & $100 \mu \mathrm{m}$ & $0,3004 \mathrm{~mm}$ & $-0,8 \mu \mathrm{m}$ & $0,8 \mu \mathrm{m}$ \\
5 & $149,490 \mathrm{~mm}$ & $100 \mu \mathrm{m}$ & $0,3986 \mathrm{~mm}$ & $-1,8 \mu \mathrm{m}$ & $1,8 \mu \mathrm{m}$ \\
6 & $149,390 \mathrm{~mm}$ & $100 \mu \mathrm{m}$ & $0,5004 \mathrm{~mm}$ & $-2,0 \mu \mathrm{m}$ & $2,0 \mu \mathrm{m}$ \\
7 & $149,290 \mathrm{~mm}$ & $100 \mu \mathrm{m}$ & $0,6016 \mathrm{~mm}$ & $-0,8 \mu \mathrm{m}$ & $0,8 \mu \mathrm{m}$
\end{tabular}


E.2. Positioniergenauigkeiten der Plattformen

\begin{tabular}{|c|c|c|c|c|c|}
\hline 8 & $149,190 \mathrm{~mm}$ & $100 \mu \mathrm{m}$ & $0,7030 \mathrm{~mm}$ & $-5,0 \mu \mathrm{m}$ & $5,0 \mu \mathrm{m}$ \\
\hline 9 & $149,090 \mathrm{~mm}$ & $100 \mu \mathrm{m}$ & $0,8030 \mathrm{~mm}$ & $1,0 \mu \mathrm{m}$ & $1,0 \mu \mathrm{m}$ \\
\hline 10 & $148,990 \mathrm{~mm}$ & $100 \mu \mathrm{m}$ & $0,9048 \mathrm{~mm}$ & $-1,4 \mu \mathrm{m}$ & $1,4 \mu \mathrm{m}$ \\
\hline 11 & $148,890 \mathrm{~mm}$ & $100 \mu \mathrm{m}$ & $1,0020 \mathrm{~mm}$ & $0,8 \mu \mathrm{m}$ & $0,8 \mu \mathrm{m}$ \\
\hline 12 & $148,790 \mathrm{~mm}$ & $100 \mu \mathrm{m}$ & $1,1000 \mathrm{~mm}$ & $-0,2 \mu \mathrm{m}$ & $0,2 \mu \mathrm{m}$ \\
\hline 13 & $148,690 \mathrm{~mm}$ & $100 \mu \mathrm{m}$ & $1,1996 \mathrm{~mm}$ & $-1,8 \mu \mathrm{m}$ & $1,8 \mu \mathrm{m}$ \\
\hline 14 & $148,590 \mathrm{~mm}$ & $100 \mu \mathrm{m}$ & $1,3002 \mathrm{~mm}$ & $-3,8 \mu \mathrm{m}$ & $3,8 \mu \mathrm{m}$ \\
\hline 15 & $148,490 \mathrm{~mm}$ & $100 \mu \mathrm{m}$ & $1,4006 \mathrm{~mm}$ & $-3,0 \mu \mathrm{m}$ & $3,0 \mu \mathrm{m}$ \\
\hline 16 & $148,390 \mathrm{~mm}$ & $100 \mu \mathrm{m}$ & $1,5014 \mathrm{~mm}$ & $-0,2 \mu \mathrm{m}$ & $0,2 \mu \mathrm{m}$ \\
\hline 17 & $148,290 \mathrm{~mm}$ & $100 \mu \mathrm{m}$ & $1,6008 \mathrm{~mm}$ & $1,4 \mu \mathrm{m}$ & $1,4 \mu \mathrm{m}$ \\
\hline 18 & $148,190 \mathrm{~mm}$ & $100 \mu \mathrm{m}$ & $1,6992 \mathrm{~mm}$ & $1,8 \mu \mathrm{m}$ & $1,8 \mu \mathrm{m}$ \\
\hline 19 & $148,090 \mathrm{~mm}$ & $100 \mu \mathrm{m}$ & $1,7986 \mathrm{~mm}$ & $1,8 \mu \mathrm{m}$ & $1,8 \mu \mathrm{m}$ \\
\hline 20 & $147,990 \mathrm{~mm}$ & $100 \mu \mathrm{m}$ & $1,8980 \mathrm{~mm}$ & $1,8 \mu \mathrm{m}$ & $1,8 \mu \mathrm{m}$ \\
\hline 21 & $147,890 \mathrm{~mm}$ & $100 \mu \mathrm{m}$ & $1,9982 \mathrm{~mm}$ & $2,4 \mu \mathrm{m}$ & $2,4 \mu \mathrm{m}$ \\
\hline 22 & $147,790 \mathrm{~mm}$ & $100 \mu \mathrm{m}$ & $2,0988 \mathrm{~mm}$ & $0,0 \mu \mathrm{m}$ & $0,0 \mu \mathrm{m}$ \\
\hline 23 & $147,690 \mathrm{~mm}$ & $100 \mu \mathrm{m}$ & $2,1992 \mathrm{~mm}$ & $-3,4 \mu \mathrm{m}$ & $3,4 \mathrm{\mu m}$ \\
\hline 24 & $147,590 \mathrm{~mm}$ & $100 \mu \mathrm{m}$ & $2,3002 \mathrm{~mm}$ & $-0,6 \mu \mathrm{m}$ & $0,6 \mu \mathrm{m}$ \\
\hline 25 & $147,490 \mathrm{~mm}$ & $100 \mu \mathrm{m}$ & $2,4016 \mathrm{~mm}$ & $-2,2 \mu \mathrm{m}$ & $2,2 \mu \mathrm{m}$ \\
\hline 26 & $147,390 \mathrm{~mm}$ & $100 \mu \mathrm{m}$ & $2,5038 \mathrm{~mm}$ & $-0,6 \mu \mathrm{m}$ & $0,6 \mu \mathrm{m}$ \\
\hline 27 & $147,290 \mathrm{~mm}$ & $100 \mu \mathrm{m}$ & $2,6048 \mathrm{~mm}$ & $-0,4 \mu \mathrm{m}$ & $0,4 \mathrm{\mu m}$ \\
\hline 28 & $147,190 \mathrm{~mm}$ & $100 \mu \mathrm{m}$ & $2,7046 \mathrm{~mm}$ & $0,8 \mu \mathrm{m}$ & $0,8 \mu \mathrm{m}$ \\
\hline 29 & $147,090 \mathrm{~mm}$ & $100 \mu \mathrm{m}$ & $2,8030 \mathrm{~mm}$ & $-3,2 \mu \mathrm{m}$ & $3,2 \mu \mathrm{m}$ \\
\hline 30 & $146,990 \mathrm{~mm}$ & $100 \mu \mathrm{m}$ & $2,9032 \mathrm{~mm}$ & $1,2 \mu \mathrm{m}$ & $1,2 \mu \mathrm{m}$ \\
\hline 31 & $146,890 \mathrm{~mm}$ & $100 \mu \mathrm{m}$ & $3,0028 \mathrm{~mm}$ & $0,0 \mu \mathrm{m}$ & $0,0 \mu \mathrm{m}$ \\
\hline 32 & $146,790 \mathrm{~mm}$ & $100 \mu \mathrm{m}$ & $3,1026 \mathrm{~mm}$ & $-0,2 \mu \mathrm{m}$ & $0,2 \mu \mathrm{m}$ \\
\hline 33 & $146,690 \mathrm{~mm}$ & $100 \mu \mathrm{m}$ & $3,2030 \mathrm{~mm}$ & $1,0 \mu \mathrm{m}$ & $1,0 \mu \mathrm{m}$ \\
\hline 34 & $146,590 \mathrm{~mm}$ & $100 \mu \mathrm{m}$ & $3,3038 \mathrm{~mm}$ & $-0,2 \mu \mathrm{m}$ & $0,2 \mu \mathrm{m}$ \\
\hline 35 & $146,490 \mathrm{~mm}$ & $100 \mu \mathrm{m}$ & $3,4050 \mathrm{~mm}$ & $-1,0 \mu \mathrm{m}$ & $1,0 \mu \mathrm{m}$ \\
\hline 36 & $146,390 \mathrm{~mm}$ & $100 \mu \mathrm{m}$ & $3,5056 \mathrm{~mm}$ & $0,2 \mu \mathrm{m}$ & $0,2 \mu \mathrm{m}$ \\
\hline 37 & $146,290 \mathrm{~mm}$ & $100 \mu \mathrm{m}$ & $3,6068 \mathrm{~mm}$ & $2,4 \mu \mathrm{m}$ & $2,4 \mathrm{\mu m}$ \\
\hline 38 & $146,190 \mathrm{~mm}$ & $100 \mu \mathrm{m}$ & $3,7080 \mathrm{~mm}$ & $-1,4 \mu \mathrm{m}$ & $1,4 \mu \mathrm{m}$ \\
\hline 39 & $146,090 \mathrm{~mm}$ & $100 \mu \mathrm{m}$ & $3,8086 \mathrm{~mm}$ & $1,6 \mu \mathrm{m}$ & $1,6 \mu \mathrm{m}$ \\
\hline 40 & $145,990 \mathrm{~mm}$ & $100 \mu \mathrm{m}$ & $3,9088 \mathrm{~mm}$ & $-1,8 \mu \mathrm{m}$ & $1,8 \mu \mathrm{m}$ \\
\hline 41 & $145,890 \mathrm{~mm}$ & $100 \mu \mathrm{m}$ & $4,0088 \mathrm{~mm}$ & $0,0 \mu \mathrm{m}$ & $0,0 \mu \mathrm{m}$ \\
\hline 42 & $145,790 \mathrm{~mm}$ & $100 \mu \mathrm{m}$ & $4,1090 \mathrm{~mm}$ & $0,2 \mu \mathrm{m}$ & $0,2 \mu \mathrm{m}$ \\
\hline 43 & $145,690 \mathrm{~mm}$ & $100 \mu \mathrm{m}$ & $4,2086 \mathrm{~mm}$ & $-0,4 \mu \mathrm{m}$ & $0,4 \mu \mathrm{m}$ \\
\hline 44 & $145,590 \mathrm{~mm}$ & $100 \mu \mathrm{m}$ & $4,3078 \mathrm{~mm}$ & $0,0 \mu \mathrm{m}$ & $0,0 \mu \mathrm{m}$ \\
\hline 45 & $145,490 \mathrm{~mm}$ & $100 \mu \mathrm{m}$ & $4,4078 \mathrm{~mm}$ & $-0,4 \mu \mathrm{m}$ & $0,4 \mu \mathrm{m}$ \\
\hline 46 & $145,390 \mathrm{~mm}$ & $100 \mu \mathrm{m}$ & $4,5074 \mathrm{~mm}$ & $0,4 \mu \mathrm{m}$ & $0,4 \mu \mathrm{m}$ \\
\hline 47 & $145,290 \mathrm{~mm}$ & $100 \mu \mathrm{m}$ & $4,6072 \mathrm{~mm}$ & $-0,2 \mu \mathrm{m}$ & $0,2 \mu \mathrm{m}$ \\
\hline 48 & $145,190 \mathrm{~mm}$ & $100 \mu \mathrm{m}$ & $4,7072 \mathrm{~mm}$ & $-0,6 \mu \mathrm{m}$ & $0,6 \mu \mathrm{m}$ \\
\hline 49 & $145,090 \mathrm{~mm}$ & $100 \mu \mathrm{m}$ & $4,8068 \mathrm{~mm}$ & $0,2 \mu \mathrm{m}$ & $0,2 \mu \mathrm{m}$ \\
\hline \multirow{2}{*}{50} & $144,990 \mathrm{~mm}$ & $100 \mu \mathrm{m}$ & $4,9068 \mathrm{~mm}$ & $0,2 \mu \mathrm{m}$ & $0,2 \mu \mathrm{m}$ \\
\hline & $144,890 \mathrm{~mm}$ & $100 \mu \mathrm{m}$ & $5,0070 \mathrm{~mm}$ & & \\
\hline
\end{tabular}

Arithmetischer Mittelwert aller Werte aus der Spalte „|Abweichung|": $\bar{x}_{|\mathrm{Abw}|}=1,2 \mu \mathrm{m}$ Standardabweichung aller Werte aus der Spalte „|Abweichung|": $s_{|\mathrm{Abw}|}=1,1 \mu \mathrm{m}$

Pro Antriebsachse werden jeweils acht Messreihen (vier Drehgeberwertintervalle mit jeweils zwei Inkrementen) zur Bestimmung der Positioniergenauigkeit auf ca. $17 \mathrm{~mm}$ unterhalb der achsspezifischen Referenzposition (Nullposition in der vertikalen z-Richtung) durchgeführt. Das Ergebnis der Auswertung $\left(\bar{x}_{|\mathrm{Abw}|} / s_{|\mathrm{Abw}|}\right)$ der jeweiligen Messreihe wird in die achsspezifischen Übersichtstabellen (vgl. Tabelle E.4) überführt. Zur Vermessung 
Anhang E. Messung der Positioniergenauigkeiten der Hubantriebsachsen

weiterer Drehgeberwertintervalle wären weitere Parallelendmaße (Positionierung auf der Oberseite der Stempelbaugruppe) notwendig gewesen.

Tabelle E.4.: Positioniergenauigkeiten der Plattformen Q1 / Q3 / Q4

\begin{tabular}{l|r|r|r|r|r}
\hline \multicolumn{5}{c}{ Hubantriebsbaugruppe Q1 samt Stempelbaugruppe (Bauplattform) } \\
\hline \multicolumn{1}{c}{ Messreihe } & Drehgeber-Startwert & Drehgeber-Endwert & Inkrement & $\bar{x}_{|\mathrm{Abw}|}$ & $s_{|\mathrm{Abw}|}$ \\
\hline 1-Q1+ST-100 & $149,890 \mathrm{~mm}$ & $144,890 \mathrm{~mm}$ & $100 \mu \mathrm{m}$ & $1,2 \mu \mathrm{m}$ & $1,1 \mu \mathrm{m}$ \\
1-Q1+ST-50 & $149,890 \mathrm{~mm}$ & $144,890 \mathrm{~mm}$ & $50 \mu \mathrm{m}$ & $0,7 \mu \mathrm{m}$ & $0,9 \mu \mathrm{m}$ \\
2-Q1+ST-100 & $145,560 \mathrm{~mm}$ & $140,560 \mathrm{~mm}$ & $100 \mu \mathrm{m}$ & $1,5 \mu \mathrm{m}$ & $1,1 \mu \mathrm{m}$ \\
2-Q1+ST-50 & $145,560 \mathrm{~mm}$ & $140,560 \mathrm{~mm}$ & $50 \mu \mathrm{m}$ & $0,9 \mu \mathrm{m}$ & $0,9 \mu \mathrm{m}$ \\
3-Q1+ST-100 & $141,795 \mathrm{~mm}$ & $136,795 \mathrm{~mm}$ & $100 \mu \mathrm{m}$ & $0,9 \mu \mathrm{m}$ & $1,0 \mu \mathrm{m}$ \\
3-Q1+ST-50 & $141,795 \mathrm{~mm}$ & $136,795 \mathrm{~mm}$ & $50 \mu \mathrm{m}$ & $0,5 \mu \mathrm{m}$ & $0,6 \mu \mathrm{m}$ \\
4-Q1+ST-100 & $137,755 \mathrm{~mm}$ & $132,755 \mathrm{~mm}$ & $100 \mu \mathrm{m}$ & $1,5 \mu \mathrm{m}$ & $1,3 \mu \mathrm{m}$ \\
4-Q1+ST-50 & $137,755 \mathrm{~mm}$ & $132,755 \mathrm{~mm}$ & $50 \mu \mathrm{m}$ & $0,8 \mu \mathrm{m}$ & $0,6 \mu \mathrm{m}$ \\
\hline
\end{tabular}

Hubantriebsbaugruppe Q3 samt Stempelbaugruppe (Zuführplattform I)

\begin{tabular}{c|r|r|r|r|r}
\hline Messreihe & Drehgeber-Startwert & Drehgeber-Endwert & Inkrement & $\bar{x}_{|\mathrm{Abw}|}$ & $s_{|\mathrm{Abw}|}$ \\
\hline 1-Q3+ST-100 & $150,430 \mathrm{~mm}$ & $155,430 \mathrm{~mm}$ & $100 \mu \mathrm{m}$ & $1,8 \mu \mathrm{m}$ & $1,4 \mu \mathrm{m}$ \\
1-Q3+ST-200 & $150,430 \mathrm{~mm}$ & $155,430 \mathrm{~mm}$ & $200 \mu \mathrm{m}$ & $3,1 \mu \mathrm{m}$ & $1,9 \mu \mathrm{m}$ \\
2-Q3+ST-100 & $146,090 \mathrm{~mm}$ & $151,090 \mathrm{~mm}$ & $100 \mu \mathrm{m}$ & $1,4 \mu \mathrm{m}$ & $1,4 \mu \mathrm{m}$ \\
2-Q3+ST-200 & $146,090 \mathrm{~mm}$ & $151,090 \mathrm{~mm}$ & $200 \mu \mathrm{m}$ & $2,7 \mu \mathrm{m}$ & $2,4 \mu \mathrm{m}$ \\
3-Q3+ST-100 & $142,295 \mathrm{~mm}$ & $147,295 \mathrm{~mm}$ & $100 \mu \mathrm{m}$ & $0,8 \mu \mathrm{m}$ & $0,6 \mu \mathrm{m}$ \\
3-Q3+ST-200 & $142,295 \mathrm{~mm}$ & $147,295 \mathrm{~mm}$ & $200 \mu \mathrm{m}$ & $1,4 \mu \mathrm{m}$ & $1,1 \mu \mathrm{m}$ \\
4-Q3+ST-100 & $138,235 \mathrm{~mm}$ & $143,235 \mathrm{~mm}$ & $100 \mu \mathrm{m}$ & $0,9 \mu \mathrm{m}$ & $1,1 \mu \mathrm{m}$ \\
4-Q3+ST-200 & $138,235 \mathrm{~mm}$ & $143,235 \mathrm{~mm}$ & $200 \mu \mathrm{m}$ & $1,6 \mu \mathrm{m}$ & $2,0 \mu \mathrm{m}$ \\
\hline
\end{tabular}

Hubantriebsbaugruppe Q4 samt Stempelbaugruppe (Zuführplattform II)

\begin{tabular}{c|r|r|r|r|r}
\hline Messreihe & Drehgeber-Startwert & Drehgeber-Endwert & Inkrement & $\bar{x}_{|\mathrm{Abw}|}$ & $s_{|\mathrm{Abw}|}$ \\
\hline 1-Q4+ST-100 & $150,390 \mathrm{~mm}$ & $155,390 \mathrm{~mm}$ & $100 \mu \mathrm{m}$ & $1,0 \mu \mathrm{m}$ & $0,7 \mu \mathrm{m}$ \\
1-Q4+ST-200 & $150,390 \mathrm{~mm}$ & $155,390 \mathrm{~mm}$ & $200 \mu \mathrm{m}$ & $1,8 \mu \mathrm{m}$ & $1,3 \mu \mathrm{m}$ \\
2-Q4+ST-100 & $146,040 \mathrm{~mm}$ & $155,390 \mathrm{~mm}$ & $100 \mu \mathrm{m}$ & $1,1 \mu \mathrm{m}$ & $0,9 \mu \mathrm{m}$ \\
2-Q4+ST-200 & $146,040 \mathrm{~mm}$ & $151,040 \mathrm{~mm}$ & $200 \mu \mathrm{m}$ & $1,9 \mu \mathrm{m}$ & $1,6 \mu \mathrm{m}$ \\
3-Q4+ST-100 & $142,240 \mathrm{~mm}$ & $147,240 \mathrm{~mm}$ & $100 \mu \mathrm{m}$ & $2,0 \mu \mathrm{m}$ & $1,9 \mu \mathrm{m}$ \\
3-Q4+ST-200 & $142,240 \mathrm{~mm}$ & $147,240 \mathrm{~mm}$ & $200 \mu \mathrm{m}$ & $3,9 \mu \mathrm{m}$ & $2,9 \mu \mathrm{m}$ \\
4-Q4+ST-100 & $138,170 \mathrm{~mm}$ & $143,170 \mathrm{~mm}$ & $100 \mu \mathrm{m}$ & $2,3 \mu \mathrm{m}$ & $3,2 \mu \mathrm{m}$ \\
4-Q4+ST-200 & $138,170 \mathrm{~mm}$ & $143,170 \mathrm{~mm}$ & $200 \mu \mathrm{m}$ & $4,3 \mu \mathrm{m}$ & $3,2 \mu \mathrm{m}$ \\
\hline
\end{tabular}




\section{F. Sonstiges}

\section{F.1. Öffnungshilfe für einen Mahlbecher der Retsch CryoMill}

Zum Einsetzen und Öffnen des Mahlbechers liefert Firma Retsch eine Öffnungshilfe, mit der konstruktiv bedingt durch den kleinen Hebelarm kaum Drehmoment übertragen werden kann. Die Entnahme des $-196{ }^{\circ} \mathrm{C}$ kalten Mahlbechers ist dadurch teilweise nicht möglich. Zur Prozessverbesserung wurde eine neue Öffnungshilfe konstruiert, die auf den Mahlbecherkopf geschoben und durch eine 1/2 Zoll Umschaltratsche mit aufgestecktem Sechskantschlüsselaufsatz der Weite $30 \mathrm{~mm}$ angetrieben wird. Um den Mahlbecher bequem öffnen zu können, wurde zusätzlich eine Aufnahme für den Mahlbecherverschluss konstruiert, die auf eine Metallplatte geschraubt und in Abbildung F.1 dargestellt ist. Die Werkzeuge sind auf einer EOS „Formiga P 100“ aus Polyamid 12 gefertigt.

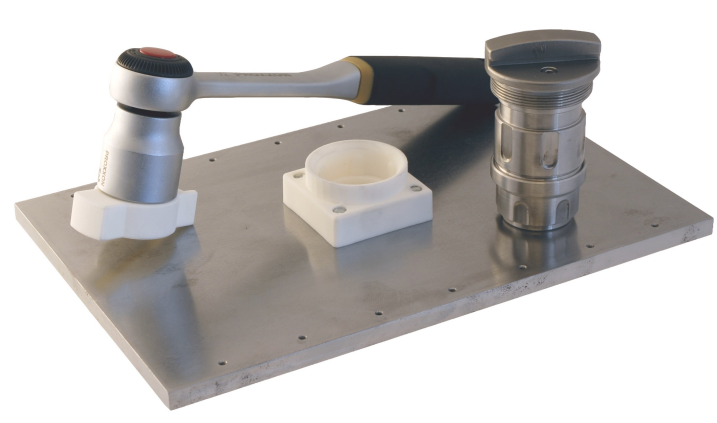

(a) Einzelkomponenten

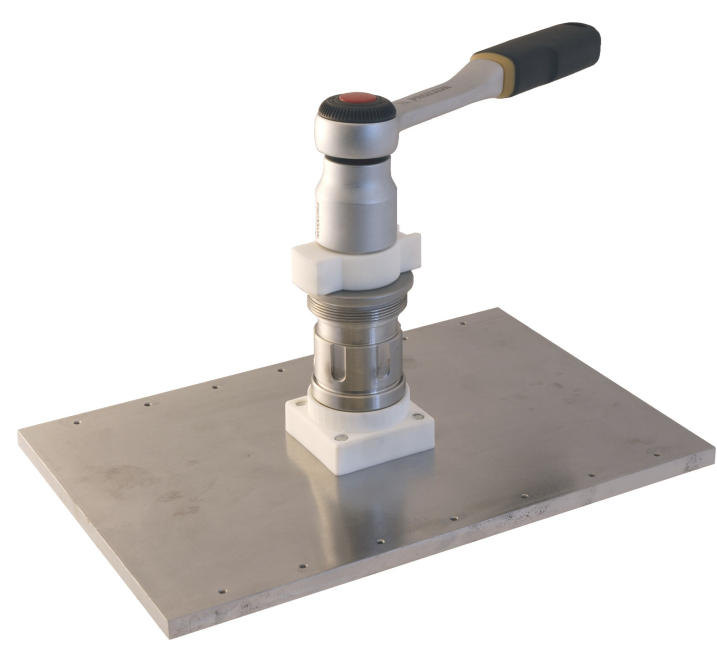

(b) Anwendung

Abbildung F.1.: Lasergesinterte Werkzeuge zum Öffnen eines $50 \mathrm{ml}$ Mahlbechers 


\section{F.2. Laser-Wegmesssystem Keyence LC-2400}

Zur Inbetriebnahme und Bestimmung der Positioniergenauigkeit der Hubantriebsachsen wird ein Keyence Laser-Wegmesssystem der Modellreihe LC-2400, bestehend aus Regler LC-2400W (vgl. Abbildung F.3) und Messkopf LC-2440 (vgl. Abbildung F.2), verwendet. In dieser Systemkonfiguration hat das Messsystem auf einem maximalen Messbereich von $\pm 3 \mathrm{~mm}$ eine Auflösung von 0,2 $\mu \mathrm{m}$ bei 512 Messungen zur Mittelwertbildung [Key96, S. 84]. Die Abbildung F.2 stellt den Messaufbau zur Höhenmessung dar. Der Bezugsabstand

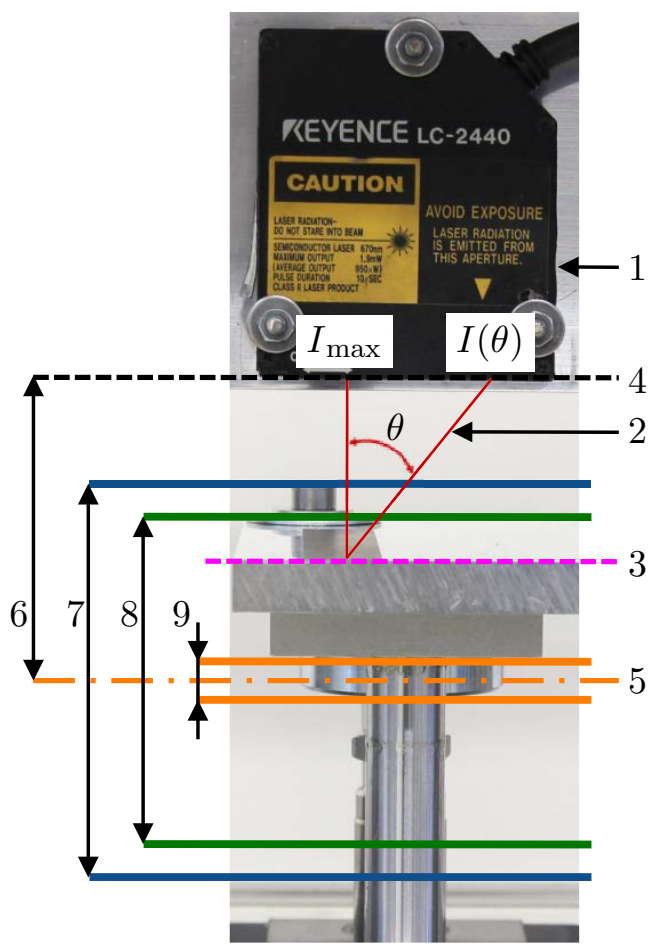

(1) Messkopf

(2) Laserstrahl

(3) Messobjektebene

(4) Laseremissionsebene

(5) Bezugsabstandsebene

(6) Bezugsabstand $30 \mathrm{~mm}$

(7) Messbereich $\pm 3 \mathrm{~mm}$

(8) Verschiebungsbereich $\pm 2,5 \mathrm{~mm}$

(9) Bezugsabstandsbereich $\pm 0,3 \mathrm{~mm}$

$(\theta)$ Winkel zw. Sende- und Empfangsstrahl

Abbildung F.2.: Mess-, Verschiebungs- und Bezugsabsandsbereich des Messkopfs

zwischen fixiertem Messkopf und beweglichem Messobjekt beträgt $30 \mathrm{~mm}$. Der Messkopf emittiert einen Laserstrahl einer zuvor eingestellten Intensität $\left(I_{\max }\right)$ auf die Oberfläche des Messobjekts. In Abhängigkeit des Abstands zwischen Messkopf und Messobjekt trifft das vom Messobjekt diffus reflektierte Licht unter dem Winkel $\theta$ auf ein im Messkopf befindliches Empfangselement. Mittels Triangulation und dem lambertschen Kosinusgesetz berechnet der Messregler den Abstand aus den Laserstrahlintensitäten des Sende- und Empfangsstrahls [Sch12, S. 216-217]. Das Messsystem wird für eine Höhenmessung gemäß den Herstellervorgaben [Key96, S. 9] vorbereitet. Die folgenden Einstellungen werden dafür vorgenommen:

1. Einstellung der Messkopfposition und Positionierung des Messobjekts in dem Bezugsabstandsbereich [Key96, S. 25-26] 
2. Wahl der Messbetriebsart „Normal“ zur Messung einer Verschiebung gegenüber einem definierten Bezugspunkt [Key96, S. 30]

3. Kalibrierempfindlichkeit (Verstärkungsgradwahl) auf die werkseitige Einstellung „AUTO“ einstellen [Key96, S. 30-31]

4. Kalibrierung anhand der Messobjektposition bei definiertem Verschiebungsbereich des Messobjekts von $\pm 2,5 \mathrm{~mm}$ [Key96, S. 32-34]

5. Offset-Wert für die Messwertausgabe auf $0 \mathrm{~mm}$ setzen (keine Subtraktion/Addition vom/zum Messwert vor Messwertausgabe) [Key96, S. 35-36]

6. Zahl der durchzuführenden Messungen auf Maximalwert von 131072 (Abtastfrequenz: $50 \mathrm{kHz}$ [Key96, S. 84]) zur Reduzierung von Messdatenabweichungen einstellen [Key96, S. 36]

7. Lichtintensität „INT.LIMIT“ auf werkseitige Einstellungen setzen [Key96, S. 37-39]

8. Einstellung der Ober-/Untergrenze der Messungen an den verwendeten Messkopf LC-2440 von $\pm 3 \mathrm{~mm}$ anpassen [Key96, S. 39-40]

9. Display-Anzeigestellen auf maximal mögliche Anzeigestellen (mm-Angabe mit vier Nachkommastellen) erhöhen [Key96, S. 40]

Die vom Messkopf emittierte Lichtintensität $\left(I_{\max }\right)$ wird durch die Wahl des Verstärkungsgrads am Regler gesteuert. Die vom Empfangselement im Messkopf gemessene Intensität $(I(\theta))$ ist abhängig vom Reflexionsgrad der Messobjektoberfläche. Zur Optimie-

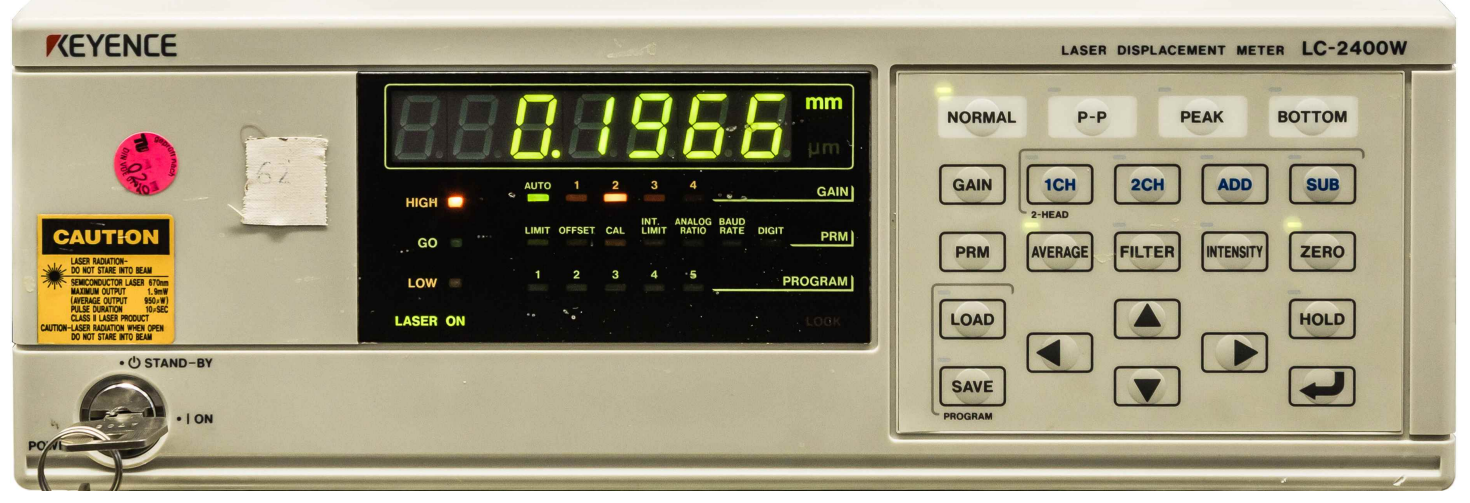

Abbildung F.3.: Regler des Laser-Wegmesssystems Keyence LC-2400

rung der Reflexionsmessung ist ein spezielles Emissionsklebeband auf die Oberfläche des Messobjekts aufgeklebt. Zusätzlich wird nach jeder Umpositionierung des Messkopfs eine erneute Kalibrierung des Messgeräts durchgeführt. Das Gerät ist nach einer Vorwärmzeit von 60 min betriebsbereit [Key96, S. 20]. 


\section{F.3. Betreute Abschlussarbeiten}

Im Rahmen der methodischen Entwicklung der Lasersintermaschine wurden die folgenden Abschlussarbeiten vom Fachgebiet Methoden der Produktentwicklung und Mechatronik der Technischen Universität Berlin vergeben und zusammen mit dem Fachgebietsleiter Herrn Prof. Dr.-Ing. Dietmar Göhlich betreut. Die in Tabelle F.1 aufgeführten Arbeiten können am Fachgebiet eingesehen werden.

Tabelle F.1.: Betreute wissenschaftliche Arbeiten

\begin{tabular}{|c|c|c|c|c|}
\hline Titel der Arbeit & Autor(in) & Тур & Datum & Quelle \\
\hline $\begin{array}{l}\text { Konzeption \& Konstruktion einer dyna- } \\
\text { mischen Pulverauftragseinheit für eine } \\
\text { SLS/SLM-Maschine }\end{array}$ & $\begin{array}{l}\text { Dimitar } \\
\text { Hristakiev }\end{array}$ & Bachelor & 10.2015 & [Hri15] \\
\hline $\begin{array}{l}\text { Konzeption \& Konstruktion einer Pul- } \\
\text { verzuführeinheit für eine LS-/LBM-Ma- } \\
\text { schine }\end{array}$ & Yue Zhang & Bachelor & 12.2015 & [Zha15] \\
\hline $\begin{array}{l}\text { Konzeption \& Konstruktion eines Pul- } \\
\text { vervorheizmoduls für den Einsatz in ei- } \\
\text { ner LS/LBM-Anlage }\end{array}$ & $\begin{array}{l}\text { Georg Möl- } \\
\text { ler }\end{array}$ & Bachelor & 12.2015 & [Möl15] \\
\hline $\begin{array}{l}\text { Konzeption \& Konstruktion eines Pro- } \\
\text { zessgasversorgungssystems für den Ein- } \\
\text { satz in einer LS/LBM-Anlage }\end{array}$ & $\begin{array}{l}\text { Manuel } \\
\text { Lang }\end{array}$ & Bachelor & 02.2016 & {$[\operatorname{Lan} 16]$} \\
\hline $\begin{array}{l}\text { Inbetriebnahme \& Parameteruntersu- } \\
\text { chung einer dynamischen Pulverauf- } \\
\text { tragseinheit zur verbesserten Schichtge- } \\
\text { nerierung von Biopolymerwerkstoffen in } \\
\text { Laser-Sinter-Anlagen }\end{array}$ & $\begin{array}{l}\text { Kostja } \\
\text { Nüchter }\end{array}$ & Bachelor & 06.2016 & [Nüc16] \\
\hline $\begin{array}{l}\text { Entwicklung eines Vorkonzepts für das } \\
\text { Lasermodul eines Laser-Sinter-Prüf- } \\
\text { stands zur Verarbeitung eines bioresor- } \\
\text { bierbaren Biopolymers als Werkstoff für } \\
\text { die additive Fertigung von künstlichen } \\
\text { Herzklappen auf Grundlage einer Lite- } \\
\text { raturrecherche }\end{array}$ & $\begin{array}{l}\text { Thomas } \\
\text { Braun }\end{array}$ & Bachelor & 02.2017 & [Bra17] \\
\hline $\begin{array}{l}\text { Konstruktion \& Inbetriebnahme einer } \\
\text { Verfahreinheit des Pulverauftragsmo- } \\
\text { duls eines Laser-Sinter-Prüfstands zur } \\
\text { Verarbeitung von Sonderwerkstoffen }\end{array}$ & $\begin{array}{l}\text { Oskar } \\
\text { Ogor }\end{array}$ & Master & 03.2017 & {$[$ Ogo17] } \\
\hline
\end{tabular}




\begin{tabular}{|c|c|c|c|c|}
\hline $\begin{array}{l}\text { Konstruktive Anpassung, Steuerung und } \\
\text { Inbetriebnahme eines Laser Scanner De- } \\
\text { monstrators als Modul für einen Laser } \\
\text { Sinter Prüfstand zur Herstellung von } \\
\text { Zellträgern für künstlichen Herzklappen }\end{array}$ & Tim Faß & Master & 04.2017 & [Faß17] \\
\hline $\begin{array}{l}\text { Konstruktion eines Prozessgehäuses ei- } \\
\text { ner Lasersinteranlage mit medizintech- } \\
\text { nischer Konfiguration }\end{array}$ & $\begin{array}{l}\text { Etienne } \\
\text { Lustig }\end{array}$ & Bachelor & 04.2017 & [Lus17] \\
\hline $\begin{array}{l}\text { Entwicklung und Inbetriebnahme eines } \\
\text { gasdichten Gehäuses für einen Lasersin- } \\
\text { ter-Prüfstand zur Herstellung künstli- } \\
\text { cher Herzklappen für die Medizintechnik }\end{array}$ & $\begin{array}{l}\text { Lukas } \\
\text { Ebeling- } \\
\text { Rump }\end{array}$ & Bachelor & 07.2018 & [Ebe18] \\
\hline $\begin{array}{l}\text { Konzeption und Implementierung eines } \\
\text { Prozessgasmoduls für einen Lasersinter- } \\
\text { Prüfstand zur Herstellung von künstli- } \\
\text { chen Herzklappen für die Medizintechnik }\end{array}$ & $\begin{array}{l}\text { Anton } \\
\text { Springer }\end{array}$ & Bachelor & 07.2018 & [Spr18] \\
\hline
\end{tabular}




\section{F.4. Konferenzbeiträge und eigene Veröffentlichungen}

Konferenz „Virtuelle Instrumente in der Praxis - VIP 2017“ / Veranstaltet durch die Firma National Instruments / 18. - 19. Oktober 2017 in Fürstenfeldbruck bei München / Titel der Präsentation: „Modulare Lasersinter-Prüfstandsentwicklung zur Fertigung von künstlichen Herzklappen mittels additiver Fertigung“"

Titel der zugehörigen Veröffentlichung „Modulare Lasersinter-Prüfstandsentwicklung zur additiven Fertigung von künstlichen Herzklappen-Scaffolds aus dem bioresorbierbaren Copolymer PLGA“ im Buch „Virtuelle Instrumente in der Praxis 2017 - Mess-, Steuer-, Regel- und Embedded-Systeme: Begleitband zum 22. VIP-Kongress" / [JH17, S. 54-57] / VDE Verlag / ISBN-13: 978-3800744411

Konferenz „Konstruktion für die Additive Fertigung“ / Veranstaltet durch das Institut für Produktentwicklung und Gerätebau (IPeG) der Universität Hannover und dem Laser Zentrum Hannover / 26. September 2018 in Hannover / Titel der Präsentation: „Methodische Entwicklung einer modularen Lasersintermaschine zur Herstellung von bioresorbierbaren Implantatmatrizen“ 


\section{Abkürzungsverzeichnis}

\begin{tabular}{ll} 
3-A SSI & 3-A Sanitary Standards, Inc. \\
3D & Dreidimensional \\
3DP & 3D-Printing \\
AM & Additive Manufacturing \\
AMF & Additive Manufacturing File Format \\
BMWi & Bundesministeriums für Wirtschaft und Energie \\
bzw. & beziehungsweise \\
ca. & circa \\
CAD & Computer-Aided Design \\
CAN & Controller Area Network \\
CCD & Charge-Coupled Device \\
CEE & Commission de l'équipement électrique \\
CMB & Controlled Metal Build Up \\
CMOS & Complementary Metal-Oxide-Semiconductor \\
CNC & Computerized Numerical Control \\
CO 2 & Kohlenstoffdioxid \\
CoE & CAN application protocol over EtherCAT \\
cRIO & CompactRIO \\
CT & Dirferential Scanning Calorimetry \\
DSC & Digital Light Processing \\
DSPC & Diretal Deposition \\
DM & Computertomographie \\
\hline
\end{tabular}


DMLS

DMP

EBM

EHEDG

EMC

EOS

etc.

EtherCAT

FDA

FDM

FKM

FPGA

FTIR

ggf.

GMP

HA

HMI

ILT

IP

IR

ISO

ISPE

LabVIEW

Laser

LBM

LCVD

LED
Direct Metal Laser Sintering

Direct Metal Printing

Electron Beam Melting

European Hygienic Engineering and Design Group

Electromechanical Cylinder

Electro Optical Systems

et cetera

Ethernet for Control Automation Technology

Food and Drug Administration

Fused Deposition Modelling

Fluorkautschuk

Field Programmable Gate Array

Fourier-Transformations-Infrarot

gegebenenfalls

Good Manufacturing Practice

Hydroxylapatit

Human Machine Interface

Institut für Lasertechnik

Internet Protocol

Infrarot

International Organization for Standardization

International Society for Pharmaceutical Engineering

Laboratory Virtual Instrument Engineering Workbench

Light Amplification by Stimulated Emission of Radiation

Laser Beam Melting

Laser Chemical Vapor Deposition

Light-Emitting Diode 


\begin{tabular}{|c|c|}
\hline LENS & Laser Engineered Net Shaping \\
\hline LLM & Layer Laminated Manufacturing \\
\hline LMF & Laser Metal Fusion \\
\hline LMP & Layer Milling Process \\
\hline LOM & Laminated Object Manufacturing \\
\hline LPBF & Laser Powder Bed Fusion \\
\hline $\mathbf{L S}$ & Laser Sintering \\
\hline M3D & Maskless Masoscale Material Deposition \\
\hline MJM & Multi-Jet Modelling \\
\hline MPM & Methoden der Produktentwicklung und Mechatronik \\
\hline Nd:YAG & Neodym-dotierter Yttrium-Aluminium-Granat \\
\hline NI & National Instruments \\
\hline NLGI & National Lubricating Grease Institute \\
\hline OEM & Original Equipment Manufacturer \\
\hline OT & Optische Tomographie \\
\hline PA & Polyamid \\
\hline PAEK & Polyaryletherketone \\
\hline PCC & Precipitated Calcium Carbonate \\
\hline PCL & Polycaprolacton \\
\hline PDLA & Poly(D-Lactic Acid) \\
\hline PDLLA & Poly(D,L-Lactic Acid) \\
\hline $\mathbf{P E}$ & Polyethylene \\
\hline PEEK & Polyetheretherketon \\
\hline PEKK & Polyetherketonketon \\
\hline PEP & Produktentstehungsprozess \\
\hline PFA & Perfluoralkoxy-Polymere \\
\hline PGA & Poly(Glycolic Acid) \\
\hline
\end{tabular}




\begin{tabular}{|c|c|}
\hline PID & Proportional-Integral-Derivative \\
\hline PJM & Poly-Jet Modelling \\
\hline PLA & Poly(Lactic Acid) \\
\hline PLDLLA & Poly(L-Lactic-co-D,L-Lactic Acid) \\
\hline PLGA & Poly(Lactic-co-Glycolic Acid) \\
\hline PLLA & Poly(L-Lactic Acid) \\
\hline PP & Polypropylen \\
\hline PPS & Polyphenylensulfid \\
\hline PS & Polystyrol \\
\hline PTFE & Polytetrafluorethylen \\
\hline PVA & Polyvinyl Alcohol \\
\hline PWM & Pulse Width Modulation \\
\hline REM & Rasterelektronenmikroskop \\
\hline $\mathbf{R M}$ & Rapid Manufacturing \\
\hline $\mathbf{R P}$ & Rapid Prototyping \\
\hline RR & Rapid Repair \\
\hline RT & Rapid Tooling \\
\hline RTD & Resistance Temperature Detector \\
\hline SAHP & Selective Adhesive and Hot Press Process \\
\hline SD & Secure Data \\
\hline SIL & Safety Integrity Level \\
\hline SL & Stereolithography \\
\hline SLI & Slice Layer Interface \\
\hline SLM & Selective Laser Melting \\
\hline SLS & Selective Laser Sintering \\
\hline SMS & Selective Mask Sintering \\
\hline SPS & speicherprogrammierbare Steuerung \\
\hline
\end{tabular}


STL

TE

TCP

TPE

TPU

TTS

TU

UI

USP

UV

VDI

vgl.

VI

YAG

Yb:YAG

z. B.

ZnSe
Standard Tessellation Language

Tissue Engineering

Tricalciumphosphat

Thermoplastische Elastomere

Thermoplastisches Polyurethan

Thermo Transfer Sintering

Technische Universität

User Interface

United States Pharmacopeia

Ultraviolett

Verein Deutscher Ingenieure

vergleiche

Virtual Instrument

Yttrium-Aluminium-Granat

Ytterbium-dotierter Yttrium-Aluminium-Granat

zum Beispiel

Zinkselenid 



\section{Symbolverzeichnis}

\section{Lateinische Symbole (Großbuchstaben)}

\begin{tabular}{|c|c|c|}
\hline$A$ & $\mathrm{~m}^{2}$ & Fläche (allgemein) \\
\hline$A_{0}$ & $\mathrm{~m}^{2}$ & Ausgangsquerschnitt \\
\hline$A_{\text {rad }}$ & 1 & Absorptionsgrad \\
\hline$D_{\mathrm{L}}$ & $\mathrm{mm}$ & Laserstrahldurchmesser vor Fokussierung \\
\hline$E$ & $\mathrm{~J}$ & Energie (allgemein) \\
\hline$E_{\mathrm{A}}$ & $\mathrm{J} / \mathrm{mm}^{2}$ & Flächenenergiedichte \\
\hline$E_{\mathrm{V}}$ & $\mathrm{J} / \mathrm{mm}^{3}$ & Volumenenergiedichte \\
\hline$F$ & $\mathrm{~N}$ & Kraft (allgemein) \\
\hline$F_{\max }$ & $\mathrm{N}$ & Maximalkraft \\
\hline$H_{\text {fus }}$ & $\mathrm{J} / \mathrm{g}$ & Schmelzenthalpie \\
\hline$I_{\max }$ & $\mathrm{W} / \mathrm{sr}$ & Maximale Strahlungsintensität \\
\hline$I(\theta)$ & $\mathrm{W} / \mathrm{sr}$ & Strahlungsintensität in Abhängigkeit vom Winkel $\theta$ \\
\hline$M^{2}$ & 1 & Beugungsmaßzahl \\
\hline $\mathrm{O}_{2}$ & $\%$ vol & Sauerstoffgehalt (Volumenanteil) \\
\hline$P$ & $\mathrm{~mm}$ & Position (allgemein) \\
\hline$P_{\mathrm{a}}$ & $\mathrm{mm}$ & Kompensierte Steigung eines Kugelgewindetriebs (Messwert) \\
\hline$P_{\mathrm{L}}$ & $\mathrm{J} / \mathrm{s}$ & Laserleistung \\
\hline$P_{\mathrm{sf}}$ & $\mathrm{mm}$ & Position (bei spezifischem „Smoothing Factor“) \\
\hline$R_{\mathrm{a}}$ & $\mu \mathrm{m}$ & Mittenrauwert \\
\hline$R_{\text {rad }}$ & 1 & Reflexionsgrad \\
\hline$T$ & ${ }^{\circ} \mathrm{C}$ & Temperatur (allgemein) \\
\hline$T_{\mathrm{c}}$ & ${ }^{\circ} \mathrm{C}$ & Kristallisationstemperatur \\
\hline$T_{\mathrm{g}}$ & ${ }^{\circ} \mathrm{C}$ & Glasübergangstemperatur \\
\hline$T_{\mathrm{HG} 1}$ & ${ }^{\circ} \mathrm{C}$ & Temperatur der Gehäuseheizung im Bereich der Achse Q1 \\
\hline$T_{\mathrm{HG} 3}$ & ${ }^{\circ} \mathrm{C}$ & Temperatur der Gehäuseheizung im Bereich der Achse Q3 \\
\hline$T_{\mathrm{HG} 4}$ & ${ }^{\circ} \mathrm{C}$ & Temperatur der Gehäuseheizung im Bereich der Achse Q4 \\
\hline$T_{\mathrm{m}}$ & ${ }^{\circ} \mathrm{C}$ & Schmelztemperatur \\
\hline$T_{\mathrm{rad}}$ & 1 & Transmissionsgrad \\
\hline$T_{\text {Heizung }}$ & ${ }^{\circ} \mathrm{C}$ & Temperatur einer Heizung (allgemein) \\
\hline$T_{\text {HS1 }}$ & ${ }^{\circ} \mathrm{C}$ & Temperatur der Stempelheizung im Bereich der Achse Q1 \\
\hline$T_{\mathrm{HS} 3}$ & ${ }^{\circ} \mathrm{C}$ & Temperatur der Stempelheizung im Bereich der Achse Q3 \\
\hline$T_{\mathrm{HS} 4}$ & ${ }^{\circ} \mathrm{C}$ & Temperatur der Stempelheizung im Bereich der Achse Q4 \\
\hline$T_{\mathrm{z}}$ & ${ }^{\circ} \mathrm{C}$ & Zersetzungstemperatur \\
\hline$V$ & $\mathrm{~m}^{3}$ & Volumen (allgemein) \\
\hline$\dot{V}$ & $1 / \min$ & Volumenstrom (allgemein) \\
\hline
\end{tabular}




\section{Lateinische Symbole (Kleinbuchstaben)}

$\begin{array}{lll}c & \mathrm{~m} / \mathrm{s} & \text { Lichtgeschwindigkeit (Konstante) } \\ d(J P, F K) & \mathrm{mm} & \text { Abstand zwischen Jochplatte und Führungseinheitkorpus } \\ d_{\mathrm{L}} & \mu \mathrm{m} & \text { Laserstrahldurchmesser nach Fokussierung (Spotsize) } \\ d_{\mathrm{P}} & \mu \mathrm{m} & \text { Schichtstärke (Schichtdicke) } \\ e_{\mathrm{a}} & \mu \mathrm{m} & \text { Wegabweichung eines Kugelgewindetriebs (Messwert) } \\ e_{\mathrm{p}} & \mu \mathrm{m} & \text { Toleranzwert für den Sollweg eines Kugelgewindetriebs } \\ f & \mathrm{~mm} & \text { Brennweite } \\ h & \mathrm{~J} \mathrm{~s} & \text { Plancksches Wirkungsquantum (Konstante) } \\ h_{\mathrm{L}} & \mathrm{mm} & \text { Laserspurabstand } \\ k & 1 & \text { Korrekturwert (allgemein) } \\ l & \mathrm{~mm} & \text { Länge (allgemein) } \\ l_{\mathrm{u}} & \mathrm{mm} & \text { Nutzweg eines Kugelgewindetriebs } \\ s_{\mathrm{A}_{\mathrm{rad}}} & 1 & \text { Standardabweichung der Absorptionsgrade } \\ s_{|\mathrm{Abw}|} & \mu \mathrm{m} & \text { Standardabweichung der Beträge der Positionsabweichungen } \\ s_{\mathrm{max}} & \mathrm{mm} & \text { Maximaler Verfahrweg eines Kugelgewindetriebs } \\ s_{\mathrm{e}} & \mathrm{mm} & \text { Überlauf eines Kugelgewindetriebs } \\ s_{\mathrm{eff}} & \mathrm{mm} & \text { Effektiver Arbeitshub eines Kugelgewindetriebs } \\ v_{\mathrm{L}} & \mathrm{mm} / \mathrm{s} & \text { Laserablenkgeschwindigkeit (Scangeschwindigkeit) } \\ v_{\mathrm{sf}} & \mathrm{mm} / \mathrm{s} & \text { Geschwindigkeit (bei spezifischem „Smoothing Factor“) } \\ \bar{x}_{\mid \mathrm{Abw}} & \mu \mathrm{m} & \text { Mittelwert der Beträge der Positionsabweichungen } \\ \bar{x}_{\mathrm{A}_{\mathrm{rad}}} & 1 & \text { Mittelwert der Absorptionsgrade }\end{array}$

\section{Griechische Symbole}

$\begin{array}{lll}\varepsilon_{\mathrm{B}} & 1 & \text { Bruchdehnung } \\ \theta & \circ & \text { Winkel } \\ \lambda & \mu \mathrm{m} & \text { Wellenlänge } \\ \nu & \mathrm{Hz} & \text { Schwingfrequenz } \\ \tilde{\nu} & 1 / \mathrm{cm} & \text { Wellenzahl } \\ \nu_{300 \mathrm{a}} & \mu \mathrm{m} & \text { Wegschwankung eines Kugelgewindetriebs (Messwert) } \\ \nu_{300 \mathrm{p}} & \mu \mathrm{m} & \text { Zulässige Wegschwankung eines Kugelgewindetriebs } \\ \sigma_{\mathrm{M}} & \mathrm{N} / \mathrm{mm}^{2} & \text { Zugfestigkeit }\end{array}$




\section{Abbildungsverzeichnis}

1.1. AM-Wechselwirkungsdreieck . . . . . . . . . . . . . . . . . . . . . . 1

2.1. Klassifizierung der additiven Fertigungsverfahren nach dem Aggregatszustand in Anlehnung an die DIN $8580 \ldots \ldots$. . . . . . . . . 7

2.2. Datentransfer der Modelldaten für den AM-Prozess . . . . . . . . . . . . . 13

2.3. Exemplarische Prozesskette der additiven Fertigung . . . . . . . . . . . . 14

2.4. Ergebnis einer STL-Tesselierung in Abhängigkeit der Auflösung . . . . . . 15

2.5. Koordinatensystem eines Bauvolumens einer Lasersintermaschine . . . . . 15

2.6. Schichtgenerierung in Abhängigkeit der Bauteilorientierung . . . . . . . . 16

2.7. Prozesskette zur Herstellung vitaler Herzklappen mittels TE und AM . . 18

2.8. Strukturmodelle der Polymergruppen . . . . . . . . . . . . . . . . . . . 24

2.9. Strukturmodelle der thermoplastischen Polymere . . . . . . . . . . . 25

2.10. Thermische Zustandsbereiche von Thermoplasten . . . . . . . . . . . 25

2.11. Eigenschaften eines Materials zum Lasersintern . . . . . . . . . . . . . 26

2.12. Bauteilbezeichnungen zur Beschreibung des Lasersinterprozesses . . . . . 27

2.13. Lasersinterprozess vom Maschinenstart bis zur Bauteilentnahme . . . . . 28

3.1. Lasersintermaschine EOS Formiga P $100 \ldots \ldots$. . . . . . . . . . . . 37

3.2. Zuführung und Pulverauftrag der EOS Formiga P $100 \ldots \ldots$

4.1. AM-TE-Wechselwirkungsdreieck . . . . . . . . . . . . . . . . . 54

5.1. Anforderungserhebung aus dem AM-TE-Wechselwirkungsdreieck . . . . . 57

5.2. Steuerungssystem / Regelungssystems . . . . . . . . . . . . . . . . . 59

5.3. Produktarchitektur dargestellt als „METUS-Raute“ . . . . . . . . . . . . . 62

5.4. Integrale / Modulare Produktarchitektur . . . . . . . . . . . . . . . 63

6.1. Darstellung (1:1) eines Scaffolds im $\varnothing 65 \mathrm{~mm} \times 80 \mathrm{~mm}$ Bauraum . . . . . . 86

6.2. Pulverauftrag mit einer Pulverzuführung bzw. zwei Pulverzuführungen . . 88

6.3. Anordnung der Linearführungen für den translatorischen Pulverauftrag . 88

6.4. Gesamtkonzept der modularen Lasersintermaschine . . . . . . . . . . . . . 90

6.5. IR-Heizmodul (optional) innerhalb der Prozesskammer . . . . . . . . . . . 91

6.6. Gesamtentwurf der modularen Lasersintermaschine . . . . . . . . . . . . 92

6.7. Maschinengestell . . . . . . . . . . . . . . . . . . . . . 93

6.8. Prozesseinsatzplatte mit Anbauteilen . . . . . . . . . . . . . . . . . 95

6.9. Hubantriebsbaugruppenpaket samt Stempelbaugruppen . . . . . . . . . 97

6.10. Pulverauftragsmodul . . . . . . . . . . . . . . . . . . . . 99

6.11. Beschichtereinheiten für das Pulverauftragsmodul . . . . . . . . . . . . 101 
6.12. Prozessgasgehäuse ． . . . . . . . . . . . . . . . . . . . . 104

6.13. Prozessgasversorgungssystem samt Sauerstoff-Messsystem . . . . . . . . 107

6.14. Lasermodul . . . . . . . . . . . . . . . . . . . . . . . . . . . 109

7.1. Materialien im Lieferzustand: Foto und zugehörige REM-Aufnahmen . . . 116

7.2. Verwendete Produkte zur Kryogenvermahlungen von PLGA . . . . . . . 118

7.3. $50 \mathrm{ml}$ Mahlbecher für Retsch CryoMill befüllt mit $2 \mathrm{~g}$ PLGA . . . . . . . . 118

7.4. Retsch Vibrationssiebmaschine AS 200 control . . . . . . . . . . . . . . 119

7.5. REM-Aufnahmen nach dem Mahl- und Siebprozess . . . . . . . . . . . . 121

7.6. DSC-Kurvenverläufe von PA12 und PLGA bei $10^{\circ} \mathrm{C} / \mathrm{min} \ldots . . . . . .123$

7.7. DSC-Kurvenverläufe von teilkristallinen und amorphen Thermoplasten . . 124

7.8. Bruker Alpha FTIR-Spektrometer mit beheizbarem ATR-Modul . . . . 126

7.9. FTIR-Spektren von PA12 und PLGA von $40001 / \mathrm{cm}$ bis $4001 / \mathrm{cm}$. . . . . . 127

7.10. FTIR-Spektren von PA12 und PLGA von $11001 / \mathrm{cm}$ bis $9001 / \mathrm{cm}$. . . . . . 128

7.11. Schnittansicht der Prozesskammer . . . . . . . . . . . . . . . 130

8.1. Aufstellung der modularen Lasersintermaschine in Laborumgebung . . . . 134

8.2. Definition von Vorder- und Rückseite der Lasersintermaschine . . . . . . . 135

8.3. Hubantriebsbaugruppen aus dem Baustempel- und Pulverzuführmodul . . 136

8.4. 6-Kanal-Heizsystem unterhalb der Prozesseinsatzplatte . . . . . . . . . . 137

8.5. Prozessrahmenplatte, Prozesseinsatzplatte und Pulverauftragsmodul . . 138

8.6. Symmetrische Prozesseinsatzplatte samt Anbauteilen . . . . . . . . . . . 139

8.7. Rückseitige Türbaugruppe der Prozesskammer . . . . . . . . . . . . . . . 139

8.8. Wechselbare Beschichtereinheiten in der Prozesskammer . . . . . . . . . 140

8.9. Lasereinsatzplatte samt Anbauteilen . . . . . . . . . . . . . . . . . . 141

8.10. Laseretage samt Prozessgasversorgung und Laser-Scanner-Dummy . . . . 141

8.11. Steuereinheit der Lasersintermaschine . . . . . . . . . . . . . . . . . 142

8.12. Datenverarbeitung mit dem cRIO-basierten Steuersystem . . . . . . . . 145

8.13. Prüfung der Hubantriebsachsen: Variation der Beschleunigungsprofile . . . 149

8.14. Prüfung der Hubantriebsachsen: Variation der Verfahrwege . . . . . . . 150

8.15. Prüfungen der Pulverauftragsachse . . . . . . . . . . . . . . . 152

8.16. Prüfung des 6-Kanal-Heizsystems: Variation der Vorheiztemperatur . . . . 154

8.17. Prüfung der Systeme zur Prozessgasversorgung und Sauerstoffmessung . . 156

8.18. Prüfung der Live-Video-Weitwinkelkamera . . . . . . . . . . . . . . . . 157

8.19. Prüfung des Laser-Scanner-Demonstrators . . . . . . . . . . . . . . 158

9.1. Laser-Scanner-Demonstrator der modularen Lasersintermaschine . . . . 169

B.1. 80x40-Etage . . . . . . . . . . . . . . . . . . . . . 180

B.2. Prozessetage samt Prozessrahmenplatte . . . . . . . . . . . . . . . . 181

B.3. Laseretage samt Laserrahmenplatte . . . . . . . . . . . . . . . . . . . 182

B.4. Prozesseinsatzplatte samt Anbauteilen . . . . . . . . . . . . . . . . . . 183

B.5. Stempelbaugruppe . . . . . . . . . . . . . . . . . . . . . . . 184

B.6. Hubantriebsbaugruppe . . . . . . . . . . . . . . . . . 185

B.7. Hubantriebsbaugruppenpaket . . . . . . . . . . . . . 186 
B.8. Lagerbaugruppe des Pulverauftragmoduls . . . . . . . . . . . . . . . . 187

B.9. Antriebsbaugruppe des Pulverauftragmoduls . . . . . . . . . . . . 188

B.10.Einleitung Antriebsmoment . . . . . . . . . . . . . . . . . . . . 189

B.11.Anbindung des Auftragsschlittens . . . . . . . . . . . . . . . . 190

B.12.Beschichtereinheit mit starrer Klinge . . . . . . . . . . . . . . . . . . 191

B.13. Beschichtereinheit mit schwingender Klinge . . . . . . . . . . . . . . 192

B.14.Beschichtereinheit mit rotierender Rolle . . . . . . . . . . . . . . . . . 193

B.15.Türgängige Prozesskammer . . . . . . . . . . . . . . . . . . . 194

B.16. Türrahmenplatte und Prozesskammerwandbaugruppe . . . . . . . . . . . . 195

B.17.Türbaugruppe und Türrahmenplatte . . . . . . . . . . . . . . . . . . 196

B.18. Antriebsseitige Nebenkammer . . . . . . . . . . . . . . . . 197

B.19.Lagerseitige Nebenkammer . . . . . . . . . . . . . . . . . . . 198

B.20. Verbindungskammer . . . . . . . . . . . . . . . . . . . . . . . 199

B.21.Gaseinlass . . . . . . . . . . . . . . . . . . . . . . 200

B.22.Gasauslass . . . . . . . . . . . . . . . . . . . 200

B.23.Laserglas-Prozessgas-Armatur . . . . . . . . . . . . . . . . . 201

B.24.Lasereinsatzplatte samt Anbauteilen . . . . . . . . . . . . . . 202

B.25.Laser-Scanner-Dummy ohne Abdeckung . . . . . . . . . . . . . . . 203

C.1. Benennung der Komponenten eines 19" Schaltschranks . . . . . . . . . . . 206

C.2. Anschlussmöglichkeiten des NI CompactRIO-Controllers 9035 . . . . . . . 207

C.3. Gehäuse zur Abdeckung der elektrischen Verbindungen . . . . . . . . . . 209

C.4. Baugruppenträger des NI cRIO-Controllers 9035 . . . . . . . . . . . . . 212

C.5. Touchscreen-Monitor mit Not-Halt-Pilztaster-Einheit . . . . . . . . . . . 213

C.6. Sicherheits-Schaltscharnier und Not-Halt-Pilztaster-Einheit . . . . . . . 214

C.7. Bronkhorst Massendurchflussregler EL-FLOW Prestige . . . . . . . . . . . 214

C.8. First Sensor Sauerstoffsensor XYA mit Steuerplatine . . . . . . . . . . 215

C.9. Baugruppenträger des NI cRIO-Erweiterungschassis $9144 \ldots \ldots 217$

C.10.Keramikheizband mit PT1000-Bajonettfühler . . . . . . . . . . . . 218

C.11.Silikonheizmatte mit PT100 in der Stempelbaugruppe . . . . . . . . . . 219

C.12.Baugruppenträger der Bosch Rexroth Antriebsregelgeräte . . . . . . . . . 221

C.13.Baugruppenträger der Bosch Rexroth Antriebsregelgeräte . . . . . . . . . 222

C.14.Laser-Scanner-Demonstrator mit hurrySCAN II 14 Scanner . . . . . . . . 224

C.15.Baugruppenträger und Steuercomputer des Laser-Scanner-Dummys . . . . 225

D.1. Anpassung der Drehgebersignalausgabe an die Einbausituation . . . . . . 232

D.2. Fahrbereichsgrenzschalter an den Hubantriebsbaugruppen . . . . . . . . . 234

D.3. Bezugsabstand einer Hubantriebsbaugruppe . . . . . . . . . . . . . . 234

D.4. Messprotokoll des EMCs aus der Hubantriebsbaugruppe Q1 . . . . . . . 238

D.5. Messprotokoll des EMCs aus der Hubantriebsbaugruppe Q3 . . . . . . . . 239

D.6. Messprotokoll des EMCs aus der Hubantriebsbaugruppe Q4 . . . . . . . 240

D.7. Messaufbau zur Bestimmung des Axialspiels . . . . . . . . . . . . . . . . . 241

D.8. Kupplungsumbau an den Festo Führungseinheiten FENG . . . . . . . . 242

D.9. Messaufbau zur Drehgeberwertreferenzierung: Hubantriebsachse . . . . . . 243 
D.10.Messaufbau zur Drehgeberwertreferenzierung: Pulverauftragsachse . . . . 245

D.11.Drehgeberwertausgabe der Pulverauftragsachse nach Referenzierung . . . 246

E.1. Messaufbau zur Bestimmung der Positioniergenauigkeit der Hubantriebsbaugruppen / Messobjekt: Führungseinheit Q1 . . . . . . . . . . . . . 248

E.2. Messaufbau zur Bestimmung der Positioniergenauigkeit der Plattformen / Messobjekt: Stempelbaugruppe Q1 . . . . . . . . . . . . . . . 252

F.1. Lasergesinterte Werkzeuge zum Öffnen eines $50 \mathrm{ml}$ Mahlbechers . . . . . . 255

F.2. Mess-, Verschiebungs- und Bezugsabsandsbereich des Messkopfs . . . . . . 256

F.3. Regler des Laser-Wegmesssystems Keyence LC-2400 . . . . . . . . . . . . 257 


\section{Tabellenverzeichnis}

3.1. 3D-Systems Maschinen für das Lasersintern . . . . . . . . . . . . . . 35

3.2. EOS Maschinen für das Lasersintern . . . . . . . . . . . . . . . . . . 36

3.3. Aspect Maschinen für das Lasersintern . . . . . . . . . . . . . . . . . . . . 39

3.4. Farsoon Maschinen für das Lasersintern . . . . . . . . . . . . . . . . . . . 39

3.5. „Prototyper"-Maschinen für das Lasersintern . . . . . . . . . . . . . . 40

3.6. Kleinformatmaschinen für das Laserstrahlschmelzen . . . . . . . . . . . . 42

3.7. Laserstrahlschmelzmaschinen mit EOS P 110 ähnlichem Bauvolumen . . . 43

6.1. Zuordnung zwischen den Funktionen und Modulen . . . . . . . . . . . . . 80

7.1. Absorptionen von PLGA im Wellenlängenbereich der $\mathrm{CO}_{2}$-Laser … . . 129

7.2. Spezifische Anforderungsliste der PLGA-Laser-Scanner-Einheit . . . . . . 131

A.1. Spezifische Anforderungsliste der modularen Lasersintermaschine . . . . . 173

A.2. Spezifische Anforderungsliste der PLGA-Laser-Scanner-Einheit . . . . . 178

D.1. Identifikationsnummern der Antriebskomponenten . . . . . . . . . . . 230

D.2. IP-Adressen und Firmware-Versionen der Antriebsregelgeräte . . . . . . . 231

D.3. Fahrbereichsbegrenzung der Achse aus dem Pulverauftragsmodul . . . . . 233

D.4. Fahrbereichsbegrenzung der Hubantriebe ohne Stempelbaugruppe . . . . 235

D.5. Toleranzwerte für Kugelgewindetriebe bis $315 \mathrm{~mm}$ Nutzweg . . . . . . . . 236

D.6. Messdaten der Kugelgewindetriebe aus den Hubantriebsbaugruppen .. . 237

D.7. Abweichungen von der Sollposition der Hubantriebsspindeln . . . . . . . . 237

D.8. Axialspielmessung bei montierter Stempelbaugruppe vor dem Umbau . . . 241

D.9. Maschinenreferenzierte Drehgeberwertausgabe in z-Richtung . . . . . . . . 243

D.10.Fahrbereichsbegrenzung der Hubantriebsachsen nach Referenzierung . . . 244

D.11.Maschinenreferenzierte Drehgeberwertausgabe in x-/y-Richtung . . . . . . 246

D.12.Fahrbereichsbegrenzung der Pulverauftragsachse nach Referenzierung . . 246

E.1. Positioniergenauigkeit der Hubantriebsbaugruppe Q1: Messreihe 1-Q1-100 249

E.2. Positioniergenauigkeiten der Hubantriebsbaugruppen Q1 / Q3 / Q4 . . 250

E.3. Positioniergenauigkeit der Bauplattform Q1: Messreihe 1-Q1+ST-100 . . . 252

E.4. Positioniergenauigkeiten der Plattformen Q1 / Q3 / Q4 . . . . . . . . 254

F.1. Betreute wissenschaftliche Arbeiten . . . . . . . . . . . . . . . . 258 



\section{Literatur}

[3D-14] 3D-Systems. „SLS Production Series. Production 3D Printers“. DATENBLATT. In: (2.2014).

[3D-15] 3D-Systems. „ProX SLS Serie. 3D Produktionsdrucker“. DATENBLATT. In: (1.2015).

[3D-18] 3D-Systems. „Selective Laser Sintering Printers. Production thermoplastic parts with ProX and sPro SLS printers". DATENBLATT. In: (3.2018).

[Asp15] Aspect. „RaFaEl II. Next Generation Powder Bed Fusion Platform“. DATENBLATT. In: (2015).

[ASW16] Daniel Alberts, Dieter Schwarze und Gerd Witt. „High speed melt pool \& laser power monitoring for selective laser melting (SLM)“. PAPER. In: Photonic Technologies LANE 2016 (2016).

[BHS13] Uwe Berger, Andreas Hartmann und Dietmar Schmid. Additive Fertigungsverfahren. Rapid Prototyping, Rapid Tooling, Rapid Manufacturing. 1. Aufl. Bd. 50335. Europa. Haan-Gruiten: Verl. Europa-Lehrmittel Nourney Vollmer, 2013. 224 S. ISBN: 978-3-8085-5033-5.

[Bon14] Christian Bonten. Kunststofftechnik. Einführung und Grundlagen. ger. 1. Aufl. s.l.: Carl Hanser Fachbuchverlag, 2014. 497 S. ISBN: 978-3-446-44171-2. DOI: 10 .3139/9783446441712. URL: http://ebooks.ciando.com/book/ index.cfm/bok_id/1551112.

[Bos13] Bosch Rexroth AG. „Rexroth IndraDyn S Synchronmotoren MSK. Projektierungsbeschreibung“. B\&P. In: (R911296288 2013).

[Bos14a] Bosch Rexroth AG. „Rexroth IndraDrive - Firmware MPx-18. Anwendungsbeschreibung“. B\&P. In: (R911338674 2014).

[Bos14b] Bosch Rexroth AG. „Rexroth IndraDrive - Zusatzkomponenten und Zubehör. Projektierungsbeschreibung“. B\&P. In: (R911306139 2014).

[Bos15a] Bosch Rexroth AG. „Elektromechanischer Zylinder EMC. Produktbeschreibung“. B\&P. In: (R999000473 1.2015).

[Bos15b] Bosch Rexroth AG. „Elektromechanische Zylinder EMC. Anleitung“. B\&P. In: (R320103102 4.2015).

[Bos15c] Bosch Rexroth AG. „Automatisierung von Mess- und Prüfmaschinen aus einem Guss. SPS-lose Programmierung von Rexroth- Antrieben mit National Instruments Steuerung". PRESSEINFORMATION. In: (8.2015). URL: http: / / dc-de.resource . bosch. com/media/de/press_release_ 1 / 2015 / august_12/PI_NIWeek_DE.pdf. 
[Bos15d] Bosch Rexroth AG. „Rexroth IndraDrive Cs - Antriebssysteme mit HCS01. Projektierungsbeschreibung“. B\&P. In: (R911322209 2015).

[Bos16] Bosch Rexroth AG. „Rexroth IndraDrive - Firmware MPx-20. Version Notes“. B\&P. In: (R911345605 2016).

[BPL+16] M. Bullemer, A. Pfister, J. Lenz, C. Gayer und L. Jauer. „Abschlussbericht zum Verbundprojekt ActiveBone - Förderkennzeichen 13N12130 - EOS GmbH. Biodegradierbare Kompositwerkstoffe für die generative Fertigung bioaktiver Knochenersatzimplantate“. ABSCHLUSSBERICHT. In: (2016).

[Bra13] Martin Bram. Pulvermetallurgische Herstellung von porösem Titan und von NiTi-Legierungen für biomedizinische Anwendungen. Zugl.: Bochum, Univ., Habil.-Schr., 2012. ger. Bd. 171. Schriften des Forschungszentrums Jülich Reihe Energie \& Umwelt. Jülich: Forschungszentrum Jülich, 2013. 238 S. ISBN: 978-3-89336-866-2.

[Bra17] Thomas Braun. Entwicklung eines Vorkonzepts für das Lasermodul eines Laser-Sinter-Prüfstands zur Verarbeitung eines bioresorbierbaren Biopolymers als Werkstoff für die additive Fertigung von künstlichen Herzklappen auf Grundlage einer Literaturrecherche. BACHELORARBEIT. Unter Mitarb. von Prof. Dietmar Göhlich und Clemens Kautz. TU Berlin / Institut für Konstruktion, Mikro- und Medizintechnik / FG Methoden der Produktentwicklung und Mechatronik, 2.2017. $165 \mathrm{~S}$.

[Bro17] Bronkhorst. „EL-FLOW Prestige. Der weltweit vielseitigste Massendurchflussmesser /-regler für Gase“. DATENBLATT. In: (2017).

[BS12] Hans-Jürgen Bargel und Günter Schulze, Hrsg. Werkstoffkunde. ger. 11., bearb. Aufl. 2012. Springer-Lehrbuch. Berlin, Heidelberg: Springer, 2012. 531 S. ISBN: 978-3-642-17716-3. DOI: 10.1007/978-3-642-17717-0. URL: http://dx.doi.org/10.1007/978-3-642-17717-0.

[Bun06] Bundesministeriums für Gesundheit. „Leitfaden der Guten Herstellungspraxis Teil I. Anlage 2 zur Bekanntmachung des Bundesministeriums für Gesundheit zu $\S 2$ Nr. 3 der Arzneimittel- und Wirkstoffherstellungsverordnung vom 27. Oktober 2006 (Banz. S. 6887)“. LEITFADEN. In: (10.2006). URL: https : / / www . bundesgesundheitsministerium . de/service/gesetzeund-verordnungen/bekanntmachungen.html.

[Bun15] Bundesministeriums für Gesundheit. „Leitfaden der Guten Herstellungspraxis Teil II. Anlage der Bekanntmachung zu $\S 2$ Nummer 3 der Arzneimittel- und Wirkstoffherstellungsverordnung - AMWHV - im Bundesanzeiger vom 27. Mai 2015“. LEITFADEN. In: (5.2015). URL: https : // www . bundesgesund \% 20heitsministerium . de / service / gesetze - und verordnungen/bekannt\%20machungen. html. 
[BWB11] Oliver Baier, Gerd Witt und Michael Busch. „Generative Herstellung von Wachsmodellen auf Trägerplatten und anschließender galvanoplastischer Aufbau zur Herstellung komplexer Innenstrukturen“. PAPER. In: RTejournal (2011). URL: https://www.rtejournal.de/.

[BWS+12] Maribel I. Baker, Steven P. Walsh, Zvi Schwartz und Barbara D. Boyan. „A review of polyvinyl alcohol and its uses in cartilage and orthopedic applications". eng. In: Journal of biomedical materials research. Part B, Applied biomaterials 100 (5 2012). Journal Article Review, S. 1451-1457. ISSN: 1552-4973. DOI: 10.1002/jbm.b.32694. eprint: 22514196.

$[\mathrm{CCK}+12]$ Tom Craeghs, Stijn Clijsters, Jean.-Pierre Kruth, Florian Bechmann und Marie.-Christin Ebert. „Detection of Process Failures in Layerwise Laser Melting with Optical Process Monitoring“. PAPER. In: Physics Procedia 39 (2012), S. 753-759. ISSN: 18753892. DOI: 10.1016/j .phpro.2012.10.097.

$[\mathrm{CCY}+11]$ Tom Craeghs, Stijn Clijsters, Evren Yasa und Jean-Pierre Kruth. „Online Quality Control of Selective Laser Melting“. PAPER. In: Solid Freeform Fabrication Symposium 2011 (8.2011), S. 212-226. URL: http://sffsymposium. engr.utexas.edu/archive.

[CGN+17] E. Ceretti, P. Ginestra, P. I. Neto, A. Fiorentino und J.V.L. Da Silva. „Multi-layered Scaffolds Production via Fused Deposition Modeling (FDM) Using an Open Source 3D Printer. Process Parameters Optimization for Dimensional Accuracy and Design Reproducibility“. PAPER. In: Procedia CIRP 65 (2017), S. 13-18. ISSN: 22128271. DOI: 10.1016/j . procir. 2017. 04.042 .

[CI02] L. Claes und A. Ignatius. „Entwicklung neuer biodegradabler Implantate“. PAPER. ger. In: Der Chirurg; Zeitschrift fur alle Gebiete der operativen Medizen 73 (10 2002). Journal Article Review, S. 990-996. ISSN: 0009-4722. DOI: $10.1007 /$ s00104-002-0543-0. eprint: 12395157.

[CKM+16] Zetao Chen, Travis Klein, Rachael Z. Murray, Ross Crawford, Jiang Chang, Chengtie Wu und Yin Xiao. „Osteoimmunomodulation for the development of advanced bone biomaterials". PAPER. In: Materials Today 19 (6 2016), S. 304-321. ISSN: 13697021. DOI: 10.1016/j .mattod.2015.11.004.

[CLT13] Qizhi Chen, Shuling Liang und George A. Thouas. „Elastomeric biomaterials for tissue engineering“. PAPER. In: Progress in Polymer Science 38 (3-4 2013), S. 584-671. ISSN: 00796700. DOI: 10.1016/j .progpolymsci.2012.05.003.

[Con15a] Concept Laser. „M2 cusing. Metall-Laserschmelzanlage“. DATENBLATT. In: (10.2015).

[Con15b] Concept Laser. „M2 cusing Multilaser. Metall-Laserschmelzanlage“. DATENBLATT. In: (10.2015).

[Con16a] Concept Laser. „Mlab cusing. Metall-Laserschmelzanlage“. DATENBLATT. In: (10.2016). 
[Con16b] Concept Laser. „Mlab cusing R. Metall-Laserschmelzanlage“. DATENBLATT. In: (10.2016).

[Cor15a] Corbion Purac. „PURASORB PLG 8523“. DATENBLATT. In: (3.2015).

[Cor15b] Corbion Purac. „PURASORB PLG 8531“. DATENBLATT. In: (3.2015).

[CXS+14] Yongjun Chen, Zhigang Xu, Christopher Smith und Jag Sankar. „Recent advances on the development of magnesium alloys for biodegradable implants". PAPER. eng. In: Acta biomaterialia 10 (11 2014). Journal Article Research Support, U.S. Gov't, Non-P.H.S. Review, S. 4561-4573. ISSN: 1878-7568. DOI: 10.1016/j.actbio.2014.07.005. eprint: 25034646 .

[DAG+17] Anh-Vu Do, Adil Akkouch, Brian Green, Ibrahim Ozbolat, Amer Debabneh, Sean Geary und Aliasger K. Salem. „Controlled and Sequential Delivery of Fluorophores from 3D Printed Alginate-PLGA Tubes". PAPER. eng. In: Annals of biomedical engineering 45 (1 2017). PMC5124557 Journal Article, S. 297-305. ISSN: 1573-9686.

[dBS17] Venina dos Santos, Rosmary Nichele Brandalise und Michele Savaris. Engineering of Biomaterials. eng. Topics in Mining, Metallurgy and Materials Engineering. Cham und s.l.: Springer International Publishing, 2017. 5 S. ISBN: 978-3-319-58606-9. DOI: 10.1007/978-3-319-58607-6.

[DD14] Michael Dr. Breit und Hans-Joachim Dr. Münzer. „Galvanometer-scanner mit digitalen positionssensoren erfüllen höchste anforderungen der Industrie“. PAPER. In: Laser Magazin (4 2014). URL: http://www. laser-magazin.de/.

[DE02] Sergey V. Dorozhkin und Matthias Epple. „Die biologische und medizinische Bedeutung von Calciumphosphaten“. PAPER. In: Angewandte Chemie 114 (17 2002), S. 3260-3277. ISSN: 00448249.

[DK08] Stephane Danjou und Horst Koehler. „Vorbereitung von CAD - Konstruktionsdaten für den RP - Einsatz - eine Schnittstellenproblematik“. PAPER. In: RTejournal (2008). URL: https://www.rtejournal.de/.

[DK09] Stephane Danjou und Peter Köhler. „Ermittlung optimaler Bauteilorientierung zur Verbesserung der Prozessplanung in der CAD/RP-Kette“. PAPER. In: RTejournal (2009). URL: https://www.rtejournal.de/.

[DLH+13] Qinglin Dong, Yi Li, Changyu Han, Xin Zhang, Kun Xu, Huiliang Zhang und Lisong Dong. „Poly( 1 -lactide)/poly( d -lactide)/multiwalled carbon nanotubes nanocomposites. Enhanced dispersion, crystallization, mechanical properties, and hydrolytic degradation". PAPER. In: Journal of Applied Polymer Science 9 (2013). ISSN: 00218995. DOI: 10.1002/app. 39667.

[DLS+15] Yingying Du, Haoming Liu, Jiaqi Shuang, Jianglin Wang, Jun Ma und Shengmin Zhang. „Microsphere-based selective laser sintering for building macroporous bone scaffolds with controlled microstructure and excellent biocompatibility". PAPER. eng. In: Colloids and surfaces. B, Biointerfaces 135 (2015). Journal Article Research Support, Non-U.S. Gov't, S. 81-89. ISSN: 1873-4367. DOI: 10.1016/j.colsurfb. 2015.06.074. eprint: 26241919. 
[DMG17] DMG MORI. „Lasertec 30 SLM. Neu bei DMG MORI: Selektives Laserschmelzen“. DATENBLATT. In: (8.2017). URL: https://journal.dmgmori. com/de-de/branches-technology-solutions/additive-manufacturing.

[Dor14] Sergey V. Dorozhkin. „Calcium orthophosphate coatings on magnesium and its biodegradable alloys". PAPER. eng. In: Acta biomaterialia 10 (7 2014). Journal Article Review, S. 2919-2934. ISSN: 1878-7568. DOI: $10.1016 / \mathrm{j}$. actbio.2014.02.026. eprint: 24607420 .

[DR 15a] DR. JOHANNES HEIDENHAIN GmbH. „Schnittstellen von Heidenhain Messgeräten“. DATENBLATT. In: (3.2015). URL: www.heidenhain.de.

[DR 15b] DR. JOHANNES HEIDENHAIN GmbH. „Drehgeber“. PRODUKTKATALOG. In: (11.2015). URL: www.heidenhain.de.

[DS15] Philipp Drescher und Hermann Seitz. „Processability of an amorphous metal alloy powder by electron beam melting". PAPER. In: RTejournal (2015). URL: https://www.rtejournal.de/.

[DWZ+10] Bin Duan, Min Wang, Wen You Zhou, Wai Lam Cheung, Zhao Yang Li und William W. Lu. „Three-dimensional nanocomposite scaffolds fabricated via selective laser sintering for bone tissue engineering“. PAPER. eng. In: Acta biomaterialia 6 (12 2010). Journal Article Research Support, Non-U.S. Gov't, S. 4495-4505. ISSN: 1878-7568. DOI: 10.1016/j . actbio. 2010.06. 024. eprint: 20601244.

[Ebe18] Lukas Ebeling-Rump. Entwicklung und Inbetriebnahme eines gasdichten Gehäuses für einen Lasersinter-Prüfstand zur Herstellung künstlicher Herzklappen für die Medizintechnik. BACHELORARBEIT. Unter Mitarb. von Prof. Dietmar Göhlich und Clemens Kautz. TU Berlin / Institut für Maschinenkonstruktion und Systemtechnik / FG Methoden der Produktentwicklung und Mechatronik, 7.2018. 119 S.

[Ede07] Ingo Ederer. „Kleinserien-Produktion mittels 3D-Druck“. PAPER. In: RTejournal (2007). URL: https://www.rtejournal.de/.

[Ede08] Ingo Ederer. „Oberflaechenverbesserung im 3D-Druck mittels hoeherer Aufloesung“. PAPER. In: RTejournal (2008). URL: https://www.rtejournal.de/.

[EEH05] Peter Eyerer, Peter Elsner und Thomas Hirth. Die Kunststoffe und ihre Eigenschaften. ger. 1. Aufl. VDI-Buch. s.l.: Springer-Verlag, 2005. 1633 S. ISBN: $3-540-21410-0$.

[EEH08] Peter Eyerer, Peter Elsner und Thomas Hirth. Polymer Engineering. Technologien und Praxis. ger. VDI-Buch. Berlin und Heidelberg: Springer, 2008. ISBN: 978-3-540-72402-5.

[EHS+16] Sarah K. Everton, Matthias Hirsch, Petros Stravroulakis, Richard K. Leach und Adam T. Clare. „Review of in-situ process monitoring and in-situ metrology for metal additive manufacturing". PAPER. In: Materials $\&$ Design 95 (2016), S. 431-445. ISSN: 02641275. DOI: 10.1016/j.matdes.2016.01.099. 
[Eic10] Michael Eichmann. „Von der Idee bis zum fertigen Produkt - 3D-Drucken mit der PolyJet-Technologie von OBJET“. PAPER. In: RTejournal (2010). URL: https://www.rtejournal.de/.

[EKL+14] Klaus Ehrlenspiel, Alfons Kiewert, Udo Lindemann und Markus Mörtl. Kostengünstig Entwickeln und Konstruieren. Kostenmanagement bei der integrierten Produktentwicklung. ger. 7. Aufl. VDI-Buch. Berlin: Springer Vieweg, 2014. 593 S. ISBN: 978-3-642-41958-4. DOI: 10.1007/978-3-64241959-1. URL: http://dx.doi.org/10.1007/978-3-642-41959-1.

[EOS02] EOS. „Materialdatenblatt. Feinpolyamid PA 2200 für EOSINT P“. DATENBLATT. In: (9.2002).

[EOS08] EOS. „Technische Beschreibung EOSINT P 800“. DATENBLATT. In: (11.2008).

[EOS10a] EOS. „Werkstoff EOS PEEK HP3“. DATENBLATT. In: (10.201).

[EOS10b] EOS. „EOS FORMIGA P 100. Kunststoff Laser-Sinter-System zur direkten Herstellung von Serien, Ersatzteilen und Funktionsprototypen“. DATENBLATT. In: (11.201).

[EOS13a] EOS. „EOS FORMIGA P 110. Kunststoff Laser-Sinter-System zur direkten Herstellung von Serien, Ersatzteilen und Funktionsprototypen“. DATENBLATT. In: (6.2013).

[EOS13b] EOS. „EOS P 396. System zur Additiven Fertigung von Serienteilen und Funktionsprototypen aus Polymerwerkstoffen". DATENBLATT. In: (11.2013).

[EOS14a] EOS. „Technische Beschreibung EOS P 396“. DATENBLATT. In: (2.2014).

[EOS14b] EOS. „EOSINT P 800. Kunststoff-Laser-Sinter-System EOSINT P 800 zur Verarbeitung von Hochleistungspolymeren bei Betriebstemperaturen von bis zu 385 Grad Celsius". DATENBLATT. In: (5.2014).

[EOS14c] EOS. „Technische Beschreibung FORMIGA P 110“. DATENBLATT. In: (9.2014).

[EOS15] EOS. „EOSTATE MeltPool. automatisierte, intelligente Echtzeit - Prozessüberwachung für das Direkte Metall Laser-Sintern (DMLS)“. PRESSEMITTEILUNG. In: (11.2015). URL: https://www.eos.info/presse/eostatemeltpool_automatisierte-echtzeit-prozessueberwachung-im-dmlsprozess.

[EOS16a] EOS. „Werkstoff EOS PA 2200 Balance 1.0“. DATENBLATT. In: (3.2016).

[EOS16b] EOS. „EOS P 770. Laser-Sinter-System mit zwei Lasern zur Herstellung großer Bauteile und zur industriellen Fertigung mit hohem Durchsatz". DATENBLATT. In: (9.2016).

[EOS16c] EOS. „Precious M 080“. DATENBLATT. In: (12.2016).

[EOS17a] EOS. „EOS M 290. Der Industrie-Benchmark für die additive Fertigung metallischer Bauteile von hoher Qualität - ab sofort mit umfangreicher Monitoring-Suite“. DATENBLATT. In: (4.2017). 
[EOS17b] EOS. „EOS M 100. High-End-System zur schnellen und wirtschaftlichen Produktion von filigranen Metallteilen per additiver Fertigung". DATENBLATT. In: (5.2017).

[EOS17c] EOS. „EOS P 500. Die automatisierbare Fertigungsplattform zum LaserSintern von Kunststoffteilen im industriellen Maßstab“. DATENBLATT. In: (11.2017).

[EOS17d] EOS. „Die perfekte Kombination. Zubehör für die EOS Lasersinter-Anlagen“. DATENBLATT. In: (2017).

[EOS18] EOS. „EOS P 810. Hochtemperatur-System für das Laser-Sintern ermöglicht erstmals Serienfertigung von anspruchsvollen Kunststoff-Verbundteilen für die Luftfahrt-, Elektronik- und Mobilitätsindustrie“. DATENBLATT. In: (4.2018).

[ES09] Hans-Josef Endres und Andrea Siebert-Raths. Technische Biopolymere. Rahmenbedingungen, Marktsitutation, Herstellung, Aufbau und Eigenschaften. ger. München: Hanser, 2009. 629 S. ISBN: 978-3-446-41683-3. URL: http : //sub-hh. ciando.com/book/?bok_id=30958.

[ES14] Enno Ebel und Thorsten Sinnemann. „Fabrication of FDM 3D objects with ABS and PLA and determination of their mechanical properties". PAPER. In: RTejournal (2014). URL: https://www.rtejournal.de/.

[ESF+10] Florencia Edith Wiria, Novella Sudarmadji, Kah Fai Leong, Chee Kai Chua, E. Wei Chng und Chian Chai Chan. „Selective laser sintering adaptation tools for cost effective fabrication of biomedical prototypes". In: Rapid Prototyping Journal 16 (2 2010), S. 90-99. ISSN: 1355-2546. DOI: 10.1108 / 13552541011025816.

$[$ ETH+11] Laura Elomaa, Sandra Teixeira, Risto Hakala, Harri Korhonen, Dirk W. Grijpma und Jukka V. Seppälä. „Preparation of poly(epsilon-caprolactone)-based tissue engineering scaffolds by stereolithography". PAPER. In: Acta biomaterialia 7 (11 2011), S. 3850-3856. ISSN: 1878-7568. DOI: 10.1016/j .actbio. 2011.06 .039 .

[Eur18] European Hygienic Engineering and Design Group. „Hygienic Design Principles DOC 8. EHEDG Guidelines“. INTERNETDOKUMENT. In: (3.2018).

[EVL+12] Szilvia Eosoly, Nihal Engin Vrana, Stefan Lohfeld, Mathilde Hindie und Lisa Looney. „Interaction of cell culture with composition effects on the mechanical properties of polycaprolactone-hydroxyapatite scaffolds fabricated via selective laser sintering (SLS)“. PAPER. In: Materials Science and Engineering: C 32 (8 2012), S. 2250-2257. ISSN: 09284931. DOI: 10.1016/j.msec.2012.06.011.

[Evo14] Evonik Nutrition \& Care GmbH. „Resomer RG 755 S. Certificate of Analysis“. DATENBLATT. In: (6.2014).

[Evo15] Evonik Nutrition \& Care GmbH. „RESOMER - Typen: L, LC, LG, LR, R, RG. Sicherheitsdatenblatt gemäß Verordnung (EG) 1907/2006“. DATENBLATT. In: (3.2015). 
[Evo17a] Evonik Nutrition \& Care GmbH. „RESOMER MD biodegradable polymers receive ISO 13485 certification“. PRESSEINFORMATION. In: (2.2017).

[Evo17b] Evonik Nutrition \& Care GmbH. „Zertifizierung nach EN ISO 13485“. PRESSEINFORMATION. In: (2.2017).

[Evo17c] Evonik Nutrition \& Care GmbH. „Resomer. Biomaterials for pharmaceuticals and medical devices". DATENBLATT. In: (2017). URL: http://healthcare . evonik.com/sites/lists/NC/DocumentsHC/Evonik_RESOMER_product_ brochure.pdf.

[Far16] Farsoon. „403P Serie. A powerful and versatile open platform system for your additive manufacturing needs“. DATENBLATT. In: (10.2016).

[Far17a] Farsoon. „252P Serie. Das kompakte und hochtemperaturfähige System - Ideal für die Kleinteilfertigung und für den Forschungsbereich“. DATENBLATT. In: (10.2017).

[Far17b] Farsoon. „eForm. Das kompakte und kostengünstige System - Ideal für den Einsteiger und den universitären Bereich“. DATENBLATT. In: (10.2017).

[Faß17] Tim Helge Faß. Konstruktive Anpassung, Steuerung und Inbetriebnahme eines Laser Scanner Demonstrators als Modul für einen Laser Sinter Prüfstand zur Herstellung von Zellträgern für künstliche Herzklappen. MASTERARBEIT. Unter Mitarb. von Prof. Dietmar Göhlich und Clemens Kautz. TU Berlin / Institut für Konstruktion, Mikro- und Medizintechnik / FG Methoden der Produktentwicklung und Mechatronik, 4.2017. 165 S.

[Fes16] Festo. „Führungseinheiten FEN/FENG für Normzylinder“. DATENBLATT. In: (2.2016).

[Fir18a] First Sensor. „Funktionsprinzip und Aufbau von XYA - Zirkoniumdioxid Sauerstoffsensoren. Anwendungshinweis“. BEDIENUNGS- ODER PROJEKTIERUNGSANLEITUNG. In: D / 11154 / C (2018).

[Fir18b] First Sensor. „ZBXYAF. Oxygen sensor control circuit board“. DATENBLATT. In: E / 11666 / B (2018).

[For17] Formlabs. „Fuse 1“. DATENBLATT. In: (6.2017).

[Fra10] Fraunhofer - Institut für Lasertechnik ILT. „Jahresabschlussbericht 2010“. In: (2010). URL: www.ilt.fraunhofer.de.

[Fra15] Fraunhofer - Institut für Lasertechnik ILT. „Jahresabschlussbericht 2015“. In: (2015). URL: www.ilt.fraunhofer.de.

[FRW+07] Lothar Fiedler, Hans Joachim Radusch, Andre Wutzler und Jörg Gerken. „Evaluation of Polypropylene Powder Grades in Consideration of the Laser Sintering Processability“. PAPER. In: WAK - Zeitschrift Kunststofftechnik (6.2007). URL: https://www.kunststofftech.com/. 
[FS12] A. Herbert Fritz und Günter Schulze. Fertigungstechnik. ger. 10., neu bearb. Aufl. 2012. Springer-Lehrbuch. Berlin, Heidelberg: Springer, 2012. 11 S. ISBN: 978-3-642-29785-4. DOI: 10 . 1007/978-3-642-29786-1. URL: http: //dx.doi.org/10.1007/978-3-642-29786-1.

[FS15] Alfred Herbert Fritz und Günter Schulze. Fertigungstechnik. ger. 11., neu bearbeitete und ergänzte Auflage. Springer-Lehrbuch. Berlin und Heidelberg: Springer Vieweg, 2015. 540 S. ISBN: 978-3-662-46554-7. DOI: 10.1007/9783-662-46555-4. URL: http://dx.doi.org/10.1007/978-3-662-46555-4.

[GAT+14] S. M. Giannitelli, D. Accoto, M. Trombetta und A. Rainer. „Current trends in the design of scaffolds for computer-aided tissue engineering“. PAPER. In: Acta biomaterialia 10 (2 2014), S. 580-594. ISSN: 1878-7568. DOI: 10.1016/j. actbio.2013.10.024.

[GBG18] Karl-Heinrich Grote, Beate Bender und Dietmar Göhlich. Dubbel - Taschenbuch für den Maschinenbau. ger. 25., neu bearbeitete und aktualisierte Auflage. Berlin: Springer Vieweg, 2018. 1 S. ISBN: 978-3-662-54805-9. URL: https : //doi.org/10.1007/978-3-662-54805-9.

[GCC+14] Piergiorgio Gentile, Valeria Chiono, Irene Carmagnola und Paul V. Hatton. „An overview of poly(lactic-co-glycolic) acid (PLGA)-based biomaterials for bone tissue engineering“. PAPER. eng. In: International journal of molecular sciences 15 (3 2014). PMC3975359 Journal Article Research Support, Non-U.S. Gov't Review, S. 3640-3659. ISSN: 1422-0067. DOI: 10.3390/ijms15033640. eprint: 24590126.

[GD14] Thomas Grünberger und Robert Domröse. „Optical In-Process Monitoring of Direct Metal Laser Sintering (DMLS)“. PAPER. In: Laser Technik Journal 11 (2 2014), S. 40-42. ISSN: 16137728. DOI: 10.1002/latj . 201400026.

[Geb05] Andreas Gebhardt. „Rapid Prototyping für metallische Werkstücke: Direkte und indirekte Verfahren“. PAPER. In: RTejournal (2005). URL: https :// www.rtejournal.de/.

[Geb13] Andreas Gebhardt. Generative Fertigungsverfahren. Additive Manufacturing und 3D Drucken für Prototyping ; Tooling ; Produktion. ger. 1. Aufl. s.l.: Carl Hanser Fachbuchverlag, 2013. 672 S. ISBN: 978-3-446-43651-0. URL: http://ebooks.ciando.com/book/index.cfm/bok_id/992132.

[GFC+09] Estelle Gautier, Patrick Fuertes, Philippe Cassagnau, Jean-Pierre Pascault und Etienne Fleury. „Synthesis and rheology of biodegradable poly(glycolic acid) prepared by melt ring-opening polymerization of glycolide". PAPER. In: Journal of Polymer Science Part A: Polymer Chemistry 47 (5 2009), S. 1440-1449. ISSN: 0887624X. DOI: 10.1002/pola. 23253.

[GH15] Wolfgang Georgi und Philipp Hohl. Einführung in LabVIEW. Mit 163 Aufgaben. ger. 6., erw. Aufl. München: Fachbuchverl. Leipzig im Carl-Hanser-Verl., 2015. 596 S. ISBN: 9783446442726. URL: http://www.geho-labview.de. 
[GKT16] Andreas Gebhardt, Julia Kessler und Laura Thurn. 3D-Drucken. Grundlagen und Anwendungen des Additive Manufacturing (AM). ger. 2., neu bearbeitete und erweiterte Auflage. München: Hanser, 2016. 218 S. ISBN: 978-3-446-44672-4.

[GR08] Detlev Ganten und Klaus Ruckpaul. Grundlagen der Molekularen Medizin. ger. 3. Aufl. s.l.: Springer-Verlag, 2008. 576 S. ISBN: 978-3-540-69412-0.

[Gro16] Stefanie Grom. „Abschlussbericht zum Verbundprojekt ActiveBone - Förderkennzeichen 13N12132 - KLM GmbH. Biodegradierbare Kompositwerkstoffe für die generative Fertigung bioaktiver Knochenersatzimplantate“. ABSCHLUSSBERICHT. In: (2016).

[Gru11] Simon Gruber. „Lithographiebasierte Fertigung keramischer Bauteile“. PAPER. In: RTejournal (2011). URL: https://www.rtejournal.de/.

[Gru15] Maike Grund. Implementierung von schichtadditiven Fertigungsverfahren. Mit Fallbeispielen aus der Luftfahrtindustrie und Medizintechnik. Light Engineering für die Praxis. Berlin, Heidelberg: Springer Vieweg, 2015. 70843207 S. ISBN: 978-3-662-44265-4. DOI: 10 .1007/978-3-662-44266-1. URL: http : //dx.doi.org/10.1007/978-3-662-44266-1.

[Hau08a] Gerhard Hauser. Hygienegerechte Apparate und Anlagen. ger. Hoboken: John Wiley \& Sons, 2008. 879 S. ISBN: 978-3-527-32291-6. URL: http://gbv .eblib . com/patron/FullRecord. aspx?p=894839.

[Hau08b] Gerhard Hauser. Hygienische Produktionstechnologie. ger. Weinheim: Wiley-VCH, 2008. ISBN: 978-3-527-30307-6. DOI: 10.1002/9783527626335. URL: http : / / site . ebrary . com/lib/alltitles/docDetail . action?docID= 10302539.

[HD10] Simon Hoeges und Wilhelm Dr. Meiners. „Abschlussbericht zum Verbundprojekt Resobone - Förderkennzeichen 16IN0442. Generative Fertigung von Knochenersatzimplantaten aus resorbierbaren Werkstoffen". ABSCHLUSSBERICHT. In: (9.201).

[Hen06] Larry L. Hench. „The story of Bioglass“. PAPER. eng. In: Journal of materials science. Materials in medicine 17 (11 2006). Historical Article Journal Article Research Support, N.I.H., Extramural Research Support, Non-U.S. Gov't Research Support, U.S. Gov't, Non-P.H.S., S. 967-978. ISSN: 1573-4838. DOI: 10.1007/s10856-006-0432-z. eprint: 17122907.

[Heu09] Ulrich Heubner. Nichtrostender Stahl - wenn die Gesundheit zählt. ger. Bd. 2. Reihe Mensch und Umwelt. Brüssel: Euro Inox, 2009. 37 S. ISBN: 978-2-87997-309-8.

[HGD+08] Pamela Habibovic, Uwe Gbureck, Charles J. Doillon, David C. Bassett, Clemens A. van Blitterswijk und Jake E. Barralet. „Osteoconduction and osteoinduction of low-temperature 3D printed bioceramic implants". PAPER. In: Biomaterials 29 (7 2008), S. 944-953. ISSN: 01429612. DOI: 10.1016/j . biomaterials.2007.10.023. 
[HH09] Jonathan D. Hiller und Lipson Hod. „STL 2.0: A proposal for a universal multi-material Additive Manufacturing File format". PAPER. In: Solid Freeform Fabrication Symposium 2009 (1.2009), S. 266-278. URL: http: //sffsymposium.engr.utexas.edu/archive.

[HKP+18] Hamid Amiri Heydary, Ebrahim Karamian, Elahe Poorazizi, Jalil Heydaripour und Amirsalar Khandan. „Electrospun of polymer / bioceramic nanocomposite as a new soft tissue for biomedical applications". In: Journal of Asian Ceramic Societies 3 (4 2018), S. 417-425. ISSN: 2187-0764. DOI: $10.1016 / j \cdot$ jascer. 2015.09.003.

[HLM+10] S. Hoeges, M. Lindner, W. Meiners und R. Smeets. „Bioresorbable Implants using Selective Laser Melting“. PAPER. In: Solid Freeform Fabrication 2010 (2010). URL: http://sffsymposium.engr.utexas.edu/archive.

[HM09] Simon Höges und Wilhelm Meiners. „SLM von Polylactiden zur Herstellung von resorbierbaren Implantaten“. PAPER. In: RTejournal (2009). URL: https : //www.rtejournal.de/.

[Hög10] Simon Höges. Entwicklung des Selective Laser Melting für die Verarbeitung bioresorbierbarer medizinischer Werkstoffe. DISSERTATION. RheinischWestfälische Technische Hochschule Aachen - Fakultät für Maschinenwesen, 2010.

[Hri15] Dimitar Hristakiev. Konzeption und Konstruktion einer dynamischen Pulverauftragseinheit für eine SLS/SLM-Maschine. BACHELORARBEIT. Unter Mitarb. von Prof. Dietmar Göhlich und Clemens Kautz. TU Berlin / Institut für Konstruktion, Mikro- und Medizintechnik / FG Methoden der Produktentwicklung und Mechatronik, 10.2015. 141 S.

[HS08] Ingolf Volker Hertel und Claus-Peter Schulz. Atome, Moleküle und optische Physik 1. Atomphysik und Grundlagen der Spektroskopie. ger. 2008. Nachdruck 2015. Lehrbuch. Berlin: Springer Spektrum, 2008. 511 S. ISBN: 978-3-662-46807-4. DOI: 10 . 1007 /978-3-662-46808-1. URL: http : / / ebooks.ciando.com/book/index.cfm/bok_id/1898559.

[HSZ+06] L. Hao, M. M. Savalani, Y. Zhang, K. E. Tanner und R. A. Harris. „Selective laser sintering of hydroxyapatite reinforced polyethylene composites for bioactive implants and tissue scaffold development". PAPER. eng. In: Proceedings of the Institution of Mechanical Engineers. Part H, Journal of engineering in medicine 220 (4 2006). Evaluation Studies Journal Article Research Support, Non-U.S. Gov't, S. 521-531. ISSN: 0954-4119. DOI: 10.1243/09544119JEIM67. eprint: 16808068.

$[\mathrm{HTF}+18]$ Fupo He, Ye Tian, Xibo Fang, Yubin Xu und Jiandong Ye. „Porous calcium phosphate composite bioceramic beads". PAPER. In: Ceramics International (2018). ISSN: 02728842. DOI: 10.1016/j.ceramint.2018.04.109. 
[Hut05] Joachim Hutfless. „TRUMPF Laserformen - Anwendung generativer Laserverfahren für den Werkzeug- und Formenbau“. PAPER. In: RTejournal (2005). URL: https://www.rtejournal.de/.

[IRH06] Lothar Issler, Hans Ruoß und Peter Häfele. Festigkeitslehre - Grundlagen. ger. 2. Aufl. korr. Nachdr. Springer-Lehrbuch. Berlin: Springer, 2006. 621 S. ISBN: $978-3-540-40705-8$.

[ite16] item Industrietechnik GmbH. „MB Systembaukasten. Der Gesamtkatalog“. PRODUKTKATALOG. In: (2016).

[JH17] Rahman Jamal und Ronald Heinze, Hrsg. Virtuelle Instrumente in der Praxis 2017. Mess-, Steuer-, Regel- und Embedded-Systeme : Begleitband zum 22. VIP-Kongress. ger;eng. Berlin und Offenbach: VDE VERLAG GMBH, 2017. 520 S. ISBN: 3800744414.

[KA05] Martin Klare und Reiner Altmann. „Rapid Manufacturing in der Hörgeräteindustrie“. PAPER. In: RTejournal (2005). URL: https://www.rtejournal. $\mathrm{de} /$.

[Kad10] Wesam Kaddar. Die generative Fertigung mittels Laser-Sintern: Scanstrategien, Einflüsse verschiedener Prozessparameter auf die mechanischen und optischen Eigenschaften beim LS von Thermoplasten und deren Nachbearbeitungsmöglichkeiten. DISSERTATION. Universität Duisburg-Essen - Fakultät für Ingenieurwissenschaften, Abteilung Maschinenbau und Verfahrenstechnik, 2010 .

[KD11] Florian Kühnlein und Dietmar Drummer. „Mechanische Eigenschaften und Bruchverhalten maskengesinterter Kunststoffbauteile“. PAPER. In: RTejournal (2011). URL: https://www.rtejournal.de/.

[Key96] Keyence Corporation. „Modellreihe LC-2400. Laser-Wegmeßsystem für ultrahohe Genauigkeit“. B\&P. In: (DLC2400-IMC-2-1297 1996).

[KG18] Dieter Krause und Nicolas Gebhardt. Methodische Entwicklung modularer Produktfamilien. Hohe Produktvielfalt beherrschbar entwickeln. ger. Unter Mitarb. von Tammo Bahns, Erik Greve, Jennnifer Hackl, Henry Jonas, Sebastian Ripperda, Olga Sankowski, Johanna Spallek und Nadine Wortmann. Berlin: Springer Vieweg, 2018. 291 S. ISBN: 978-3-662-53039-9. DOI: 10.1007/9783-662-53040-5. URL: http://dx.doi.org/10.1007/978-3-662-53040-5.

[KK11] Mont Kumpugdee Vollrath und Jens-Peter Krause, Hrsg. Easy Coating. Grundlagen und Trends beim Coating pharmazeutischer Produkte. ger. 1. Aufl. Studium. Wiebaden: Vieweg + Teubner, 2011. 255 S. ISBN: 978-3-8348-0964-3.

[KK15] Fritz Klocke und Wilhelm König. Fertigungsverfahren 5. Gießen, Pulvermetallurgie, Additive Manufacturing. 4. Auflage. VDI-Buch. s.l.: Springer Vieweg, 2015. 175 S. ISBN: 978-3-540-23453-1. DOI: 10.1007/978-3-540-69512-7. URL: http://ebooks.ciando.com/book/index.cfm/bok_id/1868428. 
[KLH+10] Krishna Kolan, Ming Leu, Gregory Hilmas und Mariano Velez. „Selective Laser Sintering of 13-93 Bioactive Glass Bone Scaffolds“. PAPER. In: ISC Research Symposium 4 (2010).

$[\mathrm{KLH}+12]$ Krishna C. R. Kolan, Ming C. Leu, Gregory E. Hilmas und Mariano Velez. „Effect of material, process parameters, and simulated body fluids on mechanical properties of 13-93 bioactive glass porous constructs made by selective laser sintering“. PAPER. eng. In: Journal of the mechanical behavior of biomedical materials 13 (2012). Journal Article Research Support, Non-U.S. Gov't Research Support, U.S. Gov't, Non-P.H.S., S. 14-24. DOI: 10.1016/j · jmbbm.2012.04.001. eprint: 22842272.

[Köh15] Jeanett Köhn. Entwicklung eines thermisch stabilen und flexiblen Polymers auf Basis von PLA für medizinische Anwendungen. DISSERTATION. Technische Universität Berlin - Fakultät für Prozesswissenschaften, 2015. 126 S.

[KRD09] Florian Kühnlein, Dominik Rietzel und Dietmar Drummer. „Funktionalisierte Bauteile durch Selektives Maskensintern“. PAPER. In: RTejournal (2009). URL: https://www.rtejournal.de/.

[KS09a] Yves Küsters und Martin Schäfer. „Pulverbettbasiertes Strahlschmelzen neue Forschungserkenntnisse“. PAPER. In: RTejournal (2009). URL: https: //www.rtejournal.de/.

[KS09b] Gerd Küveler und Dietrich Schwoch. Informatik für Ingenieure und Naturwissenschaftler. ger. 6. Aufl. Viewegs Fachbücher der Technik. Wiesbaden: Vieweg, 2009. 336 S. ISBN: 978-3-8348-0460-0.

[Kun18] Kunststoff.de. „Symbiose von EOS P 810 und Werkstoff PEKK. 3D-Drucker für die Serienfertigung von Verbundbauteilen“. INTERNETDOKUMENT. In: (4.2018).

[Lac17] Roland Lachmayer. Additive Manufacturing Quantifiziert. Visionäre Anwendungen und Stand der Technik. ger. Berlin, Heidelberg: Springer Berlin Heidelberg, 2017. 1241 S. ISBN: 978-3-662-54112-8.

[Lan16] Manuel Lang. Konzeption und Konstruktion eines Prozessgasversorgunssystems für den Einsatz in einer LS/LBM-Anlage. BACHELORARBEIT. Unter Mitarb. von Prof. Dietmar Göhlich und Clemens Kautz. TU Berlin / Institut für Konstruktion, Mikro- und Medizintechnik / FG Methoden der Produktentwicklung und Mechatronik, 2.2016. 101 S.

[LCB+12] Stefan Lohfeld, Senan Cahill, Valerie Barron, Peter McHugh, Lutz Dürselen, Ludwika Kreja, Christine Bausewein und Anita Ignatius. „Fabrication, mechanical and in vivo performance of polycaprolactone/tricalcium phosphate composite scaffolds". PAPER. eng. In: Acta biomaterialia 8 (9 2012). Journal Article Research Support, Non-U.S. Gov't, S. 3446-3456. ISSN: 1878-7568. DOI: $10.1016 / j$.actbio. 2012.05.018. eprint: 22652444. 
[Lec17] M. Dieter Lechner. Einführung in die Quantenchemie. Aufbau der Atome und Moleküle, Spektroskopie. ger. Berlin und Heidelberg: Springer Spektrum, 2017. 125 S. ISBN: 978-3-662-49882-8. DOI: 10 .1007/978-3-662-49883-5. URL: http://dx.doi.org/10.1007/978-3-662-49883-5.

[LFT10] M. Lindner, H. Fischer und R. Telle. „Abschlussbericht zum Verbundprojekt Resobone - Förderkennzeichen 16IN0443. Biodegradierbare Kompositwerkstoffe für die generative Fertigung bioaktiver Knochenersatzimplantate". ABSCHLUSSBERICHT. In: (2010).

[LGN10] M. D. Lechner, K. Gehrke und E. H. Nordmeier. Makromolekulare Chemie. Ein Lehrbuch für Chemiker, Physiker, Materialwissenschaftler und Verfahrenstechniker. ger. 4. überarbeitete und erweiterte Auflage. Basel: Birkhäuser Basel, 2010. ISBN: 978-3-7643-8890-4.

[LH04] Ulf Lindhe und Hans Joachim Hesse. „Formen aus Stahl, Bauteile aus Titan und Stahl. Direkt erstellt im Rapid Prototyping Verfahren von Arcam mit dem Elektronenstrahl“. PAPER. In: RTejournal (2004). URL: https://www . rtejournal.de/.

[LHM+11] Markus Lindner, Simon Hoeges, Wilhelm Meiners, Konrad Wissenbach, Ralf Smeets, Rainer Telle, Reinhart Poprawe und Horst Fischer. „Manufacturing of individual biodegradable bone substitute implants using selective laser melting technique“. PAPER. eng. In: Journal of biomedical materials research. Part A 97 (4 2011). Journal Article Research Support, Non-U.S. Gov't, S. 466471. DOI: $10.1002 / \mathrm{jbm} . \mathrm{a} .33058$. eprint: 21495168.

[Li17] Xiaoming Li, Hrsg. Tissue Repair. Reinforced Scaffolds. eng. Singapore und s.l.: Springer Singapore, 2017. 62 S. ISBN: 978-981-10-3553-1. DOI: 10.1007/ 978-981-10-3554-8.

[Lin09] Udo Lindemann. Methodische Entwicklung technischer Produkte. Methoden flexibel und situationsgerecht anwenden. 3., korrigierte Aufl. VDI-Buch. Berlin, Heidelberg: Springer-Verlag Berlin Heidelberg, 2009. ISBN: 978-3-642-01422-2. DOI: $10.1007 / 978-3-642-01423-9$.

[LJH+14] Cora Lueders, Ben Jastram, Roland Hetzer und Hartmut Schwandt. „Rapid manufacturing techniques for the tissue engineering of human heart valves". eng. In: European journal of cardio-thoracic surgery : official journal of the European Association for Cardio-thoracic Surgery 46 (4 2014). Journal Article Research Support, Non-U.S. Gov't Review, S. 593-601. Issn: 1873-734X.

[LK07] Hans Peter Latscha und Helmut Alfons Klein. Anorganische Chemie. ChemieBasiswissen I. ger. Neunte, vollständig überarbeitete Auflage. Springer- Lehrbuch. Berlin, Heidelberg: Springer- Verlag Berlin Heidelberg, 2007. ISBN: 978-3-540-69863-0. DOI: 10 . 1007/978-3-540-69865-4. URL: http://dx . doi.org/10.1007/978-3-540-69865-4. 
[LLF16] Roland Lachmayer, Rene Bastian Lippert und Thomas Fahlbusch, Hrsg. 3DDruck beleuchtet. Additive Manufacturing auf dem Weg in die Anwendung. ger. Berlin, Heidelberg: Springer Vieweg, 2016. 1125 S. ISBN: 978-3-662-49055-6.

[LLK18] Roland Lachmayer, Rene Bastian Lippert und Stefan Kaierle, Hrsg. Additive Serienfertigung. Erfolgsfaktoren und Handlungsfelder für die Anwendung. 1. Auflage 2018. Berlin: Springer Berlin, 2018. x, 220 Seiten in 1 Teil. ISBN: 978-3-662-56462-2.

[LRC+17] Ailing Li, Huihui Ren, Yang Cui, Chao Wang, Xiaojuan Zhou, He Lin und Dong Qiu. „Detailed structure of a new bioactive glass composition for the design of bone repair materials“. PAPER. In: Journal of Non-Crystalline Solids 475 (2017), S. 10-14. ISSN: 00223093. DOI: 10.1016/j.jnoncrysol. 2017.07 .027$.

[LSA+13] Tobias Laumer, Thomas Stichel, Peter Appel und Philipp Amend. „Untersuchungen zum Absorptionsverhalten von Pulverschüttungen für das Laserstrahlschmelzen von Kunststoffen". PAPER. In: Rapid Tech Erfurt Conference (5.2013).

[LTC+10] S. Lohfeld, M. A. Tyndyk, S. Cahill, N. Flaherty, V. Barron und P. E. McHugh. „A method to fabricate small features on scaffolds for tissue engineering via selective laser sintering". PAPER. In: Journal of Biomedical Science and Engineering 03 (02 2010), S. 138-147. ISSN: 1937-6871. DOI: 10.4236/jbise. 2010.32019 .

[Lun16] Jan Lunze. Regelungstechnik 1. Systemtheoretische Grundlagen, Analyse und Entwurf einschleifiger Regelungen : mit 425 Abbildungen, 76 Beispielen, 179 Übungsaufgaben sowie einer Einführung in das Programmsystem MATLAB. ger. 11., überarbeitete und ergänzte Auflage. Lehrbuch. Berlin: Springer, 2016. 742 S. ISBN: 978-3-662-52677-4.

[Lus17] Etienne Lustig. Konstruktion eines Prozessgehäuses einer Lasersinteranlage mit medizintechnischer Konfiguration. BACHELORARBEIT. Unter Mitarb. von Prof. Dietmar Göhlich und Clemens Kautz. 4.2017. 114 S.

[Mar15] Alexander Matthias Martha. Optimierung des Produktentwicklungsprozesses durch CAD-CAM-Integration im Kontext der additiven Fertigung. DISSERTATION. Universität Duisburg-Essen - Fakultät für Ingenieurwissenschaften, Abteilung Maschinenbau und Verfahrenstechnik, 2015.

[MBG+10] Ferry P. W. Melchels, Katia Bertoldi, Ruggero Gabbrielli, Aldrik H. Velders, Jan Feijen und Dirk W. Grijpma. „Mathematically defined tissue engineering scaffold architectures prepared by stereolithography“. PAPER. In: Biomaterials 31 (27 2010), S. 6909-6916. ISSN: 01429612. DOI: 10.1016/j . biomaterials.2010.05.068. 
[MBW10] Peter Mandl, Andreas Bakomenko und Johannes Weiß. Grundkurs Datenkommunikation. TCP/IP-basierte Kommunikation: Grundlagen, Konzepte und Standards. ger. 2., überarbeitete und aktualisierte Auflage. Wiesbaden: Vieweg+Teubner Verlag / GWV Fachverlage GmbH Wiesbaden, 2010. ISBN: 978-3-8348-0810-3. DOI: 10 . 1007/978-3-8348-9699-5. URL: http: //dx.doi.org/10.1007/978-3-8348-9699-5.

[MDV+12] Steve Meister, Dietmar Drummer, Karoline Vetter und Gottfried Ehrenstein. „Mechanische Kennwertermittlung für Mikrobauteile an spritzgegossenen Mikro-Zugprüfkörpern". PAPER. In: WAK - Zeitschrift Kunststofftechnik (12.2012). URL: https://www.kunststofftech.com/.

[Mei99] Wilhelm Meiners. Direktes selektives Laser-Sintern einkomponentiger metallischer Werkstoffe. DISSERTATION. Rheinisch-Westfälische Technische Hochschule Aachen - Fakultät für Maschinenwesen, 1999. 125 S. ISBN: 3-8265-6571-1.

[Mes15] Dieter Meschede. Gerthsen Physik. ger. 25. Aufl. Springer-Lehrbuch. Berlin: Springer Spektrum, 2015. 1000 S. ISBN: 978-3-662-45976-8. DOI: 10.1007/9783-662-45977-5. URL: http://dx.doi.org/10.1007/978-3-662-45977-5.

[MK11] Alexander Martha und Peter Köhler. „Ansätze zur Verbesserung von Qualität und Wirtschaftlichkeit bei generativen Verfahren durch Optimierung des Pre-Processes“. PAPER. In: RTejournal (2011). URL: https : //www . rtejournal.de/.

[MKM+16] Joachim Messemer, Thomas Kaufmann, Christian Martin, Malte Neises, Andre Schmidt und Henrik te Heesen. „Untersuchung der Zugfestigkeit von FLM-Zugproben aus PLA bei Variation von Schichtdicke und Füllgrad“. PAPER. In: RTejournal (2016). URL: https://www.rtejournal.de/.

[MKW+17] Ryan J. Mondschein, Akanksha Kanitkar, Christopher B. Williams, Scott S. Verbridge und Timothy E. Long. „Polymer structure-property requirements for stereolithographic 3D printing of soft tissue engineering scaffolds". PAPER. In: Biomaterials 140 (2017), S. 170-188. ISSN: 01429612. DOI: 10.1016/j . biomaterials.2017.06.005.

$[\mathrm{MLF}+17]$ Matthias Markl, Matthias Lodes, Martin Franke und Carolin Körner. „Additive Fertigung durch selektives Elektronenstrahlschmelzen“. PAPER. In: Schweisssen und Schneiden/Welding and Cutting (2017), S. 30-39.

[Möl15] Georg Möller. Konzeption und Konstruktion eines Pulvervorheizmoduls für den Einsatz in einer LS/LBM-Anlage. BACHELORARBEIT. Unter Mitarb. von Prof. Dietmar Göhlich und Clemens Kautz. TU Berlin / Institut für Konstruktion, Mikro- und Medizintechnik / FG Methoden der Produktentwicklung und Mechatronik, 12.2015. $79 \mathrm{~S}$. 
[MS11] Hirenkumar K. Makadia und Steven J. Siegel. „Poly Lactic-co-Glycolic Acid (PLGA) as Biodegradable Controlled Drug Delivery Carrier". PAPER. eng. In: Polymers 3 (3 2011). PMC3347861 Journal Article, S. 1377-1397. ISSN: 2073-4360. DOI: $10.3390 /$ polym3031377. eprint: 22577513.

[MTH13] Sankhya Mohanty, Cem Celal Tutum und Jesper Henri Hattel. „Cellular scanning strategy for selective laser melting: Evolution of optimal grid-based scanning path \& parametric approach to thermal homogeneity". PAPER. In: Proceedings of SPIE (3.2013). DOI: 10.1117/12.2004256.

$[M W L+14]$ Shawn Moylan, Eric Whitenton, Brandon Lane und John Slotwinski. „Infrared thermography for laser-based powder bed fusion additive manufacturing processes“. PAPER. In: AIP Conference Proceedings (2014), S. 1191-1196. DOI: $10.1063 / 1.4864956$.

[Nad14] Nadella GmbH. „Kugelgewindetriebe. KGT 2014 D“. PRODUKTKATALOG. In: (2014).

[Nat11] National Instruments. „Historie von DIAdem“. NI WHITEPAPER. de. In: (8.2011). URL: http://www.ni.com/white-paper/6117/de/.

[Nat12] National Instruments. „NI EtherCAT RIO: Deterministische Erweiterung für NI-LabVIEW-RIO-Systeme“. NI WHITEPAPER. de. In: (10.2012). URL: http://www.ni.com/white-paper/7299/de/.

[Nat13] National Instruments. „Die Vorteile der grafischen Programmierung mit NI LabVIEW“. NI WHITEPAPER. de. In: (8.2013). URL: http://www.ni.com/ white-paper/14556/de/.

[Nat15a] National Instruments. „Erstellen einer Human Machine Interface“. NI WHITEPAPER. de. In: (12.2015). URL: http://www . ni . com/white-paper / $12602 / \mathrm{de} /$.

[Nat15b] National Instruments. „NI cRIO-9035. Embedded CompactRIO Controller with Real-Time Processor and Reconfigurable FPGA“. DATENBLATT. In: (2015).

[Nat15c] National Instruments. „NI cRIO-9035 Getting Started Guide. Embedded CompactRIO Controller with Real-Time Processor and Reconfigurable FPGA“. B\&P. In: (2015).

[Nat15d] National Instruments. „NI cRIO-9035 User Manual. Embedded CompactRIO Controller with Real-Time Processor and Reconfigurable FPGA“. B\&P. In: (2015).

[Nat16a] National Instruments. „Industrial Communications With CompactRIO: The Ultimate Multipurpose Controller". NI WHITEPAPER. en. In: (1.2016). URL: http://www.ni.com/white-paper/52869/en/.

[Nat16b] National Instruments. „Quick Chart: Industrial Communications“. NI WHITEPAPER. en. In: (3.2016). URL: http: //www . ni .com/white-paper / 52958/en/. 
[Nat16c] National Instruments. „Vereinfachter Entwurf von Embedded-Systemen mit CompactRIO“. NI WHITEPAPER. de. In: (4.2016). URL: http://www.ni. com/white-paper/52987/de/.

[Nat16d] National Instruments. „Wie funktioniert das Erweiterungschassis NI 9144?" NI WHITEPAPER. de. In: (5.2016). URL: http: //www . ni . com/whitepaper $/ 7300 / \mathrm{de} /$.

[Nat16e] National Instruments. „Analog and Digital I/O With CompactRIO: The Ultimate Multipurpose Controller". NI WHITEPAPER. en. In: (8.2016). URL: http://www.ni.com/white-paper/53031/en/.

[Nat16f] National Instruments. „Logging and Monitoring With CompactRIO: The Ultimate Multipurpose Controller". NI WHITEPAPER. en. In: (8.2016). URL: http://www.ni.com/white-paper/53030/en/.

[Nat16g] National Instruments. „Machine Vision and Image Processing With CompactRIO: The Ultimate Multipurpose Controller". NI WHITEPAPER. en. In: (8.2016). URL: http://www.ni.com/white-paper/53026/en/.

[Nat16h] National Instruments. „Processing and Analytics With CompactRIO: The Ultimate Multipurpose Controller“. NI WHITEPAPER. en. In: (8.2016). URL: http://www.ni.com/white-paper/53028/en/.

[Nat16i] National Instruments. „NI-9201. C-Modul - 8AI - 10V“. DATENBLATT. In: (2016).

[Nat16j] National Instruments. „NI-9216. C-Modul - 8RTD - PT100“. DATENBLATT. In: (2016).

[Nat16k] National Instruments. „NI-9226. C-Modul - 8RTD - PT1000“. DATENBLATT. In: (2016).

[Nit15] Manfred Nitsche. Abluft-Fibel. Reinigung lösemittelhaltiger Abgase. ger. Berlin: Springer Vieweg, 2015. ISBN: 978-3-662-45309-4. DOI: 10.1007/978-3-66245310-0.

[NL07] Lakshmi S. Nair und Cato T. Laurencin. „Biodegradable polymers as biomaterials“. PAPER. In: Progress in Polymer Science 32 (8-9 2007), S. 762-798. ISSN: 00796700. DOI: $10.1016 / \mathrm{j}$.progpolymsci.2007.05.017.

[Nüc16] Kostja Nüchter. Inbetriebnahme und Parameteruntersuchung einer dynamischen Pulverauftragseinheit zur verbesserten Schichtgenerierung von Biopolymerwerkstoffen in Laser Sinter Anlagen. BACHELORARBEIT. Unter Mitarb. von Prof. Dietmar Göhlich und Clemens Kautz. TU Berlin / Institut für Konstruktion, Mikro- und Medizintechnik / FG Methoden der Produktentwicklung und Mechatronik, 6.2016. 77 S.

$[$ NUF+15] Bernd Niese, Uwe Urmoneit, Thomas Frick, Stephan Roth und Michael Schmidt. „Untersuchung des Auftrags von Silberpartikeltinte zur Erzeugung von leitfähigen Strukturen für die Einbettende Stereolithographie“. PAPER. In: RTejournal (2015). URL: https://www.rtejournal.de/. 
[OBr11] Fergal J. O’Brien. „Biomaterials \& scaffolds for tissue engineering“. PAPER. In: Materials Today 14 (3 2011), S. 88-95. ISSN: 13697021. DOI: 10.1016/ S1369-7021 (11) 70058-X.

[Ogo17] Oskar Ogor. Konstruktion und Inbetriebnahme einer Verfahreinheit des Pulverauftragsmoduls eines Laser-Sinter-Prüfstands zur Verarbeitung von Sonderwerkstoffen. MASTERARBEIT. Unter Mitarb. von Prof. Dietmar Göhlich und Clemens Kautz. TU Berlin / Institut für Konstruktion, Mikro- und Medizintechnik / FG Methoden der Produktentwicklung und Mechatronik, 3.2017. $98 \mathrm{~S}$.

[Par13] Parker. „Stickstoffgeneratoren“. PRODUKTKATALOG. In: (2013).

[Par16] Rainer Parthier. Messtechnik. Grundlagen und Anwendungen der elektrischen Messtechnik. ger. 8. Aufl. 2016. Wiesbaden und s.l.: Springer Fachmedien Wiesbaden, 2016. 283140 S. ISBN: 978-3-658-13597-3. DOI: 10.1007/978-3658-13598-0. URL: http://dx.doi.org/10.1007/978-3-658-13598-0.

[PBF+07] Gerhard Pahl, Wolfgang Beitz, Jörg Feldhusen und Karl-Heinrich Grote. Konstruktionslehre. Grundlagen erfolgreicher Produktentwicklung; Methoden und Anwendung. ger. 7. Aufl. Berlin und Heidelberg: Springer, 2007. ISBN: 978-3-540-34060-7. DOI: 10.1007/978-3-540-34061-4.

[PBF+13] Gerhard Pahl, Wolfgang Beitz, Jörg Feldhusen und Karl-Heinrich Grote, Hrsg. Konstruktionslehre. Methoden und Anwendung erfolgreicher Produktentwicklung. ger. 8., vollst. überarb. Aufl. Berlin: Springer Vieweg, 2013. 883 S. ISBN: 978-3-642-29568-3.

[PDG+13] T. Patrício, M. Domingos, A. Gloria und P. Bártolo. „Characterisation of PCL and PCL/PLA Scaffolds for Tissue Engineering“. PAPER. In: Procedia CIRP 5 (2013), S. 110-114. ISSN: 22128271. DOI: 10.1016/j .procir. 2013.01.022.

[Pen15] Pentair/Schroff. „Baugruppenträger. Anforderungen - Auswahlkriterien Anpassungsmöglichkeiten“. B\&P. In: (2015).

[Pen16a] Pentair/Schroff. „Baugruppenträger / 19”-Einschübe für Eurorack“. PRODUKTKATALOG. In: (5.2016).

[Pen16b] Pentair/Schroff. „Frontplatten, Steckbaugruppen, Kassetten“. PRODUKTKATALOG. In: (5.2016).

[Phe12] Phenix Systems. „Phenix Systems - a global expertise. The systems, CADCAM software, Materials, An innovative offer". DATENBLATT. In: (2012).

[Phy07] Physikalisch-Technische Bundesanstalt. „PTB-Mitteilungen 117. Das Internationale Einheitensystem (SI)“. PRESSEINFORMATION. In: (2 2.2007). URL: www.bipm.fr. 
[PK11] Fernando Puente León und Uwe Kiencke. Messtechnik. Systemtheorie für Ingenieure und Informatiker. ger. 8., gründlich überarb. Aufl. Berlin, Heidelberg: Springer-Verlag Berlin Heidelberg, 2011. ISBN: 978-3-642-20238-4. DOI: 10.1007/978-3-642-20239-1. URL: http://site.ebrary.com/lib/ alltitles/docDetail . action?docID=10494323.

[PKS14] Tuomas Purtonen, Anne Kalliosaari und Antti Salminen. „Monitoring and Adaptive Control of Laser Processes". PAPER. In: Physics Procedia 56 (2014), S. 1218-1231. ISSN: 18753892. DOI: 10.1016/j.phpro.2014.08.038.

[Pro11] Uwe Probst. Servoantriebe in der Automatisierungstechnik. Komponenten, Aufbau und Regelverfahren. ger. 1. Aufl. Studium. Wiesbaden: Vieweg+Teubner Verlag / Springer Fachmedien Wiesbaden GmbH Wiesbaden, 2011. ISBN: 978-3-8348-0927-8. URL: http://dx.doi.org/10.1007/978-38348-8169-4.

[PW18] Somasundaram Prasadh und Raymond Chung Wen Wong. „Unraveling the mechanical strength of biomaterials used as a bone scaffold in oral and maxillofacial defects". PAPER. In: Oral Science International (2018). ISSN: 13488643. DOI: 10.1016/S1348-8643(18)30005-3.

$[\mathrm{RBF}+16]$ Natacha Rodrigues, Matthew Benning, Ana M. Ferreira, Luke Dixon und Kenny Dalgarno. „Manufacture and Characterisation of Porous PLA Scaffolds". PAPER. In: Procedia CIRP 49 (2016), S. 33-38. ISSN: 22128271. DOI: 10.1016/j.procir.2015.07.025.

[RDB+11] Mohamed N. Rahaman, Delbert E. Day, B. Sonny Bal, Qiang Fu, Steven B. Jung, Lynda F. Bonewald und Antoni P. Tomsia. „Bioactive glass in tissue engineering“. PAPER. eng. In: Acta biomaterialia 7 (6 2011). Journal Article Research Support, N.I.H., Extramural Research Support, U.S. Gov't, Non-P.H.S. Review, S. 2355-2373. ISSN: 1878-7568. DOI: 10.1016/j.actbio. 2011.03.016. eprint: 21421084.

[Rea17] Realizer. „SLM 50“. DATENBLATT. In: (2017).

[Ren15] Renishaw. „Generatives Fertigungssystem AM400 von Renishaw“. DATENBLATT. In: (11.2015).

[Ren16] Renishaw. „Generatives Fertigungssystem RenAM 500M“. DATENBLATT. In: (11.2016).

[Ren17] Renishaw. „Präsentation über die Renishaw GmbH von Herrn Ralph Mayer“. PRAESENTATION. In: (1.2017).

[Ret12] Retsch GmbH. „Dewar 501. Bedienungsanleitung“. B\&P. In: (10.2012). URL: www.retsch.com.

[Ret13] Retsch GmbH. „Testbericht zum Mahlen von Evonik Resomer 755 S. Testbericht Nr.: 14515“. DATENBLATT. In: (5.2013).

[Ret14] Retsch GmbH. „Schwingmühle CryoMill. Bedienungsanleitung“. B\&P. In: (10.2014). URL: Www.retsch.com. 
[Ret16] Retsch GmbH. „Gesamtkatalog. Zerkleinern, Sieben, Assistieren“. PRODUKTKATALOG. In: (10.2016). URL: www.retsch.de.

[Ret17] Retsch GmbH. „Schwingmühle CryoMill. Produktinformation“. DATENBLATT. In: (6.2017). URL: www.retsch.com.

[Ric15a] Ricoh. „Ricoh Launches 3D Printer RICOH AM S5500P. Supports high functional materials and able to create large parts all at once". PRESSEMITTEILUNG. In: (10.2015).

[Ric15b] Ricoh. „AM S5500P. Polymer Laser Sintering System for Additive Manufacturing of Functional Prototypes and End-use Parts“. DATENBLATT. In: (2015).

[Rie11] Dominik Rietzel. Werkstoffverhalten und Prozessanalyse beim Laser-Sintern von Thermoplasten. DISSERTATION. Friedrich-Alexander-Universität Erlangen-Nürnberg - Technische Fakultät, 2011.

[RKD09] Dominik Rietzel, Florian Kühnlein und Dietmar Drummer. „Selektives Lasersintern von teilkristallinen Thermoplasten“. PAPER. In: RTejournal (2009). URL: https://www.rtejournal.de/.

[RKV+08] Annett Rechtenbach, Alaadien Khalyfa, Sebastian Vogt, Jürgen Weisser, Gabriele Grimm, Wolfgang Meyer und Matthias Schnabelrauch. „Biokompatible Pulver-Binder-Systeme für das 3D-Drucken von Implantaten“. PAPER. In: RTejournal (2008). URL: https://www.rtejournal.de/.

[RMS16] Eberhard Roos, Karl Maile und Michael Seidenfuß. Werkstoffkunde für Ingenieure. Grundlagen, Anwendung, Prüfung. ger. 6., erg. und bearb. Aufl. 2017. Berlin und s.l.: Springer Berlin, 2016. 4211 S. ISBN: 978-3-662-49531-5.

[Rod12] Werner Roddeck. Einführung in die Mechatronik. ger. 4., überarb. Aufl. Studium. Wiesbaden: Vieweg+Teubner Verlag, 2012. ISBN: 978-3-8348-1622-1. DOI: $10.1007 / 978-3-8348-8626-2$. URL: http://dx.doi .org/10.1007/ 978-3-8348-8626-2.

[Roh14] Adrian Michael Rohner. „Postprocessing of 3D printed ceramic scaffolds for bone replacement". PAPER. In: RTejournal (2014). URL: https://www . rtejournal.de/.

[RSZ17] Hans Albert Richard, Britta Schramm und Thomas Zipsner, Hrsg. Additive Fertigung von Bauteilen und Strukturen. Wiesbaden: Springer Vieweg, 2017. 299 S. ISBN: 978-3-658-17779-9. DOI: 10.1007/978-3-658-17780-5.

[RW11] Walter Roedel und Thomas Wagner. Physik unserer Umwelt. Die Atmosphäre. ger. 4. Aufl., 1. korrigierter Nachdr. Berlin: Springer, 2011. 589 S. ISBN: 978-3-642-15728-8.

[Sca17] Scanlab. „Kollimationsmodul. fiber connection for scan heads“. DATENBLATT. In: (1.2017). 
[SCC00] Roberto Solaro, Andrea Corti und Emo Chiellini. „Biodegradation of polyvinyl alcohol with different molecular weights and degree of hydrolysis". In: Polymers for Advanced Technologies 11 (812 2000), S. 873-878. ISSN: 10427147. DOI: 10 . $1002 / 1099-1581(200008 / 12) 11: 8 / 12<873::$ AID РАT35>3.3. CO;2-M.

[Sch08] Wolfgang Schneider. Praktische Regelungstechnik. Ein Lehr- und Übungsbuch für Nicht-Elektrotechniker. ger. 3., vollständig überarbeitete und erweiterte Auflage. Studium. Wiesbaden: Vieweg+Teubner / GWV Fachverlage GmbH Wiesbaden, 2008. ISBN: 978-3-528-24662-4. DOI: 10.1007/978-3-8348-95127.

[Sch12] Hans-Günter Schiele. Computergrafik für Ingenieure. Eine anwendungsorientierte Einführung. ger. Berlin: Springer Vieweg, 2012. 368 S. ISBN: 978-3-642-23842-0.

[Sch15a] Manfred Schmid. Additive Fertigung mit Selektivem Lasersintern (SLS). Prozess- und Werkstoffüberblick. Essentials. Wiesbaden: Springer Vieweg, 2015. ISBN: 978-3-658-12288-1. DOI: 10 . 1007/978-3-658-12289-8. URL: http://dx.doi.org/10.1007/978-3-658-12289-8.

[Sch15b] Manfred Schmid. Selektives Lasersintern (SLS) mit Kunststoffen. Technologie, Prozesse und Werkstoffe. ger. München: Hanser, 2015. 211 S. ISBN: 978-3-446-44562-8.

$[\mathrm{SCR}+16]$ G. V. Salmoria, M. R. Cardenuto, C.R.M. Roesler, K. M. Zepon und L. A. Kanis. „PCL/Ibuprofen Implants Fabricated by Selective Laser Sintering for Orbital Repair". PAPER. In: Procedia CIRP 49 (2016), S. 188-192. ISSN: 22128271. DOI: $10.1016 / j$.procir.2015.11.013.

[SDL+09] Hermann Seitz, Ulrike Deisinger, Barbara Leukers, Rainer Detsch und Günter Ziegler. „Different Calcium Phosphate Granules for 3-D Printing of Bone Tissue Engineering Scaffolds". PAPER. In: Advanced Engineering Materials 11 (5 2009), B41-B46. ISSN: 14381656. DOI: 10.1002/adem. 200800334.

[Seh10] Jan Torsten Sehrt. Möglichkeiten und Grenzen bei der generativen Herstellung metallischer Bauteile durch das Strahlschmelzverfahren. DISSERTATION. Universität Duisburg-Essen - Fakultät für Ingenieurwissenschaften, Abteilung Maschinenbau und Verfahrenstechnik, 2010.

[Sei07] Stefan Seidel. „Technologieintegration zur Herstellung von Serienwerkzeugen mittels Metallfolien- LOM“. PAPER. In: RTejournal (2007). URL: https : //www.rtejournal.de/.

$[$ SEK +18$]$ Nurettin Sezer, Zafer Evis, Said Murat Kayhan, Aydin Tahmasebifar und Muammer Koç. „Review of magnesium-based biomaterials and their applications". PAPER. In: Journal of Magnesium and Alloys (2018). ISSN: 22139567. DOI: $10.1016 / j \cdot j m a .2018 .02 .003$. 
[SFR+08] E. Schmachtenberg, R. Feulner, D. Rietzel und B. Wendel. „Wechselwirkungen Kunststoff - Laserprozess". PAPER. In: WAK - Zeitschrift Kunststofftechnik (3.2008). URL: https://www.kunststofftech.com/.

[SGN+11] Cijun Shuai, Chengde Gao, Yi Nie, Huanlong Hu, Ying Zhou und Shuping Peng. „Structure and properties of nano-hydroxypatite scaffolds for bone tissue engineering with a selective laser sintering system". PAPER. eng. In: Nanotechnology 22 (28 2011). Journal Article Research Support, Non-U.S. Gov't, S. 285703. DOI: 10.1088/0957-4484/22/28/285703. eprint: 21642759 .

[Sha17] Sharebot. „SnowWhite“. DATENBLATT. In: (5.2017).

[Sho10] Molly S. Shoichet. „Polymer Scaffolds for Biomaterials Applications“. PAPER. In: Macromolecules 43 (2 2010), S. 581-591. ISSN: 0024-9297. DOI: 10.1021/ ma901530r.

[SIC16] SICK AG. „Magnetischer Schalter zur Fahrbereichsbegrenzung für T-Nut Zylinder. MZT8 MZT8-03VPO-KRDS14“. DATENBLATT. In: (9.2016).

[Sin17] Sinterit. „Lisa“. DATENBLATT. In: (2017).

[Sin18a] Sinterit. „Lisa 2“. DATENBLATT. In: (2018).

[Sin18b] Sintratec. „KIT“. DATENBLATT. In: (1.2018).

[Sin18c] Sintratec. „S1“. DATENBLATT. In: (1.2018).

[SK16] Ralf Smeets und Andreas Kolk. „Osteokonduktive und -induktive Knochenersatzmaterialien“. INTERNETDOKUMENT. In: (3.2016). URL: https://www . zmk - aktuell . de / fachgebiete / implantologie / story / osteokonduk \% 20tive-und--induktive-knochenersatzmaterialien_-271.html.

[SLM17a] SLM Solutions. „Hochtemperaturheizung für SLM 280“. DATENBLATT. In: (2017).

[SLM17b] SLM Solutions. „SLM 125. Selective Laser Melting Maschine“. DATENBLATT. In: (2017).

[SLM17c] SLM Solutions. „SLM 280 2.0. Selective Laser Melting Maschine“. DATENBLATT. In: (2017).

[Spr18] Anton Springer. Konzeption und Implementierung eines Prozessgasmoduls für einen Lasersinter-Prüfstand zur Herstellung von künstlichen Herzklappen für die Medizintechnik. BACHELORARBEIT. Unter Mitarb. von Prof. Dietmar Göhlich und Clemens Kautz. TU Berlin / Institut für Maschinenkonstruktion und Systemtechnik / FG Methoden der Produktentwicklung und Mechatronik, 7.2018. $126 \mathrm{~S}$.

[SRI+05] Hermann Seitz, Wolfgang Rieder, Stephan Irsen, Barbara Leukers und Carsten Tille. "Three-dimensional printing of porous ceramic scaffolds for bone tissue engineering". PAPER. In: Journal of biomedical materials research. Part B, Applied biomaterials 74 (2 2005), S. 782-788. ISSN: 1552-4973. DOI: 10.1002/ jbm.b. 30291. 
[SS07] S. Sumathi und P. Surekha. LabVIEW based Advanced Instrumentation Systems. eng. Berlin, Heidelberg: Springer-Verlag Berlin Heidelberg, 2007. ISBN: 3-540-48500-7. DOI: 10.1007/978-3-540-48501-8. URL: http://site. ebrary.com/lib/alltitles/docDetail . action?docID=10171233.

[SS13] Sebastian Spath und Hermann Seitz. „Low-Cost-Herstellung individualisierter Produkte“. PAPER. In: RTejournal (2013). URL: https://www.rtejournal. $\mathrm{de} /$.

[SSH+16] Scott Stratton, Namdev B. Shelke, Kazunori Hoshino, Swetha Rudraiah und Sangamesh G. Kumbar. „Bioactive polymeric scaffolds for tissue engineering“. PAPER. eng. In: Bioactive materials 1 (2 2016). PMC5482547 Journal Article, S. 93-108. ISSN: 2452-199X. DOI: 10.1016/ j . bioactmat . 2016.11. 001. eprint: 28653043.

[SW09] Jan Sehrt und Gerd Witt. „Auswirkung des anisotropen Gefüges strahlgeschmolzener Bauteile auf mechanische Eigenschaftswerte“. PAPER. In: RTejournal (2009). URL: https://www.rtejournal.de/.

[SWA+08] Rebecca Louise Simpson, Florencia Edith Wiria, Andrew A. Amis, Chee Kai Chua, Kah Fai Leong, Ulrich N. Hansen, Margam Chandrasekaran und Mun Wai Lee. „Development of a 95/5 poly(L-lactide-co-glycolide)/hydroxylapatite and beta-tricalcium phosphate scaffold as bone replacement material via selective laser sintering". PAPER. In: Journal of Biomedical Materials Research Part B: Applied Biomaterials 84B (1 2008), S. 17-25. ISSN: 15524973. DOI: 10.1002/jbm.b. 30839.

[SYP+13] Cijun Shuai, Bo Yang, Shuping Peng und Zheng Li. „Development of composite porous scaffolds based on poly(lactide-co-glycolide)/nano-hydroxyapatite via selective laser sintering". PAPER. In: The International Journal of Advanced Manufacturing Technology 69 (1-4 2013), S. 51-57. ISSN: 0268-3768. DOI: $10.1007 / \mathrm{s} 00170-013-5001-2$.

[TCL+05] K.H. Tan, C.K. Chua, K.F. Leong, C.M. Cheah, W.S. Gui, W.S. Tan und F.E. Wiria. „Selective laser sintering of biocompatible polymers for applications in tissue engineering“. PAPER. In: Bio-Medical Materials and Engineering 15 (2005), S. 113-124.

[TCP+17] Gareth Turnbull, Jon Clarke, Frédéric Picard, Philip Riches, Luanluan Jia, Fengxuan Han, Bin Li und Wenmiao Shu. „3D bioactive composite scaffolds for bone tissue engineering“. PAPER. In: Bioactive materials (2017). ISSN: 2452-199X. URL: https://doi.org/10.1016/j.bioactmat.2017.10.001.

[The12] The University of Texas at Austin - Mechanical Engineering. „Selective Laser Sintering, Birth of an Industry“. INTERNETDOKUMENT. In: (12.2012). URL: http : / / www . me . utexas . edu / news / news / selective-lasersintering-birth-of-an-industry.

[Tru16] Trumpf. „TruPrint 1000. Kompakter und robuster 3D-Druck“. DATENBLATT. In: (11.2016). 
[TTZ+12] Huayu Tian, Zhaohui Tang, Xiuli Zhuang, Xuesi Chen und Xiabin Jing. „Biodegradable synthetic polymers. Preparation, functionalization and biomedical application". PAPER. In: Progress in Polymer Science 37 (2 2012), S. 237-280. ISSN: 00796700. DOI: 10.1016/j .progpolymsci.2011.06.004.

[Tür14] Oliver Türk. Stoffliche Nutzung nachwachsender Rohstoffe. Grundlagen Werkstoffe - Anwendungen. ger. Wiesbaden und s.l.: Springer Fachmedien Wiesbaden, 2014. 240 S. ISBN: 978-3-8348-1763-1. DOI: $10.1007 / 978-3-$ 8348-2199-7.

[Uni16] Union der deutschen Akademien der Wissenschaften. Stellungnahme. Additive Fertigung. INTERNETDOKUMENT. 12.2016. ISBN: 978-3-8047-3676-4. URL: http://www . akademienunion.de/publikationen/stellungnahmen-undpositionspapiere/.

[Ver14] Verein Deutscher Ingenieure e.V. „Statusreport. Additive Fertigungsverfahren“. INTERNETDOKUMENT. In: (9.2014). URL: www . vdi . de / statusadditiv.

[Ver16] Verein Deutscher Ingenieure e.V. Handlungsfelder. Additive Fertigungsverfahren. INTERNETDOKUMENT. 1. Auflage. VDI-Handlungsfelder. Düsseldorf: Verein Deutscher Ingenieure, 4.2016. 56 Seiten. ISBN: 978-3-931384-82-1.

[VM08] A. Vaseashta und I. N. Mihailescu, Hrsg. Functionalized Nanoscale Materials, Devices and Systems. eng. NATO Science for Peace and Security Series B. Dordrecht: Springer Netherlands, 2008. ISBN: 978-1-4020-8902-2.

[WAS+05] Jessica M. Williams, Adebisi Adewunmi, Rachel M. Schek, Colleen L. Flanagan, Paul H. Krebsbach, Stephen E. Feinberg, Scott J. Hollister und Suman Das. „Bone tissue engineering using polycaprolactone scaffolds fabricated via selective laser sintering“. PAPER. eng. In: Biomaterials 26 (23 2005). Evaluation Studies Journal Article Research Support, N.I.H., Extramural Research Support, U.S. Gov't, P.H.S., S. 4817-4827. ISSN: 01429612. DOI: 10.1016/j . biomaterials.2004.11.057. eprint: 15763261.

[WDJ15] Wolfgang Weißbach, Michael Dahms und Christoph Jaroschek. Werkstoffkunde. Strukturen, Eigenschaften, Prüfung. ger. 19., vollst. überarb. und erw. Aufl. Lehrbuch. Wiesbaden: Springer Vieweg, 2015. 133888883 S. ISBN: 978-3-658-03918-9. DOI: 10 .1007/978-3-658-03919-6. URL: http://dx . doi .org/10.1007/978-3-658-03919-6.

[Weg15] Andreas Wegner. Theorie über die Fortführung von Aufschmelzvorgängen als Grundvoraussetzung für eine robuste Prozessführung beim Laser-Sintern von Thermoplasten. DISSERTATION. Universität Duisburg-Essen - Fakultät für Ingenieurwissenschaften, Abteilung Maschinenbau und Verfahrenstechnik, 2015.

[Wei08] Bastian Weimer. „SD300 - 3D Drucken wie es sein soll“. PAPER. In: RTejournal (2008). URL: https://www.rtejournal.de/. 
[WG14] Terry Wohlers und Tim Gornet. „History of additive manufacturing“. In: Wohlers Report (2014). URL: http: //www . wohlersassociates . com/history\% 202014.pdf.

[WH08] Erich Wintermantel und Suk-Woo Ha. Medizintechnik. Life Science Engineering (German Edition). ger. 4th ed. Dordrecht: Springer, 2008. 1786 S. ISBN: 978-3-540-74924-0.

[WH09] Erich Wintermantel und Suk-Woo Ha, Hrsg. Medizintechnik. Life Science Engineering ; Interdisziplinarität, Biokompatibilität, Technologien, Implantate, Diagnostik, Werkstoffe, Zertifizierung, Business. ger. 5., überarb. und erw. Aufl. 2009. ISBN: 978-3-540-93935-1. DOI: 10 . 1007/978-3-540-93936-8. URL: http://ebooks.ciando.com/book/index.cfm/bok_id/229580.

[WH14] Marco Wirth und Heiko Heckner. „Vergleich von Dateiformaten für 3D-Modelle. CEDIFA Arbeitsbericht 7“. INTERNETDOKUMENT. In: (5.2014).

[WLC+07] F. E. Wiria, K. F. Leong, C. K. Chua und Y. Liu. „Poly - epsilon - caprolactone / hydroxyapatite for tissue engineering scaffold fabrication via selective laser sintering“. PAPER. eng. In: Acta biomaterialia 3 (1 2007). Journal Article, S. 1-12. ISSN: 1878-7568. DOI: $10.1016 /$ j . actbio.2006.07.008. eprint: 17055789.

[WMJ+15] Herbert Wittel, Dieter Muhs, Dieter Jannasch und Joachim Voßiek. Roloff/Matek Maschinenelemente. Normung, Berechnung, Gestaltung. ger. 22., überarb. und erw. Aufl. Wiesbaden: Springer Vieweg, 2015. 50103 S. ISBN: 9783658090814. DOI: 10.1007/978-3-658-09082-1. URL: http://dx.doi. org/10.1007/978-3-658-09082-1.

[WW13] Andreas Wegner und Gerd Witt. „Ursachen für eine mangelnde Reproduzierbarkeit beim Laser-Sintern von Kunststoffbauteilen“. PAPER. In: RTejournal (2013). URL: https://www.rtejournal.de/.

[WW15] Gerd Witt und Andreas Wegner. Neue Entwicklungen in der Additiven Fertigung. Beiträge aus der wissenschaftlichen Tagung der Rapid.Tech 2015. ger. SpringerLink. Berlin und Heidelberg: Springer Berlin Heidelberg, 2015. 1 S. ISBN: 978-3-662-48472-2. URL: http://lib.myilibrary.com/detail. asp?id=879587.

[WWD+11] Engelbert Westkämper, Hans-Jürgen Warnecke, Max Dinkelmann und Holger Haag. Einführung in die Fertigungstechnik. ger. 8., aktualisierte und erw. Aufl.., korrigierter Nachdr. Fertigung. Wiesbaden: Vieweg + Teubner, 2011. 302 S. ISBN: 978-3-8348-0835-6.

[YKN16] Yuki Yamauchi, Takashi Kigure und Toshiki Niino. „Low Temperature Laser Sintering of PA Powder Using Fiber Laser". PAPER. In: Solid Freeform Fabrication Symposium 2016 (2016), S. 2204-2216. URL: http://sffsymposium. engr.utexas.edu/archive. 
[YSH11] C. Yan, Y. Shi und L. Hao. „Investigation into the Differences in the Selective Laser Sintering between Amorphous and Semi-crystalline Polymers". PAPER. In: International Polymer Processing 26 (4 2011), S. 416-423. ISSN: 0930-777X. DOI: $10.3139 / 217.2452$.

[YYG+18] Hairong Yin, Chen Yang, Yang Gao, Cuicui Wang, Mingyang Li, Hongwei Guo und Qiang Tong. „Fabrication and characterization of strontium-doped borate-based bioactive glass scaffolds for bone tissue engineering". PAPER. In: Journal of Alloys and Compounds 743 (2018), S. 564-569. ISSN: 09258388. DOI: $10.1016 / j \cdot j a l l c o m .2018 .01 .099$.

[Zäh13] Michael F. Zäh. Wirtschaftliche Fertigung mit Rapid-Technologien. AnwenderLeitfaden zur Auswahl geeigneter Verfahren. ger. unveränderter Nachdruck der 1. Aufl. 2006. München: Hanser, 2013. 259 S. ISBN: 978-3-446-43916-0.

[Zha15] Yue Zhang. Konzeption und Konstruktion einer Pulverzuführeinheit für eine $L S$-/LBM-Maschine. BACHELORARBEIT. Unter Mitarb. von Prof. Dietmar Göhlich und Clemens Kautz. TU Berlin / Institut für Konstruktion, Mikro- und Medizintechnik / FG Methoden der Produktentwicklung und Mechatronik, 12.2015. 137 S.

[ZHH+14] Guenter Zenzinger, Benjamin Henkel, Thomas Hess und Alexander Ladewig. "Online-Prozesskontrolle bei der additiven Fertigung mittels Laserstrahlschmelzen". PAPER. In: ZfP-Zeitung 140 (6.2014), S. 51-54.

[zKS+13] Joschka zur Jacobsmühlen, Stefan Kleszczynski, Dorian Schneider und Gerd Witt. „High Resolution Imaging for Inspection of Laser Beam Melting Systems". PAPER. In: Instrumentation and Measurement Technology Conference (I2MTC), 2013 IEEE International (2013), S. 707-712.

[ZLW+07] Wen You Zhou, S. H. Lee, Min Wang und W. L. Cheung. „Selective Laser Sintering of Tissue Engineering Scaffolds Using Poly(L-Lactide) Microspheres". PAPER. In: Key Engineering Materials 334-335 (2007), S. 1225-1228. ISSN: 1662-9795. DOI: 10.4028/www. scientific.net/KEM.334-335.1225.

[ZLW+08] Wen You Zhou, Siu Hang Lee, Min Wang, Wai Lam Cheung und Wing Yuk Ip. „Selective laser sintering of porous tissue engineering scaffolds from poly(L: -lactide)/carbonated hydroxyapatite nanocomposite microspheres". PAPER. eng. In: Journal of materials science. Materials in medicine 19 (7 2008). Journal Article Research Support, Non-U.S. Gov't, S. 2535-2540. ISSN: 1573-4838. DOI: 10.1007/s10856-007-3089-3. eprint: 17619975.

[ZPG+13] Kai Zeng, Nachiket Patil, Hengfeng Gu, Haijun Gong, Deepankar Pal, Thomas Starr und Brent Stucker. „Layer by Layer Validation of Geometrical Accuracy in Additive Manufacturing processes". PAPER. In: Solid Freeform Fabrication Symposium 2013 (1.2013), S. 76-87. URL: http://sff symposium. engr. utexas.edu/archive. 



\section{Normen}

[DIN 11866]

[DIN 1319-3]

[DIN 1319-4]

[DIN 33402-2]

[DIN 41652-1]

[DIN 51818]

[DIN 53733]

[DIN 6912]

[DIN 8580]

[DIN EN 12020-2]

[DIN EN 1672-2]

[DIN EN 573-3]
DIN 11866:2016-11, Komponenten aus nichtrostendem Stahl für aseptische Anwendungen in der chemischen und pharmazeutischen Industrie - Rohre.

DIN 1319-3:1996-5, Grundlagen der Meßtechnik - Teil 3: Auswertung von Messungen einer einzelnen Meßgröße, Meßunsicherheit.

DIN 1319-4:1999-2, Grundlagen der Meßtechnik - Teil 4: Auswertung von Messungen; Meßunsicherheit.

DIN 33402-2:2005-12, Ergonomie - Körpermaße des Menschen - Teil 2: Werte.

DIN 41652-1:1990-6, Steckverbinder für die Einschubtechnik, trapezförmig, runde Kontakte $1 \mathrm{~mm}$; Gemeinsame Einbaumerkmale und Maße; Bauformenübersicht.

DIN 51818:1981-12, Schmierstoffe; Konsistenz-Einteilung für Schmierfette; NLGI-Klassen.

DIN 53733:2015-10, Prüfung von Kunststoffen - Zerkleinerung von Kunststofferzeugnissen für Prüfzwecke.

DIN 6912:2009-6, Zylinderschrauben mit Innensechskant Niedriger Kopf, mit Schlüsselführung.

DIN 8580:2003-9, Fertigungsverfahren - Begriffe, Einteilung.

DIN EN 12020-2:2015-12, Aluminium und Aluminiumlegierungen - Stranggepresste Präzisionsprofile aus Legierungen EN AW-6060 und EN AW-6063 - Teil 2: Grenzabmaße und Formtoleranzen; Deutsche und Englische Fassung FprEN 12020-2:2015.

DIN EN 1672-2:2009-7, Nahrungsmittelmaschinen - Allgemeine Gestaltungsleitsätze - Teil 2: Hygieneanforderungen; Deutsche Fassung EN 1672-2:2005+A1:2009.

DIN EN 573-3:2013-12, Aluminium und Aluminiumlegierungen - Chemische Zusammensetzung und Form von Halbzeug - Teil 3: Chemische Zusammensetzung und Erzeugnisformen; Deutsche Fassung EN 573-3:2013. 
[DIN EN 60297-3-100]

[DIN EN 60297-3-101]

[DIN EN 60529]

[DIN EN 60715]

[DIN EN 60751]

[DIN EN 61508-1]

[DIN EN 61511-1]

[DIN EN 62061]

[DIN EN ISO 10524-1]

[DIN EN ISO 10524-3]
DIN EN 60297-3-100:2009-9, Bauweisen für elektronische Einrichtungen - Maße der 482,6-mm-(19-Zoll-)Bauweise Teil 3-100: Hauptmaße von Frontplatten, Baugruppenträgern, Einschüben, Gestellen und Schränken (IEC 602973-100:2008); Deutsche Fassung EN 60297-3-100:2009.

DIN EN 60297-3-101:2005-6, Bauweisen für elektronische Einrichtungen - Maße der 482,6-mm-(19-Zoll-)Bauweise Teil 3-101: Baugruppenträger und Baugruppen (IEC 602973-101:2004); Deutsche Fassung EN 60297-3-101:2004.

DIN EN 60529:2014-9, Schutzarten durch Gehäuse (IPCode) (IEC 60529:1989 + A1:1999 + A2:2013); Deutsche Fassung EN 60529:1991 + A1:2000 + A2:2013.

DIN EN 60715:2001-9, Abmessungen von Niederspannungsschaltgeräten - Genormte Tragschienen für die mechanische Befestigung von elektrischen Geräten in Schaltanlagen (IEC 60715:1981 + A1:1995); Deutsche Fassung EN 60715:2001.

DIN EN 60751:2009-5, Industrielle Platin - Widerstandsthermometer und Platin - Temperatursensoren (IEC 60751:2008); Deutsche Fassung EN 60751:2008.

DIN EN 61508-1:2011-2, Funktionale Sicherheit sicherheitsbezogener elektrischer/elektronischer/programmierbarer elektronischer Systeme - Teil 1: Allgemeine Anforderungen (IEC 61508-1:2010); Deutsche Fassung EN 615081:2010.

DIN EN 61511-1:2012-10, Funktionale Sicherheit - Sicherheitstechnische Systeme für die Prozessindustrie - Teil 1: Allgemeines, Begriffe, Anforderungen an Systeme, Software und Hardware (IEC 65A/622/CD:2012).

DIN EN 62061:2017-10, Sicherheit von Maschinen - Funktionale Sicherheit sicherheitsbezogener elektrischer, elektronischer und programmierbarer elektronischer Steuerungssysteme (IEC 44/788/CD:2017).

DIN EN ISO 10524-1:2006-5, Druckminderer zur Verwendung mit medizinischen Gasen - Teil 1: Druckminderer und Druckminderer mit Durchflussmessgeräten (ISO 105241:2006); Deutsche Fassung EN ISO 10524-1:2006.

DIN EN ISO 10524-3:2013-6, Druckminderer zur Verwendung mit medizinischen Gasen - Teil 3: Druckminderer in Flaschenventilen (ISO 10524-3:2005 + Amd 1:2013); Deutsche Fassung EN ISO 10524-3:2006 + A1:2013. 
[DIN EN ISO 10642]

[DIN EN ISO 10993-1a]

[DIN EN ISO 10993-1b]

[DIN EN ISO 10993-2]

[DIN EN ISO 10993-6a]

[DIN EN ISO 10993-6b]

[DIN EN ISO 10993-9]

[DIN EN ISO 1101]

[DIN EN ISO 11145]

[DIN EN ISO 11357-1]
DIN EN ISO 10642:2013-4, Senkschrauben mit Innensechskant (ISO 10642:2004 + Amd 1:2012); Deutsche Fassung EN ISO 10642:2004 + A1:2012.

DIN EN ISO 10993-1:2010-4, Biologische Beurteilung von Medizinprodukten - Teil 1: Beurteilung und Prüfungen im Rahmen eines Risikomanagementsystems (ISO 109931:2009); Deutsche Fassung EN ISO 10993-1:2009.

DIN EN ISO 10993-1:2017-4, Biologische Beurteilung von Medizinprodukten - Teil 1: Beurteilung und Prüfungen im Rahmen eines Risikomanagementsystems (ISO/DIS 10993-1:2017); Deutsche und Englische Fassung prEN ISO 10993-1:2017.

DIN EN ISO 10993-2:2006-10, Biologische Beurteilung von Medizinprodukten - Teil 2: Tierschutzbestimmungen (ISO 10993-2:2006); Deutsche Fassung EN ISO 10993-2:2006.

DIN EN ISO 10993-6:2009-8, Biologische Beurteilung von Medizinprodukten - Teil 6: Prüfungen auf lokale Effekte nach Implantationen (ISO 10993-6:2007); Deutsche Fassung EN ISO 10993-6:2009.

DIN EN ISO 10993-6:2014-12, Biologische Beurteilung von Medizinprodukten - Teil 6: Prüfungen auf lokale Effekte nach Implantationen (ISO/DIS 10993-6:2014); Deutsche Fassung prEN ISO 10993-6:2014.

DIN EN ISO 10993-9:2010-4, Biologische Beurteilung von Medizinprodukten - Teil 9: Rahmen zur Identifizierung und Quantifizierung von möglichen Abbauprodukten (ISO 10993-9:2009); Deutsche Fassung EN ISO 10993-9:2009.

DIN EN ISO 1101:2017-9, Geometrische Produktspezifikation (GPS) - Geometrische Tolerierung - Tolerierung von Form, Richtung, Ort und Lauf (ISO 1101:2017); Deutsche Fassung EN ISO 1101:2017.

DIN EN ISO 11145:2016-10, Optik und Photonik - Laser und Laseranlagen - Begriffe und Formelzeichen (ISO 11145:2016); Deutsche Fassung EN ISO 11145:2016.

DIN EN ISO 11357-1:2017-2, Kunststoffe - Dynamische Differenz-Thermoanalyse (DSC) - Teil 1: Allgemeine Grundlagen (ISO 11357-1:2016); Deutsche Fassung EN ISO 1135\%-1:2016. 
[DIN EN ISO 12100]

[DIN EN ISO 13849-1]

[DIN EN ISO 13850]

[DIN EN ISO 14159]

[DIN EN ISO 14644-1]

[DIN EN ISO 17296-4]

[DIN EN ISO 20753]

[DIN EN ISO 286-2]

[DIN EN ISO 4287]

[DIN EN ISO 4762]

[DIN EN ISO 7153-1]
DIN EN ISO 12100:2011-3, Sicherheit von Maschinen Allgemeine Gestaltungsleitsätze - Risikobeurteilung und Risikominderung (ISO 12100:2010); Deutsche Fassung EN ISO 12100:2010.

DIN EN ISO 13849-1:2016-6, Sicherheit von Maschinen Sicherheitsbezogene Teile von Steuerungen - Teil 1: Allgemeine Gestaltungsleitsätze (ISO 13849-1:2015); Deutsche Fassung EN ISO 13849-1:2015.

DIN EN ISO 13850:2016-5, Sicherheit von Maschinen - Not-Halt-Funktion - Gestaltungsleitsätze (ISO 13850:2015); Deutsche Fassung EN ISO 13850:2015.

DIN EN ISO 14159:2008-7, Sicherheit von Maschinen Hygieneanforderungen an die Gestaltung von Maschinen (ISO 14159:2002); Deutsche Fassung EN ISO 14159:2008.

DIN EN ISO 14644-1:2016-6, Reinräume und zugehörige Reinraumbereiche - Teil 1: Klassifizierung der Luftreinheit anhand der Partikelkonzentration (ISO 14644-1:2015); Deutsche Fassung EN ISO 14644-1:2015.

DIN EN ISO 17296-4:2016-12, Additive Fertigung - Grundlagen - Teil 4: Überblick über die Datenverarbeitung (ISO 17296-4:2014); Deutsche Fassung EN ISO 17296-4:2016.

DIN EN ISO 20753:2014-7, Kunststoffe - Probekörper (ISO 20753:2008); Deutsche Fassung EN ISO 20753:2014.

DIN EN ISO 286-2:2010-11, Geometrische Produktspezifikation (GPS) - ISO-Toleranzsystem für Längenmaße Teil 2: Tabellen der Grundtoleranzgrade und Grenzabmaße für Bohrungen und Wellen (ISO 286-2:2010); Deutsche Fassung EN ISO 286-2:2010.

DIN EN ISO 4287:2010-7, Geometrische Produktspezifikation (GPS) - Oberflächenbeschaffenheit: Tastschnittverfahren - Benennungen, Definitionen und Kenngrößen der Oberflächenbeschaffenheit (ISO 4287:1997 + Cor 1:1998 + Cor 2:2005 + Amd 1:2009); Deutsche Fassung EN ISO 4287:1998 + AC:2008 + A1:2009.

DIN EN ISO 4762:2004-6, Zylinderschrauben mit Innensechskant (ISO 4762:2004); Deutsche Fassung EN ISO 4762:2004.

DIN EN ISO 7153-1:2017-2, Chirurgische Instrumente Werkstoffe - Teil 1: Metalle (ISO 7153-1:2016); Deutsche Fassung EN ISO 7153-1:2016. 
[DIN EN ISO 7380-1]

[DIN EN ISO 7396-1]

[DIN EN ISO 9000]

[DIN EN ISO 9170-1]

[DIN EN ISO ASTM 52900]

[DIN EN ISO ASTM 52915]

[DIN EN ISO ASTM 52921]

[DIN IEC 60050-351]

[DIN ISO 15552]

[DIN ISO 3408-1]

[DIN ISO 3408-3]

[DIN ISO 3601-1]
DIN EN ISO 7380-1:2011-11, Schrauben mit abgeflachtem Halbrundkopf - Teil 1: Schrauben mit abgeflachtem Halbrundkopf mit Innensechskant (ISO 7380-1:2011); Deutsche Fassung EN ISO 7380-1:2011.

DIN EN ISO 7396-1:2016-9, Rohrleitungssysteme für medizinische Gase - Teil 1: Rohrleitungssysteme für medizinische Druckgase und Vakuum (ISO 7396-1:2016); Deutsche Fassung EN ISO 7396-1:2016.

DIN EN ISO 9000:2015-11, Qualitätsmanagementsysteme - Grundlagen und Begriffe (ISO 9000:2015); Deutsche und Englische Fassung EN ISO 9000:2015.

DIN EN ISO 9170-1:2008-10, Entnahmestellen für Rohrleitungssysteme für medizinische Gase - Teil 1: Entnahmestellen für medizinische Druckgase und Vakuum (ISO 9170-1:2008); Deutsche Fassung EN ISO 9170-1:2008.

DIN EN ISO / ASTM 52900:2017-6, Additive Fertigung - Grundlagen - Terminologie (ISO/ASTM 52900:2015); Deutsche Fassung EN ISO/ASTM 52900:2017.

DIN EN ISO / ASTM 52915:2017-10, Spezifikation für ein Dateiformat für Additive Fertigung (AMF) Version 1.2 (ISO/ASTM 52915:2016); Deutsche Fassung EN ISO/ASTM 52915:2017.

DIN EN ISO / ASTM 52921:2017-1, Normbegrifflichkeiten für die Additive Fertigung - Koordinatensysteme und Prüfmethodologien (ISO/ASTM 52921:2013); Deutsche Fassung EN ISO/ASTM 52921:2016.

DIN IEC 60050-351:2014-9, Internationales Elektrotechnisches Wörterbuch - Teil 351: Leittechnik (IEC 60050351:2013).

DIN ISO 15552:2005-12, Fluidtechnik - Pneumatikzylinder mit demontierbaren Befestigungsteilen, 1 000-kPa-(10bar-)Reihe, Zylinderbohrungen von $32 \mathrm{~mm}$ bis $320 \mathrm{~mm}$ Grund-, Anschluss- und Zubehörmaße (ISO 15552:2004).

DIN ISO 3408-1:2011-4, Kugelgewindetriebe - Teil 1: Begriffe und Bezeichnungssystem (ISO 3408-1:2006).

DIN ISO 3408-3:2011-4, Kugelgewindetriebe - Teil 3: Abnahmebedingungen und Abnahmeprüfungen (ISO 34083:2006).

DIN ISO 3601-1:2013-11, Fluidtechnik - O-Ringe - Teil 1: Innendurchmesser, Schnurstärken, Toleranzen und Bezeichnung (ISO 3601-1:2012 + Cor. 1:2012). 
[DIN ISO 3601-2]

[DIN ISO 5832-1]

[ISO 6983-1]

[ISO ASTM 52900]

[ISO IEC 7498-1]

[VDI 2206]

[VDI 2221]

[VDI 2263 Blatt 2]

[VDI 3405]

[VDI 3405 Blatt 1]
DIN ISO 3601-2:2010-8, Fluidtechnik - O-Ringe - Teil 2: Einbauräume für allgemeine Anwendungen (ISO 36012:2008).

DIN ISO 5832-1:2017-4, Chirurgische Implantate - Metallische Werkstoffe - Teil 1: Nichtrostender Stahl (ISO 5832-1:2016).

ISO 6983-1:2009-12, Automation systems and integration - Numerical control of machines - Program format and definitions of address words - Part 1: Data format for positioning, line motion and contouring control systems.

ISO ASTM 52900:2015-12, Additive manufacturing - General principles - Terminology.

ISO / IEC 7498-1:Informationstechnik - Kommunikation Offener Systeme - Basis-Referenzmodell.

VDI 2206:2004-6, Entwicklungsmethodik für mechatronische Systeme.

VDI 2221:1993-5, Methodik zum Entwickeln und Konstruieren technischer Systeme und Produkte.

VDI 2263 Blatt 2:1992-5, Staubbrände und Staubexplosionen; Gefahren, Beurteilung, Schutzmaßnahmen; Inertisierung.

VDI 3405:2014-12, Additive Fertigungsverfahren - Grundlagen, Begriffe, Verfahrensbeschreibungen.

VDI 3405 Blatt 1:2013-10, Additive Fertigungsverfahren, Rapid Manufacturing - Laser-Sintern von Kunststoffbauteilen - Güteüberwachung. 


\section{Patente}

[DE102005015870 B3] „Vorrichtung und Verfahren zum Herstellen eines dreidimensionalen Objekts". Thomas Halder, Thomas Mattes, Jochen Philippi, 10.2006.

[DE102005016940 B4] „Vorrichtung und Verfahren zum Auftragen von Schichten eines pulverförmigen Materials auf eine Oberfläche". Gerd Cantzler, Michael Göth, Thomas Halder, Peter Keller, Hans Perret, Jochen Philippi, 3.2007.

[DE102005022308 B4] „Vorrichtung und Verfahren zum Herstellen eines dreidimensionalen Objekts mit einem beheizten Beschichter für pulverförmiges Aufbaumaterial“. Helmar Langer, Hans Perret, Jochen Philippi, 3.2007.

[DE102005030854 B3] „Vorrichtung zum Herstellen eines dreidimensionalen Objektes". Oliver Heinlein, 3.2007.

[DE102005034155 B3] „Lens for focusing electromagnetic radiation in forming layers in three-dimensional rapid prototyping includes a heating element in the exit window". Hans Perret Albert Fruth, 11.2016.

[DE102006021504 A1] „Gasvorhang zur Fensterreinigung einer Lasersinter - Prozesskammer in einem Lasersintersystem“. Raymond J. Santa Clarita Bishop, Jouni P. Santa Monica Partanen, Ning Santa Clarita Zheng, 4.2008.

[DE102006053121 B3] „Vorrichtung und Verfahren zum Herstellen eines dreidimensionalen Objektes mittels eines Beschichters für pulverförmiges Aufbaumaterial“. Frank Müller Peter Hein, 12.2007 .

[DE102007062129 B3] Verfahren zum Herstellen eines dreidimensionalen Objekts". Jochen Philippi, 6.2009.

[DE102011085154 A1] „Vorrichtung zur Vermeidung von Ablagerungen an optischen Komponenten im Laser-Sintern". Maik Grebe, Sigrid Hessel, Wolfgang Diekmann, 4.2013.

[DE102012004587 A1] „Filtereinrichtung zum Anschluss an eine Lasersinter- oder Laserschmelzanlage“. Florian Bechmann, Frank Schödel, Frank Herzog, 9.2013. 
[DE10244859 B4]

[DE10349688 A1]

[DE19511772 C2]

[DE19516972 C1]

[DE19530295 C1]

[DE19530296 B4]

[DE19649865 C1]

[DE19747309 A1]

[DE19813742 C1]

[DE19846478 C5]

[DE19939616 C5]

[DE20107262 U1]

[DE202008011727 U1]

[DE202009012628 U1]
„Bioreaktor mit modularem Aufbau, insbesondere zur ex-vivo Zellvermehrung“. Heinz Körber, Uwe Streller, Carsten Werner, 1.2007.

„Bioreaktor für das Tissue Engineering sowie zur ex situ Testung tissue engineerter und biologischer Materialien“. Ulrich Stock, Günter Ditze, Günter Sammler, 6.2005.

„Vorrichtung und Verfahren zum Herstellen eines dreidimensionalen Objektes“. Andreas Lohner Christian Wilkening, 9.1997.

„Vorrichtung zum Herstellen eines dreidimensionalen Objektes mittels Lasersintern". Tim Sievers Christian Wilkening, 12.1996.

„Vorrichtung zur schichtweisen Herstellung eines Objektes mittels Lasersintern". Thomas Mattes Christian Wilkening, 1.1997.

"Vorrichtung zum schichtweisen Herstellen eines Objektes". Christian Wilkening Thomas Mattes, 1.2004.

„Verfahren zur Herstellung eines Formkörpers“. Wilhelm Meiners, Dr. Konrad Wissenbach, Dr. Andres Gasser, 2.1998 .

„Verwendung eines Polyamids 12 für selektives Laser-Sintern“. Dr. Heinz Scholten, Wolfgang Christoph, 4.1999.

„Vorrichtung und Verfahren zum Herstellen eines dreidimensionalen Objektes sowie Vorrichtung zum Aufbringen einer Schicht eines pulverförmigen Materials auf eine Oberfläche“. Bernhard Graf, Thomas Mattes, Lutz Reichmann, 7.1999 .

„Laser-Sintermaschine“. Robert Hofmann, 10.2004.

"Vorrichtung zur generativen Herstellung eines dreidimensionalen Objektes". Hans Perret, Harald Türck, Jochen Weidinger, 5.2008.

„Gebrauchsmuster - Vorrichtung zur Herstellung eines dreidimensionalen Objekts". EOS GmbH Electro Optical Systems, 8.2001.

„Gebrauchsmuster - Modul zur Verbesserung der Pulverförderung". EOS GmbH Electro Optical Systems, 12.2008.

„Gebrauchsmuster - Vorrichtung zum generativen Herstellen eines dreidimensionalen Objektes“. EOS GmbH Electro Optical Systems, 1.201. 
[DE202014009275 U1]

[DE202016004832 U1]

[DE29506204 U1]

[DE29506716 U1]

[DE4400523 C2]

[DE9400346 U1]

[DE9410503 U1]

[EP0835895 B1]

[EP1466718 A2]

[EP2151491 B1]

[EP2484512 A1]

[EP2586597 A1]
„Gebrauchsmuster - Strahlaufweiter und additive Fertigungsvorrichtung mit einem Strahlaufweiter". EOS GmbH Electro Optical Systems, 4.2015.

„Gebrauchsmuster - Gasüberwachungssystem zur Überwachung von Gaskonzentrationen in einer additiven Fertigungsvorrichtung". EOS GmbH Electro Optical Systems, 10.2016 .

„Gebrauchsmuster - Vorrichtung zum Herstellen eines dreidimensionalen Objektes". EOS GmbH Electro Optical Systems, 7.1995.

„Gebrauchsmuster - Einrichtung zur Nachbearbeitung eines aus einem pulverförmigen oder körnigen Material hergestellten Objektes". EOS GmbH Electro Optical Systems, 6.1995 .

„Verfahren und Vorrichtung zum Herstellen eines dreidimensionalen Objekts". Dr. Dave Retallick, Dr. Hans J. Langer, 7.1996.

„Gebrauchsmuster - Vorrichtung zum Herstellen eines dreidimensionalen Objekts". EOS GmbH Electro Optical Systems, 4.1994.

„Gebrauchsmuster - Vorrichtung zum schichtweisen Herstellen eines dreidimensionalen Objekts". EOS GmbH Electro Optical Systems, 12.1994.

„Chirugisches Nahtmaterial aus Triblockterpolymer, seine Verwendung in der Chirurgie und Verfahren zur Herstellung“. Sven Dr. Oberhoffner, Heinrich Prof. Dr.-Ing. Planck, 4.1998.

„Sintering using thermal image feedback“. Mark Chung Andre-Luc Allanic, 10.2004.

„Multichamber bioreactor with bidirectional perfusion integrated in a culture system for tissue engineering strategies". Pedro Ferreira da Costa, Albino Manuel Pereira Martins, Maria Manuela Estima Gomes, Nuno João Meleiro Alves das Neves, Rui Luís Gonçalves dos Reis, 7.2009.

„Verfahren und Vorrichtung zur besseren Inertisierung von Lasersinteranlagen". Maik Grebe, Wolfgang Diekmann, Stefan Altkemper, 1.2012.

„Vorrichtung zur Vermeidung von Ablagerungen an optischen Komponenten im Laser-Sintern". Maik Grebe, Sigrid Hessel, Wolfgang Diekmann, 5.2013. 
[EP2596901 B1]

[EP2617389 B1]

[EP2666612 A1]

[US4863538 A]

[US4938816 A]

[US6215093 B1]

[US7713048 B2]

[US8568124 B2]
„Optische Bestrahlungsvorrichtung für eine Anlage zur Herstellung von dreidimensionalenWerkstücken durch Bestrahlen von Pulverschichten eines Rohstoffpulvers mit Laserstrahlung". Andreas Wiesner, Dieter Schwarze, Henner Schöneborn, 11.2014.

„Method of manufacturing a tissue-engineered prosthesis and bioreactor therefor". Carlijn V. C. Bouten, Anita Mol, Marcel C. M. Rutten, Simon P. Hoerstrup, Franck P. T. Baaijens, 2.2006.

„Verfahren und Vorrichtung zum Abbilden wenigstens eines dreidimensionalen Bauteils". Günter Zenzinger, Wilhelm Satzger, Dr. Joachim Bamberg, Thomas Hess, 11.2013.

„Method and apparatus for producing parts by selective sintering“". Carl R. Deckard, 10.1986.

„Selective laser sintering with assisted powder handling“. Joseph J. Beaman, Carl R. Deckard, 7.199.

„Selective laser sintering at melting temperature“. Wilhelm Meiners, Dr. Konrad Wissenbach, Dr. Andres Gasser, 4.2001 .

„Device for a layerwise manufacturing of a three-dimensional object". Peter Keller Hans Perret, 5.201.

„Powder spreader“. Dan Brunermer, 10.2013. 